Danmarks Geologiske Undersøgelse.

II. Række. Nr. 50.

\title{
DAS GRUNDGEBIRGE VON BORNHOLM
}

\author{
VON \\ KAREN CALLISEN
}

MIT 8 TAFELN UND EINER KARTE

I Kommission hos

C. A. Reitzels Forlag

Kjøbenhavn

1934.

Pris : $10 \mathrm{Kr}$. 
Danmarks Geologiske Undersøgelse.

II. Række. Nr. 50.

\title{
DAS GRUNDGEBIRGE VON BORNHOLM
}

\author{
VON \\ KAREN CALLISEN
}

MIT 8 TAFELN UND EINER KARTE

I Kommission hos

C. A. Reitzels Forlag

Kjøbenhavn

1934. 
FR, BAGGES KGL. HOFBOGTRYKKERI 


\section{In halt.}

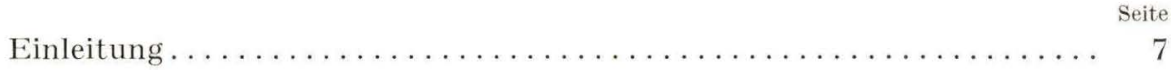

I. Die Granite. . . . . . . . . . . . . . . . . . 12

Uebersicht über die Granitvarietäten und deren Verbreitung ........ 12

Literatur über das Bornholmer Grundgebirge ............... 18

Geologisch-petrographische Beschreibung der Granite ........... 23

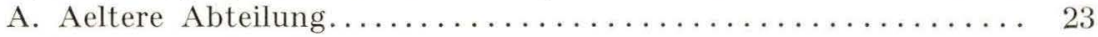

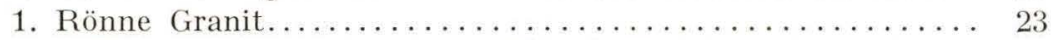

Einschluss von einem Quarz-Titanit-Gestein im Rönne Granit 41

Feldspateinschlüsse im Rönne Granit............. 48

Pegmatit und Aplit im Rönne Granit............. 50

2. Grenzgebiet des Rönne Granits................ 53

3. Paradisbakke Granit...................... 60

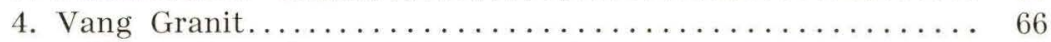

Pegmatit und Aplit im Vang Granit............ 74

5. Kleinere Vorkommen von hornblendeführendem Granit.... 76

6. Streifiger Granit....................... 78

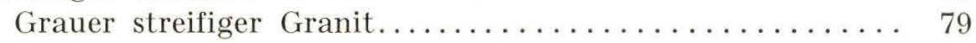

Roter schwach streifiger Granit.............. 88

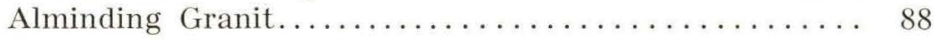

Christiansö............................. 90

Roter feinkörniger aplitischer Granit (»Hasle Granit»)... . 91

Pegmatit- und Aplitgänge im streifigen Granit......... 92

B. Jüngere Abteilung.......................... 94

1. Hammer Granit....................... 94

Die Grenze zwischen dem Hammer- und dem Vang Granit 97

2. Svaneke Granit...................... 108

Die Alters- und Grenzbeziehungen des Svaneke Granits zum streifigen Granit................. 117

Das Zerfallen des Svaneke Granits.............. 121

Die chemische Differentiation und die Relationen der Granitvarietäten.. 126

Zur Altersfrage der Bornholmer Granite ................. 139

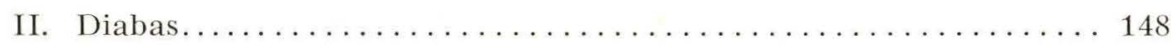

Der Diabas von Kjeldsea...................... 150

Kontaktwirkungen des Kjeldseaa-Diabases auf das Nebengestein 157

Der Diabasgang bei Kaas. . . . . . . . . . . . . . . . . . . . . 164

Der Diabasgang von Listed-Tamperdal . . . . . . . . . . . . . . 164 
Kleinere Gänge aus Olivindiabas................... 173

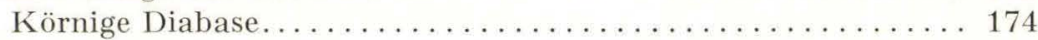

Olivindiabasporphyrite .................... 176

Feldspatarme Diabase......................... 184

Zersetzte Diabase........................ 185

Kontaktwirkungen bei den kleineren Diabasgängen.......... 187

Das Alter der Diabasgänge und ihre Beziehung zu den Spaltentälern. 193

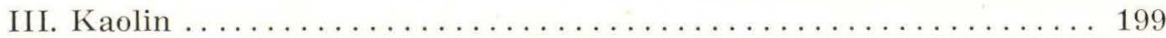

Das Kaolingebiet bei Rönne ......................... 199

Lagerungsverhältnisse. ....................... 199

Mineralbestand und chemische Zusammensetzung des Kaolins. . 221

Die untere Grenze des Kaolins und der Uebergang zum frischen Granit................................. 228

Kaolinvorkommen anderswo auf Bornholm................. 232

Alter und Entstehung des Kaolins................... 236

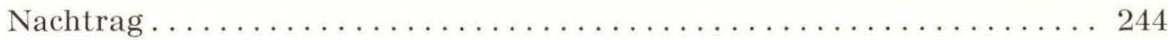

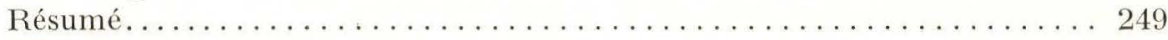




\section{Vorwort.}

D ie vorliegende Arbeit ist eine Fortsetzung der von N. V. Ussing in Angriff genommenen Untersuchung des Bornholmer Grundgebirges. Der erste Teil, S. 7-147, ist bereits früher als Sonderdruck erschienen unter dem Titel: »Beiträge zur Kenntnis des Granitgrundgebirges von Bornholm, Kjøbenhavn 1932«. In diesem Teil ist nur die Karte auf S. 13 durch eine andere, verbesserte Übersichtsskizze ersetzt worden, die im Nachwort noch besonders besprochen wird. Im übrigen ist der Text unverändert.

Für Hilfe bei der Durchführung der Arbeit und für Drucklegung und Ausstattung der Veröffentlichung sage ich dem Direktor von Danmarks Geologiske Undersögelse, Herrn Dr. phil. Victor Madsen, meinen besten Dank. Ebenfalls danke ich aufrichtig Herrn Museumsdirektor Prof. O. B. BöGGILD, der meiner Arbeit ungeteiltes Interesse entgegenbrachte. Durch Vermittlung des Mineralogischen Museums habe ich von Seiten des Etatsraadinde KofokD's Legats Unterstützung zu geologischen Untersuchungen auf Bornholm erhalten. Mit einer Beihilfe von CARLSENLANGE's Legatstiftelse, der ich für diese wertvolle Hilfe bestens danke, unternahm ich Exkursionen in Schweden und untersuchte Grundgebirgsgesteine in Stockholm. Sehr verbunden bin ich Sveriges Geologiska Undersökning für eine Sammlung von schwedischen Gesteinen, und namentlich bin ich Herrn Staatsgeologen Dr. N. SunduUs und dem verstorbenen Staatsgeologen Dr. H. E. Johansson für ihr ausserordentlich bereitwilliges Entgegenkommen und ihren wertvollen Beistand zu Dank verpflichtet. Gleichfalls möchte ich dem Direktor der A/S Hasle Klinker- og Chamottestensfabrik, Bornholms Kaolin-, Chamotte- og Klinkerfabriker, Herrn Ingenieur J. C. Clausen meinen Dank aussprechen für das ausserordentliche Entgegenkommen, mit dem er mir Material für die Untersuchung des Kaolinvorkommens bei Rönne zur Verfügung gestellt hat. Endlich danke ich Herrn Assistenten cand. polyt. JoHs. Andersen, der mir bei den Dichtebestimmungen geholfen hat, und Herrn Assistenten L. H. C. Halkier für ausgezeichnete Hilfe bei den mikrophotographischen Aufnahmen. Die Klischees zu den Textfiguren und Tafeln wurden von F. Hendriksen's Reproduktionsatelier angefertigt.

In der Abhandlung kommen einige Ortsbenennungen vor, die auf der Karte keinen Platz fanden. Diese kann man auf den topographischen Karten finden, am besten auf den Messtischblättern des Geodätischen Instituts im Masstabe 1:20000. 


\section{Abkürzungen.}

D. G. U. = Danmarks Geologiske Undersøgelse.

S. G. U. = Sveriges Geologiska Undersökning.

N. G. U. = Norges Geologiske Undersøkelse.

G. F. F. = Geologiska Föreningens i Stockholm Förhandlingar.

Bull. Upsala $=$ Bulletin of the Geological Institution of the University of Upsala.

T. M. P. M. = Tschermaks Mineralogische und Petrographische Mitteilungen.

N. JB. $\quad=$ Neues Jahrbuch für Mineralogie etc.

N. JB. BB. = Neues Jahrbuch für Mineralogie etc., Beilage-Band.

Q. J. G. S. = The Quarterly Journal of the Geological Society of London.

E. Cohen und W. Deecke: Ueber das krystalline Grundgebirge der Insel

Bornholm. IV. Jahresber. der Geographischen Gesellschaft zu Greifswald 1889-1890, Greifswald 1891, und

GEORG KaLB: Petrographische Untersuchungen am Granit von Bornholm. Mitt. d. naturwiss. Ver. f. Neuvorpommern u. Rügen in Greifswald, 45. Jahrg., 1913.

werden als Cohen und Deecke 1. c. respektive G. Kalb 1. c. angeführt.

D. G. U. I. R. Nr. 13: K. A. Grönwall og V. Milthers: Beskrivelse til Geologisk Kort over Danmark (i Maalestok 1:100 000). Kortbladet Bornholm, wird oft als die Kartenblatterläuterung erwähnt. 


\section{Einleitung.}

as Bornholmer Granitgebiet bildet den südlichsten Vorsprung des Grundgebirges von Fennoskandia. Es nimmt ein Areal von etwa $400 \mathrm{~km}^{2}$ oder zwei Drittel der ganzen Insel ein. Eine weitere Fortsetzung in nordöstlicher Richtung wird von den kleinen, isoliert aus der Ostsee emporragenden Felsen von Christiansö angedeutet. Auf Bornholm stellt das Granitgebirge einen in NW-SO Richtung sich hinziehenden, langgestreckten Horst dar; an diesen lehnen sich im Süden und im Westen altpaläozoische und mesozoische Sedimente. Im Verhältnis zum Sedimentgebiet liegt das Granitterrain hoch, grösstenteils über $100 \mathrm{~m}$, und es läuft gegen Nordosten und Nordwesten in steile Felsenwände an der Küiste aus. Das sedimentäre Vorland fällt allmählich nach dem Meere zu ab. Auf diesem Gebiet findet man nur ausnahmsweise Höhen von mehr als $80 \mathrm{~m}$, und die vorhandenen Unebenheiten rühren im wesentlichen von einer ungleichmässigen Verteilung der glazialen Ablagerungen her. Die tektonischen Störungen, denen der Untergrund hier ausgesetzt gewesen ist, haben nur in geringem Masse die Gestalt und den Charakter der Landschaft geprägt.

Die Oberflächenformen des Granits tragen deutliche Spuren der Tätigkeit des Inlandeises. Zwar ist der Granit von zahlreichen Klüften und Spalten, die an vielen Stellen der Landschaft eine malerische Schönheit verleihen, durchsetzt, aber im grossen und ganzen ist nicht nur die ganze Insel vom Eise abgerundet, so dass ihre Kontur vom Meere gesehen eine ziemlich ebene, gebogene Linie bildet, sondern auch die Mehrzahl der aufragenden Granitpartien hat die charakteristische Form der Rundhöcker (Fig. 1), und an mehreren Stellen beobachtet man eine schön polierte Oberfläche mit wohlerhaltenen Gletscherschrammen.

Im Innern des Granitterrains, auf dem »Höjlyng» (Hohe Heide), machen die diluvialen Ablagerungen nur eine dünne sandige Decke aus, die jetzt grösstenteils mit Wald bestanden ist. Dagegen ist ein breiter Gürtel längs der Nordküste von fruchtbarem Geschiebemergel bedeckt, der zum Teil die Vertiefungen ausfüllt und nur selten von aufragenden Granitpartien unterbrochen wird. 


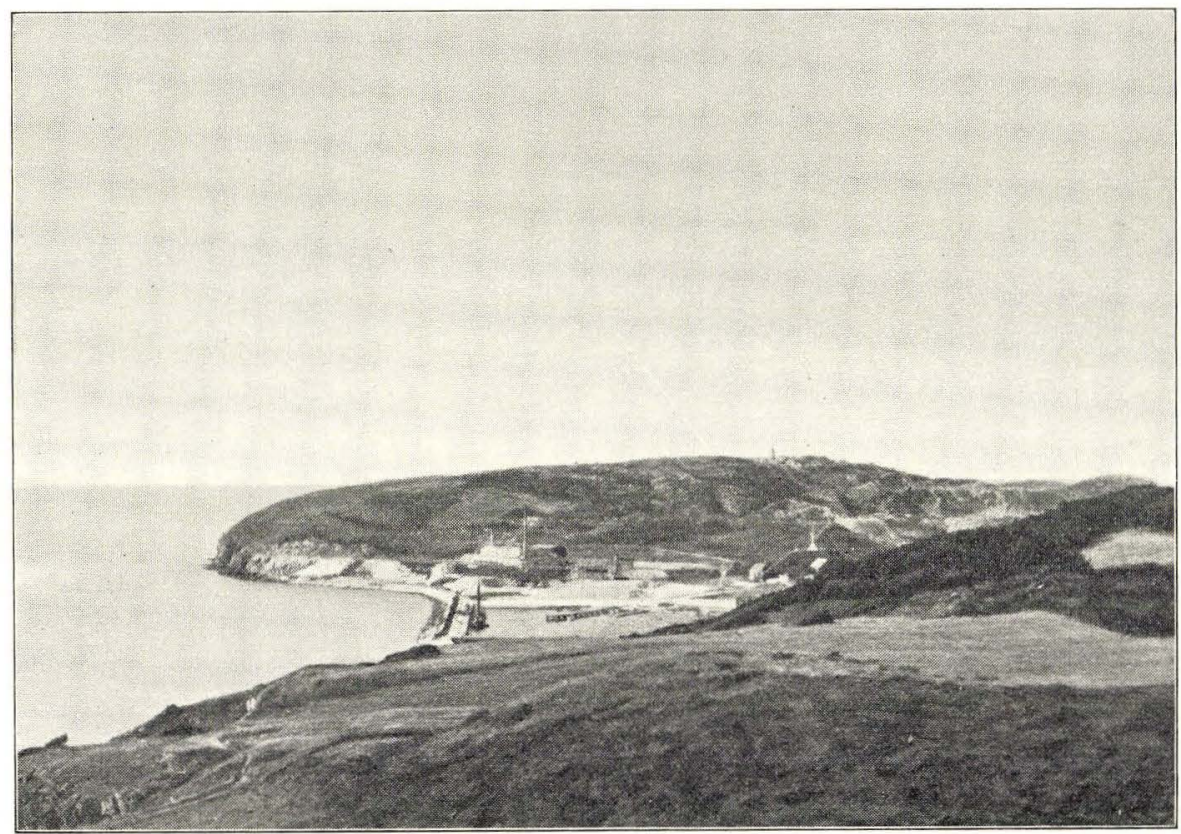

Fig. 1. Hammeren, Abgerundete Fläche des Hochplateaus.

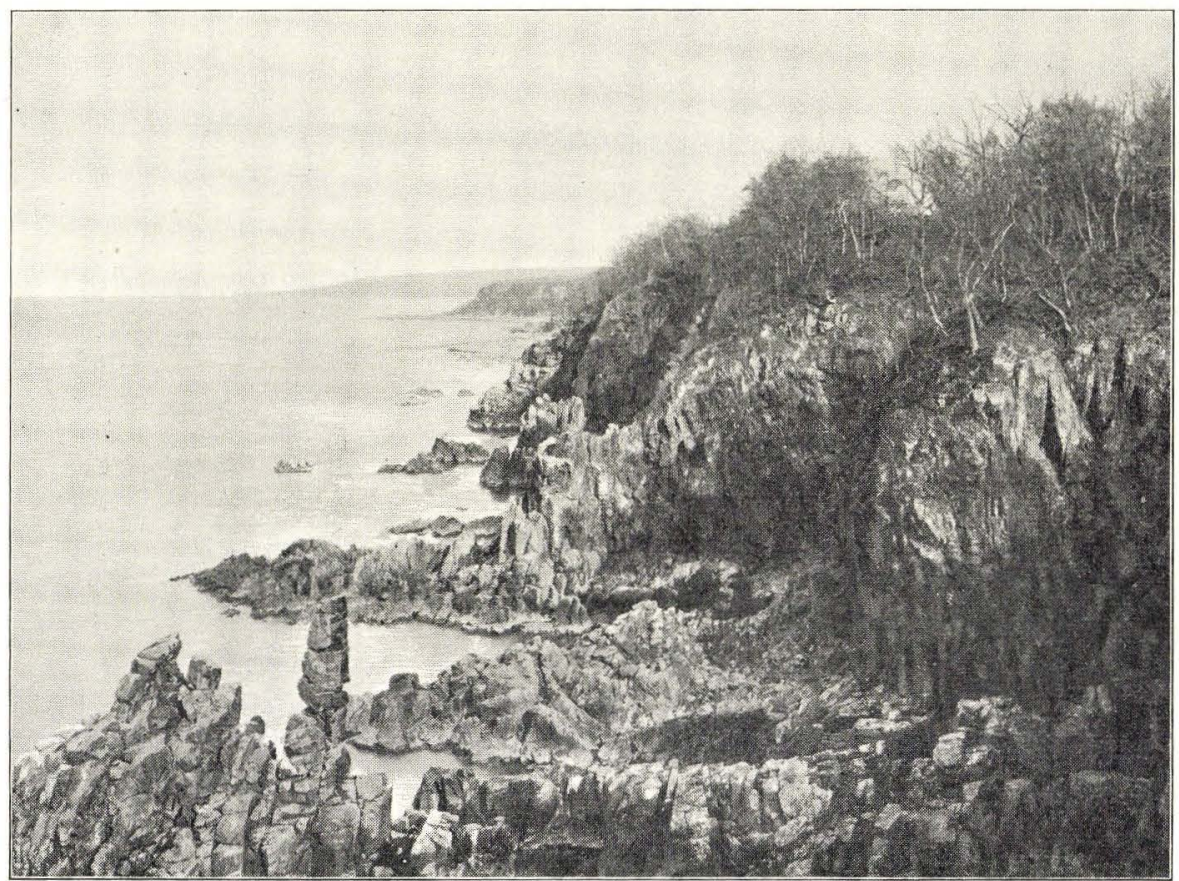

Fig. 2. Felsenküste bei Helligdommen. 
Längs der Küsten, wo die Brandung den Granit bis zu einer Höhe von ca. $20 \mathrm{~m}$ rein gespült hat, weisen die steilen Felswände scharfe, gezackte und ausserordentlich unregelmässige Formen auf. Tiefe Felsspalten, zahlreiche vorspringende Halbinseln, kleine Einschnitte und Schären gewähren den Anblick eines Schärenhofs im kleinen (Fig. 2).

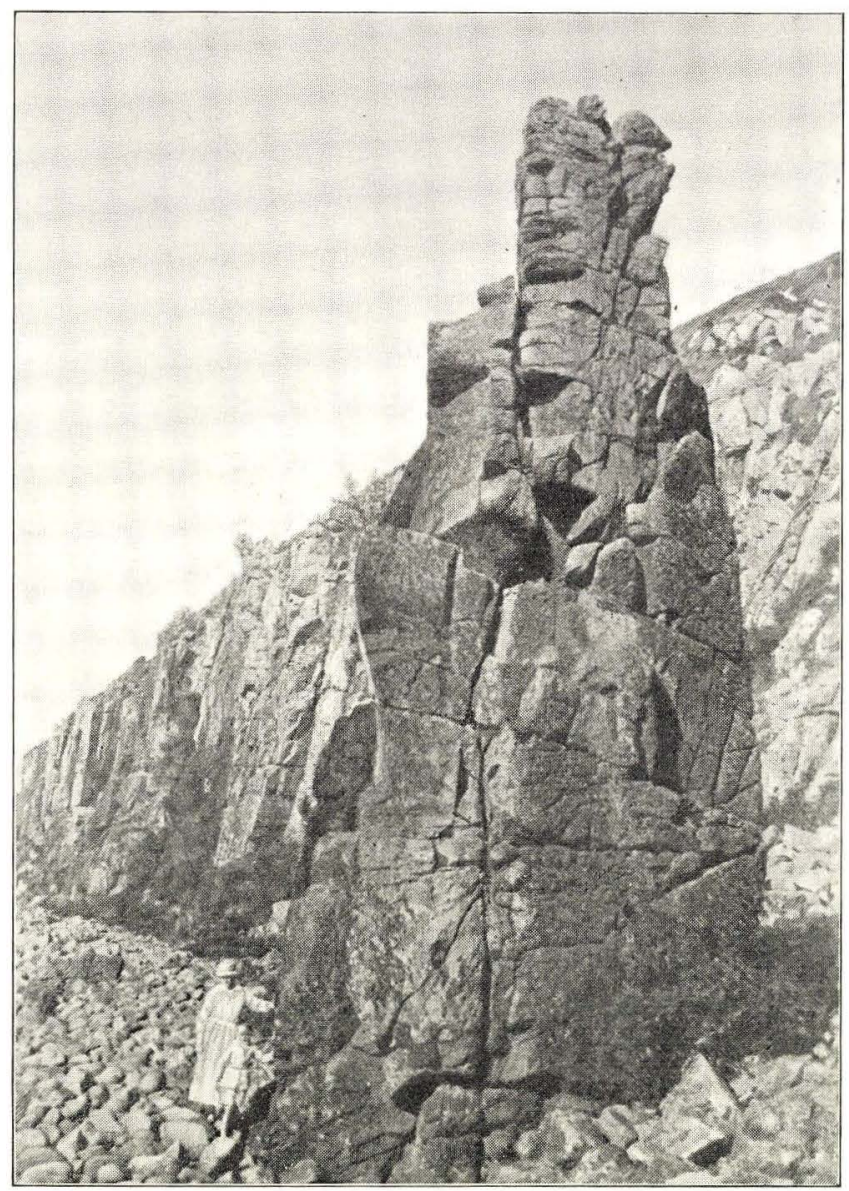

Fig. 3. "Krogeduren", südlich von Vang.

An einzelnen Stellen hat die Küstenerosion grössere oder kleinere, isolierte, steil emporragende Klippenpartien, von denen die eigentümlichsten »Krogeduren« südlich von Vang (Fig. 3) und »Lyseklippen« bei Helligdommen sind, zurückgelassen. An anderen Stellen ist die Steilküste von ansehnlichen, tiefen Klüften durchfurcht (Fig. 4), oder die Brandung hat sich in die senkrechten Spalten des Granits hineingefressen und sie zu Felsenhöhlen, den sogenannten »Oefen«, erweitert. Die grösste von diesen Felsengrotten, der »vaade Ovn« (nasser Ofen) an der Westküste unter Hammershus, ist $40 \mathrm{~m}$ lang und $12 \mathrm{~m}$ hoch. Bei stillem Wetter kann man 
mehrere Bootslängen in diese Grotte hineinrudern. »'Trockene Oefen« sind bei einem früher höheren Meeresniveau entstanden. Auch an der NOKüste in den hohen Helligdomsfelsen gibt es mehrere solcher Felsenhöhlen.

Die steilen Küstenfelsen vermitteln somit einen deutlichen Eindruck von der ausserordentlich starken Zerklüftung des Granits. In einem

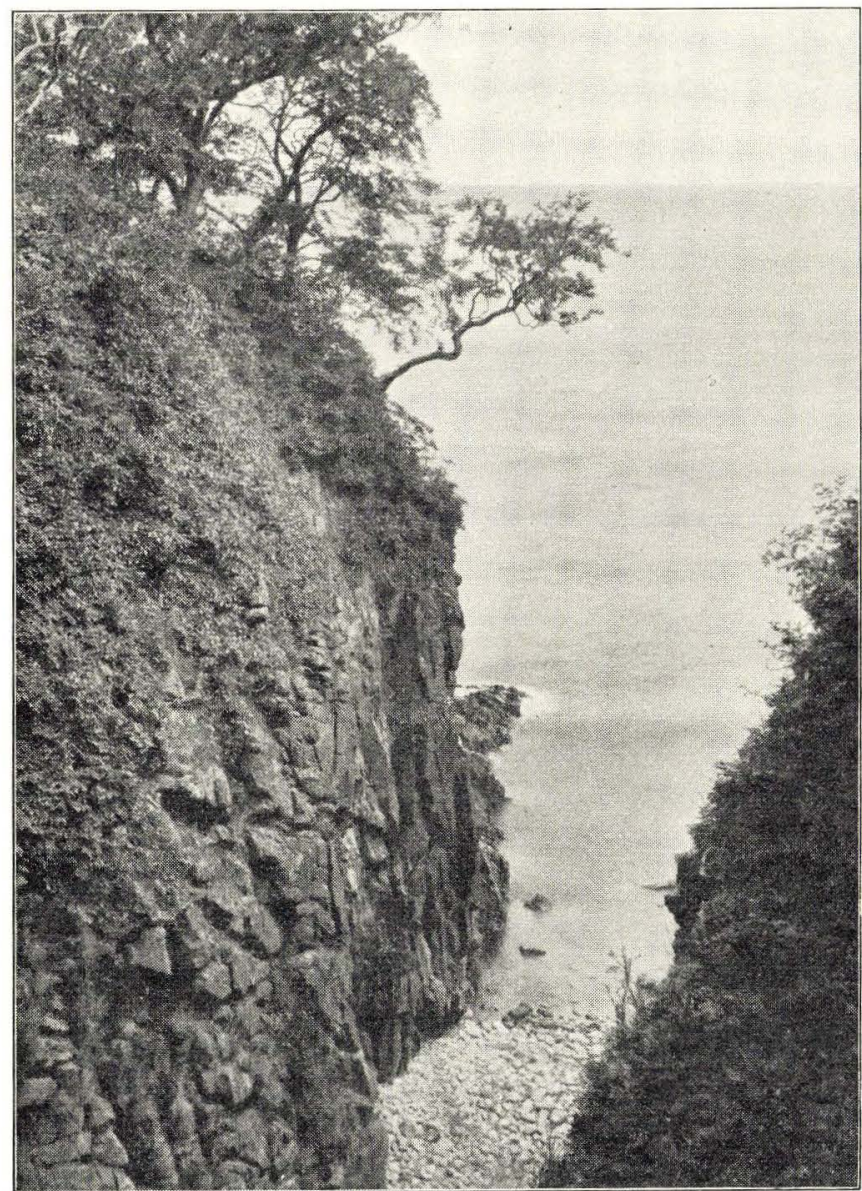

Fig. 4. Felsenkluft bei Helligdommen.

noch höheren Grade zeigt sich die Zerklüftung in den zahlreichen Spaltentälern, die durch ihre Grösse und Ausdehnung so wesentlich dazu beitragen, das Relief und den Charakter der Landschaft zu bestimmen. Viele dieser Täler erstrecken sich bei einem geradlinigen Verlauf auf mehrere Kilometer hin; ein einzelnes, das Kjeldseaa-Ekkodal, lässt sich sogar auf eine Entfernung von $12 \mathrm{~km}$ verfolgen. Oft haben die Spaltentäler steile oder senkrechte Wände, die mitunter deutliche Spuren einer Glättung durchs Eis aufweisen; an anderen Stellen sind die Talwände teilweise von losgerissenen Felsblöcken bedeckt. Namentlich das 
stark kupierte Terrain der Paradisbakker ist in Wirklichkeit dadurch entstanden, dass dieser an sich recht niedrige Höhenzug von zahlreichen, parallel verlaufenden Spaltentälern durchschnitten ist. Diese tiefen Klüfte haben in der Regel senkrechte Felsenwände; auch finden sich in ihnen sehr oft kleine Gebirgsseen (Fig. 5). Häufig sind die Täler recht schmal, was besonders in den Paradisbakker der Fall ist, aber manche von ihnen erreichen doch eine ansehnliche Breite, so z. B. ist das Dynddal ca. $80 \mathrm{~m}$, das Ekkodal ca. $60 \mathrm{~m}$ und das Dövredal ca. $50 \mathrm{~m}$ breit. Die Richtung der

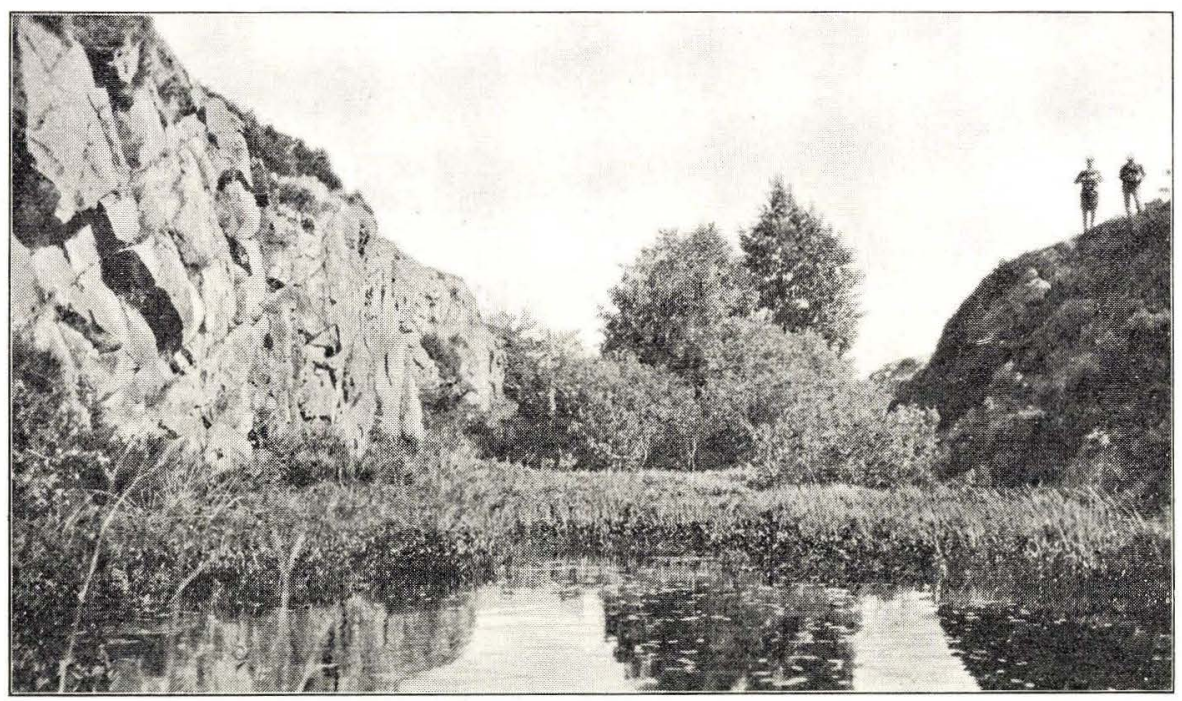

Fig. 5. Das Maidal in den Paradisbakker.

Spaltentäler liegt vorwiegend zwischen $\mathrm{NO}-\mathrm{SW}$ und $\mathrm{N}-\mathrm{S}$, doch gibt es im südlichen Teil der Paradisbakker ausserdem ein anderes System mit der Richtung WNW-OSO. Die gleiche Richtung haben die mit Sandsteingängen ausgefüllten Spalten im Granit im nördlichen Teil der Paradisbakker.

Die zahlreichen Diabasgänge, die den Granit durchsetzen, machen sich im allgemeinen sehr wenig im Terrain bemerkbar. Der Erosion hat der Diabas in der Regel einen geringeren Widerstand zu leisten vermocht als der Granit, so dass die Gänge bisweilen Vertiefungen bilden. Nur ein paar der grössten Gänge lassen sich auf längere Strecken hin verfolgen. Die Diabasgänge streichen gewöhnlich zwischen $\mathrm{NO}-\mathrm{SW}$ und $\mathrm{N}-\mathrm{S}$. Nur an einzelnen Stellen, z. B. im westlichen Teil von Hammeren, findet man Gänge mit einer Streichrichtung zwischen N-S und WNW-OSO. Die Diabasgänge treten auf Bornholm ausschliesslich innerhalb des Granitgebiets, nicht in den sedimentären Bildungen auf; ihrem Alter nach dürften sie daher dem Präkambrium angehören. 


\section{Die Granite.}

\section{Uebersicht über die Granitvarietäten und deren Verbreitung.}

D as Bornholmer Grundgebirge besteht aus einer Reihe von Granitvarietäten (Fig. 6) von den salischen, ausgesprochen kalibetonten Graniten des Hammer und in Almindingen (Bjergbakke) bis zu dem syenitischen, hornblendereichen Rönne Granit. In Habitus, Struktur und Differentiationsweise schliessen sie sich am ehesten an die Gruppe der Urgranite (Gneisgranite) und sind deshalb als eine Fortsetzung der älteren Abteilung des dem Archäikum angehörenden schwedischen Grundgebirges zu betrachten.

Die Hauptgemengteile der Gesteine sind Quarz, Mikroklin, Plagioklas und Biotit, wozu in einigen Varietäten beträchtliche Mengen von Hornblende kommen. Nur selten und rein lokal ist der Mikroklin durch Orthoklas ersetzt. Akzessorisch finden sich titanhaltiger Magnetit, Titanit (oft im Kranz um Magnetit), Apatit und Zirkon, selten Eisenkies, Orthit und Flusspat.

Die Einteilung des Bornholmer Granits in verschiedene Typen wurde zum ersten Male von N. V. Ussing ${ }^{1}$ ) durchgeführt, während andere Verfasser, E. Cohen und W. Deecke und später G. KaLB, in ihren petrographischen Untersuchungen der Bornholmer Granitarten — wahrscheinlich infolge fehlender Lokalkenntnisse - nur unvollständige Angaben über die Varietäten und deren Verbreitung machen.

In grossen Zügen lässt sich das Bornholmer Grundgebirge folgendermassen einteilen: in eine ältere Abteilung, die aus dem streifigen

1) N. V. Ussing: D. G. U. II. R. Nr. 12. 1902, D. G. U. III. R. Nr. 2. 2. Udg. 1904 und Handbuch der Regionalen Geologie, Bd. I, Abt. 2, 1910. 
Granit besteht, an den sich die schwach gestreiften oder ganz ungestreiften Varietäten Paradisbakke Granit, Vang Granit und Rönne Granit schliessen, und in eine jüngere Abteilung: Svaneke Granit und Hammer Granit. Der Altersunterschied zwischen diesen beiden Abteilungen muss jedoch für relativ gering angesehen werden.

Streifiger Granit. Im grössten Teile des Bornholmer Granitgebiets hat das Gestein eine mehr oder weniger ausgeprägte Parallelstruktur,

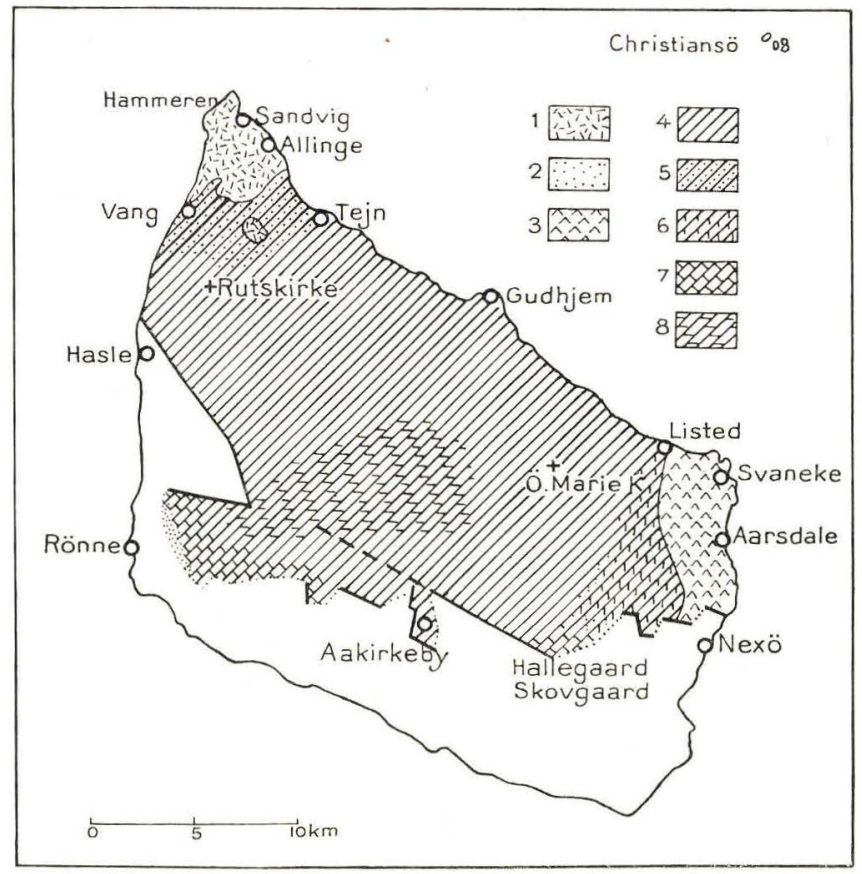

Fig. 6. Kartenskizze über die Verbreitung der Granitvarietäten auf Bornholm. $1=$ Hammer Granit. $2=$ Kaolin. $3=$ Svaneke Granit. $4=$ streifiger Granit. $5=$ Vang Granit $6=$ Paradisbakke Granit. $7=$ Rönne Granit. $8=$ Alminding Granit.

die dadurch entsteht, dass die dunklen Mineralien überwiegend in kurzen Streifen oder in länglichen flachen Anhäufungen gesammelt auftreten. Die Biotitblätter, welche den wesentlichsten Bestandteil der Haufen ausmachen, liegen beinahe alle in derselben Richtung, wodurch der Granit ausgesprochen schiefrig wird. Nur ausnahmsweise breiten sich die dunklen Flecken zu annähernd zusammenhängenden Schichten aus. An einigen Stellen sind die dunklen Mineralien in schmalen Streifen angereichert, so dass der Granit eine deutlich lineare Parallelstruktur erhält. Die hellen Mineralien tragen nicht oder nur in geringem Masse zur Parallelstruktur bei, jedoch haben in den am stärksten schiefrigen 
Varietäten auch Feldspat und Quarz eine geringe Tendenz zur länglichen Form in der Richtung der Streifen.

Der streifige Granit ist mittel- bis feinkörnig und häufig etwas porphyrisch, wobei einzelne Feldspatkörner eine Grösse von etwa $1 \times 1,5$ $\mathrm{cm}$ erreichen können. Im übrigen wechselt der Granit so ziemlich von Ort zu Ort, doch dergestalt, dass ebenmässige Uebergänge die verschiedenen lokalen Entwicklungsformen verbinden. Die Farbe ist meistens grau in den tieferen, frischen Partien und in der Regel rötlich in den Partien, die der Oberfläche am nächsten liegen. Doch findet man helle rote Varietäten mit einem geringen Gehalt an dunklen Mineralien und mit nur wenig ausgeprägter Streifung auch an mehreren Stellen innerhalb des Gebiets des streifigen Granits. Pegmatit tritt überall in reichlicher Menge auf, und zwar teils in Gestalt von scharf begrenzten Gängen, teils als pegmatitische Schlieren.

Als die typischste und am weitesten verbreitete Form muss das graue, stellenweise deutlich schiefrige Gestein angesehen werden, das in der Gegend von Gudhjem vorkommt, der Gudhjem Granit. Es ist dies ein ziemlich quarzreiches Gestein, dessen vorwiegender Bestandteil der Mikroklin ist; lokal ist Plagioklas reichlich vorhanden. Der Gehalt der dunklen Mineralien variiert ziemlich stark, Hornblende ist untergeordnet und kann stellenweise völlig fehlen. Dieser Granit hält sich einigermassen gleichartig in einem breiten Gürtel an der NO-Küste entlang, etwa von - Ostermarie bis Ruts Kirke, und ungefähr derselbe Granit findet sich auch weiter südlich im Granitgebiet nordwestlich und westlich von Almindingen. Nach Norden zu geht diese Varietät nach und nach in Vang Granit über. Nach SO zu wird der streifige Granit meistens dunkler gefärbt und oft recht reich an Hornblende. Allmählich geht er in den Paradisbakke Granit über. In der Umgegend von Aakirkeby hat der Granit in Stufen grosse Aehnlichkeit mit dem Gudhjem Granit, meistens jedoch weist er einen beträchtlicheren Hornblendegehalt und eine stärker porphyrische Struktur auf.

Der graue, mehr oder weniger schiefrige, streifige Granit wird oft in Schrift und Wort als »der gewöhnliche streifige Granit « bezeichnet, ein Ausdruck, der keineswegs genaue Aufklärungen über die Beschaffenheit des Gesteins gibt.

Im zentralen Teile des Granitgebiets, in Almindingen, kommt ein rötlicher, mittelkörniger Granit vor, der einen reichlicheren Gehalt an Quarz und Mikroklin aufweist als der graue streifige Granit. Die dunklen Gemengteile sind in unregelmässigen Flecken angeordnet, welche sich in der Regel nicht über grössere Flächen ausbreiten, so dass die Streifung im Gestein oft nur andeutungsweise zum Ausdruck kommt. Der rötliche Farbton rührt von der roten Farbe des Feldspats sowie von Ausschei- 
dungen rötlicher Ferriverbindungen in Rissen im Quarz und Feldspat her. Am typischsten findet sich diese Granitvarietät in einem grossen Steinbruch in Bjergbakke in Vestermarie. Im übrigen tritt er in einem geschlossenen Gebiet von der Gegend zwischen Ringeby und Ringeby Bro durch ganz Almindingen gegen Norden bis nach Stavsdal zu, gegen Osten bis über die Station Christianshöj hinaus und gegen Süden im ganzen Ekkodal auf. — Auf der Insel Christiansö findet sich ein ähnlicher rötlicher Granit, der auch nicht ausgeprägt streifig ist.

An zahlreichen Stellen, besonders in der Gegend zwischen Hasle und Gudhjem finden sich kleine, eng begrenzte Vorkommen von hellrotem, seltener von hellgrauem aplitischen Granit. Die sparsamen dunklen Gemengteile sind oft ebenmässig in der ganzen Gesteinsmasse verteilt; in einigen Vorkommen ist der Granit jedoch deutlich gestreift. Bei Frigaard, östlich von Hasle und bei Birkelund, südlich von Rö, wird ein derartiger Granit für Pflastersteine gebrochen. Von anderen Vorkommen wären Nygaard in Klemensker und Lensklint, südwestlich von Gudhjem, zu nennen.

Ebenfalls lokal und untergeordnet tritt ein dunkler, hornblendereicher, sogenannter "blauer《Granit in ganz kleinen Vorkommen auf, von denen die bedeutendsten bei Haldegaard, südlich von Gudhjem, und bei Tækkeregaard, nordnordöstlich von Hasle, liegen. Meistens ist dieser Granit etwas parallelstruiert, stellenweise kann er aber auch ganz ungestreift auftreten und hat dann oft ein fleckiges Aussehen, das teils von porphyrischen Feldspatkörnern, teils von unregelmässigen Anhäufungen dunkler Mineralien herrührt. Er geht ohne deutliche Abgrenzung allmählich in den benachbarten streifigen Granit über. Der dunkle Granit in diesen kleinen Vorkommen hat in Bezug auf Zusammensetzung und Struktur eine ausserordentlich grosse Aehnlichkeit mit den übrigen hornblendeführenden Granitvarietäten, vor allem mit dem Paradisbakke Granit und dem streifigen Uebergangsgestein des Rönne Granits.

Der Paradisbakke Granit, der den südöstlichsten Teil des streifigen Granits ausmacht, ist eine hornblendereiche, dunkelgraue und weissgeflammte Granitvarietät, deren helle Gemengteile hauptsächlich in verzweigten aplitischen Schlieren angereichert sind. Hierdurch erhält das Gestein ein ausserordentlich charakteristisches Aussehen. Die dunklen Teile haben eine sehr feinkörnige Grundmasse mit Einsprenglingen von Plagioklas. Der Paradisbakke Granit geht nach Norden und Westen zu allmählich in den gewöhnlichen grauen streifigen Granit über; gegen Norden kann der geflammte Charakter hie und da beinahe bis Listed festgestellt werden. Gegen Osten hat er eine scharfe Grenze gegen den Svaneke Granit.

Der Vang Granit kommt in einem schmalen Gürtel quer durch den 
nördlichen Teil von Bornholm zwischen den Fischerdörfern Vang und Tejn vor. Wie es mit dem Paradisbakke Granit der Fall war, geht auch er ebenmässig und ohne bestimmte Grenzen in den streifigen Granit vom Gudhjemtypus über. Im grössten Teile des Gebiets hat der Vang Granit eine schwache Streifung, geht aber in den Küstenfelsen südlich von Vang in ein regellos körniges, graues Gestein mit einem mehr oder weniger rötlichen Anstrich über. Dieses Gestein, das als Typus des Vang Granits angesehen werden muss, zeichnet sich durch einen reichlichen Gehalt an Hornblende und Biotit aus, welche mit den übrigen dunklen Mineralien in deutlich wahrnehmbaren Flecken oder Anhäufungen angereichert sind. Der Feldspat besteht aus rötlichem Mikroklin und grauem, halbklarem Plagioklas, der teilweise in Gestalt von grösseren. viereckigen Körnern auftritt. Der Quarz ist oft ein wenig rauchfarbig. Gegen Norden ist der Vang Granit scharf vom Hammer Granit abgegrenzt.

Der Rönne Granit nimmt den südwestlichsten Teil des Granitgebiets von der nordwestlichen Ecke des Knudskerplateaus bis Baunklint in Vestermarie ein. Er ist ein dunkelgrauer mittelkörniger Granit ganz ohne Parallelstruktur. Er steht den beiden letztgenannten Varietäten sehr nahe, hat aber einen etwas grösseren Gehalt an Plagioklas und Hornblende. Der Plagioklas ist stets von Mikroklin parallel umwachsen, eine Strukturerscheinung, die sich mehr oder weniger ausgesprochen bei fast allen Bornholmer Granitvarietäten, besonders bei den hornblendereichen, nachweisen lässt. Die Hornblende ist dieselbe wie in sämtlichen anderen Granitvarietäten, und zwar eine grüne, hastingsitähnliche Varietät mit einem hohen $\mathrm{FeO}$-Gehalt und einem kleinen optischen Achsenwinkel. Durch eine streifige, porphyrische Randzone, mit einsprenglingsartigem Plagioklas und abnehmendem Hornblendegehalt, geht der Rönne Granit nach Osten zu in den grauen hornblendearmen, streifigen Granit über.

Die Granite der jüngeren Abteilung, der Hammer Granit und der Svaneke Granit, sind helle, regellos körnige Varietäten.

Der Svaneke Granit, der den östlichsten Teil des Bornholmer Grundgebirges in dem Gebiet zwischen Svaneke und Nexö ausmacht, ist im nördlichen Teile grobkörnig und hellgrau, in der Nähe von Nexö etwas rötlicher. Unter den dunklen Mineralien ist Biotit vorherrschend, Titanit ist relativ reichlich, fast in derselben Menge wie Hornblende vorhanden. An einigen Stellen, wie z. B. bei Listed und Aarsdale, neigt der Svaneke Granit stark zum Zerfallen. Die Grenze zwischen dem streifigen Granit und dem Svaneke Granit verläuft wie eine beinahe gerade Linie von den Helvedesbakker bis zur Nord-Ostküste westlich von Listed. Unmittelbar an der Grenze ist der Svaneke Granit aplitisch und relativ feinkörnig. Sein jüngeres Alter geht ausserdem daraus hervor, dass er an vielen Stellen Fragmente des streifigen Granits umschliesst. 
Der Hammer Granit nimmt das nördlichste Dreieck von Bornholm ein. Er ist ein helles, rotgraues, mittelkörniges Gestein. Unter den dunklen Mineralien, die überhaupt nur eine sehr kleine Rolle spielen, überwiegt der Biotit. Eine deutlich eruptive Grenze mit einer schmalen aplitischen Zone trennt den Hammer Granit vom Vang Granit.

Während somit die beiden letztgenannten Granitvarietäten sich jede für sich als jünger als der angrenzende streifige Granit erweisen, so lässt sich das Altersverhältnis zwischen dem Svaneke Granit und dem Hammer Granit nicht feststellen. Der Altersunterschied zwischen den Graniten der älteren und denen der jüngeren Abteilung dürfte jedoch, wie schon oben erwähnt, nur gering sein. Sowohl mineralogisch als chemisch betrachtet haben wie der Hammer Granit so auch der Svaneke Granit grosse Aehnlichkeit mit den Varietäten der älteren Abteilung, so dass es am nächsten liegt anzunehmen, dass die Unterschiede in der Zusammensetzung auf Differentiation eines ursprünglich einheitlichen Magmas zurückgeführt werden können. Meiner Ansicht nach vertreten der Hammer Granit und der Svaneke Granit die jüngsten Differentiationsprodukte, welche erst nach Erstarrung der übrigen Teile des Granits vorgedrungen sind.

Pegmatitgänge von unregelmässigem Verlauf sind im ganzen Granitgebiet häufig. Thre Mächtigkeit ist sehr variierend, von 1-2 cm bis zu mehreren Metern. Ihr Hauptgemengteil ist immer Mikroklinperthit; Schriftgranit kommt oft vor, stellenweise ist Quarz stark vorherrschend, wie z. B. in Hvidehald bei Aakirkeby. In zweiter Linie kommen weisser, saurer Plagioklas und Biotit vor, seltener Magneteisen, Titaneisen, Molybdänglanz und Flusspat. Grössere Pegmatitmassen finden sich in Vestermarie Höjlyng, bei Skovgaard in Bodilsker, in Hvidehald, bei Nörrevig nördlich von Svaneke und an anderen Stellen.

Aplitgänge sind bei weitem nicht so allgemein wie Pegmatit, nur im Vang Granit treten sie ausserordentlich häufig auf. Wie es indessen späterhin des Näheren nachgewiesen werden soll, gehören diese Aplitgänge genetisch nicht mit dem Vang Granit zusammen, sondern sind in Wirklichkeit Ausläufer des feinkörnigen Grenzgesteins des Hammer Granits. Im gesamten übrigen Granitgebiet treten Aplitgänge nur vereinzelt auf. 


\section{Literatur über das Bornholmer Grundgebirge.}

Das lebhafte Interesse, das man um die Mitte des 18. Jahrhunderts in Dänemark der Frage, inwieweit wertvolle Rohstoffe innerhalb der Grenzen des eigenen Landes zu finden seien, entgegenbrachte, zeitigte — was Bornholm betrifft - mehrere Beschreibungen der Naturverhältnisse dieser Insel. Ganz natürlich wurde in diesen Arbeiten besonders auf diejenigen Vorkommen Gewicht gelegt, von denen man annehmen konnte, dass sie ökonomischen Wert hätten, wie z. B. die Bornholmer Kohlen, Tonarten, Zementstein u. a., und von den geologischen Arbeiten aus älterer und neuerer Zeit behandelt die weitaus überwiegende Mehrzahl die sedimentären Bildungen Bornholms, während die kristallinischen, präkambrischen Gesteine sich mit einer kürzeren Erwähnung begnügen müssen. In den Jahren 1818 und 1819 unternahmen Professor H. C. ØRsted und Justizrat L. Esmarck zusammen mit ihrem damaligen Assistenten, dem späteren Professor der Mineralogie J. G. ForсннаммеR eine Untersuchung des Bornholmer Mineralreichs. In den beiden Berichten ${ }^{1}$ ), die von dieser Kommission veröffentlicht wurden, werden Betrachtungen darüber angestellt, inwiefern das Bornholmer Grundgebirge als Gneis oder als Granit anzusehen sei. Die Verfasser betonen stark die Schwierigkeiten einer sicheren Entscheidung, was mit der variierenden Beschaffenheit des Gesteins, das an einigen Stellen granitisch körnig, an anderen streifig und schiefrig ist, zusammenhängt. Da aber Leop. v. Buch und Hausmans sich kurz vorher auf ihrer Reise durch Skandinavien nach einigem Schwanken dafür entschieden hatten, viele der skandinavischen Granite dem Gneis zuzurechnen, so entschlossen sich auch ØrSTED und Esmarck dazu, das Bornholmer Gestein als Gneis zu bezeichnen, jedoch wie CoHen u. DeEcke später ein wenig maliziös

1) H. C. Ørsted og L. Esmarck. Beretning om en Undersøgelse over Bornholms Mineralrige, udført 1818 og 1819 efter Kongelig Befalning gjennem Rentekammeret. Kiøbenhavn 1819 og 1820. 
bemerken yaugenscheinlich mehr aus Courtoisie gegen L. V. BucH, als auf Grund eigener Ueberzeugung«. In der darauf folgenden Zeit werden die Bezeichnungen Granit, Gneis und Granitgneis denn auch stets durcheinander verwendet.

Zerstreute, das Grundgebirge betreffende Beobachtungen findet man bei Vargas Bedemar: Die Insel Bornholm in geognostischer Hinsicht (Frankfurt a. Main 1819) und bei Rawert u. Garlieb: Bornholm beskreven paa en Reise i Aaret 1815 (Kjøbenhavn 1819). Im Universitätsprogramm für das Jahr 1835 gibt G. ForсhнаммеR eine kurzgefasste und für seine Zeit ausgezeichnete Uebersicht über das Bornholmer Grundgebirge mit den dazugehörigen Gangbildungen. Eine sehr grosse Fülle von Beobachtungen sind von M. Jespersen eingesammelt worden, der eine lange Reihe von Jahren als Oberlehrer am Gymnasium in Rönne tätig war; sie wurden namentlich in seinem "Liden geognostisk Vejviser« (Rönne 1865) mitgeteilt.

Die erste Specialabhandlung über das Bornholmer Grundgebirge wurde von E. Cohen und W. Deecke ${ }^{1}$ ) anlässlich der Exkursion der Deutschen Geologischen Gesellschaft nach der Insel Bornholm im Anschluss an die Allgemeine Versammlung in Greifswald 1889 ausgearbeitet. Auf Grund von Beobachtungen an Ort und Stelle und nach dem Resultat der mikroskopischen Untersuchungen halten diese Forscher das ganze Grundgebirge Bornholms für Granit und zwar wahrscheinlich als eine seiner Entstehung nach im wesentlichen einheitliche Masse. Und in einer $\mathrm{Zu}$ sammenfassung ihrer Untersuchungen fügen sie hinzu (pag. 35-36): "Nach unserer Ansicht würde also auf Bornholm ein Granit vorliegen, welcher seiner Hauptmasse nach eine deutliche Streckung und Schieferung zeigt«. Cohen u. Deecke meinten ferner nach einer kurzen Reise nach Blekinge, den Svaneke Granit mit dem Gestein in der Gegend zwischen Ronneby und Tokaryd (Karlshamn Granit) ${ }^{2}$ ) und den streifigen Granit zwischen Svaneke und Gudhjem mit dem Felsengrund westlich von Tokaryd (Blekinge Küstengneis) ${ }^{2}$ ) parallelisieren zu können; vom letzteren bemerken sie (pag. 39), dass er zwar »auf der schwedischen Uebersichtskarte als Gneis ausgeschieden ist, . . . aber gleichfalls ein streifiger Granit sein dürfte«. Auf Grund hiervon und infolge der nahen geographischen Lage halten sie das Bornholmer Grundgebirge für zugehörig zum grossen Blekinge Granitgebiet. Im übrigen geben CoHex und Deecke, wie schon bemerkt, in dieser Arbeit nur sehr unvollständige Mitteilungen über die Bornholmer Gesteinsvarietäten und deren Verbreitung.

Eine ausführliche Untersuchung im Felde und eine Einteilung der

1) E. Cohen und W. DeEcke: Ueber das krystalline Grundgebirge der Insel Bornholm. IV. Jahresber. der Geographischen Gesellschaft zu Greifswald $\mathbf{1 8 8 9 - \mathbf { 1 }} \mathbf{1 8 9 0 .}$

2) Anm. des Verfassers. 
Gesteinsvarietäten wurden erst von N. V. Ussing vorgenommen; leider aber ward es diesem hochverdienten Forscher, der im Alter von nur 48 Jahren starb, nicht vergönnt, seine zahlreichen Beobachtungen selbst zu bearbeiten. Nur in der Form von kurzen Uebersichten in »Danmarks Geologi« und ähnlichen Handbüchern hat er seine Graniteinteilung und kurze Schilderungen der Gesteinsvarietäten veröffentlicht (siehe die Literaturhinweise oben pag. 12). Die Laboratorienuntersuchung bereitete er zwar dadurch vor, dass er einige Analysen unternehmen und einige mikroskopische Präparate herstellen liess, allein er erlebte nicht das Ergebnis der Analysen, und es liegt kein Mikroskopie-Journal vor. Ausser den genannten Publikationen hat Ussing keine anderen schriftlichen Mitteilungen über das Bornholmer Grundgebirge hinterlassen als Aufzeichnungen in seinen Reisetagebüchern, und aus letzteren geht deutlich hervor, dass Ussing selbst seine Felduntersuchung nicht als abgeschlossen betrachtete.

Ich habe daher auch durch meine Untersuchung Ussing's Beobachtungen an mehreren Punkten supplieren können. In einigen Fällen freilich hat dies bewirkt, dass ich zu einer anderen Auffassung gelangt bin als er, z. B. in Bezug auf das relative Altersverhältnis der Gesteinsvarietäten. Ussing hält z. B. den Rönne Granit für jünger als die übrigen Gesteinsvarietäten, während ich keine ausreichenden Anhaltspunkte für diese Annahme habe finden können. Ferner äussert Ussing ${ }^{1}$ ), dass der Svaneke Granit wahrscheinlich durch eine alte Verwerfung vom streifigen Granit scharf getrennt worden sei. Wie es später beschrieben werden wird, hat der Svaneke Granit einen deutlich eruptiven Kontakt gegen den streifigen Granit; es geht hieraus sowie aus den zahlreichen Fragmenten des grauen streifigen Granits, welche im Svaneke Granit eingeschlossen sind, hervor, dass letzterer zu einer Zeit gefördert worden sein muss, wo der streifige Granit als festes Gestein vorlag. Es geht aus Ussing's Tagebüchern hervor, dass er zum mindesten einige der eingeschlossenen Fragmente gesehen, dass er aber die genauere Untersuchung und Deutung dieser Beobachtungen (Tagebuch 1898, pag. 114, 9.-10. August) auf später verschoben hat, und einige der kleineren Fragmente hat er mit basischen Ausscheidungen im Svaneke Granit verwechselt. Dies dürfte wahrscheinlich zu seiner oben referierten Auffassung vom Grenzverhältnis mit beigetragen haben.

Was nun die Beziehungen des Bornholmer Granits zum schwedischen Grundgebirge betrifft, so schliesst sich Ussing ohne Vorbehalt CoHen und Defcke an. So sagt $\mathrm{er}^{2}$ ): „Nach Cohen und Deecke, denen wir eine ausführliche petrographische Beschreibung des Bornholmer Grundgebirges verdanken, zeigt dieses eine bedeutende Uebereinstimmung mit

1) Ussing. Danmarks Geologi. D. G. U. III R. Nr. 2. 1904, p. 35.

2) Ussing. Handb. d. Reg. Geol. Bd. I, 2. Abt., 1910, pag. 4. 
den Graniten des südöstlichen Schwedens und kann als die südliche Fortsetzung des grossen, teilweise zu der oberen Abteilung des Archäikums gerechneten Granitgebietes von Bleking betrachtet werden«.

Dieselbe Auffassung von der Entstehung der Bornholmer Granite wird auch von G. KALB geteilt, der in seiner Arbeit über die Bornholmer Granite $^{1}$ ) die mineralogischen und chemischen Verhältnisse der Gesteine behandelt und recht eingehend auf die chemische Differentiation zu sprechen kommt. In seiner Zusammenfassung sagt er, "dass in den einzelnen Granitarten nur chemische Differentiationen eines einheitlichen Magmas zum Ausdruck kommen«.

Ich kann mich in dieser letzteren Beziehung G. KALB und den früheren Verfassern völlig anschliessen. Zu den von KALB mitgeteilten Analysen kann ich einige andere hinzufügen, nämlich einerseits die drei von Ussing vorbereiteten, andererseits eine neue vom Svaneke Granit und eine vom Alminding Granit. Leider habe ich in der »Übersicht über die Geologie von Dänemark«, D. G. U. V. R. Nr. 4. 1928, zwei fehlerhafte Analysen von Alminding Granit und Svaneke Granit mitgeteilt. Diese habe ich hier durch neue ersetzt. Ferner sind kleinere Korrektionen in der Analyse des Rönne Granits aus der Randzone bei Store Almegaard vorgenommen worden. Diese Analysen passen gut in die von KALB aufgestellte Differentiationsreihe hinein. Die jüngeren Hammer- und Svaneke Granite halte ich für späte Differentiationsprodukte, Nachschübe desselben Magmas, das die älteren Bornholmer Granitvarietäten geliefert hat.

Was dagegen die stratigraphische Lage des Bornholmer Grundgebirges betrifft, so bin ich der Ansicht, dass dieses zur älteren Abteilung des Archäikums gerechnet werden muss. Eine sichere Entscheidung dieser Frage für ein isoliertes Gebiet wie Bornholm darf jedoch kaum erwartet werden, bevor man - vielleicht vermittels der Radioaktivitätsmethode oder auf neue Wege — bestimmte Daten für eine Alterseinteilung des Grundgebirges gewinnen kann. Vom heutigen Standpunkt der Wissenschaft aus bilden die Struktur der Gesteine und ihre Differentiation beinahe die einzigen Anhaltspunkte für die Altersbestimmung. Und hier meine ich, dass sowohl die Differentiation als die gneisartige Struktur der Gesteine, welche stellenweise sogar eine typische »Eisengneisstruktur« ist, entschieden auf eine Anknüpfung an die Gneise und Gneisgranite (Urgranite) Schonens und des südwestschwedischen Grundgebirges hindeuten (vergl. unten pag. 139). Im übrigen sollte man kein allzu grosses Gewicht darauf legen, dass Cohen und Dewcke das Bornholmer Grundgebirge mit den jüngeren schwedischen Graniten parallelisieren, da sie ja, wie oben angeführt, gerade der Ansicht waren,

1) Georg Kalb: Petrographische Untersuchungen am Granit von Bornholm. Mitt. d. naturwiss. Ver. f. Neuvorpommern u. Rügen in Greifswald, 45. Jahrg., 1913. 
dass der Blekinge Küstengneis dem Gudhjem Granit äquivalent sei. Nur durch eine direkte Bestreitung des Gneischarakters des Blekinge Küstengneises wurde es ihnen möglich, die Bornholmer Gesteine zur oberen Abteilung des Archäikums zu rechnen.

Die Bornholmer Granite müssen meiner Auffassung nach am ehesten als Gneisgranite bezeichnet werden. Ich habe es jedoch nicht für notwendig erachtet, diesen langen Terminus in die Bezeichnungen der Gesteinsvarietäten einzuführen, sondern habe es vorgezogen, die hier zu Lande üblichen, von Ussing aufgestellten Varietätsbezeichnungen zu benutzen. In diesem Zusammenhang muss es entschieden bedauert werden, dass $\mathrm{K}_{\mathrm{ALB}}$ - in Uebereinstimmung mit Cohen und Deecke - den Rönne Granit "Knudsbakkegranit» nennt. Das Wort »Knudsbakke« ist von CoHEN und DEEcke konstruiert worden, welche möglicherweise damit den von M. JESPERSEN benutzten Ausdruck "Knudskirke Forbjerg« haben übersetzen wollen. Diese Benennung lässt sich indessen nicht durch eine Bornholmer Ortsbezeichnung belegen. Der in Frage kommende Hügel, der aus Rönne Granit besteht, heisst Snorrebakke. Wenn KaLB ferner die Benennung »Hauptgranit« auf den Vang Granit anwendet, dürfte dies von CoHen und DeEcke übernommen sein, von denen er sich infolge fehlender Lokalkenntnisse nicht hat freimachen können, obgleich er sich in seiner Arbeit Ussing's Kartenskizze über die Verbreitung der Granitvarietäten bedient, aus welcher hervorgeht, dass der Vang Granit nur ein kleines Gebiet einnimmt. Sollte überhaupt eine der Granitvarietäten als »Hauptgranit« bezeichnet werden, so dürfte am ehesten der graue streifige Granit wegen seiner grossen Verbreitung in Frage kommen. Da jedoch auch diese Varietät, die häufig »der gewöhnliche streifige Granit» genannt wird, von Ort zu Ort ziemlich stark wechselt, so dünkt es mir am korrektesten, die Bezeichnung "Hauptgranit» ganz fallen zu lassen. Auch die Benennung "Klondyke» für den Vang Granit halte ich für durchaus unangebracht, ja sogar für direkt irreführend, wenn sie in der Literatur zitiert wird, aus der nicht hervorgeht, dass »Klondyke« ein Steinbruch an der Westküste von Bornholm ist. Allerdings hat Ussing das völlig ungestreifte Gestein im Steinbruch »Klondyke» als Typus der Vang Granits aufgestellt, allein er fasst gerade das etwas wechselnde Gestein im Gebiet zwischen den Fischerdörfern Vang und Tejn unter dem Varietätsnamen „Vang Granit« zusammen. Es ist daher sehr zu bedauern, dass die Bezeichnungen "Knudsbakkegranit« und »Klondyke« in die Literatur des Auslandes, speziell in Handbücher wie das von Rosenbusch: „Elemente der Gesteinslehre« und in A. Osann's und H. S. Washington's Analysesammlungen eingedrungen sind. 


\title{
Geologisch-petrographische Beschrei- bung der Gesteine.
}

\author{
A. Aeltere Abteilung.
}

Im Folgenden werden die einzelnen Gesteinsvarietäten, deren geologisches Vorkommen, Verbreitung und petrographische Beschaffenheit näher besprochen. Da es nicht möglich ist, innerhalb der älteren Abteilung eine Altersfolge zwischen den einzelnen Gesteinsabarten mit Sicherheit nachzuweisen, habe ich mich dahin entschieden, erst die plagioklas- und hornblendereichen Varietäten, danach die hornblendeführenden oder hornblendefreien Biotitgranite und zuletzt die salischen Mikroklingranite und Aplite zu beschreiben.

\section{Rönne Granit.}

Der Rönne Granit nimmt ein schmales Gebiet längs des südwestlichen Randes des Granitterrains von Almegaard, NNO von Rönne, bis Baunklint in Vestermarie ein. Die grösste Ausdehnung dieses Gebiets beträgt $8-9 \mathrm{~km}$, die Breite kaum mehr als $3 \mathrm{~km}$ (in den nördlichen und östlichen Ecken ist sie doch wesentlich geringer).

Der Rönne Granit ist diejenige der Bornholmer Granitvarietäten, die zuerst abgebaut worden ist. Schon zu Anfang des 19. Jahrhunderts wurden bei Rönne Steine gebrochen, und seit 1826 hatte der Kaufmann Jens Hansen Rönne einen Bruch im feststehenden Granit auf dem Grundstück des Klippegaards, ein paar km ONO von Rönne. Von hier wurde seither der Granit sowohl nach Dänemark als nach dem Auslande geliefert. Ausser in den ansehnlichen Steinbrüchen bei Klippegaard und Stubbegaard wurde derselbe Granit für lokale Verwendung in mehreren kleinen Brüchen im Gebiet östlich von Rönne gebrochen; auch tritt er hie und da in kleinen Hügeln in der sonst gut angebauten Landschaft an den Tag. 1930 wurde ferner ein grösserer Bruch in Baunklint erschlossen. Von hier und vom Steinbruch bei Klippegaard wird der Granit für die Brücke über den Kleinen Belt geliefert. 
Der Rönne Granit ist ein mittelkörniges, dunkelgraues Gestein, das an den polierten Flächen beinahe schwarz erscheint. Im westlichen Teil des Gebiets um Klippegaard herum und in Baunklint ist das Gestein gänzlich ungestreift. Die Korngrösse ist etwas variierend; es gibt eine gröbere Varietät mit einem etwas rötlichen Feldspat und einen feinkörnigeren, ganz grauen Granit. In der Nähe der Oberfläche ist das Gestein rotbraun; diese Zone ist jedoch selten mehr als einige wenige Centimeter stark. Der grösste Teil des Feldspats ist makroskopisch grau, manchmal ein wenig grünlich; im frischen Granit, welcher von Steinhauern und Architekten »blau« genannt wird, ist er beinahe klar und durchsichtig, so dass die dunklen Gemengteile einen wesentlichen Einfluss auf die Farbe des Granits ausüben. In den gröberen Varietäten liegt die Grösse der Feldspatkörner zwischen 2-5 mm; einzelne von rundlicher oder bisweilen eher rechtangulärer Form erreichen doch einen Querschnitt von mehr als $1 \mathrm{~cm}$, aber diese Körner treten nie in einer solchen Anzahl auf, dass das Gestein dadurch porphyrisch wird. Die Quarzkörner sind gräulich, selten mehr als millimetergross. Dunkle Mineralien, Biotit und namentlich Hornblende sind reichlich vorhanden; infolge der äusserst unregelmässigen Form und der starken Verwachsung lassen sich diese Gemengteile nur schwierig mit blossem Auge unterscheiden.

Den Pegmatitgängen entlang ist der Rönne Granit, wie von KaLB betont (l. c. pag. 65-66, 79-81), stellenweise deutlich gestreift. Die Streifung ist dadurch entstanden, dass dunkle Mineralien, besonders Biotit und Titanit, in gewissen Schichten parallel mit dem Pegmatit angehäuft sind; in der Nähe desselben treten sogar centimeterbreite dunkle, feinkörnige Bänder auf, in welchen der Titanit, der im Rönne Granit sonst ziemlich spärlich vorkommt, in so reichlicher Menge vorhanden ist, dass er makroskopisch ins Auge springt. Diese Parallelstruktur in Verbindung mit der mineralogischen Zusammensetzung des Pegmatits zeigt, dass die Pegmatitgänge im Zusammenhang mit der Erstarrung des Granits gebildet worden sind. Diese gestreifte Struktur ist bei weitem kein gewöhnliches Phänomen. KaLB schreibt hierüber (l. c. pag. 80): „Uebrigens findet sich streifige Textur keineswegs immer oder gleichmässig als Begleiterscheinung der Bildung pegmatitischer Schlieren: so ist sie z. B. auf derselben Seite des Pegmatitganges in sehr verschiedener Stärke ausgebildet oder sie kann auf einer Seite fast vollständig verschwinden, während sie auf der entgegengesetzten Seite des Ganges sehr scharf ausgeprägt ist«. Entlang der grösseren Pegmatigänge, z. B. des etwa $30 \mathrm{~cm}$ mächtigen, sehr ins Auge springenden Ganges im Bruch bei Klippegaard und im alten Bruch in einem grossen Pegmatitgange unmittelbar südlich von Knuds Kirke, ist eine derartige Streifung durchaus nicht die Regel. 
Feinkörnige, besonders hornblendereiche, basische Ausscheidungen sind nicht selten vorhanden. Ausserdem trifft man hie und da Einschlüsse aus grauen oder roten Feldspatkörnern von $10-15 \mathrm{~cm}$ im Querschnitt. Meistens besteht der ganze Einschluss aus einem einzelnen Mikroklinperthit-Individuum, das von einem schmalen Rand von Plagioklas umsäumt ist. Sowohl diese pegmatitischen Feldspate wie die basischen Ausscheidungen, die sich in ihrem Aeusseren auffällig vom Granit unterscheiden, werden von den Arbeitern "Admiräle« genannt. In seltenen Fällen findet man auch einzelne grössere Labradorkristalle von 3-5 cm Länge. Und schliesslich habe ich im Rönne Granit in der Nähe des Armenhauses südwestlich von der Knuds Kirke einen eigentümlichen feinkörnigen, eisenkiesführenden Einschluss, dessen wesentlichste Bestandteile Quarz und Titanit waren, gefunden. - Auf diese verschiedenen Bildungen werden wir später zurückkommen.

Mineralogische Zusammensetzung. Die Hauptbestandteile des Rönne Granits sind: Quarz, Mikroklin, selten Orthoklas, Plagioklas, Hornblende, brauner Biotit; untergeordnet kommen Erzkörner, Apatit, Titanit, Zirkon und in sehr geringer Menge Muskovit und Kalkspat sowie Epidot und Chlorit vor.

Der Quarz ist im Rönne Granit spärlicher vorhanden als in den übrigen Granitvarietäten auf Bornholm. In den gröberen Partien erreichen die Körner manchmal einen Querschnitt von ein paar mm, meistens sind sie aber kleiner. Ein kleiner Teil des Quarzes ist in der Hornblende und im Biotit eingeschlossen. Flüssigkeitsinterpositionen, zum Teil mit beweglicher Libelle, kommen nur șelten vor; dagegen findet man häufig kleine, feste, braunviolette oder dunkelbraune Körper mit guter Kristallbegrenzung, welche — nach dem meistens hexagonalen Querschnitt, der hohen Lichtbrechung und dem Fehlen des Pleochroismus zu urteilen - aus Titaneisen bestehen. Im Basisschnitt erscheinen sie als zierliche Perlenreihen, die sich unter einem Winkel von $60^{\circ}$ schneiden. Seltener trifft man Einschlüsse von Apatit und von kleinen Muskovitblättern. Nur stellenweise hat der Quarz undulöse Auslöschung.

Feldspat. Plagioklas ist etwas reichlicher als Kalifeldspat vorhanden und tritt meistens in grösseren Kristallindividuen auf. Gewöhnlich sind die Plagioklaskörner von Mikroklin parallel umwachsen, so dass der Mikroklin einen mehr oder weniger vollständigen Mantel um den Plagioklas bildet (Fig. 1, Taf. I). Derartige Feldspatkörner haben oft eine annähernd ovale oder fast rechtanguläre Form; sie erreichen eine Grösse von $5 \times 4 \mathrm{~mm}$, der Querschnitt ist gewöhnlich $2-3 \mathrm{~mm}$. Kleine Mikroklinkörner ohne Plagioklaskern sind in den Zwischenräumen vorhanden.

Der Kalifeldspat ist im grossen und ganzen ausserordentlich frisch. 
Er besteht in der Regel aus Mikroklinperthit. Im allgemeinen ist der Albit sehr fein verzweigt, doch bildet er stellenweise breitere Bänder. Der Winkel der Perthitstreifen mit den Spaltrissen nach Basis wurde im Schnitt $\|(010)$ zu etwa $73^{\circ}$ ) gemessen. Die Verwachsungsfläche der beiden Feldspate ist somit ein steiles Orthodoma, wahrscheinlich (701), das für die beiden Kristallindividuen gemeinsam ist $\left.{ }^{2}\right)$. Kristallographisch sind die Perthitstreifen wie der Plagioklaskern orientiert und bilden eine Fortsetzung desselben. Der Kern muss daher auch mit dem ihn umgebenden Mikroklin nach der Perthitregel verwachsen sein. Orthoklasperthit wurde in vier Dünnschliffen des Granits vom Klippegaard-Bruch gefunden, u. a. in einer Probe aus dem westlichsten Aufschluss. In diesen Dünnschliffen ist Mikroklinstruktur nicht beobachtet worden. Im Schnitt $\perp$ MP hat der Kalifeldspat parallele Auslöschung und im konvergenten Lichte sieht man Bisectrix $\alpha$ in der Mitte des Gesichtfeldes.

Der Mikroklinperthit enthält oft kleine rundliche Einschlüsse von Quarz, die darin an Schriftgranit erinnern, dass sie gruppenweise auslöschen. Kleine Blätter aus Titaneisen und dünne dunkle Nadeln, die nicht genauer bestimmt werden können, kommen ziemlich oft vor, wenn auch bei weitem nicht so zahlreich wie im Quarz. Apatit ist nicht selten vorhanden, seltener Hornblende und Biotit.

Der Plagioklas ist kaum so frisch wie der Kalifeldspat. Die Mitte der Kristalle ist meistens etwas getrübt und enthält häufig einige kleine Muskovitschuppen sowie Körnchen aus Kalkspat und Epidot. Quarz ist oft schriftgranitisch im Plagioklas eingelagert. Als Einschlüsse treten Apatit, seltener Titanit und Erzmineralien auf; Verwachsungen mit anderen Mineralien werden unten näher besprochen werden.

Im allgemeinen hat der Plagioklas eine feine Zwillingsstreifung nach dem Albitgesetz, bisweilen ist er zugleich Zwilling nach dem Karlsbader Gesetz, seltener sieht man Periklinlamellen. Bavenozwillinge sind selten vorhanden. Die Kristalle haben keine ausgesprochene Zonarstruktur; eine ziemlich schmale Randzone hat jedoch einen etwas niedrigeren Anorthitgehalt. Nur wo der Plagioklas nicht an parallel angewachsenen Mikroklin grenzt, hat er eine äusserste Zone von Albit mit etwa $10 \%$ An., welcher sich sowohl durch seinen Auslöschungswinkel als durch seine niedrigere Lichtbrechung deutlich vom Hauptindividuum unterscheidet. In Plagioklaskristallen ohne Albitrand wurde gemessen:

1) Ussing gibt für Perthit von Klippegaard $74^{\circ}$ an. Medd. om Grönland. 14, 1893, p. 77.

2) Vergl. O. B. Böggild : D. Kgl. Danske Vid. Selskab. Math.-fys. Medd. VI. 3. 1924 , p. 21. 


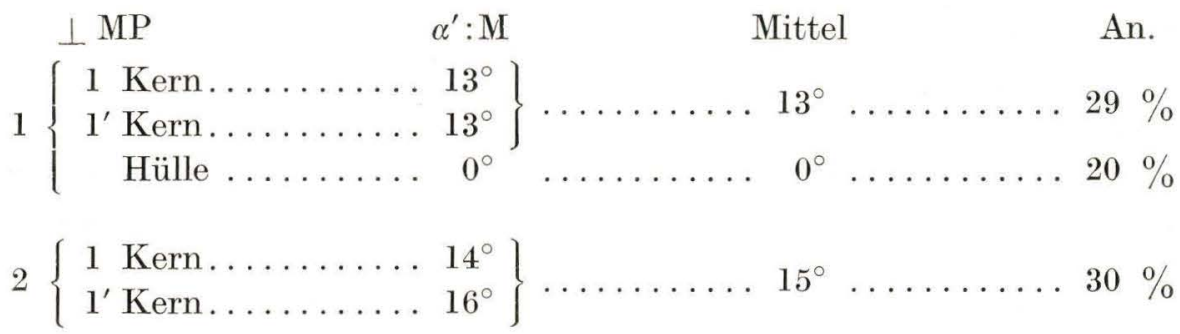

Viele der Plagioklaskristalle des Rönne Granits zeigen in polarisiertem Licht ein sehr charakteristisches, geflecktes Bild, was davon herrührt, dass der Anorthitgehalt in den verschiedenen Teilen des Plagioklaskerns etwas variiert. Der Auslöschungswinkel ist daher in gewissen Feldern merkbar kleiner als in dem sie umgebenden Teile des Plagioklases. Diese Felder sind oft rundlich oder von unregelmässiger Form, können jedoch auch annäherungsweise rechtangulär sein; in letzterem Falle entsprechen die Grenzen den Spaltrichtungen des Plagioklases. Die Grenzen sind niemals scharf, der Auslöschungswinkel ändert sich ebenmässig und zeigt, dass die sauerste Zusammensetzung dieser Felder in der Mitte liegt. Manchmal verlaufen die Zwillingslamellen unverändert durch mehrere solcher Flecken, doch sind sie meistens in den sauersten Feldern ganz oder teilweise verwischt. Fig. 2 und 3, Taf. I zeigen einen solchen gefleckten Plagioklas im Schnitt $\perp$ MP. Der grösste Teil des Plagioklases hat den Auslöschungswinkel $\alpha^{\prime}: \mathrm{M}=12^{\circ}$, während die sauersten Teile $\alpha^{\prime}: \mathrm{M}=0$ (Fig. 3, Taf. I) haben. Der Plagioklas ist somit ein Oligoklas, dessen Zusammensetzung zwischen 28-20\% An. variiert. In der schmalen Randzone an der Grenze des Mikroklinmantels wurde $\alpha^{\prime}: \mathrm{M}=4,5^{\circ}$ gemessen, was etwa $17 \%$ An. entspricht. Die saureren Felder machen meistens nur einen kleineren Teil der gesamten Kristalle aus, wie es aus Fig. 3, Taf. I hervorgeht, und in mehreren der untersuchten Dünnschliffe gibt es sogar fast keine derartigen Plagioklase. Manchmal ist der Plagioklaskern stark durchlöchert und verzweigt, und die Löcher sind teils mit Quarz, teils mit Mikroklin, der eine direkte Fortsetzung des Mikroklinmantels bildet, ausgefüllt.

Diese Struktur erinnert sehr an diejenige in dem von F. BECKE ${ }^{1}$ ) beschriebenen Plagioklas im Tonalit der Rieserferner, und es darf angenommen werden, dass der Plagioklas des Rönne Granits in analoger Weise dadurch entstanden ist, dass der frühzeitig auskristallisierte Plagioklas später zum Teil resorbiert worden ist, und dass die hierdurch entstandenen Hohlräume wieder von einer alkalireicheren Plagioklassubstanz oder in einigen Fällen mit Mikroklin oder Quarz ausgefüllt

1) F. Becke. T. M. P. M. Bd. 13, 1892, p. 389 u. p. $417-19$. 
worden sind; vom ursprünglichen Plagioklas ist somit nur ein mehr oder weniger schwammiges Kerngerüst erhalten.

Dann und wann beobachtet man kleine Verschiebungen innerhalb des Plagioklaskernes, wodurch der chemisch gleichartige Teil des Plagioklases in mehrere kleinere Bruchstücke aufgeteilt worden ist. Die Auslöschung und die Richtung der Zwillingslamellen variieren dann ein wenig von Feld zu Feld. Die Begrenzung der Bruchstücke fällt im grossen und ganzen mit den Spaltrichtungen des Plagioklases zusammen. In einem einzelnen Falle hatten die Bruchstücke sich etwas von einander getrennt, und die Zwischenräume waren mit Quarz, der innerhalb grösserer Teile des Kristalls dieselbe optische Orientierung hatte, ausgefüllt.

Bisweilen ist der Plagioklas in schriftgranitischer Weise mit Hornblende, Biotit, Quarz und Mikroklin verwachsen. So zeigt Fig. 4, Taf. I einen Teil eines grossen Plagioklasindividuums, das unten links ein skelettartiges Hornblendeindividuum und sonst zum grössten Teil unregelmässig geformte Quarzeinlagerungen, welche gruppenweise gleichzeitig auslöschen, enthält. Auch Mikroklineinlagerungen kommen ziemlich reichlich in diesem Plagioklaskristall vor; sie unterscheiden sich aber in der Reproduktion nicht deutlich vom Plagioklas. Dieser Mikroklin ist wie gewöhnlich mit dem Plagioklas parallel verwachsen und wie der äussere Mikroklinmantel orientiert. In der Mitte der Figur sieht man ein kleines Biotitblatt, und ausserhalb des abgebildeten Teiles enthält dieser Plagioklaskristall ferner ein grösseres, skelettartig verzweigtes Biotitindividuum. Der äussere Mikroklinmantel ist zum grossen Teil schriftgranitisch mit Quarz verwachsen (siehe Fig. 4, Taf. I oben links). Ferner zeugt von gleichzeitiger Auskristallisation die eigentümliche, gezackte Verwachsung, die hie und da zwischen Hornblende und Plagioklas beobachtet wird. Aus Fig. 5, Taf. I geht hervor, wie die gezackte Kontur der Hornblende gleich einem Zahnrade in die Lamellen des Plagioklases eingreift.

Schliesslich sind im Rönne Granit bei Klippegaard ein paar grössere einsprenglingsartige Plagioklaskristalle gefunden worden. Die untersuchten Kristalle waren etwa $1 \mathrm{~cm}$ im Querschnitt und gut $3 \mathrm{~cm}$ lang. Im Gestein erscheinen sie blank und schwarz. Ein Dünnschliff $\perp \mathrm{MP}$ (Fig. 6, Taf. I) zeigte, dass der Plagioklas nach dem Albit- und dem Karlsbader Gesetz verzwillingt war. Der Plagioklas ist von einem schmalen Saum aus parallel angewachsenem Mikroklin umgeben, doch gibt es stellenweise Quarzeinlagerungen zwischen dem Plagioklas und dem Mikroklin, und ein einzelnes Hornblendekorn haftet direkt an der Basisfläche des Plagioklases. Der Plagioklas selber schliesst zahlreiche kurze, dünne, undurchsichtige Nadeln ein, welche überwiegend $\|(010)$ eingelagert sind, sowie einige wenige Körnchen aus Hornblende und Biotit. 
Der Plagioklas besteht zum grössten Teil aus Labrador und hat nur eine schmale Randzone aus Oligoklas.

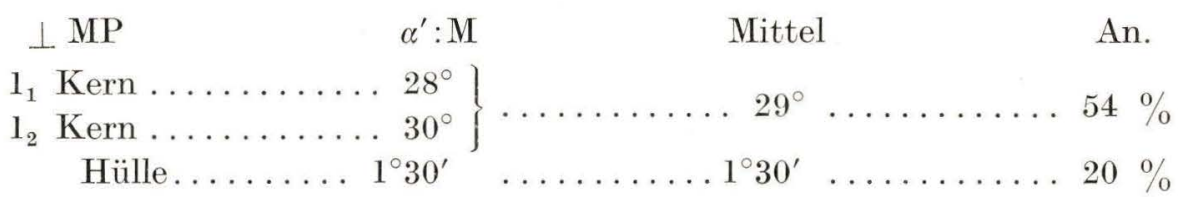

Die Lichtbrechung der Hülle ist höher als die des Canadabalsams.

Im umgebenden Granit beobachtet man die gewöhnlichen Gemengteile und die Struktur des Rönne Granits.

Die Hornblende ist grün und kräftig gefärbt. Da diese Hornblende interessante chemische und optische Verhältnisse aufweist, und da sie ausserdem in all den anderen hornblendeführenden Granitvarietäten auf Bornholm vorkommt, wird sie hier ausführlich beschrieben werden. Die Körner messen meistens 1 à $2 \mathrm{~mm}$ im Querschnitt, selten bis $3 \times 5 \mathrm{~mm}$, wogegen noch kleinere Körner häufig vorkommen. Die Form ist sehr unregelmässig, und die Hornblende ist stets mit Biotit und mit anderen der Mineralien des Granits verwachsen (Fig. 7-8 und Taf. I Fig. 5). Nichtsdestoweniger kommt es vor, dass der Querschnitt von kleinen Kristallen hie und da deutliche Spuren von Prismenflächen zeigt. Zwillingsbildung nach (100) wird dann und wann beobachtet.

Die zahlreichen Einschlüsse und Verwachsungen mit anderen Mineralien verleihen der Hornblende ein durchlöchertes oder sogar ein skelettartiges Aussehen und eine stark wellige und lappige Kontur. Als Einschlüsse treten Apatit in gut entwickelten Kristallen, Zirkon von pleochroitischen Höfen umgeben, Eisenerz und Titanit auf; manchmal sind die Erzkörner von einem Titanitrand umgeben. Biotit ist stets mit der Hornblende verwachsen, teils völlig in der Hornblende eingelagert und zwar durchgehend am häufigsten in der Randzone, teils über den Rand derselben hinauswachsend, wodurch der ganze Komplex sehr lappig und gefranst erscheint (Fig. 8). Manchmal liegt die Basis des Biotits parallel mit den Prismenflächen der Hormblende, meistens ist jedoch die Verwachsung ganz regellos. Sehr oft treten zahlreiche kleine abgerundete Quarzkörner auf und zwar besonders in der Mitte der Hornblendekristalle; mehrere derselben löschen in der Regel gleichzeitig gruppenweise aus. Bisweilen sind solche Körner in derselben Art wie ein grösseres Quarzkorn ausserhalb des Hornblendekristalls orientiert, so dass eine Art von schriftgranitischer Verwachsung von Quarz und Hornblende vorliegt. Auch Mikroklin und Plagioklas sind bisweilen in der Hornblende eingelagert, und zwar dann meistens schriftgranitisch wie vorher erwähnt. Mitunter sieht man einzelne kleine, rundliche Körner aus Kalkspat in derselben Weise wie die Quarzkörner in der Hornblende eingeschlossen. 
Die optischen Verhältnisse der Hornblende sind sehr charakteristisch. Die Lichtbrechung ist ziemlich hoch; sie ist am Pulver des Analysenmaterials mittels Immersion in eine Mischung von Monobromnaphtalin und Methylenjodid annäherungsweise bestimmt worden. Die Mischung wurde auf $\alpha^{\prime}$ beziehungsweise $\gamma^{\prime}$ der am stärksten doppelbrechenden Körner eingestellt, wonach der Brechungsquotient der Flüssigkeit mittels eines Hohlprismas aus Glas bestimmt wurde. Hierdurch fand ich $\alpha^{\prime}=$

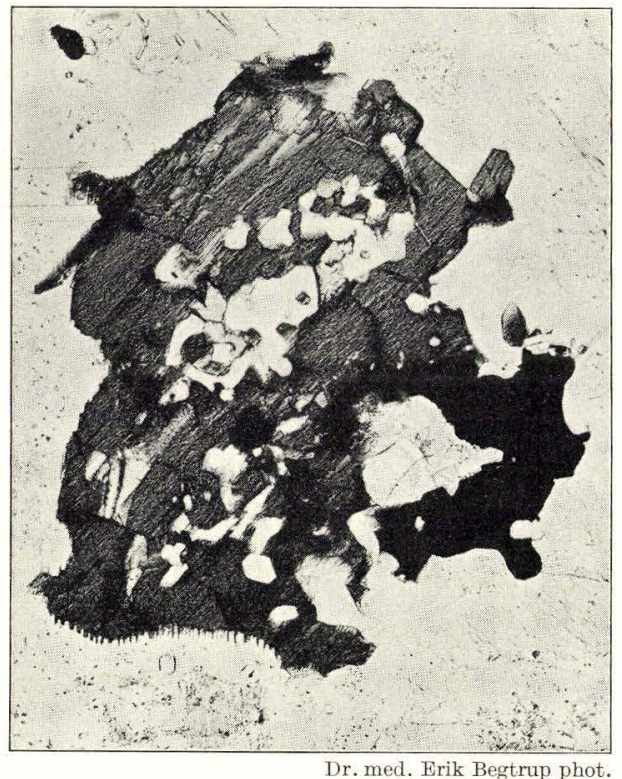

Fig. 7. Hornblende aus dem Rönne Granit, Klippegaard. Vergr. $48 \times$. Nic. $\|$. $1,676, \gamma^{\prime}=1,702$. Die Doppelbrechung ist negativ. Die Ebene der optischen Achsen (010). c: $\gamma$ $=15^{\circ}$. Der Achsenwinkel ist kleiner, als es gewöhnlich bei Hornblende der Fall zu sein pflegt. Da die Kristalle nur wenig durchsichtig sind und sich nur in ganz kleinen Bruchstükken isolieren lassen, konnte eine Achsenwinkelmessung nur in geeigneten Schnitten in den Gesteinspräparaten vorgenommen werden. Die Hyperbelscheitel sind dann recht breit und unscharf, weshalb die Messung keinen Anspruch auf allzu grosse Genauigkeit erheben kann. Nichtsdestoweniger hat eine Wertangabe ein gewisses Interesse, da ein kleiner optisçher Achsenwinkel für solche Hornblenden charakteristisch ist, deren chemische Zusammensetzungen derjenigen dieser Hornblende nahe stehen. In Schnitten senkrecht zur Bisectrix $\alpha$ wurde mit Schraubenmikrometerokular $2 \mathrm{E}=75^{\circ}$ festgestellt. Bei Annahme von $\beta=1,69$ entspricht dieser Wert $2 \mathrm{~V}=$ ca. $42^{\circ}$. Achsendispersion schwach $\varrho>v$. Pleochroismus kräftig: $\alpha$ hell graugelb mit schwach grünlichem Ton, $\beta$ olivgrün, $\gamma$ dunkel blaugrün; in dünnen Blättern wird $\gamma$ beinahe ganz blau. $\mathrm{Ab}$ sorption $\gamma \geqq \beta>\alpha$.

Für die chemische Analyse wurde die Hornblende aus dem Rönne Granit von Klippegaards Bruch isoliert. Infolge der starken Verwachsung der Hornblende mit anderen Mineralien war es notwendig, das Gestein sofort ziemlich fein zu pulverisieren. Durch Schlämmung mit Wasser wurde zuerst das ganz staubförmige Material abgeschieden, wonach ein feines Pulver gewonnen wurde, von dem sich bei der mikroskopischen Untersuchung herausstellte, dass es viele Hornblendekörner, welche nicht 
mit anderen Mineralien verwachsen waren, enthielt. Dies Pulver wurde in einem Scheidetrichter mit Bromoform behandelt, wodurch Quarz und Feldspat entfernt wurden. Mittels Methylenjodid wurde der Biotit abgetrennt, und mittels eines Magnets wurde ein wesentlicher Teil des Magneteisens extrahiert. Herr Staatsgeolog, fil. dr. NiLs Sundius in Stockholm war so liebenswürdig, auf meine Bitte hin eine letzte Reinigung des Materiels mittels CleRICI's Lösung vorzunehmen, wodurch die Hornblende von den schwereren Mineralien völlig abgetrennt wurde. Ich bin Herrn Dr. Sundius für diese wertvolle Hilfe sehr zu Dank verpflichtet. Die Analyse und Bestimmung des spez. Gewichts sind vom Herrn Stadskemist, fil. dr. G. KarL AlmsтRöm in Göteborg ausgeführt und durch MnO-Bestimmung von Herrn fil. dr. A. Bygdén in Stockholm vervollständigt worden (Tab. I).

Da der für die Hornblende des Rönne Granits besonders charakteristische $\mathrm{FeO}$-Gehalt in den von NiggLI im allgemeinen angegebenen Molekularwerten nur durch den niedrigen mgWert zum Ausdruck gelangt, ist hier auch der o-Wert mitgenom-

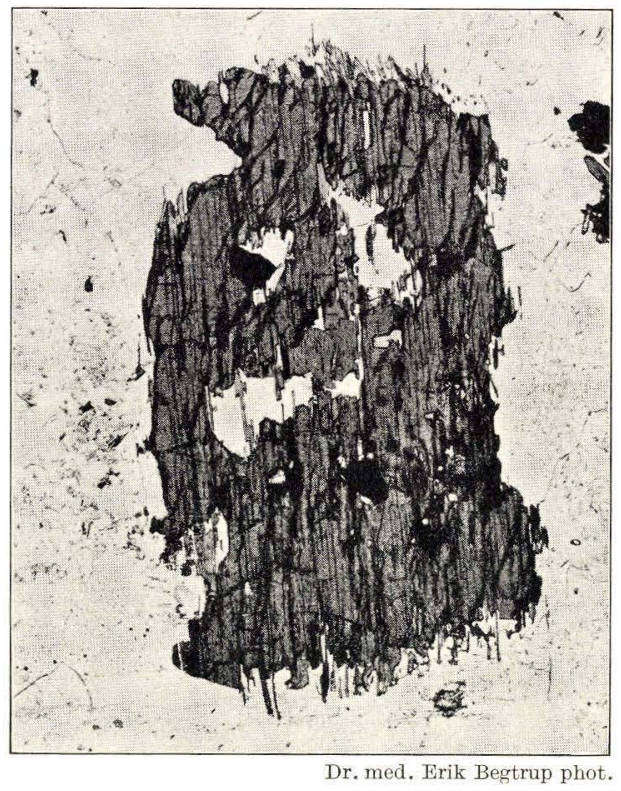

Fig. 8. Hornblende aus dem Rönne Granit, Klippegaard. Biotitfransen sehr deutlich am Rande. Vergr. $17 \times$. Nic. $\|$. men: $\mathrm{Fe}_{2} \mathrm{O}_{3}: \mathrm{FeO}+\mathrm{MnO}+\mathrm{MgO}$.

Diese Hornblende zeichnet sich durch grossen Reichtum an Eisenoxydul sowie durch relative Armut an Kalk und Magnesia aus. Zum Vergleich werden in der Tab. II einige Analysen von Hornblenden angeführt, welche sowohl in ihrer chemischen Zusammensetzung als auch in ihren optischen Eigenschaften grosse Aehnlichkeit mit der Hornblende des Rönne Granits aufweisen. Besonders charakteristisch für diese Hornblenden sind der kleine optische Achsenwinkel und die blauen oder blaugrünen Absorptionsfarben. Sie ähneln dem typischen Hastingsit, unterscheiden sich jedoch von demselben dadurch, dass die optische Achsenebene in allen Fällen || 010 ist, während sie im Hastingsit oft normalsymmetrisch ist. Der optische Achsenwinkel ist ausserdem etwas grösser als es für den Hastingsit charakteristisch ist.

Manchmal beobachtet man im Inneren der Hornblendekristalle ein stengliges Aggregat von Kalkspat. In einigen Fällen enthält das Aggregat 
Tab. I.

\begin{tabular}{|c|c|c|}
\hline & $\%$ & Mol-quot. \\
\hline $\mathrm{SiO}_{2}$ & 41.46 & 6910 \\
\hline $\mathrm{TiO}_{2}$ & 1.26 & 157 \\
\hline $\mathrm{Al}_{2} \mathrm{O}_{3}$ & 8.70 & 853 \\
\hline $\mathrm{Fe}_{2} \mathrm{O}_{3}$ & 5.84 & 365 \\
\hline $\mathrm{FeO}$ & 21.14 & 2936 \\
\hline $\mathrm{MnO}$ & 0.55 & 77 \\
\hline $\mathrm{MgO}$ & 5.50 & 1375 \\
\hline $\mathrm{CaO}$ & 11.32 & 2021 \\
\hline $\mathrm{Na}_{2} \mathrm{O}$ & 2.04 & 329 \\
\hline $\mathrm{K}_{2} \mathrm{O}$ & 1.29 & 137 \\
\hline $\mathrm{H}_{2} \mathrm{O}$ & 1.34 & 744 \\
\hline \multirow[t]{2}{*}{$\mathrm{F}$} & 0.22 & \multirow[t]{4}{*}{58} \\
\hline & 100.66 & \\
\hline \multirow[t]{2}{*}{$\mathrm{Ab} O$ für $\mathrm{F}=$} & 0.09 & \\
\hline & 100.57 & \\
\hline
\end{tabular}

Sp. Gew. 3,338.

Molekularwerte nach NigGLI:

\begin{tabular}{c|c|c|c|c|c|c|c|c|c}
\hline $\mathrm{si}$ & al & $\mathrm{fm}$ & $\mathrm{c}$ & $\mathrm{alk}$ & $\mathrm{k}$ & $\mathrm{mg}$ & $\mathrm{o}$ & $\mathrm{c} / \mathrm{fm}$ & Schnitt \\
\hline \hline $\mathrm{s1}$ & 10 & 60.5 & 24 & 5.5 & 0.30 & 0.25 & 0.14 & 0.39 & III
\end{tabular}

zugleich Eisenerz. Cohen und DeEcke schreiben von diesem Aggregat (l. c. pag. 30), dass es: wim Auftreten und nach der Begrenzung den Eindruck macht, als wäre dasselbe aus einem augitischen Kerne hervorgegangen, wie sich solche in Hornblenden der Granite nicht allzu selten finden«. Es ist jedoch nie gelungen, Ueberreste von Augit in der Hornblende nachzuweisen, und diese Karbonatausscheidungen kommen in der Tat nicht häufig im gewöhnlichen Rönne Granit vor, in den meisten Fällen sind nur ein paar der Hornblendekörner in einem Dünnschliff in dieser Weise umgewandelt und häufig sogar keine. Dagegen sind Kalkspataggregate in der Hornblende in den basischen Ausscheidungen in reichlicher Menge vorhanden.

In anderen Gesteinsproben ist die Hornblende mehr oder weniger in ein serpentinähnliches Produkt umgewandelt. In einigen Fällen sind die zentralen Teile der Hornblendekristalle am stärksten angegriffen, an anderen Stellen trifft man den Serpentin hauptsächlich in Spaltrissen oder in unregelmässigen Sprüngen. Im ersten Stadium hat das Produkt eine schmutzig gelbe Farbe, ist etwas pleochroitisch und ziemlich stark doppelbrechend. Bei fortgesetzter Umwandlung bleicht die Farbe und die Doppelbrechung nimmt ab; die Lichtbrechung ist stets höher als die des Canadabalsams. 
Tab. II.

\begin{tabular}{|c|c|c|c|c|c|c|}
\hline & 1 & 2 & 3 & 4 & 5 & 6 \\
\hline $\mathrm{SiO}_{2}$ & 41.46 & 39.86 & 40.88 & 38.26 & 38.03 & 43.24 \\
\hline $\mathrm{TiO}_{2}$ & 1.26 & 0.73 & 0.22 & 1.00 & 0.22 & - \\
\hline $\mathrm{Al}_{2} \mathrm{O}_{3}$ & 8.70 & 11.43 & 11.04 & 14.66 & 11.59 & 12.53 \\
\hline $\mathrm{Fe}_{2} \mathrm{O}_{3}$ & 5.84 & 4.72 & 7.56 & 4.32 & 6.81 & 5.85 \\
\hline $\mathrm{FeO}$ & 21.14 & 20.61 & 17.41 & 22.66 & 23.72 & \\
\hline $\mathrm{MnO}$ & 0.55 & - & 1.32 & 0.35 & 1.11 & 18.32 \\
\hline $\mathrm{MgO}$ & 5.50 & 5.87 & 5.92 & 4.23 & 2.87 & 4.93 \\
\hline $\mathrm{CaO}$ & 11.32 & 10.06 & 10.46 & 9.67 & 9.75 & 9.34 \\
\hline $\mathrm{Na}_{2} \mathrm{O}$ & 2.04 & 3.24 & 3.75 & 1.34 & 2.30 & 2.92 \\
\hline $\mathrm{K}_{2} \mathrm{O}$ & 1.29 & 1.48 & 0.78 & 1.98 & 1.90 & 1.24 \\
\hline $\mathrm{H}_{2} \mathrm{O}$ & 1.34 & 2.03 & 1.16 & 1.97 & 1.20 & 1.57 \\
\hline $\mathrm{F}$ & 0.22 & 一 & - & 0.09 & 0.05 & - \\
\hline \multirow[t]{2}{*}{$\mathrm{Ab} O$ für $\mathrm{F}$} & $\begin{array}{r}100.66 \\
0.09\end{array}$ & 100.03 & 100.50 & $\begin{array}{r}100.53 \\
0.03\end{array}$ & $\begin{array}{r}99.55 \\
0.02\end{array}$ & 100.00 \\
\hline & 100.57 & & & 100.50 & 99.53 & \\
\hline Sp. Gw. & 3.338 & 3.408 & 3.418 & & & \\
\hline & $\alpha^{\prime} 1.676$ & $\alpha 1.678$ & $\alpha 1.691$ & & & \\
\hline & $\gamma^{\prime} 1.702$ & $\gamma 1.696$ & $\gamma 1.707$ & & & \\
\hline$\gamma \div \alpha$ & & 0.018 & 0.016 & & & 0.021 \\
\hline Opt. Orient. & $\mathrm{b}=\beta$ & $\mathrm{b}=\beta$ & $\mathrm{b}=\beta$ & $\mathrm{b}=\beta$ & $\mathrm{b}=\beta$ & \\
\hline$c: \gamma$ & $15^{\circ}$ & $18^{\circ}$ & $16^{\circ}$ & $23^{\circ}-25^{\circ}$ & $18^{\circ}-19^{\circ}$ & $15^{\circ}-17^{\circ}$ \\
\hline $\begin{array}{l}\text { Opt. Charakt. } \\
2 \mathrm{E}\end{array}$ & $\begin{array}{c}\div \\
75^{\circ}\end{array}$ & $\div$ & $\div$ & $\frac{\div}{\text { ca. } 70^{\circ}}$ & $\begin{array}{c}\div \\
50^{\circ}-55^{\circ}\end{array}$ & $\div$ \\
\hline Dispersion & $\varrho>v$ & & & $\varrho>v$ & $Q>v$ & \\
\hline Pleochr. $\alpha$ & $\begin{array}{l}\text { hell grünlich } \\
\text { gelb }\end{array}$ & & $\begin{array}{c}\text { hell bräunlich } \\
\text { gelb }\end{array}$ & hell gelbbraun & $\begin{array}{l}\text { hell gelblich } \\
\text { grün }\end{array}$ & gelb \\
\hline " $\quad \beta$ & olivgrün & & bräunlichrot & olivgrün & olivgrün & grün \\
\hline$\Rightarrow \quad \gamma$ & tief blaugrün & & $\begin{array}{l}\text { tief braun } \\
\text { mit einem } \\
\text { Stich ins } \\
\text { Grüne }\end{array}$ & $\begin{array}{c}\text { blaugrün bis } \\
\text { blau }\end{array}$ & tief blaugrün & blaugrün \\
\hline Absorption & $\gamma \geq \beta>\alpha$ & & $\gamma>\beta>\alpha$ & $\gamma=\beta>\alpha$ & $\gamma>\beta>\alpha$ & $\gamma>\beta>\alpha$ \\
\hline
\end{tabular}

1. Hornblende aus Rönne Granit, Klippegaard.

2. Hastingsit, Shoal Creek. W. Kunitz. N. Jb. B-B. 60. Abt. A. 1930. pag. 245.

3. Barkevikit, Skudesundsskjär. Langesundsfjord. W. Kunitz ib. und W. C. BrögGer. Zeitschr. f. Kryst. 16, 1890. p. 412.

4. Hornblende aus Pegmatit, Stockholm. P. GeiJer. G. F. F. 35, 1913. pag. 126 und 138.

5. Hornblende aus Pegmatit, Österskjär. P. GeiJer: ib. pag. 146-47.

6. Hornblende aus Kirunagrünstein, Pahtosvaara (aus der Gesteinsanalyse berechnet). N. Sundius i Beitr. z. Geol. d. südlichen Teils des Kirunagebiets. 1915.

Der Biotit ist im frischen Zustand braun und kräftig pleochroitisch; $\alpha$ hell gelb, $\gamma$ sehr dunkel braun. In weniger frischen Gesteinsproben ist der Biotit etwas grünlich. Die Doppelbrechung ist hoch, der optische Achsenwinkel $=0$ oder sehr klein. Die Lichtbrechung ist hoch, im 
Pulverpräparat fand ich $\beta=\gamma>1,6573$ (Monobromnaphtalin). Der Biotit ist also genauer bezeichnet ein Lepidomelan.

Der Biotit hat wie die Hornblende eine sehr unregelmässige Form, meistens ist er stark lappig und löcherig, manchmal skelettartig entwickelt. Die Korngrösse ist selten grösser als $1 \mathrm{~mm}$. Die Einschlüsse sind im wesentlichen dieselben wie bei der Hornblende. Um den Zirkon herum findet man stark pleochroitische Höfe; dasselbe gilt — wenn auch etwas weniger ausgesprochen - für den Apatit. Ausser den oben erwähnten Verwachsungen mit Hornblende und Plagioklas beobachtet man oft, dass der Biotit ein Erzkorn dergestalt umschliesst, dass es scheint, als hätte das Erzkorn dem Biotit als Kristallisationszentrum gedient. An einigen Stellen tritt der Biotit nur dort auf, wo das Erzkorn an Feldspat grenzt, und scheint in diesem Falle einen »Reaktionsrand« zu bilden, während er an jenen Stellen, wo Erz an Quarz grenzt, fehlt. In grösseren Biotitindividuen ist der zentrale Teil im allgemeinen kompakt, während die Randzone stark gefranst und in myrmekitähnlicher Weise mit Quarz verwachsen ist. Namentlich tritt dieser »Biotitmyrmekit« dort auf, wo der Biotit mit Feldspat in Berührung ist. SEDERHOLM, der diese Bildungen sehr ausführlich beschrieben hat $^{1}$ ), erklärt derartigen Biotit für ursprünglich primäre Kristalle, die am Ende der Kristallisation des Magmas ausgeschieden sind und sich dann später, nach Verfestigung der meisten Bestandteile des Gesteins und unter Einwirkung der noch vorhandenen Lösungen und Gase kristalloblastisch auf Kosten des Feldspates entwickelt haben. Im Rönne Granit findet man in einzelnen Fällen eine geringe Menge Flusspat zwischen den Biotitblättern ausgeschieden, woraus man schliessen kann, dass Fluor während der Autometamorphose tätig gewesen ist. In Fig. 9 grenzt der Biotit an zwei Stellen an Myrmekit, sonst an Feldspat und Hornblende. Während Sederholm den Biotitmyrmekit nur als eine an der Grenze zwischen Biotit und Feldspat vorkommende Bildung erwähnt, findet man im Rönne Granit diese Implikation auch an solchen Stellen, wo der Biotit an Quarz grenzt (Fig. 1, Taf. II). Man sieht dann, dass die Quarzstengel in derselben Weise zwischen den Biotitfransen orientiert sind wie das angrenzende Quarzkorn. Möglicherweise liegt hier also eine primäre gleichzeitige Auskristallisation vor, oder vielleicht ist ein älteres Biotitindividuum von noch nicht erstarrtem Quarz korrodiert worden.

Sederholm hat diese Art Verwachsungen von Biotit (Biotit-QuarzSymplektit) in vielen verschiedenen Gesteinsarten: Anorthosit, dioritischen, monzonitischen und granitischen Gesteinsarten beobachtet; sehr häufig hat er sie in Rapakiwi und in schwach metamorphen, jüngeren archäischen Graniten in Finnland und Schweden vorgefunden.

\footnotetext{
1) J. J. Sederholm. Bull. Com. géol. de Finlande. Nr. 48. 1916.
} 
Apatit ist reichlich vorhanden und in der Regel in guter Kristallform; grössere Individuen können doch auch unregelmässig begrenzt sein.

Titanit kommt in etwas variierender Menge vor, in einem Dünnschliff recht reichlich und im nächsten spärlich. Nur selten ist er idiomorph, meistens tritt er in Form von unregelmässigen Körnern zusammen mit Hornblende, Biotit, Erzmineralien, Apatit und Zirkon auf, und einen

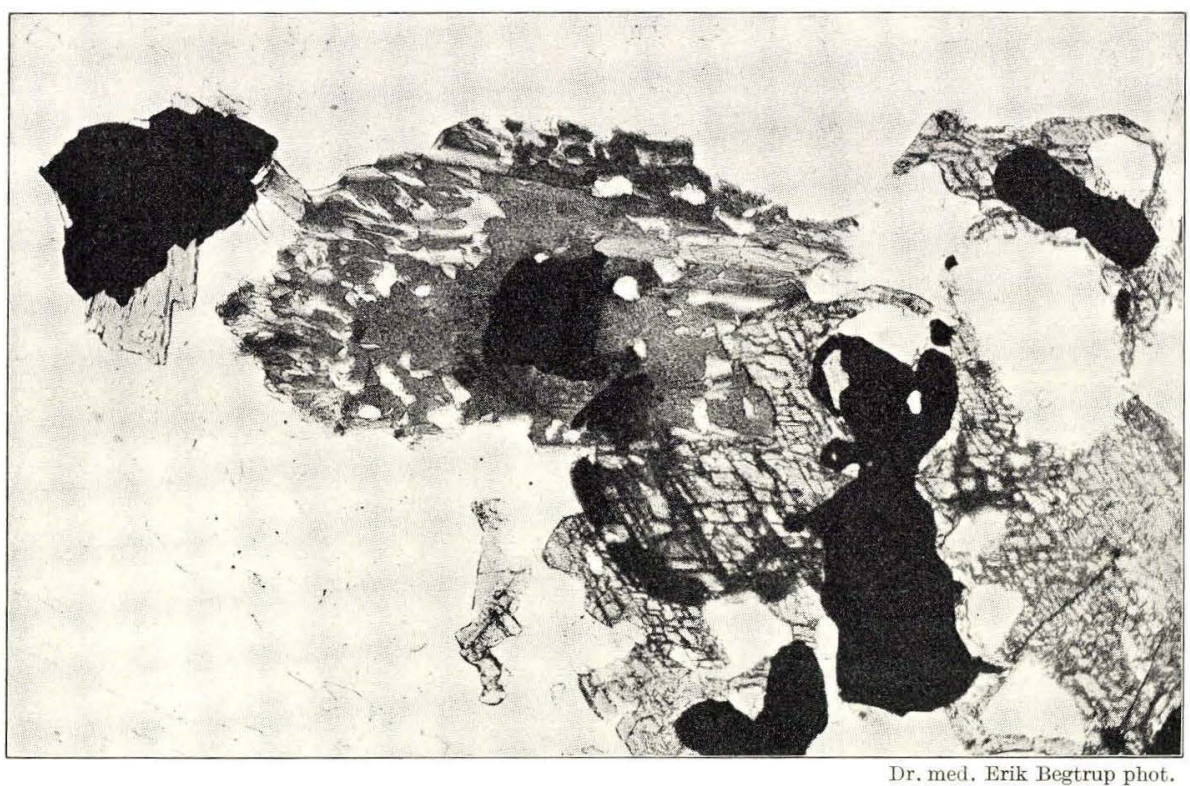

Fig. 9. Biotit aus dem Rönne Granit, Klippegaard, myrmekitisch mit Quarz verwachsen. In der Mitte ein Erzkorn. Rechts Hornblende mit Erzkörnern u. Quarzeinschlüssen. Vergr. $67 \times$. Nic. $\|$.

sehr wesentlichen Teil findet man als Titanitrand um die Erzkörner herum. Dieser letztere Titanit ist zweifellos aus den Erzkörnern sekundär ausgeschieden. In denjenigen Dünnschliffen, wo der Titanitrand der Erzkörner ganz oder teilweise fehlt, ist Titanit nur spärlich vorhanden. Nur wo der Rönne Granit an Pegmatitgängen entlang gestreift ist, tritt der Titanit in grösseren Anhäufungen auf.

Die Erzkörner bestehen grösstenteils aus titanhaltigem Magneteisen, das sich nur unvollständig mit Hilfe eines Magneten entfernen lässt. Das extrahierte Erzpulver gibt eine deutliche Ti-Reaktion. Eisenkies ist stets vorhanden, jedoch nur in geringer Menge.

Ferner gibt es eine unbedeutende Menge Orthit. Als Umwandlungsprodukte findet man stellenweise häufig ein wenig Epidot, Serpentin, Muskovit und Chlorit. Nur an einzelnen Stellen treten diese Mineralien in beträchtlicheren Mengen auf. 
Aus obiger Beschreibung geht hervor, dass die Struktur des Rönne Granits am einfachsten als ein Produkt magmatischer Korrosion während der Auskristallisation des Gesteins aufźufassen ist. Sowohl die unregelmässige Auslöschung des Plagioklases als die lappige und löcherige Form der Hornblende und des Biotits finden ihre natürliche Erklärung durch die Annahme, dass diese Mineralien zu einer gewissen Zeit nicht länger in der Restlösung des Magmas bestandfähig gewesen, sondern teilweise gelöst worden sind, und dass dann die Löcher mit jüngeren Mineralien, vor allem mit Quarz, ausgefüllt worden sind. Es ist möglich, bis zu einem gewissen Grade eine Reihenfolge in der Ausscheidung festzustellen. Die akzessorischen Mineralien sind an ihren guten Kristallformen und auf Grund ihrer Einlagerung in anderen Mineralien als die zuerst auskristallisierten unmittelbar kenntlich. Ebenso deutlich sind die Beziehungen des Plagioklases zum Mikroklin, stellenweise ist der Plagioklas jedoch teilweise resorbiert und wieder mit saurerem Plagioklas, Mikroklin und Quarz ausgeheilt worden. Die Hornblende ist in einzelnen Fällen idiomorph gegen Plagioklas; die schriftgranitische Verwachsung und das gezackte Eingreifen der Hornblende in die Plagioklaslamellen zeigen jedoch, dass die Kristallisation dieser Mineralien zum mindesten teilweise gleichzeitig stattgefunden hat. Die poikilitische Ausbildung der Hornblende und deren zahlreiche Quarzeinschlüsse zeigen ausserdem, dass die Hornblende in einem späteren Stadium des Kristallisationsprozesses stark korrodiert worden ist. Wie schon erwähnt kann man den Biotit schriftgranitisch mit dem Plagioklas verwachsen finden. Bei der Verwachsung mit der Hornblende ist der Biotit teils in der Randzone der Hornblende, teils im Kerne der Hornblendekristalle besonders angereichert, und dann meistens in Verbindung mit Quarz, Erz und anderen Einschlüssen. Man erhält daher den Eindruck, dass die Biotitbildung hier zum Teil im Anschluss an die Korrosion der Hornblende vor sich gegangen ist. Möglicherweise ist der Biotit durch Reaktion zwischen Hornblende und Feldspat bei Ausscheidung von Quarz und kleinen Mengen von Kalkspat entstanden. Das für die Biotitbildung notwendige $\mathrm{K}_{2} \mathrm{O}$ dürfte vielleicht durch die Myrmekitbildung in Lösung gebracht worden $\operatorname{sein}^{1}$ ). Und ferner ist möglicherweise der Biotit in einem noch späteren Stadium als Reaktionsrand um die Erzkörner herum ausgeschieden worden. Die Umwandlung des Titaneisens in Magnetit mit Titanitrand ist vermutlich gleichfalls während der letzten Periode der Gesteinsverfestigung vor sich gegangen.

In seinem Aussehen und in seiner Frische variiert der Rönne Granit nur wenig, rein örtlich aber kommen einzelne Abweichungen von der gewöhnlichen Beschaffenheit vor. Im westlichsten Aufschluss im Stein-

1) Vergl. Тн. Vogt: N. G. U. Nr. 121, 1927, pag. 413 ff. 
bruch bei Klippegaard hat der Granit eine etwas hellere Färbung mit einem grünlichen Ton; ausserdem ist er von recht lockerer Beschaffenheit und eignet sich nicht dafür poliert zu werden, ist dagegen ausgezeichnet für Skulpturarbeiten. Ein Dünnschliff dieses Granits wies keinen wesentlichen Unterschied in der Zusammensetzung auf. Der Feldspat ist ebenso frisch wie gewöhnlich. Plagioklas ist schätzungsweise vielleicht ein wenig reichlicher vorhanden als sonst; der Kalifeldspat besteht aus Orthoklasperthit. Der Biotit ist braun und vollkommen frisch. Nur die Hornblende scheint häufiger als sonst etwas zersetzt zu sein; die meisten Kristalle enthalten eine grössere oder kleinere Menge des obenerwähnten serpentinähnlichen Umwandlungsproduktes.

Im östlichsten Teile des Rönne Granit Gebiets, etwa $1 \mathrm{~km}$ westlich von Imminggaard, kommt ein Granit vor, dessen Hornblende in hohem Masse unter Ausscheidung von kleinen Erzkörnern in Serpentin umgewandelt ist. Hier ist auch der Biotit etwas zersetzt, teils ist er etwas chloritisiert, teils scheint er unter Ausscheidung von Erzpartikeln partiell gelöst; in letzterem Falle ist er stark pleochroitisch, und die Farbe ist schmutzig braungrün. Das Gestein als solches ist bräunlich und heller als der gewöhnliche Rönne Granit. Die Farbe rührt daher, dass der Feldspat ein bräunliches Pigment einschliesst, und sowohl Feldspat- als Quarzkörner sind mit einer dünnen bräunlichen Rinde überzogen. Ausserdem sind die Umwandlungsprodukte der dunklen Mineralien oft in die Spaltrisse des Feldspates eingedrungen.

Eine ähnliche Umwandlung von Hornblende und von Biotit findet man ferner in einem rötlichen, ein wenig gestreiften Granit bei Kroggaard im südwestlichsten Teile des Granitgebietes. Und dasselbe serpentinähnliche Aggregat tritt in den halbumgewandelten Klumpen von Rönne Granit im Kaolin als Umwandlungsprodukt der Hornblende auf.

An der Südseite von Degnebakke, südöstlich von Knuds Kirke, tritt ein stark verklüfteter, roter Granit an den Tag. Im Dünnschliff sieht man sofort, dass das Gestein ein umgewandelter Rönne Granit ist. Sowohl der Mikroklin als der charakteristische Plagioklas sind trotz der rötlichen Pigmentierung deutlich erkennbar. Apatit und Erzkörner sind vollkommen frisch, die Hornblende aber ist ganz verschwunden und der Biotit in Chlorit umgewandelt. Dafür ist Epidot in reichlicher Menge vorhanden: er nimmt nicht nur den Platz der dunklen Mineralien ein, sondern findet sich auch im Inneren der Plagioklaskristalle und in unregelmässigen Rissen im Gestein.

Diese Umwandlungsprozesse und Neubildungen von Mineralien, die Epidotisierung, Serpentinisierung und Chloritisierung sind solche Vorgänge, die normal in der postmagmatischen, pneumatolytischen oder hydrothermalen Periode der Eruptivgesteine vor sich gehen, und es wäre denkbar, dass sie auch hier im Anschluss an die Verfestigung des 
Rönne Granits entstanden wären. Aber es muss doch bemerkt werden, dass sich an anderen Stellen auf Bornholm ähnliche Umbildungen des Granits finden, die zweifellos von dem viel später hervorbrechenden Diabas verursacht worden sind. So hat z. B. eine durchgreifende Epidotisierung des Granits längs dem Diabas bei Salene und eine starke Chloritisierung in Verbindung mit reichlicher Kalkspatausscheidung am Diabas bei Ypnasted stattgefunden. Es ist daher möglich, dass auch diese Umbildungen im Rönne Granit durch spätere Einwirkungen hervorgerufen worden sind. Im besonderen scheinen gewisse Umstände dafür zu sprechen, dass die Serpentinisierung der Hornblende in einer wesentlich späteren Zeit vor sich gegangen sein kann.

Man hat allen Grund anzunehmen, dass der Rönne Granit gegen Westen durch eine Verwerfung vom sedimentären Vorlande geschieden ist, und dass der Granit in der Nähe dieser Verwerfung stark verklüftet ist. Nach Norden zu gibt es unbestreitbare Spuren einer solchen Verwerfung im Granithorst bei Sorthat. In der Fortsetzung desselben liegt längs dem Granitrande die schmale, langgestreckte Kaolinlagerstätte, und ich halte es für wahrscheinlich, dass die Bildung des Kaolins von Spaltzonen im Untergrunde bedingt ist. Im halbkaolinisierten Granit, der die Ostwand in der Kaolingrube von Buskeværk bildet, ist die Verklüftung des Granits sehr auffallend. In der Nähe des Granitrandes hat der Rönne Granit eine ausgesprochene Neigung zum Zerbröckeln. Dies lässt sich besonders im Walde bei Kanegaard am südöstlichen Ende der Kaolinlagerstätte feststellen, und auch schon früher hat man dieselbe Beobachtung in alten Kaolingruben östlich von Buskeværk gemacht. Der Granit löst sich in konzentrischen Schalen um grosse, rundliche, feste Klumpen in derselben Weise wie bei den grossen Klumpen von halbumgewandeltem Rönne Granit, die namentlich in der Torneværk Grube im Kaolin eingeschlossen gefunden wurden. Im Granitbruch bei Stubbegaard, etwa $0,5 \mathrm{~km}$ östlich vom Kaolin, findet man an mehreren Stellen zerbröckelnden Granit oder stark rotpigmentierten Granit den Spalten entlang. Endlich gibt es in der südwestlichsten Ecke des Granitgebietes, östlich von der Station Robbedale, einen ausserordentlich stark bröckelnden und verwitterten Granit, der übrigens nicht zum Rönne Granit gehört (siehe weiter unten, pag. 60). Es hat sich an verschiedenen Stellen auf Bornholm bestätigt, dass der Granit geneigt ist an Stellen zu zerbröckeln, wo er stark verklüftet ist, z. B. in der Gegend um Aakirkeby, in den Helligdomsklippen und vor allen Dingen an mehreren Stellen im Svaneke Granit. Man darf daher wohl auch in den hier dargelegten Verhältnissen ein Zeugnis dessen sehen, dass der Rönne Granit in der Nähe des Granitrandes stark verklüftet ist.

Es scheint, als ob die Serpentinisierung der Hornblende am stärkesten in der Nähe der Grenze des Granitgebietes vorgeschritten ist; im übrigen 
habe ich auf Grund von zahlreichen Beobachtungen konstatiert, dass diese Umbildung besonders charakteristisch für den halbkaolinisierten Granit ist. Ich halte es daher für wahrscheinlich, dass die Umwandlung der Hornblende an den genannten Stellen in der Nähe der Grenze des Granits von denselben Agenzien — wohl hauptsächlich kohlensäurehaltigem Wasser — verursacht ist, die bei anhaltender Einwirkung zur Kaolinbildung geführt haben und die in reichem Masse den stark verklüfteten Granit haben durchtränken können.

Chemische Zusammensetzung. Es liegen drei Analysen des Rönne Granits vor, die in der beigefügten Tabelle III mitgeteilt werden. Die Analysen I und II sind von Prof. Dr. Max Ditrrich, Heidelberg, ausgeführt und von G. KALB mitgeteilt worden. Analyse III wurde auf

Tab. III.

\begin{tabular}{|c|c|c|c|c|c|c|c|c|c|}
\hline \multirow[b]{2}{*}{$\mathrm{SiO}_{2}$} & \multirow{2}{*}{$\frac{\mathrm{I}}{64.49}$} & \multirow{2}{*}{$\begin{array}{c}\text { Mol. } \\
\text { quot. } \\
\text { von I }\end{array}$} & \multirow{2}{*}{$\begin{array}{c}\begin{array}{c}\text { Mol. } \\
\% \\
\text { von I }\end{array} \\
71.34\end{array}$} & \multirow{2}{*}{$\frac{\text { II }}{64.13}$} & \multirow{2}{*}{$\begin{array}{c}\text { III } \\
65.39\end{array}$} & \multicolumn{2}{|c|}{$\begin{array}{c}\text { Norm } \\
\text { aus I berechnet }\end{array}$} & \multicolumn{2}{|c|}{$\begin{array}{l}\text { Modus } \\
\text { aus III berechnet. }\end{array}$} \\
\hline & & & & & & $Q$ & 18.00 & \multirow{9}{*}{$\begin{array}{l}\text { Quarz } \\
\text { Mikroklin } \\
\text { Albit } \\
\text { Anorthit } \\
\text { Hornblende } \\
\text { Biotit } \\
\text { Erz } \\
\text { Titanit } \\
\text { Apatit }\end{array}$} & 20.85 \\
\hline $\mathrm{TiO}_{2}$ & 1.22 & 152 & 1.01 & 0.99 & 0.28 & Or & 26.13 & & 22.57 \\
\hline $\mathrm{Al}_{2} \mathrm{O}_{3}$ & 13.67 & 1340 & 8.89 & 13.57 & 14.32 & $\mathrm{Ab}$ & 30.39 & & 29.18 \\
\hline $\mathrm{Fe}_{2} \mathrm{O}_{3}$ & 1.63 & 102 & - & 2.40 & 7.85 & An & 8.06 & & 8.50 \\
\hline $\mathrm{FeO}$ & 4.42 & 614 & 5.43 & 4.11 & - & $\Sigma$ sal & 82.58 & & e 9.96 \\
\hline $\mathrm{MnO}$ & 0.14 & 20 & 0.13 & 0.06 & - & & & & 5.00 \\
\hline $\mathrm{MgO}$ & 1.38 & 345 & 2.29 & 1.45 & 1.12 & di & 3.25 & & 3.42 \\
\hline $\mathrm{CaO}$ & 3.12 & 557 & 3.70 & 2.91 & 3.53 & hy & 6.89 & & 0.69 \\
\hline $\mathrm{Na}_{2} \mathrm{O}$ & 3.57 & 576 & 3.82 & 4.31 & 3.64 & $\mathrm{mt}$ & 2.32 & & 0.90 \\
\hline $\mathrm{K}_{2} \mathrm{O}$ & 4.40 & 468 & 3.12 & 3.46 & 4.40 & il & 2.28 & \multirow{7}{*}{$\div \mathrm{P}_{2} \mathrm{O}_{5}$} & 101.07 \\
\hline $\mathrm{P}_{2} \mathrm{O}_{5}$ & 0.58 & 41 & 0.27 & 0.56 & - & ap & 1.34 & & 0.41 \\
\hline $\mathrm{CO}_{2}$ & - & - & - & 0.59 & - & $\Sigma$ fem & 16.08 & & 100.66 \\
\hline $\mathrm{H}_{2} \mathrm{O}$ über $110^{\circ}$ & 1.11 & 617 & - & 1.45 & - & & 98.66 & & \\
\hline $\mathrm{H}_{2} \mathrm{O}$ unter $110^{\circ}$ & 0.46 & 一 & - & 0.37 & - & \multirow{3}{*}{\multicolumn{2}{|c|}{$\begin{array}{l}\text { "II. 4. 2. } 3 . \\
\text { Adamellose }\end{array}$}} & & \\
\hline \multirow[t]{2}{*}{ Glühverlust } & - & 一 & - & 一 & 0.13 & & & & \\
\hline & 100.19 & - & 100.00 & 100.36 & 100.66 & & & & \\
\hline
\end{tabular}

Dichte 2.758

Aktueller Durchschnittsplagioklas $\mathrm{Ab}_{77 \cdot 4} \mathrm{An}_{22 \cdot 6}$

Aktueller Durchschnittsfeldspat $\mathrm{Or}_{37 \cdot 5} \mathrm{Ab}_{48 \cdot 4} \mathrm{An}_{14 \cdot 1}$

\begin{tabular}{r|c|ccc|ccc|c|c|} 
Molekularwerte nach OsANN & $\mathrm{s}$ & $\mathrm{A}$ & $\mathrm{C}$ & $\mathrm{F}$ & $\mathrm{a}$ & $\mathrm{c}$ & $\mathrm{f}$ & $\mathrm{n}$ & $\mathrm{k}$ \\
von I & 72.4 & 6.9 & 2.0 & 9.6 & 11.5 & 3.0 & 15.5 & 5.5 & 1.31
\end{tabular}

I Rönne Granit. Anal. M. Ditrtrich.

II Rönne Granit am Pegmatit. Anal. M. Diтtrich.

III Rönne Granit, Klippegaard. Anal. Chr. Detrefsen. 
Ussing's Aufforderung von Herrn Laboratorienvorsteher Chr. DetLEFSEn, Kopenhagen, ausgeführt. Die mineralogische Zusammensetzung ist aus der Analyse III unter Berücksichtigung einer RosiwalMessung berechnet. Diese Analyse ergibt für die Hauptgemengteile Resultate, die aufs genaueste mit den auf geometrischem Wege gefundenen Werten übereinstimmen. Dabei wurde von Zirkon und anderen unwesentlichen Bestandteilen abgesehen. Geometrisch wurde bestimmt $0,90 \%$ Apatit, was etwas weniger ist als was dem $\mathrm{P}_{2} \mathrm{O}_{5}$-Gehalt der Analyse I entspricht. Für Biotit ergab die Berechnung folgende Zusammenzetzung:

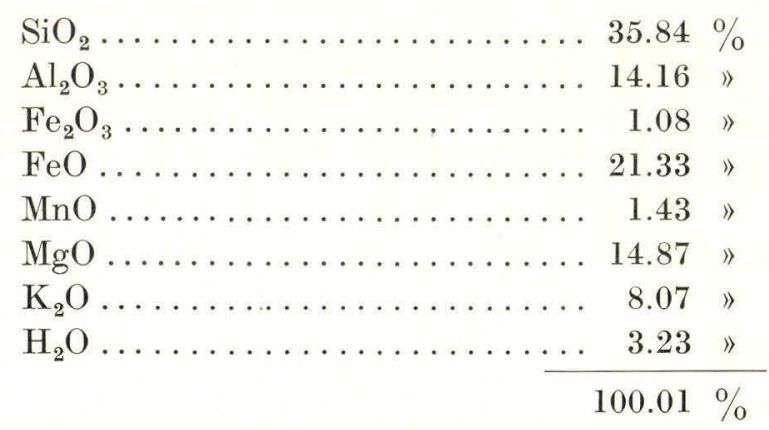

Aus Niggli's Formel geht hervor, dass der Rönne Granit wohl am ehesten zu dem normalgranitischen Magmatypus gehört, dass er jedoch wegen seines recht niedrigen Quarzgehalts und seines relativ hohen Alkaliwerts dem syenitgranitischen Magmatypus nahe steht.

Basische Ausscheidungen. Feinkörnige dunkle Ausscheidungen sind öfters im Rönne Granit vorhanden. In Bezug auf Grösse variieren sie meistens von einigen wenigen cm im Querschnitt bis zu Faustgrösse. Sie bestehen aus den gewöhnlichen Gemengteilen des Rönne Granits, enthalten aber dunkle Mineralien und besonders Hornblende in weit grösserer Menge (Taf. II Fig. 2).

Quarz ist nur spärlich vorhanden. Mikroklin tritt in wesentlich geringerer Menge als Plagioklas auf. Der Plagioklas hat keinen Mikroklinmantel; die Form ist im allgemeinen unregelmässig. Kleine Plagioklaskristalle haben keine Zonarstruktur; in den grösseren Kristallen unterscheidet sich die Zusammensetzung der Randzone nur wenig von der des Kernes. In der Mitte eines grösseren Kristalls wurde im MP-Schnitt $\alpha^{\prime}: \mathrm{M}=5^{\circ}$ gemessen, entsprechend Oligoklas mit etwa $23 \%$ An.; in der Randzone: $\alpha^{\prime}: \mathrm{M}=0$, entsprechend etwa $20 \%$ An. Die grösseren Plagioklaskristalle schliessen in der Regel kleine, wahllos angeordnete Körner der übrigen Mineralien, besonders der Hornblende, ein. Die Mitte der Kristalle ist meistens etwas unfrisch. Stellenweise ist der Plagioklas bei- 
nahe leistenförmig entwickelt, und zwar in einer Weise, die stark an Diabasplagioklas erinnert.

Die Hornblende stimmt in ihren optischen Verhältnissen mit der Hornblende des Hauptgesteins überein. Ganz kleine Körner sind oft kompakt und weisen deutliche Spuren von Prismenflächen auf, doch hat der Hauptteil der Hornblendekörner eine ganz unregelmässige Form und ist stark siebartig durchlöchert mit Quarz in den Fenstern. Eingeschlossen in der Hornblende treten ausserdem Erzkörner, oft von einem schmalen Titanitrand umgeben, Apatit und stellenweise Biotit auf. Die zentralen Teile der Hornblendekristalle enthalten sehr häufig ein körniges Aggregat von Kalkspat und zwar häufiger, als es sonst im Rönne Granit der Fall ist. Dieses Aggregat nimmt in mehreren Fällen einen so grossen Teil des Hornblendekristalls ein, dass man Kalkspataggregate beobachtet, die nur noch von einem ganz schmalen Hornblenderand umgeben sind. Der Biotit ist im Gegensatz zur Hornblende nicht angereichert, nur stellenweise ist er in ungefähr derselben Menge wie im Granit vorhanden, während man im grössten Teil eines Dünnschliffes überhaupt keinen Biotit findet. Die Farbe ist braun. Die Form ist nicht die im Hauptgestein übliche zerlappte und durchlöcherte, sondern eine weit regelmässigere; Biotitmyrmekit fehlt gänzlich. Der Biotit schliesst oft Erzkörner ein, ist aber sonst arm an Einschlüssen. Zwischen den Glimmerspaltblättchen kommt hie und da ein wenig Flusspat vor. In den biotitführenden Teilen der basischen Ausscheidungen trifft man auch kleine Biotitblätter im Plagioklas eingeschlossen. Magneteisen und Titanit sind etwas reichlicher als im Hauptgestein vorhanden; der letztere tritt nicht nur als sekundär ausgeschiedener Titanitrand um die Erzkörner herum, sondern auch in Form von selbständigen Körnern auf. Apatit ist sehr reichlich vorhanden, Zirkon dagegen spärlich. Myrmekit findet man an einigen Stellen in grossen Mengen. Die basischen Ausscheidungen unterscheiden sich also vom Hauptgestein nur durch eine Verschiebung der Mengenverhältnisse der Bestandteile; es besteht kein Zweifel darüber, dass sie magmatischen Ursprungs sind.

\section{Einschluss von einem Quarz-Titanit-Gestein im Rönne Granit.}

In einem ganz kleinen Schotterbruch südwestlich von der KnudsKirke, in der Nähe des Armenhauses, fand ich einen Einschluss von einem höchst eigentümlichen quarz-titanitreichen Gestein, der in einem losgesprengten Block aus Rönne Granit eingelagert war. Der Einschluss scheint nur aus einem einzigen rundlichen Klumpen von etwa $0,5 \mathrm{~m}$ im Querschnitt zu bestehen. Die Grenze gegen den Rönne Granit ist scharf, nur hie und da dehnen sich kleine, kaum centimeterbreite Schlieren aus Rönne Granit in den Klumpen hinein, und in der Verlängerung derartiger Schlieren können einzelne Körner aus dem gewöhnlichen Feldspat 
oder aus der Hornblende des Rönne Granits auftreten. Eine Anhäufung von Biotit wie in den gestreiften Partien längs des Pegmatits gibt es nicht im angrenzenden Rönne Granit. Dieser hat seine normale Zusammensetzung, ist aber relativ grobkörnig. Der Mikroklin hat eine sehr fein lamellierte Gitterstruktur, die stellenweise submikroskopisch wird. Titanit war im Dünnschliff nicht nachweisbar, dagegen war Zirkon recht reichlich vorhanden.

Der Einschluss besteht aus einem sehr feinkörnigen, grauen Quarzgestein, welches einige dunkel-grünliche, chloritische Partien mit reichlicher Ausscheidung von Eisenkies enthält. In diesen Partien und um sie herum ist die Korngrösse etwas variierend; es gibt sowohl grössere Quarzkörner als auch äusserst feinkörnige, beinahe ganz dichte Felder.

Das hellere, ziemlich homogene Gestein besteht zum weit überwiegenden Teile aus Quarz, der stets in Gestalt von Einzelindividuen mit polygonalem Umriss auftritt (Taf. II Fig. 3 und 4). Die Korngrösse ist durchschnittlich 0,2 $\mathrm{mm}$. Die Kontur der meisten Körner ist ebenmässig und scharf markiert, sowohl zwischen den Quarzkörnern unter sich als auch dort, wo der Quarz an andere Mineralien grenzt; gezackte Verwachsung kommt selten vor. Als wesentliche Gemengteile sind ausserdem Titanit und Mikroklinperthit in ungefähr gleicher Menge vorhanden; Plagioklas, Hornblende, Erzmineralien und Granat treten spärlich auf.

Die Korngrösse des Titanits ist kleiner als die des Quarzes. Die Kontur ist meistens ganz unregelmässig, was von der Lage in den Winkeln zwischen den Quarzkörnern bedingt ist, wo er die Zwischenräume ganz oder teilweise ausfüllt. Nur selten findet man Titanit völlig im Quarz eingeschlossen. Manchmal hat der Titanit einen kleinen Kern aus Magnetit oder noch häufiger aus Eisenkies. Hie und da gibt es kleine Aggregate aus Titanit.

Die Hornblende tritt teils in Form von kleinen isolierten Körnern, teils mit dem Titanit verwachsen auf. Die Anzahl der Körner ist zu gering und ihre Grösse zu klein, um eine optische Untersuchung durchzuführen; in der Farbe und im Pleochroismus stimmen sie aber mit der Hornblende des Rönne Granits überein; ferner ähneln sie letztgenannter Hornblende darin, dass sie poikilitisch eingelagerte Quarzkörner führen.

Mikroklinperthit tritt ausschliesslich als eine Art von Grundmasse oder Zement zwischen den übrigen Mineralien auf (Taf. II Fig. 4). An einigen Stellen kann ein einzelnes, verzweigtes Mikroklinindividuum mehrere Titanit- und Quarzkörner einschliessen, an anderen Stellen ist Mikroklin nur spärlich vorhanden. Perthiteinlagerungen sind ziemlich reichlich vorhanden; sie bestehen aus Albit.

Plagioklas ist in einzelnen Körnern mit deutlicher Zwillingsstreifung $\mathrm{zu}$ beobachten. Er ist im allgemeinen ein wenig getrübt. Im MP-Schnitt 
wurde im Kern $\alpha^{\prime}: \mathrm{M}=14^{\circ}$ gemessen. Der Plagioklas ist somit ein saurer Oligoklas. Einzelne Körner haben eine frische und deutlich saurere Randzone.

In den dunkleren, grünen Partien ist Chlorit stark dominierend. Er ist hie und da ein wenig bräunlich. Pleochroismus: gelb-grün mit etwas bläulichem Ton. Der Chlorit hat eine feinschuppige oder faserige Struktur, die in Verbindung mit einzelnen stark gebleichten, jedoch einigermassen deutlich erkennbaren Partien von Biotit auf seinen Ursprung durch Umwandlung des Biotits hinweist. Zwischen den Chloritblättern ist häufig ein braunes Pigment vorhanden. Der Chlorit enthält kleine Erzpartikel und Quarzkörner von sehr unregelmässiger Form.

In den chloritischen Feldern haben die grösseren Quarzkörner eine etwas undulöse Auslöschung. Titanit ist reichlich angehäuft und bildet grössere Aggregate. Ferner gibt es hier etwas Apatit in relativ grossen Kristallen; um die Apatitkristalle herum ist der Chlorit dunkler und stark pleochroitisch. Auch Eisenkies und Magneteisen (oder Titaneisen) sind besonders in diesen Partien anzutreffen; der Eisenkies bildet dort sowohl kleine wohlentwickelte Kristalle als unregelmässige Massen von 3-5 cm im Querschnitt; Magneteisen ist in zahlreichen kleinen Partikeln vorhanden. Ferner findet man Granat in farblosen Körnern von einigen mm Grösse; sie haben eine recht unregelmässige Form und eine sehr gebuchtete äussere Kontur. Der Granat schliesst sowohl Titanit als Quarzkörner ein. Er ist hie und da ein wenig chloritisiert und von Rissen, die mit chloritischer Substanz gefüllt sind, durchsetzt.

Feldspat kann in den chloritischen Partien nicht mit Sicherheit nachgewiesen werden. In der nächsten Umgebung derselben ist der Feldspat etwas unfrisch und mehr oder weniger von Muskovitschuppen oder von chloritischer Substanz ausgefüllt. Es scheint, als bestünde hier der ganze Feldspat aus Plagioklas. Zwillingsstreifung ist oft erkennbar. In einem Schnitt fast $\perp \mathrm{MP}$ wurde $\alpha^{\prime}: \mathrm{M}=14^{\circ}$ gemessen. Eine saurere Randzone ist nicht vorhanden. Die Lichtbrechung des Plagioklases ist überall niedriger als die des Quarzes und höher als die des Canadabalsams oder dieselbe wie diese. Er ist demnach ein fast reiner Albit.

Charakteristisch für den Quarz in diesem Gestein sind seine Interpositionen, welche besonders in der Nähe der chloritischen Partien in ausserordentlich reichlicher Menge auftreten. Ausser den gewöhnlichen Einschlüssen im Quarz des Rönne Granits kommen noch zwei andere Mineralien vor, die sehr zahlreich, jedoch in variierender Menge je nach der Zusammensetzung des Gesteins auftreten können. Die eine Art von ihnen besteht aus klaren Kristallen, deren Form rechtangulär, quadratisch oder abgerundet ist; einige Individuen sind sechseckig. Die Lichtbrechung ist ein wenig schwächer als die des Quarzes, ungefähr wie die des Canadabalsams. Die Kristalle sind schwach doppelbrechend, einige 
wenige der grösseren mit einem Querschnitt von etwa 0,01 mm können jedoch eine schwach graue Interferenzfarbe aufweisen, wenn der Quarz in der Auslöschungslage ist. In den länglichen Kristallen ist $\alpha^{\prime}$ parallel mit der Längsrichtung. Diese Umstände deuten darauf, dass die Kristalle aus Cordierit bestehen.

Die andere Art von Interpositionen besteht ebenfalls aus klaren, farblosen Kristallen, zeichnet sich aber durch eine hohe Lichtbrechung — ungefähr wie die des Apatits — aus. Diese Interpositionen treten nicht nur im Quarz eingelagert auf, sondern auch in wohlausgebildeten Eisenkieskristallen; dagegen sind sie weder im Titanit noch im Feldspat beobachtet worden. Die Form der Körner kann fast ganz rund sein, häufiger jedoch ist sie länglich abgerundet, bisweilen schlank säulenförmig. Die grösseren Individuen erreichen einen Querschnitt von 0,02—0,05 mm und können eine Interferenzfarbe bis zu Blau II. Ordnung haben. Sie sind optisch zweiachsig, positiv, der Achsenwinkel $2 \mathrm{~V}$ wird auf etwa $60^{\circ}$ geschätzt. In den grösseren Kristallen lässt sich hie und da eine deutliche Spaltrichtung, die parallel mit der Längsrichtung der Kristalle verläuft, beobachten. Die langgestreckten Kristalle haben meistens schiefe Auslöschung, und der Auslöschungswinkel gegen die Längsrichtung oder gegen die Spaltrisse kann bis zu $45^{\circ}$ anwachsen. Ein recht grosser, in einem Eisenkieskristall eingeschlossener Kristall zeigte eine optische Achse im Gesichtsfelde. Ferner hatte er einen deutlichen Spaltriss, der einen Winkel von etwa $45^{\circ}$ mit der Achsenebene bildete, und es scheint, als ob Spuren von noch einer Spaltrichtung — ungefähr senkrecht auf der ersteren — vorhanden waren. Diese Verhältnisse deuten entschieden auf ein Pyroxenmineral hin.

An dem feinkörnigen quarzreichen, ziemlich homogenen Teil des Gesteins wurde eine Rosiwal-Messung vorgenommen, die folgendes Resultat ergab:

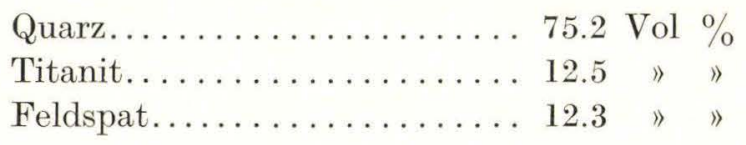

Hierbei wurden Hornblende und Erzmineralien ausser acht gelassen. Sieht man ferner vom spärlichen Plagioklasgehalt ab, und rechnet man allen Feldspat als Kalifeldspat, erhält man folgendes Gewichtsverhältnis:

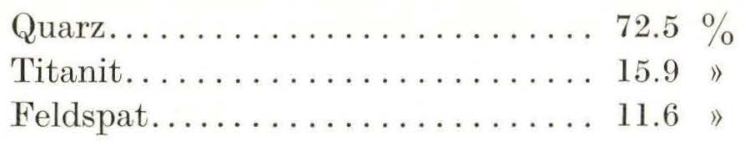

Dem entspricht folgende Zusammensetzung: 


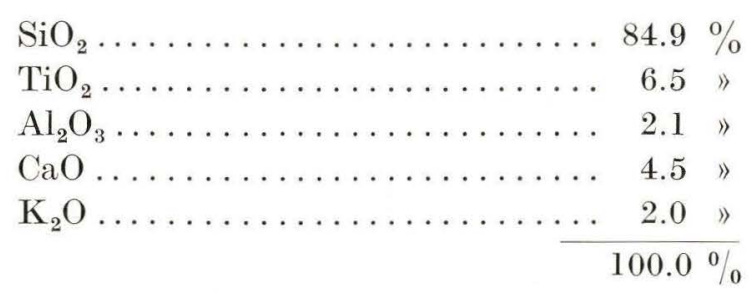

Wenn auch die Bestimmung dieser Zusammensetzung nur eine annähernde ist und nicht für den Einschluss im ganzen gilt, so geht doch deutlich aus derselben hervor, dass letzterer einen ausserordentlich hohen Gehalt an $\mathrm{SiO}_{2}$ und $\mathrm{TiO}_{2}$ hat. Ein Gestein dieser Beschaffenheit scheint recht einzig dazustehen, jedenfalls ist es mir nicht gelungen, etwas Entsprechendes in der Literatur erwähnt zu finden.

Es scheint mir ganz unzweifelhaft, dass dieser Einschluss im Rönne Granit als eine endogene Bildung aufgefasst werden muss, wenn auch der hohe Quarzgehalt im ersten Augenblick an einen Sandstein oder Quarzit denken lässt. Von anderen Vorkommen her kennt man noch quarzreichere Eruptive. Der charakteristische Mineralbestand, die Struktur, speziell das Auftreten des Mikroklins als jüngster, sowohl Titanit als Quarz einschliessender Gemengteils, sowie der Umstand, dass die Interpositionen des Quarzes von Pyroxen etc. am zahlreichsten in der Nähe der Chlorit- und Eisenkies-führenden Teile des Gesteins auftreten, zeigen jedenfalls, dass das Gestein seine jetzige Gestalt an Ort und Stelle erhalten hat.

Einen ähnlichen Quarzgehalt und die gleiche Struktur habe ich nur in der von O. H. Erdinansdörffer beschriebenen endogenen Granitfazies am Kontakt mit Quarzeinschlüssen im Brockengranit vom Unteren Meineckenberg ${ }^{1}$ ) erwähnt gefunden. Auch dort bildet der Feldspat eine Art von Kitt, in dem die Körner von Quarz liegen; der Feldspatgehalt ist jedoch bedeutend grösser als im Bornholmer Quarz-Titanitgestein. Die Zusammensetzung wird folgendermassen angegeben:

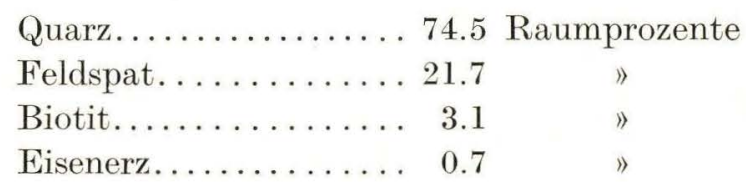

ErdmannsdörfFer vergleicht dieses Gestein mit gewissen quarzreichen Teilen pegmatitischer Gänge und bemerkt, dass nur die Struktur und die feine Korngrösse es von den Pegmatiten unterscheiden, und er lehnt die Vermutung ab, dass dieses Gestein ein Mischprodukt von Granit und

1) Jahrb. d. K. Preuss. Geol. Landesanst. 32. II. 1911, p. 377-78. 
Quarzit sein sollte. Dagegen spricht seiner Ansicht nach vor allem der Umstand, dass sich derartige extrem quarzreiche Gesteine in der gleichen Weise auch um und in den Einschlüssen von Tonschieferhornfelsen im Granit finden.

Als ein anderes Beispiel von extremer Quarzanreicherung in der Grenzfazies kann der Eskdale Granit ${ }^{1}$ ) aus Cumberland, England, genannt werden, in welchem der Kieselsäuregehalt bis auf 96,16\% steigt, während er in dem normalen Eskdale Granit 76,43\% beträgt. Dass dieses Grenzgestein, welches fast ausschliesslich aus einer feinkörnigen Quarzmosaik besteht, nicht durch eine Assimilation von Kieselsäuregesteinen entstanden sein kann, geht daraus hervor, dass der Granit in Laven, Aschen und Breccien von andesitischer Zusammensetzung intrudiert ist. Hätte hier ein Einschmelzen des Nebengesteins stattgefunden, so hätte man in der Randzone einen höheren Gehalt von basischem Material als im normalen Granit erwarten müssen. - Es scheint mir daher auch nicht notwendig, für die Erklärung der Quarzmenge im Bornholmer Einschluss die Assimilation von einem Quarzitfragment oder etwas Aehnlichem, das lokal einen besonders hohen $\mathrm{SiO}_{2}$-Gehalt im Granitmagma ergeben könnte, annehmen zu müssen.

Zum mindesten ebenso auffällig wie der Quarzreichtum des Einschlusses ist dessen hoher Titanitgehalt. In dieser Hinsicht erinnert das Bornholmer Gestein an die hellen Flecken in den sogenannten »Titanitfleckengraniten", die von mehreren Vorkommen her bekannt sind. Aus A. OsANN's ${ }^{2}$ ) Untersuchung von derartigen Fleckenbildungen geht hervor, dass Titanitanreicherung im allgemeinen nicht in Verbindung mit hohem Quarzgehalt auftritt; reichliche Titanitausscheidung scheint im Gegenteil eher in quarzarmen basischen Ausscheidungen aufzutreten. Die grösste Aehnlichkeit mit dem vorliegenden Gestein weisen die von P. GEIJER ${ }^{3}$ ) beschriebenen Titanitfleckenbildungen im Stockholmer Granit auf. Von diesen Flecken unterscheidet GEIJER zwei Typen. In dem verbreitetsten derselben bestehen die Flecken aus Feldspat, Quarz und Titanit, zuweilen mit etwas Erz zusammen. Hornblende fehlt gänzlich und von Biotit sind nur einige sehr kleine, chloritisierte Schuppen zu sehen. Korngrösse, Struktur und relatives Mengenverhältnis der hellen Mineralien sind dieselben wie im umgebenden Granit. Der Titanit tritt dort meistens als ein Kern im Fleck in der Form eines einzelnen allotriomorphen und schwammartig verzweigten Individuums auf. GEIJER fasst diese Flecke als ein aplitisches Sekret auf, das sich bei reichlichem Vorhandensein von Mineralisatoren gebildet hat, und stützt $u$. a. diese

1) A. R. Dwerryhouse. Q. J. G. S. Vol. 65, 1909, p. 64.

2) A. Osann. N. JB. BB. 48, 1923, p. 223.

3) P. Geijer. Bull. Upsala. 8, 1908, p. 190. P. Geijer. G. F. F. 35, 1913, p. 123. 
Ansicht auf die Beobachtung eines direkten Uebergangs zwischen den titanitreichen Stellen und den aplitischen Gängen oder Schlieren. Er bemerkt hierüber (1. c. p. 139-140): »Der einzige Unterschied zwischen den Flecken und den Aplitschlieren mit dem typischen Charakter der Sekretgänge liegt . . . in der Form«. Und ferner: »Es ist wahrscheinlich, dass die Titansäure als eine gasförmige Verbindung nach den Flecken hingewandert ist «.

Es ist naheliegend, in diesem Zusammenhang daran zu erinnern, dass Titanit oft in der endomorphen Kontaktzone der Tiefengesteine angereichert ist. Beispiele hierfür findet man in der Kontaktzone des Nordmarkits und des Drammengranitits im Kristianiagebiet. Wenn man ferner in Betracht zieht, dass Titanit längs der Pegmatitgänge und in den pegmatitischen Schlieren im Rönne Granit reichlich vorhanden ist, also an Stellen, wo, wie man annehmen darf, Mineralisatoren eine wichtige Rolle gespielt haben, so scheint es mir am wahrscheinlichsten zu sein, dass das in Frage kommende Quarz-Titanit-Gestein eine Art aplitischer Bildung - wenn zwar auch von exzeptioneller Zusammensetzung ist, die durch magmatische Differentiation entstanden sein dürfte. Selbstverständlich will ich nicht die Möglichkeit in Abrede stellen, dass ein eingeschmolzenes Quarzitfragment oder etwas Aehnliches es verursacht hat, dass das Magma gerade an dieser Stelle einen extrem hohen Kieselsäuregehalt erhalten hat; eine Erklärung betreffs des Titanitgehalts bietet eine solche Annahme jedoch nicht.

Von einer so kieselsäurereichen Schmelzmasse, wie es dieses QuarzTitanit-Gestein seinerzeit sicherlich gewesen ist, darf angenommen werden, dass sie trotz einem gewissen Gehalt an leichtflüchtigen Bestandteilen sehr zähflüssig gewesen sein muss und daher nicht geneigt, sich mit dem Granitmagma zu vermischen. Hierauf deutet die scharfe Grenze des Einschlusses gegen den umgebenden Rönne Granit.

In der petrographischen Literatur ist die Entwicklung von zwei oder mehreren unmischbaren flüssigen Phasen nebeneinander im Magma mehrfach zur Erklärung der magmatischen Differentiation herangezogen worden, und speziell ist diese Deutung auf Silikat-Sulfidsysteme angewandt worden. Für Silikatschmelzlösungen dagegen sind mehrere Verfasser der letzten Jahrzehnte am ehesten geneigt gewesen, volle Mischbarkeit anzunehmen. Indessen hat J. W. GREIG ${ }^{1}$ ) experimentell nachgewiesen, dass in gewissen kieselsäurereichen Schmelzlösungen von $\mathrm{SiO}_{2}$ und Oxyden von vielen Metallen, z. B. $\mathrm{CaO}, \mathrm{MgO}$ und $\mathrm{FeO}$, eine Sonderung in zwei unmischbare Schmelzen stattfindet. Die Experimente wurden bei hohen Temperaturen um $1700^{\circ}$ herum, wo alles geschmolzen war, ausgeführt. Bei schneller Abkühlung gelang es GrEIG, die Schmelz-

1) J. W. Greig. Am. Journ. of Sc. 5. Ser. Vol. 13, 1927, p. 1-44, 133-54. 
masse als zwei verschiedene Sorten von Glas zum Erstarren zu bringen, von denen die eine tropfenförmig in der anderen eingelagert war. Laut GreIg ist die Bedingung für die Nicht-Mischbarkeit ein hoher Gehalt von $\mathrm{SiO}_{2}$ und ein sehr geringer Gehalt von $\mathrm{Al}_{2} \mathrm{O}_{3}$ und Alkalien, da diese letzteren Bestandteile die Mischbarkeit in hohem Masse begünstigen. GrEig hat einen Vergleich zwischen den angewandten Schmelzmassen und schon bekannten, von DALY und WASHIngTos publizierten Gesteinsanalysen vorgenommen und ist zu dem Ergebnis gekommen, "that the composition of igneous rocks, even of the extrem cases from WASHINGTON's tables, are well removed from the area of immiscibility« (pag. 150).

Nun dünkt es mich, dass wenn man überhaupt jemals geologische Beweise einer Entmischung in Silikatschmelzlösungen, in Analogie mit den von GREIG experimentell nachgewiesenen, erbringen könnte, so dürfte das wohl jedenfalls auf einen Fall wie den hier vorliegenden zutreffen. Leider berichtet Greig nichts über Experimente mit $\mathrm{TiO}_{2}$-haltigen Schmelzmassen. Darf aber angenommen werden, dass $\mathrm{TiO}_{2}$ imstande ist, anstatt $\mathrm{SiO}_{2}$ in das System einzugehen, so kommt dieses Quarz-Titanit-Gestein den von Greig benutzten Schmelzmassen in der Zusammensetzung sehr nahe. Es muss ja nämlich in Betracht gezogen werden, dass die oben (pag. 45) angegebene approximative Zusammensetzung nicht für das Gestein im ganzen gilt. Rechnet man die untergeordneten Chlorit- und Eisenkies-haltigen Teile mit, so erhält die Analyse ausserdem einen Gehalt von $\mathrm{FeO}$ und $\mathrm{MgO}$, was die Annahme berechtigt, dass die Prozentmenge von Tonerde und Alkalien eher niedriger liegt, als es die angegebenen Werte zum Ausdruck bringen.

\section{Feldspateinschlüsse im Rönne Granit.}

Die faustgrossen, isoliert auftretenden Feldspateinschlüsse, welche dann und wann im Rönne Granit gefunden werden, ähneln am ehesten dem Pegmatitfeldspate. Sie bestehen aus Mikroklinperthit von fleischroter oder von dunkelgraugrüner Farbe (Fig. 10). Die äussere Form ist unregelmässig gebuchtet ohne Kristallbegrenzung. Meistens erreichen sie eine Länge von etwa $10 \mathrm{~cm}$. Die Spaltrisse verlaufen in einigen Fällen durch den ganzen Einschluss hindurch, in anderen Fällen findet man am Rande entlang einige kleinere und anders orientierte Feldspatkörner. Zwischen dem Mikroklin und dem ihn umgebenden Granit liegt ein schmaler Saum von ein paar mm Dicke, der aus schriftgranitisch mit Quarz verwachsenem Plagioklas besteht.(siehe Fig. 6, Taf. II).

Wie im Feldspat des Rönne Granits üblich, treten die Perthitstreifen sowohl als feine spindelförmige Einlagerungen als auch als gröbere Schnüre oder Bänder auf, in denen man im Basisschnitt oft Lamellen nach dem Albitgesetz beobachtet. Im Schnitt \| (010) hat der Plagioklas einen Auslöschungswinkel $\alpha^{\prime}: \mathrm{P}=+15^{\circ}$; er ist somit ein Albit mit etwa 
$10 \%$ An. Häufig erweitern sich die breiten Bänder zu grösseren, unregelmässig geformten Einlagerungen, in denen in der Regel Zwillingslamellen nach dem Albit- oder dem Periklingesetz oder nach diesen beiden beobachtet werden. Diese Plagioklaseinschlüsse haben stets eine schmale Randzone, die gleichzeitig mit den Albitbändern auslöscht und

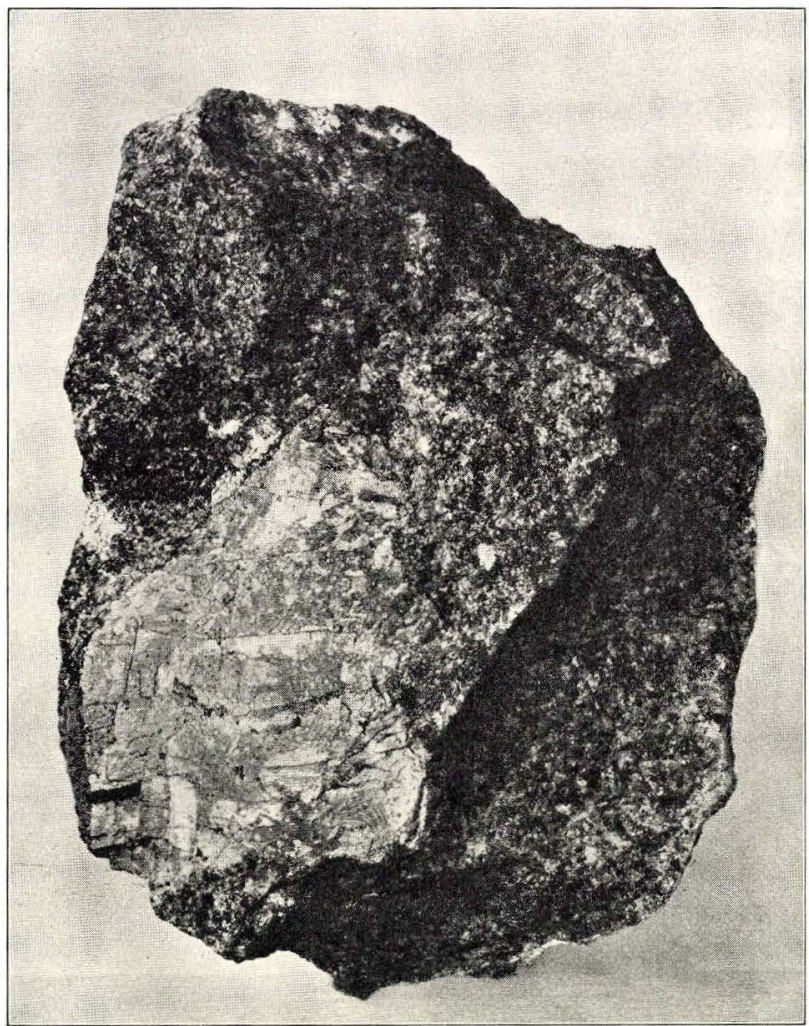

Fig. 10. Einschluss von Mikroklinperthit im Rönne Granit, Klippegaard. ${ }^{5 / 8}$ nat. Gr.

eine direkte Fortsetzung derselben bildet, während der Kern aus Oligoklas mit etwa $24 \%$ An. besteht. Meistens sind diese Einschlüsse von Quarz umgeben und hie und da mit demselben schriftgranitisch verwachsen; auch in den Albitbändern beobachtet man häufig ähnliche Quarzeinschlüsse (siehe Fig. 5, Taf. II).

Der Mikroklin hat meistens eine ziemlich feine Gitterstruktur mit sehr kurzen und dünnen Lamellen. An einigen Stellen in den Zwischenräumen zwischen den Albitschnüren sind die Lamellen sogar submikroskopisch (siehe Fig. 5, Taf. II). Derartige Felder haben im Basisschnitt die für den sehr feingegitterten Mikroklin charakteristische undulöse Auslöschung, welche früher von BoRIs POPOFF in seiner Abhandlung »Ueber 
Rapakiwi aus Süd-Russland «1 $\left.{ }^{1}\right)$ beschrieben worden ist. Diese Felder gehen allmählich in die gegitterten Stellen über, und in direkter Nähe der Albitschnüre hat der Mikroklin stets eine deutliche Gitterstruktur. - In einem der untersuchten Mikroklinkristalle ist Zwillingsbildung nach dem Bavenoer Gesetz beobachtet worden; die Grenze zwischen den beiden Zwillingsindividuen war mit einer feinen Quarz-Plagioklas-Mosaik bekleidet.

Der äussere Plagioklasmantel ist wie die Perthiteinlagerungen orientiert. Er ist in derselben Weise, wie es beim gewöhnlichen Plagioklas des Rönne Granits bisweilen der Fall ist, in kleinere Stücke, die nicht genau gleichzeitig auslöschen, aufgeteilt (siehe Fig. 6, Taf. II). Die Zusammensetzung der am meisten basischen Partien ist Oligoklas mit $20-22 \%$ An. Die Begrenzung der Stücke fällt einigermassen mit den Spaltrichtungen des Plagioklases zusammen. Häufig liegt zwischen den Plagioklasstücken schriftgranitischer Quarz, so dass der äussere Mantel vielleicht eher als ein Quarz-Plagioklas-Schriftgranit bezeichnet werden müsste. An vielen Stellen liegt zwischen dem Mantel und dem Mikroklinperthit ein ganz schmaler Saum aus Myrmekit (siehe Fig. 6, Taf. II). An einzelnen Stellen umschliesst der Plagioklasmantel nicht unmittelbar den Mikroklin, sondern verläuft konzentrisch mit demselben in einer Entfernung von etwa $1 \mathrm{~cm}$. Im Zwischenraum liegt in solchen Fällen eine feinkörnige Granitmasse. Im Granit um diese Feldspateinschlüsse herum sind granophyrische Verwachsungen reichlich vorhanden.

\section{Pegmatit und Aplit im Rönne Granit.}

Während man im deutlich gestreiften Bornholmer Granit Pegmatit sowohl in der Form von scharf abgegrenzten Pegmatitgängen als in der Form von pegmatitischen Schlieren antrifft, findet man in den regellos körnigen Graniten den Pegmatit gewöhnlich in Gestalt von Gängen mit einer scharfen Grenze gegen das Nebengestein. Das ist z. B. der Fall im westlichen Teil des Rönne Granits. Dagegen findet man im östlichsten Vorkommen des Rönne Granits in Baunklint ausser den scharf abgegrenzten Pegmatitgängen gleichzeitig auch zahlreiche pegmatitische Schlieren, die stellenweise dem Stein ein stark geflammtes Aussehen geben. Die mineralogische Zusammensetzung der Bornholmer Pegmatitgänge ist stets sehr einfach. In den Pegmatitgängen des Rönne Granits bildet ein fleischroter Mikroklin den Hauptbestandteil; er ist oft schriftgranitisch mit Quarz verwachsen, so dass der grösste Teil des Pegmatits aus Schriftgranit besteht. Quarz in grösseren reinen Aggregaten ist nur

1) B. Popoff. Travaux de la Société Impériale des Naturalistes de St.Pétersbourg. Vol. 31, livr. 5. Section de Géologie et de Minéralogie, 1903, pag. 179. 
sehr selten vorhanden; oft ist der Quarz rauchfarbig, manchmal sogar sehr dunkel. Der Plagioklas ist in ziemlich reichlicher Menge vorhanden. Die Körner sind hellgrau, durchscheinend und bisweilen bläulich labradorisierend $^{1}$ ). Der Plagioklas enthält etwas antiperthitisch eingewachsenen Kalifeldspat. Die Zusammensetzung ist Albit-Oligoklas mit etwa $10 \%$ An. Im Schnitt $\|(010)$ wurde $\alpha^{\prime}: \mathrm{P}=13^{\circ}$ gemessen. Der optische Charakter ist negativ. Zwillingsbildung nach dem Albitgesetz ist gewöhnlich mit derjenigen nach dem Karlsbader Gesetz kombiniert. Stellenweise findet man Plagioklasschriftgranit, in welchem die Plagioklasindividuen $10 \mathrm{~cm}$ oder mehr im Querschnitt erreichen. Als untergeordnete Gemengteile im Pegmatit trifft man Biotit und in kleinen Mengen Magnetoder Titaneisen, Molybdänglanz, Titanit und Flusspat. Titanit ist, wie schon erwähnt, stellenweise im Nebengestein unmittelbar am Pegmatit angereichert, und auch im Pegmatit scheint er sich in der Nähe der Ganggrenze zu halten. Orthit wurde vereinzelt vorgefunden.

Infolge der stark roten Farbe des Feldspates treten die Pegmatitgänge im dunkelgrauen Granit der Steinbrüche sehr scharf und auffällig hervor. Im Bruch bei Klippegaard sind die Gänge selten mehr als $0,25-0,5 \mathrm{~m}$ mächtig. Grössere Pegmatitgänge findet man südlich von Knuds Kirke und in Baunklint. An diesen beiden Stellen wurde früher Feldspat gebrochen. In Baunklint bildet der Pegmatit die oberste Partie, und der Gang, der beinahe gänzlich aus Schriftgranit besteht, ist etwa $30 \mathrm{~m}$ mächtig. Auch im nördlichen Teil des Rönne Granitgebiets findet sich am Wege, etwa 300-400 m NNO von Store Almegaard, eine grössere Pegmatitmasse, die hauptsächlich aus Schriftgranit besteht.

Aplitgänge trifft man in der Regel nicht im Rönne Granit, doch fand im Jahre 1930 O. B. BöGGILD ein eigentümliches, feinkörniges Gestein im Rönne Granit eingeschlossen, und zwar in einem kleinen Aufschluss 400-500 m östlich vom Torneværk. Der Finschluss bestand aus einer aplit-pegmatitischen Masse von unregelmässiger Form. Ein Teil derselben war durch Steinabbau entfernt worden, der Rest hatte eine Länge von etwa $4-5 \mathrm{~m}$ in der Richtung $\mathrm{O}-\mathrm{W}$. Nur an der Südseite war die Grenze gegen den Rönne Granit erhalten. Die Grenze war scharf gekennzeichnet. In der Nähe des Rönne Granits ist der Einschluss sehr feinkörnig, hell rotgrau und arm an dunklen Mineralien; diese sind parallel mit der Grenzfläche in deutlichen Streifen oder Schlieren angeordnet. In einer Entfernung von etwa 10-20 cm von der Grenze wird das Gestein gröber, ausgesprochen gestreift und von gneisähnlichem Charakter. Es geht danach allmählich in eine pegmatitische Masse mit grösseren, schriftgranitischen Feldspatindividuen und rauchfarbigem,

1) O. B. Böggild. Det Kgl. Danske Vid. Selsk. Math.-fys. Medd. VI. 3. 1924, pag. 33 . 
relativ spärlichem Quarz über. In der östlichen Wand des Steinbruches sah man den feinkörnigen Einschluss als eine schmale, ziemlich steile Linse; sie hatte die Streichrichtung etwa $\mathrm{O}-\mathrm{W}$ und fiel ein wenig nach Süden zu ab. Nach unten zu ging das Gestein an dieser Stelle in Pegmatit über.

Der feinkörnige Teil des Einschlusses, der unmittelbar an Rönne Granit grenzt, besteht hauptsächlich aus Mikroklin und Quarz. Der Mikroklin ist arm an Perthit, oft schliesst er kleine Quarzkörner ein; umgekehrt findet man im Quarz auch häufig Mikroklineinschlüsse. Plagioklas ist in untergeordneter Menge vorhanden; er ist ein Oligoklas mit 16-20\% An. Die Mitte der Kristalle ist meistens etwas unfrisch, dann und wann findet man hier Epidotausscheidungen. Dunkle Mineralien sind im grossen und ganzen spärlich vertreten; sie bestehen hauptsächlich aus Hornblende und Biotit. Die Hornblende stimmt in ihren optischen Verhältnissen mit der des Hauptgesteins überein, und die etwas grösseren Individuen haben dieselbe unregelmässige und durchlöcherte Form. Manchmal sind die Hornblendekörner unter Ausscheidung von Karbonat und Erz umgewandelt worden. Im übrigen scheint auch Kalkspat als primärer Bestandteil, wenn auch in sehr geringer Menge, aufzutreten. Apatit ist reichlich vorhanden.

Die Korngrösse variiert etwas. Nicht nur wird das Gestein in einer Entfernung von wenigen Centimetern von der Grenze des Einschlusses mittelkörnig, sondern auch in den einzelnen Dünnschliffen sieht man Quarz- und Mikroklinkörner von wesentlich verschiedener Grösse. In den feinkörnigsten Partien hat der grösste Teil der Körner einen Querschnitt von $0,2-0,3 \mathrm{~mm}$, doch erreichen einige einen Querschnitt von ein paar $\mathrm{mm}$; diese letzteren Körner liegen dann meistens einigermassen regelmässig in Streifen angeordnet, und namentlich ist der Quarz oft langgedehnt in der Richtung der Streifung. Die Parallelstruktur des Gesteins rührt aber auch daher, dass Hornblende und Biotit in der Regel als kleine längliche Blätter von einigermassen gleichartiger Orientierung auftreten. Auch die mineralogische Zusammensetzung ist etwas variierend. So fand ich z. B. nicht in allen untersuchten Dünnschliffen Hornblende. Im etwas gröberen Teile des Gesteins in der Nähe des Pegmatits war die Zusammensetzung des Plagioklases basischer (25-26\% An.), und in demselben Dünnschliff fanden sich ein paar Orthit-Körner, während Hornblende so gut wie gar nicht vorhanden war. Der pegmatitische Teil des Einschlusses bestand hauptsächlich aus schriftgranitischem rotem Mikroklin. Reine Quarzausscheidungen sind selten und klein. Im schlierigen Uebergangsgestein zwischen dem feinkörnigen und dem pegmatitischen Teile des Einschlusses fanden sich hie und da linsenförmige Ausscheidungen von dunklem Quarz. 


\section{Grenzgebiet des Rönne Granit.}

Nach Osten zu geht der Rönne Granit durch eine porphyrische und stellenweise deutlich gestreifte Randzone mit einsprenglingsartigem Plagioklas und abnehmendem Hornblendegehalt in den grauen, hornblendearmen, streifigen Granit über. Ussing, der als erster diese porphyrische Grenzzone entdeckt hat, hielt sie für ziemlich schmal; an einer Stelle (Lokalität 75, auf der Detailkarte Fig. 11) fand er sie drei Meter breit. Er fasste dieses porphyrische Gestein als eine eruptive Grenzfazies des Rönne Granits auf, und zwar entstanden durch raschere Abkühlung an der unmittelbaren Grenzfläche gegen das Nebengestein; daher hielt er den Rönne Granit für etwas jünger als den streifigen Granit $^{1}$ ). Es ist mir jedoch nicht möglich gewesen, irgendwo eine scharfe Grenze zwischen dem porphyrischen Gestein und dem streifigen Granit zu finden, wie man es doch erwarten müsste, falls Ussing's Auffassung richtig wäre. Dagegen steht es fest, dass die porphyrische Zone an gewissen Stellen eine weit grössere Breite hat. Im allgemeinen ist das Gestein in einer etwa $1 \mathrm{~km}$ breiten Zone östlich vom eigentlichen Rönne Granit von sehr variierender Beschaffenheit. Ausserdem findet man Granitvarietäten, die dem porphyrischen Grenzgestein des Rönne Granits in Bezug auf Struktur und Mineralbestand sehr nahe stehen, an verschiedenen Stellen auf Bornholm, z. B. in den Paradisbakker und in der Umgegend von Aakirkeby sowie auch an mehreren Stellen innerhalb des nördlichen Teiles des Gebiets des streifigen Granits, z. B. bei Haldegaard südlich von Gudhjem und bei Tækkeregaard NNO von Hasle. Ich bin daher der Ansicht, dass Ussing's Auffassung vom Rönne Granit als einem jüngeren, durchbrechenden Granit sich nicht aufrecht erhalten lässt, sondern meine, dass es einen ebenmässigen Uebergang zwischen dem typischen Rönne Granit und dem streifigen Granit im westlichen und südlichen Teile von Bornholm gibt, etwa in ähnlicher Weise wie beim Uebergang des streifigen Granits in Vang Granit und in Paradisbakkegranit.

In der Uebergangszone östlich vom Rönne Granit-Gebiet lassen sich drei Gesteinstypen unterscheiden: I. Porphyrischer Rönne Granit, II. Das Grenz- oder Uebergangsgestein des Rönne Granits, und III. Streifiger Granit.

I. An der von Ussing untersuchten Lokalität 75 (von ihm als »kleiner Hügel«, $300 \mathrm{~m}$ nördlich vom 0,5-Meilenstein auf der Landstrasse von Rönne nach Almindingen bezeichnet) steht an der Westseite ein ziemlich dunkler, braungrauer Granitporphyr, welchen Ussing »Rönne Granit

1) Ussing. Danmarks Geologi. D. G. U. III. R. Nr. 2. 2. Udg. 1904, p. 35. Ussing. Handb. d. Regionalen Geologie. I, 2. Dänemark. 1910, p. 4. 
an der Grenze«nannte, den ich jedoch vorziehen möchte, »p or phy ris c hen Rönne Granit«zu nennen. Makroskopisch macht er allerdings keinen stark porphyrischen Eindruck, da die Plagioklaskörner, welche die Einsprenglinge ausmachen, nur selten einen Querschnitt von etwa $1 \mathrm{~cm}$ erreichen. Im Dünnschliff sieht man jedoch, dass Plagioklas und Hornblende als Individuen von ungefähr derselben Grösse wie im eigentlichen Rönne Granit auftreten, und dass das übrige Gestein aus einer feinkörnigen Mischung sämtlicher Mineralien des Rönne Granits besteht. Hornblende und Biotit sind in gleich grosser Menge wie im Hauptgestein vorhanden. Die Hornblende ist wie gewöhnlich stark durchlöchert und von unregelmässiger Form. Den Plagioklaskörnern fehlt meistens der vollständige Mikroklinmantel, in der Regel findet man aber am Rande etwas parallel angewachsenen Mikroklin. Stellenweise sind geringe Spuren eines Albitsaumes zu beobachten. Im MP-Schnitt wurde gemessen:

$$
\begin{aligned}
& \perp \text { MP } \quad \alpha^{\prime}: \mathrm{M} \quad \text { Mittel } \% \text { An. }
\end{aligned}
$$

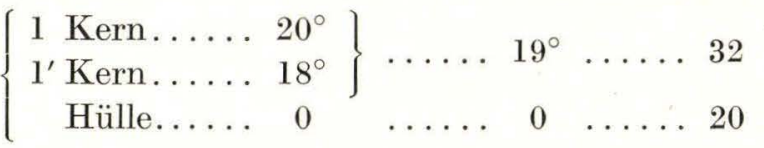

Häufig haben die Plagioklaseinsprenglinge dieselbe charakteristische unregelmässige, gefleckte Auslöschung wie der Plagioklas im Hauptgestein. Einige der Einsprenglinge enthalten ausserordentich zahlreiche Einschlüsse, besonders von kleinen Quarzkörnern, jedoch auch in geringer Menge von den übrigen Mineralien der Grundmasse. In einigen Fällen liegen die Einschlüsse ebenmässig verteilt im Plagioklas, in anderen scheinen sie verzweigte Kanäle, die durch Korrosion entstanden sind, auszufüllen. Hie und da liegen verschiedenartig orientierte Plagioklaskörner dicht beieinander in kleinen Haufen. In der Grundmasse sind die Plagioklaskörner meistens mit einem Albitsaum versehen. Der Mikroklin ist schwach perthitisch. Apatit und dunkle Mineralien sind reichlich vertreten; die Erzkörner haben in der Regel einen Titanitrand. Myrmekit ist fast immer vorhanden.

Dies Gestein kann in Abständen von wenigen Metern etwas in der Korngrösse variieren. Manchmal ist es schwach gestreift; an einigen Stellen ist die Farbe heller und rötlich, doch dürfte dies nur ein Oberflächenphänomen sein. - Genau dasselbe Gestein findet man weiter nach NW an der Lokalität 45, etwa $300 \mathrm{~m}$ nördlich von Kirkebogaard. Eine Rosiwal-Messung (Tab. IV a) einer Probe von dieser Lokalität ergab ungefähr dieselbe Zusammensetzung wie die des typischen Rönne Granits (b). Zum Vergleich wird ferner-auf Tab. IV unter c die Zusammensetzung des Paradisbakke Granits angeführt. Sämtliche Zahlenwerte in Gewichtsprozenten. 


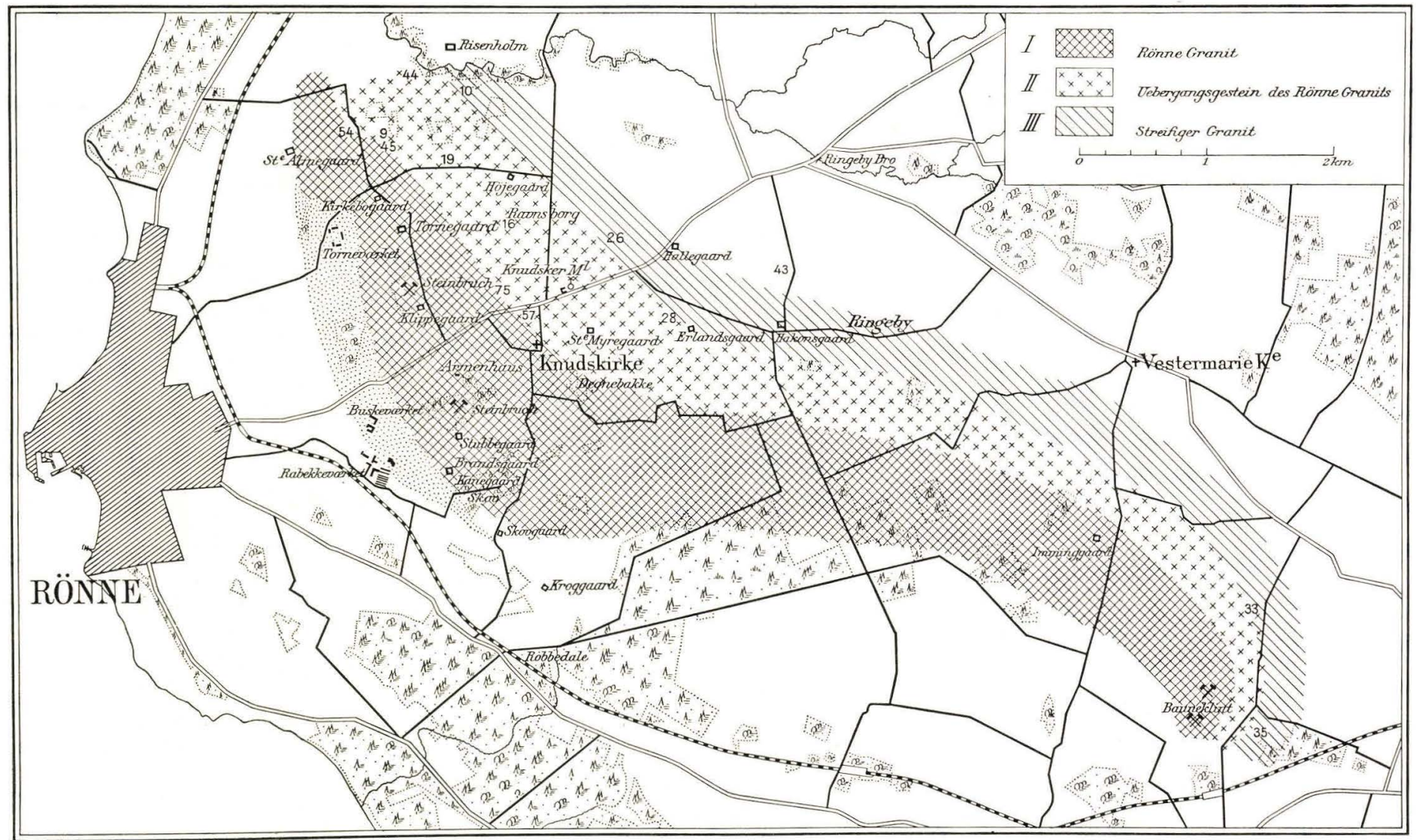

Fig. 11. Grenzgebiet des Rönne Granits. 
Tab. IV.

\begin{tabular}{|c|c|c|c|c|c|}
\hline \multirow[t]{2}{*}{. } & \multirow{2}{*}{\begin{tabular}{|c||} 
a \\
Porphyrischer \\
Rönne Granit \\
Lok. 45
\end{tabular}} & \multicolumn{2}{|c|}{$\begin{array}{c}\text { b } \\
\text { Rönne Granit }\end{array}$} & \multicolumn{2}{|c|}{$\begin{array}{c}\mathrm{c} \\
\text { Paradisbakke Granit }\end{array}$} \\
\hline & & $\begin{array}{l}\text { Geometr. } \\
\text { Anal. }\end{array}$ & Modus & $\begin{array}{l}\text { Geometr. } \\
\text { Anal. }\end{array}$ & Modus \\
\hline Quarz & 21.57 & 20.14 & 20.85 & 23.05 & 22.41 \\
\hline Mikroklin & $27.86\} 56.63$ & $28.30\} 59.63$ & $22.57\}_{60.25}$ & $27.16\} 57.40$ & $21.96\} 56.55$ \\
\hline Plagioklas & $28.77\}^{56.63}$ & $31.33\}^{59.63}$ & $37.68\}^{60.25}$ & $30.24\} 57.40$ & $34.59\} 56.55$ \\
\hline Hornblende & $8.97^{\prime}$ & 10.00 & 9.96 & 8.29 & 8.29 \\
\hline Biotit & 7.80 & 5.01 & 5.00 & 6.61 & 7.00 \\
\hline Erz & 3.81 & 3.32 & 3.42 & 1.35 & 1.35 \\
\hline Titanit & 1.14 & 0.80 & 0.69 & 1.50 & 1.50 \\
\hline Apatit & 0.88 & 0.89 & 0.90 & 0.43 & 0.41 \\
\hline
\end{tabular}

Etwas weiter gegen NW an der Lokalität 54, etwa $500 \mathrm{~m}$ NNO von Store Almegaard, hat der Granit die am deutlichsten ausgesprochene porphyrische Struktur (Taf. III Fig. 1-2). Plagioklas und poikilitische Hornblende bilden die Einsprenglinge in einer äusserst feinkörnigen Grundmasse, in welcher Mikroklin das vorherrschende Mineral ist. Biotit ist in weit geringerer Menge als Hornblende vorhanden. Titanit ist reichlich vertreten.

II. Das Uebergangsgestein des Rönne Granits findet man in einer etwas unregelmässigen, ca. $1 \mathrm{~km}$ breiten Zone östlich von der genannten Linie von Lok. 75 bis zur Lok. 54. Der Granit hat hier einen wesentlich geringeren Gehalt an Hornblende und Biotit, und das Mengenverhältnis zwischen diesen beiden Mineralien wechselt von Ort zu Ort. Erzkörner und namentlich Titanit sind in der Regel reichlich vertreten; das letztere Mineral tritt sowohl als Titanitrand um die Erzkörner als auch in Gestalt von selbständigen Kristallen auf. Die Farbe des Gesteins wechselt zwischen grau und rötlichgrau. Die Struktur ist auch hier porphyrisch; oft ist das Gestein zugleich deutlich gestreift. Die Einsprenglinge bestehen aus Plagioklas, doch erreichen auch einzelne Mikroklinkörner eine einsprenglingsartige Grösse. Die Plagioklaseinsprenglinge haben dieselbe unregelmässige Form wie im porphyrischen Rönne Granit und weisen oft zahlreiche Einschlüsse auf. Die Zusammensetzung ist jedoch etwas anorthitärmer; stellenweise findet sich ein Albitsaum.

Vom Granit in dieser Zone liegt eine Analyse (Tab. V) vor, die auf Ussing's Wunsch von Crr. Detlefsen, Kopenhagen, ausgeführt wurde. Die analysierte Granitprobe entstammt Lokalität 9, $800 \mathrm{~m}$ östlich von Store Almegaard. Ferner gibt es in UssING's Sammlung einen Dünnschliff, der dieser Probe entspricht. Die aktuelle Mineralkombination lässt sich aus der Analyse durch eine RosiwaL-Messung und mittels Verwendung der aus dem Rönne Granit ermittelten Biotitzusammensetzung einiger- 
Tab. V.

\begin{tabular}{|c|c|c|c|c|c|c|c|}
\hline & $\%$ & $\begin{array}{l}\text { Mol. } \\
\text { quot. }\end{array}$ & $\begin{array}{c}\text { Mol. } \\
\%\end{array}$ & \multicolumn{2}{|c|}{ Norm } & \multicolumn{2}{|c|}{ Modus } \\
\hline $\mathrm{SiO}_{2}$ & 63.54 & 10590 & 70.33 & $\mathrm{Q}$ & 15.36 & Quarz & 16.77 \\
\hline $\mathrm{TiO}_{2}$ & 1.15 & 144 & 0.96 & Or & 36.14 & Mikroklin & 33.13 \\
\hline $\mathrm{Al}_{2} \mathrm{O}_{3}$ & 14.23 & 1395 & 9.26 & $\mathrm{Ab}$ & 26.20 & Albit & 25.28 \\
\hline $\mathrm{Fe}_{2} \mathrm{O}_{3}$ & 3.56 & 222 & - & An & 6.67 & Anorthit & 7.40 \\
\hline $\mathrm{FeO}$ & 3.40 & 472 & 6.09 & $\Sigma \mathrm{sal}$ & 84.37 & Hornblende & 6.62 \\
\hline $\mathrm{MnO}$ & 0.24 & 34 & 0.22 & & & Biotit & 3.27 \\
\hline $\mathrm{MgO}$ & 0.91 & 227 & 1.51 & di & 6.40 & Erz & 4.45 \\
\hline $\mathrm{CaO}$ & 3.27 & 584 & 3.88 & hy & 1.00 & Titanit & 2.59 \\
\hline $\mathrm{Na}_{2} \mathrm{O}$ & 3.12 & 503 & 3.34 & $\mathrm{mt}$ & 5.10 & Apatit & 0.50 \\
\hline $\mathrm{K}_{2} \mathrm{O}$ & 6.09 & 648 & 4.30 & il & 2.13 & & 100.01 \\
\hline $\mathrm{P}_{2} \mathrm{O}_{5}$ & 0.23 & 16 & 0.11 & ap & 0.67 & & \\
\hline \multirow[t]{2}{*}{ Glühverlust } & 0.27 & 150 & - & $\Sigma$ fem & 15.30 & & \\
\hline & 100.01 & - & 100.00 & $\begin{array}{l}\text { "II. } 4 \\
\text { Adam }\end{array}$ & $\begin{array}{l}99.67 \\
2 . \\
\text { 2. } 3 . \\
\text { se }\end{array}$ & & \\
\hline
\end{tabular}

Dichte 2.744

Aktueller Durchschnitts plagioklas $\mathrm{Ab}_{77} \mathrm{An}_{23}$ Aktueller Durchschnittsfeldspat $\mathrm{Or}_{50 \cdot 3} \mathrm{Ab}_{38 \cdot 4} \mathrm{An}_{11 \cdot 3}$

\begin{tabular}{l|c|ccc|ccc|c|c|} 
Molekularwerte nach OSANN & $\mathrm{s}$ & $\mathrm{A}$ & $\mathrm{C}$ & $\mathrm{F}$ & $\mathrm{a}$ & $\mathrm{c}$ & $\mathrm{f}$ & $\mathrm{n}$ & $\mathrm{k}$ \\
& 71.3 & 7.6 & 1.6 & 10.1 & 12.0 & 2.5 & 15.5 & 4.4 & 1.21
\end{tabular}

Uebergangsgestein des Rönne Granits, Store Almegaard. Anal. Chr. Detrefsen.

massen berechnen. Die Analyse ergibt einen kleinen Mangel an Tonerde. Geometrisch wurde $1 \%$ Apatit festgestellt, also das Doppelte der Menge, die dem $\mathrm{P}_{2} \mathrm{O}_{5}$-Gehalt der Analyse entspricht. Der Erzgehalt wurde geometrisch auf $4,45 \%$ bestimmt. In NiggLi's System gehört das Gestein zu dem syenitgranitischen Magmatypus.

Der Kürze halber habe ich den analysierten Granit »Uebergangsgestein des Rönne Granits« genannt, obwohl die Zusammensetzung dieses Gesteins nicht als typisch für den Granit der Uebergangszone bezeichnet werden kann, da dieser im allgemeinen einen wesentlich höheren Quarzgehalt aufweist. Auf Lok. 9 ist der Granit schwach gestreift und etwas schlierig. Unter den von Ussing gesammelten Gesteinsproben von dieser Stelle gibt es noch ein Handstück, in welchem makroskopisch zahlreiche kleine Plagioklaseinsprenglinge von etwa $0,5 \mathrm{~cm}$ im Querschnitt sowie Haufen von dunklen Mineralien in einer feinkörnigen rotgrauen Grundmasse mit einigen dünnen hellroten, aplitischen Schlieren beobachtet werden. Ein Dünnschliff von diesem Stück ergab auf Grund einer RosiwaLMessung die unter a auf Tab. VI angeführte Mineralkombination. 
Tab. VI.

\begin{tabular}{|c|c|c|}
\hline & a. Lok. 9. & b. Lok. 75 . \\
\hline Quarz & 23.42 & 26.32 \\
\hline Mikroklinperthit & 63.08 & $31.67\rceil_{60} 39$ \\
\hline Plagioklas & $37.33\}^{03.08}$ & $28.72\}^{00.39}$ \\
\hline Hornblende & 2.86 & 4.28 \\
\hline Biotit & 3.72 & 1.48 \\
\hline Erz & 3.49 & 4.37 \\
\hline Titanit & 2.01 & 1.78 \\
\hline \multirow[t]{2}{*}{ Apatit } & 0.53 & 0.52 \\
\hline & 99.11 Gew. \% & 99.14 Gew. \% \\
\hline
\end{tabular}

Uebergangsgestein des Rönne Granits.

Dieselbe dürfte in der Tat der Durchschnittszusammensetzung des porphyrischen Gesteins in der Uebergangszone entschieden näher kommen als die auf Tab. V angeführte, während die Analyse zweifellos den quarzarmen, dunklen Schlieren im Gestein an dieser Lokalität entspricht. Die mikroskopische Untersuchung ergibt ein deutliches Bild von der wechselnden Beschaffenheit des Gesteins dieser Zone. Eine Zusammensetzung, die mit der unter a auf Tab. VI angeführten nahe verwandt ist, wurde z. B. in einer Probe von Lok. 45 gefunden, also unmittelbar neben dem oben beschriebenen porphyrischen Rönne Granit (Tab. IV a). Ferner wurden ähnliche Gesteine, in denen der Mikroklingehalt jedoch meistens ebenso gross oder grösser als der Plagioklasgehalt ist, und in denen das Verhältnis zwischen dem Hornblende- und dem Biotitgehalt variierend ist, in Proben von Lok. 44 südlich von Risenholm, Lok. 19 bei Höjegaard, Lok. 16 bei Ravnsborg, Lok. 57 bei Knudsker Mühle und etwa $150 \mathrm{~m}$ östlich von Store Myregaard gefunden. Die Korngrösse der Grundmasse kann in diesen Vorkommen etwas verschieden sein. In einigen Proben beobachtet man granophyrähnliche Verwachsungen von Mikroklin und Quarz, in anderen wieder hat die Grundmasse eine pflasterähnliche Struktur. In der Regel ist ein wenig Myrmekit vorhanden.

Noch ein wenig quarzreicher ist der Granit an der Ostseite von Ussing's Lokalität 75, also nur etwa $3 \mathrm{~m}$ östlich vom porphyrischen Rönne Granit. Dieser Granit ist ziemlich hell, rötlich und schwach gestreift. Die Grundmasse ist verhältnismässig grobkörnig, und Einsprenglinge sind nur spärlich vorhanden. Die mineralogische Zusammensetzung ist auf Tab. VI b angeführt. Das Verhältnis zwischen dieser Varietät und dem dunklen porphyrischen Rönne Granit erinnert sehr an das Verhältnis zwischen den hellen und dunklen Schlieren im Paradisbakke Granit (vgl. p. 62 ff.). Im besprochenen Gebiete findet man jedoch keine derartige Schlierigkeit im Granit. Somit hat Ussing allen Grund gehabt, an dieser Stelle eine scharfe Grenze zwischen dem Rönne Granit und dem 
streifigen Granit zu ziehen. Dass jedoch eine solche Grenze in der Tat nicht besteht, geht aus dem Umstande hervor, dass der quarzärmere, porphyrische Granit (Tab. VI a) auch an mehreren Stellen im Terrain östlich von diesem Punkt gefunden worden ist.

Pegmatit ist innerhalb der granitporphyrischen Zone recht reichlich vertreten; im Gegensatz zu den scharf begrenzten Pegmatitgängen des Rönne Granits trifft man hier oft pegmatitische Schlieren oder grössere unregelmässige Massen an.

III. Erst in einer noch grösseren Entfernung vom typischen Rönne Granit, nämlich von einer Linie ungefähr von Lok. 10 (SSO von Risenholm) bis zur Lok. 28 bei Erlandsgaard trägt der Granit den Charakter von "streifigem Granit«. Im nördlichsten Gebiete bei Risenholm ist er recht hell rötlich, und die dunklen Mineralien sind in deutlichen Streifen angeordnet. Hornblende tritt spärlich auf. Wie es beim streifigen Granit der Fall zu sein pflegt, ist das Gestein etwas porphyrisch: in einer feinbis mittelkörnigen Grundmasse liegen grössere Feldspatkörner, sowohl Plagioklas als Mikroklin, nicht selten Mikroklin mit einem parallel orientierten Plagioklaskern. Grössere Plagioklaskörner sind in der Regel im Inneren so stark getrübt, dass ihre Zusammensetzung nicht bestimmt werden kann. Die kleineren Plagioklaskörner in der Grundmasse bestehen aus Oligoklas-Albit mit 13-14\% An. Manchmal bestehen die "Einsprenglinge« aus mehreren dicht beieinander liegenden, verschieden orientierten Feldspatkörnern (Taf. V Fig. 1). Im südlichen Teile des Gebiets, bei Hallegaard und Erlandsgaard, ist die Farbe des Granits ein dunkleres Grau; im übrigen ist das Gestein wie soeben beschrieben. Die Fortsetzung nach Südosten zu bildet der graue streifige Granit in der Gegend von Aakirkeby, wo der Granit wie im Gebiet östlich vom Rönne Granit etwas variierend ist, mehr oder weniger porphyrisch und mit grösserem oder geringerem Hornblendegehalt.

Es wäre an dieser Stelle noch zu erwähnen, dass am Abhange einige Hundert Meter NO von Hallegaard in der Knudsker Gemeinde ein heller, roter mittelkörniger und schwach gestreifter Granit desselben Typus wie der Granit im Steinbruch von Bjergbakke und in Almindingen vorkommt. Der Uebergang zwischen diesem Granit und dem vorhin erwähnten grauen streifigen Granit war nicht blossgelegt, doch muss er an dieser Stelle ziemlich schroff sein, denn unmittelbar östlich von Hallegaard fand ich diese beiden Granitvarietäten in einer Entfernung von etwa $100 \mathrm{~m}$ von einander feststehend.

Auch gegen Südwesten in der Gegend von Kroggaard geht der Rönne Granit in einen quarzreicheren und hornblendeärmeren, schwach gestreiften rötlichen Granit über. Der Mineralbestand entspricht ungefähr dem des oben beschriebenen Uebergangsgesteins (II), porphyrische Struktur wurde jedoch nicht beobachtet. 
In der südwestlichsten Ecke des Granitgebiets, etwa 500 m SSO von Kroggaard, in der Nähe der Grenze gegen den Nexö Sandstein, findet sich in einer Kluft am Wege von Robbedale Station ein stark verwitterter streifiger Granit, der zum Teil in groben Grus zerfallen ist. Im Dünnschliff der noch zusammenhängenden Teile ist zu ersehen, dass das Gestein sehr quarzreich ist. Die Quarzkörner haben durchschnittlich einen Querschnitt von etwa 0,5 mm und liegen ebenmässig im Gestein verteilt. Von den ursprünglichen Mineralien ist übrigens Mikroklin nachweisbar; er ist ziemlich stark verwittert und durchsetzt von Rissen, die mit glimmerähnlichen Umwandlungsprodukten angefüllt sind. Ein farbloser oder von Ferriverbindungen braunrot pigmentierter Glimmer mit lebhaften Polarisationsfarben dürfte zweifellos neugebildet sein. Wahrscheinlich ersetzt dieser Glimmer die ursprünglichen dunklen Mineralien des Gesteins; oft sind undurchsichtige rostfarbige Anhäufungen zwischen den Glimmerblättern eingelagert. An einzelnen Stellen beobachtet man Ueberreste von Erzkörnern, die von einer bräunlichen Kruste umgeben sind. Plagioklas ist nicht erhalten. Selbst wenn man annehmen würde, dass der Platz des Plagioklases im Gestein von den Umwandlungsprodukten angefüllt worden ist, so ist es doch augenscheinlich, dass dieses Gestein niemals einen bedeutenden Plagioklasgehalt gehabt haben kann: dazu ist das feste Gerüst aus Quarz und Mikroklin gar zu zusammenhängend. Hier liegen somit Ueberreste eines Granits vor, der sich ursprünglich wesentlich vom Rönne Granit unterschieden hat; das Gebiet, in welchem er gefunden wurde, ist jedoch so klein, dass es auf der Karte nicht vermerkt werden konnte.

\section{Paradisbakke Granit.}

Diese Varietät des streifigen Granits tritt in den Paradisbakker (NW von Nexö) am charakteristischsten in Erscheinung. Es ist ein grauer, schwarz- und weissgeflammter, feinkörniger Granit, in welchem graue oder gelbgrünliche Plagioklaskristalle als Einsprenglinge auftreten, was dem Gestein ein lebhaftes Aussehen verleiht. Dieser Granit wird in einem recht ansehnlichen Steinbruch auf dem Terrain des Præstebogaard im nördlichen Teile der Paradisbakker abgebaut und findet beim Bauen Verwendung, besonders für Fassadensteine, Säulen u. dgl. In der Nähe der Oberfläche ist der Granit oft rötlich und ziemlich hell.

Die hellen Gemengteile des Gesteins sind in aplitischen Schlieren angereichert, die an der dunkelgrauen, vom Inlandeise polierten Felsenoberfläche Wellenschlaglinien mit Richtung etwa N $10^{\circ} \mathrm{W}$ gleichen. Diese Richtung behauptet sich in sehr konstanter Weise im ganzen Gebiet der Paradisbakker. Die Grenze zwischen den dunklen und hellen 
Schlieren ist nicht scharf; an den wagerechten Granitflächen im Steinbruch bei Præstebo sieht man jedoch, dass die hellen Schlieren zum grössten Teile recht einfach gezeichnet und meistens nur ein paar Centimeter breit und $10-20 \mathrm{~cm}$ lang sind; nur selten sind sie stärker verzweigt und haben einen unregelmässigen Verlauf. An den senkrechten Bruchflächen im Granit beobachtet man, dass die aplitischen Schlieren in der Tat am ehesten die Form von dünnen, oft etwas wellenförmigen

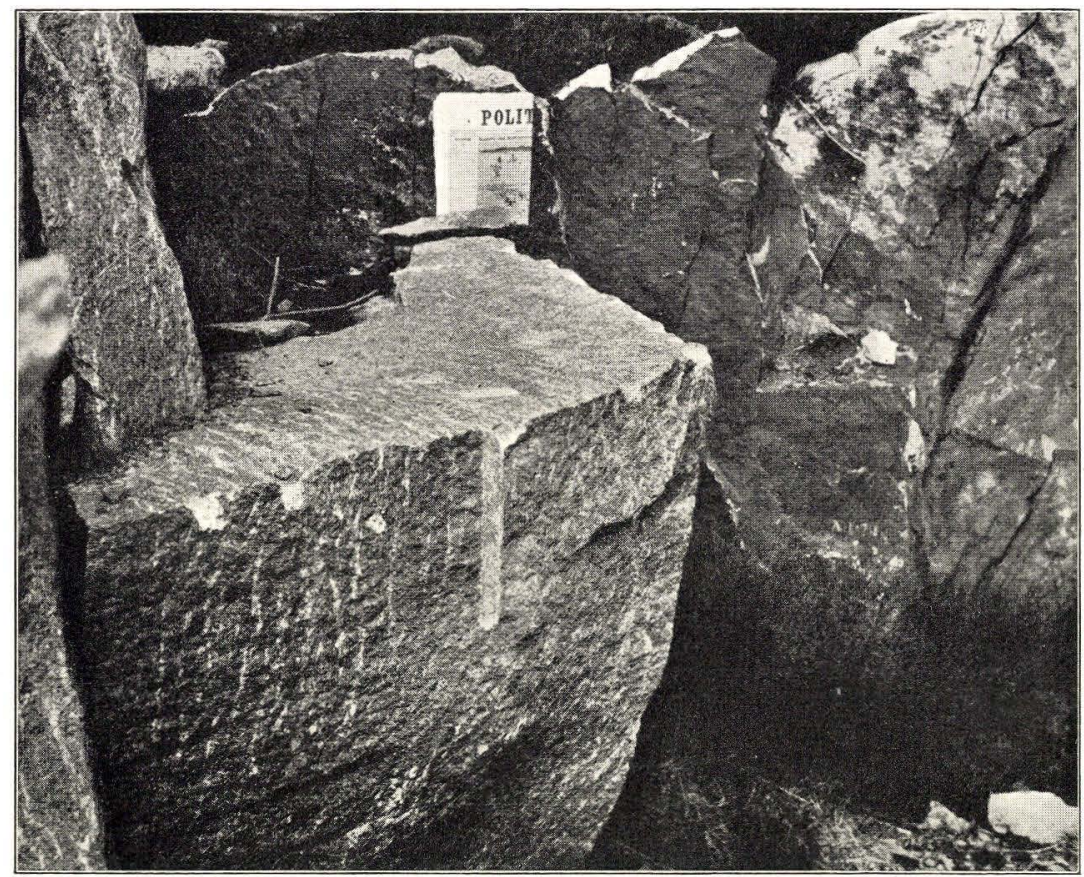

Fig. 12. Aplitschlieren im Paradisbakke Granit. Querschnitt.

und stark verwischten Adern oder Spindeln haben, die den Granit senkrecht durchsetzen. Oft sind sie durch grössere Queradern verbunden. Auf Fig. 12 sieht man zwei Bruchflächen, eine horizontale und eine vertikale, welche die Schlieren winkelrecht getroffen haben, und Fig. 13 zeigt eine Granitwand, die ungefähr der Längsrichtung der Schlieren folgt, wodurch der geflammte Charakter des Granits besonders deutlich wird. Eine schräge Bruchfläche ist selbverständlich noch unregelmässiger geflammt, was in der Steinindustrie ausgenützt wird. In den aplitischen Schlieren sind die Plagioklaseinsprenglinge sehr selten; manchmal beobachtet man pegmatitische Partien, und die Korngrösse ist überhaupt ein wenig gröber als in der Grundmasse der dunklen Schlieren.

In den dunklen Teilen des Paradisbakke Granits sind Biotit und Hornblende meistens in mehr oder weniger deutlichen Streifen angeordnet, die bisweilen ungefähr parallel mit den aplitischen Schlieren verlaufen, 
oft aber einen Winkel mit denselben bilden. Die Streifung zeitigt keine Schiefrigkeit; eher hat das Gestein eine unregelmässige, lineare Struktur.

Peg $\mathrm{m}$ a tit ist im Paradisbakke Granit nicht sehr reichlich vorhanden, kommt aber doch hie und da in Form von recht ansehnlichen Gängen, die die Schlieren unregelmässig durchschneiden, vor. Der Pegmatit besteht überwiegend aus Mikroklinperthit und Quarz. Der Mikroklin ist hell rötlich, der Quarz farblos oder rotbraun; die Farbe stammt von Ferriverbindungen her, die in Spalten oder als Rinden um die Körner ausgeschieden sind. Untergeordnet tritt weisser Plagioklas mit 14-15\% An. auf, und in sehr kleinen Mengen kommen Biotit und Magnetit vor.

Gegen Osten zu ist der Paradisbakke Granit von dem jüngeren Svaneke Granit durch eine scharfe Grenze (siehe pag. 117 ff.) getrennt; nach Norden und Westen zu geht er allmählich in den »streifigen Granit« über; gegen Süden zu wird er vom Nexö Sandstein begrenzt.

Mineralogische Zusammensetzung. 1) Die dunklen Teile bilden die Hauptmasse des Paradisbakke Granits. Ihrer Zusammensetzung nach stehen sie dem Rönne Granit ausserordentlich nahe und sind im Dünnschliff kaum von jenem Gestein zu unterscheiden, das oben als "porphyrischer Rönne Granit« (vgl. pag. 56, Tab. IV) bezeichnet wurde. Die makroskopisch ins Auge springenden Plagioklaseinsprenglinge können einen Querschnitt von über $1 \mathrm{~cm}$ erreichen, sind aber gewöhnlich wesentlich kleiner. Auch im Dünnschliff stellt sich das Gestein als porphyrisch heraus, mit Plagioklaseinsprenglingen von einem Querschnitt von ein paar Millimetern in einer feinkörnigen Grundmasse (Taf. III Fig. 3 und 4).

Die Plagioklaseinsprenglinge haben eine unregelmässige Kontur, doch mit rechtangulärer Tendenz. Die zentralen Teile sind oft etwas unfrisch und getrübt. Sie bestehen aus Oligoklas, der in vielen Fällen dieselbe unregelmässige, undulöse Auslöschung wie der Plagioklas des Rönne Granits zeigt. In der Regel haben sie eine schmale, saurere Randzone, die stellenweise in einen scharf markierten Albitrand übergeht. Von Messungen führe ich folgende an:

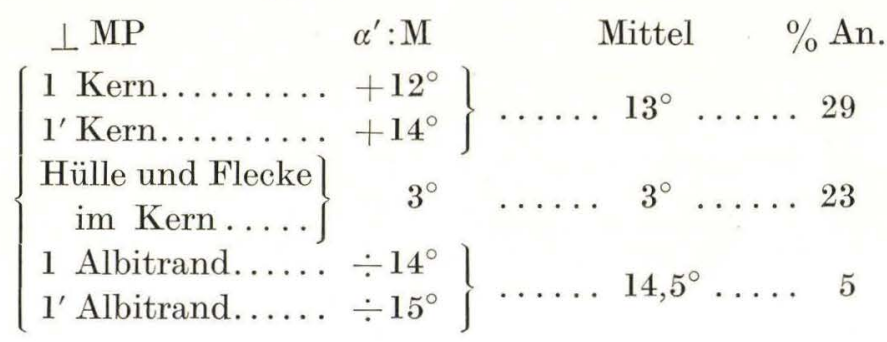

Die Plagioklaseinsprenglinge enthalten häufig Einschlüsse von den übrigen Mineralien des Gesteins. Einige der Plagioklaskristalle sind in hohem Masse poikilitisch von Quarz, Mikroklin, Hornblende und Biotit 
durchwachsen. Stellenweise scheint es, als füllten die Einschlüsse unregelmässig verzweigte Korrosionskanäle aus. In vielen Fällen sind kleine Biotitblätter parallel mit der Basis des Plagioklases, mit Prismenflächen u. a. Kristallflächen eingelagert. Hie und da beobachtet man parallel angewachsenen Mikroklin.

In der Grundmasse bilden Quarz und Mikroklin die wesentlichsten Gemengteile, doch kommen auch Plagioklas, Hornblende und Biotit in

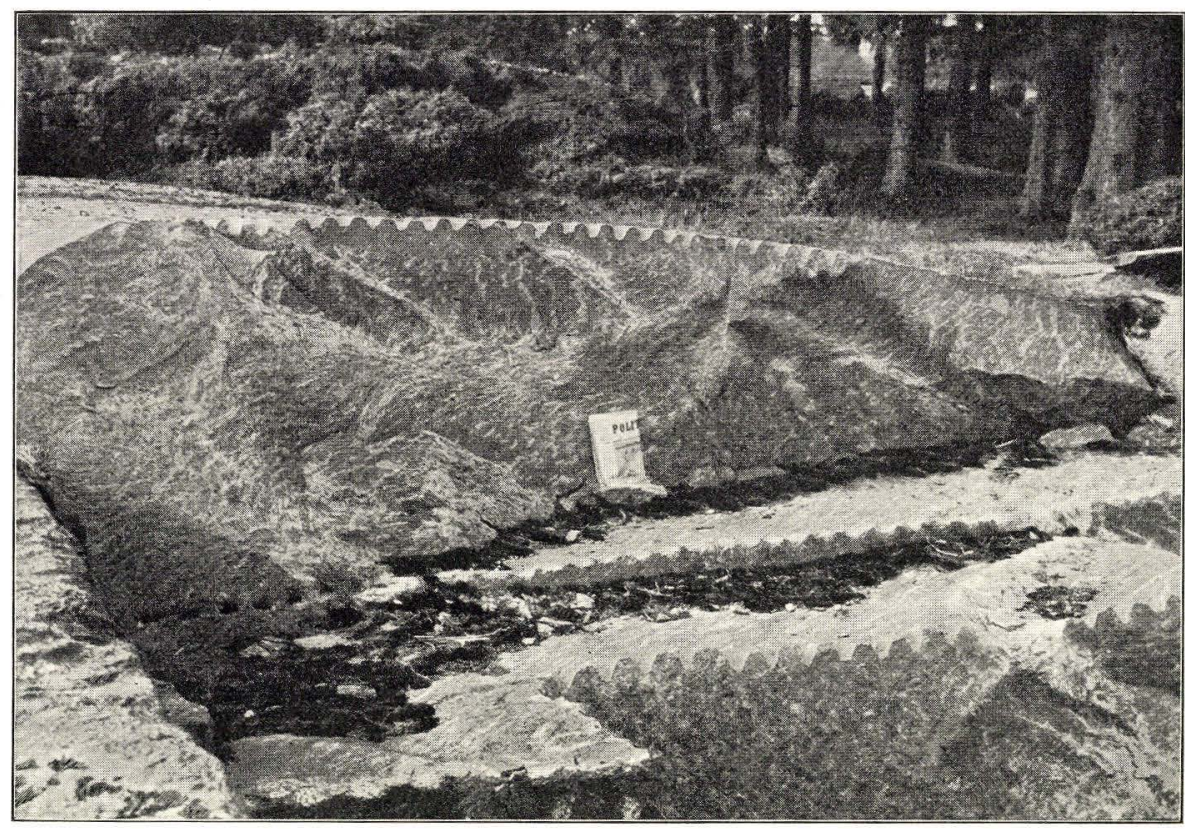

Fig. 13. Aplitschlieren im Paradisbakke Granit. Granitwand, die ungefähr der Längsrichtung der Schlieren folgt.

beträchtlicher Menge vor. Der grösste Teil der Grundmasse ist sehr feinkörnig; doch findet man meistens in jedem Dünnschliff einige kleinere Partien von etwas gröberer Korngrösse; sie bestehen fast ausschliesslich aus einem regellos körnigen Gemenge von Quarz und Mikroklin. Der Quarz ist stellenweise rötlich gefärbt. Der Mikroklin ist frisch und vollkommen klar; in der Regel ist er ziemlich arm an Perthit. Der Plagioklas der Grundmasse hat oft einen schmalen Albitrand und besteht im übrigen aus Oligoklas mit etwa $20 \%$ An. Myrmekit wird häufig beobachtet. Die Hornblende ist dieselbe wie im Rönne Granit, nur scheint der optische Achsenwinkel noch kleiner oder sogar $=0 \mathrm{zu}$ sein. Kleine Hornblendekristalle haben oft Prismenflächen und manchmal ausserdem 010; grössere Individuen haben dieselbe unregelmässige und stark durchlöcherte Form mit Quarz in den Fenstern wie im Rönne Granit. Der Biotit ist ein wenig grünlich, Pleochroismus: hell grünlichgelb-oliv- 
braun. Oft tritt er in Gestalt von kleinen länglichen Blättern von recht regelmässiger Form auf. Titanit ist reichlich vorhanden. Zum grössten Teil kommt er als ein kräftig entwickelter Titanitrand um die Erzkörner herum vor, ist jedoch auch in selbständiger Kristallform vorhanden; Zwillingslamellen werden hie und da beobachtet. Akzessorisch treten ferner Magneteisen, Apatit, Zirkon und (sehr selten) Orthit, Kalkspat und Epidot auf.

Die dunklen Mineralien sind teils recht gleichmässig zwischen den hellen verteilt, teils dichter in Streifen oder länglichen Anhäufungen angesammelt, innerhalb welcher sie aber gänzlich regellos angeordnet sind; nur neigt der Biotit dazu, sich den Plagioklaseinsprenglingen anzuschmiegen.

2) Die hellen Schlieren bestehen überwiegend aus Mikroklinperthit und Quarz. Einzelne Plagioklaskörner können eine einsprenglingsartige Grösse erreichen, und dasselbe gilt, wenn auch seltener, für den Mikroklin. Im letzteren beobachtet man dann und wann, dass die Lamellen des einen Individuums im Mikroklin derartig stark entwickelt sind, dass sie innerhalb gewisser Teile der Körner beinahe alleinherrschend werden. Diese erhalten dadurch eine undulöse Auslöschung, welche an diejenige in zonargebauten Plagioklas erinnert. Diese charakteristische Struktureigentümlichkeit ist in den hellen mikroklinreichen Teilen des Granits augenfälliger als in den dunklen feinkörnigen. Myrmekit ist reichlich vorhanden. Die dunklen Mineralien sind natürlich in wesentlich geringerer Menge als in den dunklen Teilen des Gesteins vorhanden, doch sind sie nicht gerade spärlich vertreten; zum Teil sind sie in Anhäufungen angeordnet. Der Mineralbestand ist im übrigen derselbe wie in den dunklen Teilen des Gesteins, nur ist das Mengenverhältnis der Mineralien etwas verändert.

Chemische Zusammensetzung. Vom Paradisbakke Granit teilt KaLb (l. c. p. 62) eine Analyse mit, die in seinem Auftrag im Laboratorium Diтtrich, Heidelberg, ausgeführt worden ist. Laut KALB wurde das Material zu einer Analyse seiner grossen Zahl von Gesteinsstücken entnommen, in denen die Adern wenig scharf ausgebildet waren, so dass folgende Analyse Durchschnittswerte des Paradisbakke Granits gibt«. Die aktuelle Mineralkombination (Tab. VII) ist auf Grund dieser Analyse und der RosiwaL-Messung eines Dünnschliffes, der aus einer typischen Probe des Paradisbakke Granits vom Bruche bei Præstebogaard gewonnen wurde, hergestellt. Diese Probe ist dunkelgrau mit relativ fein verteilten aplitischen Schlieren. Die Uebereinstimmung zwischen der chemischen und der geometrischen Analyse war eher grösser, als man es im voraus in Anbetracht der unregelmässigen Struktur des Gesteins hätte erwarten dürfen. Nur bleibt bei dem angenommenen Biotitgehalt: von $7 \%$ (gemessen 6,61) ein ziemlich hoher $\mathrm{Al}_{2} \mathrm{O}_{3}$-Wert für den Biotit 
Tab. VII.

\begin{tabular}{|c|c|c|c|c|c|c|c|}
\hline & $\%$ & $\begin{array}{l}\text { Mol. } \\
\text { quot. }\end{array}$ & Mol. \% & \multicolumn{2}{|c|}{ Norm } & \multicolumn{2}{|c|}{ Modus } \\
\hline $\mathrm{SiO}_{2}$ & 65.40 & 10900 & 73.55 & $\mathrm{Q}$ & 20.28 & Quarz & 22.41 \\
\hline $\mathrm{TiO}_{2}$ & 1.01 & 126 & 0.85 & Or & 25.58 & Mikroklin & 21.96 \\
\hline $\mathrm{Al}_{2} \mathrm{O}_{3}$ & 14.73 & 1444 & 9.74 & $\mathrm{Ab}$ & 29.87 & Albit & 28.67 \\
\hline $\mathrm{Fe}_{2} \mathrm{O}_{3}$ & 1.14 & 71 & 一 & An & 11.40 & Anorthit & 5.92 \\
\hline $\mathrm{FeO}$ & 2.92 & 406 & 3.70 & \multirow[t]{2}{*}{$\Sigma$ sal } & \multirow[t]{2}{*}{87.13} & \multirow{2}{*}{$\begin{array}{l}\text { Hornblende } \\
\text { Biotit }\end{array}$} & 8.29 \\
\hline $\mathrm{MnO}$ & 0.06 & 8 & 0.05 & & & & 7.00 \\
\hline $\mathrm{MgO}$ & 1.02 & 255 & 1.72 & $\mathrm{~d} \mathbf{i}$ & 1.39 & \multirow{2}{*}{$\begin{array}{l}\text { Magnetit } \\
\text { Titaneisen }\end{array}$} & 0.80 \\
\hline $\mathrm{CaO}$ & 2.78 & 496 & 3.35 & hy & 4.54 & & 0.55 \\
\hline $\mathrm{Na}_{2} \mathrm{O}$ & 3.54 & 571 & 3.85 & $\mathrm{mt}$ & 1.62 & \multirow{2}{*}{$\begin{array}{l}\text { Titanit } \\
\text { Apatit }\end{array}$} & 1.50 \\
\hline $\mathrm{K}_{2} \mathrm{O}$ & 4.31 & 459 & 3.10 & il & 1.98 & & 0.41 \\
\hline $\mathrm{P}_{2} \mathrm{O}_{5}$ & 0.19 & 13 & 0.09 & ap & 0.34 & \multirow{3}{*}{$\begin{array}{l}\text { Rest } \mathrm{H}_{2} \mathrm{O} \\
\mathrm{CO}_{2}\end{array}$} & 1.72 \\
\hline $\mathrm{CO}_{2}$ & 0.68 & 155 & & $\Sigma$ fem & 9.87 & & 0.68 \\
\hline $\mathrm{H}_{2} \mathrm{O}$ über $110^{\circ}$ & 1.58 & 878 & & \multirow{3}{*}{\multicolumn{2}{|c|}{$\begin{array}{l}\quad 97.00 \\
\text { I (II). } 4.2 .3 . \\
\text { Toscanose }\end{array}$}} & & \multirow[t]{3}{*}{99.91} \\
\hline \multirow[t]{2}{*}{$\mathrm{H}_{2} \mathrm{O}$ unter $110^{\circ}$} & 0.55 & - & & & & & \\
\hline & 99.91 & & 100.00 & & & & \\
\hline
\end{tabular}

Dichte 2.765

Aktueller Durchschnittsplagioklas $\mathrm{Ab}_{83} \mathrm{An}_{17}$

Aktueller Durchschnittsfeldspat $\mathrm{Or}_{38 \cdot 8} \mathrm{Ab}_{50 \cdot 7} \mathrm{An}_{10^{\circ} 5}$

\begin{tabular}{l|c|ccc|ccc|c|c|c} 
Molekularwerte nach OSANN & $\mathrm{s}$ & $\mathrm{A}$ & $\mathrm{C}$ & $\mathrm{F}$ & $\mathrm{a}$ & $\mathrm{c}$ & $\mathrm{f}$ & $\mathrm{n}$ & $\mathrm{k}$ \\
& 74.4 & 7.0 & 2.8 & 6.0 & 13 & 5.5 & 11.5 & 5.5 & 1.40
\end{tabular}

Paradisbakke Granit. Anal. M. Dittrich.

übrig. Bei der Mineralberechnung wurde keine Rücksicht auf den $\mathrm{CO}_{2}$-Gehalt der Analyse genommen, da die mikroskopische Untersuchung ergeben hatte, dass Karbonat im frischen Gestein nur in unbeträchtlichen Mengen vorhanden war.

Als Durchschnitt für die Zusammensetzung des Gesteins darf somit diese Berechnung für zuverlässig angesehen werden, und da die dunklen Partien den grössten Teil der gesamten Gesteinsmasse ausmachen, gilt sie mit einer recht grossen Annäherung auch für diese. Die aplitischen Schlieren dagegen sind wesentlich reicher an Quarz und Mikroklin und ärmer an Hornblende und Biotit. Eine geometrische Analyse eines hellen Gesteinsstückes ergab folgende Werte: Quarz: 29,23\%, Mikroklinperthit: 31,46, Plagioklas: 23,71, Hornblende : 4,08, Biotit : 5, 17, Erz: 2,94, Titanit: 1,06, Apatit: 0,41; stellenweise dürften die aplitischen Schlieren eine noch mehr salische Zusammensetzung aufweisen. Die geflammte und schlierige Struktur des Paradisbakke Granits lässt sich meiner Ansicht nach nur durch chemische Differentiation während der Erstarrung des Magmas erklären. 
Die Zusammensetzung des Paradisbakke Granits variiert ein wenig von Ort zu Ort. In einer Probe aus dem Bruch bei Elisegaard in der Anhöhe Slamrebjerg, südlich von den Paradisbakker, gab es z. B. Biotit in sehr reichlicher Menge, während die Hornblende relativ spärlich vertreten war (Taf. III Fig. 4). Die Biotitblätter waren schlank und länglich und lagen in ausgesprochenen Streifen parallel angeordnet. Ferner traten einige granophyrische Verwachsungen von Quarz und Mikroklin auf, die sonst im Paradisbakke Granit nicht beobachtet wurden. Im übrigen war das Gestein schwarz- und weissgeflammt und ähnelte in seinem Aeusseren vollkommen dem Granit im Bruche bei Præstebo.

Im nordöstlichen Teile der Paradisbakker, etwa $350 \mathrm{~m}$ südlich von Aspegaard, ist der Granit ziemlich hell grau und weist grosse Aehnlichkeit mit dem porphyrischen Granit der Lokalität 54, NNO von Store Almegaard bei Rönne, auf. Hornblende ist hier relativ reichlich vorhanden und tritt in Form von verhältnismässig grossen, unregelmässigen, durchlöcherten Individuen auf. Die Grundmasse ist ausserordentlich feinkörnig.

\section{Vang Granit.}

Der Vang Granit ist mittelkörnig und dunkelgrau mit einem mehr oder weniger ausgesprochenen Stich ins Rötliche; in der Nähe der Oberfläche ist er meistens ziemlich rot. Der rötliche Ton rührt vom Mikroklin her; die Plagioklaskörner sind gräulich klar und fallen oft durch ihre einsprenglingsartige Grösse und ihre rechtanguläre Form auf. Der Granit enthält Hornblende und Biotit in ziemlich reichlicher Menge, und diese Mineralien sind vorwiegend in kleinen Anhäufungen angeordnet. Stellenweise und zwar besonders im nördlichen Teile des Gebiets ist der Vang Granit regellos körnig, an anderen Stellen ist er mehr oder weniger gestreift, da die Anhäufungen von dunklen Mineralien flacher werden und parallel geordnet sind; alle Uebergänge zwischen diesen Formen kommen vor. Die stark streifigen Varietäten treten besonders im südlichen Teile des Gebiets auf.

Der Vang Granit bildet einen Gürtel quer durch den nördlichen Teil der Insel ungefähr zwischen dem Fischerdorf Vang an der Westküste und den Ortschaften Sandkaas und Tejn an der Nordostküste. Gegen Norden ist er vom Hammer Granit durch eine scharfe Grenze, die deutlich das jüngere Alter des letzteren erkennen lässt, getrennt; nach Süden zu geht der Vang Granit ganz allmählich in den gewöhnlichen streifigen Granit über.

Der Vang Granit dient in ausgedehntem Masse als Baumaterial und Pflasterstein; er wird in zahlreichen Brüchen gebrochen, u. a. in den 
Küstenfelsen südlich von Vang, wo auch Steine behauen und zu Schotter zertrümmert werden, ferner auf Ringebakke, bei Bakkemölle etwa $1 \mathrm{~km}$ nördlich von Ols Kirke und an mehreren anderen Stellen. In den steilen Küstenfelsen an der Westseite von Ringebakke ist der Vang Granit regellos körnig und völlig ungestreift. Hier legte $J_{A C O B}$ Mogensen 1899 den ansehnlichen Steinbruch »Klondyke« an, der durch ein 1,6 km langes Förderwagen-Geleise mit dem kleinen Verschiffungshafen in Vang verbunden war. Der »Klondyke«-Granit zeichnet sich durch seine vorzügliche Qualität aus und weist an vielen Stellen eine ungewöhnlich geringe Anzahl von Klüften auf; seitdem aber vor 10-15 Jahren das Geleise während einer Sturmflut ins Meer gespült worden ist, hat man den Bruch ausser Betrieb gesetzt.

Dieser regellos körnige, völlig ungestreifte »Klondyke«-Granit wurde im Jahre 1901 von Ussing als Typus des Vang Granits aufgestellt.

In seiner mineralogischen Zusammensetzung hat der Vang Granit eine grosse Aehnlichkeit mit dem Rönne Granit, doch ist er etwas salischer. Der Quarz hat eine schwach undulöse Auslöschung. Der Feldspat ist in der Regel ausserordentlich frisch. Der Mikroklinperthit macht etwas mehr als die Hälfte desselben aus. Wie im Rönne Granit ist er auch hier oft mit dem Plagioklas parallel verwachsen, und die grösseren Mikroklinkörner haben meistens einen Kern aus Plagioklas. Granophyrische Verwachsungen von Mikroklin und Quarz sind in der Regel reichlich vorhanden, und manchmal ist die Granophyrstruktur so stark entwickelt, dass man, wie schon $\mathrm{K}_{\mathrm{ALB}}$ (l. c. p. 55) bemerkt hat, den Eindruck gewinnt, als ob die grösseren Feldspatkörner in einer feinkörnigen Grundmasse aus Kalifeldspat und Quarz eingebettet lägen. Stellenweise beobachtet man, dass die zahlreichen Perthitspindeln im Mikroklin parallel den kristallographischen Wachstumsgrenzen angehäuft sind, was dem Kalifeldspat eine Art von zonarem Bau verleiht (Fig. 5, Taf. III).

Plagioklas tritt hauptsächlich in relativ grossen Körnern mit einem Querschnitt von 2-4 mm auf (Taf. III, Fig. 6). Die Form derselben ist bald ganz unregelmässig, bald annähernd rechtangulär. Der parallel angewachsene Mikroklin bildet nur selten einen völligen Mantel. Der Plagioklas hat im allgemeinen eine feine Zwillingsstreifung nach dem Albitgesetz, hie und da beobachtet man ausserdem Zwillingsbildung nach dem Periklin- und Karlsbader Gesetz. Die Kristalle haben oft einen etwas unregelmässigen Bau; der Auslöschungswinkel ändert sich, wie es auch im Plagioklas des Rönne Granits der Fall ist, nicht regelmässig von der Mitte aus nach dem Rande zu. In den am meisten basischen Partien wurde im MP-Schnitt $\alpha^{\prime}: \mathrm{M}=14^{\circ}$ gemessen, was $28 \%$ An. entspricht, wogegen an mehreren Stellen in den inneren Teilen des 
Plagioklases $\alpha^{\prime}: \mathrm{M}=$ ca. $10^{\circ}$ gemessen wurde, was $26-27 \%$ An. entspricht. In der schmalen äusseren Randzone ergaben die Messungen im allgemeinen $20-23 \%$ An., nur an einzelnen Stellen geht die Randzone in reinen Albit über. Die Mitte der Plagioklaskristalle ist meistens von zahlreichen ganz kleinen Einschlüssen etwas getrübt: zum grossen Teile sind es dünne, schwarze, unbestimmbare Nadeln sowie kleine Blätter aus Titaneisen und Biotit. Als etwas grössere Einschlüsse beobachtet man häufig die übrigen Mineralien des Gesteins. Der Quarz ist manchmal schriftgranitisch im Plagioklase eingelagert. Die schwarzen Nadeln und die schlanken Biotitblätter sind häufig in Streifen parallel den Kristallflächen im Plagioklase angeordnet. - Die Zwischenräume zwischen den grösseren Feldspatindividuen werden teils von den genannten granophyrischen Verwachsungen, teils von einem feinkörnigen Gemenge aus Quarz und Feldspat, in welchem die kleinen Plagioklaskörner sehr oft in myrmekitähnlicher Weise von Quarzstengeln durchwachsen sind, und endlich von Anhäufungen dunkler Mineralien ausgefüllt. Myrmekit ist reichlich vorhanden. Die Hornblende ist dieselbe wie im Rönne Granit, nur wurde in ein paar vereinzelten Querschnitten von Hornblendekristallen eine zonare Farbenverteilung beobachtet: die Mitte der Kristalle war braungrün, die Randzone etwas dunkler grün. Der Biotit ist kräftig pleochroitisch: hell gelb — dunkelbraun oder häufiger oliv bis beinahe schwarz. Er tritt teils in Gestalt von länglichen Blättern auf, teils hat er eine ganz unregelmässige Form (Taf. IV, Fig. 1); myrmekitähnliche Verwachsungen sind nur in einzelnen Fällen beobachtet worden. Stellenweise enthält der Biotit eine ausserordentlich grosse Menge von stark pleochroitischen Höfen um Einschlüsse herum, die sich in vielen Fällen als Orthit herausstellten. Erz, Titanit und Apatit sind reichlich vorhanden; der grösste Teil des Titanits bildet Kränze um die Erzkörner herum. Orthit kommt oft in verhältnismässig grossen Körnern vor.

Chemische Zusammensetzung. Vom Vang Granit liegen zwei Analysen (Tab. VIII) vor, die im Laboratorium von Diтtrich, Heidelberg, ausgeführt sind und die von KaLB (1. c. pag. 57 u. pag. 59) mitgeteilt werden. Der aktuelle Mineralbestand ist aus Analyse I unter Berücksichtigung der mikroskopischen Untersuchung und der RosiwaL-Messungen von Granit von "Klondyke« und Ringebakke berechnet.

In einer schmalen Zone parallel den relativ wenigen Pegmatitgängen ist der Granit oft ausgesprochen streifig. Die hellen Partien haben zum Teil die Form von stark ausgezogenen Linsen, in deren Mitte oft ein grösseres Korn von rotem Mikroklin vorkommt. Die Plagioklasmenge ist wesentlich geringer als die des Mikroklins. In den dunklen Streifen dominiert grünlicher Biotit, während die Hornblende nur spärlich auf- 
Tab. VIII.

\begin{tabular}{|c|c|c|c|c|c|c|c|c|}
\hline \multirow[b]{2}{*}{$\mathrm{SiO}_{2}$} & \multirow{2}{*}{$\begin{array}{c}\text { I } \\
66.99\end{array}$} & \multirow{2}{*}{$\begin{array}{l}\text { Mol. } \\
\text { quot. } \\
\text { von I }\end{array}$} & \multirow{2}{*}{$\begin{array}{c}\text { Mol. } \\
\% \\
\text { von I }\end{array}$} & \multirow{2}{*}{$\begin{array}{c}\text { II } \\
69.01\end{array}$} & \multicolumn{2}{|c|}{$\begin{array}{c}\text { Norm } \\
\text { aus I berechnet }\end{array}$} & \multicolumn{2}{|c|}{$\begin{array}{c}\text { Modus } \\
\text { aus I berechnet }\end{array}$} \\
\hline & & & & & $Q$ & 26.04 & \multirow{11}{*}{$\begin{array}{l}\text { Quarz } \\
\text { Mikroklin } \\
\text { Albit } \\
\text { Anorthit } \\
\text { Hornblende } \\
\text { Biotit } \\
\text { Magnetit } \\
\text { Titaneisen } \\
\text { Titanit } \\
\text { Apatit } \\
\text { Rest } \mathrm{H}_{2} \mathrm{O}\end{array}$} & 26.91 \\
\hline $\mathrm{TiO}_{2}$ & 0.71 & 89 & 0.60 & 0.97 & Or & 26.13 & & 22.57 \\
\hline $\mathrm{Al}_{2} \mathrm{O}_{3}$ & 13.00 & 1275 & 8.56 & 12.16 & $\mathrm{Ab}$ & 27.77 & & 26.97 \\
\hline $\mathrm{Fe}_{2} \mathrm{O}_{3}$ & 2.98 & 186 & 一 & 2.07 & An & 7.51 & & 5.07 \\
\hline $\mathrm{FeO}$ & 2.23 & 310 & 4.58 & 2.40 & \multirow[t]{2}{*}{$\Sigma$ sal } & \multirow[t]{2}{*}{87.45} & & 5.06 \\
\hline $\mathrm{MnO}$ & 0.11 & 15 & 0.09 & 0.06 & & & & 6.17 \\
\hline $\mathrm{MgO}$ & 0.65 & 162 & 1.09 & 0.93 & di & 1.79 & & 2.32 \\
\hline $\mathrm{CaO}$ & 2.64 & 471 & 3.16 & 2.28 & hy & 1.40 & & 0.19 \\
\hline $\mathrm{Na}_{2} \mathrm{O}$ & 3.28 & 529 & 3.55 & 3.65 & $\mathrm{mt}$ & 4.41 & & 1.32 \\
\hline $\mathrm{K}_{2} \mathrm{O}$ & 4.39 & 467 & 3.14 & 4.81 & il & 1.37 & & 1.24 \\
\hline $\mathrm{P}_{2} \mathrm{O}_{5}$ & 0.57 & 40 & 0.27 & 0.11 & ap & 1.34 & & 1.21 \\
\hline $\mathrm{CO}_{2}$ & - & - & - & 0.42 & $\Sigma$ fem & 10.31 & & 99.03 \\
\hline $\mathrm{H}_{2} \mathrm{O}$ über $110^{\circ}$ & 0.70 & 389 & - & 0.42 & & 97.76 & & \\
\hline \multirow[t]{2}{*}{$\mathrm{H}_{2} \mathrm{O}$ unter $110^{\circ}$} & 0.78 & - & - & 0.44 & \multirow{2}{*}{\multicolumn{2}{|c|}{$\begin{array}{l}\text { I (II). 4. 2. } 3 . \\
\text { Toscanose }\end{array}$}} & & \\
\hline & 99.03 & & 100.00 & 99.73 & & & & \\
\hline
\end{tabular}

Dichte 2.705

Aktueller Durchschnittsplagioklas $\mathrm{Ab}_{84} \quad \mathrm{An}_{16}$ Aktueller Durchschnittsfeldspat $\mathrm{Or}_{41.3} \quad \mathrm{Ab}_{49.4} \mathrm{An}_{9.3}$

\begin{tabular}{r|c|ccc|ccc|c|c|c} 
Molekularwerte nach OsanN & $\mathrm{s}$ & $\mathrm{A}$ & $\mathrm{C}$ & $\mathrm{F}$ & $\mathrm{a}$ & $\mathrm{c}$ & $\mathrm{f}$ & $\mathrm{n}$ & $\mathrm{k}$ & \\
von I & 75.6 & 6.7 & 1.9 & 7.1 & 13.0 & 3.5 & 13.5 & 5.3 & 1.48 & \\
Molekularwerte nach NiggLi & $\mathrm{si}$ & $\mathrm{al}$ & $\mathrm{fm}$ & $\mathrm{c}$ & $\mathrm{alk}$ & $\mathrm{k}$ & $\mathrm{mg}$ & $\mathrm{c} / \mathrm{fm}$ & Schnitt & $\mathrm{qz}$ \\
von I & 311 & 35.5 & 24 & 13 & 27.5 & 0.47 & 0.19 & 0.55 & 4 & 101
\end{tabular}

I. Vang Granit, "Klondyke«, Rödklöv, südlich von Vang. Anal. M. DitTrich.

II. Vang Granit am Pegmatit, "Klondyke». Anal. M. Diтtrich.

tritt. Von den Akzessorien ist namentlich Apatit angereichert, was doch nicht aus der Analyse II, Tab. VIII hervorgeht.

Im übrigen verändert sich das mikroskopische Bild des Vang Granits nicht wesentlich von den regellos körnigen zu den deutlich streifigen Varietäten. Nur scheint das Mengenverhältnis zwischen Hornblende und Biotit von einer Stelle zur anderen etwas zu variieren, doch ist dieses Verhältnis offenbar nicht von der Streifung abhängig. Charakteristisch für den Vang Granit im Gegensatz zum gewöhnlichen streifigen Granit bleibt doch stets: 1) ein beträchtlicher Hornblendegehalt, 2) die Ansammlung von dunklen Mineralien in Haufen, 3) die relativ grossen Mikroklin- und Plagioklaskörner, die nach rechtangulärer Form tendieren, sowie 4) die zahlreichen granophyrischen Verwachsungen von Quarz und Mikroklin, die fast in jedem Dünnschliff reichlich vorhanden sind. Diese 
Eigenschaften treten noch so weit nach Süden zu wie bis Jons Kapel und Ols Kirke und an der Nordostküste bis zur Gegend von Tejn deutlich im Granit hervor.

Unmittelbar an der Grenze gegen die feinkörnige Grenzfazies des Hammer Granits ist der Vang Granit hie und da ein wenig schlierig. So beobachtet man an einigen Stellen längs der Grenze in den Küstenfelsen unmittelbar nördlich vom Vang Hafen und im Steinbruch beim Moor Sjelle Mose (vgl. pag. 100 u. 104) eine ziemlich feinkörnige, schlierenartige Verwachsung der beiden Granite. Diese Zone hat vorwiegend die Zuzammensetzung des Vang Granits. Das Gestein ist dunkel, rotgrau. Die Korngrösse ist zum Teil kleiner als gewöhnlich im Vang Granit, doch enthält das Gestein eine beträchtliche Menge der für den Vang Granit charakteristischen grösseren Feldspatkörner, und zwar besonders Plagioklaskörner; die Form der Körner ist jedoch recht unregelmässig. Quarz ist etwas reichlicher als sonst vorhanden und hat eine stärkere undulöse Auslöschung. Die dunklen Mineralien bestehen vorwiegend aus Biotit, der in Streifen angeordnet ist; zwischen den Spaltblättern beobachtet man an einzelnen Stellen Flusspatausscheidungen. Hornblende tritt verhältnismässig spärlich auf. Dunkle, undurchsichtige Partikel oder rotbraune, durchscheinende Ferriverbindungen kommen in recht grosser Anzahl vor, teils als unregelmässige Einschlüsse in Feldspat, Quarz, Hornblende und Titanit, teils als Ausscheidungen in Spalten oder als Rinden um die Mineralkörner herum. Namentlich ist derjenige Teil des Titanits, der den Kranz um die Erzkörner bildet, auf diese Weise so stark getrübt, dass er gänzlich undurchsichtig ist. Myrmekit ist in ungefähr derselben Menge wie gewöhnlich vorhanden. Die Granophyrstruktur fehlt in diesem Uebergangsgestein; dagegen ist sie an anderen Stellen im Vang Granit, wo die Grenze sehr scharf und so gut wie ohne schlierigen Uebergang ist, vorhanden.

Die für die Struktur des Vang Granits so charakteristischen granophyrischen Verwachsungen von Mikroklin und Quarz sind in den älteren skandinavischen Gesteinen freilich nicht häufig, doch kommen sie an mehreren Stellen vor und zwar in Gesteinen sehr verschiedenen Alters. Sie scheinen besonders in der Nähe der Grenzen der Granitmassive aufzutreten, teils als exogene, teils als endogene Kontaktbildungen. An mehreren Stellen im südlichen Schweden ist die Mikropegmatitstruktur nachweislich durch Kontakteinwirkung postarchäischer Diabase auf das Nebengestein oder auf eingeschlossene Bruchstücke desselben entstanden. Dasselbe ist der Fall auf Bornholm längs des Diabasganges im Bach Kjeldseaa. In diesen Fällen ist die Mikropegmatitstruktur im Granit nur in unmittelbarer Nähe des Diabases entwickelt und verliert sich in einer Entfernung von wenigen Metern. Als endogene Kontaktbildung hat die Granophyrstruktur eine grössere Verbreitung. So z. B. findet man sie 
sehr schön entwickelt in der Grenzfazies des Upsalagranits gegen die Hälleflinta ${ }^{1}$ ), besonders in der Gegend um Vaxala Kirche herum, hier jedoch in einer ziemlich schmalen Zone, die von Нӧявом auf vielleicht nur einige Dutzend Meter breit geschätzt wird. Eine sich auf grössere Gebiete erstreckende Granophyrstruktur trifft man dagegen im Ålands-

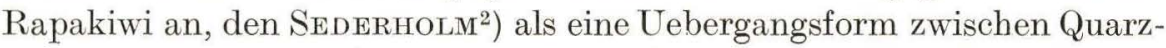
porphyr und dem grobkörnigen Wiborg-Rapakiwi auffasst. Nach SEDERHOLM wäre der Ålands-Rapakiwi als "eine etwas tiefer krystallisierte Form des Magmas, welches nahe an der Oberfläche zu Quarzporphyr erstarrt ist, der Wiborg-Rapakiwi wieder als eine noch tiefer krystallisierte Ausbildungsform desselben Magmas anzusehen«.

Es fragt sich nun, ob es denkbar wäre, dass die granophyrischen Verwachsungen im Vang Granit auf die eine oder die andre der genannten Weisen entstanden sind. Doch vorerst muss an dieser Stelle daran erinnert werden, dass Granophyrstruktur nicht nur als randliche Fazies beim Granit auftritt, sondern auch in vielen Fällen im Hauptgesteinskörper selbst vorkommt. Sie könnte demnach sehr wohl im Vang Granit ein primäres Strukturphänomen sein, das mit Kontaktphänomenen irgendwelcher Art nichts zu tun hätte. Da nun aber der Hammer Granit eine entschieden eruptive Grenze gegen den Vang Granit hat und sich aller Wahrscheinlichkeit nach weit unter demselben ausdehnt, liegt der Gedanke nahe, dass die Granophyrstruktur durch Kontakteinwirkung des Hammer Granits entstanden sein könnte. Hierfür spräche vielleicht die Tatsache, dass die granophyrischen Verwachsungen in den parallelstruierten Varietäten des Vang Granits ebenso gut ausgebildet auftreten wie in den regellos körnigen Varietäten desselben. Ferner ist der Vang Granit im Gegensatz zu den übrigen Bornholmer Graniten stark von Aplitgängen durchsetzt; aber während ein solcher Aplitreichtum oft ein für die endogene Kontaktzone charakteristisches Phänomen ist, darf man ihn hier doch nicht in dieser Weise auffassen, da die Verhältnisse am Kontakt gegen den Hammer Granit dafür sprechen, dass die Aplitgänge in Wirklichkeit Apophysen der feinkörnigen Grenzfazies des Hammer Granits sind. Man könnte daher wohl versucht sein anzunehmen, dass der Hammer Granit eine recht kräftige Kontakteinwirkung auf den Vang Granit ausgeübt hat, obschon gerade das feinkörnige Grenzgestein des Hammer Granits zeigt, dass die Abkühlung und die Erstarrung längs der Grenzfläche ziemlich schnell stattgefunden haben müssen.

Indessen sprechen verschiedene andere Umstände dafür, dass der Vang Granit analog dem Ålands-Rapakiwi einen Teil des älteren Born-

1) A. G. Нӧввом: G. F. F., Bd. 15, 1893, pag. 260.

2) J. J. Sederholm: T. M. P. M. Bd. 12, 1891, pag. 17--20. 
holmer Granits repräsentiert, der in der Nähe der Randzone dieses Granits erstarrt ist. So fand ich einen eigentümlichen, aplitähnlichen, feinkörnigen Einschluss im Vang Granit in der Ostwand von Storedal, ca. $500 \mathrm{~m}$ NO von Bækkegaard. Dieser Einschluss hatte eine abgerundete ovale Form, war etwa $2 \mathrm{~m}$ lang und ca. $0,75 \mathrm{~m}$ breit. Das hellgraue Gestein war schwach gestreift parallel der Längsrichtung des Einschlusses. Die Korngrösse ist durchschnittlich unter $1 \mathrm{~mm}$. Sowohl die Gemengteile als auch das Mengenverhältnis derselben sind im wesentlichen wie im Hauptgestein. Der Hauptgemengteil ist Mikroklin, der schwach perthitisch ist. Plagioklas ist ein wenig saurer und schätzungsweise etwas spärlicher als im typischen Vang Granit vertreten. Er hat in den meisten Fällen eine scharf gezeichnete albitische Randzone. Im MP-Schnitt wurde im Kern $\alpha^{\prime}: \mathrm{M}=5^{\circ}$, in der Hülle $\alpha^{\prime}: \mathrm{M}=15^{\circ}$ gemessen. Die Lichtbrechung des Kerns ist ungefähr wie die des Quarzes (in Kreuzstellung: $\alpha^{\prime}<\varepsilon, \gamma^{\prime} \geqq \omega$ ), der Plagioklaskern besteht somit aus Oligoklas mit etwa $24 \%$ An. - Hornblende und Biotit sind in ungefähr derselben Menge wie im Hauptgestein vorhanden. Zwischen den Biotitspaltblättern findet man dann und wann ein wenig Flusspat. Titanit, Apatit und Orthit sind verhältnismässig reichlich vertreten, hie und da werden kleine Muskovitblätter beobachtet.

Dieses feinkörnige Gestein stimmt also in seiner Zusammensetzung so genau mit derjenigen des Vang Granits überein, dass der Gedanke an einen Einschluss eines fremden Gesteins sofort ausgeschaltet werden muss. Am ehesten liesse sich die Vermutung aufstellen, dass dieser klumpenförmige Einschluss ein Fragment einer früher erstarrten und später zum Teil wieder resorbierten Grenzfazies des Vang Granits wäre. Ich möchte in diesem Zusammenhang daran erinnern, dass A. G. Högвом $^{1}$ ) im Vänge Granit bei Ekeby einen feinkörnigen Einschluss gefunden hat, der sich in genau der gleichen Weise zum Vänge Granit verhält wie der hier beschriebene Einschluss zum Vang Granit. Нӧявом fasst ebenfalls den genannten Einschluss als ein losgerissenes Stück der früher erstarrten Grenzfazies des Granits auf.

Im Sommer 1931 fand Mag. sc. Helge Gry im Granit im Steinbruch südlich von Vang einige eingeschlossene kleine Fragmente eines fremden Gesteins. Diese Fragmente, von denen das grösste etwa $2 \times 10 \times 7 \mathrm{~cm}$ mass, hatten eine unregelmässige Form und scharfe Konturen, die dadurch noch stärker hervorgehoben wurden, dass im Vang Granit etliche kleine Hornblendekristalle in einem ganz schmalen Streifen längs der Grenzfläche ausgeschieden waren; im übrigen wurde in der Nähe der Einschlüsse keine Aenderung in der Zusammensetzung des Vang Granits festgestellt.

1) A. G. Нӧявом: G. F. F., 15, 1893, pag. 272. 
Die Fragmente bestehen aus einem feinkörnigen dunkelgrauen, ein wenig schiefrigen Gestein, dessen Hauptgemengteile Plagioklas und brauner Biotit sind. Der Plagioklas besteht aus Oligoklas mit ca. $23 \%$ An., im MP-Schnitt wurde $\alpha^{\prime}: \mathrm{M}=4,5^{\circ}$ gemessen. Die Lichtbrechung ist etwas höher als die des Canadabalsams. Die Körner sind frisch und durchsichtig; sie haben eine polygonale oder abgerundete Form; in der Regel sind sie aus recht wenigen Zwillingslamellen aufgebaut. Eine Zonarstruktur kommt nicht vor. Der Plagioklas führt Einschlüsse von Apatit, Biotit und Erz; in einem vereinzelten Fall ist auch Mikroklin beobachtet worden. Der Biotit tritt grösstenteils in kleinen, länglichen Blättern mit deutlicher Tendenz zu paralleler Anordnung auf. Untergeordnet kommen Erz, das im wesentlichen aus Eisenkies mit Rostkrusten besteht, ferner Titanit, Orthit, Zirkon und in reichlichem Masse Apatit vor. Quarz konnte dagegen nicht nachgewiesen werden.

Ihrer Zusammensetzung nach weichen also diese Fragmente stark von allen anderen Gesteinen auf Bornholm ab, und sie müssen — wie auch das kleine Quarzitfragment im Granit nördlich von Gudhjem (siehe pag. 87) — zweifellos von Gesteinen herrühren, die älter als die Bornholmer Granite sind. Da diese Zusammensetzung an und für sich ungewöhnlich für Gesteine ist, habe ich diese Fragmente dem Staatsgeologen, Dr. N. Sundius, Sveriges Geologiska Undersökning, vorgewiesen; er hat mir gütigst mitgeteilt, dass Gesteine dieser Art nicht unter den Gneisgraniten in Schweden gefunden worden sind. Vermutlich liegt hier ein Hornfels vor, der durch Kontaktumwandlung aus Amphibolit entstanden ist. Dieses setzt doch keine sonderlich starke Kontaktmetamorphose und Resorption voraus, da nach Sundius biotitreiche und hornblendearme Fazies in recht grossem Umfang unter den schwedischen Amphiboliten auftreten. Selbstverständlich können solche Fragmente in einem Granitmagma weit vom Nebengestein fortkommen, aber ihr Vorhandensein hier bestärkt doch den Eindruck, dass der Vang Granit in der Nähe der ursprünglichen Grenze des älteren Granits auskristallisiert ist.

Basische Ausscheidungen von verschiedener Gestalt und Grösse kommen recht häufig im Vang Granit vor und wurden schon von KALB (1. c. pag. 58) erwähnt: „Gegenüber dem Muttergestein lassen die feinkörnigen dunklen Flecken eine starke Anreicherung der dunklen Gemengteile, besonders des Biotits, erkennen, während eine Veränderung des Mengenverhältnisses des nach seiner Zusammensetzung unveränderten Plagioklases zum Kalifeldspat und Quarz nicht zu erkennen ist. In den mit dem Muttergestein in der Korngrösse übereinstimmenden Flekken zeigt sich eine für Biotit und Hornblende gleich starke Anreicherung«. Hier kann hinzugefügt werden, dass ich im streifigen Vang Granit dunkle feinkörnige und regellos körnige Partien gefunden habe, in denen die Hornblende in grösserer Menge als Biotit angereichert war. 
Ferner wurde Erz in zahlreichen kleinen Körnern, die zum grossen Teil in Quarz und Feldspat eingeschlossen waren, beobachtet. Unter den hellen Bestandteilen war Mikroklinperthit dominierend und kam in weit grösserer Menge als Plagioklas vor.

\section{Pegmatit und Aplit im Vang Granit.}

Pegmatitgänge kommen im Vang Granit verhältnismässig spärlich vor: Der Pegmatit besteht hauptsächlich aus einem recht hellen roten Mikroklinperthit und einem grauen oder bisweilen rötlichen Quarz sowie kleinen Mengen von saurem Plagioklas und schwarzem oder ein wenig grünlichem Biotit, welcher letztere besonders in der Nähe der Ganggrenze auftritt. Stellenweise findet man ein wenig violetten Flusspat. Vom Mikroklin aus Ringebakke haben CoHen und DeEcke beistehende Analyse (1. c. Anhang) veröffentlicht:

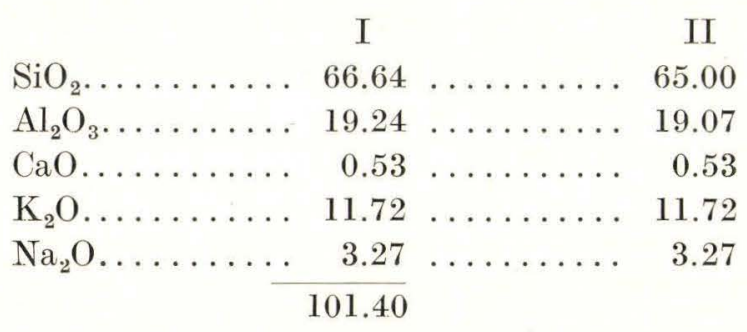

I gibt die gefundene Zusammensetzung, II diejenige einer Mischung von 69.33 Kalifeldspat, 27.62 Natronfeldspat, 2.64 Anorthit. Ferner bemerken CoHen und DeEcke: „Der gefundene Ueberschuss von 1.64 Proc. Kieselsäure dürfte von eingewachsenem Quarz herrühren, welcher sich auch durch das Mikroskop nachweisen lässt«.

Wie vorhin erwähnt (pag. 68), ist der Vang Granit längs der Pegmatitgänge stellenweise stark gestreift; so z. B. kann dies im grossen Steinbruch südlich von Vang beobachtet werden. Diese Parallelstruktur ist jedoch keineswegs ein konstantes Phänomen, sie kann in sehr verschiedenem Grade ausgebildet sein und z. B. auf der einen Seite eines Ganges sehr ausgeprägt sein, während sie auf der gegenüberliegenden Seite ganz fehlt. Im äusseren Teil der gestreiften Zone hat das Gestein die gewöhnliche Zusammensetzung des Vang Granits, aber in unmittelbarer Nähe vom Pegmatit überwiegt der Biotit deutlich gegenüber der Hornblende, Plagioklas tritt in geringerer Menge auf und weist eine etwas saurere Zusammensetzung auf. Diese Verhältnisse sind schon früher von G. KALB beobachtet worden, der auf Grund hiervon und der mineralogischen Uebereinstimmung von Pegmatit und Granit zum Schlusse gelangt, »dass in diesen Pegmatiten Differentiationen vorliegen, die gleichzeitig mit der Hauptmasse erstarrt sind« (l. c. pag. 81). 
An Stellen aber, wo die Grenze zwischen dem Vang Granit und dem Hammer Granit aufgeschlossen ist, wie z. B. im Steinbruch bei Sjelle Mose und in den Küstenfelsen bei der Station Sandkaas, sieht man, dass die Pegmatitgänge vom Hammer Granit die Granitgrenze durchschneiden und sich in den Vang Granit hinein fortsetzen. Das Gestein in diesen Pegmatitgängen weist eine so grosse Uebereinstimmung mit demjenigen in den obengenannten Gängen auf, dass es sich kaum durch eine petrographische Untersuchung entscheiden lässt, ob der Pegmatit dem einen oder dem anderen Granit entstammt.

Wie schon erwähnt, treten Aplitgänge im Vang Granit weit zahlreicher auf als in irgend einer anderen Bornholmer Granitvarietät. Doch ist es wahrscheinlich, dass diese Aplitgänge genetisch nicht mit dem Vang Granit zusammengehören, sondern dass sie in Wirklichkeit Ausläufer der feinkörnigen Grenzfazies des Hammer Granits sind. Jedenfalls sieht man bei Korsbjerg, dass ein roter Aplit deutlich den Vang Granit intrudiert hat, und am Kontakt gegen den Hammer Granit bei Sjelle Mose beobachtet man im Vang Granit einen Aplitgang, der eine direkte Fortsetzung des Grenzgesteins des Hammer Granits ist (Fig. 19). Da ferner das Gestein in den Aplitgängen petrographisch vollkommen identisch mit gewissen Teilen der Grenzfazies des Hammer Granits ist, erseheint es mir wahrscheinlich, dass alle Aplitgänge den gleichen Ursprung haben. Deshalb werden wir wieder im Zusammenhang mit der Kontaktzone des Hammer Granits auf sie zurückkommen. Indessen will ich nicht die Möglichkeit in Abrede stellen, dass sowohl von den Aplitgängen als auch von den Pegmatitgängen zwei Generationen vorliegen können, die sich petrographisch nicht von einander scheiden lassen. Ihrem Aussehen nach sind nämlich die Aplite etwas verschieden. In den meisten Gängen, und zwar in den mächtigsten, ist das Gestein hellrot, in den kleineren Gängen kann es ab und zu ganz weiss sein. Mineralogisch kann jedoch kein Unterschied nachgewiesen werden. Die Hauptgemengteile sind in allen Fällen Mikroklin und Quarz. Plagioklas kommt in geringerer Menge vor. Der Mikroklin ist entweder ganz oder fast ganz perthitfrei. Dunkle Mineralien sind im allgemeinen sehr spärlich vertreten, besonders in den weissen Apliten. Der Unterschied im Aussehen der Aplite geht hier nicht auf einen Unterschied in der Art des Feldspats zurück, wie es von N. Sundus ${ }^{1}$ ) in Bezug auf den Loftehammaraplit beschrieben worden ist, wo der weisse Aplit nur Plagioklas, der rote nur Mikroklin führt. Im roten Bornholmer Aplit ist der Plagioklas in einer wenigstens ebenso grossen oder vielleicht eher in einer grösseren Menge vorhanden als im weissen. Nach der mikroskopischen Untersuchung zu urteilen gibt es keinen anderen Grund für den Farben-

1) N. Sundius: S. G. U. Ser. C, Nr. 336, 1926. 
unterschied, als dass der rote Aplit etwas mehr pigmentiert und seine Körner in einem etwas höheren Grade mit roten Rinden von Ferriverbindungen überzogen zu sein scheinen, als es im weissen der Fall ist.

\section{Kleinere Vorkommen von hornblendeführendem Granit.}

An einigen Stellen innerhalb des nördlichen Teiles des streifigen Granitgebiets findet man einige kleine, eng begrenzte Vorkommen von dunklem, hornblendereichem Granit, der an Mineralbestand und Struktur dem Paradisbakke Granit und dem Uebergangsgestein des Rönne Granits sehr nahe steht, und der an Hornblendegehalt sogar alle die übrigen Bornholmer Granitvarietäten übertrifft. Das bedeutendste dieser Vorkommen wurde im Jahre 1903 von Grönwall bei Haldegaard, Gudhjem, gefunden. Ferner berichtet GrönwaLL (Kartenblatterläuterung, p. 12), dass ein ähnlicher dunkler Granit an einigen Stellen bei Spæling Mose (Moor) südwestlich von Rö auftritt; diese Lokalitäten gelang es mir doch nicht wiederzufinden. Dagegen fand ich ganz ähnliche kleine Gebiete von dunklem (»blauem«) hornblendereichem Granit bei Store Spagergaard, ein paar $\mathrm{km}$ westlich von Østerlars, und bei Tækkeregaard, etwa $2 \mathrm{~km}$ nordnordöstlich von Hasle.

Der dunkle Granit bei Gudhjem tritt in einem niedrigen Hügel an der Nordseite der Landstrasse östlich von Haldegaard an den Tag. Die gesamte Länge des Gebiets beträgt etwa $300-400 \mathrm{~m}$; nur innerhalb gewisser Teile desselben ist der Granit gänzlich ungestreift, stellenweise wird er streifig oder vielleicht eher schlierig. In der Nähe der Grenzen des Gebiets ist das Gestein deutlich gestreift und geht ebenmässig in den streifigen Gudhjem Granit über. Das Gestein ist feinkörnig und scheint etwas porphyrisch zu sein, da einige der Feldspatkörner in Gestalt von grösseren, einsprenglingsartigen Kristallen, die eine Grösse von $1 \times 2 \mathrm{~cm}$ erreichen können, auftreten (vergl. Taf. IV, Fig. 2). Der grösste Teil der Einsprenglinge besteht aus gräulichem Plagioklas, der manchmal eine ziemlich regelmässige, rechtanguläre Form hat, aber auch der rötliche Mikroklin tritt in Form von grösseren Körnern auf. Oft liegen mehrere der grösseren Feldspatkörner zu kleinen Haufen angeordnet. Auch die dunklen Mineralien liegen überwiegend in Haufen gesammelt, wodurch das Gestein ein etwas geflecktes Aussehen erhält.

Im Dünnschliff machen sich die grösseren Plagioklaskristalle stark geltend. Nur selten sind sie von einem vollständigen Mantel aus Mikroklin umgeben, jedoch beobachtet man in der Regel längs dem Rande etwas parallel angewachsenen Mikroklin; wo dieser fehlt, hat der Plagioklas bisweilen einen schmalen Albitsaum. Die Auslöschung kann in einigen Fällen etwas unregelmässig sein wie im Plagioklas des Rönne Granits. In der Mitte eines grösseren Kristalls wurde im MP-Schnitt 
$\alpha^{\prime}: \mathrm{M}=+13^{\circ}$ gemessen, was einem Oligoklas mit etwa $28 \%$ An. entspricht. Einige der Plagioklaskristalle enthalten zahlreiche Einschlüsse von den übrigen Mineralien des Gesteins, und wie im Plagioklas des Rönne Granits beobachtet man häufig schriftgranitisch eingelagerten Quarz, Biotit und Hornblende. Ausserdem sind oft relativ grosse Kalkspatkörner im Plagioklase eingeschlossen. In anderen Fällen ist der Plagioklas, besonders im Kern, etwas unfrisch und von zahlreichen kleinen Muskovitschuppen getrübt. - Die kleinen Plagioklaskörner sind in der Regel völlig frisch. Sie haben eine ganz unregelmässige Form und oft einen deutlichen Albitsaum; manchmal sind sie ganz im Mikroklin eingeschlossen.

In der feinkörnigen Grundmasse bildet der Mikroklin den Hauptbestandteil. Meistens ist er nur schwach perthitisch. Quarz tritt in Form von kleinen unregelmässig geformten Körnern auf, bisweilen mikropegmatitisch mit dem Mikroklin verwachsen. Unter den dunklen Mineralien überwiegt die Hornblende. An und für sich tritt sie in relativ grossen Kristallindividuen auf, jedoch sind diese, genau wie im Rönne Granit, derartig stark durchlöchert und unregelmässig verzweigt, dass verschiedene Teile desselben Hornblendeindividuums im Dünnschliff oft völlig getrennt von einander liegen. Nur im Querschnitt ganz kleiner Kristalle beobachtet man manchmal Prismen- und Längsflächen. Nicht nur ihrer äusseren Form nach, sondern auch in den optischen Verhältnissen stimmt diese Hornblende völlig mit der des Rönne Granits überein. Der Biotit ist braun und stark pleochroitisch, an Menge bleibt er weit hinter der Hornblende zurück. Schwarze Erzkörner sind recht reichlich vorhanden; einige der Körner sind von einem Titanitsaum umgeben. Titanit tritt ausserdem in Gestalt von selbständigen Körnern auf. Orthit wurde vereinzelt beobachtet. Apatit ist stark vertreten, und zwar teilweise in ziemlich grossen Kristallen. Unter den akzessorischen Gemengteilen ist Kalkspat relativ reichlich vorhanden. - Das Mengenverhältnis zwischen den wichtigsten Gemengteilen wurde mittels einer geometrischen Analyse festgestellt, welche folgendes Resultat ergab:

Tab. IX.

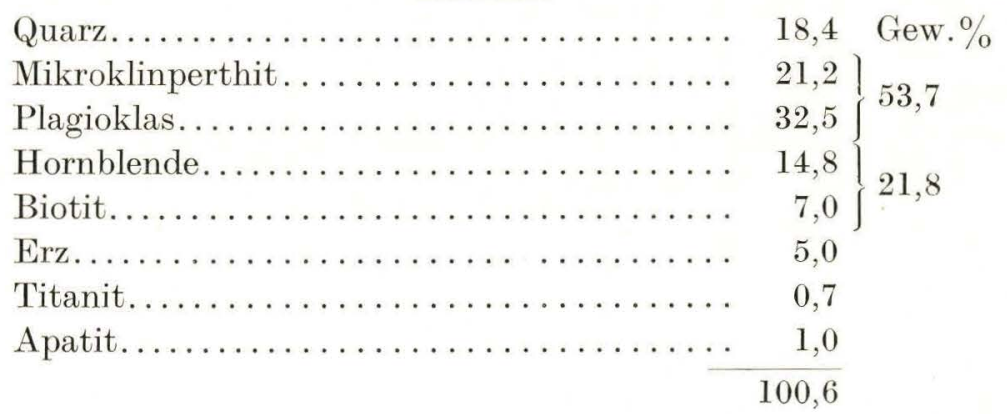


Im dunklen Granit bei Haldegaard kommen verhältnismässig viele feinkörnige basische Ausscheidungen vor. Im Querschnitt erreichen sie bis etwa $0,5 \mathrm{~m}$. In Stufen ist das Gestein ganz massig, und nur einzelne Plagioklaskörner haben eine Grösse von ein paar mm. Im Dünnschliff beobachtet man, dass die länglichen Hornblende- und Biotitindividuen eine deutlich parallele Anordnung aufweisen. Die Gemengteile sind dieselben wie im Hauptgestein, die dunklen Mineralien machen aber hier schätzungsweise die Hälfte des gesamten Gesteins aus. Von den hellen Mineralien ist der Mikroklin reichlicher als der Plagioklas vertreten. Quarz kommt spärlich vor.

Das Vorkommen bei Store Spagergaard ist ganz unbedeutend. Der dominierende Granit in dieser Gegend ist ein grauer streifiger Gudhjem Granit; unmittelbar östlich vom Hofe kommt innerhalb eines ganz kleinen Gebiets ein sehr dunkler und stark pegmatitschlieriger Granit vor. Das Gestein ist stark variierend, meistens ist es unregelmässig gestreift, stellenweise ist es aber vollständig massig und hat eine ausgesprochene Aehnlichkeit mit dem Rönne Granit.

Bei Tækkeregaard findet sich der dunkle Granit in einem kleinen Steinbruch südöstlich vom Hofe. Das Gebiet dürfte kaum gross sein; die Grenzen sind nicht sichtbar, da sie mit Erde bedeckt sind. Der Granit ist ziemlich feinkörnig, und die dunklen Gemengteile sind in schmalen Streifen angeordnet. Vereinzelte Feldspatkörner erreichen einen Querschnitt von etwa $1-1,5 \mathrm{~cm}$; im übrigen stimmt das Gestein an Mineralbestand und Struktur sehr genau mit dem Granit von Haldegaard überein (Taf. IV, Fig. 2). Hornblende ist das überwiegende dunkle Mineral; in einzelnen Fällen erreichen die Kristalle sogar eine Länge von etwa $1 \mathrm{~cm}$. Nur der geringe Kalkspatgehalt fehlt in diesem Granit.

Der Granit bei Tækkeregaard wird von einem Pegmatitgang von etwa $60 \mathrm{~cm}$ Mächtigkeit durchsetzt. Der Pegmatit ist zum Teil recht grobkörnig; die dunkelroten Feldspatkörner erreichen oft einen Querschnitt von etwa $10 \mathrm{~cm}$ oder mehr. Der Quarz ist grösstenteils sehr dunkel rotbraun. Biotit tritt spärlich auf. Ferner beobachtet man einige ganz kleine Pegmatitgänge und pegmatitische Schlieren. Die Richtung der Gänge folgt der Streifung des Granits. In der Nähe des Pegmatits ist der Granit gewöhnlich etwas reicher an dunklen Mineralien.

\section{Streifiger Granit.}

Wie es aus der einleitenden Uebersicht über die Gesteinsvarietäten hervorgeht, gibt es innerhalb des streifigen Granits mehrere scharf getrennte Typen. Von diesen haben wir den Paradisbakke Granit, den 
Vang Granit und die kleinen Vorkommen von »blauem«, hornblendereichem Granit bereits besprochen; im folgenden werden die übrigen Variationen näher beschrieben.

\section{Grauer streifiger Granit.}

Nördliches Gebiet. Der graue, deutlich gestreifte und oft schiefrige Granit hat im ganzen nördlichen und westlichen Teile des Gebiets ein einigermassen gleichartiges Aussehen; in Einzelheiten variiert er jedoch etwas. Teils kann die Schiefrigkeit mehr oder weniger deutlich ausgesprochen sein, teils wechselt der Gehalt an dunklen Mineralien, speziell an Hornblende, und schliesslich kann auch der Plagioklasgehalt etwas schwanken. Es geht daher kaum an, das Gestein eines einzelnen Vorkommens unter dem Gesichtswinkel der Allgemeingültigkeit für das ganze Gebiet zu betrachten.

Wie bereits (S. 13) erwähnt, rührt die Parallelstruktur des Granits vorwiegend daher, dass die dunklen Mineralien in dünnen Streifen oder Schichten angeordnet sind. Es wäre noch hinzuzufügen, dass man in den Steinbrüchen und in den Küstenfelsen längs der NO-Küste die Beobachtung machen kann, dass die Streifung über grosse Strecken hin einigermassen konstant die Richtung um WNW-OSO herum beibehält. Im einzelnen zeigt die Streifung einen schlenkernden Verlauf, und lokal kann sie, besonders in unmittelbarer Nähe der Pegmatitgänge, sogar sehr unregelmässig werden, da die dunklen Schlieren hier bisweilen ausnehmend stark angereichert sind und sich gleichsam dem Pegmatit anschmiegen. Oft aber folgen die Pegmatitgänge ungefähr der vorherrschenden Streifrichtung des Granits oder sie überschneiden dieselbe unter ziemlich kleinen Winkeln. Pegmatit ist im allgemeinen in diesem Granit überall recht reichlich vorhanden, zum grossen Teil in Gestalt von pegmatitischen Schlieren, die stellenweise aplitisch entwickelt sind und meistens der Streifung des Granits folgen; mitunter findet man jedoch Pegmatitgänge, die einen ausserordentlich unregelmässigen und gebuchteten Verlauf aufweisen.

Der graue streifige Granit ist im allgemeinen ziemlich stark verklüftet und wird daher nur selten als Baustein verwandt, doch hat man ihn für die Kirchenbauten in Gudhjem, Østermarie, Rö und Klemensker, die Ende des 19. Jahrhunderts aufgeführt wurden, benutzt. Dieser Granit wird nur in kleineren Steinbrüchen gebrochen und findet hauptsächlich beim Strassenbau Verwendung.

Unter den Kluftrichtungen machen sich in diesem Gebiete namentlich zwei senkrechte oder beinahe senkrechte stark geltend. Die eine von ihnen, die in den Küstenfelsen am meisten auffällt, folgt der Streifrichtung WNW-OSO oder W-O, während die andere, die in rechtem Win- 
kel zu ihr verläuft, im grossen und ganzen der Richtung der grossen Spaltentäler im Innern der Insel und derjenigen der Diabasgänge entspricht. In den Küstenfelsen sind es die Granitspalten in dieser Querrichtung (Q-Klüfte nach H. Cloos), welche sich an gewissen Stellen stark erweitern und die sogenannten »Oefen« bilden. Die Ebene der besten

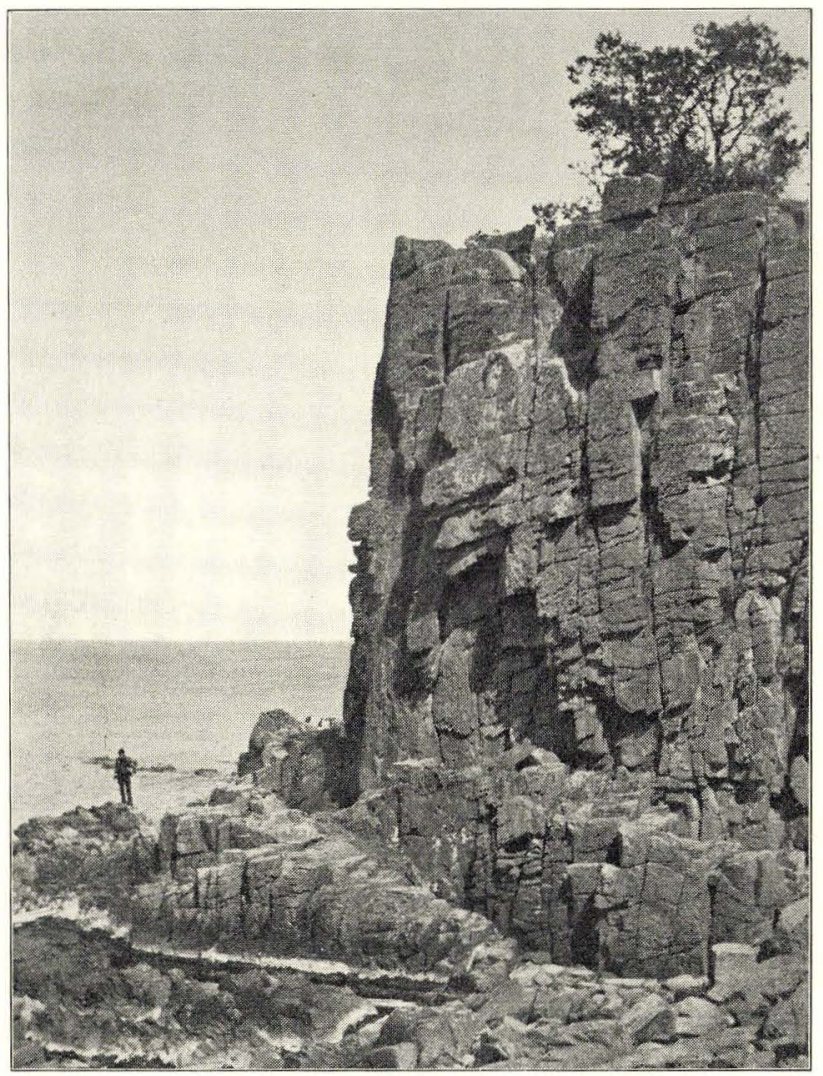

Fig. 14. Helligdomsklippen.

Spaltbarkeit des Granits verläuft parallel mit der Schieferungsebene, d. h. dass sie im wesentlichen von der parallelen Lage der Glimmerblättchen bedingt ist. Diese Richtung, die den Arbeitern in den Steinbrüchen sehr genau bekannt ist, bildet im allgemeinen nur kleine Winkel von $10^{\circ}-30^{\circ}$ mit der Horizontalen, stellenweise erreicht der Winkel jedoch etwa $40^{\circ}$, selten mehr. Im Terrain macht sich diese Richtung nicht immer sonderlich bemerkbar, doch findet man an mehreren Stellen in den Küstenfelsen eine ausgesprochene Neigung zu fast wagerechter Absonderung, z. B. in den hohen Helligdomsklippen (Fig. 14) und noch stärker an mehreren Stellen an der Küste zwischen Listed und Bölshavn, wo die Uferfelsen geradezu regelmässige, flache Dielen bilden (Fig. 15). 
Es scheint mir ausser allem Zweifel, dass die hier hervorgehobenen Kluftrichtungen in ihrer Anlage mit der Struktur des Granits eng verbunden und von derselben bedingt sind, und dass man sie somit nur als ursprüngliche tektonische Merkmale auffassen kann. Wenn aber die senkrechten Spalten und besonders die in der Richtung NNO-SSW verlaufenden, welche der schlechtesten Teilbarkeit des Granits entsprechen, sich im Terrain derart scharf entwickelt erweisen (Spaltentäler), so muss

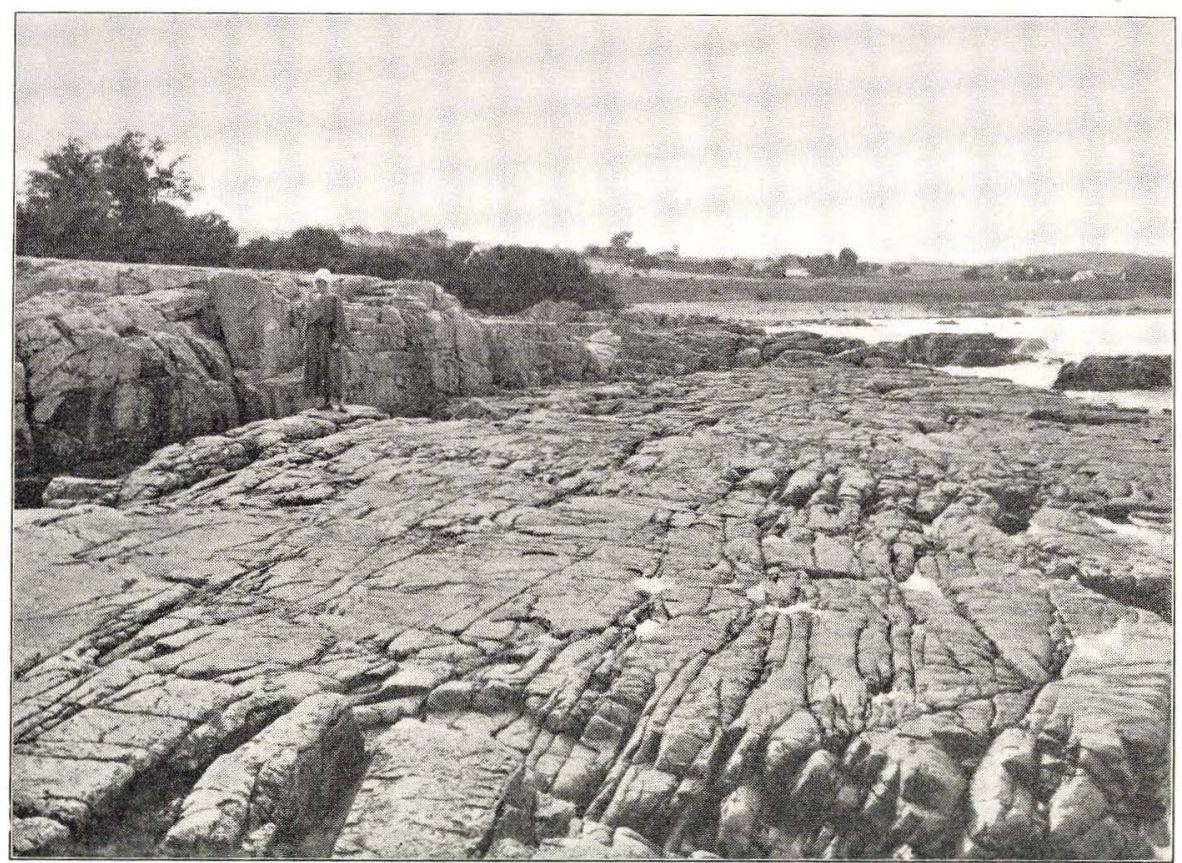

Fig. 15. Flache Küstenfelsen bei "Helligkvinde«, V f. Listed.

dies ebenso unzweifelhaft späteren tektonischen Vorgängen zugeschrieben werden.

Der typische Gudhjem Granit ist ziemlich feinkörnig und feingestreift. Er ist an frischen Flächen in den Steinbrüchen recht hell und rein grau in der Farbe mit einzelnen roten Schlieren, an der Oberfläche dagegen ist er stets rötlich. Dies gilt übrigens im allgemeinen für den grössten Teil des streifigen Granits, und da man ausserdem sehr oft in der Gegend zwischen Gudhjem und Hasle kleine Vorkommen vom hellen, rötlichen, aplitischen Granit antrifft, so gewinnt man unmittelbar den Eindruck, dass der Felsengrund im ganzen aus einem recht hellen, rotgrauen Granit besteht.

Der Gudhjem Granit ist in geringem Grade porphyrisch, hie und da finden sich Feldspatkörner mit einem Querschnitt von etwa $0,5 \mathrm{~cm}$ und einer Länge bis zu etwa $1 \mathrm{~cm}$ in der Richtung der Streifung. Im übrigen

Danmarks geologiske Undersøgelse. II. R. Nr. 50. 
haben die Gemengteile eine recht verschiedene Korngrösse, die meisten sind doch unter $1 \mathrm{~mm}$ im Querschnitt (Taf. IV, Fig. 3-4-5). Die grösseren Körner bestehen fast ausschliesslich aus Plagioklas, und in der Regel bestehen »die Augen« nicht aus einem Einzelindividuum, sondern aus mehreren angehäuften, verschieden orientierten Plagioklaskörnern ohne Kristallbegrenzung. Die Mitte dieser Kristalle ist oft von feinschuppigen, muskovitähnlichen Zersetzungsprodukten angefüllt; häufig schliessen sie kleinere Körner der übrigen Mineralien des Gesteins ein. Stellenweise sieht man, wie im Plagioklas des Rönne Granits, in der Mitte der Kristalle eine unregelmässige, wellige Auslöschung; die äusserste Zone besteht aber im allgemeinen aus einem scharf markierten Albitrande. Von den Messungen führe ich folgende an:

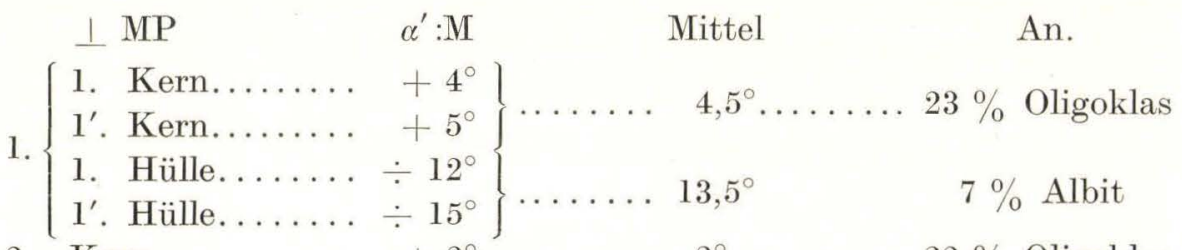

2. Kern......... $+2^{\circ} \ldots \ldots \ldots 2^{\circ} \ldots \ldots \ldots 22 \%$ Oligoklas

Wo der Albitrand fehlt, findet man oft etwas parallel angewachsenen Mikroklin längs des Randes des Plagioklases.

Im übrigen besteht das Gestein vorwiegend aus Mikroklin und Quarz, doch sind auch kleinere Plagioklaskörner in recht grosser Menge vorhanden. Diesen Mineralien ist eine leichte Tendenz zu länglicher Form in der Richtung der Streifung eigen, wodurch sie etwas zur Parallelstruktur des Granits beitragen. Die Körner haben jedoch eine ganz unregelmässige Kontur und greifen mit welligen und gezackten Rändern ineinander. Im Feldspat finden sich häufig Einschlüsse der übrigen Gemengteile, besonders von kleinen abgerundeten Quarzkörnern, und umgekehrt findet man auch Feldspat, Titanit, Biotit u. a. im Quarz eingeschlossen. Es ist somit nicht möglich, in diesem Gestein eine Reihenfolge der Mineralbildungen nachzuweisen. Der Quarz bildet etwas abgerundete, zum Teil jedoch völlig unregelmässig konturierte Körner mit einer schwach undulösen Auslöschung. Der Mikroklin ist ausserordentlich frisch. In der Regel ist er nur spärlich perthitisch, und manchmal ist die Perthitstruktur sehr fein verzweigt. In einem einzelnen Dünnschliff eines Granitstückes von Kaas weist der Kalifeldspat keine Mikroklingitterstruktur auf. Die kleinen Plagioklaskörner sind meistens frisch. Sie bestehen aus Oligoklas mit $20 \%$ An. (im MP-Schnitt wurde $\alpha^{\prime}: \mathrm{M}=0^{\circ}$ gemessen) und haben einen schmalen Albitsaum mit etwa $7 \%$ An. Myrmekit ist stets, wenn auch in wechselnder Menge vorhanden; dagegen fehlen gewöhnlich granophyrische Verwachsungen von Mikroklin 
und Quarz. Unter den dunklen Mineralien überwiegt der Biotit. Er tritt in kleinen, länglichen, grünlichen Blättern auf, oft zusammen mit einem recht kräftig gefärbten Epidot. Bisweilen findet sich eine geringe Menge Flusspat zwischen den Biotitspaltblättern. Die Hornblende, deren optische Eigenschaften mit denen der Hornblende des Rönne Granits übereinstimmen, tritt gewöhnlich spärlich auf und zwar nur in Form von kleinen, unregelmässig begrenzten Körnern; jedoch an Stellen, wo der Granit einen grösseren Gehalt an dunklen Mineralien aufweist, steigt der Hornblendegehalt ebenfalls. Titanit ist meistens reichlich vertreten und ist hie und da nach dem Biotit das wesentlichste dunkle Mineral des Gesteins. Er kommt in Gestalt von zerstreuten Körnern oder Aggregaten vor, die bisweilen ansehnliche Kränze um die Erzkörner herum bilden. In anderen Dünnschliffen dagegen haben die Erzkörner keinen Titanitrand. Auch A patit kommt reichlich und zwar in recht grossen Kristallen vor. Orthit tritt vereinzelt auf. Zirkon scheint relativ spärlich vorhanden zu sein.

Granit von dieser Beschaffenheit macht den grössten Teil des Felsengrundes in der Umgegend von Gudhjem aus und findet sich u. a. in den Steinbrüchen oberhalb des nördlichen Hafens in Gudhjem. Derselbe Granit mit einem etwas schwankenden Gehalt an dunklen Gemengteilen und von leicht variierender Korngrösse dominiert in den Uferfelsen an der NO-Küste und zwar ungefähr von Randkleven bis Kaas, ferner in der Gegend südlich von Gudhjem sowie nach Westen und Norden zu in dem sich durch die Kirchspiele Østerlars, Rö, Klemensker und Rutsker hinziehenden unfruchtbaren, steinigen Hochplateau, das früher »Höjlyngen« (»Hohe Heide«) genannt wurde, wo aber jetzt grosse Pflanzungen angelegt sind.

Eine graue Varietät, die sich dadurch auszeichnet, dass sie in einigen Partien einen recht grossen Hornblendegehalt hat, wird in einem Steinbruch in Svartingedal etwa $1 \mathrm{~km}$ SO vion Frigaard (in der Nähe von Hasle) gebrochen. Dieser Granit ist feinkörnig und ausgesprochen gestreift. Im Ganzen genommen ist er ziemlich hell grau, aber an einer Stelle im Bruch fand sich eine etwas dunklere graue Partie, in welcher dunkle Mineralien, besonders Hornblende und Titanit, reichlich vorhanden waren. Die Hornblende trat hier in unregelmässig begrenzten, durchlöcherten Individuen auf, die einen Querschnitt von ca. 0,5 cm erreichten. Unter den hellen Gemengteilen war Mikroklin vorherrschend, der Plagioklasgehalt aber schien doch etwas grösser und die Quarzmenge etwas geringer zu sein als sonst im Gudhjem Granit.

In diesem dunklen Gestein fand ich einen auffälligen weissen, ein paar cm breiten Streifen, der schwarze Hornblendekristalle von etwa $1 \mathrm{~cm}$ im Querschnitt enthielt. Der weisse Streifen war etwas grobkörniger als das ihn umgebende dunkle Gestein und verlief parallel mit 
dessen Schichtung. Das weisse Gestein besteht vorwiegend aus Plagioklas. Der Quarz- und Mikroklingehalt ist wesentlich geringer als im grauen Granit. Der Plagioklas ist ein Oligoklas mit ca. $20 \%$ An. Er schliesst häufig kleine runde Quarzkörner ein, die bisweilen von einem Rande von Mikroklin umgeben sind. Die grossen Hornblendekristalle sind wie gewöhnlich durchlöchert und mit Biotit verwachsen. Ausser Quarz schliessen sie etwas Epidot und eine unbedeutende Menge von Flusspat sowie reichlich Titanit ein. Epidot und etwas Kalkspat findet sich fernerhin längs der Kontur der Hornblende. Aehnliche grosse Hornblendekristalle habe ich übrigens nur in einem einzelnen Falle gefunden, nämlich in einer pegmatitischen Schliere im feinkörnigen roten, aplitischen Granit in der Nähe der Rundkirche von Østerlars (siehe pag. 92). - Der Biotit hat oft eine gefranzte Kontur. Die Erzkörner bestehen teils aus Magnetit mit einem Titanitrande, teils aus Eisenkies.

Bei Dynddalen fängt der Granit an, den Charakter von Vang Granit anzunehmen: die Anzahl der grösseren Feldspatkörner wächst ein wenig, wodurch das Gestein im grossen und ganzen etwas gröber wird. Die grossen Körner neigen zu rechtangulärer Form, und man findet unter ihnen häufiger Mikroklin, welcher oft einen Kern von parallel orientiertem Plagioklas enthält. Wie im Vang Granit ist der Mikroklin oft granophyrisch mit Quarz verwachsen. Der Plagioklas- und Hornblendegehalt steigt, je mehr man sich dem Vang Granit nähert. Die Grundmasse zwischen den grossen Feldspatkörnern ist auch hier feinkörnig. Bei Baadsted treten die dunklen Mineralien teils in deutlichen kurzen Streifen, teils in rundlichen Haufen auf.

Oestliches Gebiet. Während die Küstenfelsen um Randkleveskaaret herum und sogar etwas südlicher noch aus hellem rötlichem Gudhjem Granit bestehen, zeigt der Granit um Saltuna herum und auf der Strecke von Kjeldseaa Tal über Skrulle, Østermarie, Gyldensaa, Lyrsby bis zu den Paradisbakker eine dunklere graue Färbung und ist reicher an Plagioklas, Biotit und Hornblende, doch behält er an der Oberfläche oft einen rötlichen Ton bei. Im allgemeinen ist die Streifung sehr ausgeprägt, eine deutliche lineare Parallelstruktur kommt hier vielleicht etwas häufiger als im eigentlichen Gudhjem Granit vor, rein lokal jedoch kann die Parallelstruktur fast ganz verschwinden. Die Kluftrichtungen sind dieselben wie im vorhergehenden Gebiet. Die porphyrische Struktur ist recht deutlich, da der Plagioklas zum Teil in Form von zentimetergrossen grauen, oft tafelförmigen Kristallen, welche doch stets eine unregelmässige gebuchtete Kontur haben, auftritt. Im übrigen ist der Granit feinkörnig und wird es immer mehr, je weiter man nach SO kommt. Die grossen Plagioklaskristalle sind in der Regel im Innern etwas zersetzt. Häufig fehlt ihnen der Albitsaum, dafür sind sie oft parallel mit Mikroklin verwachsen. Die Auslöschung ist unregelmässig 
undulös, so dass die Kristalle überhaupt stark an den Plagioklas des Paradisbakke Granits erinnern. In einigen dieser Kristalle gibt es viele Einschlüsse von Quarz und Mikroklin, die bisweilen schriftgranitisch orientiert sind, seltener findet man Biotit, Hornblende, Titanit und Erz im Plagioklas eingeschlossen. Mikroklin tritt nicht in grösseren Körnern auf. Hornblende kommt meistens in Form von kleinen, unregelmässigen und oft stark durchlöcherten Körnern vor; an Menge bleibt sie hinter Biotit zurück. Die akzessorischen Mineralien sind dieselben wie im nördlichen Gebiete.

Im östlichsten Teile des Gebiets wird der Granit stellenweise ausgesprochen geflammt und nimmt sowohl makroskopisch als mikroskopisch völlig den Charakter von Paradisbakke Granit an, während man $20-30 \mathrm{~m}$ weiter davon wiederum den regelmässig gestreiften Granit antrifft. Manchmal sind die hellen Schlieren recht grobkörnig. Derartig geflammten Granit findet man z. B. in einigen kleinen Steinbrüchen östlich von Gyldensaa; im dunkelgrauen Granit in den Küstenfelsen zwischen Bölshavn und Listed sieht man oft helle aplitische Flammen oder Schlieren, welche teils dieselbe nordsüdliche Richtung haben wie im Paradisbakke Granit, teils der Parallelstruktur des Granits, die hier wie auch sonst längs der NO-Küste die Richtung WNW-OSO hat, folgen.

Im südlichen Gebiet ändert sich der Charakter des Granits in ähnlicher Weise von Osten nach Westen. In einem grossen Teil der Gegend westlich von den Paradisbakker ist der Felsengrund von Pflanzungen und sumpfigen Strecken bedeckt. Wo der Granit an den Tag tritt, ist er sogar an der Oberfläche ziemlich dunkel, sehr häufig recht dünnstreifig und an einigen Stellen rotschlierig. In der Nähe von Aakirkeby ist das Gestein an der Oberfläche rötlich oder gelbgrau und hat in Handstücken grosse Aehnlichkeit mit dem Gudhjem Granit; meistens sind doch die dunklen Mineralien stärker vorherrschend als in diesem, und stellenweise, z. B. in der Gegend NO von Faareby, tritt immer noch sehr dünnstreifiger, glimmerreicher Granit auf. In den dunklen Varietäten hat das Gestein eine sehr feinkörnige Grundmasse, in welcher zentimetergrosse Feldspatkörner zerstreut oder zu kleinen Haufen gesammelt liegen. Die grösseren dieser Feldspatkörner bestehen fast ausschliesslich aus Plagioklas, der überall in dieser Gegend derartig stark serizitisiert und epidotisiert ist, dass eine nähere Bestimmung der Zusammensetzung nicht durchgeführt werden konnte. Die Form der Plagioklaskörner ist stets sehr unregelmässig, meistens fehlt ihnen ein frischer Albitrand. Häufig führen sie schriftgranitähnliche Einschlüsse aus Quarz und Mikroklin, seltener aus den dunklen Mineralien. Die Plagioklaskörner in der Grundmasse unterscheiden sich nur in der Grösse von den Einsprenglingen. 
In den helleren Granitvarietäten, welche z. B. im Klint südlich von Aakirkeby vorkommen, tritt auch Mikroklin in Form von grösseren Körnern auf, in der Regel mit Plagioklas oder mit einem Kern desselben parallel verwachsen. In der Grundmasse findet man häufig granophyrische Verwachsungen von Quarz und Mikroklin und zwar oft — wie im Vang Granit — als eine Zone um die Plagioklaskörner herum. Die grösseren Mikroklinkörner sind etwas zersetzt, die kleineren in der Regel frisch. Hornblende ist meistens reichlich vorhanden und steht in vielen Fällen kaum hinter dem Biotit zurück (Taf. IV, Fig. 6). Ueberhaupt hat dieses Gestein eine etwas grössere Aehnlichkeit mit dem Vang- und Paradisbakke Granit als der Gudhjem Granit. Epidot ist im Granit des südlichen Gebiets meistens reichlich vorhanden, und zwar nicht nur als Umwandlungsprodukt im Plagioklas, sondern auch in der Grundmasse und besonders in Verbindung mit den dunklen Mineralien.

Westlich von Aakirkeby wird der Granit allmählich heller und rötlicher. Der Feldspat und besonders der Plagioklas machen immer noch die grössten Körner aus. Die Korngrösse ist im übrigen sehr ungleich, wenn auch ganz feinkörnige Partien nur selten vorkommen. Dagegen liegen die grösseren Feldspatkörner oft zu kleinen Haufen gesammelt, und diese »doppelkörnige« Struktur verleiht dem Gestein ein gewisses porphyrisches Aussehen (Taf. V, Fig. 1). Die grösseren Plagioklaskörner bestehen aus Oligoklas (etwa $28 \%$ An.); die kleineren aus Albit-Oligoklas (13-14\% An.). Der Mikroklin ist in der Regel arm an Perthit. Die dunklen Mineralien variieren sowohl in der Menge als in der Art von einem Ort zum anderen, in einigen Gesteinsproben ist die Hornblende vorherrschend, während sie in anderen beinahe fehlt. Im grossen und ganzen nimmt der Hornblendegehalt doch gegen Westen ab, und das ziemlich hornblendereiche Gestein in der Umgegend von Aakirkeby geht allmählich in den streifigen Granit im Gebiete östlich von Rönne, welcher schon oben (pag. 59) erwähnt wurde, über.

An einigen Stellen hat der streifige Granit eine ausgesprochene Neigung zum Zerfallen. So gibt es z. B. an der NO-Küste etwa $100 \mathrm{~m}$ südöstlich von der Mündung des Kobbeaa (Kobbebach) einen zerfallenden Gudhjem Granit, der zum Teil in konzentrischen Schalen um frische Granitklumpen herum abbröckelt. Hie und da ist im Granit ein wenig violetter Flusspat ausgeschieden, und im Grus findet man Spuren von Diabasgängen. Eine ganz ähnliche konzentrische Abschalung beobachtet man in Bavnebakke nördlich von Aakirkeby und im Klint südlich von Aakirkeby. Es ist evident, dass die Abschalung von der Verklüftung des Granits bedingt ist, denn stellenweise sieht man, dass die Streifung des Gesteins schräg durch die losgetrennten Schalen hindurch geht. - Ferner findet man abbröckelnden Granit u. a. bei Gadegaard östlich von 
Aakirkeby und in einer Kluft in den Helligdoms-Klippen; am letzteren Ort geht ein Diabasgang durch den verwitterten Granit hindurch.

Ein granitporphyrisches Gestein, dessen Struktur ein wenig an die des Paradisbakke Granits erinnert, wurde zwischen Gudhjem und Melsted an der NO-Küste gefunden; an Material liegt nur ein einzelnes Handstück im Mineralogischen Museum vor, das von F. Johnstrup 1871 eingesammelt wurde. Die Lokalität ist nicht genau angegeben, und es ist mir nicht gelungen, sie wiederzufinden, so dass sicher vermutet werden darf, dass diese Gesteinsvarietät nur eine geringe Verbreitung hat. Das Gestein besteht aus einer sehr feinkörnigen Grundmasse, in der zahlreiche Einsprenglinge aus rotem, oft stark pigmentiertem Feldspat vorkommen. Die dunkle Farbe rührt hauptsächlich von einem Chloritgehalt her. Epidot ist an Rissen im Gestein angereichert. Streifung oder geflammte Struktur sind nicht wahrnehmbar. Die Grundmasse ist so feinkörnig, dass Feldspatkörner mit einem Querschnitt von 1 à $2 \mathrm{~mm}$ im Dünnschliff als Einsprenglinge erscheinen. Sie besteht hauptsächlich aus einem Gemenge von Quarz, Mikroklin und Plagioklas. Hie und da beobachtet man granophyrähnliche Verwachsungen von Quarz und Mikroklin. Die wesentlichsten dunkklen Mineralien sind Chlorit und Erz. Manchmal haben die Erzkörner einen Titanitrand, im übrigen tritt Titanit spärlich auf. Apatit ist reichlich vorhanden. Die Einsprenglinge können eine Grösse von $2 \times 1 \mathrm{~cm}$ im Querschnitt erreichen, messen in der Regel aber $0,5-1 \mathrm{~cm}$; der Form nach sind sie abgerundet oder oval und mehr oder weniger korrodiert. Sie bestehen vorwiegend aus Plagioklas, unter den grösseren, rotfarbigen Einsprenglingen gibt es aber auch etwas Mikroklin. Der Mikroklin ist durch dunkle Partikeln ein wenig getrübt; wie die Plagioklaseinsprenglinge ist er etwas resorbiert und mit Quarz wieder ausgeheilt. Die Plagioklaseinsprenglinge bestehen aus Oligoklas-Albit mit etwa $10 \%$ An., ihre Lichtbrechung ist stets niedriger als die des Quarzes. Stellenweise sind sie mit einer schmalen äusseren Randzone aus parallel angewachsenem Mikroklin versehen. Auch eingeschlossen im Plagioklase findet man etwas Mikroklin und zwar teils in Form von sehr unregelmässig begrenzten, verschwommenen, antiperthitischen Einlagerungen, teils mit Quarz verwachsen als Füllmasse in Korrosionshohlräumen; im letzteren Falle liegt der Quarz meistens in der Mitte, durch den Mikroklin vom Plagioklase getrennt. Hie und da ist der Plagioklas etwas epidotisiert; nur in selteneren Fällen enthält er wesentliche Mengen von Chlorit. Auch Quarz tritt als Einsprenglinge von abgerundeter, recht stark korrodierter Form und mit zahlreichen Einlagerungen von Mikroklin auf.

Endlich muss erwähnt werden, dass Ussing ein kleines, im grauen streifigen Granit etwas W von Gudhjem eingeschlossenes Quarzitfrag- 
ment gefunden hat. Der Quarzit ist hell, rötlich und sehr feinkörnig. Er besteht stark überwiegend aus Quarz, der selbst in den kleinen Körnern undulöse Auslöschung hat. Ausserdem enthält er etliche feine Muskovitschuppen, aber in der Regel grenzen doch die Quarzkörner direkt an einander. Die Quarzkörner sind unregelmässig in Bezug auf ihre Grösse, die von ea. 0,03-4 à $5 \mathrm{~mm}$ im Querschnitt variiert; die grösseren Körner sind langgestreckt. Erzkörner scheinen fast ganz zu fehlen. Von stark lichtbrechenden Mineralien sind nur ganz vereinzelte Rutilkristalle gefunden worden. Dieser Quarzit gehört somit einem in den schwedischen Urbergsquarziten allgemein verbreiteten Typus an und ist zweifellos ein Fragment eines Gesteins, das älter als der Bornholmer Granit ist.

\section{Roter, schwach streifiger Granit.}

Alminding Granit.

Im zentralen Teile des Granitgebiets, in Almindingen, ist das Gestein mittelkörnig und hell rotgrau, an der verwitterten Oberfläche etwas gelblich. Der rötliche Ton rührt teils von der hellroten Farbe des Feldspats her, teils von rot durchscheinenden Ausscheidungen von Ferriverbindungen in Rissen im Quarz und im Feldspat, wodurch der Stein mit zahlreichen kleinen, intensiv roten Höfen bestreut wird. Dem Aussehen nach hat dieses Gestein eine überaus grosse Aehnlichkeit mit dem Hammer Granit, von dem es sich aber durch eine zwar nicht sehr ausgeprägte, jedoch deutlich konstatierbare Streifung unterscheidet. Die Grenzen dieser Granitvarietät lassen sich nicht angeben, da das Innere von Bornholm in hohem Masse von Glazialablagerungen bedeckt ist, doch scheint es, als gehe sie nach Norden und nach Süden zu ebenmässig in den grauen, streifigen Granit über, während der Uebergang nach Westen zu schroffer zu sein scheint. Der einzige grössere Steinbruch von Alminding Granit ist in Bjergbakke bei dem Hofe Hakkeled in Vestermarie, und das Gestein in diesem Bruch, wo die frischesten Proben zu haben sind, ist als Typus dieser Varietät anzusehen.

Der Alminding Granit hat einen wesentlich geringeren Gehalt an dunklen Mineralien als die früher erwähnten Varietäten. Die Streifung des Gesteins entsteht dadurch, dass die dunklen Gemengteile vorzugsweise in unregelmässigen Flecken, welche sich nur in Ausnahmefällen über zusammenhängende Flächen hin erstrecken, gesammelt liegen. Im Bjergbakke-Bruch ist die Streifung hauptsächlich horizontal, jedoch mit einzelnen Abweichungen. Stellenweise findet man schlierige Anhäufungen von dunklen Mineralien, und hie und da treten feinkörnige, einige wenige Zentimeter mächtige glimmerreiche Streifen auf.

Die Korngrösse ist ziemlich ungleich. Grössere Feldspatkörner erreichen einen Querschnitt von über $1 \mathrm{~cm}$, in den Zwischenräumen sind jedoch alle Grössen bis zu ganz kleinen Körnern vertreten. Der Alminding 
Granit ist recht quarzreich. Der Quarz tritt in unregelmässig begrenzten Körnern mit ein wenig undulöser Auslöschung auf; er ist oft von Rissen durchsetzt und schliesst häufig Mikroklin oder anders orientierte Quarzkörner ein. Umgekehrt findet man auch kleine Quarzkörner im Mikroklin, der ausserdem oft Biotit und andere dunkle Mineralien enthält. Der Mikroklin ist häufig stark verwachsen mit Plagioklas, wie es aus den Fig. 2 u. 3, Taf. V hervorgeht, bildet aber nur selten einen vollständigen Mantel um den Plagioklas herum. In anderen Schnitten weist der Mikroklin die gewöhnliche Perthitstruktur auf, aber die spindelförmigen Plagioklaseinlagerungen sind stets äusserst dünn und dicht beieinander liegend; stellenweise sind sie wahrscheinlich submikroskopisch vorhanden. Myrmekit ist sehr reichlich vertreten. Der Plagioklasgehalt ist' im allgemeinen ein beträchtlicher. Die Kristalle desselben haben, wie es auch im Mikroklin der Fall ist, eine sehr unregelmässige Begrenzung; der Albitrand fehlt oft. Sie bestehen aus einem recht anorthitarmen Oligoklas mit etwa $17 \%$ An. Als Durchschnitt bei Messungen in Schnitten $\perp \mathrm{MP}$ fand ich $\alpha^{\prime}: \mathrm{M}=6^{\circ}$; der optische Achsenwinkel $2 \mathrm{~V}=$ ca. $90^{\circ}$; die Lichtbrechung gleich oder niedriger als die des Quarzes. In

Tab. X.

\begin{tabular}{|c|c|c|c|c|c|c|c|}
\hline & $\%$ & $\begin{array}{l}\text { Mol. } \\
\text { quot. }\end{array}$ & Mol. & \multicolumn{2}{|c|}{ Norm } & \multicolumn{2}{|c|}{ Modus } \\
\hline $\mathrm{SiO}_{2}$ & 74.17 & 12362 & 80.75 & Q & 31.02 & Quarz & 32.37 \\
\hline $\mathrm{TiO}_{2}$ & 0.40 & 50 & 0.33 & Or & 33.92 & Mikroklin & 31.12 \\
\hline $\mathrm{Al}_{2} \mathrm{O}_{3}$ & 12.89 & 1264 & 8.26 & $\mathrm{Ab}$ & 26.72 & Albit & 26.88 \\
\hline $\mathrm{Fe}_{2} \mathrm{O}_{3}$ & 0.69 & 43 & - & An & 3.89 & Anorthit & 2.48 \\
\hline $\mathrm{FeO}$ & 1.07 & 149 & 1.53 & $\Sigma$ sal & 95.55 & Hornblende & 0.70 \\
\hline $\mathrm{MnO}$ & Sp & - & - & & & Biotit & 4.05 \\
\hline $\mathrm{MgO}$ & 0.28 & 70 & 0.46 & di & 1.39 & Erz & 0.78 \\
\hline $\mathrm{CaO}$ & 1.14 & 204 & 1.33 & hy & 0.80 & Titanit & 0.95 \\
\hline $\mathrm{Na}_{2} \mathrm{O}$ & 3.18 & 513 & 3.35 & $\mathrm{mt}$ & 0.93 & Apatit & 0.09 \\
\hline $\mathrm{K}_{2} \mathrm{O}$ & 5.72 & 608 & 3.97 & il & 0.76 & Kalkspat & 0.43 \\
\hline $\mathrm{P}_{2} \mathrm{O}_{5}$ & 0.04 & 3 & 0.02 & $\Sigma$ fem & 3.88 & & 99.85 \\
\hline $\mathrm{CO}_{2}$ & 0.19 & 43 & - & & 99.43 & & \\
\hline $\mathrm{H}_{2} \mathrm{O} 100^{\circ}$ & 0.08 & 44 & - & I. "4 (' & 2). 3. & & \\
\hline & 99.85 & & 100.00 & Liparos & & & \\
\hline
\end{tabular}

Dichte 2.641

Aktueller Durchschnittsplagioklas $\mathrm{Ab}_{92} \mathrm{An}_{8}$

Aktueller Durchschnittsfeldspat $\mathrm{Or}_{51 \cdot 5} \mathrm{Ab}_{44 \cdot 4} \mathrm{An}_{4 \cdot 1}$

\begin{tabular}{l|c|ccc|ccc|c|c|c} 
Molekularwerte nach OSANN & s & A & C & F & a & c & f & n & k \\
& 81.1 & 7.3 & 0.9 & 2.4 & 20.5 & 2.5 & 7.0 & 4.6 & 1.68 & \\
Molekularwerte nach NIGgLi & si & al & $\mathrm{fm}$ & $\mathrm{c}$ & alk & $\mathrm{k}$ & $\mathrm{mg}$ & $\mathrm{c} / \mathrm{fm}$ & Schnitt & qz \\
& 425 & 43.5 & 10.5 & 7.0 & 39.0 & 0.54 & 0.23 & 0.67 & $4 / 5$ & 169
\end{tabular}

Alminding Granit, Bjergbakke. Anal. Chr. Detlefsen. 
einigen Proben vom Alminding Granit hat der Plagioklas dieselbe unregelmässige, fleckenweise variierende Auslöschung wie der Plagioklas des Rönne Granits. Die grösseren Körner sind oft etwas unfrisch. Als Einschlüsse findet man recht oft Biotit, seltener Quarz und manchmal Mikroklin, der stellenweise antiperthitisch eingelagert ist. Hornblende ist sehr spärlich im Alminding Granit vorhanden. Das vorherrschende dunkle Mineral ist ein olivbrauner oder grünlicher, stark pleochroitischer Biotit. Danach kommen Titanit und Erz. Unter den Akzessorien findet sich etwas Orthit. Ferner gibt es in so gut wie allen Dünnschliffen vom Alminding Granit eine kleine Menge Flusspat.

Die chemische Zusammensetzung geht aus umstehender Analyse (Tab. X) hervor. Der aktuelle Mineralbestand ist auf Grund der Analyse und einer geometrischen Messung berechnet. Wie es aus dem Schema hervorgeht, beschränkt sich die Aehnlichkeit zwischen dem Almindingund dem Hammer Granit (vgl. pag. 97) nicht auf das Aeussere allein. Sowohl in Bezug auf die chemische als auf die mineralogische Zusammensetzung stehen sich die beiden Granite ausserordentlich nahe; bloss ist der Alminding Granit etwas salischer und dessen Plagioklas im grossen und ganzen etwas anorthitärmer.

\section{Christiansö.}

Das Gestein auf Christiansö und den umliegenden Schären muss an dieser Stelle erwähnt werden, da von den Bornholmer Granitvarietäten der Alminding Granit derjenige ist, der dem Christiansö Granit am nächsten steht. Der Christiansö Granit ist ebenfalls schwach gestreift und etwas rot gefleckt, nur in selteneren Fällen ist die Farbe rötlichgrau. Pegmatitische und aplitische Ausscheidungen kommen häufig vor, stellenweise trifft man reine Quarzausscheidungen. An einer vereinzelten Stelle fand ich eine basische Ausscheidung, von der jedoch kein Stück zu bekommen war.

Der Granit ist mittelkörnig und ein wenig grobkörniger als der Alminding Granit. Der Hauptgemengteil ist roter Mikroklin. Die kleineren Körner sind sehr arm an Perthit, die grösseren oft mit Plagioklas verwachsen; die beiden Feldspate sind in diesem Fall parallel orientiert, doch ist die Grenzfläche ausserordentlich gebuchtet und unregelmässig. In einigen Fällen ist der Plagioklas in der äusseren Zone des Mikroklins eingelagert, in anderen umschliesst der Mikroklin einen Kern aus Plagioklas. Der Plagioklas tritt übrigens zum Teil in relativ grossen grauen Kristallen mit Tendenz zu rechtangulärer Form auf. Im Innern sind dieselben oft stark zersetzt und mit Epidot und muskovitähnlichen Schuppen gefüllt. Die Zusammensetzung liess sich daher nicht mit Sicherheit feststellen, jedoch wurde in einem einzelnen Schnitt $\perp$ MP gemessen $\alpha^{\prime}: \mathrm{M}=$ ca. $9^{\circ}$ und $\alpha^{\prime}<\mathrm{n}$-Canadabalsam $<\gamma^{\prime}$, was in Verbin- 
dung mit positiver Doppelbrechung zeigt, dass der Plagioklas ein saurer Oligoklas ist. Die grösseren Plagioklaskörner haben stellenweise eine myrmekitische äussere Zone. Quarz ist reichlich vorhanden. Dunkle Mineralien treten spärlich auf, das wesentlichste ist grünlicher Biotit, in welchem gelegentlich eine unbeträchtliche Menge Flusspat vorkommt. Hornblende wurde im gewöhnlichen Granit nicht gefunden, dagegen in geringer Menge im Aplit. Ausser den gewöhnlichen Akzessorien, Titanit, Erz und Apatit, gibt es ein wenig Epidot und Chlorit.

\section{Roter feinkörniger aplitischer Granit. »Hasle Granit«.}

An zahlreichen Stellen innerhalb des nördlichen Gebiets des grauen streifigen Granits gibt es kleine und eng begrenzte Vorkommen von hellem, rotem oder graurotem feinkörnigen Granit. Das bedeutendste derselben liegt etwa $2 \mathrm{~km}$ nordöstlich von Hasle, wo der Granit in einem Steinbruch bei Frigaard gebrochen und zu Pflastersteinen gehauen wird. Der Granit ist hier ein wenig variierend in der Korngrösse und stellenweise fast mittelkörnig. Etwas östlicher, bei Nygaard in Klemensker, gibt es einen alten Bruch in einem ähnlichen roten, aplitischen Granit. Dasselbe Gestein findet man ferner in Lensklint, südwestlich von Gudhjem, und an mehreren Stellen in den Küstenfelsen zwischen Gudhjem und der Mündung des Kobbeaa sowie nördlicher u. a. bei Baadsted, Stammershalde und Tejn. Seit einigen Jahren bricht man bei Birkelund im Kirchspiel Rö einen sehr feinkörnigen und ganz hellen rötlichen Granit. Ausserdem gibt es zahlreiche kleine Vorkommen, die man nur auf kurzen Strecken von etwa 100-200 Metern verfolgen kann. Sie treten vorzugsweise in der Gegend zwischen Gudhjem und Hasle auf.

Der feinkörnige rote Granit ist sehr arm an dunklen Mineralien; diese sind meistens in dünnen Streifen oder in flachen Haufen angeordnet, was dem Stein oft eine deutliche Parallelstruktur gibt, jedoch stellenweise ist das Gestein fast gänzlich ungestreift, z. B. im Bruche bei Frigaard. Pegmatit ist gewöhnlich reichlich vorhanden, teils in Gangform, teils als Schlieren. In Bezug auf Mineralbestand und Struktur hat der feinkörnige helle Granit eine ausserordentlich grosse Aehnlichkeit mit dem grauen Gudhjem Granit und unterscheidet sich von demselben in der Hauptsache nur durch seine Armut an dunklen Mineralien, seine hellere Farbe und eine durchgängig geringere Korngrösse, in einigen der Vorkommen jedoch ist er bedeutend quarzreicher, als es sonst beim grauen Granit der Fall zu sein pflegt. Das Mengenverhältnis zwischen den Gemengteilen ist etwas wechselnd, der Hauptbestandteil ist aber stets Mikroklin, der in der Regel sehr perthitarm ist. Sowohl Mikroklin als Plagioklas treten mit stark variierender Korngrösse auf, was für das mikroskopische Bild sehr charakteristisch ist 
(Taf. V, Fig. 4), doch der Feldspat erreicht im allgemeinen keine derartige Grösse, dass das Gestein dadurch makroskopisch ein porphyrisches Aussehen erhält. Der Plagioklas ist ein Oligoklas, dessen Lichtbrechung höher als die des Canadabalsams ist. Hornblende fehlt beinahe immer; nur in einem einzelnen Vorkommen an der Landstrasse etwa $400 \mathrm{~m}$ NNW von Østerlars Rundkirche fand ich in einer pegmatitischen Schliere im Granit mehrere zentimetergrosse Hornblendekristalle. Disse Hornblende war die auf Bornholm gewöhnliche blaugrüne Varietät. Der Biotit ist meistens grünlich und bisweilen etwas chloritisiert. An einzelnen Stellen fand ich kleine Mengen von Flusspat, z. B. im Gestein bei Birkelund.

An verschiedenen Stellen längs der NO-Küste findet man einen ebenmässigen und unmerklichen Uebergang zwischen diesem Granit und dem grauen Gudhjem Granit; und man erhält den bestimmten Eindruck, dass dasselbe in der Gegend NO von Hasle, im Kirchspiel Rö und anderwärts, wo der Felsengrund zum Teil mit Diluvialablagerungen bedeckt ist, der Fall ist. Dies geht u. a. daraus hervor, dass man an Stellen, wo der Uebergang nicht an den Tag tritt, Granitvarietäten findet, die als Uebergangsformen zwischen dem feinkörnigen, roten Aplit und dem gewöhnlichen streifigen Granit bezeichnet werden müssen. Aber an einzelnen Stellen, z. B. bei den Kongensmark Huse (Häusern) südlich von Melsted sowie im kleinen nördlichen Hafen in Gudhjem ist der Uebergang schroff; die Grenze ist dann sehr unregelmässig, und man beobachtet eine stark schlierenartig wechselnde Verwachsung von rotem und grauem Granit. Nur an einer Stelle, bei Stavsdal N von Almindingen, habe ich ein kleines Vorkommen von Aplit in Gangform gefunden.

\section{Pegmatit- und Aplitgänge im streifigen Granit.}

Es wurde schon mehrmals erwähnt, dass der streifige Granit beträchtliche Mengen von Pegmatit enthält; doch wären noch ein paar Bemerkungen hinzuzufügen.

Das Hauptmineral des Pegmatits ist wie gewöhnlich ein roter Mikroklinperthit, und gutentwickelte Kristalle desselben kommen nicht ganz selten vor. Sehr oft besteht ein grosser Teil des Pegmatits aus Schriftgranit, aber im übrigen kann das Verhältnis zwischen Feldspat und Quarz recht variierend sein. Mitunter findet man z. B. grössere, beinahe feldspatfreie Quarzausscheidungen, z. B. auf Hvidehald nördlich von Aakirkeby und in "Sölvklippen« (dem »Silbernen Felsen«) bei Gudhjem, aber auch an diesen Stellen besteht der Gang als solcher grösstenteils aus Feldspat. Eine Nutzbarmachung des Pegmatits ist doch nur an einer einzelnen Stelle westlich von Almindingen versucht worden, wo der Feldspat eine Zeitlang für die Porzellanindustrie gebrochen wurde; leider erwies sich der Feldspat als zu unrein für diesen Zweck. 
Plagioklas kommt häufig vor, jedoch nur in untergeordneter Menge. Im Pegmatit von Bölshavn fand ich weissen Oligoklas $(1.54<\beta<1.55)$, und im Pegmatit von Hvidehald kommen zahlreiche kleine, farblose Plagioklaskörner mit einem kräftigen blauen Labradorisieren vor. O. B. BöGGLLD ${ }^{1}$ ) bestimmte diesen Plagioklas als Peristerit.

Biotit ist im allgemeinen spärlich und Muskovit überhaupt nicht vorhanden. Magnetit wird oft in kleinen Mengen gefunden; Bleiglanz kam nur in einem einzelnen Vorkommen bei Knappegaard, ein paar km südlich von Listed, vor. Flusspat wurde an mehreren Stellen gefunden, u. a. auf Hvidehald und vielleicht am reichlichsten im alten Feldspatbruch westlich von Almindingen, wo die Flusspatausscheidungen einen Querschnitt von mehreren Zentimetern erreichen können.

Einer der grössten Pegmatitgänge auf Bornholm ist der bei Skovgaard in Bodilsker; seine Mächtigkeit beträgt etwa $30 \mathrm{~m}$. Seiner Zusammensetzung nach unterscheidet er sich nicht von den übrigen Gängen, wiewohl man in der geologischen Literatur oft auf die Bemerkung stösst, dass Beryll an dieser Stelle gefunden worden ist. Dieses Vorkommen wird zum ersten Male von ForсннаммеR ${ }^{2}$ ) erwähnt, dessen Mitteilung in deutscher Uebersetzung folgendermassen lautet: „Beryll (Skovgaard auf dem Wege von Rönne nach Nexö, in der Sammlung Seiner Königlichen Hoheit Prinz Christian)«, und in einer Fussnote fügt er hinzu: »Herr Graf Vargas entdeckte diesen Beryll in einem Granit-Gang." Diese Mitteilung dürfte jedoch auf einem Irrtum beruhen, zum mindesten ist weder von diesem noch von irgend einem anderen Vorkommen auf Bornholm ein Beryll bewahrt. Die einzige Spur, die ich hiervon gefunden habe, ist ein kleines Handstück im Mineralogischen Museum, dessen Etikette folgenden Wortlaut hat: "Kristallisierter Feldspath (Var. dihexaëdre Haüy) mit gemeinem Schmaragd bei St. Bodils Kirche«. Dieses Stück stammt aus dem früheren Königl. naturhistorischen Museum, dessen geologisch-mineralogische Abteilung mit den Sammlungen des Prinzen Christian (Christian VIII) später dem Mineralogischen Museum einverleibt wurde. Es lässt sich nicht mehr feststellen, wann dieses Stück eingesammelt worden ist. Es ist ein Bruchstück eines einzelnen Feldspatkristalls von 5,5 cm Querschnitt (rötlichen Mikroklinperthits) mit wohlentwickelten Kristallflächen. Im Feldspat ist etwas Quarz eingewachsen, von Beryll findet sich jedoch keine Spur.

Aplitgänge sind im grossen und ganzen selten im streifigen Granit. Sie sind in der Regel ganz schmal und haben einen geradlinigen Verlauf. Einen etwa 0,25 m mächtigen Aplitgang fand ich ca. $200 \mathrm{~m}$ nördlich

1) O. B. Bögrild. Det kgl. Danske Vidsk. Selsk. Math.-fys. Medd. VI. 3. 1924, pag. 32.

2) G. Forchinmer. Danmarks geognostiske Forhold (Universitätsprogramm) 1835. 
vom Stavsdal Pulverturm, nördlich von Almindingen; sonst findet man die meisten Aplitgänge in der Gegend von Aakirkeby. Das Gestein ist stets hell rot und sehr feinkörnig, und dem Aussehen nach sind sich alle Aplite sehr gleich. Nichtsdestoweniger stellte sich ihre Zusammensetzung als etwas verschiedenartig heraus. In einem Aplitgang in der Anhöhe Skaglfald nördlich von Aakirkeby sind die Hauptgemengteile Mikroklin und Quarz, und überhaupt steht das Gestein den im Vang Granit auftretenden Apliten sehr nahe. Dagegen war in einem anderen Aplit, den Ussing bei Tvillinggaarde WNW von Aakirkeby fand, das Hauptgemengteil ein saurer Plagioklas (Oligoklas-Albit mit etwa $12 \%$ An.). Mikroklin und Quarz waren schätzungsweise in ungefähr gleicher Menge vorhanden, akzessorisch traten brauner Biotit, Erz und stellenweise Epidot auf. Dieser Aplitgang steht laut UssING senkrecht oder schroff abfallend gegen NO. Einige glimmerreiche Zonen mit parallel gestellten schwarzen Glimmerschuppen verleihen dem Gestein eine gewisse Schiefrigkeit. Charakteristisch für beide Arten von Aplit sind die zahlreichen Einschlüsse von kleinen abgerundeten Feldspatkörnern im Quarz und von ähnlichen kleinen Quarzkörnern im Feldspat. - Auf der Insel Christiansö fand ich einen etwas grobkörnigeren grauen Aplit, der Oligoklas in wesentlich geringerer Menge als Mikroklin und Quarz enthielt. Im übrigen unterscheidet er sich dadurch von den anderen Apliten, dass er Hornblende enthält, welche zusammen mit Erz und Titanit die spärlichen dunklen Gemengteile ausmacht. Von braunem Biotit und Epidot wurden vereinzelte Körner gefunden.

\section{B. Jüngere Abteilung.}

\section{Hammer Granit.}

Der Hammer Granit nimmt das nördlichste Vorgebirge Bornholms, Hammeren, sowie den direkt angrenzenden Teil der Insel ein. Das dreieckige Gebiet hat von Norden nach Süden eine Ausdehnung von etwa $5 \mathrm{~km}$. Die Grenze gegen den Vang Granit verläuft als eine stark gebuchtete Linie mit einer Zunge nach Süden von Vang nach Sandkaas südöstlich von Allinge. Ferner tritt der Hammer Granit in einem kleinen Gebiet zwischen Dalegaard und Maegaard westlich von Ols Kirke an den Tag. Das Gestein ist frisch und fest und findet häufig Verwendung als Bau- und Pflastermaterial. Es wird in mehreren grossen Steinbrüchen gebrochen, von denen der grösste an der Südseite von Hammeren liegt. Zur Gewinnung des Gesteins werden hier moderne maschinenmässige Hilfsmittel verwandt; etwas vom Gestein wird an Ort und Stelle zu 
Schottern für den Strassenbau bearbeitet; ein Geleise erleichtert den Transport zu den Steinhauerwerkstätten und dem für die Ausschiffung angelegten Hammer Hafen an der Westküste. - Etwas südlicher gibt es weitere zahlreiche Brüche, z. B. bei Hammersholm, bei Borrelyng und an verschiedenen Stellen in der Umgegend von Allinge sowie bei Dalegaard und Maegaard.

Der Hammer Granit ist ein helles rotgraues, regellos mittelkörniges Gestein. Die Farbe hält sich unverändert in den tiefer gelegenen Partien, ist jedoch etwas ungleich verteilt in den kräftiger rotgefärbten kleinen Flecken, welche wie im Alminding Granit von rötlichen Ferriverbindungen herrühren, die einen Ueberzug an den Mineralkörnern bilden oder die Risse — besonders in den Quarz- und Feldspatkörnern - ausfüllen. Dunkle Mineralien sind nur spärlich vorhanden. Sie sind zum Teil in zerstreuten Haufen gesammelt, die an einigen Lokalitäten eine gewisse Neigung zu einer Anordnung in Streifen haben; eine deutliche Streifung findet man aber nur in der Nähe der Grenze gegen den Vang Granit. - Die Pegmatitgänge des Hammer Granits stimmen in der Zusammensetzung mit dem Muttergestein überein. Wie gewöhnlich auf Bornholm ist der Pegmatit häufig schriftgranitisch entwickelt. Von selteneren Mineralien wurde Molybdänglanz an einzelnen Stellen in geringer Menge gefunden.

Die Hauptbestandteile, nach ihrem Mengenverhältnis angeführt, sind folgende: Mikroklinperthit, Quarz und saurer Oligoklas (Taf. V, Fig. 5 u. 6). Die Quarzkörner haben eine unregelmässige Form und oft eine stark gebuchtete Kontur; sie sind von zahlreichen Rissen durchsetzt. Die Auslöschung ist ein wenig undulös. Als Einschlüsse im Quarz findet man häufig kleine Körner aus Mikroklin, Biotit, Titanit etc. und in einigen Fällen eine ausserordentlich grosse Menge ganz kleiner Biotitblätter von eleganter Kristallform und mit kräftigem Pleochroismus. Dieselben kleinen Biotitkristalle treten auch manchmal als kleine Schwärme im Mikroklin und im Plagioklas auf. Der Mikroklin ist ausserordentlich frisch. Die Gitterstruktur ist stellenweise sehr fein lamelliert. In einzelnen Körnern beobachtet man, dass das eine Lamellensystem so stark zurücktritt, dass gewisse Teile des Kristalls einheitliche Auslöschung erhalten. Der Mikroklin hat immer eine äusserst unregelmässige Begrenzung und führt Einschlüsse von all den übrigen Mineralien, besonders vom Plagioklas und von kleinen abgerundeten Quarzkörnern, die oft gruppenweise gleichzeitig auslöschen. Die Perthitstruktur ist etwas verschiedenartig entwickelt. In einigen Fällen liegt der Plagioklas wie üblich in Form von dünnen Perthitspindeln eingelagert; ihrer Lichtbrechung nach, die niedriger als die des Canadabalsams ist, zu urteilen, bestehen sie aus Albit. In anderen Fällen ist der Perthitplagioklas unregelmässiger, fleckenweise im Mikroklin verteilt und steht 
dann oft in Verbindung mit grösseren Plagioklaseinlagerungen. Die grösseren Plagioklaskörner sind im allgemeinen mit Mikroklin parallel verwachsen. G. KaLB bemerkt hierüber (1. c. pag. 51): „Hierbei verlaufen die Grenzen meist ausserordentlich unregelmässig; vereinzelt tritt sogar Kalifeldspat als Kern auf, eine Erscheinung, welche sehr an die Ausbildung des Rapakiwi erinnert«. Dieses Phänomen beobachtete ich nirgends in den vielen Dünnschliffen von Hammer Granit, die ich untersucht habe. Nur ganz kleine Mikroklineinlagerungen fand ich recht oft im Plagioklas, und diese müssen jedenfalls zum Teil der sehr unregelmässigen und stark verzweigten Verwachsung der beiden Feldspate zugeschrieben werden. Dagegen trifft man nicht ganz selten, wie es auch im Rönne Granit und in den übrigen Bornholmer Gesteinsvarietäten der Fall war, das umgekehrte Verhältnis an, nämlich dass der Mikroklinperthit einen parallel umwachsenen, mehr oder weniger vollständigen Mantel um den Plagioklas herum bildet, was ja eher als eine Anti-Rapakiwi-Struktur zu bezeichnen wäre.

Der Plagioklas bleibt an Menge entschieden hinter dem Mikroklin zurück. Die grösseren Körner sind oft ein wenig zersetzt und teilweise mit einem feinschuppigen, serizitähnlichen Aggregat gefüllt. Wo parallel angewachsener Mikroklin fehlt, hat der Plagioklas meistens einen deutlichen Albitrand. Das Innere der Körner kann ab und zu eine etwas unregelmässige, undulöse Auslöschung haben. Die Zusammensetzung entspricht einem Oligoklas mit etwa $25 \%$ An. Von den Messungen führe ich an:

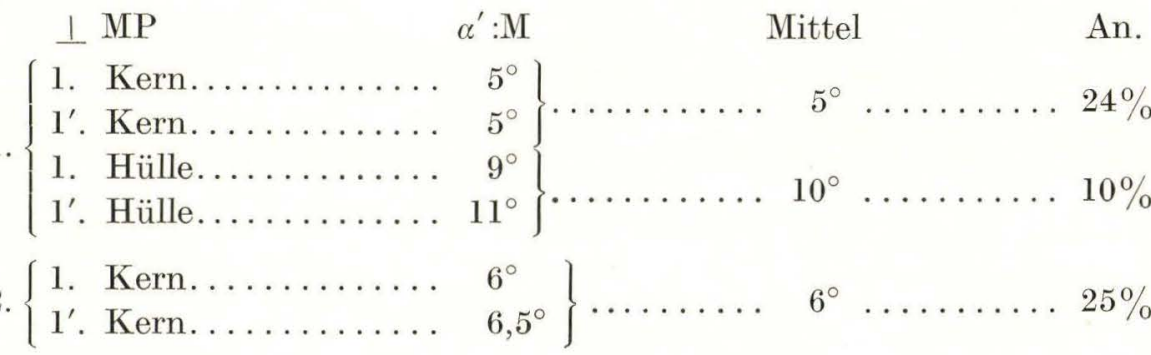

Die Lichtbrechung des Kerns ist höher als die des Canadabalsams.

Ausser den schon genannten Einschlüssen findet man dann und wann Biotit, Erz, Titanit und andere Akzessorien im Plagioklas eingeschlossen; Quarz ist dagegen verhältnismässig selten vorhanden und tritt eigentlich nur in der äusseren Zone des Plagioklases auf. Ferner trifft man wie im Alminding Granit häufig ganz kleine Flusspatkörner im Plagioklas eingeschlossen. Vereinzelt wurde Kalkspat angetroffen. - Myrmekit ist im Hammer Granit reichlich vorhanden, und oft ist die äussere Zone der grösseren Plagioklaskörner als Myrmekit entwickelt.

Hornblende ist äusserst spärlich. Biotit ist das wichtigste unter 
den dunklen Mineralien; er ist braun oder oliv mit sehr kräftiger Absorption: $\alpha$ hell gelb, $\gamma$ beinahe schwarz. Die Erzkörner treten teils mit, teils ohne Titanitkranz auf. Titanit kommt ausserdem in selbständigen Kristallen vor. Orthit ist hier häufiger vertreten als in den übrigen Bornholmer Granitvarietäten.

Vom Hammer Granit liegen zwei chemische Analysen vor: I (siehe Tab. XI) ist im Laboratorium von DiтTrich, Heidelberg, ausgeführt und wird hier nach G. KaLB (l. c. pag. 52) zitiert; II ist von Chr. DetrefSEN, Kopenhagen, auf Veranlassung von N. V. Ussing ausgeführt. Der Mineralbestand ist auf Grund der Analyse I und einer geometrischen Messung berechnet.

Tab. XI.

\begin{tabular}{|c|c|c|c|c|c|c|c|c|}
\hline & I & $\begin{array}{l}\text { Mol. } \\
\text { quot. } \\
\text { von I }\end{array}$ & $\begin{array}{c}\text { Mol. } \\
\% \\
\text { von I }\end{array}$ & II & \multicolumn{2}{|c|}{$\begin{array}{c}\text { Norm } \\
\text { aus I berechnet }\end{array}$} & \multicolumn{2}{|c|}{$\begin{array}{l}\text { Modus } \\
\text { aus I berechnet }\end{array}$} \\
\hline $\mathrm{SiO}_{2}$ & 73.77 & 12295 & 81.20 & 72.82 & $\mathrm{Q}$ & 33.72 & \multicolumn{2}{|c|}{ Quarz $\quad 33.94$} \\
\hline $\mathrm{TiO}_{2}$ & 0.32 & 40 & 0.27 & 0.63 & Or & 33.36 & \multicolumn{2}{|c|}{ Mikroklin $\quad 31.66$} \\
\hline $\mathrm{Al}_{2} \mathrm{O}_{3}$ & 11.97 & 1174 & 7.75 & 13.42 & $\mathrm{Ab}$ & 23.58 & \multirow{2}{*}{$\begin{array}{l}\text { Albit } \\
\text { Anorthit }\end{array}$} & 23.24 \\
\hline $\mathrm{Fe}_{2} \mathrm{O}_{3}$ & 1.84 & 115 & - & 2.33 & An & 3.34 & & 3.79 \\
\hline $\mathrm{FeO}$ & 0.78 & 108 & 2.24 & - & $\Sigma$ sal & 94.00 & \multirow{6}{*}{\multicolumn{2}{|c|}{$\begin{array}{ll}\text { Hornblende } & 0.43 \\
\text { Biotit } & 3.50 \\
\text { Magnetit } & 1.09 \\
\text { Titanit } & 0.75 \\
\text { Apatit } & 0.15 \\
\text { Rest } \mathrm{H}_{2} \mathrm{O} & 1.03\end{array}$}} \\
\hline $\mathrm{MnO}$ & - & - & - & 0.24 & & & & \\
\hline $\mathrm{MgO}$ & 0.23 & 57 & 0.38 & 0.13 & di & 1.30 & & \\
\hline $\mathrm{CaO}$ & 1.10 & 196 & 1.29 & 1.61 & wo & 0.23 & & \\
\hline $\mathrm{Na}_{2} \mathrm{O}$ & 2.75 & 444 & 2.93 & 3.25 & $\mathrm{mt}$ & 1.62 & & \\
\hline $\mathrm{K}_{2} \mathrm{O}$ & 5.61 & 597 & 3.94 & 5.47 & il & 0.61 & & \\
\hline $\mathrm{H}_{2} \mathrm{O}$ über $110^{\circ}$ & 0.49 & 272 & - & - & $\mathrm{hm}$ & 0.80 & \multirow{3}{*}{\multicolumn{2}{|c|}{99.58}} \\
\hline $\mathrm{H}_{2} \mathrm{O}$ unter $110^{\circ}$ & 0.65 & 一 & - & - & $\Sigma$ fem & 4.56 & & \\
\hline \multirow[t]{2}{*}{ Glühverlust } & - & - & - & 0.21 & & 98.56 & & \\
\hline & 99.51 & & 100.00 & 100.11 & \multicolumn{2}{|c|}{$\begin{array}{l}\text { I. (3) } 4.1 \text { (2). " } 3 . \\
\text { Liparose. }\end{array}$} & & \\
\hline
\end{tabular}

Dichte 2.653

Aktueller Durchschnittsplagioklas $\mathrm{Ab}_{86} \mathrm{An}_{14}$

Aktueller Durchschnittsfeldspat $\mathrm{Or}_{53 \cdot 9} \mathrm{Ab}_{39 \cdot 6} \mathrm{An}_{6 \cdot 5}$

\begin{tabular}{r|c|ccc|ccc|c|c|c} 
Molekularwerte nach OSANN & $\mathrm{s}$ & $\mathrm{A}$ & $\mathrm{C}$ & $\mathrm{F}$ & $\mathrm{a}$ & $\mathrm{c}$ & $\mathrm{fm}$ & $\mathrm{n}$ & $\mathrm{k}$ \\
von I & 81.5 & 6.9 & 0.9 & 3.0 & 19.0 & 2.5 & 8.5 & 4.3 & 1.77 \\
Molekularwerte nach NiggLI & $\mathrm{si}$ & $\mathrm{al}$ & $\mathrm{fm}$ & $\mathrm{c}$ & $\mathrm{alk}$ & $\mathrm{k}$ & $\mathrm{mg}$ & $\mathrm{c} / \mathrm{fm}$ & Schnitt & $\mathrm{qz}$ \\
von I & 440 & 42 & 14 & 7 & 37 & 0.57 & 0.14 & 0.50 & 4 & 192
\end{tabular}

I. Hammer Granit. Anal. M. Diтtrich.

II. Hammer Granit, Hammeren. Anal. Chr. Detlefsen.

\section{Die Grenze zwischen dem Hammer und dem Vang Granit.}

Die Grenze zwischen dem Hammer Granit und dem Vang Granit habe ich an verschiedenen Lokalitäten aufgeschlossen gefunden; die drei wichtigsten von diesen sind folgende: 1) die Uferfelsen an der West- 
küste ca. $125 \mathrm{~m}$ nördlich vom Hafen in Vang, 2) ein Steinbruch bei Sjelle Mose ca. $2 \mathrm{~km}$ südlich von Allinge und 3) die Uferfelsen an der Nordostküste ca. $1 \mathrm{~km}$ SSO von Allinge. Die Verhältnisse sind an diesen drei Stellen ganz gleichartig. Von Vang verläuft die Grenze in nordöstlicher Richtung, bis sie bei einem alten Steinbruch $400-500 \mathrm{~m}$ SW von Skovbo Kilde (Quelle) jäh gegen Süden abbiegt. In Ussing's Tagebuch vom Jahre 1901, pag. 76, steht (ins Deutsche übertragen): „In den alten

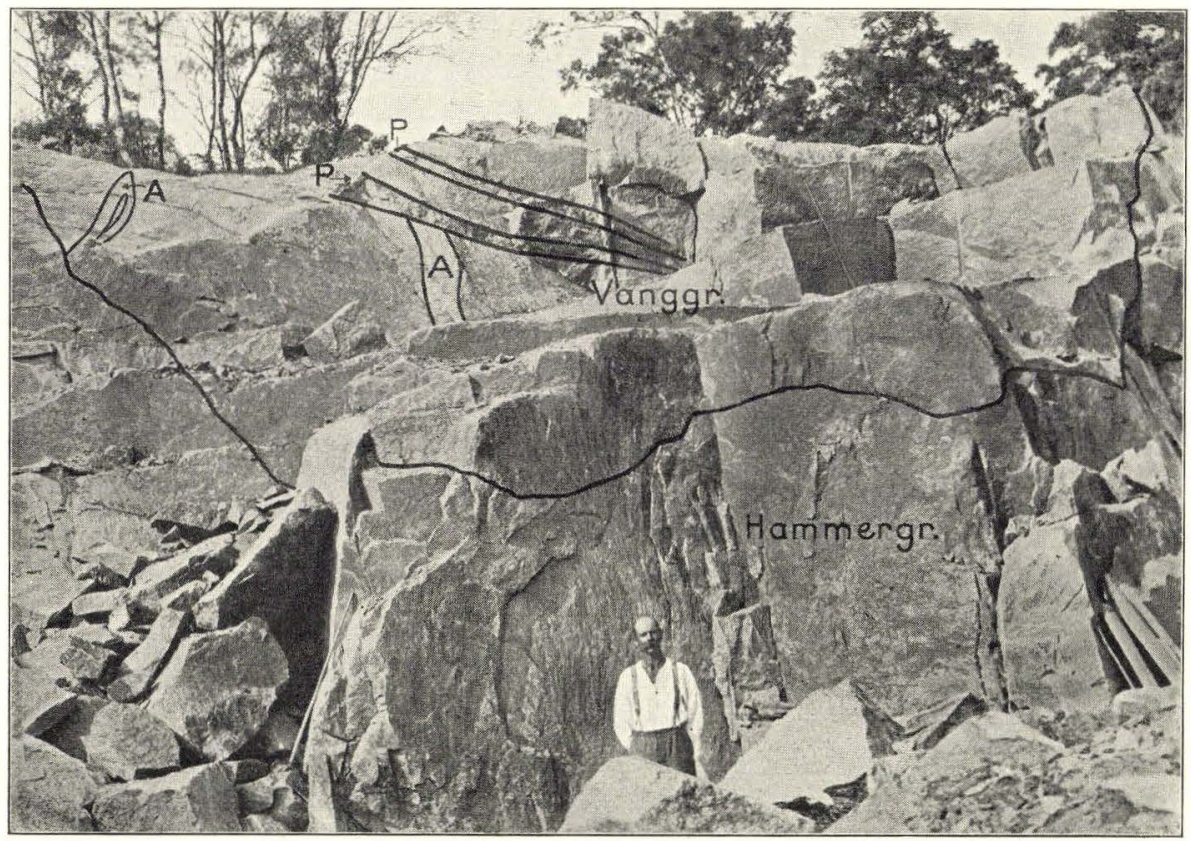

Fig. 16. Südwand im Steinbruch bei Sjelle Mose. $\mathrm{A}=$ Aplit. $\mathrm{P}=$ Pegmatit.

Steinbrüchen an der genannten Nordspitze der Grenze [bei Skovbo] findet man sowohl Vang Granit als Hammer Granit. An abgesprengten Stücken im Abfall gibt es Spuren einer feinkörnigen und pegmatitschlierigen Grenzfazies des Hammer Granits, welcher somit der jüngere zu sein scheint, aber die Grenze ist nicht aufgeschlossen und die Richtung nicht deutlich wahrnehmbar ... Dagegen steht es fest, dass die Grenze scharf und ohne Uebergang ist. "Ussing ist sich also in der Tat über das Altersverhältnis zwischen dem Hammer- und dem Vang Granit im Klaren gewesen; ihm fehlte nur der entscheidende Beweis. Bei meinem Besuch an diesem Ort war der Steinbruch wieder in Betrieb. In einem kleinen Teil der Westwand des Bruches war der Hammer Granit von Vang Granit überlagert. Obgleich die Wand sehr bestaubt und schmutzig war, war die Grenze deutlich zu sehen. Der Hammer Granit hat im grössten Teil dieses Bruches seine gewöhnliche Korngrösse und Struktur, aber dem 
Vang Granit zunächst hat er eine ganz schmale — soweit man sehen konnte, nur einige wenige cm starke - feinkörnige aplitische Randzone. In einem grossen losgebrochenen Block von Vang Granit fand sich ein ca. $1 \mathrm{~m}$ mächtiger Aplitgang.

Von den Vorkommen, in denen ich den Kontakt aufgeschlossen fand, ist der Steinbruch bei Sjelle Mose am instruktivsten. Dieser Steinbruch ist am Ostende eines kleinen Höhenzuges, der grösstenteils aus

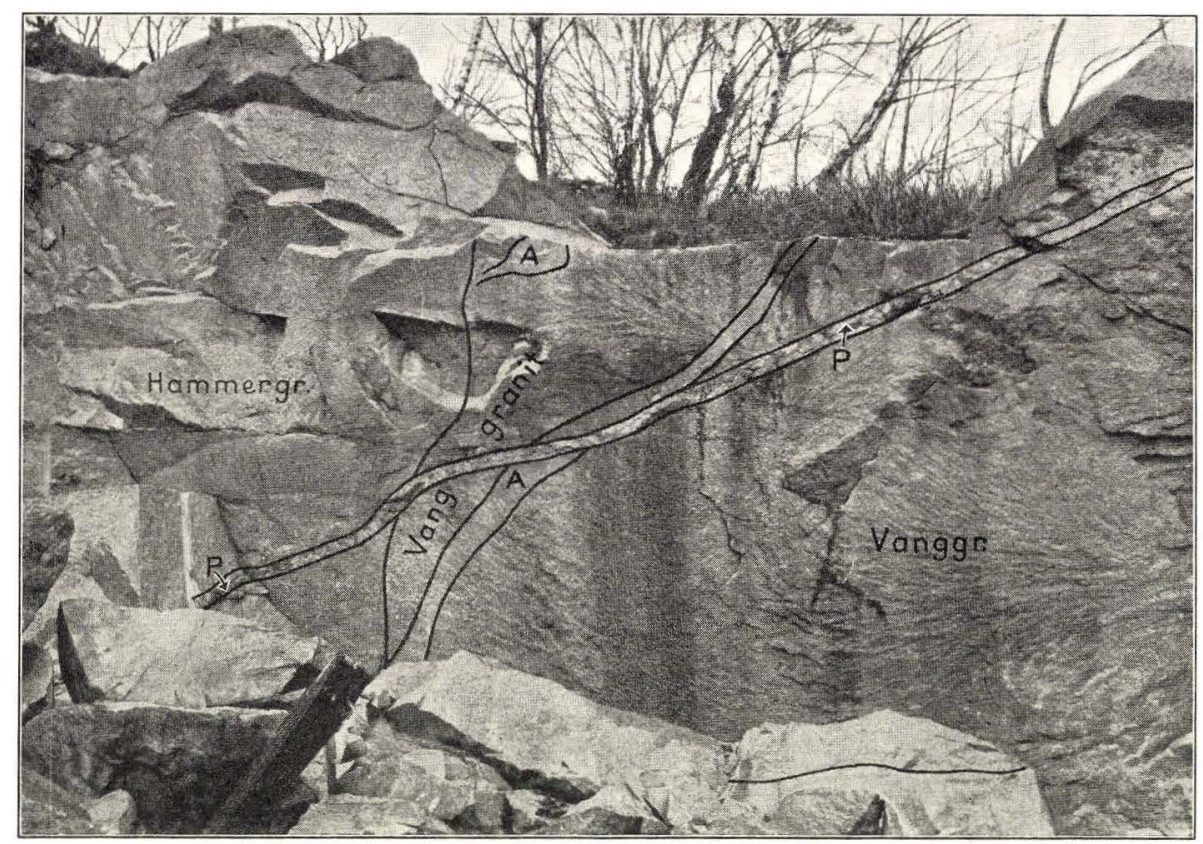

Fig. 17. Nordwand im Steinbruch bei Sjelle Mose. $\mathrm{A}=$ Aplit. $\mathrm{P}=$ Pegmatit.

Hammer Granit besteht, angelegt, aber gerade im Steinbruch ist die Grenze zwischen den beiden Graniten besonders gut aufgeschlossen. In der Südwand des Bruches (Fig. 16) sieht man zu oberst den Vang Granit mit eispolierter Oberfläche unter der Moränendecke, zu unterst den Hammer Granit, der deutlich unter den Vang Granit hineingeht. In der Nordwand liegt der Vang Granit auf einer 11-12 m langen Strecke über dem Hammer Granit (Fig. 17), aber diese Partie des Vang Granits hat nur eine geringe Ausdehnung; an der Nordseite des Hügels findet sich nur Hammer Granit. Als ich zum ersten Mal im Jahre 1920 die Grenze zwischen dem Hammer- und dem Vang Granit in diesem Steinbruch fand, bestand die Nordwand ausschliesslich aus Hammer Granit. Bei fortgesetztem Abbau trat der Vang Granit auch in dieser Wand zutage. Der unterste Teil des Kontaktes liegt hier auf einem etwas niedrigeren Niveau als in der Südwand. Diese Partie des Vang Granits scheint also 
eine etwas tiefer herabgesunkene Scholle zu sein. Im übrigen aber hat die Grenze zwischen den beiden Graniten in Einzelheiten einen ausserordentlich unregelmässigen Verlauf.

Im grössten Teil des Bruches hat der Hammer Granit sein normales Aussehen und seine gewöhnliche Korngrösse, in der Nähe der Grenze aber wird er zuerst etwas porphyrisch mit aplitischen und pegmatitischen Schlieren, zuletzt ganz feinkörnig. Das feinkörnige Grenzgestein ist etwas pegmatitschlierig, und die spärlichen dunklen Mineralien sind in länglichen Haufen angeordnet, wodurch das Gestein eine deutliche Streifung erhält, welche parallel mit der Grenzfläche verläuft. Diese Streifung setzt sich ein Stück in den etwas gröberen Hammer Granit hinein fort. Die Mächtigkeit der feinkörnigen Grenzfazies variiert von $4-5 \mathrm{~m}$ bis zu einigen $\mathrm{dm}$. Im Kontakt selber enthält der feinkörnige Hammer Granit einige dunkle Mineralien, welche in dünnen Streifen längs der Grenze angehäuft sind, und im Vang Granit sind die Haufen von dunklen Mineralien etwas ausgedehnt und geschleppt (Fig. 18). Oft ist die Grenze ausserordentlich scharf, stellenweise jedoch findet man eine ganz schmale Zone von einem sehr streifigen und schlierigen dunklen Uebergangsgestein, das im wesentlichen die Zusammensetzung des Vang Granits aufweist (vgl. pag. 70). Wo ein solches Uebergangsgestein beobachtet worden ist, hat es doch stets nur einen ganz untergeordneten Teil der Grenzzone ausgemacht.

Die feinkörnige Grenzfazies des Hammer Granits besteht hauptsächlich aus Mikroklin und Quarz. Die Körner sind äusserst unregelmässig begrenzt, und die Korngrösse ist etwas ungleich (Taf. VI, Fig. 1). Häufig gibt es Einschlüsse von kleinen abgerundeten Quarzkörnern im Mikroklin, und ebenfalls im Quarz treten kleine runde Mikroklinkörner auf. Der Mikroklin ist sehr perthitarm oder fast ganz perthitfrei; es hat somit während der Kristallisation eine beinahe vollständige Differentiation im Kalifeldspat und Plagioklas stattgefunden. Der Quarz hat ein wenig undulöse Auslöschung, und die grösseren Körner sind von Rissen durchsetzt. Plagioklas tritt nur in Form von kleinen, im Innern oft getrübten Körnern auf. Soweit es feststellbar ist, besteht der Kern aus Oligoklas-Albit mit etwa $13 \%$ An.; in der Regel gibt es eine Randzone aus Albit. Myrmekit ist recht spärlich vorhanden. Die wenigen dunklen Mineralien bestehen im wesentlichen aus Biotit, Erz und Titanit. Stellenweise hat der Biotit eine gefranzte, myrmekitähnliche Kontur gegen den Feldspat. Ausserdem gibt es geringe Mengen von Chlorit, Flusspat, Orthit, Zirkon und selten Muskovit.

Ein paar Meter vom Kontakt ist das Gestein im grossen und ganzen gröber, die Korngrösse aber noch ungleichmässiger (Taf. VI, Fig. 2). Mikroklinperthit, Quarz und zum Teil Plagioklas treten nun sowohl in feinkörnigem Gemenge als auch in der Gestalt von grösseren Individuen auf, von denen namentlich der Mikroklin zahlreiche Einschlüsse von 
Quarz und Plagioklas enthält. Die grösseren Plagioklaskörner sind im Innern meistens ziemlich stark von kleinen Muskovitschuppen und -Blättern getrübt, seltener beobachtet man auch Epidot. Nur in einem einzelnen Schnitt liess sich die Zusammensetzung des Kerns als Oligoklas mit etwa $18 \%$ An. bestimmen. Der Plagioklas schliesst oft Biotitblätter

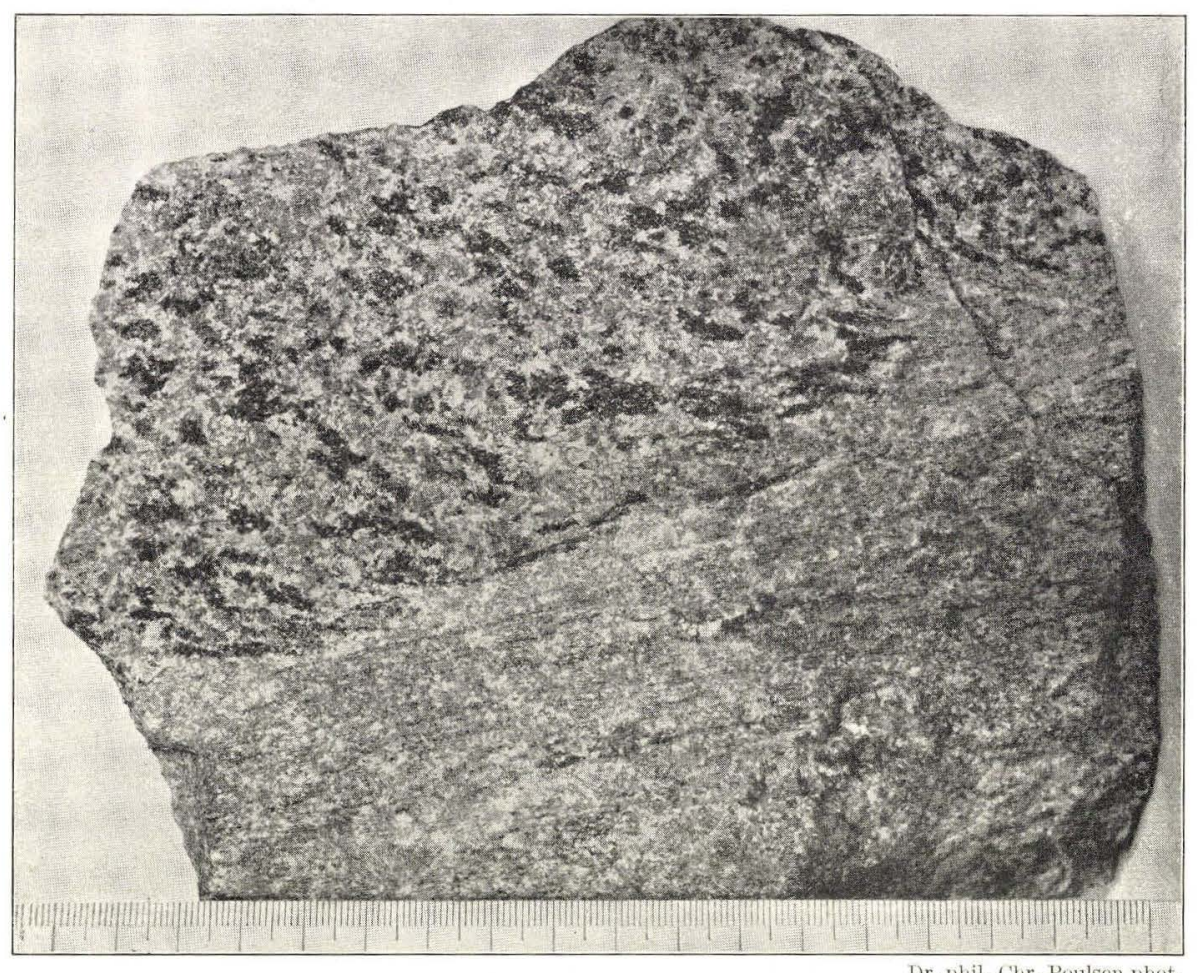

Fig. 18. Grenze zwischen Hammer- und Vang Granit (Sjelle Mose). Man beachte die Parallelstruktur im Randaplit des Hammer Granits; desgleichen, dass die dunklen Nineralien im Vang Granit etwas geschleppt sind.

und schriftgranitische Quarzeinlagerungen ein. Myrmekit ist ausserordentlich reichlich vorhanden. Die untergeordneten Mineralien sind wie in der feinkörnigen Zone.

Die aplitische Randfazies des Hammer Granits durchsetzt in zahlreichen Gängen den Vang Granit. Diese Gänge haben einen höchst unregelmässigen Verlauf, was namentlich in der Felsenoberfläche oberhalb der Südwand des Bruches beobachtet werden konnte, als diese nach Forträumung der Moräne noch frisch dalag. In der Nordwand, wo man jetzt den Kontakt am reinsten und deutlichsten sieht, ist die sehr feinkörnige Randzone des Hammer Granits ganz schmal und längs der Grenze ausgesprochen gestreift (Fig. 18). Hier kann man sehen, dass ein Aplitgang 
im Vang Granit (A-A in Fig. 17) ein Ausläufer des Hammer Granits ist. Fig. 19 zeigt, wie die schlierige Struktur des Randaplits sich längs der Ganggrenze im Aplitgang fortsetzt, während sie in der Mitte des untersten, trichterförmig erweiterten Teiles grobkörniger ist. Ferner sieht man in der Nordwand einen Pegmatitgang (P-P in Fig. 17), der sowohl den Hammer Granit als auch den Vang Granit durchsetzt und die Aplitapophyse durchschneidet. Dasselbe Altersverhältnis zwischen Aplit- 'und Pegmatitgängen beobachtet man auch in der Südwand des Bruches. Der Aplitgang A in Fig. 16 hat ein feinkörniges Salband und eine pegmatitschlierige Mitte. Er wird von zwei grossen Pegmatitgängen, P-P, deren Fortsetzung im Hammer Granit westlicher im Steinbruch zu sehen ist, durchschnitten. Die Verbindung zwischen diesem Aplitgang und dem Randaplit des Hammer Granits ist dagegen an dieser Stelle nicht sichtbar.

Unlängst hat Professor S. v. Bubnoff, Greifswald, eine Arbeit über den Hammer Granit ${ }^{1}$ ) publiziert, in welcher er den Kontakt bei Sjelle Mose recht ausführlich behandelt und mir dadurch die Möglichkeit vorwegnimmt, selbst als erste eine Beschreibung dieser interessanten Lokalität veröffentlichen zu können. In ein paar Profilzeichnungen (1. c. pag. 17) der Nord- und Südwand des Steinbruchs hat v. Bubnoff die hier in Fig. 16 und 17 abgebildeten Aplitgänge als Fortsetzungen von Aplitgängen im Hammer Granit eingezeichnet. Dieses ist absolut nicht der Fall. Im Hammer Granit ist eine Fortsetzung der Aplitgänge niemals sichtbar gewesen. Sie sind fraglos Ausläufer des Randaplits des Hammer Granits, und sie müssen somit im ersten Stadium der Intrusion entstanden sein, wogegen die grossen Pegmatitgänge sich während des letzten Stadiums der Kristallisation des Hammer Granits gebildet haben. Das Gestein in den Aplitgängen ist in Bezug auf die Zusammensetzung vollkommen identisch mit dem Randaplit und wie dieser stellenweise pegmatitschlierig; die Pegmatitbildung hat also in beiden Stadien stattgefunden.

Der Pegmatit ist meistens schriftgranitisch entwickelt. Die grossen Pegmatitgänge in der Südwand des Bruches (Fig. 16) haben eine Mächtigkeit von ca. $1 \mathrm{~m}$. An einigen Stellen sind sie symmetrisch aufgebaut mit grobkörnigem Quarz-Feldspat in der Mitte, während längs der Ganggrenzen Feldspat vorherrscht; an anderen Stellen findet man grössere Quarzausscheidungen in den Salbändern. Im Hammer Granit habe ich keine Parallelstruktur längs der Pegmatitgänge gefunden. Der Pegmatit ist kräftig rot, und besonders sind die Quarzkörner im Schriftgranit tiefrot gefärbt. Der grösste Teil des Feldspates besteht aus Mikroklinperthit,

1) S. v. Bubnoff: Der Hammergranit von Bornholm. Fortschritte der Geologie und Paläontologie, Bd. XI. Heft 33. (DEEcke-Festschrift). 1932. 
rötlicher Plagioklas kommt doch in recht beträchtlicher Menge vor. Der Plagioklas enthält unregelmässig begrenzte Einlagerungen von Mikroklinperthit in paralleler Verwachsung; Fig. 3, Taf. VI zeigt diese Verwachsung; der Schnitt ist ungefähr $\perp$ Bisectrix $\gamma$ in den beiden Feldspaten.

Dieselben Verhältnisse, dass nämlich der Vang Granit wie ein Dach den Hammer Granit überdeckt, fand ich ferner an einer Stelle etwa $1,5 \mathrm{~km}$ SW von Sjelle Mose, wo die Granitgrenze Kampelykke-Aa (Bach) passiert. Im Abhang an der Westseite des Baches haben wir zu unterst gewöhnlichen Hammer Granit, der nach oben zu in die feinkörnige Grenzfazies übergeht. Höher oben in der Felsenvand steht grauer Vang Granit, der Uebergang selber war aber an dieser Stelle nicht deutlich zu sehen.

An der NO-Küste liegt die Granitgrenze in den Uferfelsen gegenüber der Station Sandkaas, sie ist aber nur auf den äussersten kahlen Schären deutlich wahrnehmbar, und zwar am besten, wo diese unter Wasser stehen. Die Mächtigkeit der feinkörnigen Zone beträgt kaum mehr als $0,25-0,5 \mathrm{~m}$, danach wird der Hammer Granit bedeutend gröber und deutlich porphyrisch, wobei Mikroklin und ein-

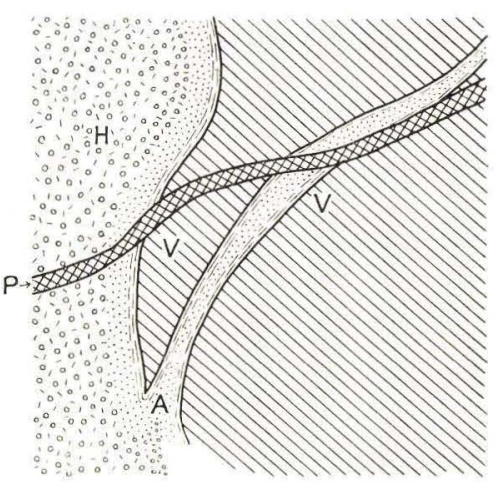

Fig. 19. Profil der Granitgrenze in der Nordwand vom Steinbruch bei Sjelle Mose. zelne Plagioklaskörner rundliche Ein-

sprenglinge mit einem Querschnitt von $1-1,5 \mathrm{~cm}$ bilden (Taf. VI, Fig. 2). Diese porphyrische Struktur findet man hier in den Uferfelsen noch deutlich in einer Entfernung von etwa $500 \mathrm{~m}$ vom Kontakt. In der Nähe der Grenze ist der Hammer Granit ausserordentlich pegmatitreich und stellenweise recht glimmerreich und ausgesprochen gestreift. Die dunklen Mineralien sind in flachen Haufen angeordnet, welche $2-3 \mathrm{~cm}$ lang werden können. Hierin findet man häufig Flusspatkörner, und hie und da gibt es kleine Hohlräume, welche teilweise mit Flusspatkristallen angefüllt sind. Die streifige, porphyrische Randzone des Hammer Granits unterscheidet sich weiter oben am Ufer in den mit Flechten bekleideten Felsen nicht sehr deutlich vom Vang Granit, der hier an der Oberfläche ziemlich hell und rötlich ist, und die Grenze ist hier um so schwieriger feststellbar, als auch der Vang Granit in der Nähe der Grenze von zahlreichen Pegmatitgängen vom Hammer Granit durchsetzt ist.

Etwa 200-300 m nördlich vom Hafen in Vang bestehen die niedrigen Küstenfelsen aus gewöhnlichem Hammer Granit. Folgt man von hier aus dem Ufer gegen Süden, sieht man denselben Uebergang wie in den oben erwähnten Vorkommen: durch eine porphyrische Zone geht der Hammer Granit allmählich in die feinkörnige rote Grenzfazies über. 
Diese letztere ist parallel der Grenze stellenweise deutlich gestreift. Die feinkörnige Zone erreicht hier eine Breite von mindestens $10 \mathrm{~m}$, also beträchtlich mehr als an den beiden anderen Lokalitäten, doch bedeutet dies kaum, dass sie eine derartig grosse Mächtigkeit hat. Den Kontakt zwischen den beiden Graniten sieht man nämlich in einer kleinen

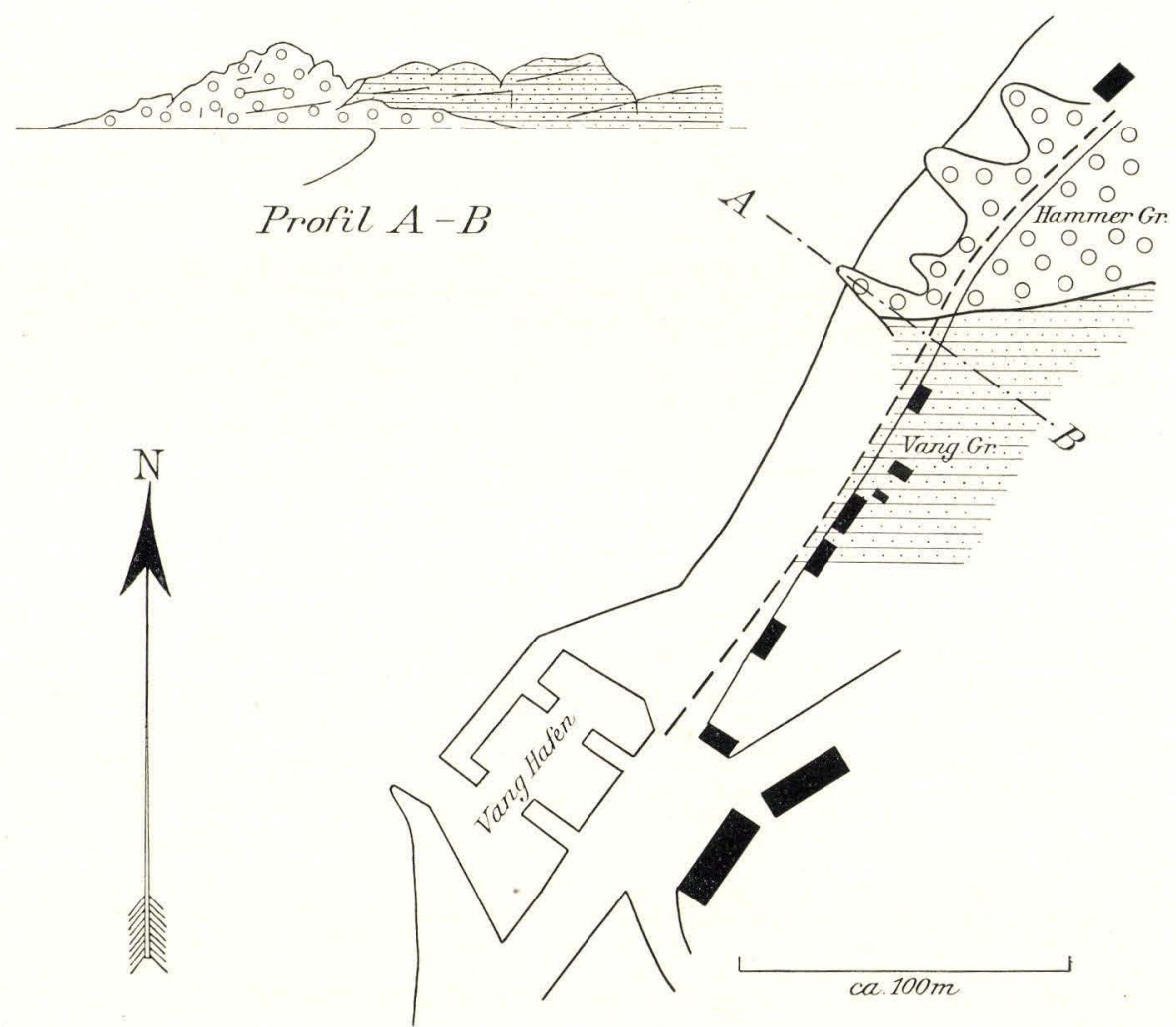

Fig. 20. Kartenskizze und Profilzeichung der Granitgrenze N von Vang Hafen.

emporragenden Felsenpartie etwa 125 m nördlich vom Hafenbassin, und auch hier zeigt es sich wieder, dass sich der Hammer Granit unter den Vang Granit hineinstreckt (Fig. 20 und 21). Das Ufer vertritt daher einen schrägen Schnitt durch die Grenzfläche. In der in Fig. 21 abgebildeten Felsenpartie verläuft die Grenze als eine sehr scharfe Linie. Vom Randaplit des Hammer Granits verzweigen sich mehrere kleine, zum Teil pegmatitschlierige Apophysen in den Vang Granit hinein. Nicht weit davon entfernt findet man ein dunkles glimmerreiches und stark gestreiftes Uebergangsgestein mit zahlreichen roten, teilweise pegmatitisch oder porphyrisch entwickelten Schlieren. Im wesentlichen hat dieses Uebergangsgestein die Zusammensetzung des Vang Granits (vgl. pag. 70 und pag. 100). 
In den Uferfelsen südlich von Vang kann man auf einer längeren Strecke eine ansehnliche Aplitmasse längs dem jetzt abgebauten Förderwagengeleise vom Hafen zum Steinbruch »Klondyke« beobachten. Im Laufe der Zeit ist jedoch der Aplit teilweise von losgerissenen Felsblöcken verdeckt worden. Der Aplit tritt zu unterst in der Felsenwand ungefähr in der Höhe des Bahnkörpers zutage; seine obere Grenze gegen den Vang Granit ist ziemlich unregelmässig gebuchtet, die untere Grenze

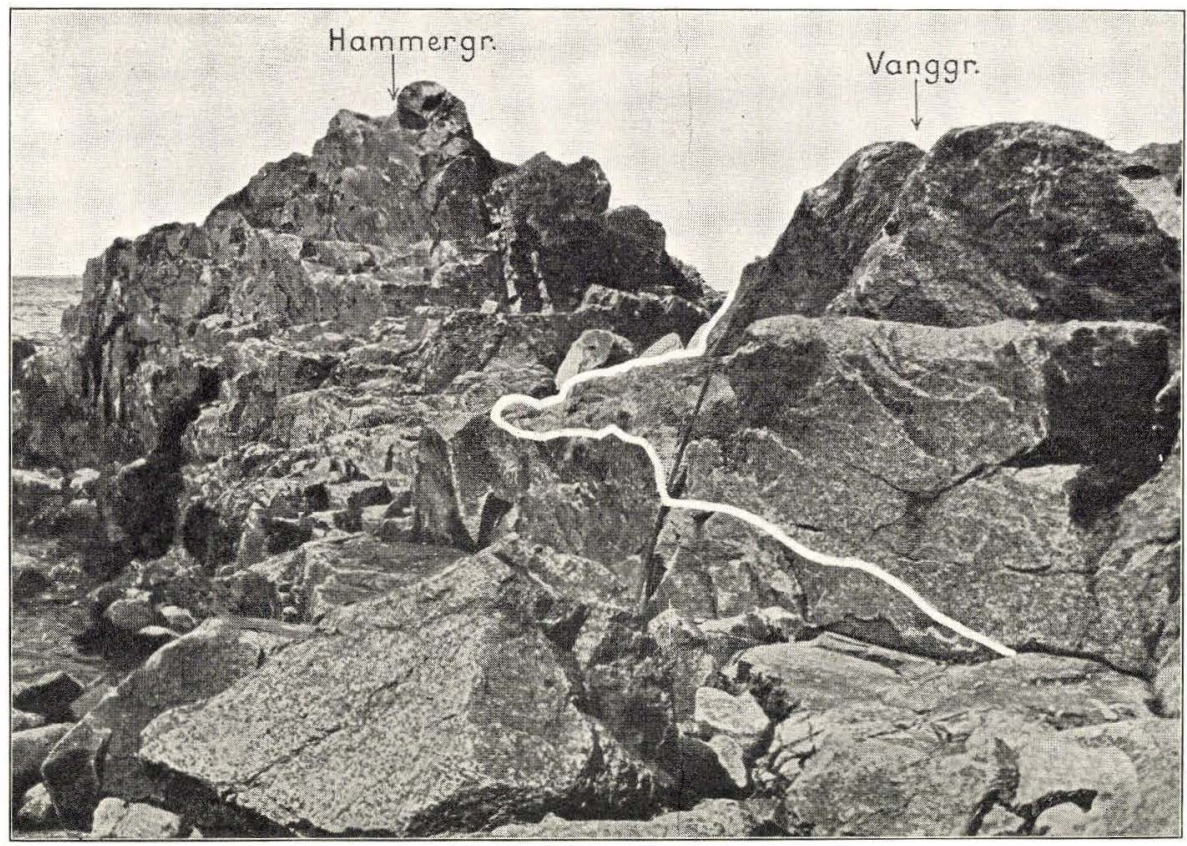

Fig. 21. Grenze zwischen Hammer- und Vang Granit in den Küstenfelsen N von Vang Hafen (Profil A-B, Fig. 20).

ist nie sichtbar gewesen. Eine Streifung ist in diesem Gestein kaum wahrnehmbar. Die Korngrösse ist weniger gleichartig als in den schmalen Aplitgängen, und Feldspatkörner mit einem wesentlich grösseren Querschnitt als dem der übrigen Gemengteile kommen häufig vor. Der Biotit ist etwas chloritisiert, und Muskovit ist nicht selten vorhanden, allerdings hauptsächlich als Umwandlungsprodukt im Plagioklas. Ausserdem gibt es Orthit und Flusspat in verhältnismässig reichlicher Menge. Dieser Aplit stimmt also in seiner Zusammensetzung und in seiner etwas ungleichartigen Korngrösse genau mit dem Randaplit des Hammer Granits, so wie dieser in einer geringen Entfernung von der Grenze entwickelt ist, überein. In Anbetracht der horizontalen Lage der Aplitmasse halte ich es für sehr wahrscheinlich, dass es in Wirklichkeit der Kontakt zwischen dem Hammer- und dem Vang Granit ist, der hier wieder zutage tritt. 
Von Vang verläuft die Granitgrenze in nordöstlicher Richtung. In der Ostseite von Finnedalen, ungefähr beim Hotel Finnedalen, findet man wieder die feinkörnige Grenzfazies des Hammer Granits und nicht weit davon entfernt den gewöhnlichen mittelkörnigen Hammer Granit. Wie schon erwähnt, sieht man die Grenze weiterhin in den Steinbrüchen in der Nähe der Quelle Skovbo Kilde, wonach sie nach Süden abbiegt. Auf Borrelyng werden sowohl Hammer- als Vang Granit in eng benachbarten Brüchen gebrochen, und im südlichsten Aufschluss ganz nahe von der Landstrasse war der Kontakt eine Zeitlang sichtbar. Man findet im Vang Granit in der dortigen Gegend zahlreiche Gänge von hellem, rotem Aplit; mehrere von diesen sind derart symmetrisch aufgebaut, dass die Mitte des Ganges aus grobkörnigem Pegmatit, die Salbänder aus Aplit bestehen.

Bei den Kenntnissen vom Lagerungsverhältnis zwischen den beiden Graniten, welche die oben beschriebenen Lokalitäten ergeben haben, muss man es für sehr wahrscheinlich halten, dass der Hammer Granit ein gutes Stück nach Süden zu die Unterlage des Vang Granits bildet. Dies wird von der Tatsache bestätigt, dass der Hammer Granit wieder in dem kleinen, isolierten Gebiet zwischen Dalegaard und Maegaard westlich von Ols Kirke zutage tritt. Die Entfernung zwischen diesem Vorkommen und der Südgrenze des eigentlichen Hammer Granit Gebiets beträgt etwa $1200-1400 \mathrm{~m}$. Innerhalb dieses Gebiets treten sowohl typischer Hammer Granit als auch eine etwas porphyrische Varietät auf, welche stellenweise ein wenig reicher an dunklen Mineralien und schwach gestreift ist. Ferner findet man an zahlreichen Stellen in der Gegend zwischen Maegaard, Dalegaard und Korsbjerg roten, feinkörnigen, schwach streifigen Granit, der oft stark pegmatitschlierig ist.

Von besonderem Interesse ist das Vorkommen von grösseren Aplitmassen bei Korsbjerg, etwa $1200 \mathrm{~m}$ nördlich von Ols Kirke. In einer kleinen, in NO-SW-licher Richtung verlaufenden Talung zwischen Korsbjerg und Bakkemölle tritt der helle rote, deutlich gestreifte Aplit an mehreren Stellen zutage. In ein paar der vielen kleinen Steinbrüche, die sich hier finden, liegt der Vang Granit über dem Aplit, so z. B. in einem Bruch an der Nordseite des Tals in der Nähe von dessen Ostende. Der Aplit bildet den Boden des Bruches und den untersten Teil der Wand bis zu einer Höhe von 2-4 m. Das gleiche Verhältnis finden wir in einem anderen Steinbruch ca. $500 \mathrm{~m}$ weiter nach SW wieder. Auch hier besteht der Boden des Bruches aus hellem, rotem Aplit, aber an dieser Stelle durchsetzt der Aplit den hangenden Vang Granit in mehreren Lagergängen, die in grossen Zügen der Streifung des Vang Granits folgen (Fig. 22). Im Aplit sieht man einige auskeilende und deutlich gestreifte Linsen aus Vang Granit. Der Aplit enthält reichlich Pegmatit, und ausserdem beobachtet man ansehnliche Pegmatitgänge, die zum 
Teil den Aplitgängen folgen, zum Teil einen unregelmässigeren Verlauf haben. Der Aplit ist gestreift oder schlierig parallel der Grenze gegen den Vang Granit. Sein intrusiver Charakter geht des weiteren daraus hervor, dass er an einer Stelle eine der im Vang Granit so gewöhnlichen dunklen, feinkörnigen Ausscheidungen durchschneidet. Aller Wahrscheinlichkeit nach macht diese Aplitmasse einen Teil des Randaplits des Hammer Granits aus. Der typische mittelkörnige Hammer Granit ist freilich weder

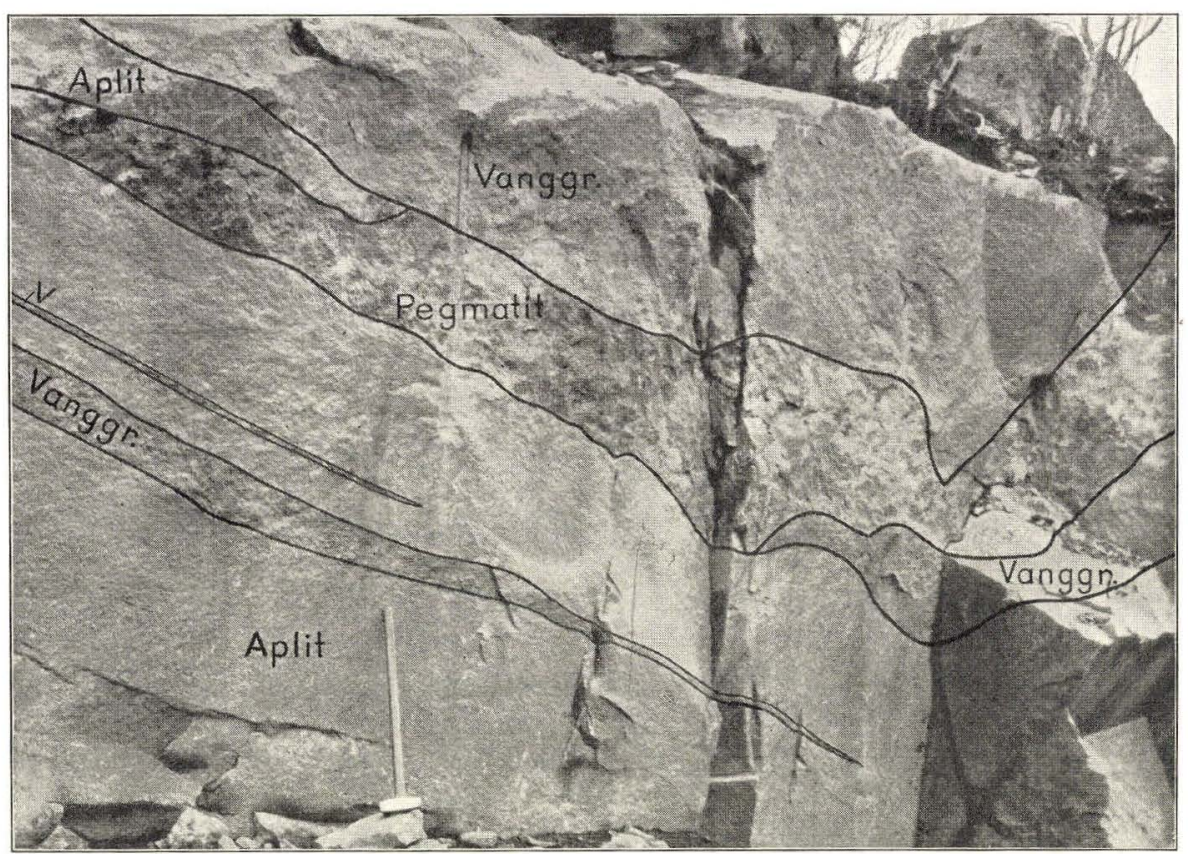

Fig. 22. Aplit- und Pegmatitgänge im Vang Granit. Steinbruch bei Korsbjerg.

an dieser Stelle noch in deren unmittelbaren Nähe feststehend gefunden worden, aber er tritt in demselben Tal ca. $1 \mathrm{~km}$ weiter nach Südwesten zutage, wo er in einem »Östre Vang« genannten Steinbruch gebrochen wird.

Man findet also innerhalb dieses kleinen Gebiets $W$ und NW von Ols Kirke alle die drei Gesteinstypen, welche den Hammer Granit und dessen Grenzzone kennzeichnen. Ich bin daher der Ansicht, dass der feinkörnige rote Granit in diesem Terrain als die Grenzfazies des Hammer Granits aufzufassen ist. Dasselbe gilt wahrscheinlich auch für einige ähnliche kleine Vorkommen des roten aplitischen Granits in den Uferfelsen zwischen Sandkaas und Tejn.

Dagegen dürfte es zweifellos unberechtigt sein, diese Auffassung auf alle die früher erwähnten Vorkommen von feinkörnigem, rotem Granit, die innerhalb des nördlichen Gebiets des grauen streifigen Granits zer- 
streut auftreten, ausdehnen zu wollen. An Stellen, wo ein schroffer Uebergang zwischen diesen aplitischen Graniten und dem grauen streifigen Granit sichtbar gewesen ist, z. B. bei den Häusern Kongensmark Huse SO von Gudhjem (vgl. pag. 92), waren die beiden Granite schlierenartig in einander verwoben. Nur an einer Stelle, N von Stavsdal, habe ich einen kleinen Aplitgang im grauen streifigen Granit gesehen, wogegen ich an verschiedenen Stellen, und zwar an den meisten, einen ebenmässigen und unmerklichen Uebergang gefunden habe. Diese Verhältnisse sind also wesentlich verschieden von dem deutlich intrusiven Charakter, den der Randaplit des Hammer Granits stets da aufweist wo der Kontakt zu sehen ist, und der sich im Aplit bei Korsbjerg wiederfindet.

Dieses südliche Vorkommen des Hammer Granits westlich von Ols Kirke hat Professor BuBnoff mit dem »streifigen Hauptgranit« verwechselt. Das geht aus den Profilzeichungen (1. c. pag. 21) hervor, speziell aus dem Profil »Allinge - Sjelle Mose - Korsbjerg — westl. Olskirche«, wo der Granit westl. Ols Kirke als »streifiger Granit« bezeichnet ist. Dieser Granit ist in Wirklichkeit der Hammer Granit im oben beschriebenen kleinen Gebiet zwischen Østre Vang, Dalegaard und Maegaard. Professor BubNoFF ist dadurch zu einer fehlerhaften Auffassung von der Verbreitung des Vang Granits gekommen. Wenn das erwähnte Profil noch $1 \mathrm{~km}$ weiter nach Süden fortgesetzt worden wäre, hätte es wieder grauen, streifigen Vang Granit mit allen für diesen Granit charakteristischen mineralogischen und strukturellen Kennzeichen getroffen: relativ grosse Feldspatkörner, beträchtlichen Hornblendegehalt, Ansammlung von dunklen Mineralien in Haufen, Granophyrstruktur und dunkle feinkörnige Ausscheidungen.

\section{Svaneke Granit.}

Der Svaneke Granit nimmt den östlichsten Teil des Bornholmer Granitgebietes in einer $3-4 \mathrm{~km}$ breiten Zone ein. Gegen Westen grenzt er längs einer scharfen und fast geraden Linie an den streifigen Granit; diese Grenzlinie verläuft von Listed an der NO-Küste annähernd gerade gegen Süden und ist etwa $8 \mathrm{~km}$ lang. Der Svaneke Granit findet in steigendem Masse Verwendung als Bau- und Pflastersteine, die in mehreren kleineren Brüchen in der Gegend von Svaneke und Nexö gebrochen werden.

Der Svaneke Granit ist bedeutend grobkörniger als die übrigen Granitvarietäten auf Bornholm. Die Feldspatkörner messen oft 1 bis $2 \mathrm{~cm}$ im Querschnitt. Der Quarz, welcher an Menge weit hinter dem Feldspat zurückbleibt, bildet körnige Aggregate und macht sich makroskopisch 
nur wenig bemerkbar. Der Gehalt an dunklen Mineralien ist beträchtlich; der Hauptbestandteil derselben ist Biotit; diese Mineralien sind zu unregelmässigen, meistens deutlich getrennten Anhäufungen gesammelt, was dem Stein ein lebhaftes Aussehen verleiht. Diese Anhäufungen sind öfters etwas ausgedehnt und derart angeordnet, dass der Granit eine Andeutung von Parallelstruktur erhält, was sich doch im allgemeinen nur im Felsen geltend macht; in Handstücken erscheint der typische

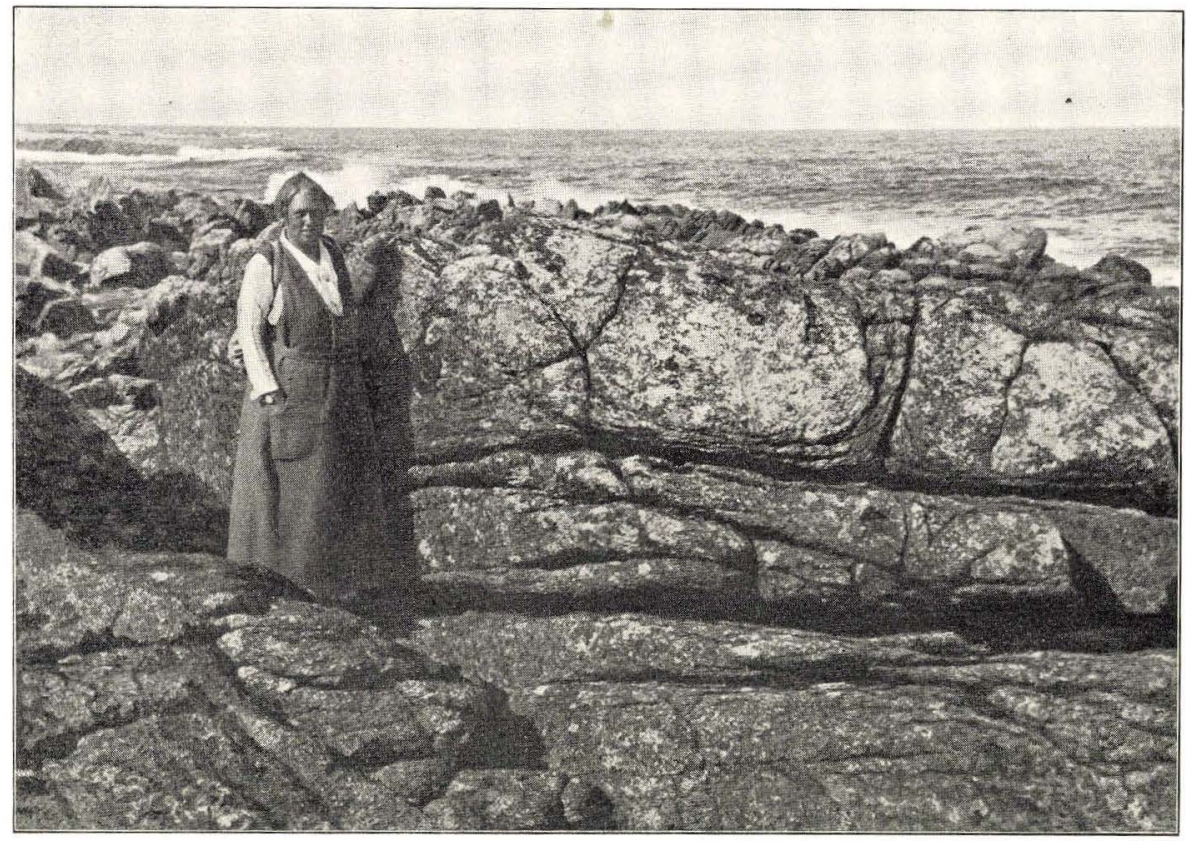

Fig. 23. Svaneke Granit in den Küstenfelsen, Frenneodde S von Svaneke.

Svaneke Granit fast immer regellos körnig. Dagegen kommt es vor, dass der Granit lokal eine deutliche Parallelstruktur aufweist, z. B. in der kleinen Bucht Nörrevig westlich von Svaneke, und hie und da findet man im Granit dunkle, glimmerreiche, stark gestreifte Schlieren. Basische Ausscheidungen von rundlicher Form und verschiedener Grösse kommen recht häufig vor. Im südlichen Teile des Gebietes, in der Gegend von Nexö, ist der Granit recht stark rotpigmentiert, während er im nördlichen Teile wesentlich heller und beinahe grau ist.

Der Svaneke Granit ist oft stark verkluftet, was namentlich die Uferfelsen kennzeichnet, und an vielen Stellen, besonders innerhalb der nördlichen Hälfte des Gebietes, hat der Granit eine starke Neigung, in Grus zu zerfallen, wodurch die Risse erweitert und vertieft werden. Im allgemeinen lässt sich eine parallelepipedische Verkluftung nachweisen (Fig. 23), wenn auch hierzu oft ausserordentlich viele ganz un- 
regelmässige Spalten kommen. Ein vorherrschendes System von vertikalen Klüften weist Richtungen auf, die durchschnittlich zwischen O $10^{\circ} \mathrm{S}$ und $\mathrm{O} 20^{\circ} \mathrm{S}$ liegen. Diese Klüfte sind an mehreren Stellen von Sandstein ausgefüllt, z. B. bei Listed und bei Grisby. Die Sandsteingänge, welche zuerst von UssING ${ }^{1}$ ) beschrieben wurden, haben öfters eine ansehnliche Länge, bei Listed z. B. über $70 \mathrm{~m}$. Auch die normal dazu verlaufenden Klüfte machen sich recht stark geltend, und der

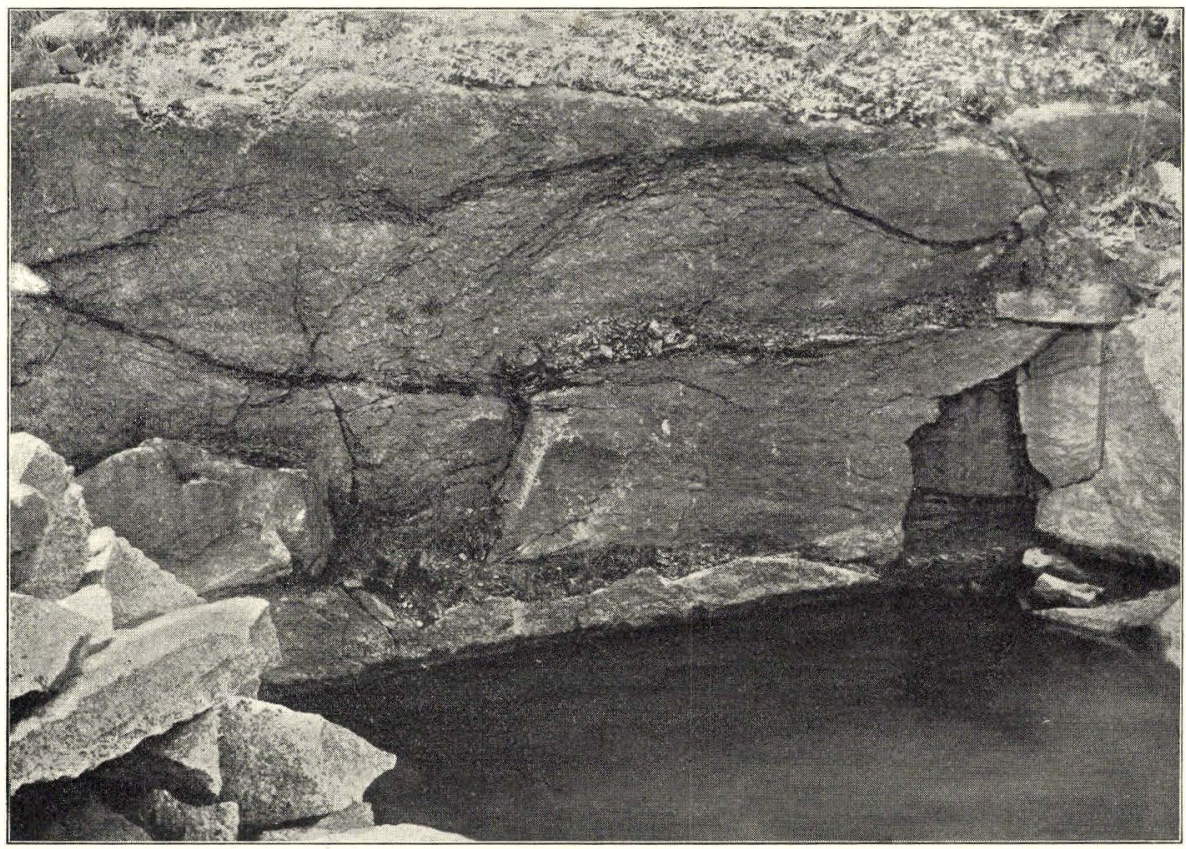

Fig. 24. Zerbröckeln des Svaneke Granits in den Klüften. Steinbruch Dorrille bei Listed.

letzteren Richtung folgen auch einzelne kleinere Spaltentäler im südlichen Teile des Svaneke Granit Gebietes. Noch ausgeprägter ist jedoch eine horizontale oder schwach abfallende Verkluftung oder Bankung im Granit. Diesen Klüften entlang hat der Granit die Neigung zu zerfallen, und dies sogar an Stellen, wo zwischen den zerfallenden Zonen völlig frische und sehr spaltenarme grosse Blöcke liegen. Fig. 24 z. B. zeigt horizontale Grusschichten von einer Mächtigkeit von mehreren Zentimetern in einem im übrigen frischen Granit im Steinbruch in der Dorrille Klippe südlich von Listed. Dasselbe Verhältnis habe ich an mehreren anderen Stellen beobachtet. - Nicht ganz selten findet man im Svaneke Granit grössere und kleinere Rutschflächen; am häufigsten scheinen sie

1) N. V. Ussing. D. G. U. II. R. Nr. 10. 1899. — Siehe auch: Kartenblatterläuterung. D. G. U. I. R. Nr. 13. 1916, pag. 19 ff. u. V. Milthers: Bornholms Geologi. D. G. U. V. R. Nr. 1. 2. Udg. 1930, pag. 22. 
in den Felsen nördlich von Aarsdale vorzukommen. Fig. 25 zeigt eine kleine Rutschfläche durch einen beinahe senkrechten, etwa $\mathrm{O}-\mathrm{W}$ verlaufenden Pegmatitgang in Pærebakken südlich von Svaneke.

Mineralogische Zusammensetzung. Die Mineralkörner haben im Svaneke Granit relativ ebenmässige Begrenzungsflächen, und na-

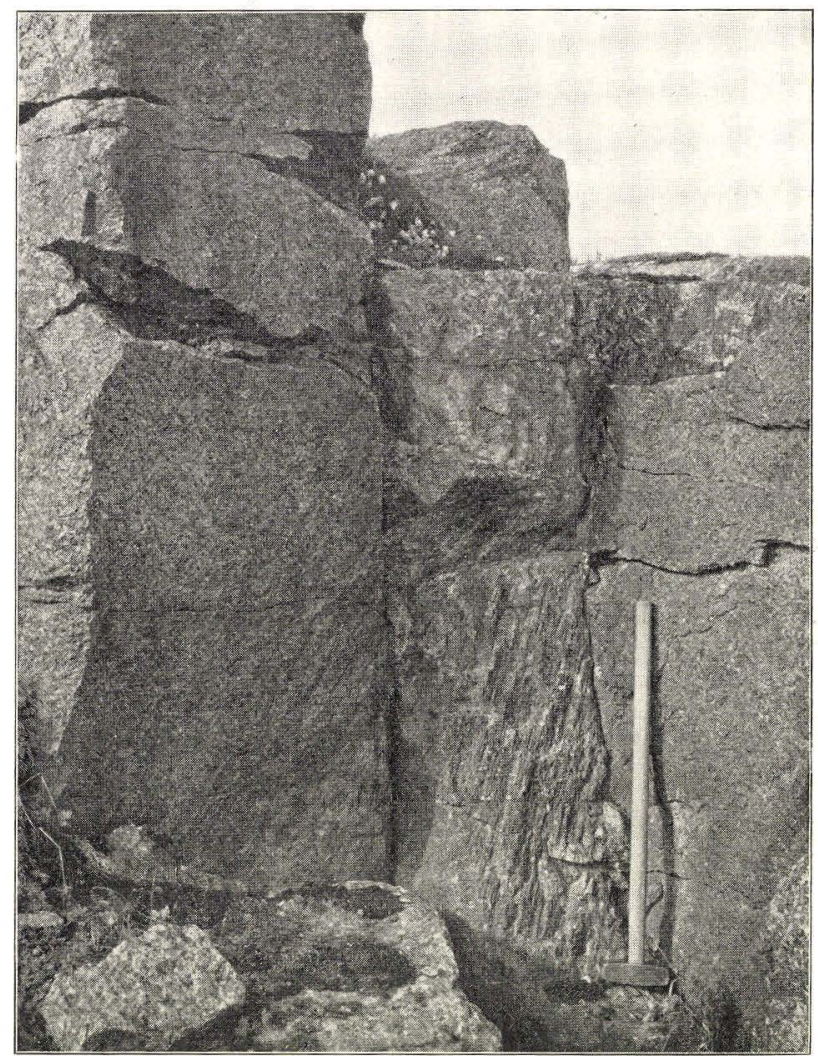

Fig. 25. Rutschfläche im Svaneke Granit. Pærebakken S von Svaneke.

mentlich sind die Grenzen zwischen Feldspat und Quarzkörnern weit weniger gezackt und gebuchtet als sonst in irgend einer der übrigen Bornholmer Granitvarietäten. Der Quarz, der eine etwas undulöse Auslöschung hat, tritt dagegen stellenweise in Aggregaten auf, in denen die Grenze zwischen den einzelnen Körnern ausserordentlich unregelmässig verläuft. Der Quarz führt nur wenige Einschlüsse, von denen einzelne aus Feldspat bestehen. Das Hauptgemengteil des Granits ist Mikroklinperthit. Die Farbe ist hell rötlich. Der Mikroklin ist stets völlig frisch, während der Perthitplagioklas, der teils als dünne Spindeln, teils als recht grosse Plagioklaseinlagerungen entwickelt ist, im allgemeinen etwas zersetzt ist. Die Mikroklinstruktur ist etwas verschieden- 
artig gestaltet, indem stellenweise das eine System von Zwillingslamellen derartig stark vorherrscht, dass grosse Teile eines Mikroklinkornes einheitliche Auslöschung erhalten (Fig. 4, Taf. VI). Der Mikroklin schliesst häufig kleine Quarzkörner und zufällig orientierte Plagioklaskörner ein, seltener Biotit, Titanit u. a. dunkle Mineralien. Plagioklas ist in beträchtlicher Menge vorhanden und tritt zum Teil in zentimetergrossen Körnern auf. Die Zusammensetzung ist hauptsächlich Oligoklas mit etwa $25-27 \%$ An. Der Zonarbau ist in der Regel wenig ausgesprochen, einige der Körner aber haben eine unregelmässig begrenzte, ein wenig saurere Randzone, die stellenweise in einen Albitsaum übergeht. Der Plagioklas ist meistens etwas unfrisch und hie und da stark von kleinen muskovitähnlichen Schuppen gefüllt (Taf. VI, Fig. 5); ausserdem gibt es im Plagioklase oft einige relativ grosse Muskovitblätter sowie ein wenig Kalkspat und Epidot. Einschlüsse von Quarz und den dunklen Mineralien des Gesteins kommen stellenweise vor und zwar vorwiegend in der äusseren Zone des Plagioklases. Längs des Randes desselben tritt bisweilen parallel angewachsener Mikroklin auf, einen vollständigen Mikroklinmantel um ein grösseres Plagioklasindividuum fand ich jedoch nirgends im Svaneke Granit. Nicht selten sind grössere Teile der äusseren Zone der Plagioklaskörner myrmekitisch entwickelt. Myrmekit ist überhaupt sehr reichlich vorhanden und tritt besonders dort auf, wo Mikroklin und Oligoklas sich berühren. In den eckigen Zwischenräumen zwischen den grossen Feldspatkristallen liegen die erwähnten Quarzaggregate und die Haufen von dunklen Mineralien. Stellenweise findet man auch feinkörnige Partien, welche im wesentlichen aus zum Teil myrmekitisch entwickeltem Plagioklas, aus Quarz und aus dunklen Mineralien bestehen. Kleine Mikroklinkörner kommen dagegen verhältnismässig spärlich vor. Der Biotit ist grünlich oder oliv. Der Achsenwinkel ist 0, die Lichtbrechung $\gamma=\beta \leqq 1,657$ (Monobromnaphtalin); in einigen Fällen hat der Biotit eine sehr kräftige Absorption, so dass $\gamma^{\prime}$ beinahe schwarz ist. Der Biotit ist oft gefranzt und myrmekitähnlich mit Feldspat verwachsen, hat aber gegen den Quarz stets eine ruhige Kontur. Er schliesst oft Apatit ein, und häufig sieht man zahlreiche pleochroitische Höfe um kleine Zirkon- oder Orthitkristalle herum. Zwischen den Spaltblättern ist oft ein wenig violetter Flusspat ausgeschieden, bisweilen auch Epidot. Stellenweise ist der Biotit ein wenig chloritisiert. Hornblende kommt in wesentlich geringerer Menge als Biotit vor, in einigen Dünnschliffen ist sie relativ reichlich vorhanden, während sie in anderen gänzlich fehlt. Es ist dieselbe blaugrüne Varietät mit einem kleinen optischen Achsenwinkel wie im Rönne Granit. Nur einzelne kleine Körner weisen eine Andeutung von Prismenflächen auf, im übrigen ist die Form ganz unregelmässig. Die Hornblende ist häufig mit Biotit verwachsen, und sie schliesst meistens 
zahlreiche Apatitkristalle, Quarzkörner, Zirkon und Orthit ein. Oft ist sie längs der Spaltenrisse etwas umgewandelt. Die Farbe ist in solchen Fällen verblichen, die Ränder manchmal rostfarbig, und hie und da sieht man kleine Ausscheidungen von Kalkspat. Titanit kommt im Svaneke Granit in einer grösseren Menge als in irgend einer der anderen Bornholmer Gesteinsvarietäten vor. In Dünnschliffen des Granits findet man oft Titanitkörner mit einem Querschnitt von $1-2 \mathrm{~mm}$, und an einigen Stellen, z. B. im Granit an der Ostseite von Nörrevig kann man recht wohlentwickelte Kristalle von $4-5 \mathrm{~mm}$ finden. Die grösseren Körner schliessen oft zahlreiche Apatitkristalle und Erzkörner, manchmal auch Biotit und Orthit ein. A patit ist reichlich vorhanden. Epidot tritt in nicht unbeträchtlicher Menge auf, und zwar besonders mit Erz und den übrigen dunklen Mineralien zusammen. Flusspat kann stellenweise derartig angereichert sein, dass er makroskopisch augenfällig wird. Seltener findet man ein wenig Kupferkies, und in einem vereinzelten Falle wurde eine ganz kleine Menge Eisenglanz gefunden.

Tab. XII.

\begin{tabular}{|c|c|c|c|c|c|c|c|}
\hline & $\%$ & $\begin{array}{l}\text { Mol. } \\
\text { quot. }\end{array}$ & $\begin{array}{l}\text { Mol. } \\
\%\end{array}$ & \multicolumn{2}{|c|}{ Norm } & \multicolumn{2}{|l|}{ Modus } \\
\hline $\mathrm{SiO}_{2}$ & 69.06 & 11510 & 75.78 & \multirow{2}{*}{$\begin{array}{l}\mathrm{Q} \\
\mathrm{Or}\end{array}$} & 22.08 & \multirow{3}{*}{$\begin{array}{l}\text { Quarz } \\
\text { Mikroklin } \\
\text { Albit }\end{array}$} & 24.74 \\
\hline $\mathrm{TiO}_{2}$ & 0.65 & 81 & 0.53 & & 30.02 & & 26.27 \\
\hline $\mathrm{Al}_{2} \mathrm{O}_{3}$ & 14.15 & 1387 & 9.13 & $\mathrm{Ab}$ & 31.44 & & 30.87 \\
\hline $\mathrm{Fe}_{2} \mathrm{O}_{3}$ & 1.27 & 79 & - & An & 6.95 & Anorthit & 5.02 \\
\hline $\mathrm{FeO}$ & 2.44 & 339 & 3.27 & $\Sigma$ sal & 90.49 & Hornblende & 2.27 \\
\hline $\mathrm{MnO}$ & Sp. & - & - & & & Biotit & 7.10 \\
\hline $\mathrm{MgO}$ & 0.82 & 205 & 1.35 & $\mathrm{di}$ & 2.32 & Erz & 1.23 \\
\hline $\mathrm{CaO}$ & 2.02 & 361 & 2.38 & hy & 3.27 & Titanit & 1.51 \\
\hline $\mathrm{Na}_{2} \mathrm{O}$ & 3.69 & 595 & 3.92 & $\mathrm{mt}$ & 1.86 & Apatit & 0.26 \\
\hline $\mathrm{K}_{2} \mathrm{O}$ & 5.12 & 545 & 3.59 & il & 1.22 & Kalkspat & 0.34 \\
\hline $\mathrm{P}_{2} \mathrm{O}_{5}$ & 0.12 & 8 & 0.05 & ap & 0.34 & & 99.61 \\
\hline $\mathrm{CO}_{2}$ & 0.15 & 34 & - & $\Sigma$ fem & 9.01 & & \\
\hline $\mathrm{H}_{2} \mathrm{O} \quad 100^{\circ}$ & 0.12 & 67 & - & & 99.50 & & \\
\hline & 99.61 & & 100.00 & $\begin{array}{l}\mathrm{I}^{\prime \prime} .4 . \\
\text { Tosear }\end{array}$ & 3. & & \\
\hline
\end{tabular}

Dichte 2.706

Aktueller Durchschnittsplagioklas $\mathrm{Ab}_{86} \quad \mathrm{An}_{14}$ Aktueller Durchschnittsfeldspat $\mathrm{Or}_{42 \cdot 26} \quad \mathrm{Ab}_{49 \cdot 66} \quad \mathrm{An}_{8 \cdot 08}$

\begin{tabular}{l|c|ccc|ccc|c|c|c|} 
Molekularwerte nach OSANN & $\mathrm{s}$ & $\mathrm{A}$ & $\mathrm{C}$ & $\mathrm{F}$ & $\mathrm{a}$ & $\mathrm{c}$ & $\mathrm{f}$ & $\mathrm{n}$ & $\mathrm{k}$ \\
& 76.3 & 7.5 & 1.6 & 5.4 & 15.5 & 3.5 & 11.0 & 5.2 & 1.42 & \\
Molekularwerte nach NiggLI & $\mathrm{si}$ & $\mathrm{al}$ & $\mathrm{fm}$ & $\mathrm{c}$ & $\mathrm{alk}$ & $\mathrm{k}$ & $\mathrm{mg}$ & $\mathrm{c} / \mathrm{fm}$ & Schnitt & $\mathrm{qz}$ \\
& 320 & 38.5 & 19.5 & 10.0 & 32.0 & 0.48 & 0.29 & 0.51 & 4 & 92
\end{tabular}

Svaneke Granit, Ibs Kirke. Anal. Chr. Detlefsen, Kopenhagen.

Danmarks geologiske Undersogelse. II. R. Nr. 50. 
Die chemische Zusammensetzung des Svaneke Granits geht aus umstehender, vom Laboratorienvorsteher Chr. Detlefsen, Kopenhagen, ausgeführten Analyse (Tab. XII) hervor. Der Mineralbestand ist wie gewöhnlich aus der Analyse und einer geometrischen Messung berechnet.

Basische Ausscheidungen findet man, wie schon erwähnt, recht oft im Svaneke Granit, doch sind sie nicht so zahlreich wie früher angenommen. Im Svaneke Granit sind nämlich häufig grössere und kleinere z. T. abgerundete Fragmente des dunkelgrauen, streifigen Granits eingeschlossen. Diese Einschlüsse, längs deren Ränder der Biotit oft angereichert ist, sind häufig mit basischen Ausscheidungen verwechselt worden. Die von mir untersuchten basischen Ausscheidungen waren alle klein, nur einige Zentimeter im Querschnitt. Sie bestehen überwiegend aus Biotit. Hornblende wurde nur in ziemlich geringer Menge gefunden, dagegen treten Titanit, Erz und Apatit in verhältnismässig grossen Kristallen auf, ferner ein wenig Quarz und eine kleine Menge Mikroklin.

Ein eigentümliches Gestein wurde von Ussing im Svaneke Granit etwas westlich von der Mündung des Baches Vaseaa gefunden. Es hat ein syenitähnliches Aussehen, ist gelblichrot mit einem schwachen violetten Ton. Die mikroskopische Untersuchung ergab, dass das Gestein vorwiegend aus einem ziemlich grobkörnigen Aggregat von Albit bestand. Die einzelnen Albitkörner können einen Querschnitt von 0,5-1 $\mathrm{cm}$ erreichen, das Gestein ist jedoch recht stark zerquetscht und von feingranulierten Zonen durchsetzt; viele Albitkörner sind in mehrere Bruchstücke geteilt. Quarz ist nur in ganz geringer Menge vorhanden, und zwar sekundär an Rissen ausgeschieden. Kalifeldspat fehlt völlig. Die dunklen Mineralien sind fast gänzlich in ein dunkelbraunes oder rostfarbiges Produkt, das zum Teil in die Risse des Gesteins eingedrungen ist, umgewandelt. Von Biotit gibt es nur vereinzelte nachweisbare, jedoch stark umgewandelte Reste. Die Erzkörner sind mit einer Rostkruste überzogen, und der Titanit ist teilweise getrübt. Dagegen haben sich die Apatitkristalle völlig frisch erhalten.

Leider ist es mir nicht gelungen, dieses Gestein wiederzufinden, und Ussing gibt keine weitere Aufklärung über dessen Vorkommen, als dass es in zerfallendem Granit ("Aarsdale Granit«) eingeschlossen ist. Es kann somit im Laufe der Zeit leicht vom Verwitterungsgrus verdeckt worden sein. Es dürfte jedoch kein Zweifel darüber bestehen, dass dieser Einschluss genetisch mit dem Svaneke Granit zusammengehört und als magmatische Ausscheidung aufgefasst werden muss.

Der Svaneke Granit enthält zahlreiche Pegmatitgänge, welche ihrer Zusammensetzung nach dem Muttergestein sehr nahe kommen. An mehreren Stellen, z. B. bei Aarsdale und auf Pærebakken, wurden wohlentwickelte Mikroklinkristalle mit einem Querschnitt von mehreren 
Zentimetern gefunden. Flusspat findet man sehr häufig im Pegmatit. Biotit ist verhältnismässig reichlich vorhanden. Grössere Pegmatitgänge kommen recht häufig vor, so gibt es z. B. bei Möllenakke nördlich von Svaneke einen $4 \mathrm{~m}$ mächtigen Gang. A plit kommt sehr selten vor, und ich habe nur eine einzelne Probe zur Untersuchung gehabt. Diese stammt von den Strandklippen nördlich von Skovsholm Bæk. Das Gestein ist mittelkörnig und besteht vorwiegend aus Mikroklin und Quarz.

Nach Süden zu grenzt der Svaneke Granit an den Nexö Sandstein. Unmittelbar nördlich vom Frederiks Steinbruch bei Nexö und etwas westlicher davon bei Slamregaard ist der Granit durch deutliche Verwerfungen vom Sandstein getrennt. Auf einem dazwischenliegenden Stück scheint nach GrönwaLL (Kartenblatterläuterung, pag. 54) der Sandstein den Granit normal zu überlagern. Nördlich vom Frederiks Steinbruch ragt der Granit wie eine steile Wand über dem Sandstein empor. Die Grenze selber war früher scharf in den Küstenfelsen zu sehen, jetzt ist die Stelle von Sandsteingerölle bedeckt. Der Sandstein ist in einer Entfernung bis zu ein paar Metern südlich von der Verwerfung stark verklüftet und zerspalten. Der Granit nördlich von der Grenze ist ebenfalls von Spalten durchsetzt. Parallel der Verwerfungsgrenze findet sich an dieser Stelle im Granit eine Breccie, der sogenannte »Kupfergang«, der sich dadurch auszeichnet, dass er einige auffallende Mineralien, besonders Flusspat, Quarzkristalle und Kupferkies, enthält.

Die erste Untersuchung dieses Vorkommens wurde von H. C. ØRSTED und L. Esmarch ${ }^{1}$ ) vorgenommen, die einen kleinen, etwa $4 \mathrm{~m}$ tiefen Schacht in die Breccie, die sie »Kobberindlaget« (das Kupferlager) nannten, graben liessen. Sie geben an, dass die Wände im oberen Teil des Schachtes auf der einen Seite aus Sandstein, auf den anderen Seiten aus dem kupferhaltigen Gestein bestanden. In einer Tiefe von einigen Fuss verschwand der Sandstein. Ganz zu oberst fanden sie Feldspat und andere Granitreste sowie Quarzkristalle; weiter nach unten fand sich Chlorit in Menge.

Unter den genannten Mineralien ist Flusspat am reichlichsten vorhanden. Er ist teils grün oder graugrün, teils violett, selten weiss. In Spalten und kleinen Hohlräumen ist der Flusspat häufig in Oktaeder kristallisiert, die in einigen Fällen Zwillinge nach (111) sind. Einzelne kleine Kristalle können recht flächenreich sein. Quar z findet sich stellenweise in Form von kleinen klaren Kristallen, die eine Länge von 1 à $2 \mathrm{~cm}$ erreichen können. Kupferkies kommt nur in geringer Menge vor, am häufigsten als kleine Körner, seltener in Tetraedern kristallisiert. Bleiglanz ist sehr spärlich vorhanden, kann aber in schöne Würfel kristallisiert vorkommen. ØRSTED und EsMaRch bemerken, dass sie gediegenes

1) H. C. Ørsted og L. Esmarch: Beretning. 1820, pag. 27, und 1819, pag. 16. 
Kupfer gefunden haben. Im Mineralogischen Museum ist eine Probe davon bewahrt, das Material ist aber äusserst spärlich, und es ist zweifelhaft, ob es wirklich gediegenes Kupfer enthält. Ferner soll Kupferglanz gefunden worden sein, doch gibt es davon keine Proben. Stellenweise enthält das Gestein eine recht auffallende Menge von braunroten, erdigen oder feinblättrigen Massen, die zum mindesten teilweise aus Roteisenerz oder ähnlichen Ferriverbindungen bestehen.

Das Gestein besteht aus Svaneke Granit. In seiner am stärkesten umgewandelten Gestalt ist der Granit vollständig zerquetscht und wieder zusammengekittet. Das Bindemittel besteht im wesentlichen aus Chlorit, der dem Stein eine dunkle, fast schwarze Färbung gibt. Bruchstücke von Feldspat und Quarzkörnern können doch stets erkannt werden, oft aber ist der Feldspat von Ferriverbindungen, die in sehr fein verteilten Partikelchen in alle Spalten und Risse eingedrungen sind, rotbraun gefärbt. In den nackten Küstenfelsen fand ich feststehenden Svaneke Granit mit charakteristisch abgerundeten Formen ungefähr wie bei Listed und Aarsdale. Die Farbe des Granits ist hier dunkel grünlich, aber die grossen Feldspatkörner sind leicht zu erkennen. Im Dünnschliff erwies sich doch dieses Gestein als recht stark zerquetscht. Biotit fehlte gänzlich, statt seiner waren bedeutende Mengen von Chlorit, die alle feinen Risse im Feldspate ausfüllten, ausgeschieden. Der Chlorit ist teils feinschuppig, teils blättrig. In vielen Blättern traten kleine pleochroitische Höfe ausserordentlich zahlreich auf. Ein Teil der Chloritblätter hat eine violette Interferenzfarbe. Bisweilen sind die Blätter getrübt und zum Teil von Roteisenerzpartikeln braun gefärbt. Offenbar besteht das obengenannte feinblättrige Roteisenerz aus solchen stark imprägnierten Chloritblättern. Erzkörner sind in der Regel recht reichlich vorhanden. Sehr spärlich treten Zirkon und Epidot auf. - Unmittelbar bei diesem Gestein, nur durch eine schmale Spalte von ihm getrennt, fand sich sehr stark brecciierter und umgewandelter Granit, der sich mindestens $6-8 \mathrm{~m}$ nach Süden zu fortsetzte, und zwar bis zum Sandstein; 3-4 m nördlich von der genannten Spalte bestehen die Felsen aus gewöhnlichem Svaneke Granit.

Ein paar einzelne Proben von dieser Stelle bestehen aus einem feinkörnigen, plagioklasreichen Gestein, das deutlich ein umgewandelter Paradisbakke Granit ist. Die untersuchten Proben sind weniger zerquetscht als die obenbeschriebenen. Der Plagioklas tritt in Form von grösseren, einsprenglingsartigen Individuen auf; in der Regel ist er etwas getrübt. Der Biotit ist chloritisiert, einzelne nicht umgewandelte Ueberreste kommen jedoch vor. Die Hornblende ist etwas umgewandelt, aber doch recht stark doppelbrechend; man kann sie leicht an den Spaltenrissen und an der für die Bornholmer Hornblende so charakteristischen 
unregelmässigen und stark durchlöcherten Form erkennen. Zweifellos liegt hier einer der im Svaneke Granit so gewöhnlichen Einschlüsse des älteren Granits vor.

Die Alters- und Grenzbeziehungen des Svaneke Granits zum streifigen Granit.

Der Svaneke Granit ist zu einer Zeit gefördert worden, als der graue streifige Granit bereits als ein festes Gestein (von seiner heutigen Beschaffenheit) vorlag. Dies geht teils aus den zahlreichen eingeschlossenen Fragmenten des älteren streifigen Granits und teils aus dem Umstande hervor, dass der Svaneke Granit an der Grenze gegen den streifigen Granit in eine relativ feinkörnige, aplitische Grenzfazies übergeht.

Die Einschlüsse von streifigem Granit sind ihrer Form und Grösse nach sehr variierend. Die kleinsten sind abgerundete, oft linsenförmige Bruchstücke von Faust- oder Kopfgrösse; die grössten sind unregelmässig begrenzte Blöcke, die einen Querschnitt von 30-40 m erreichen können. An einigen Stellen, z. B. im Steinbruch in der Dorille Klippe bei Listed sah ich mehrere linsenförmige Blöcke in schwach streifigem oder schlierigem Granit eingeschlossen und fand, dass die Linsen ganz zufällige Stellungen im Verhältnis zur Parallelstruktur des Svaneke Granits einnahmen. Aber unmittelbar an der Oberfläche der Fragmente kommt stellenweise etwas Biotitanreicherung vor, was zu der Verwechselung der Fragmente mit basischen Ausscheidungen geführt haben mag. An einigen Stellen findet man einen etwas verwischten Uebergang, meistens aber ist die Grenze scharf, und beide Granite sind bis an den Kontakt unverändert geblieben. Die Einschlüsse bestehen aus demselben grauen streifigen Granit, der den Felsengrund westlich von Svaneke Granit bildet. Wie man sich entsinnen wird, variiert dieser Granit etwas in der Struktur (vgl. pag. 84), und zwar von einem ausgesprochen streifigen Gestein mit einigermassen gleichartiger Korngrösse zu schwach streifigen, schwarz- und weissgeflammten Varietäten mit porphyrischer Struktur. Dieselbe Variation gibt es in den Einschlüssen im Svaneke Granit. Der Erhaltungszustand ist in den Fragmenten im allgemeinen ebenso gut wie im feststehenden streifigen Granit, nur in einzelnen Fällen beobachtet man einen etwas reichlicheren Epidotgehalt.

Das grösste Fragment wurde in zerfallendem Granit vom Aarsdaletypus etwas westlich von der Mündung des Vaseaa bei Listed eingeschlossen gefunden. Es liegt direkt am Strande, teilweise unter Wasser, und misst etwa $30 \times 40 \mathrm{~m}$, die Form ist aber ganz unregelmässig. Die Streifung im Fragment verläuft ungefähr horizontal. An einigen Stellen beobachtet man, dass vom Svaneke Granit kleine Apophysen in Spalten parallel der Schiefrigkeit des Einschlusses hineingehen. Die Grenze zwischen den beiden Granitarten ist zum grössten Teile sehr scharf und 
an einigen Stellen durch Biotitanreicherung markiert, an anderen dagegen beobachtet man eine schlierenartige Verwachsung.

Am gleichen Orte wurden mehrere kleine Einschlüsse von grauem streifigen Granit gefunden, von denen sich einer als stark zerquetscht herausstellte. Der Quarz hat undulöse Auslöschung, und die Plagioklaseinsprenglinge sind etwas getrübt und von zahlreichen Rissen durchsetzt. Die dunken Mineralien sind in derselben Weise wie im früher er-

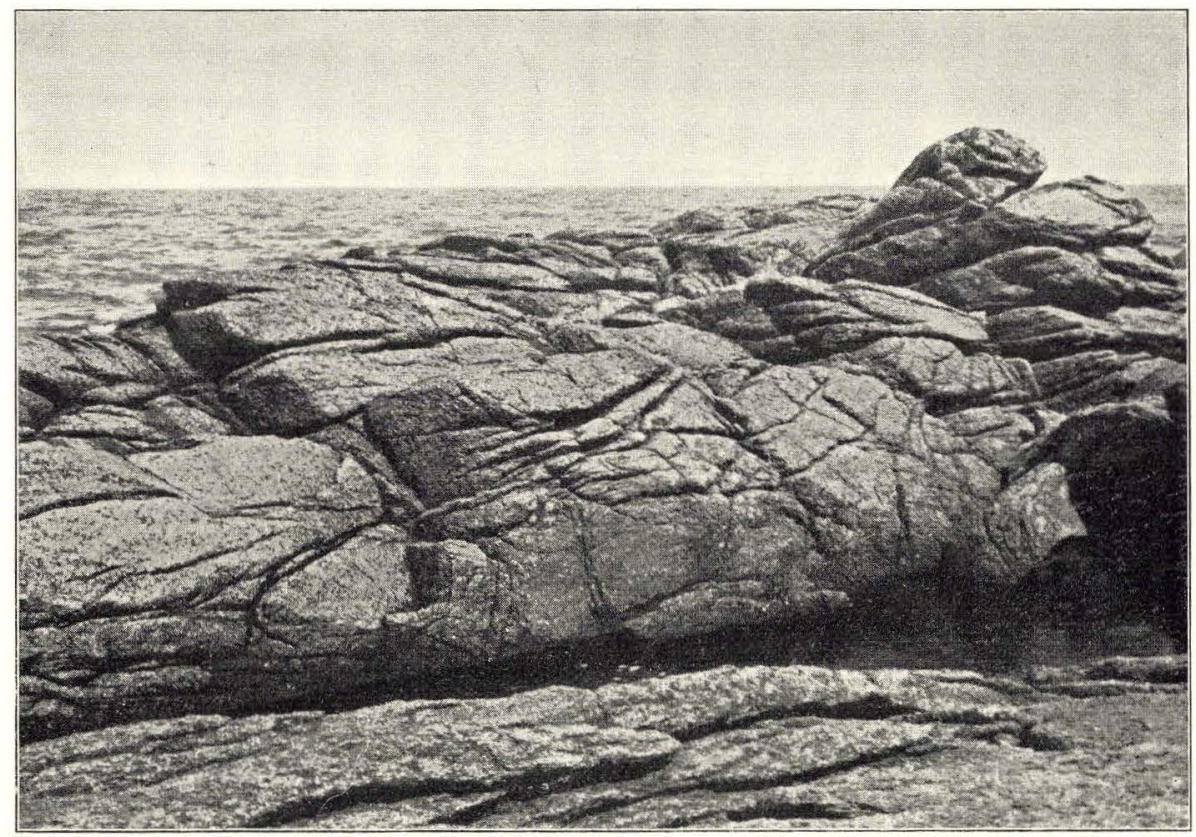

Fig. 26. Svaneke Granit unmittelbar O von der Granitgrenze, Listed.

wähnten Albitgestein in ein rostartiges Produkt umgewandelt, nur ist der Biotit in diesem Falle zum Teil chloritisiert. Der Apatit ist völlig frisch. Die Umwandlungsprodukte haben sich in Rissen im Gestein verbreitet und haben letzterem eine dunkle rotbraune Farbe verliehen, so dass es sich in seinem Aussehen stark vom gewöhnlichen grauen streifigen Granit unterscheidet.

Bei Kodalhuse im nordöstlichen Teile der Paradisbakker fand ich einen Block von typischem schwarz- und weissgeflammtem Paradisbakke Granit im Svaneke Granit vom gewöhnlichen grobkörnigen Typus eingeschlossen. Das Fragment hatte eine sehr unregelmässige Form und einen Diameter von ungefähr $4 \mathrm{~m}$. Die Grenze zwischen den beiden Graniten war teils scharf und ohne Uebergang, teils gab es eine schlierenartige Verwachsung.

Der Kontakt zwischen dem Svaneke Granit und dem streifigen Granit 
ist nur in den Uferfelsen im westlichen Teile des Fischerdorfes Listed gut aufgeschlossen; an mehreren Stellen südlich von Listed treten aber die beiden Granite in einer so geringen Entfernung von einander zutage, dass die Grenze ohne Schwierigkeiten auf der Karte eingezeichnet werden kann, so z. B. auf Hagelbjerg SSW von Ibs Kirke und in den Paradisbakker etwa $100 \mathrm{~m}$ westlich von Kodalhuse; ferner $400-500 \mathrm{~m}$ westlich von Helvedesgaarden (Höllenhof), wo die Grenze auf einer

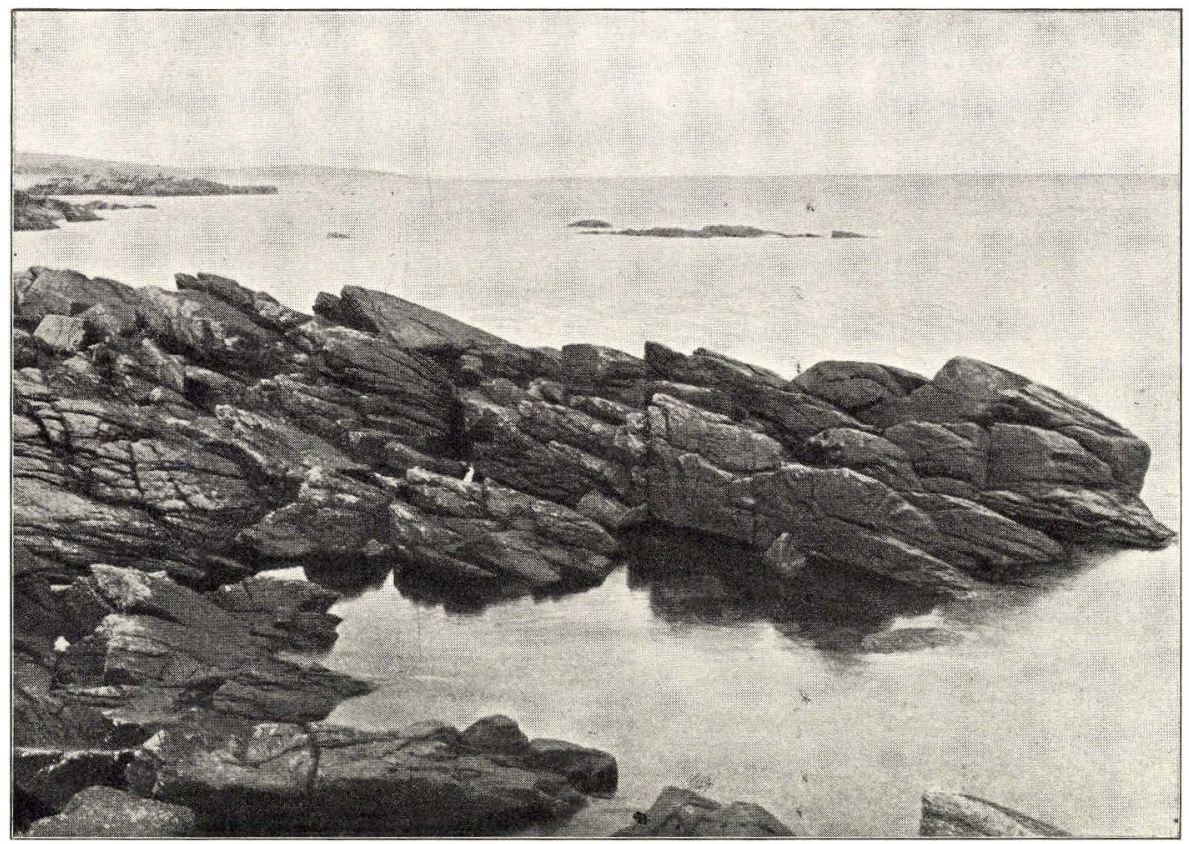

Fig. 27. Streifiger Granit unmittelbar W von der Granitgrenze, Listed.

Strecke von etwa $100 \mathrm{~m}$ eine öst-westliche Richtung hat. Etwa $400 \mathrm{~m}$ direkt südlich von Aspegaard fand ich den Kontakt, jedoch schlecht aufgeschlossen. Der Paradisbakke Granit scheint an dieser Stelle besonders arm an hellen aplitischen Schlieren zu sein, stimmt aber sonst in der Struktur und im Mineralbestand völlig mit dem Granit im Steinbruch bei Præstebo überein. Der Svaneke Granit ist hier ein wenig heller als sonst und etwas porphyrisch entwickelt.

In den Uferfelsen bei Listed macht sich die Granitgrenze recht deutlich im Terrain geltend, da der Svaneke Granit hier ziemlich stark zerfällt und daher einigermassen weiche, abgerundete Oberflächenformen hat, während der streifige Granit scharfeckige Klippen und Schären bildet (siehe Fig. 26 und Fig. 27). Der Kontakt ist nicht so scharf wie zwischen dem Hammer- und dem Vang Granit und in Einzelheiten sehr gebuchtet, doch lässt er sich ganz gut verfolgen. Der Svaneke Granit bewahrt seine 
grobkörnige Struktur ungefähr bis an die Grenze, ist aber in der Nähe derselben etwas pegmatitschlierig. Unmittelbar am Kontakt geht der Svaneke Granit dagegen in eine relativ feinkörnige, gänzlich ungestreifte und manchmal schwach porphyrische Grenzfazies über, der es stellenweise fast ganz an dunklen Mineralien fehlt. Dies Grenzgestein besteht überwiegend aus Mikroklinperthit und Quarz (Taf. VI, Fig. 6). Der Quarz hat dieselbe undulöse Auslöschung und tritt in denselben Aggregaten auf wie im Hauptgestein, nur ist der Quarzgehalt wesentlich grösser. Der Mikroklinperthit bildet unregelmässig begrenzte Körner von wechselnder Grösse, die einen Querschnitt von etwa 0,5 cm erreichen können. Häufiger als im Hauptgestein schliesst der Mikroklin kleine rundliche Quarzkörner ein, welche gruppenweise gleichzeitig auslöschen. Myrmekit ist reichlich vorhanden. Im übrigen ist Plagioklas spärlich vorhanden, doch sieht man einige unregelmässig begrenzte Oligoklaskörner mit deutlich markiertem Albitsaum; sie können einen Querschnitt von ein paar Millimetern erreichen. An dunklen Mineralien gibt es nur einige wenige grünliche Biotitblätter sowie sehr spärlich Erz, Apatit und Titanit, letzterer zum Teil um Erzkörner herum. Flusspat ist nicht beobachtet worden.

Die Mächtigkeit dieses Grenzgesteins lässt sich nicht genau feststellen. In der oben beschriebenen rein aplitischen Form erreicht es nur eine geringe Stärke von einigen Zentimetern bis etwa $0,5 \mathrm{~m}$, es durchsetzt aber den streifigen Granit in zahlreichen Apophysen und unregelmässigen Schlieren, die $4-5 \mathrm{~m}$ in den grauen streifigen Granit hinein verfolgt werden können. Das Magma des Svaneke Granits ist offenbar in den grauen Granit einigermassen parallel der Schiefrigkeit desselben hineingedrungen, so dass durch teilweise Aufschmelzung des älteren Granits ein Mischgestein von schnell wechselnder Zusammensetzung entstanden ist. Dieses Mischgestein trägt jedoch zum grossen Teile den Charakter des streifigen Granits. Stellenweise finden sich fast unveränderte Partien desselben, stellenweise Teile, die sich nur durch einen etwas grösseren Quarzgehalt vom angrenzenden grauen streifigen Granit unterscheiden. In diesen Partien ist der Plagioklasgehalt beträchtlich. An anderen Stellen sind aplitische oder pegmatitische Schlieren vorherrschend, doch auch in diesen Partien beobachtet man zerstreut glimmerreiche Schlieren, so dass die Streifung des grauen Granits sich durch diese Zone hindurch fortsetzt. Hie und da findet man im grauen streifigen Granit, oft mehrere Meter vom Kontakt entfernt, kleine grobkörnige Klumpen oder Schlieren mit den für den Svaneke Granit charakteristischen grossen rötlichen Mikroklinkristallen.

Ussing, der als erster die Granitgrenze bei Listed gefunden hat, erwähnt dies Gestein in der Grenzzone nicht als ein Mischgestein, sondern betont nur dessen streifige Struktur. Er behandelt diese Grenze nur 
kurz in einer Erörterung der Parallelstruktur des streifigen Granits, die seiner Auffassung nach nur in den wenigsten Fällen von Bewegungen im Granitmagma zu einer Zeit, wo dieses noch nicht völlig erstarrt war, herrühren kann ${ }^{1}$ ). Dagegen nimmt er an, dass die Streifung in den meisten Fällen durch starken Druck und durch Bewegungen in der Erdkruste, welche erst $\mathrm{na} \mathrm{ch}$ der Entstehung des Granits stattgefunden haben, entstanden ist, und er begründet seine Ansicht damit, dass die Streifung oft auf grosse Strecken hin in derselben Richtung verläuft, und dass man bei Listed beobachten kann, wie sie sich in den angrenzenden Svaneke Granit hinein fortsetzt, wo sie sich jedoch in weiterer Entfernung von der Grenze verliert.

Dieser Auffassung Ussing's kann ich nicht beipflichten. Dass der streifige Granit zur Zeit der Förderung des Svaneke Granits schon als festes Gestein mit seiner heutigen Struktur vorlag, geht deutlich aus dem Umstande hervor, dass die eingeschlossenen Fragmente dieselbe Struktur haben wie der unmittelbar angrenzende streifige Granit. Ich bin vielmehr der Ansicht, dass die Parallelstruktur des streifigen Granits in wesentlichem Grade die Bildung der schlierigen und streifigen Kontaktzone bedingt hat, indem sie dem Eindringen des Svaneke Granit-Magmas parallel der Schiefrigkeit den Weg geebnet hat. Das Svaneke GranitMagma hat offenbar eine relativ niedrige Temperatur gehabt, nachdem es seinen jetzigen Platz eingenommen hatte. Hierauf deuten die verhältnismässig geringe Mächtigkeit der Kontaktzone sowie der Umstand, dass die eingeschlossenen Fragmente des streifigen Granits nur in geringem Masse der Resorption ausgesetzt gewesen sind. Nur die kleineren Fragmente haben eine abgerundete Form erhalten, ihr Mineralbestand ist jedoch unverändert geblieben, und nur in einzelnen Fällen wurden kleine Apophysen des Svaneke Granits in den Fragmenten gefunden.

\section{Das Zerfallen des Svaneke Granits.}

Wie schon erwähnt, ist der Svaneke Granit an vielen Stellen stark geneigt zu zerfallen, und namentlich bei den Fischerdörfern Aarsdale und Listed ist diese Neigung so auffallend, dass man den Granit an diesen Stellen sogar für eine besondere Modifikation, den "Aarsdale Granit» angesehen hat. Durch den Zerfall des Granits sind mächtige Grusschichten entstanden, während andererseits zahlreiche grosse, runde, widerstandsfähigere Felsenblöcke von eigentümlicher wollsackähnlicher Form stehen geblieben sind. Namentlich unmittelbar nördlich von Aarsdale, wo die Wellen den Grus zum Teil weggespült haben, erhält die Landschaft dadurch einen eigenartigen Charakter (Fig. 28). Der Grus besteht hauptsächlich aus Mikroklin, teils aus Fragmenten von

1) Ussing: Danmarks Geologi. D. G. U. III. R. Nr. 2. 2. Udg., 1904, pag. 36. 
grösseren Mikroklinkristallen, teils aus kleineren Granitstücken, in denen jedoch dunkle Mineralien spärlich vorkommen und der Biotit etwas verblichen ist. Die Grösse dieser Bruchstücke ist ausserordentlich variierend, doch haben die meisten von ihnen Nuss- bis Erbsengrösse. Feinerer Sand und Staub kommt im Gruse fast nicht vor. Die widerstandsfähigen Granitklumpen haben eine abgerundete, rauhe Oberfläche; ihr Zerfall geht derart vor sich, dass konzentrische Schalen sich allmählich abtrennen und zerbröckeln. Ussing ${ }^{1}$ ) war der Ansicht, dass der "Aarsdale Granit« nördlich von Aarsdale durch einen Dislokationsspalt, durch den ein Diabasgang hervorgedrungen ist, vom gewöhnlichen Svaneke Granit getrennt sei. Er begründet diese Annahme damit, dass der Svaneke Granit jenseits dieses Spaltes im Gegensatze zum Aarsdale Granit scharfeckige Klippenformen und eine glatte Oberfläche hat und von zahllosen Rissen durchsetzt ist. Ich kann dieser Auffassung Ussing's nicht beipflichten. Dagegen hat GRönwalL ${ }^{2}$ ) zweifellos recht, wenn er meint, dass der Zerfall in sehr wesentlichem Grade von der durchgreifenden Verklüftung des Granits bedingt ist. Die wollsackförmigen Ueberreste bilden derartige Partien des Granits, welche gerade infolge ihrer Armut an Rissen dem Zerfall grösseren Widerstand leisten.

Das Zerfallen des Svaneke Granits ist in der Tat ein weit verbreiteteres Phänomen, als es aus der vorliegenden geologischen Literatur hervorgeht. Folgt man der Küste von Listed nach Svaneke und weiter gegen Süden, findet man an zahlreichen Stellen zwischen mehr oder weniger abgerundeten Klippen grössere und kleinere Grusmengen, und wie schon erwähnt, beobachtet man sehr oft abbröckelnde Zonen längs der Risse in dem sonst vollkommen frischen Granit (Fig. 23 und 24). Rawert und Garlie ${ }^{3}$ ) berichten, dass bei der Anlage des SvanekeHafens im Jahre 1815 die Arbeit wesentlich dadurch erleichtert wurde, dass der Granit dort, wo das Hafenbassin ausgegraben wurde, sehr mürbe und stark zerfallen war. Auch der Glimmer war beinahe gänzlich verwittert.

Noch grössere Grusmengen als bei Aarsdale und Listed gibt es nördlich von Grisby, wo der Grus in mehreren grossen Gruben gewonnen und in recht beträchtlichen Quantitäten als Wegebaumaterial u. dergl. ausgeführt wird; besonders häufig wird er als Kies für Fusspfade verwendet.

Auch nördlich von dem von Ussing angenommenen Verwerfungsspalt, an der Mündung des Baches Skovsholm Bæk, hat der Granit die Neigung zu zerfallen. Etwa $300 \mathrm{~m}$ nördlicher, in Hesteklöven, gibt es stark ver-

1) Ussing. D. G. U. II. R. Nr. 10. 1899, pag. 98-99.

$\left.{ }^{2}\right)$ Grönwall. Kartenblatterläuterung, pag. 13.

${ }^{3}$ ) Rawert und Garlieb: Bornholm beskreven paa en Reise i Aaret 1815. Kjöbenhavn 1819, pag. 71. 
klufteten und zum Teil zerfallenden Svaneke Granit. Hier findet man stellenweise den Granit durchsetzt von zahllosen, dicht beieinander liegenden Rissen in vielen verschiedenen Systemen mit Klumpen und Linsen von relativ frischem Granit (Fig. 29). Am meisten machen sich die Risse parallel der Längsrichtung der Linsen bemerkbar, doch fällt auch ein anderes, ungefähr normal dazu verlaufendes Spaltsystem recht stark auf und begrenzt die Linsen. Diese haben wie die "Wollsäcke«

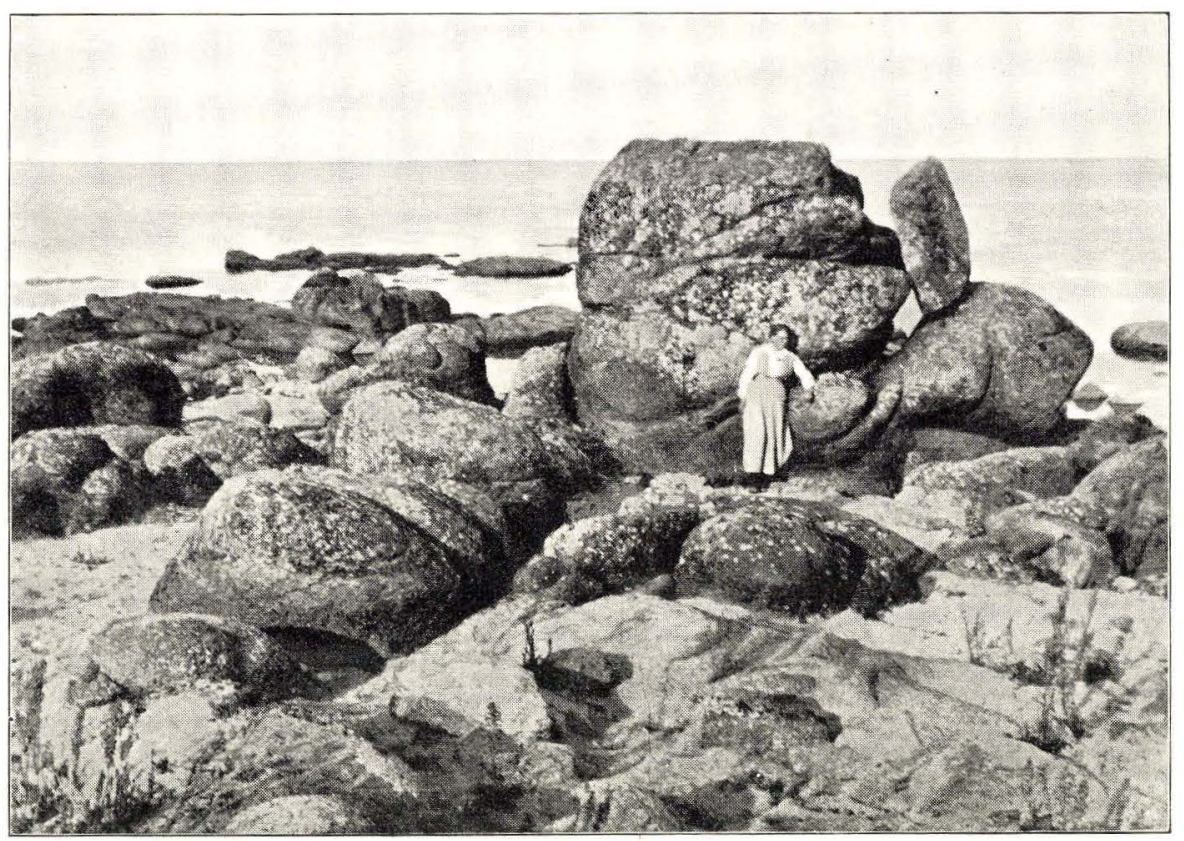

Fig. 28. Granitfelsen nördlich von Aarsdale. Im Vordergrunde Kies.

bei Aarsdale konzentrische Abschalung. Nicht weit davon entfernt ist der Granit vorwiegend frisch, jedoch stark verkluftet und in den Rissen bröckelig. In diesem kompakten Granit sieht man mehrere Rutschflächen. Im südlichen Teile des Svaneke Granits kommt zerfallender Granit etwas seltener vor, doch wurde ein solcher an mehreren Stellen, z. B. bei Sortegaard nördlich von Nexö und in den Paradisbakker angetroffen.

Die konzentrische Abschalung, die im Svaneke Granit zu beobachten ist, darf nicht einer besonderen Kugel- oder Klumpenstruktur zugeschrieben werden. Weder makroskopisch noch mikroskopisch kann in dem halbzerfallenen Granit irgendeine abweichende Struktur nachgewiesen werden. Die Abschalung rührt zweifellos von der gewöhnlichen Oberflächenverwitterung her, welche an mehreren anderen Stellen auf Bornholm den Granit in derselben Weise beeinflusst hat, so z. B. am 
Klint südlich von Aakirkeby. Namentlich am letztgenannten Ort, wo der Zerfall stark vorgeschritten ist, und wo die abgetrennten Schalen verschiedene Winkel zur Parallelstruktur des Granits bilden, ist es ganz evident, dass die Abschalung von ursprünglichen Verklüftungsrissen ausgegangen ist (vgl. oben pag. 86). Dass dasselbe bei Aarsdale der Fall ist, geht ferner daraus hervor, dass die frischen »Kerne« an einigen Stellen aus eingeschlossenen Fragmenten von grauem streifigem Granit bestehen. Man findet dann, dass nicht nur der Aarsdale Granit um das Fragment herum, sondern auch die äussere Zone desselben sich in konzentrischen Schalen löst.

Die Ursache zum Zerfall des Svaneke Granits muss somit meiner Ansicht nach in erster Linie der Verklüftung des Granits zugeschrieben werden, welche an einigen Stellen ausserordentlich durchgreifend ist und einer tiefgehenden atmosphärischen Verwitterung den Weg gebahnt hat. Die vorhandenen Rutschflächen zeigen, dass die Verklüftung jedenfalls zum Teil von Erdkrustebewegungen herrührt, die später als die Erstarrung des Granits vor sich gegangen sind. Dass glattpolierte Rutschflächen sich in den am stärksten verwitterten Teilen des Granits nicht nachweisen lassen, liegt in der Natur der Sache. Was die früher erwähnten Vorkommen von zerfallendem Granit betrifft, darf sicher angenommen werden, dass der Zerfall einzig und allein der atmosphärischen Verwitterung, die durch starke Verklüftung im Granit befördert wird, zuzuschreiben ist. Diese Vorkommen liegen teils in der Umgegend von Aakirkeby, teils an der NO-Küste bei Kobbeaa und an der Helligdomsklippe sowie im Walde bei Kanegaard in der Nähe der Südspitze der Kaolinlagerstätte, d. h. entweder in unmittelbarer Nähe von sicher nachgewiesenen Verwerfungslinien oder an Stellen, wo auch andere Gründe es wahrscheinlich machen, dass der Untergrund stark zerklüftet ist.

Wenn aber der Svaneke Granit in einem so viel höheren Grade als der Granit an den genannten Stellen dem Zerfall zum Opfer gefallen ist, so muss diese Tatsache zweifellos der speziellen Struktur dieses Granits zugeschrieben werden, welche es bewirkt, dass die einzelnen Bestandteile sich verhältnismässig leicht voneinander trennen. Hierzu tragen die abgerundete Form und die recht ebenmässige Oberfläche der grossen Feldspatkörner bei. Wo eine Zwischenmasse auftritt, besteht diese teils aus Quarzaggregaten, teils aus Haufen von dunklen Mineralien und teils aus einem feinkörnigen Gemenge, worin Plagioklas eine wichtige Rolle spielt. In einem solchen Gestein werden Temperaturvariationen oder kleine Erdkrustebewegungen leicht feine Risse hervorbringen, durch welche das Wasser hineindringt und eine chemische Verwitterung von Plagioklas und Biotit veranlässt. Dadurch wird der Zusammenhang des Gesteins zerstört, und die übrigen, frischen Mineralien fallen aus- 
einander. Durch Experimente habe ich vor einigen Jahren nachgewiesen, dass schon eine Destruktion des Biotits den inneren Zusammenhang des Granits in wesentlichem Grade herabsetzt. Ein Stück eines frischen Kernes in zerfallendem Granit von Aarsdale wurde 4 Monate hindurch mit $3 \%$ Salzsäure ausgelaugt und danach gründlich mit destilliertem Wasser gewaschen. Nach dieser Behandlung war der Biotit

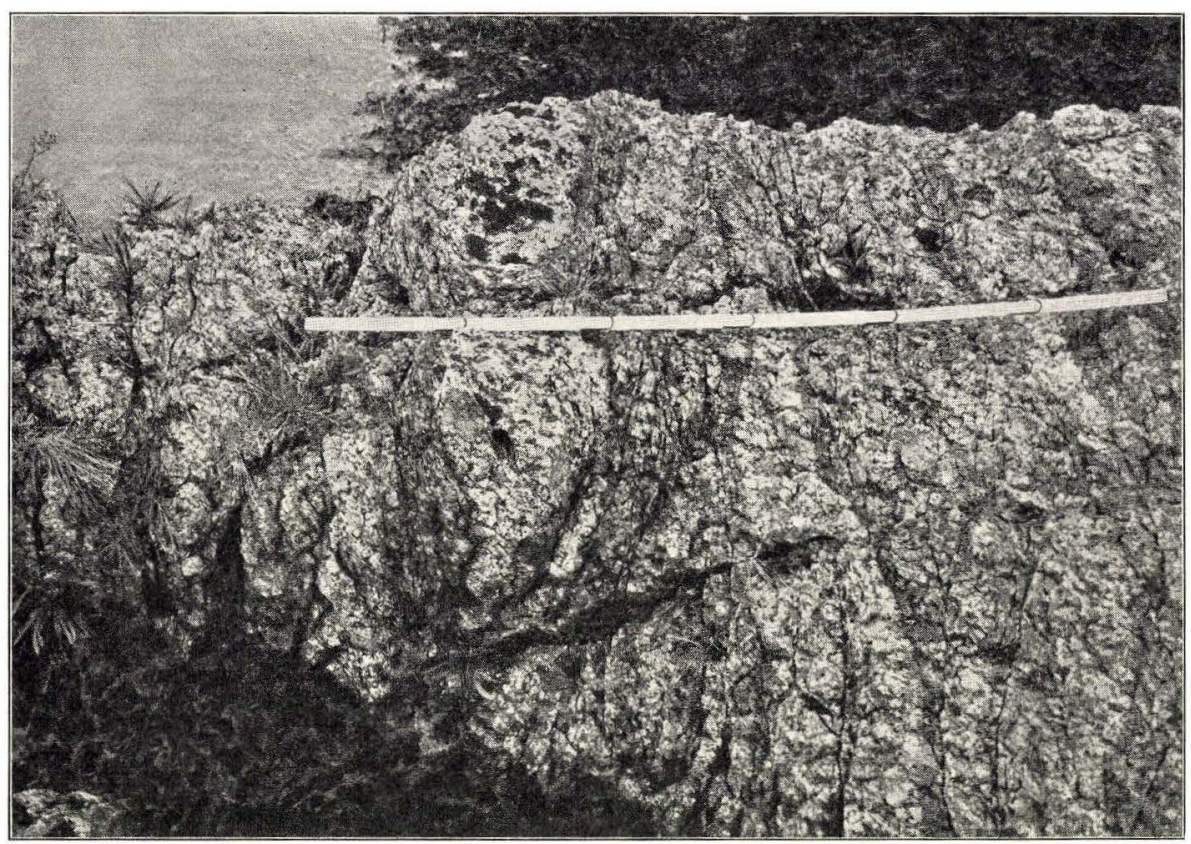

Fig. 29. Zerbröckelnder Svaneke Granit, Hesteklöven N von Aarsdale.

völlig farblos, ganz ohne Doppelbrechung, und die Lichtbrechung war auf 1,46 gesunken. Er bröckelte in kleinen, sehr mürben Blättern von 1-2 mm Querschnitt ab. Der Granit liess sich danach leicht mit den Fingern zerbrechen, was vorher nicht möglich war. Ich meine daher, dass die Struktur des Gesteins an sich von wesentlicher Bedeutung für den starken Zerfall des Granits ist. Im übrigen fand ich diese Auffassung bestätigt in einer unlängst von EsKoLA ${ }^{1}$ ) veröffenlichten Abhandlung, in welcher er die ausgesprochene Neigung des Rapakiwis zum Zerfallen in analoger Weise deutet.

[) Pentti Eskola: On the disintegration of Rapakiwi. C. R. Soc. géol. de Finlande. No. 3. 1930. 


\section{Die chemische Differentiation und die Relationen der Granitvarietäten.}

Ihrer Zusammensetzung nach verhalten sich die Bornholmer Granite wie verschiedene Glieder einer kontinuierlichen Reihe von Gesteinen, deren Endglieder einerseits aus den hellen, ziemlich quarzreichen, alkalinen Graniten von Hammeren und Almindingen, andererseits aus dem kalkfeldspatreicheren, dunkelgrauen Rönne Granit bestehen. Die Reihe, welche durch die Analysen dargestellt wird (Tab. XIII), weist keine weitgehende Differentiation auf, urteilt man aber nach der mikroskopischen Untersuchung der untergeordnet auftretenden, feinkörnigen hellen Granitvarietäten, so gehören diese stellenweise einem noch kalireicheren Typus als dem des Hammer- und Alminding Granits an, da sie durch einen vorherrschenden Gehalt an sehr perthitarmem Mikroklin und durch einen sehr geringen Gehalt an dunklen Mineralien charakterisiert werden. Ganz besonders gilt dies von der feinkörnigen Grenzfazies des Hammer Granits, in welcher der Plagioklas stark zurücktritt. Dunkle Gesteine von dioritischer oder gabbroider Zusammensetzung, die im süd- und westschwedischen Grundgebirge so häufig auftreten, fehlen gänzlich auf Bornholm.

In erster Linie zeigen die Analysen, dass die Bornholmer Granite alle im Bereich des Eruptiv-Feldes der Gesteine liegen. Die nahe Verwandtschaft der Granitvarietäten lässt sich am anschaulichsten durch Eintragung der Osann'schen Werte (Tab. XIV) in das bekannte Dreieck (Fig. 30) darstellen. Die Analysenpunkte sammeln sich hier wesentlich innerhalb des für die Alkalikalkgesteine charakteristischen Feldes; die hellen Varietäten sind typische Alkalikalkgranite, während die hornblende- und plagioklasreicheren Gesteinsabarten sich dem Syenit und Quarzdiorit nähern. Eine einzelne Varietät, nämlich der Vang Granit am Pegmatit, steht infolge seines niedrigen c-Wertes den Alkaligesteinen nahe, diese Analyse betrifft aber nur eine Gesteinszusammensetzung von sehr untergeordnetem und rein lokalem Auftreten. 
Tab. XIII.

\begin{tabular}{l|r|c|r|r|r|r|r|r|r|r|r}
\hline & 1 & 2 & 3 & 4 & 5 & 6 & 7 & 8 & 9 & 10 & 11 \\
\hline \hline $\mathrm{SiO}_{2}$ & 74.17 & 73.77 & 72.82 & 69.06 & 69.01 & 66.99 & 65.40 & 65.39 & 64.49 & 64.13 & 63.54 \\
$\mathrm{TiO}_{2}$ & 0.40 & 0.32 & 0.63 & 0.65 & 0.97 & 0.71 & 1.01 & 0.28 & 1.22 & 0.99 & 1.15 \\
$\mathrm{Al}_{2} \mathrm{O}_{3}$ & 12.89 & 11.97 & 13.42 & 14.15 & 12.16 & 13.00 & 14.73 & 14.38 & 13.67 & 13.57 & 14.23 \\
$\mathrm{Fe}_{2} \mathrm{O}_{3}$ & 0.69 & 1.84 & 2.33 & 1.27 & 2.07 & 2.98 & 1.14 & 7.85 & 1.63 & 2.40 & 3.56 \\
$\mathrm{FeO}$ & 1.07 & 0.78 & - & 2.44 & 2.40 & 2.23 & 2.92 & - & 4.42 & 4.11 & 3.40 \\
$\mathrm{MnO}$ & $\mathrm{Sp}$ & - & 0.24 & $\mathrm{Sp}$. & 0.06 & 0.11 & 0.06 & 0.00 & 0.14 & 0.06 & 0.24 \\
$\mathrm{MgO}$ & 0.28 & 0.23 & 0.13 & 0.82 & 0.93 & 0.65 & 1.02 & 1.12 & 1.38 & 1.45 & 0.91 \\
$\mathrm{CaO}$ & 1.14 & 1.10 & 1.61 & 2.02 & 2.28 & 2.64 & 2.78 & 3.53 & 3.12 & 2.91 & 3.27 \\
$\mathrm{Na}_{2} \mathrm{O}$ & 3.18 & 2.75 & 3.25 & 3.69 & 3.65 & 3.28 & 3.54 & 3.64 & 3.57 & 4.31 & 3.12 \\
$\mathrm{~K}_{2} \mathrm{O}$ & 5.72 & 5.61 & 5.47 & 5.12 & 4.81 & 4.39 & 4.31 & 4.40 & 4.40 & 3.46 & 6.09 \\
$\mathrm{P}_{2} \mathrm{O}_{5}$ & 0.04 & - & - & 0.12 & 0.11 & 0.57 & 0.19 & - & 0.58 & 0.56 & 0.23 \\
$\mathrm{CO}_{2}$ & 0.19 & - & - & 0.15 & 0.42 & - & 0.68 & - & - & 0.59 & - \\
$\mathrm{H}_{2} \mathrm{O}$ über $110^{\circ}$ & - & 0.49 & - & - & 0.42 & 0.70 & 1.58 & - & 1.11 & 1.45 & - \\
$\mathrm{H}_{2} \mathrm{O}$ unter $110^{\circ}$ & 0.08 & 0.65 & - & 0.12 & 0.44 & 0.78 & 0.55 & - & 0.46 & 0.37 & 0.27 \\
$\mathrm{Glüh}^{\circ}$ rülust & - & - & 0.21 & - & - & - & - & 0.13 & - & - & - \\
\hline
\end{tabular}

1. Alminding Granit, Bjergbakke. Anal. Chr. Detlefsen.

2. Hammer Granit. Anal. M. Dittrich.

3. Hammer Granit. Anal. Chr. Detlefsen.

4. Svaneke Granit, Ibskirke. Anal. Chr. Detrefsen.

5. Vang Granit am Pegmatit, "Klondyke». Anal. M. Diтtrich.

6. Vang Granit, „Klondyke». Anal. M. Dittrich.

7. Paradisbakke Granit. Anal. M. Ditrrich.

8. Rönne Granit, Klippegaard. Anal. Chr. Detlefsen.

9. Rönne Granit. Anal. M. Dittrich.

10. Rönne Granit am Pegmatit. Anal. M. Diтtrich.

11. Uebergangsgestein des Rönne Granits, Store Almegaard. Anal. Chr. Detrefsen.

Tab. XIV.

\begin{tabular}{|c|c|c|c|c|c|c|c|c|c|c|}
\hline & $\mathrm{s}$ & A & C & $\mathrm{F}$ & a & c & f & $\mathrm{n}$ & $\mathrm{k}$ & Reihe \\
\hline 1. Alminding Granit (Detlefsen) & 81.1 & 7.3 & 0.9 & 2.4 & 20.5 & 2.5 & 7.0 & 4.6 & 1.68 & $\gamma$ \\
\hline 2. Hammer Granit & 81.5 & 6.9 & 0.9 & 3.0 & 19.0 & 2.5 & 8.5 & 4.3 & 1.77 & $\delta$ \\
\hline 3. Hammer Granit & 79.9 & 7.2 & 1.4 & 2.8 & 19.0 & 3.5 & 7.5 & 4.7 & 1.63 & $\gamma$ \\
\hline 4. Svaneke Granit & 76.3 & 7.5 & 1.6 & 5.4 & 15.5 & 3.5 & 11.0 & 5.2 & 1.42 & $\gamma$ \\
\hline 5. Vang Gr. a. Pegmat. (Ditтrich) & 76.7 & 7.3 & 0.6 & 7.6 & 14.0 & 1.0 & 15.0 & 5.3 & 1.47 & $\gamma$ \\
\hline 6. Vang Granit $\left(\begin{array}{lll} & -\end{array}\right)$ & 75.6 & 6.7 & 1.9 & 7.1 & 13.0 & 3.5 & 13.5 & 5.3 & 1.48 & $\gamma$ \\
\hline 7. Paradisbakke Granit ( & 74.4 & 7.0 & 2.8 & 6.0 & 13.0 & 5.5 & 11.5 & 5.5 & 1.40 & $\beta$ \\
\hline 8. Rönne Granit & 71.5 & 6.9 & 2.3 & 10.1 & 10.5 & 3.5 & 16.0 & 5.6 & 1.28 & $\beta$ \\
\hline 9. Rönne Granit & 72.4 & 6.9 & 2.0 & 9.6 & 11.5 & 3.0 & 15.5 & 5.5 & 1.31 & $\beta$ \\
\hline $\begin{array}{l}\text { 10. Rönne Gr.a.Pegmat. ( }- \text { - }) \\
\text { 11. Uebergangsgestein d. Rönne }\end{array}$ & 72.1 & 7.1 & 1.8 & 10.0 & 11.0 & 3.0 & 16.0 & 6.5 & 1.29 & $\beta$ \\
\hline (DETLEFSEN) & 71.3 & 7.6 & 1.6 & 10.1 & 12.0 & 2.5 & 15.5 & 4.4 & 1.21 & $\delta$ \\
\hline
\end{tabular}

Molekularwerte nach OSANN. 
Die Beziehungen der Granite zu den Alkaligesteinen und Alkalikalkgesteinen treten deutlicher hervor, wenn die Analysen ins NIGGLI'sche System eingeordnet werden (Tab. XV). Es stellt sich dann heraus, dass die Gesteine eine Serie von Mischungscharakter bilden. Die Hammerund Alminding Granite gehören dem engadinitischen Magmentypus an, doch bemerkt man, dass Analyse Nr. 2 ebenso gut zu den rapakiwitischen

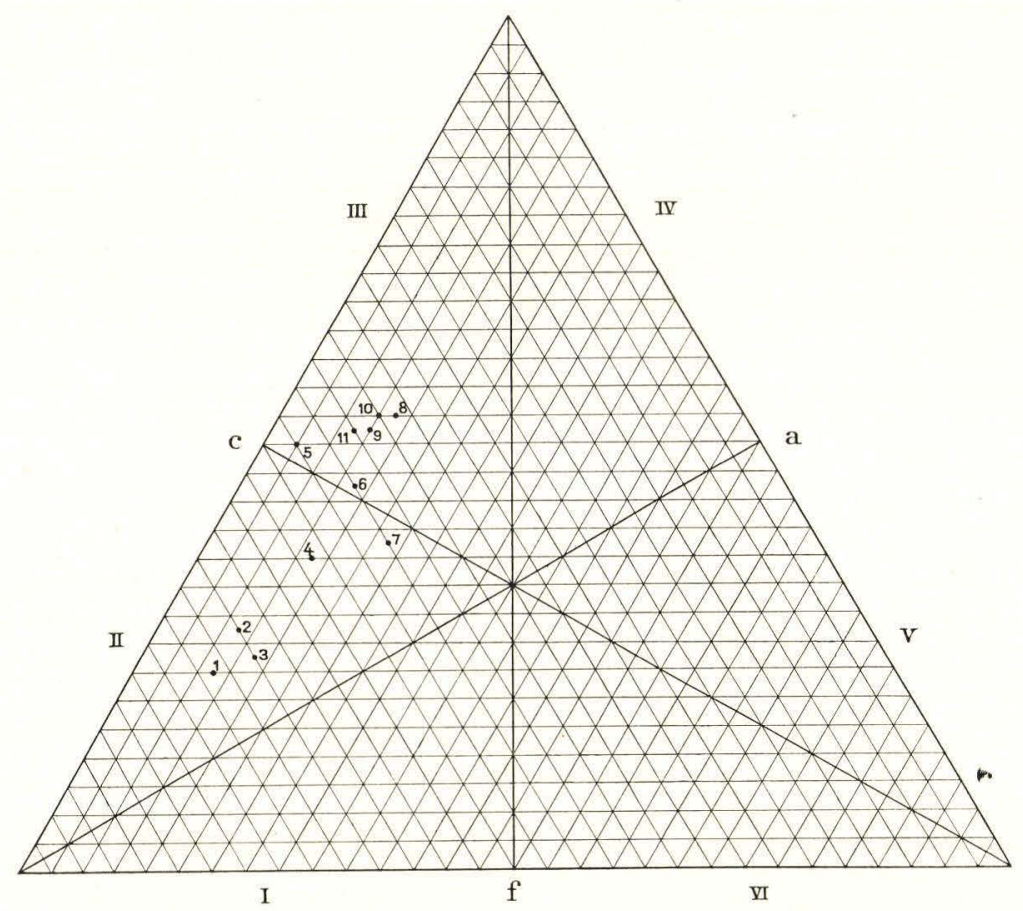

Fig. 30. Projektion der Osann'schen Werte.

Magmen gerechnet werden könnte. Dagegen weist Analyse Nr. 3 den Hammer Granit entschieden den engadinitischen Magmen zu. Der Rönne Granit gehört zum normalgranitischen Magmentypus, doch zeigen die Analysen Nr.9 und 10 durch ihren hohen alk-Wert eine Tendenz nach den syenitgranitischen Magmen zu. Die übrigen Gesteinsarten: der Svaneke Granit, der Vang Granit, der Paradisbakke Granit sowie das Uebergangsgestein des Rönne Granits müssen dagegen zu Niggli's Kalireihe oder der mediterranen Reihe gerechnet werden. Das intermediäre Verhältnis zwischen $\mathrm{Na}_{2} \mathrm{O}$ und $\mathrm{K}_{2} \mathrm{O}$ geht ganz klar aus dem k-mg Diagramm (Fig. 31) hervor, jedoch zeigt dieses deutlich die für die Alkalikalkgesteine charakteristische Biegung des Punktfeldes nach oben links gegen die mg-Achse. Eine vollständige Differentiation in $\mathrm{K}_{2} \mathrm{O}$ und $\mathrm{Na}_{2} \mathrm{O}$-Gesteinen wurde nur in Aplitgängen in der Gegend westlich von Aakirkeby beobachtet; dieser Unterschied in der Zusammen- 
Tab. XV.

\begin{tabular}{|c|c|c|c|c|c|c|c|c|c|c|c|}
\hline & si & al & $\mathrm{fm}$ & c & alk & $\mathrm{k}$ & $\mathrm{mg}$ & $\mathrm{c} / \mathrm{fm}$ & $\left|\begin{array}{l}\vec{\Xi} \\
\vec{\Xi} \\
0 \\
\tilde{S}\end{array}\right|$ & $\mathrm{qz}$ & $\begin{array}{l}\text { Magmen- } \\
\text { typen }\end{array}$ \\
\hline 1. Alminding Gr. (Detlefsen) & 425 & 43.5 & 10.5 & 7.0 & 39.0 & 0.54 & 0.23 & 0.67 & $1 / 5$ & 169 & engadinitisch \\
\hline 2. Hammer Gr. & 440 & 42.0 & 14.0 & 7.0 & 37.0 & 0.57 & 0.14 & 0.50 & 4 & 192 & 一 \\
\hline 3. Hammer Gr. (Detlefsen) & 397 & 43.0 & 11.5 & 9.5 & 36.0 & 0.53 & 0.09 & 0.80 & 5 & 153 & - \\
\hline 4. Svaneke Gr. ( & 320 & 38.5 & 19.5 & 10.0 & 32.0 & 0.48 & 0.29 & 0.51 & 4 & 92 & rapakiwitisch \\
\hline 5. Vang Gr. am Pegmatit & & & & & & & & & & & \\
\hline (DitTrich) & 328 & 34.0 & 23.5 & 11.5 & 31.0 & 0.47 & 0.28 & 0.49 & 4 & 104 & adamellitisch \\
\hline 6. Vang Gr. & 311 & 35.5 & 24.0 & 13.0 & 27.5 & 0.47 & 0.19 & 0.55 & 4 & 101 & - \\
\hline 7. Paradisbakke Gr.( & 287 & 38.0 & 21.5 & 13.0 & 27.5 & 0.45 & 0.31 & 0.61 & 4 & 77 & 一 \\
\hline 8. Rönne Gr. & 248 & 32.0 & 29.0 & 15.0 & 24.0 & 0.44 & 0.22 & 0.50 & 4 & 52 & normalgranitiseh \\
\hline 9. Rönne Gr. & 261 & 32.5 & 28.5 & 13.5 & 25.5 & 0.45 & 0.29 & 0.47 & 4 & 59 & - \\
\hline 10. Rönne Gr. am Pegmatit & & & & & & & & & & & \\
\hline $\begin{array}{l}\text { (Dittrid } \\
\text { st. d. Rön }\end{array}$ & 257 & 32.0 & 30.0 & 12.5 & 25.5 & 0.35 & 0.29 & 0.42 & 3 & 55 & - \\
\hline (Detlefsen) & 243 & 32.0 & 27.0 & $\mid 14.0$ & $27.0 \mid$ & 0.56 & 0.19 & 0.52 & 4 & 35 & syenitgranitisch \\
\hline
\end{tabular}

Molekularwerte nach NiggLI.

setzung macht sich jedoch nicht durch ein verschiedenartiges Aussehen der Aplite bemerkbar. Ferner zeigt das k-mg Diagramm den für sämtliche Bornholmer Granite charakteristischen niedrigen mg-Wert.

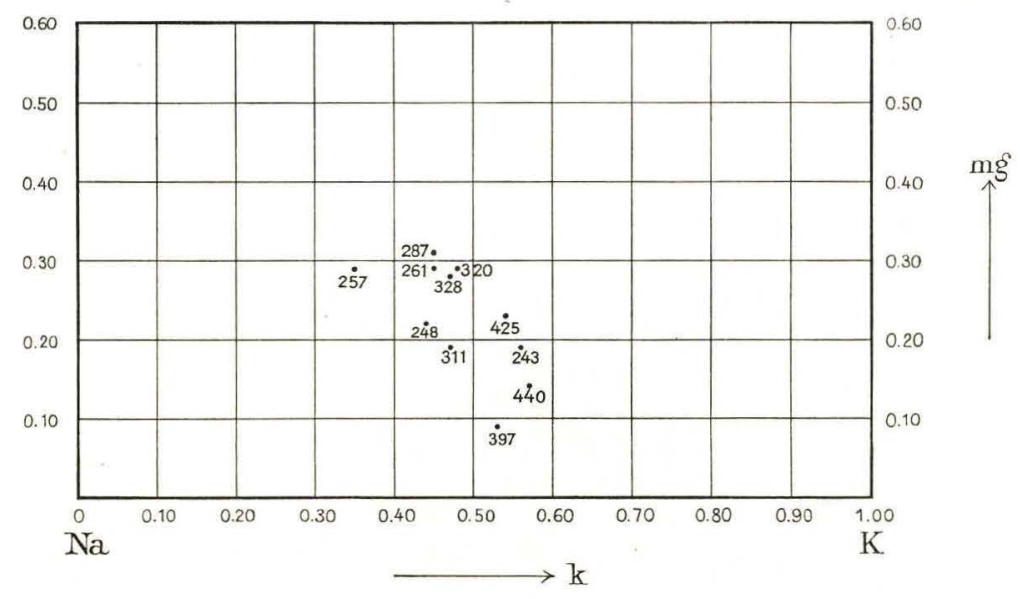

Fig. 31. k-mg Verhältnisse. Die Zahlen entsprechen den si-Zahlen.

Der Mineralbestand der Granite ist selbstverständlich von der chemischen Zusammensetzung bedingt. Die Quarzmenge nimmt bei sinkendem $\mathrm{SiO}_{2}$-Gehalt ab. Gleichzeitig steigt der Gehalt an zweiwertigen Metallen, was einen dementsprechend höheren Gehalt an Biotit, Hornblende und Plagioklas mit sich führt. Tab. XVI gibt eine Uebersicht über die Variation

Danmarks geologiske Undersøgelse. II. R. Nr. 50. 
Tab. XVI.

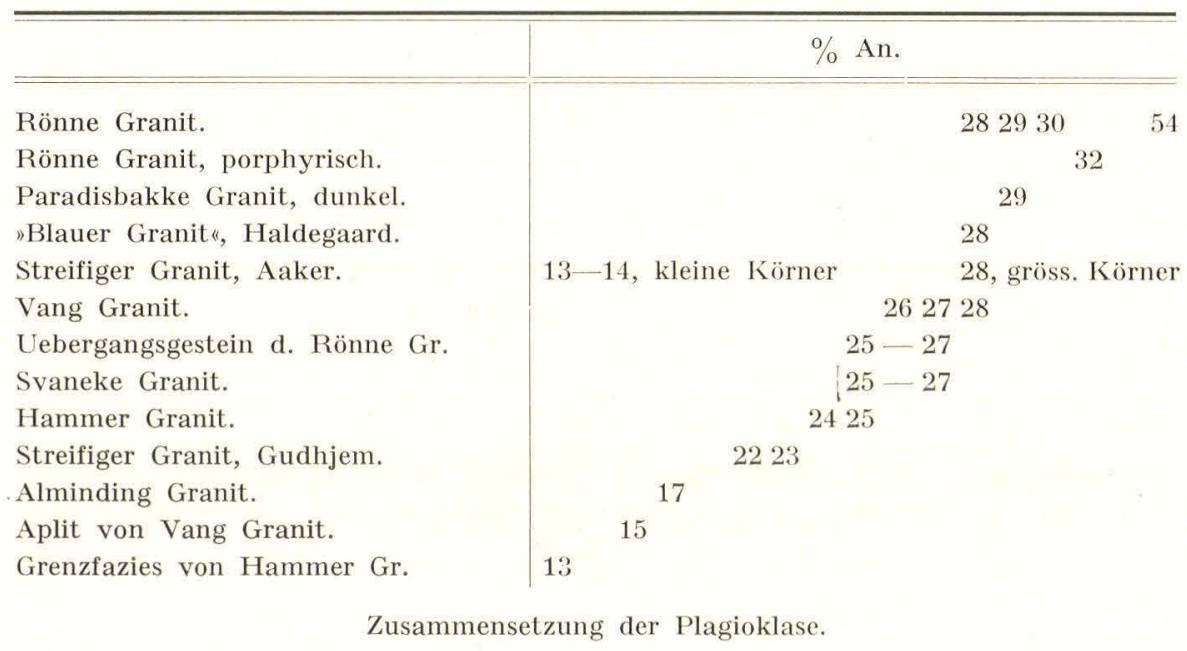

in der Zusammensetzung des Plagioklases, so wie diese mittels der Winkelwerte der Auslöschung im Kern der Plagioklaskristalle bestimmt ist. In sämtlichen Graniten findet man im Plagioklase mehr oder weniger ausgeprägt dieselbe unregelmässige, fleckenweise variierende Auslöschung, die für den Plagioklas des Rönne Granits so charakteristisch ist. Der Mikroklin ist in den dunklen, femischen Graniten stark perthithaltig, in den hellen, salischen Gesteinen dagegen perthitarm. In sämtlichen Gesteinsabarten findet man dieselbe charakteristische Hornblende; nur der Gehalt derselben variiert. Auch in der Gesteinsstruktur finden wir gewisse Spuren von primärer Kristallisationsstruktur, die von der chemischen Zusammensetzung bedingt wird. In den kalkreicheren Graniten hat somit der Plagioklas früher angefangen auszukristallisieren als der Mikroklin, welcher im Rönne Granit in der Regel einen vollständigen Mantel um die Plagioklaskörner herum bildet. In den plagioklasärmeren Graniten tritt diese Strukturerscheinung allmählich zurück, kann jedoch immer noch in den hellen Graniten, wie z. B. im Hammer Granit, stellenweise vorkommen. Im übrigen geht aus der oben dargelegten Gesteinsbeschreibung hervor, dass eine deutliche Reihenfolge der Mineralbildung sich nur unvollständig in den Bornholmer Graniten nachweisen lässt.

Auf Grund der deutlichen Uebergänge in der chemischen Zusammensetzung der Bornholmer Granitarten und der damit übereinstimmenden Variation im Mineralbestand teile ich ganz and gar die Ansicht von Cohen und Deecke (l. c. pag. 3 und pag. 35-36) und G. Kalb (1. c. pag. 84), dass in den einzelnen Granitarten nur chemische Differentiationen eines einheitlichen Magmas zum Ausdruck kommen. 
Versucht man es, sich den Verlauf der Differentiation klarzumachen, müssen neben der chemischen Zusammensetzung der Gesteine auch ihre Struktur und ihre geologische Erscheinungsweise in Betracht gezogen werden. Die Kennzeichen, die zur Klärung der Differentiationstheorie beitragen müssten, sind in erster Reihe die granulierte Struktur der Granite mit einer mehr oder weniger deutlichen Altersfolge der Mineralgemengteile, die mehr oder weniger entwickelte Parallelstruktur und der gneisähnliche äussere Habitus; ferner die Tatsache, dass das geologische Auftreten der Gesteine durch ebenmässige Uebergänge zwischen den Granitvarietäten innerhalb des grössten Teiles des Granitgebiets charakterisiert wird, dass es aber dennoch einen deutlichen Altersunterschied gibt, der durch eine scharfe geologische Grenze zwischen dem streifigen Granit und den massigen Graniten, den Hammer- und Svaneke Graniten, markiert wird.

Gewöhnlich nimmt man an, dass die Erstarrungsgesteine ihre heutige Entwicklung durch eine Kristallisationsdifferentiation erlangt haben, wodurch zeitlich sich folgende Gesteinsglieder sehr häufig eine fortschreitende Reihenfolge von basischen zu kieselsäure- oder alkalireicheren Gesteinen aufweisen. Würden wir annehmen, dass die Bornholmer Granitvarietäten durch eine Kristallisationsdifferentiation entstanden wären, so müssten wir daher erwarten, dass die basischen Varietäten die ältesten, die salischen die jüngsten wären. Dies hält bis zu einem gewissen Grade stich.

Aus den geologischen Verhältnissen geht mit Sicherheit hervor, dass die salischen Granite, der Hammer- und der Svaneke Granit, jünger sind als der angrenzende, dunkle, graue streifige Granit. Der Unterschied in der chemischen und mineralogischen Zusammensetzung zwischen diesen jüngeren und den angrenzenden älteren Graniten ist, wie oben gezeigt, gerade von einer solchen Art, wie es in Differentiationsprodukten desselben Magmas zu erwarten ist. Dagegen ist der Unterschied nicht von einer solchen Art und Grösse, dass man die Hammer- und Svaneke Granite einer ganz anderen Eruptionsperiode in einer weit jüngeren geologischen Zeit zuweisen könnte.

Die ältere Granitabteilung ist stark von den relativ basischen Varietäten, dem Rönne Granit, dem Paradisbakke Granit, dem Vang Granit und von grossen Teilen des grauen streifigen Granits geprägt. Hierzu kommen ferner die kleinen, unregelmässig begrenzten Vorkommen von dunklem, plagioklas- und hornblendereichem Granit, dem sogenannten »blauen Granit« bei Haldegaard (Gudhjem), Tækkeregaard und Spagergaard, welche in ihrer Zusammensetzung dem Rönne- und dem Paradisbakke Granit ausserordentlich nahe stehen, ja sogar einen höheren Hornblendegehalt und eine geringere Quarzmenge als diese aufweisen. Zugleich aber umfasst die ältere Granitabteilung die salischen Varietäten 
des streifigen Granits: den Alminding Granit, der in chemischer und mineralogischer Hinsicht dem Hammer Granit ausserordentlich verwandt ist, und die noch mikroklin- und quarzreicheren hellen aplitischen Granite innerhalb des Gudhjem Granitgebiets, die häufig eine genaue Uebereinstimmung mit der feinkörnigen Grenzfazies des Hammer Granits aufweisen. Ein Altersunterschied zwischen den hellen und dunklen Varietäten innerhalb der älteren Granitabteilung ist nicht direkt nachweisbar; dagegen lässt es sich in den meisten Fällen feststellen, dass die verschiedenen Gesteinsabarten ebenmässig ineinander übergehen. Am stärkesten variiert die Zusammensetzung des Felsengrundes innerhalb des Gudhjem Granitgebiets, wo grauer streifiger Granit, »blauer Granit« und heller roter Aplitgranit häufig miteinander wechseln. An Stellen, wo die Grenze zwischen dem feinkörnigen roten und dem grauen streifigen Granit aufgeschlossen ist, beobachtet man bisweilen eine intime schlierenartig wechselnde Verwachsung der beiden Granite; aber in den meisten Fällen scheint der Uebergang ein allmählicher zu sein. In der Gegend östlich von Rönne scheint, wie früher erwähnt (pag. 59), der Uebergang zwischen dem Alminding Granit und dem grauen streifigen Granit sehr schroff zu sein. Gegen Osten und und Süden ist der Uebergang vom Alminding Granit zum grauen streifigen Granit von den Paradisbakke- und Aakirkeby-Typen durch sumpfige Strecken verdeckt. Dagegen scheint der Alminding Granit nach Norden zu allmählich in den Gudhjem Granit, der im südlichen Teil der Klemensker Plantage etwas gröber als gewöhnlich ist und sich dem Alminding-Typus stark nähert, überzugehen. Der rote Alminding Granit unterscheidet sich vom grauen Gudhjem Granit u. a. durch seine beträchtlich weniger ausgesprochene Parallelstruktur. Dies ist eine natürliche Folge dessen, dass die Streifung von der parallelen Anordnung der dunklen Gemengteile herrührt, die im Alminding Granit nur spärlich vorhanden sind. Dagegen finden wir in diesem ungefähr dieselbe annähernd horizontale Streifung mit ost-westlicher Richtung, die sich im grössten Teil des Gebiets des streifigen Granits einigermassen konstant behauptet.

Die hier besprochenen Verhältnisse lassen sich schwierig vom Gesichtspunkte der Theorie einer Kristallisationsdifferentiation erklären. Eine Differentiation, die während der Verfestigung des Magmas stattfindet, geht dergestalt vor sich, dass die zuerst auskristallisierten Mineralien von dem noch flüssigen Restmagma getrennt werden. Wenn auf diese Weise aus einem Magma zwei verschiedene Gesteine entstehen, so wird das jüngere Differentiationsprodukt hauptsächlich aus denjenigen Mineralien bestehen, die im älteren Gestein die zuletzt auskristallisierten Gemengteile ausmachen. Es liesse sich denken, dass die Separation von der Schwerkraft verursacht wäre, da die spezifisch schwereren 
Mineralien in die Tiefe sinken, während die leichteren in den oberen Teilen des Magmabehälters angereichert werden. Die Differentiationsprodukte erhalten dadurch eine räumlich geregelte Anordnung, die im geologischen Auftreten der Gesteine nachweisbar ist. Es dürfte aus dem früher Gesagten hervorgehen, dass der häufige Wechsel von basischen und sauren Gesteinsabarten, den man im Bornholmer Granit und speziell innerhalb des streifigen Granits findet, sich nicht durch die Theorie einer gravitativen Differentiation erklären lässt. Beispielsweise soll hier an die schlierigen Verwachsungen von hellem, feinkörnigem Aplitgranit und grauem Gudhjem Granit erinnert werden; des weiteren kann angeführt werden, dass sich in unmittelbarer Nähe vom basischen »blauen« Granit bei Haldegaard, Gudhjem, sowohl nach NO als auch nach NW zu eine ausgeprägt helle, salische Form des Gudhjem Granits findet; etwas weiter entfernt kommt ein ähnlicher salischer Granit in Lensklint, ca. $1 \mathrm{~km}$ SW von Haldegaard, vor.

Indessen liesse es sich sehr gut denken, dass die roten salischen Granite, der Hammer- und der Svaneke Granit, durch eine fraktionierte Kristallisation gebildet wären. Mit den vorliegenden Verhältnissen am besten vereinbar wäre alsdann die Annahme, dass die Separation auf Abpressung (Squeezing) eines flüssigen Restmagmas von dem schon kristallisierten Teil zurückzuführen sei. Ein solcher Vorgang könnte stattfinden, wenn ein Magma, das sich im Kristallisationsstadium befindet, tektonischen Bewegungsvorgängen ausgesetzt würde. Der noch flüssige Teil des Magmas könnte dadurch an Stellen mit einem geringeren Druck befördert werden. Durch diese Theorie könnte man vielleicht die Parallelstruktur des älteren Granits als Resultat der Druckwirkung auf den zuerst auskristallisierten, skelettartigen Rest erklären. Dagegen gibt die Squeezing-Theorie keine Erklärung für die heterogene Beschaffenheit des älteren Granits. Im Gegenteil, man müsste vom Standpunkt dieser Betrachtung aus erwarten, dass der zuerst auskristallisierte Teil eine gleichartige Zusammensetzung erhalten hätte. Da diese Theorie somit kein befriedigendes Totalbild ergibt, habe ich keine Veranlassung, sie auf den Hammer- und Svaneke Graniten anzuwenden.

Die Tatsache, dass die Parallelstruktur im grössten Teil des Granitgebiets dieselbe Richtung hat, und dass die verschiedenen Gesteinsvarietäten in diesem Gebiete ebenmässig in einander übergehen oder in selteneren Fällen durch schlierenartige Verwachsungen mit einander verbunden sind, zeigt, dass die einzelnen Gesteinsarten nicht sukzessiv gebildet sind, sondern dass die Verfestigung dieses ganzen Teils des Granits annähernd gleichzeitig erfolgt sein muss, und dass das Magma schon vor der Verfestigung bis zu einem gewissen Grade in mehrere Teilmagmen von verschiedenartiger chemischer Zusammensetzung gespaltet war. 
Ich bin daher der Ansicht, dass wir unter allen Umständen annehmen müssen, dass Liquation eine wesentliche Rolle bei der Differentiation gespielt haben muss, und ich glaube, dass die magmatische Differentiationstheorie, die H. E. JoHAnsson ${ }^{1}$ ) unter Bezugnahme auf das südschwedische Grundgebirge dargelegt hat, in Wirklichkeit diejenige ist, die mit den vorliegenden Verhältnissen am besten übereinstimmt. Gegen die Liquationstheorie ist wiederholt Einspruch erhoben worden und zwar hauptsächlich aus dem Grunde, dass die Laboratorienuntersuchungen für eine völlige gegenseitige Löslichkeit in Silikatschmelzungen zu sprechen scheinen. Indessen darf man nicht davon ausgehen, dass die im Grössenbereich der Laboratoriumsversuche erhaltenen Ergebnisse ohne weiteres auf tiefmagmatische Vorgänge übertragbar sind. Gewichtige und überzeugende Gründe hierfür sind früher von H. E. Johansson angeführt worden (G. F. F. 29, 1907; vgl. ferner: G. F. F. 53, 1931, pag. 462 ff.). In neuerer Zeit hat dann auch B. AskLUND $^{2}$ ) in Bezug auf die Stavsjö-Gesteine die beschränkte Mischbarkeit zur Erklärung der Differentiation herangezogen, und zweifellos lassen sich viele geologische Erscheinungen nur durch diese Hypothese befriedigend deuten.

Von der magmatischen Anschaungsweise ausgehend, müssen wir annehmen, dass die Bornholmer Granite aus einer grossen, in situ differentiierten Magmamasse hervorgegangen sind, welche sich bis zu einem gewissen Grade in chemisch verschiedene Teile gespaltet hat. Die Parallelstruktur der Granite deutet darauf, dass zu einer gewissen Zeit der Differentiation das ganz oder z. T. flüssige Magma in Bewegung geraten ist. Dass die Parallelstruktur sich nur durch Primärentstehung erklären lässt, hat bereits G. KALB betont (1. c. pag. 84). Meines Erachtens ist sie als Fluidalstruktur aufzufassen. Bewegungsvorgänge im Magma werden in erster Linie die Separation beschleunigen, so dass die basischen und sauren Teile stärker ausgeschieden werden. Von einer gestörten Kristallisation zeugen die granulierten Strukturen, die zur Verschleierung der Altersfolge der Mineralien beigetragen haben.

Diese Annahme einer Differentiation und Verfestigung bei gleichzeitiger Bewegung im Magma macht es verständlich, dass die Differentiation an verschiedenen Stellen ungleich weit vorgeschritten ist, so dass im streifigen Granit Seite an Seite mit plagioklas- und hornblendereichem »blauem Granit« Varietäten auftreten, die ebenso quarz- und mikroklinreich sind wie der jüngere Hammer Granit und dessen Randaplit. Ferner zeigt die schlierenartige Verwachsung von hellem Aplit und grauem

1) H. E. Johansson: G. F. F. 28, 1906, 29, 1907.

H. Munthe, H. E. Johansson u. R. Sandegren: Göteborgstraktens geologi. 1924.

$\left.{ }^{2}\right)$ B. Asklund: S. G. U. Ser."C. Nr. 325, 1925. 
Gudhjem Granit, dass die Differentiation an diesen Stellen verschiedenartig zusammengesetzte Teilmagmen, die zu gleicher Zeit auskristallisiert sind, gezeitigt hat, während man an Stellen, wo die Differentiation zu keiner eigentlichen Separation geführt hat, allmähliche Uebergänge von einer Gesteinsvarietät zur anderen findet. Auf derselben Annahme fussend, meine ich auch, dass die aplitschlierige und geflammte Struktur des Paradisbakke Granits eine natürliche Erklärung findet. — Eine ähnliche Auffassung der Parallelstruktur und der Granulierung in Granitgesteinen, und zwar speziell in den älteren derselben, als primäre, während der Verfestigung des Magmas entstandene Struktur wurde in den letzten Jahren mehrmals von verschiedenen Geologen in Schweden und Finnland ${ }^{1}$ ) vertreten. Im besonderen scheinen mir die von MäkineN beschriebenen Differentiationsmigmatite aus Ostbothnien viele Strukturähnlichkeiten mit dem Paradisbakke Granit aufzuweisen.

Was die Hammer- und Svaneke Granite betrifft, müssen wir annehmen, dass sie Teile des Magmas repräsentieren, welche durch die Differentiation eine salische Zusammensetzung erreicht haben, jedoch nicht gleichzeitig mit demjenigen Teil des Magmas, der tektonischen Bewegungsvorgängen ausgesetzt wurde, zur Verfestigung gelangt sind, und dass sie zu einem späteren Zeitpunkt den bereits verfestigten streifigen Granit intrudiert haben.

In Bezug auf die Entstehung der Parallelstruktur weicht die hier dargelegte Auffassung wesentlich von derjenigen von CoHen und DeEcke ab, indem diese Forscher (l. c. pag. 35) auf Grund der Mörtelstruktur, der polysynthetischen Quarze, der undulösen Auslöschung und gestörten Zwillingsbildung, "Erscheinungen, welche allerdings nicht in hervorragendem, Grade entwickelt sind«, die Parallelstruktur auf sekundäre Einwirkungen zurückführen.

Nach dem Erscheinen von KaLB's Abhandlung, in der er (l. c. pag. 78) nachdrücklich betont, dass er nirgends Erscheinungen gefunden habe, die als Mörtelstruktur gedeutet werden könnten, und dass die Parallelstruktur der Granite sich nur durch Primärentstehung erklären lasse Resultate, denen ich ganz beipflichte - wäre es an und für sich überflüssig, sich weiter mit CoHEN und DeEcke's Ansicht auseinanderzusetzen, wenn nicht Ussing sich ihr angeschlossen und sie suppliert hätte, was dazu beigetragen hat, dass sich diese Auffassung in ausgedehntem Masse in der dänischen Geologie eingebürgert hat. UssING ${ }^{2}$ ) bemerkt, dass die Streifung in den meisten Fällen vermutlich durch starken

1) H. E. Johansson: G. F. F. l. c.

P. Eskola: Bull. Com. Géol. Finl. 40, pag. 26; G. F. F. 41 pag. 206-207.

E. Mäkinen: Bull. Com. Géol. Finl. 4\%, pag. 80-82.

N. Sundius: S. G. U. Ser. C. Nr. 306, 1921, pag. 62 ff.

$\left.{ }^{2}\right)$ Ussing: Danmarks Geologi. D. G. U. III. R. Nr. 2. 2. Udg., 1904, pag. 36. 
Druck und Bewegungen in der Erdkruste, welche erst nach der Bildung des Granits stattgefunden haben, entstanden sein muss; hierfür spricht seiner Ansicht nach, dass die Streifung des Granits oft auf grosse Strekken hin in derselben Richtung verläuft, und dass man oft, z. B. bei Listed, beobachten kann, dass sie sich in den angrenzenden Svaneke Granit hinein fortsetzt, wo sie sich jedoch in einer grösseren Entfernung von der Grenze verliert. Später schreibt er ${ }^{1}$ ), dass der streifige Granit eine sehr deutliche Kataklasstruktur habe.

Ich habe schon oben bei der Besprechung der Granitgrenze bei Listed (pag. 120) versucht klarzulegen, dass Ussing's Aeusserung betreffs der Streifung an dieser Stelle nicht stichhaltig sei. Jedenfalls steht es fest, dass die Parallelstruktur des streifigen Granits nicht durch eine Deformation des festen Gesteins, die nach der Intrusion der Hammer- und Svaneke Granite erfolgt ist, entstanden sein kann. Denn in diesem Falle wären die Kontakte nicht so unberührt und gut erhalten, wie es der Fall ist. Wäre die Parallelstruktur durch eine solche Deformation entstanden, so müsste diese also vor der Intrusion der Hammerund Svaneke Granite stattgefunden haben; dies setzt aber einen weit grösseren Altersunterschied zwischen diesen Graniten und dem übrigen Bornholmer Granit voraus, als man anzunehmen Veranlassung hat. Wenn Ussing in seiner späteren Arbeit die Bezeichnung »Kataklasstruktur benutzt, wird man unwillkürlich versucht, hierin nur eine Umschreibung von Coнes und DeEcke's »Mörtelstruktur« etc. zu sehen, oder mit anderen Worten: da Ussing's eigene Untersuchungen auf diesem Punkt nicht genügend weit vorgeschritten waren, zitierte er loyal die vorliegende ältere Literatur. Ausgesprochene Kataklasphänomene habe ich nur ausnahmsweise gefunden, und zwar im Svaneke Granit, wo gerade die mechanische Deformation zu keiner Art von Parallelstruktur geführt hat. Was sich im übrigen an Anzeichen einer Kataklasstruktur findet, muss zweifellos am ehesten einer protoklastischen Deformation zugeschrieben werden.

Bedeutend radikaler als die obendargelegte Auffassung von der Bildungsart der Bornholmer Granite dürfte der Gedanke sein, dass der Hammer Granit nicht nur den älteren Bornholmer Granit im nördlichsten Teil der Insel durchbrochen hätte, sondern dass er sich in Wirklichkeit auch unter den grössten Teil von Bornholm hinein erstrecke und wieder viel südlicher in Gestalt des roten Alminding Granits zutage getreten wäre, und ferner, dass die zahlreichen kleinen Vorkommen von feinkörnigem aplitischen Granit innerhalb des Gudhjem Granit-

1) Ussing: Handb. d. Regionalen Geologie. Bd. 1, Abt. 2. Dänemark, 1910, pag. 4. 
gebiets in Wirklichkeit verschiedene »outcrops" des Randaplits des Hammer Granits wären. Reste des älteren Granits wären dann Rönne Granit, Paradisbakke Granit und der übrige graue Granit. Eine solche Hypothese würde eine einfache Erklärung der nahen petrographischen Uebereinstimmung zwischen den hellen salischen Gesteinen ergeben, allein sie scheint mir nicht haltbar zu sein.

Es ist schon im Vorhergehenden betont worden, dass es sich erwiesen hat, dass der Randaplit des Hammer Granits überall deutlich den Vang Granit intrudiert und Gänge in demselben bildet. Dagegen ist das Verhältnis zwischen dem grauen Gudhjem Granit und dem roten aplitischen Granit (»Hasle Granit«) ein wesentlich anderes: in der Regel scheint der Uebergang zwischen den Graniten ein allmählicher zu sein, stellenweise sieht man einen Schlierkontakt, aber nur an einer Stelle im Gudhjem Granit habe ich einen Aplitgang gefunden. Ferner geht der Gudhjem Granit, soweit sich feststellen lässt, ebenmässig in den Alminding Granit über. Diese Verhältnisse lassen sich meiner Auffassung nach nur durch die Annahme erklären, dass sich diese Granite ungefähr gleichzeitig verfestigt haben. Wäre diese Struktur des Felsengrundes durch das Vordringen des Hammer Granits entstanden, so setzt dies voraus, dass das hervorbrechende Magma imstande gewesen wäre, den älteren Granit zum Teil aufzuschmelzen und sich mit ihm zu assimilieren, also eine sehr eingreifende Umformung desselben zu verursachen, und zwar in Verbindung mit tektonischen Bewegungsvorgängen, durch welche die Parallelstruktur entstanden wäre. Des weiteren müsste vorausgesetzt werden, dass dieser ganze Teil des Granits erstarrt wäre und seine heutige heterogene Gestalt erreicht hätte, bevor der Rest des Hammer Granitmagmas wieder diesen nun abgekühlten Granit im nördlichsten Teil von Bornholm durchbrach. Ich meine, dass diese Konsequenz die genannte Hypothese unannehmbar macht. Im Gegenteil, ich sehe in der genauen chemischen und mineralogischen Uebereinstimmung zwischen dem Hammer- und dem Alminding Granit und zwischen dem Randaplit des Hammer Granits und dem übrigen aplitischen Granit ("Hasle Granit«) eine Bestätigung der Annahme, dass diese Gesteinsabarten Differentiationsprodukte desselben Magmas sind, die an verschiedenen Stellen und zu etwas verschiedenen Zeiten verfestigt sind. Man darf daher nicht den Hammer Granit allein auf Grund seines stark durchbrechenden Kontakts in eine ganz andere geologische Zeit verlegen als den ïbrigen Bornholmer Granit.

Eine ganz analoge Betrachtung könnte in Bezug auf den Svaneke Granit angestellt werden, der in vielen Beziehungen eine so charakteristische Uebereinstimmung mit den aplitischen Schlieren im Paradisbakke Granit aufweist, dass man sie mit guten Gründen für Differentiations- 
produkte desselben ursprünglichen Magmas ansehen kann. Die Kontaktverhältnisse des Svaneke Granits und seine zahlreichen Einschlüsse von streifigem Granit, u. a. vom typischen geflammten Paradisbakke Granit, zeigen mit Sicherheit, dass er zu einer Zeit hervorgebrochen ist, wo der streifige Granit als festes Gestein in seiner jetzigen Gestalt vorlag. 


\section{Zur Altersfrage der Bornholmer Granite.}

Die Frage betreffend das Alter der Bornholmer Granite und ihren Platz in der skandinavischen Grundgebirgsstratigraphie lässt sich infolge fehlender Kontakte mit anderen Grundgebirgsgesteinen nicht mit Sicherheit entscheiden. Einschlüsse von älteren Gesteinen, wurden auf Bornholm spärlich gefunden, nämlich nur ein Quarzitfragment im Gudhjem Granit und ein hornfelsähnliches Gestein, wohl ein kontaktumgewandelter Amphibolit, im Vang Granit (siehe oben pag. 87 und pag. 72). Dagegen kommen Fragmente vom Nebengestein im älteren südostschwedischen Gneisgebiet ganz allgemein vor, sind aber auch in den jüngeren Graniten zu finden. Sie gewähren daher keinen wesentlichen Anhaltspunkt für eine Altersbestimmung. Nur auf Grund von petrographischen und geologischen Aehnlichkeiten Parallelen zu ziehen, ist selbstverständlich immer problematisch, aber in diesem Falle gibt es z. Z. keinen anderen Ausweg. Ausserdem berechtigt uns die geographische Nähe des südschwedischen Grundgebirges dazu, Vergleiche mit diesem Gebiete anzustellen, wie dies auch früher von Cohen und Deecke versucht worden ist. Diese Forscher gelangten dabei zu der Auffassung, dass Bornholm einen Teil des grossen Blekinger Granitgebietes ausmacht (l. c. pag. 34 ff.), oder mit anderen Worten, dass die Bornholmer Granite sich am ehesten den Gesteinsarten der jüngeren Abteilung des schwedischen Grundgebirges anschliessen. Indessen verhält sich die Sache heute anders als im Jahre 1889, als CoHen und DeEcke's Arbeit erschien. Für diese Forscher galt es zu entscheiden, ob das Bornholmer Grundgebirge als Granit oder als Gneis anzusehen sei, und sie bemerken ausdrücklich, dass »da Granit und Gneiss unserer Ansicht nach genetisch durchaus verschiedene Bildungen sind, so erscheinen uns Bezeichnungen wie Granitgneiss und Gneissgranit nicht angemessen«. Seit jener Zeit ist die Auffassung vom Hervorgehen der Gneise und Gneisgranite aus einer grossen in situ differentiierten Magmamasse immer mehr durch- 
gedrungen ${ }^{1}$ ), so dass die Erkenntnis von der Entstehung der Bornholmer Granite durch chemische Differentiationen eines einheitlichen Magmas jetzt nicht mehr der Auffassung im Wege steht, sie zum älteren Grundgebirge zu rechnen. CoHen und DeEcke dagegen mussten sich — von ihrer Voraussetzung ausgehend — dafür entscheiden, das Bornholmer Grundgebirge als Granit zu bezeichnen, obschon sie selbst wiederholt betonen, dass der streifige Granit einem Gneis überaus ähnlich sei, und z. B. sich so äussern (l. c. pag. 13): »In seiner charakteristischen Ausbildung bei Gudhjem dürfte dieser Granit wohl dem Gneissgranit oder "stribet Granit« der skandinavischen Geologen vollständig entsprechen«.

Versucht man, einen Vergleich zwischen Bornholm und dem übrigen Skandinavien, speziell dem schwedischen Grundgebirge, zu ziehen, fällt es natürlich, mit dem geologischen Auftreten der Gesteine anzufangen. Es stellt sich dann heraus, dass nicht allein das intime Wechseln im grossen wie im kleinen zwischen den verschiedenen Differentiationsgliedern ${ }^{2}$ ), sondern auch die ebenmässigen unmerkbaren Uebergänge von ganz massigen Graniten zu schiefrigen, gneisartigen Gesteinen charakteristische Züge sind, die für Bornholm und die schwedische Urgranitoder Gneisgranitformation gemeinsam sind. Doch lassen sich weder die für die schwedischen Urgranite so charakteristische Abhängigkeit von der Struktur und Schichtung der älteren Superkrustalserie noch die konformen Intrutionskontakte irgendwo auf Bornholm nachweisen. In HögBom's Beschreibung vom Auftreten der Urgranite in Upland ${ }^{3}$ ) finden wir viele der charakteristischen Züge wieder, die wir von Bornholm her kennen. So berichtet Нӧ́вом z. B. (pag. 269), dass innerhalb der grösseren Granitgebiete sich oft - wie es auch ТöRnевонм an verschiedenen Stellen erwähnt — mehr oder weniger deutlich charakterisierte Granite unterscheiden lassen, die bald mit scharfem Kontakt an einander grenzen, bald durch Zwischenformen in einander übergehen. Innerhalb der grossen Upländischen Urgranitgebiete trifft man neben den verbreiteten Hornblendegraniten andere, die infolge des Zurücktretens der Hornblende und der dunklen Mineralien sowie durch ihren grösseren Quarz- und Orthoklasgehalt ausgesprochen saure Gesteine sind. Diese meistens roten Granite sind manchmal durch recht markierte Grenzen von den ersteren getrennt (z. B. der Vängegranit vom Upsalagranit), in anderen Fällen fliessen die Granite mehr in einander über. In Bezug auf das Altersverhältnis dieser Granite zu einander gibt HöGBom an, dass man bei Verfolgung der Kontaktzone den Eindruck gewinnt, dass bald der saure, bald der hornblendeführende Granit verfestigt war,

1) Vergl.: W. Ramsay, Geologiens grunder, 1931, II, pag. 302 u. a. St.

$\left.{ }^{2}\right)$ Vergl. u. a.: W. Ramsay, Geologiens grunder, 1931, II, pag. 302 u. a. St., und N. Sundius, G. F. F. 43, 1921, pag. 548 ff.

$\left.{ }^{3}\right)$ A. G. Нӧявом, G. F. F. 15, 1893, pag. 241 ff. 
während der andere noch flüssig war, und manchmal sieht es so aus, als stünden sie alle beide in Schlierkontakt, woraus man wohl schliessen darf, dass kein eigentlicher Unterschied hinsichtlich des Alters (Eruptionszeit) besteht, sondern nur teilweise ein Zeitunterschied zwischen der Erstarrung der basischen und der sauren Partien derselben Magmamasse. НӧGвом gelangt dadurch zu derselben Vorstellung von einer Entmischung im ganz oder teilweise flüssigen Zustand des Magmas, die oben für Bornholm geltend gemacht wurde. - Es dürfte überflüssig sein, weitere Beschreibungen vom Auftreten der Urgranite wiederzugeben, da ständig die gleichen Hauptzüge hervorgehoben werden, um die Urgranite im Verhältnis zu den jüngeren Graniten zu charakterisieren. (Vergl. u. a.: P. Geijer, S. G. U. Arsbok 10, 1916; P. GeiJer, Bull. Upsala. 15, 1916; N. Sundius, S. G. U. Arsbok 15, 1921; B. Asklund, S. G. U. Ser. Aa, Nr. 153, 1923).

Im Gegensatz zu den Urgraniten ist es für die Gesteine der jüngeren Granitgruppe charakteristisch, dass sie grosse Gebiete hindurch an Aussehen und Zusammensetzung gleichartig sind. In den meisten Fällen haben sie eine typisch massige Entwicklung. Im übrigen aber besteht auch diese Gruppe aus einer sehr wechselnden Gesteinsserie, deren älteste Glieder sich aus verschiedenen Gabbros und dioritischen Gesteinen zusammensetzen. Die Granite, welche oft unter der Bezeichnung Filipstad-Smålandsgranite zusammengefasst werden, bestehen aus verschiedenen Typen, die von hornblende- und plagioklasreichen, quarzdioritischen oder quarzsyenitischen Gesteinen zu einfachen PerthitQuarzgraniten variieren. Oft sind sie mehr oder weniger porphyrisch entwickelt mit grösseren Mikroklinaugen, die in einer mittel- oder manchmal ziemlich grobkörnigen Grundmasse zerstreut liegen. Am meisten verbreitet sind der Filipstadsgranit in Mittelschweden, die grauen und roten Växiögranite sowie die Augengranite im süd-östlichen Schweden. Zwischen diesen in Bezug auf Habitus und chemische Verhältnisse verschiedenen Gruppen treten alle Uebergangsformen auf. Eine grosse Anzahl dieser Granite sind in der Steinindustrie unter verschiedenen Lokalbenennungen bekannt. Als das jüngste Glied dieser grossen Eruptionsserie werden heutzutage im allgemeinen die gewöhnlich als »serarchäisch« bezeichneten Granite, aufgefasst, zu denen ausser den Stockholmer- und Bohusgraniten u. a. auch die kleineren Granitmassive in Blekinge: der Karlshamn Granit m. w. ${ }^{1}$ ) gerechnet werden. Den jüngeren Graniten schliessen sich mehrere Kleinmassive von feinkörnigen roten und grauen Graniten an, welche als Randfazies derselben anzusehen sind.

Die jüngeren Granite treten in Massiven oder Batholithen auf, welche

1) N. Sundius, G. F. F. 43, 1921, pag. 548 ff. W. Ramsay, Geologiens grunder. 1931, II, pag. 303. 
den älteren Gebirgsgrund durchbrechen, stellenweise brecciieren und in grossen Zügen gesehen die Struktur desselben durchqueren. Dies gilt besonders die serarchäischen, stark durchbrechenden Granite. Das jüngere Alter der Granite geht ferner daraus hervor, dass sie stellenweise zahlreiche Bruchstücke sowohl aus der Leptit-Schiefer-Quarzitserie als auch von den Urgraniten enthalten. Aber auch die Gesteine der jüngeren Granitgruppe können lokal mehr oder weniger verschiefert und namentlich längs der Grenzen stark gneisartig sein, was es schwierig macht, die Grenzen detailliert festzulegen und in den einzelnen konkreten Fällen zu entscheiden, ob der betreffende Granit zu der einen oder der anderen Altersgruppe gerechnet werden muss. Dieser Umstand, der immer wieder in den schwedischen Kartenblatterläuterungen und in der übrigen geologischen Literatur betont wird, ruft eine beträchtliche Unsicherheit hervor, wenn es sich darum handelt, das Alter eines kleinen isolierten Grundgebirgsgebietes wie das von Bornholm zu bestimmen. Als Stützpunkt bleibt uns dann nur noch die Beschaffenheit der Gesteine selbst, und zwar in erster Linie die Struktur derselben.

Als einen wesentlichen Strukturunterschied zwischen den Graniten der beiden Gruppen führt Sundius (G. F. F. 43, 1921, pag. 555 f.) den relativen Mangel der Urgranite an groben und grob augenartigen Strukturen an, welche unter den jüngeren Graniten so verbreitet sind. Zwar fehlen diese Strukturen nicht gänzlich in den Urgraniten, sie sind aber im grossen und ganzen wesentlich weniger verbreitet und schlechter entwickelt als in den jüngeren Graniten. Auf Bornholm finden wir kein Gegenstück zu diesen grob augenstruierten Graniten, welche sich ausserdem in ihren chemischen Verhältnissen über grössere Gebiete hin als gleichartig erweisen, so dass man wohl mit Sicherheit sagen darf, dass die Bornholmer Granite jedenfalls keine typischen »jüngeren Granite« sind. Dagegen finden wir eine Parallelerscheinung zu den Gneisgebieten in den vorherrschenden mittel- bis feinkörnigen Strukturen der Bornholmer Granite sowie in ihrer Inhomogenität der Zusammensetzung und in der Schlierigkeit mit Ausscheidung von pegmatit-aplitischem Material.

Endlich muss bemerkt werden, dass die Streichrichtung im südschwedischen Gneisgebiet im wesentlichen parallel der Längsrichtung des Gneisgebietes verläuft ${ }^{1}$ ), $d . h$. im westlichen Teil etwa $\mathrm{N}-\mathrm{S}$, in Blekinge vorwiegend $\mathrm{O}-\mathrm{W}$, doch kommen oft recht grosse lokale $\mathrm{Ab}$ weichungen vor. Ferner findet man, dass das Fallen im grossen und ganzen nur kleine Winkel zum Horizontalplan bildet, in Blekinge meistens $10-40^{\circ}$ nach N. Was Bornholm betrifft, wird man sich dessen entsinnen, dass die Richtung der Parallelstruktur im Gebiet des streifigen Granits

1) A. G. Нӧgвом, Precambrian Geology of Sweden. Bull. Upsala. 10, 1910, pag. 37.

H. Hedström och C. Wiman: S. G. U. Ser. Aa, Bl. 5, 1906, pag. 8. 
grosse Strecken hindurch einigermassen konstant WNW-OSO bis $\mathrm{O}--\mathrm{W}$ ist; an Stellen, wo die Schiefrigkeit soweit ausgesprochen ist, dass der Fallwinkel gemessen werden kann, finden wir, besonders die NO-Küste entlang, in der Regel kleine Werte für denselben, meistens $10-30^{\circ}$, selten über $40^{\circ}$ nach $\mathrm{N}$.

Wenn wir die einzelnen Gesteinsvarietäten aus Bornholm mit denen aus Schonen-Blekinge vergleichen, stellt sich heraus, dass gewisse Partien des südschwedischen Felsengrundes eine grosse Aehnlichkeit mit verschiedenen Bornholmer Granitvarietäten haben. In Karlshamn und in der Umgebung dieser Stadt tritt z. B. eine mittelkörnige, deutlich parallelstruierte, etwas hornblendeführende, schwach porphyrische Varietät auf, die sowohl makroskopisch als mikroskopisch besonders gut mit dem grauen streifigen Bornholmer Granit übereinstimmt. Mikroklinperthit, Quarz und Plagioklas treten in sehr unregelmässig begrenzten Körnern von etwas wechselnder Grösse auf. Die Parallelstruktur rührt von der annähernd parallelen Anordnung kleiner Biotitblätter her, denen sich lappige und löcherige Körner aus Hornblende sowie Titanit und Erzkörner, die letzteren oft von Titanit umrandet, anschliessen. Aehnliche mittelkörnige, streifige Varietäten finden wir recht häufig in den Küstenfelsen und auf den Inseln südlich vom Karlshamngranitmassiv, wo sie in zahlreichen Steinbrüchen gebrochen werden. Im übrigen ist es bemerkenswert, dass die hornblendeführenden Küstengneise oft eine deutlich lineare Parallelstruktur haben; stellenweise werden sie beinahe ganz massig und erhalten dadurch ein fast granitisches Aussehen. Nördlicher bei Bökemåla in der Gemeinde Asarum ist der Küstengneis feinkörniger und dünnschiefrig, die Korngrösse ist etwas gleichartiger, doch hat auch hier der Plagioklas die Tendenz, in grösseren Körnern als die übrigen Gemengteile aufzutreten. Hornblende fehlt in diesem Gestein, das etwas plagioklasreicher als der Gudhjem Granit $\mathrm{zu}$ sein scheint. Als Schicht in den typischen Küstengneisen kommt ein helleres graues, wesentlich mikroklinreicheres Gestein vor, das sowohl in Bezug auf Struktur als auf Mineralbestand den helleren Teilen des Gudhjem Granits nahesteht.

Ferner hat der graue streifige Granit auf Bornholm im äusseren Habitus und in der mikroskopischen Struktur eine auffallende Aehnlichkeit mit dem Näflingegneis im Gebiet von Ringsjön über Näflingeås nach Hästveda zu. Doch ist der Näflingegneis durchschnittlich reicher an Hornblende und Plagioklas und führt anorthitreicheren Plagioklas als der Bornholmer Granit. Eine zum mindesten ebenso auffallende strukturelle Aehnlichkeit finden wir in Gesteinen aus Söderås, der Gemeinde Risenberga und aus Skäralid, wo Gneisvarietäten mit einem intermediären Verhältnis zwischen Kalifeldspat und Plagioklas recht häufig vorkommen. Doch scheinen auch diese Gesteine etwas hornblendereicher als der sstreifige 
Granit« zu sein. Die Hornblendeindividuen haben dieselbe lappige und löcherige Ausbildung wie in den Bornholmer Graniten. Im Gneise tritt stellenweise, z. B. bei Skäralid, Granat auf, während derselbe auf Bornholm nur ausnahmsweise gefunden worden ist.

Auch zu den feinkörnigen hellen aplitischen Graniten ("Hasle Granit«), die innerhalb des nördlichen Teiles des streifigen Granits auf Bornholm zerstreut vorkommen, finden wir entsprechende Gesteine in Schonen. So ist z. B. auf dem Linderödås östlich und südlich vom NäflingegneisGebiet eine helle rote aplitische Form der kalkfeldspatarmen, salischen Gesteinsglieder der »Järngneis«-Formation sehr verbreitet. Sie entspricht sowohl makroskopisch als mikroskopisch dem »Hasle Granit«. Ein ähnliches feinkörniges Gestein kommt auf dem Romeleås bei Dalby vor. Im übrigen besteht der Romeleås aus etwas verschiedenartigen Gesteinen, darunter Varietäten mit deutlicher Gneisstruktur, und aus anderen Abarten von granitischem oder granitporphyrischem Aussehen. Unter diesen können sich auch Partien, die sowohl in Bezug auf Mineralbestand als Struktur dem streifigen Bornholmer Granit ähnlich sind, finden. In Stenshufvud tritt ein recht feinkörniges Gestein mit charakteristischen Feldspataggregaten auf, die in der Regel nur aus einigen wenigen Feldspatkörnern, zum grössten Teil Oligoklas, doch auch aus einzelnen Kalifeldspatkörnern, bestehen, welche alle grösser sind als die Körner der Grundmasse, die überwiegend aus Mikroklin bestehen. Eine ganz ähnliche Struktur finden wir im streifigen Granit auf Bornholm und zwar besonders im Gebiet östlich von Rönne, z. B. in der Nähe von Hakonsgaard und weiter gegen SO in der Richtung nach Aakirkeby (vergl. Taf. V, Fig. 1).

Es ist somit sehr wohl möglich, verschiedene Aehnlichkeiten zwischen den südschwedischen Gneisgesteinen und dem streifigen Granit auf Bornholm nachzuweisen. Ferner ist es für das süd- und südwestschwedische ältere Grundgebirge charakteristisch, dass die Gesteine an vielen Stellen eine durchaus massige Entwicklung haben. Von solchen Varietäten hat der Beden Granit im südlichen Teil des Romeleås verschiedene Charakterzüge mit dem Rönne Granit gemeinsam.

Auch in Bezug auf die chemische Zusammensetzung können im schwedischen Grundgebirge eine Reihe von Gesteinen genannt werden, die den Bornholmer Graniten nahestehen; so z. B. weist der rote »Augengneisgranit« aus Slottsskogen, Göteborg ${ }^{1}$ ), fast dieselbe Analyse wie der Hammer Granit auf, und eine ähnliche Uebereinstimmung gibt es zwischen dem Vang Granit und dem Gneisgranit (oder Järngneis) aus Lönhult in Schonen ${ }^{2}$ ). Ein grösseres Interesse jedoch als ein einfaches

1) P. J. Holmeuist: Bull. Upsala. 8, Nr. 131, pag. 268.

2) Ib. Nr. 122, pag. 266. 
Zusammenstellen der Analysen hat es, die Analysenpunkte in ein Feldspatdiagramm (Fig. 32) einzutragen, so wie es im allgemeinen in der schwedischen Geologie üblich ist. Dadurch erhalten wir ein anschauliches

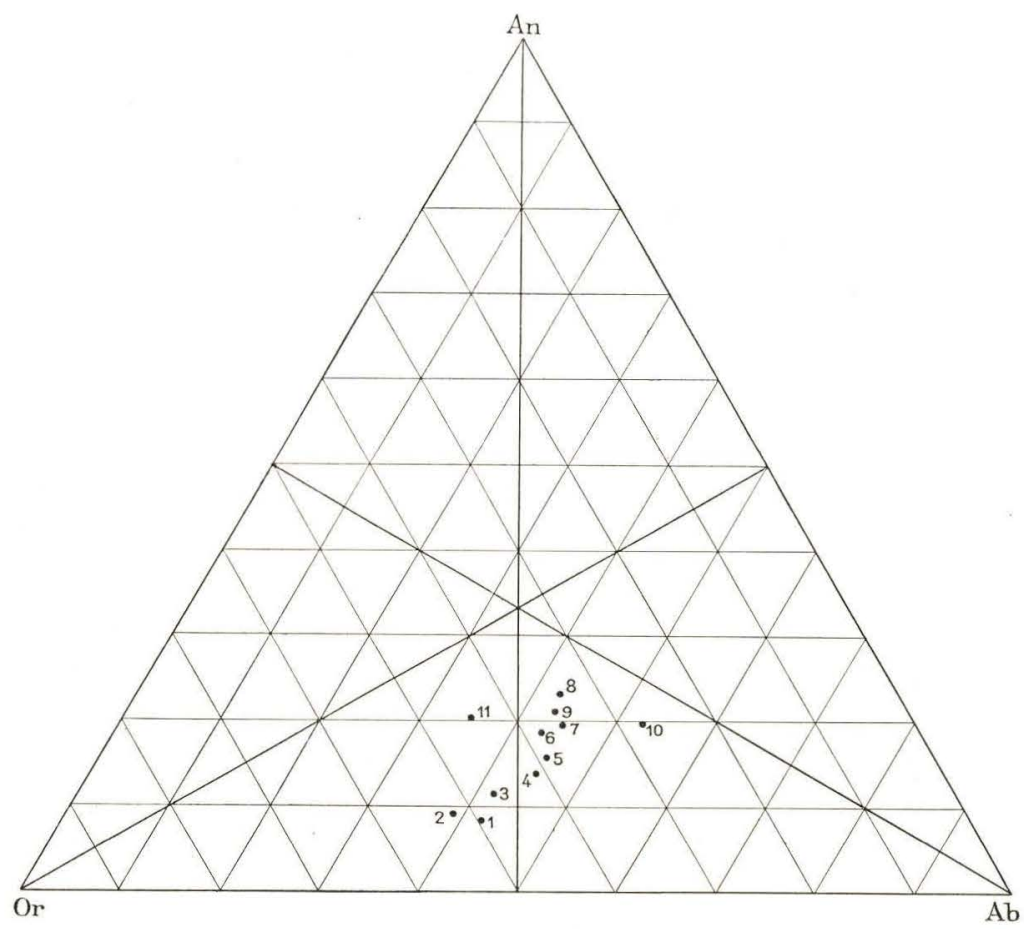

Fig. 32. Feldspatdiagramm.

Bild der Hauptzüge der Differentiationen und sind imstande, in übersichtlicher Weise die Gesteine mit den entsprechenden schwedischen vergleichen zu können. Die Analysen in der Tab. XVII sind nach der

Tab. XVII.

\begin{tabular}{|c|c|c|c|c|c|c|}
\hline & & Or & $\mathrm{Ab}$ & An & $\mathrm{SiO}_{2}$ & $\div \mathrm{Al}_{2} \mathrm{O}_{3}$ \\
\hline 1. Alminding Granit & (DEtLEFSEN) & 49.7 & 42.0 & 8.3 & 74.17 & $\div 61$ \\
\hline 2. Hammer Granit & (DitTRICH) & 52.4 & 39.0 & 8.6 & 73.77 & $\div 63$ \\
\hline 3. Hammer Granit & (DETLEFSEN) & 46.6 & 41.9 & 11.5 & 72.82 & $\div 78$ \\
\hline 4. Svaneke Granit & - & 41.3 & 45.0 & 13.7 & 69.06 & $\div 114$ \\
\hline 5. Vang Granit am Pegmatit & (DITTRICH) & 39.3 & 45.1 & 15.6 & 69.01 & $\div 316$ \\
\hline 6. Vang Granit & - & 37.9 & 42.9 & 19.2 & 66.99 & $\div 192$ \\
\hline 7. Paradisbakke Granit & - & 35.9 & 44.7 & 19.4 & 65.40 & $\div 82$ \\
\hline 8. Rönne Granit & (Detlefsen) & 34.2 & 42.8 & 23.0 & 65.39 & $\div 281$ \\
\hline 9. Rönne Granit & (DITTRICH) & 35.4 & 43.5 & 21.1 & 64.49 & $\div 261$ \\
\hline 10. Rönne Granit am Pegmatit & - ) & 27.8 & 52.5 & 19.7 & 64.13 & $\div 251$ \\
\hline 11. Uebergangsgestein d. Rönne Granits & (DETLEFSEN) & 44.9 & 34.9 & 20.2 & 63.54 & $\div 340$ \\
\hline
\end{tabular}


von H. E. Johansson ${ }^{1}$ ) angewandten Methode berechnet, wonach die Feldspatproportionen aus den Analysenwerten für Alkalien und Kalk ohne Abzug von femisch gebundenem $\mathrm{K}_{2} \mathrm{O}$ und $\mathrm{CaO}$ berechnet werden. Die Analysenpunkte geraten dadurch in eine etwas zu hohe Lage im Diagramm, und namentlich werden die hornblendeführenden Varietäten im Verhältnis zu den hornblendefreien nach oben verschoben. Ich habe diese Berechnungsart im Hinblick auf den Vergleich mit den besonders von Sundus ${ }^{2}$ ) und H. E. Johansson veröffentlichten Zusammenstellungen gewählt. Es stellt sich dann sofort heraus, dass die Bornholmer Granite im wesentlichen denselben Platz im Diagramm einnehmen wie die intermediären Gneise in der Gneisformation der Gegend von Göteborg, und dass der Rönne Granit gewissen Varietäten der grauen Plagioklasgneise desselben Gebietes entspricht ${ }^{3}$ ).

Nach Sundius (1. c., pag. 568) werden die Urgranite durch ihren durchschnittlich hohen Plagioklasgehalt sowie durch ihre starke Aufteilung in Fazies mit wechselndem Or-Gehalt charakterisiert. Das letztere wird im Diagramm durch eine horizontale Verteilung der Analysenpunkte (siehe Fig. 1 in der genannten Arbeit, pag. 586) ausgedrückt. In dem von SunduUs benutzten Material sind intermediäre Gesteinstypen, die sich wie die Bornholmer um die vertikale Mittellinie des Diagramms gruppieren, nur spärlich vertreten, doch bemerkt SundIUs, dass solche Gesteine quantitativ immerhin eine recht wichtige Rolle spielen, wenn sie auch an Verbreitung den plagioklasreicheren nachstehen. Vertreter der intermediären Gruppen sind u. a. die Loftehammargranite und der Upsalagranit. Die extremsten Kaligesteine der Urgranitgruppe (Vängegranit und roter Gneisgranit von Åtvidaberg) liegen im Diagramm der Or-Ecke etwas näher als die kalireichsten Bornholmer Granite. In seinen Diagrammen hat Sundius die Analysenpunkte desselben Gebietes mit gestrichelten Kurven verbunden, wodurch die horizontale Verteilung der Punkte markiert wird. Hierdurch wird gleichzeitig eine charakteristische Neigung des Punktfeldes nach unten zu in der Richtung der Or-Ecke hervorgehoben, die der während der Kristallisation stattfindenden Anreicherung von Quarz und Alkalifeldspat entspricht, die auf Kosten von früh ausgeschiedenem Anorthit und dunklen Mineralien vor sich geht.

Im Gegensatz hierzu treffen wir unter den jüngeren Graniten vorwiegend intermediäre Gesteine, deren Analysenpunkte sich um die vertikale Mittellinie im Diagramm (1. c., Fig. 2, pag. 586) und im Felde zwischen derselben und der Or-Ecke ansammeln. Die Differentiation

1) H. E. Johansson: G. F. F. 32. 1910, pag. 250.

2) N. Sundius: G. F. F. 43, 1921, pag. 548 ff.

$\left.{ }^{3}\right)$ H. E. Johansson: Göteborgtraktens geologi av H. Munthe, H. E. JoHansson, R. SANDEgren, 1924, pag. 32. 
zeigt sich hier hauptsächlich in einer vertikalen Verteilung der Analysenpunkte. Dies besagt, dass bei Abnahme des Gehalts an Anorthit und dunklen Mineralien und bei gleichzeitiger Zunahme des Quarzgehalts keine wesentliche Veränderung im Verhältnis von Or: Plagioklas eintritt. Besonders deutlich zeigt sich dieses Verhältnis in den Smålandsgraniten. Dagegen zeigt der Karlshamngranit bei zunehmender Azidität eine grössere Verschiebung des Or:Ab-Verhältnisses, wodurch er in dieser Hinsicht den Urgraniten nahegerückt wird.

Es geht aus diesem Vergleich hervor, dass weder die Differentiation, noch die chemischen Verhältnisse der Gesteine oder die Feldspatproportionen eine Entscheidung der Frage bringen, inwieweit die Bornholmer Granite zu der älteren oder der jüngeren Gruppe gerechnet werden müssen. Aus Sundius' Darstellung ist es ersichtlich, dass Gesteine mit einem intermediären Feldspatverhältnis in beiden Gruppen auftreten, und dass eine ziemlich geringe horizontale Verteilung der Analysenpunkte offenbar für Gesteine dieser Zusammensetzung charakteristisch ist. Jedenfalls dürfte der intermediäre Charakter der Bornholmer Granite nicht genügen, um sie zur jüngeren Grundgebirgsabteilung zu rechnen; dazu weist das Diagramm Fig. 32 eine viel zu ausgesprochene Uebereinstimmung mit den intermediären Göteborg Gneisen und dem Upsalagranit auf.

Als Resultat dieser Untersuchung ergibt sich somit, dass die Alterslage der Bornholmer Granite sich zwar nicht mit Sicherheit entscheiden lässt, dass aber immerhin die meisten geologisch-petrographischen Charakteristika in die Richtung der Gneisgranite der älteren Grundgebirgsabteilung deuten. Für meine Auffassung der Bornholmer Granite als Gneisgranite sind vor allen Dingen folgende Kennzeichen entscheidend gewesen: die granulierte Struktur der Gesteine, die mehr oder weniger entwickelte Parallelstruktur und vor allem die in Einzelheiten auftretende Differentiation und die schlierenartige Anordnung der Differentiate, die den Gesteinen einen gneisartigen Habitus verleihen. - Ferner kann ich nicht umhin, hinzuzufügen, dass die äussere Aehnlichkeit zwischen den Granitvarietäten aus Bornholm und den Gneisgesteinen aus Südschweden sowie die Uebereinstimmung der mikroskopischen Struktur in vielen Fällen so schlagend sind, dass man sich unwillkürlich von der Zusammengehörigkeit Bornholms mit dem uralten südschwedischen Grundgebirge überzeugt fühlt. 


\section{Diabas.}

Diabasgänge kommen auf Bornholm sehr zahlreich vor. Sie treten überall innerhalb des Granitgebiets auf ${ }^{1}$ ), sind aber nirgends in den sedimentären Bildungen gefunden worden. Die Gänge durchsetzen den Granit vertikal oder weichen nur wenige Grade von der vertikalen Lage ab. Die Mächtigkeit variiert von $20-30 \mathrm{~cm}$ bis zu $60 \mathrm{~m}$, meistens aber sind die Gänge ganz schmal, so dass eine Mächtigkeit von 2-4 m schon für ansehnlich gerechnet werden muss. Der mächtigste Gang ist der Kjeldseaa [Kjeldsebach]-Diabasgang, der bei Saltuna eine Breite von $60 \mathrm{~m}$ erreicht. Grosse Gänge gibt es ferner bei Kaas, südöstlich von Tejn $(40 \mathrm{~m})$ und bei Listed $(30 \mathrm{~m})$. Kleine Gänge treten stellenweise in Schwärmen auf, besonders an der Küstenstrecke zwischen Helligdommen und Tejn. An solchen Stellen beobachtet man ein sich oft wiederholendes Wechseln von Diabas und Granit, wo sowohl die Gänge als auch die Zwischenräume auf $20 \mathrm{~cm}$ und weniger heruntergehen können. Die Diabasgänge haben in derartigen Schwärmen vorwiegend eine gleichartige Richtung, können aber in Einzelheiten unregelmässig verlaufen und auskeilen.

Die grosse Mehrheit der Gänge ist nur in den kahlen Uferfelsen längs der Küste sichtbar, während sie weiter drinnen im Lande gewöhnlich unter der Erddecke verborgen liegen. Die weitaus meisten von ihnen beobachtet man längs der NO Küste, was natürlich damit zusammenhängt, dass diese Küstenstrecke quer zur Richtung der Diabasgänge verläuft. Die Streichrichtungen der Gänge sind im grossen und ganzen gleichartig, von ungefähr genau $\mathrm{N}-\mathrm{S}$ bis $\mathrm{NO}-\mathrm{SW}$ variierend. Es liegen Messungen von einigen 70 Gängen vor, die von Johnstrup, Ussing, O. B. BøGGILD und dem Verfasser ausgeführt worden sind; in Anbetracht

1) Sonderbarerweise gibt H. KLÄHN (Sitzungsber. u. Abhandl. d. naturf. Ges. Rostock, III. Folge, Bd. 1) an, Diabas sei südlich von einer Linie von »Frederiks Stenbrud"bis Jons Kapel nicht beobachtet worden, obgleich derselbe Forscher mehrmals die Kartenblatterläuterung zitiert (D. G. U., I, Nr. 13), wo u. a. kaolinisierte Diabasgänge in der Kaolingrube vom Tornewerk bei Rönne sowohl erwähnt als abgebildet sind. 
dessen, dass die Gänge sich meistens nur auf kurze Strecken hin verfolgen lassen, ist die Uebereinstimmung der Streichrichtungen auffallend gross. Die grösste Abweichung kommt in Gängen des Hammer Granits vor, so u. a. N $55^{\circ} \mathrm{W}$ von einem Gange beim Hause des Feuerwärters und $\mathrm{N} 25^{\circ} \mathrm{W}$ von einem Gange südlich von Allinge.

K. A. Grönwall und V. Milthers ${ }^{1}$ ) haben früher darauf aufmerksam gemacht, dass die Richtungen der Diabasgänge im wesentlichen mit denen der Spaltentäler zusammenfallen. Dies rührt zweifellos daher, dass der Diabas bei seinem Vordringen den Schwächezonen des Granitfelsengrundes gefolgt ist und stellenweise zur Bildung der Spaltentäler beigetragen hat. Die Diabasgänge sind keinen grösseren Erdkrustenbewegungen ausgesetzt gewesen, dagegen sind hie und da Spuren kleinerer Verwerfungen vorhanden, z. B. gibt es im Diabas bei Saltuna einige schön gestreifte Rutschflächen.

Das Gestein der Diabasgänge ist Olivindiabas; es ist in vielen Fällen ausgezeichnet erhalten. Die Struktur ist häufig ophitisch, in einigen Gängen porphyrisch, und in einzelnen Gängen ist das Gestein als Mandelstein ausgebildet. Die Zusammensetzung variiert etwas nach dem Mengenverhältnis von Olivin und monoklinem Pyroxen. In einzelnen Gängen ist Hypersthen untergeordnet vorhanden. Biotit tritt häufig, braune und grüne Hornblende seltener auf. Serpentin ist als Umwandlungsprodukt von Olivin weit verbreitet, und in einigen Gängen ist der Diabas unter Ausscheidung von Serizit, Serpentin, Chlorit, Kalkspat, Quarz u. s. w. stark zersetzt, was davon zeugt, dass sich eingreifende Umwandlungsvorgänge während des letzten Stadiums der Kristallisation des Diabasmagmas oder nach dessen Verfestigung abgespielt haben. In einigen Fällen hat auch das Granitnebengestein hierbei eine radikale Umwandlung erlitten, so ist z. B. der Granit längs des Diabasganges bei Salene, wo auch der Diabas selber stark umgewandelt ist, ausgesprochen epidotisiert. Bei Ypnasted sind sowohl der Diabas als auch das Granitnebengestein unter Ausscheidung von Chlorit, Kalkspat, Quarz u. s. w. stark zersetzt. Auf Hammeren gibt es im Granit mehrere Kalkspatgänge, welche zweifellos benachbarten Diabasgängen ihre Entstehung verdanken. Neben Kalkspat kommen kleinere Mengen von Quarz und Serpentin in der Füllmasse vor. Eine Kontakteinwirkung mit teilweiser Aufschmelzung des Nebengesteines ist nur längs des Kjeldseaa-Diabasganges beobachtet worden.

Der Diabas ist überall von zahlreichen Spalten durchsetzt, was in Verbindung mit der erwähnten Zersetzung eine kräftige Erosion befördert hat. Die Diabasgänge treten daher in der Regel als Vertiefungen

1) K. A. Grönwall og V. Milthers: (Kartenblatterläuterung). D. G. U. I. R. Nr. 13. 1916. V. Milthers: D. G. U., V. R., Nr. 1, 1916, pag. 17. (2. Udg. 1930, pag. 24). 
im Gebiet auf; an einigen Stellen sind sie so vollständig zerstört, dass der Diabas nur noch im Boden von Klüften (z. B. Jons Kapel) vorhanden ist, und an mehreren Stellen an der Küste werden derartige Klüfte, wo die Diabasgänge ganz erodiert sind, als kleine Bootshäfen benutzt. Die härteren Varietäten des Diabases wurden früher auf Bornholm als Zapfenlager [sogen. »Sölesten«] in den Mühlen verwendet.

Die Diabasgänge auf Bornholm sind wiederholt in der geologischen Literatur erwähnt worden. Schon Ørsted, Esmarch und VARgas BedeMAR berichten von mehreren Beobachtungen von Diabas (Grünstein und Grünsteingänge). Die ausführlichste Darstellung der petrographischen Beschaffenheit des Diabases verdanken wir CoHen und DeEcke (1891); später hat Ussıng auf wesentlichen Punkten unsere Kenntnisse von den Diabasgängen vervollständigt. Im folgenden werden die wichtigsten Gänge ausführlicher besprochen.

\section{Der Diabas von Kjeldseaa.}

Der Diabasgang von Kjeldseaa ist der mächtigste von allen Diabasgängen auf Bornholm. Wir können ihn von den Uferfelsen bei Saltuna an der Nordostküste Bornholms an durch das KjeldseaaTal hindurch bis zu einem Punkte gegenüber dem Flæskedals-Hus, etwa $1300 \mathrm{~m}$ WNW von der Station Aalöse, verfolgen. Auf dieser etwa $6 \mathrm{~km}$ langen Strecke tritt der Diabas hie und da zu Tage. Südwestlich von der Eisenbahnlinie Aakirkeby - Gudhjem ist jedoch ausser der genannten südlichsten Lokalität nur noch ein Vorkommen von feststehendem Diabas gefunden worden, nämlich an der östlichen Talseite bei Gamle Toftegaard in Skrulle. Geschiebe von diesem sehr charakteristischen Diabas trifft man dagegen häufig im Tale des Baches, und sie zeugen zweifellos von der unmittelbaren Nähe des Ganges. Da die Diluvialschrammen in diesem Teil der Insel vorwiegend die gleiche Richtung wie das Kjeldseaa-Tal haben, darf man annehmen, dass die Geschiebe des Diabases fast ausschliesslich in der Richtung des Ganges befördert worden sind. Nordöstlich von der Eisenbahn kommt der Diabas dagegen an verschiedenen Stellen im Tale des Baches vor. Auf einer Strecke von etwa $700 \mathrm{~m}$ zwischen Lille Frigaard und Hullegaard liegt er fast ohne Unterbrechungen in der rechten Talseite, wo er hohe, oft senkrechte Felsenwände bildet. Bei Saltuna trifft man ihn im Ufer unmittelbar östlich von der Kjeldseaa-Mündung. Hier wie überall, wo dieser Diabas gefunden wurde, ist nur die Ostseite des Ganges aufgeschlossen. Während der Granit der Uferfelsen sich an der Ostseite ziemlich steil erhebt, liegt der Diabas hier in einer Niederung. Die Westgrenze und der grösste Teil des Ganges sind von Schottern und grossen 
erratischen Blöcken verdeckt. Der Gang ist hier etwa $60 \mathrm{~m}$ breit, die Streichrichtung ist $\mathrm{N} 40^{\circ} \mathrm{O}$. Er durchsetzt fast vertikal den Granit; bei Saltuna ist die Grenze jedoch unregelmässig windschief.

Dieser grosse Diabasgang ist in der geologischen Literatur relativ unbeachtet geblieben. Er wird zwar von ØRSTED und Esmarch ${ }^{1}$ ) und später von Forchнамmer ${ }^{2}$ ) erwähnt, sie fassen ihn aber als eine »Einlage im Gneise auf und schreiben, dass er aus Diorit mit Uebergang zum Gabbro bestehe. CoHen und DeEcke ${ }^{3}$ ), die den Gang nicht selbst gesehen haben, sondern das Gestein nur durch von anderen eingesammelte Handstücke kennen, vermuten, dass diese Proben von einem erratischen Block aus Aasbydiabas herrühren. In der Kartenblatterläuterung (D. G. U., I. R., Nr. 13, 1916, pag. 18) wird der Gang nur mit ein paar Zeilen erwähnt, in denen auf CoHen und DeEcke verwiesen wird. Ussing erwähnt $1904^{4}$ ) zum ersten Male diesen Diabas als einen Gang, während er ihn in der ersten Ausgabe von »Danmarks Geologi«, 1899, vorsichtig "eine Grünsteinmasse, wohl die grösste auf Bornholm« nennt. Ussing hebt die grobkörnige Beschaffenheit des Diabases und die Streichrichtung des Ganges, die von der der übrigen Diabasgänge etwas abweicht, hervor. Im Jahre $1910^{5}$ ) teilt er ausserdem mit, dass sich derselbe durch eine granitporphyrische Randzone auszeichnet. Im übrigen enthält sein Tagebuch für 1899 eine Reihe von Beobachtungen, denen ich ganz und gar beipflichten kann.

Der Diabas des Kjeldseaa-Ganges erinnert in seinem Aeusseren sofort auffallend an den Aasbydiabas, mit dem er ebenfalls in Bezug auf Struktur und Mineralbestand übereinstimmt. Wo er im Tale des Baches grössere Felsenpartien bildet, ist er in einem bemerkenswerten Grade frei von Rissen und daher sehr widerstandsfähig, so dass er mit abgerundeten Kanten und glatten Seiten auftritt. Der Diabas ist grobkörnig oder sogar grosskörnig. Besonders grobkörnige Partien scheinen als Klumpen oder Schlieren, die in auffallendem Masse ohne Risse sind, vorzukommen. In derartigen Partien können die tafelförmigen Plagioklaskristalle eine Länge von $2 \mathrm{~cm}$ und eine Dicke von 2-3 $\mathrm{mm}$ erreichen. Nach der Grenze zu wird das Gestein mittelkörnig und direkt am Kontakt ziemlich feinkörnig, doch ist es überall deutlich kristallinisch; ein dichtes Salband ist nirgends beobachtet worden. Die Farbe ist grau und verhältnismässig hell, was den makroskopisch stark hervortretenden

1) H. C. Ørsted und L. Esmarch: Beretning om en Undersogelse over Bornholms Mineralrige, udført 1819, Kjøbenhavn 1820, pag. 21.

2) Forchinamer: Danmarks geognostiske Forhold. Universitetsprogram 1835, pag. 21.

3) Cohen und Deecke, 1891, pag. 58.

4) Ussing: Danmarks Geologi, 2. Udg. 1904, pag. 42.

5) Ússing: Dänemark (Handb. d. Reg. Geol., I, 2. Abt.), 1910, pag. 4. 
Plagioklaskristallen zuzuschreiben ist. In der Regel hat er infolge der Chloritbildung einen grünlichen Schimmer erhalten. Im grossen und ganzen ist der Diabas recht frisch; wo eine Verwitterungskruste vorhanden ist, ist diese kaum $1 \mathrm{~mm}$ stark.

Das Gestein ist ein Olivindiabas vom Aasbydiabas-Typus. Die Hauptgemengteile sind Plagioklas, Olivin und Augit, die beiden letzteren in ungefähr gleichem Mengenverhältnis. Dazu kommen titanhaltiger Magnetit, Biotit, grüne Hornblende und Apatit, sowie sehr kleine Mengen von Hypersthen, Mikroklin und Quarz und schliesslich lokal wechselnde Mengen von Serpentin, Chlorit, Epidot und Kalkspat.

Die Struktur des Diabases ist etwas variierend. In der Regel ist sie ophitisch und kann ausserordentlich schön und typisch entwickelt sein, besonders in den feinkörnigen Partien in einiger Entfernung vom Salband. In der Gangmitte, vor allem in den grobkörnigen, klumpenförmigen Partien des Diabases, ist die Struktur eher gabbroid, indem der Plagioklas hier relativ dicke Tafeln bildet und oft eine ziemlich unregelmässige Form hat, wobei gleichzeitig der Augit eine schwache Tendenz zu selbständiger Kristallbegrenzung zeigt. Augit und Olivin haben in solchen Varietäten die Neigung, sich in Haufen zu sammeln, während der Plagioklas hie und da sternförmige Aggregate bildet. Unmittelbar am Granitkontakt ist die Struktur etwas porphyrisch, indem der Olivin in verhältnismässig grossen Körnern auftritt, die meistens in Haufen gesammelt liegen.

Der Plagioklas ist zonar gebaut, doch in der Regel ohne scharfe Grenze zwischen den Zonen. Zwillingsbildung nach dem Karlsbadergesetz kommt häufig neben der gewöhnlichen Lamellierung nach dem Albit- und Periklingesetz vor. Ein vereinzelter Bavenozwilling wurde beobachtet. Im grosskörnigen Diabas in der Gangmitte besteht die Mitte des Plagioklases aus basischem Labrador mit etwa 70\% An., die Randzone aus Oligoklas mit etwa 20\% An. Im feinkörnigen Gestein nahe der Ganggrenze steigt der Anorthitgehalt, so dass man den Plagioklas hier als Bytownit mit bis zu $83 \%$ An. bezeichnen kann. $2 \mathrm{~V}$ ist beinahe $90^{\circ}$. In diesen Kristallen sind Karlsbaderzwillinge selten. Von den Messungen führe ich folgende an:

\begin{tabular}{|c|c|c|c|c|c|c|c|}
\hline \multirow{2}{*}{\multicolumn{4}{|c|}{$\begin{array}{c}\text { Plagioklase des Diabases: } \\
\perp \mathrm{MP}\end{array}$}} & \multicolumn{2}{|c|}{ Mitte } & \multicolumn{2}{|c|}{ Randzone } \\
\hline & & & & $\alpha^{\prime}: \mathrm{M}$ & $\% \mathrm{An}$. & $\alpha^{\prime}: \mathrm{M}$ & $\%$ An. \\
\hline \multicolumn{4}{|c|}{ Grosskörniger Diabas, Kjeldseaa.......... } & $36^{\circ} 30^{\prime}$ & 69 & $+1^{\circ} 00^{\prime}$ & 21 \\
\hline 》) & " & $\Rightarrow \quad$. & $\ldots \ldots \ldots$ & $37^{\circ} 00^{\prime}$ & 70 & $0^{\circ} 00^{\prime}$ & 20,5 \\
\hline$"$ & 》) & $"$ & $\ldots \ldots \ldots$ & $37^{\circ} 00^{\prime}$ & 70 & $\div 1^{\circ} 00^{\prime}$ & 20 \\
\hline Mittelkörniger & 》 & " & $\ldots \ldots \ldots$ & $38^{\circ} 30^{\prime}$ & 77 & $2^{\circ} 40^{\prime}$ & 22 \\
\hline \multirow{2}{*}{\multicolumn{4}{|c|}{$\begin{array}{ccc}\text { Ziemlich feinkörn. Diabas, Saltuna.......... } \\
\text { » }\end{array}$}} & $37^{\circ} 30^{\prime}$ & 73 & $4^{\circ} 00^{\prime}$ & 23 \\
\hline & & & & $40^{\circ} 00^{\prime}$ & 83 & $15^{\circ} 30^{\prime}$ & 30 \\
\hline
\end{tabular}


In mehreren Partien des Diabases ist der Plagioklas völlig klar. Fremde Einschlüsse sind sehr selten, hie und da findet man Apatit und in einzelnen Kristallen zahlreiche feine nadelförmige, stark doppelbrechende Mikrolite. In den gröberen Varietäten des Gesteins setzen sich die äussersten Schichten des Plagioklases oft in die Zwickel zwischen den Leisten hinaus fort, und hier tritt in einzelnen Fällen Mikroklin in paralleler Verwachsung mit dem Plagioklase auf; meistens wird der Mikroklin von kleinen Q uarzkörnern, Biotit und Erzkörnern begleitet. Es geht daraus hervor, dass der letzte Kristallisationsrest des Diabasmagmas stellenweise eine granitische Zusammensetzung erreicht hat. Im übrigen ist der Plagioklas in anderen Partien des Diabases mehr oder weniger stark in Serizit und Epidot umgewandelt. In einer Probe des Diabases, die eine $1 \mathrm{~cm}$ breite epidotgefüllte Spalte enthält, ist der Plagioklas unter reichlicher Ausscheidung von Epidot saussuritisiert, vom Plagioklas ist nur noch der Albit übrig.

Der Olivin ist farblos oder hell gelblichgrau. Nur äusserst selten zeigt er eine Andeutung von Kristallform. $2 \mathrm{~V} \alpha$ wird auf etwa $80^{\circ}$ geschätzt, der Fayalitgehalt beträgt also gegen $40 \%$. Der Olivin schliesst ganz oder teilweise kleine wohlentwickelte Kristalle aus Plagioklas und Apatit sowie einige Erzkörner ein. In vielen Fällen findet man zahlreiche feine, nadelförmige Einschlüsse aus Magnetit oder Titaneisen, die parallel der optischen Normalen angeordnet sind. Flüssigkeitsinterpositionen mit stationärer Libelle sind nicht selten vorhanden. Im frischen Gestein ist der Olivin ausserordentlich wohl erhalten, während er in anderen Partien unter Ausscheidung von Eisenerz ganz oder teilweise in Serpentin umgewandelt ist. Einige der Pseudomorphosen sind ziemlich stark doppelbrechend und deutlich pleochroitisch: $\alpha^{\prime}$ rotgelb, $\gamma^{\prime}$ blaugrün; in einem späteren Stadium der Umwandlung aber verschwindet erst die Doppelbrechung, dann später der Pleochroismus. Manchmal hat sich das Eisenerz in eleganten Kristallskeletten ausgeschieden, die sich in einigen Fällen zwischen die angrenzenden Mineralien hineinkeilen, während die Olivinpseudomorphosen selber nur von sehr feinen, dunklen Partikelchen getrübt sind. Wo die Umwandlung am weitesten vorgeschritten ist, ist jede Spur der ursprünglichen Olivinkörner verschwunden, und andere Umwandlungsprodukte wie Biotit, Serpentin, Chlorit, Kalkspat und kleine Körner von Albit sowie Epidot und Amphibol in farblosen oder grünen, zum Teil stengligen Aggregaten füllen die Zwischenräume in den Eisenerz-Kristallskeletten aus und verzweigen sich zwischen die übrigen Mineralien des Gesteins hinein. Es ist in solchen Fällen nicht möglich $\mathrm{zu}$ entscheiden, wie viele von diesen Aggregaten dem Olivin und wie viele dem Augit ihre Entstehung verdanken. Quarz habe ich in keinem dieser Aggregate gefunden. Im frischen Diabas ist die Grenze 
zwischen Olivin und Plagioklas völlig rein und scharf, nicht selten gibt es aber zwischen diesen Mineralien eine schmale Zone, die aus stengligen oder buschigen Aggregaten aus Hornblende und Biotit besteht.

Der Augit ist im Dünnschliff fast gänzlich farblos oder graugelb, seltener hat er einen schwach rötlichen Ton. Pleochroismus lässt sich nur selten feststellen. Zwillinge nach (100) sind hie und da vorhanden. Schnitte $\perp$ zur optischen Achse B zeigen Dispersion $\varrho>v .2$ E wurde mit Schraubenmikrometerokular zu 91 gemessen. c: $\gamma=$ etwa $45^{\circ}$. Manchmal führt der Augit Glas- oder Flüssigkeitsinterpositionen, davon einige mit stationärer Libelle.

Längs der Peripherie ist der Augit oft in stärkerem oder schwächerem Masse in uralitische Hornblende umgewandelt. Die neugebildete Hornblende ist hellgrün oder bräunlich-grün und stark pleochroitisch. Die Doppelbrechung ist etwas höher als bei gewöhnlicher Hornblende. Bisweilen ist sie in unmittelbarer Nähe des Augits sehr hell, während der äusserste Rand stark gefärbt und pleochroitisch ist: $\alpha$ grünlich-gelb, $\gamma$ tief bläulich-grün. Wo der Augit nach (100) verzwillingt ist, setzt sich dieselbe Zwillingsbildung in der Hornblende fort. Manchmal ist die Hornblende über die ursprüngliche Kontur des Augits, die jedoch in einigen Fällen deutlich nachweisbar ist, hinausgewachsen und verzweigt sich in Läppchen zwischen die sie umgebenden Feldspatkristalle hinein. Sehr oft ist die periphere Hornblende weiter in Biotit umgewandelt, seltener in Chlorit, der bisweilen mit der Hornblende parallel verwachsen, in anderen Fällen in kleinen buschigen Blättern von derselben hinausgewachsen ist. Ganz dieselben Phänomene sind früher ausführlich von R. D. Irving und C. R. van Hise ${ }^{1}$ ) sowie von F. Becke ${ }^{2}$ ) beschrieben und abgebildet worden.

In der Hornblende treten oft dunkle, stark pleochroitische Höfe rings um äusserst kleine, braune oder klare Kristallkörner, wahrscheinlich Rutil, auf. Diese Kristalle sind oft länglich, zigarrenförmig mit quadratischem Querschnitt, optisch einachsig, positiv, stark lichtbrechend und stark doppelbrechend.

Hypersthen wurde in kleinen Mengen gefunden, besonders im feinkörnigen Gestein in der Nähe der Grenze. Er fällt wegen seines, wenn auch schwachen so doch deutlichen Pleochroismus auf. Der optische Achsenwinkel ist ziemlich gross.

Eisenerz tritt als primärer Gemengteil am häufigsten in den Zwickeln zwischen den Plagioklasleisten oder in Augit und Olivin eingeschlossen auf. So gut wie alle Erzkörner lassen sich leicht aus

1) R. D. Irving and C. R. van Hise: U. S. G. S. Monographs 19, 1892, pag. $353-54$ und $411 \mathrm{ff}$.

2) F. Becke: Tschermak's Min. u. Petr. Mitth. 5, pag. 158 und 171. 
dem Gesteinspulver mittels eines gewöhnlichen Handmagneten ausziehen. Das extrahierte Material ist stark magnetisch und zum Teil in Salzsäure löslich; der Rest gibt beim Kochen mit Zinn und Salzsäure eine Titanreaktion. Das Erz muss somit als titanhaltiger Magnetit bezeichnet werden. Eisenkies tritt in kleinen Mengen, manchmal intim mit Magnetit verwachsen, auf.

A patit ist in verhältnismässig grossen wohlentwickelten Kristallen, die bis $0,1 \mathrm{~mm}$ im Diameter und 0,5 mm Länge erreichen, vorhanden. Die aneinander gereihten Kristalle sind bisweilen mit ihren Basisflächen verwachsen.

Biotit ist relativ reichlich vertreten. In einigen Handstücken von Diabas ist er sogar makroskopisch sichtbar und kann eine Grösse von $1-2 \mathrm{~mm}$ erreichen. Meistens ist er braun, manchmal grün. Häufig findet man stark pleochroitische Höfe rings um kleine Mineralkörner, wahrscheinlich Rutil; in vielen Fällen sind die Höfe in konzentrische Zonen verschiedener Stärke aufgeteilt. Der Biotit umgibt fast sämtliche Erzkörner in Gestalt eines schmalen Randes, der sich mit einer mehr oder weniger gezackten Kontur in den angrenzenden Plagioklas hineinerstreckt. Zweifellos ist dieser Biotit autometamorphisch durch Umwandlungsreaktionen, die von den letzten Lösungsresten des Magmas verursacht worden sind, auf die Art entstanden, wie sie SEDERHoLm ${ }^{1}$ ) ausführlich beschrieben hat. Der Glimmergehalt ist am grössten in den am stärkesten umgewandelten Partien des Diabases, und der Biotit tritt dort in ziemlich weit verzweigten, buschigen Aggregaten auf, die zum Teil an die Erzkörner geheftet sind, von denen zum mindesten einige mit skelettförmiger Entwicklung als sekundäre Ausscheidungen des Olivins angesehen werden müssen. In zersetzten Diabasproben findet man in der äusseren Zone der Augitkörner zahlreiche kleine Blätter von Biotit; sie scheinen fast immer an Risse im Augit geknüpft zu sein, fehlen aber beinahe ganz in den besterhaltenen Proben des Diabases. Ferner findet man, wie schon erwähnt, Biotit als weiteres Umwandlungsprodukt von uralitischer Hornblende. In vielen Fällen ist der Biotit zum Teil weiter in Chlorit umgewandelt. Ausserdem aber tritt der Biotit, wie oben gesagt, zusammen mit Mikroklin und Quarz als Füllmasse in den Zwickeln zwischen den Feldspattafeln auf. Der Biotit ist hier zweifelsohne ein im eigentlichsten Sinne primäres, vom letzten Restmagma des Diabases auskristallisiertes Mineral, das durch Anreicherung von Kali und freier Kieselsäure eine granitische Zusammensetzung erlangt hat. Unter diesen Mineralien treten bisweilen Erzkörner auf, die einen biotitfreien, scharfen Kontakt mit dem Plagioklase haben.

Kalkspat kommt im allgemeinen nur spärlich im Diabase vor und

1) J. J. Sederholm: Bull. de la Comm. Géol. de Finlande, No. 48, 1916, pag. $3-4$. 
wenn, dann mit Chlorit und anderen Umwandlungsprodukten zusammen; manchmal findet man ihn als langgedehnte Einlagerungen im Biotit, die parallel mit den Spaltflächen des Glimmers angeordnet sind. Als Füllmasse der Spalten im Diabase dagegen kann er in auffallender Menge angereichert sein. Er wird dann von reichlichen Epidotausscheidungen, Serpentin, manchmal Albit, kleinen Mengen von Prehnit und Eisenkies begleitet.

Die Spaltenausfüllungen bestehen in einigen Fällen nur aus Epidot, stellenweise aber haben sie einen fast symmetrischen Aufbau, in welchem zuerst Epidot längs der Wände der Spalten auskristallisiert ist; etwas später hat dann die Kristallisation des Albits eingesetzt, wonach diese beiden Mineralien gleichzeitig weiter gewachsen sind; in kleineren Hohlräumen findet man sie bisweilen als schön entwickelte Kristalle. Danach haben sich Prehnit und Serpentin ausgeschieden, und zuletzt hat Kalkspat den grössten Teil der übriggebliebenen Hohlräume ausgefüllt.

Der Serpentin ist dicht, in der Regel dunkelgrün, seltener hell gelbgrün. Er tritt hie und da in kugel- oder schalenförmigen Aggregaten auf. Wo die Serpentinkugeln von Kalkspat umgeben sind, beobachtet man eine eigentümliche Verwachsung der beiden Mineralien, bei der die äusserste Zone der Serpentinkugel so stark mit Kalkspat imprägniert ist, dass die Spaltflächen des Kalkspats als nur etwas schwächer reflektierende Spaltflächen durch einen grossen Teil des Serpentins hindurch fortsetzen.

Epidot tritt in Form von gelbgrünen oder dunkelgrünen körnigen Massen und als ziemlich wohlentwickelte, dunkelgrüne, durchscheinende Kristalle auf. Von Kristallformen fand ich durch Messung: (001), (100), (010), (101), (101), (102), (210). Der Winkel der optischen Achsen ist etwa $80^{\circ}$. Dispersion der optischen Achse A : $\varrho<v$. Doppelbrechung negativ.

Die Albit-Kristalle sind tafelförmig, ein paar Millimeter dick, bis $8 \mathrm{~mm}$ lang und bis $5 \mathrm{~mm}$ breit. Sie sind nach dem Albitgesetz verzwillingt. Von Kristallformen wurden beobachtet: (001), (010), 110), (1 $\overline{1} 0)$, (130), (1 $\overline{3} 0),(\overline{1} 01),(\overline{1} 1 \overline{1})$. In Basisspaltstücken wurde gemessen $\alpha^{\prime}:$ M $=3,5^{\circ}$.

Prehnit kommt im grossen und ganzen recht spärlich vor. Er tritt stellenweise in skelettartigen Aggregaten, deren Hohlräume mit Kalkspat gefüllt sind, auf, bildet aber auch unregelmässige, zum Teil blättrige Aggregate. Viele der Prehnitkörner zeigen die gewöhnlichen abnormen optischen Erscheinungen, indem sie zwischen gekreuzten Nicols bei keiner Stellung dunkel werden; während der Umdrehung können einige Teile eines Kristalls blau, andere lederbraun verbleiben. Von einem solchen Felde zum anderen variiert der optische Achsenwinkel beträchtlich; mit Schraubenmikrometerokular wurde (bei Tageslicht) 
$2 \mathrm{E} \mathrm{zu} 59^{\circ}, 67^{\circ}$ und $102^{\circ}$ gemessen. Die positive Doppelbrechung ist stark. Dispersion um Bisektrix $\gamma$ ist kräftig, in Kristallen mit kleinem $2 \mathrm{E}$ war $\varrho<v$, und in Kristallen mit grossem $2 \mathrm{E}$ war $\varrho>v$; einige Körner zeigten gekreuzte Dispersion.

Die Kristallisation des Diabases lässt sich somit in Kürze folgenderweise zusammenfassen: in der ersten Phase haben sich Apatit und basischer Labrador oder Bytownit ausgeschieden, wogegen das Wachstum der äusseren und saureren Teile des Plagioklases sich während der Auskristallisation der folgenden Mineralien fortgesetzt hat. Von diesen haben zuerst Titanomagnetit und Olivin zu kristallisieren angefangen, etwas später Hypersthen und Augit. Am Ende der Kristallisation des Magmas ist nur ein geringer Magmarest in den Zwischenräumen der früheren Mineralien übrig geblieben. Während der Bildung der saureren Plagioklaszonen sind Kali und freie Kieselsäure in diesem Restmagma angereichert worden, welches nun mit den früher auskristallisierten femischen Gemengteilen unter Ausscheidung von Biotit und Hornblende reagiert. Stellenweise sind ganz kleine Mengen eines Restmagmas von granitischer Zusammensetzung auskristallisiert. Bei genügend grossem Wassergehalt in der Restlösung haben sich der Biotit in Chlorit, der Olivin in Serpentin umwandeln und weitere ähnliche Vorgänge sich abspielen können. Durch epimagmatische Prozesse werden Epidot und Serpentin an Spalten im Diabase, wo zugleich Albit, Prehnit und Kalkspat ausgeschieden werden, angereichert.

\section{Kontaktwirkungen des Kjeldseaa-Diabases auf das Nebengestein.}

Wie schon erwähnt, teilt Ussing ${ }^{1}$ ) mit, dass der Diabasgang bei Saltuna sich durch eine granitporphyrische Randzone auszeichnet. Die genauere Untersuchung der Gesteine, die es Ussing nicht vergönnt war vorzunehmen, zeigt indessen unwiderlegbar, dass dieser "Granitporphyr durch Kontaktwirkung des Diabases auf das Nebengestein entstanden ist.

Die Kontaktverhältnisse können am besten bei Saltuna studiert werden, wo die Ostgrenze des Ganges auf einer 10-12 m langen Strecke aufgeschlossen ist. Ferner gelang es mir, die granitporphyrische Kontaktzone zwischen Diabas und Granit an zwei neuen Lokalitäten im Kjeldseaa-Tal zu finden, und zwar bei Gamle Toftegaard in Skrulle und gegenüber Flæskedals Hus bei Aalöse.

Die mikroskopische Untersuchung einer Serie von Gesteinsproben, die in verschiedenen Entfernungen vom Diabase genommen sind, erklärt die Kontaktmetamorphose sehr überzeugend.

An beiden Seiten des Kjeldseaa-Diabasganges besteht der Untergrund aus ziemlich feinkörnigem, etwas porphyrischem und ausgesprochen

1) N. V. Ussing: Handbuch d. Reg. Geologie, Bd. I, 2. Abt., 1910, pag. 4. 
streifigem Gudhjem Granit (vgl. pag. 84-85). Die Farbe des Granits ist vorwiegend ein dunkles Rötlichgrau, wie es gewöhnlich auf der Strecke von hier an über Østermarie nach den Paradisbakker zu der Fall ist. Die Oberfläche ist oft etwas heller. Untergeordnet treten kleine Partien von hellem rotem, feinkörnigem, streifigem Granit (»Hasle Granit«) auf. Pegmatitgänge und pegmatitische Schlieren kommen ausserordentlich häufig vor.

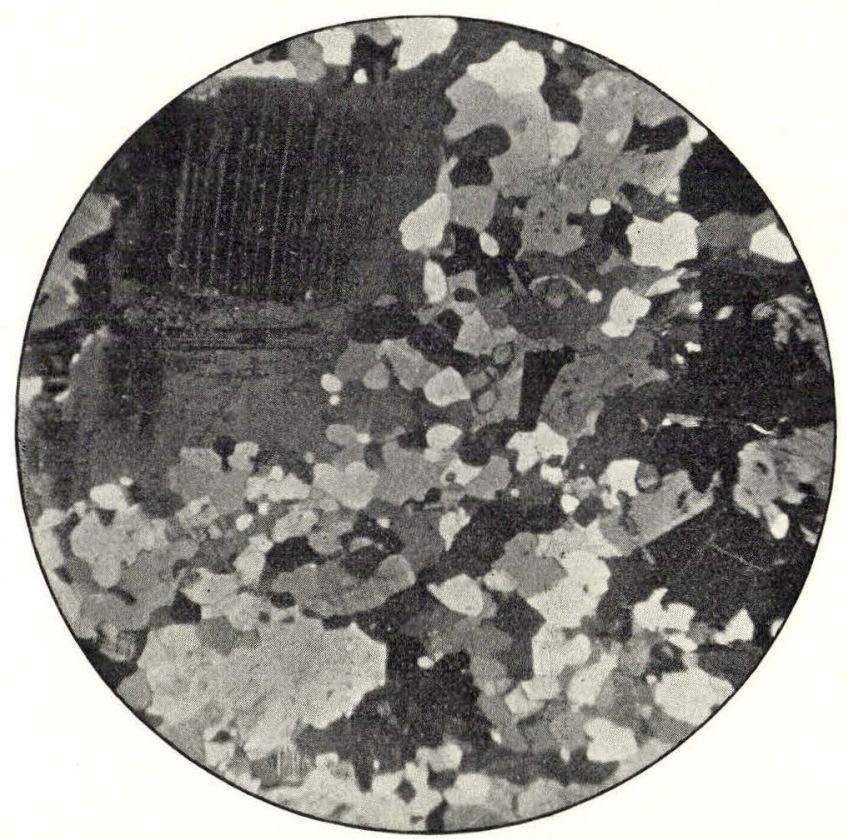

Fig. 33. Streifiger Granit, etwas porphyrisch. Etwa $100 \mathrm{~m}$ östlich vom Diabas, Saltuna. Nic. + . Vergr. $17 \times$.

In den Uferfelsen bei Saltuna tritt der feststehende Granit an der NW-Seite des Ganges erst in einer Entfernung von etwa $100 \mathrm{~m}$ vom Diabase zu Tage. Er ist völlig identisch mit dem Granit in der gleichen Entfernung an der SO-Seite des Ganges. Auf den äussersten Schären unmittelbar SO vom Diabas gibt es einen grösseren, fast horizontalen, etwa $1 \mathrm{~m}$ mächtigen Pegmatitgang. Er besteht vorwiegend aus rotem Feldspat.

Im unvervänderten, etwas porphyrischen Granit (vgl. Fig. 33 und Taf. IV, Fig. 3-5) besteht die Grundmasse aus Mikroklin, Quarz und Plagioklas mit etwa $15 \%$ An. Unter den dunklen Mineralien ist Hornblende etwas reichlicher vorhanden als es gewöhnlich im Gudhjem Granit der Fall zu sein pflegt; es ist die übliche grüne Varietät mit einem kleinen optischen Achsenwinkel. Der Biotit ist grün. Titanit bildet oft einen Kranz um Magnetit herum. Alle diese Mineralien haben unregel- 
mässige Formen, sind aber scharf konturiert. Die Einsprenglinge bestehen aus Plagioklas mit etwa 25\% An. in der Mitte und etwa 20\% An. in der Randzone. Bisweilen sind sie teilweise von parallel angewachsenem Mikroklin umgeben. In der Mitte sind sie oft etwas zersetzt. Der Durchmesser der Körner ist meistens etwa $0,5 \mathrm{~cm}$, kann aber $1-1,5 \mathrm{~cm}$ erreichen. Die äussere Form ist unregelmässig und die Kontur stark gebuchtet. Sie führen oft Einschlüsse aus Quarz und Mikroklin, meistens so, dass der Quarz vom Mikroklin umgeben ist.

In einer Entfernung von 25 m vom Diabas ist der Biotit am Rande zerfetzt und gefranst. $4 \mathrm{~m}$ vom Diabas sind in den Hornblendekristallen zahlreiche kleine Löcher oder Vertiefungen sowie Ausscheidungen von kleinen Erzpartikeln vorhanden. Der Biotit ist noch stärker gefranst, ebenfalls unter Ausscheidung von Erzpartikeln, die zum Teil die Form von skelettähnlichen Stäben haben. Die Grenze zwischen den Feldspatkörnern ist etwas wollig. Makroskopisch hat sich der Granit hierdurch nicht sonderlich verändert, macht aber sozusagen einen etwas kompakteren Eindruck.

In einer Entfernung von etwa 1 m vom Diabas zeigen die Dünnschliffe eine durchgreifende Umwandlung des Granits. Hornblende und Biotit sind nun stark zerfetzt und von zahlreichen Erzpartiklen durchsetzt (vgl. Taf. VII, Fig. 1). In und zwischen den Feldspatkörnern treten mikropegmatitische Verwachsungen von Mikrolin und Quarz in grosser Menge auf, doch ist der ursprüngliche Aufbau des Gesteins aus grösseren und kleineren Körnern deutlich zu erkennen (Taf. VII, Fig. 2). Es ist charakteristisch, dass die Mikropegmatitbildung damit anzufangen scheint, dass sich etwas innerhalb des Randes des Mikrolins eine Zone von kleinen gebuchteten Quarzstengeln ausscheidet. Wo der Mikroklin einen Mantel um den Plagioklas herum bildet, heften sich die Quarzstengel oft an den Rand des Plagioklases und verzweigen sich von da aus in den Mikroklin hinein. Letzterer hat meistens eine zusammenhängende Kontur gegen angrenzende Quarzkörner, und der Mikropegmatitquarz ist in der Regel nicht in derselben Weise orientiert wie diese.

Unmittelbar am Kontaktgestein ist die Grundmasse beinahe völlig in Mikropegmatit umgewandelt, der auch längs des Randes und durch Risse in die grösseren Plagioklaskörner hineingedrungen ist (Taf. VII, Fig. 3). Der Titanit ist von den Erzkörnern resorbiert worden. Je näher man dem Diabas kommt, um so schmäler wird der Titanitrand der Erzkörner, um zuletzt fast ganz zu verschwinden; in einigen Fällen sind kleine Erzkörner als ein äusserer Kranz um den Titanitrand herum gelagert, so dass diese Haufen geradezu eine konzentrische Struktur erhalten.

Zwischen dem in dieser Weise umgewandelten Granit und dem Diabas 
findet man ein dunkelgraues, anscheinend porphyrisches Gestein. Dies Kontaktgestein (der "Granitporphyr«) variiert recht beträchtlich in Bezug auf seine Mächtigkeit, die wenige Zentimeter bis etwa $1 \mathrm{~m}$ ausmachen kann. Wo das Gestein am stärkesten umgewandelt ist, hat es eine feinkörnige Grundmasse und führt nur wenige »Einsprenglinge«, die aus Feldspat oder anderen Ueberresten von Granitmineralien bestehen. Oft jedoch ist die Umwandlung nicht so weit vorgeschritten und dann sind solche mehr oder weniger umgewandelte Granitüberreste in beträchtlicher Menge vorhanden; wo der angrenzende Granit grössere Pegmatitmassen enthält, schliesst das Kontaktgestein sowohl Quarzals Feldspatfragmente sowie Klumpen von Pegmatit ein. In diesem feinkörnigen dunkelgrauen Kontaktgestein treten immer braune oder graue Schlieren auf, die ganz feinkörnig sein können, häufiger jedoch ungefähr dieselbe Korngrösse haben wie der Granit. Aehnliche Schlieren kommen manchmal auch im angrenzenden Diabas vor. An einigen Stellen ist eine bestimmte Grenze zwischen dem Kontaktgestein und dem Granit nicht nachweisbar, während sie an anderen Stellen oft makroskopisch scharf und sehr deutlich ist und sich sogar unter dem Mikroskop in einem und demselben Dünnschliff nachweisen lässt.

Die »Einsprenglinge« im Kontaktgestein bestehen im wesentlichen aus Ueberresten vom Plagioklas des Granits. Grössere Mikroklin- und Quarzkörner sind selten. Die äussersten Teile des Plagioklases sind stark resorbiert. Die Randzone ist meistens getrübt von Serizit, kleinen Epidotkörnern und undefinierbaren grauen Partikeln. Im Innern der grösseren Kristalle sind granophyrische Einlagerungen aus Quarz sehr verbreitet; seltener ist auch Mikroklin in derselben Weise vorhanden; manchmal sind die grösseren Feldspate dadurch in kleinere Körner aufgeteilt worden. Die nicht-umgewandelten Teile des Plagioklases — die »Einsprenglinge« - haben dieselbe Zusammensetzung wie der Plagioklas im angrenzenden, unveränderten Granit, d. h., dass der Kern etwa 25\% An. enthält und die Lichtbrechung ungefähr wie die des Quarzes ist. In gewissen Teilen der Kristalle beobachtet man bisweilen eine — wahrscheinlich neugebildete — ganz feinlamellierte Zwillingsstruktur. Hier ist der Plagioklas dann auch schriftgranitisch verwachsen mit untergeordneten Mengen von Mikroklin und Quarz, die vorwiegend parallel den Spaltrissen des Plagioklases nach (001) und (010) eingelagert sind.

Die grösste Veränderung in der Zusammensetzung des Gesteins zeigt sich jedoch in der Grundmasse, die einen zum Teil neuen, von demjenigen des Granits abweichenden Mineralbestand und eine regellos körnige Struktur, in welcher der Mikropegmatit stark zurücktritt, erhalten hat (vgl. Taf. VII, Fig. 4). Der Quarzgehalt ist schätzungsweise etwas geringer als im Granit. Der Feldspat besteht aus Mikroklin und aus neugebildeten, kleinen rechtangulären Plagioklaskristallen, die in 
der Regel eine deutliche Zonarstruktur haben und nach dem AlbitGesetz, manchmal zugleich auch nach dem Periklin-Gesetz verzwillingt sind. Die Zusammensetzung dieser Plagioklaskristalle ist ein wenig basischer als die des Granitplagioklases. In MP-Schnitten wurde gemessen:

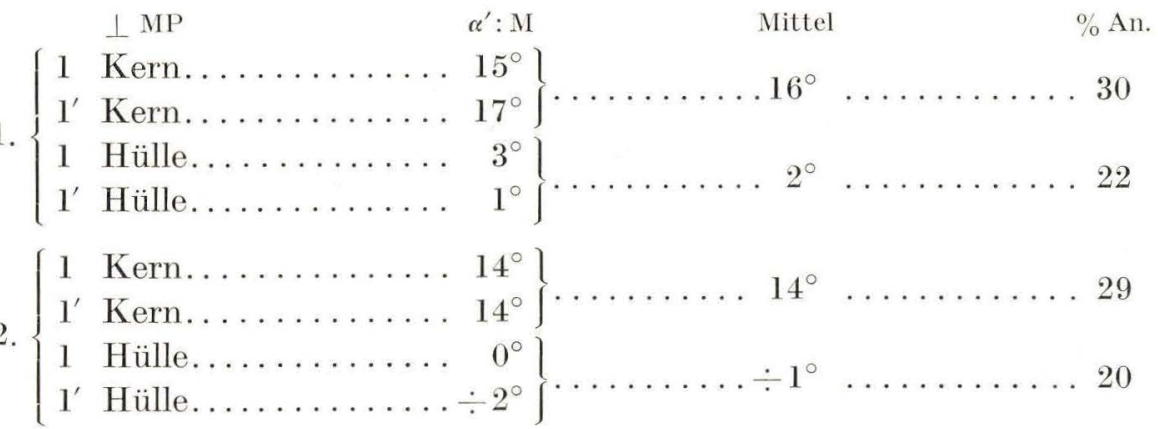

Lichtbrechung des Kerns ungefähr wie die des Quarzes. Diese Plagioklaskristalle sind meistens von parallel angewachsenem Mikroklin oder von Mikroklin-Mikropegmatit umgeben.

In den gröberen, d. h. »Einsprenglings«-reicheren Varietäten des Kontaktgesteins lassen sich einige Ueberreste der ursprünglichen Haufen von dunklen Mineralien des Granits erkennen. Biotit und Hornblende sind dann in hohem Masse von Erzpartikeln angefüllt. Oft hat sich das Erz so reichlich ausgeschieden, dass es relativ grosse, zusammenhängende oder durchlöcherte Klumpen bildet; besonders haben die ursprünglichen Erzkörner der Ausscheidung als Ansatzpunkte gedient. Hierdurch ist der Titanitrand derselben in der Regel völlig resorbiert worden, nur vereinzelt sieht man kleine Titanitkörner, die ganz vom Erz umgeben sind.

Aber der grösste Teil der dunklen Mineralien ist ganz augenscheinlich neugebildet, und in den feinkörnigsten Teilen verschwinden die obengenannten Haufen beinahe vollständig. An ihrer Stelle treten kleine Körner von Hornblende, Biotit und Erz auf, die ebenmässig über die gesamte Grundmasse zerstreut sind. Der neugebildete Biotit ist braun und hat lebhafte Polarisationsfarben; er ist oft mit Hornblende verwachsen, kommt aber auch in Form von isolierten Körnern vor. Hornblende ist in bedeutend grösserer Menge als Biotit vorhanden. Sie bildet teils kleine Körner von sehr unregelmässiger Form, an denen jedoch hie und da andeutungsweise Kristallflächen vorkommen, teils schlanke, 0,5-1 mm lange Kristalle, die meistens einen Kern aus Augit haben (vgl. Taf. VII, Fig. 5); die Farbe ist grün, der Pleochroismus: $\alpha$ hell gelb, $\beta$ olivgrün, $\gamma$ grün, nur selten mit einem Stich ins Blaugrüne. Der optische Achsenwinkel ist gross im Gegensatz zum kleinen $2 \mathrm{~V}$ der Granit-Hornblende. Der Kern besteht aus einem farblosen monoklinen 
Pyroxen. In einzelnen Fällen sind die Kristalle nach (100) verzwillingt; die Zwillingsgrenze setzt sich dann sowohl durch den Augitkern als durch den Hornblendemantel fort. In einem Schnitt $\|$ (010) wurde gemessen: c : $\gamma=17^{\circ} \mathrm{im}$ Hornblendemantel und c : $\gamma=46^{\circ}$ im Augitkern. $\mathrm{Ab}$ und zu findet man Augit, der nur einen ganz schmalen oder fast keinen Hornblenderand hat. Die schwarzen Erzkörner neigen häufig zu einer kubischen Form; sie treten sowohl isoliert in der Grundmasse als eingeschlossen in den dunklen Mineralien auf.

Dies feinkörnige Gestein kann infolge seines Mineralbestandes nur als ein Mischgestein von Granit und Diabas aufgefasst werden. Es kommt jedoch nicht als ein konstantes Uebergangsglied zwischen dem Diabas und dem Granit vor. Stellenweise findet man gröbere Partien oder Schlieren in unmittelbarer Angrenzung an den Diabas, deren Grundmasse zum grossen Teil aus Mikropegmatit besteht, während die kleinen neugebildeten Plagioklaskristalle nur spärlich vorhanden sind; die dunklen Mineralien sind teils neugebildet, teils Ueberreste der ursprünglichen des Granits. Im angrenzenden Diabas gibt es ausser den gewöhnlichen Diabasmineralien eine beträchtliche Menge Hornblende, die mit Augit verwachsen ist, ferner ein wenig braunen Biotit, seltener etwas Quarz. In der äussersten Randzone des Diabases sind Olivinpseudomorphosen reichlich vorhanden. Sie sind von einer kelyphitischen Zone von stengligem, farblosem oder schwach grünem Amphibol mit einem Mantel von Biotitblättchen umgeben.

An den übrigen Lokalitäten, wo der Kontakt längs dem Kjeldseaa Dal (Klövedal) aufgeschlossen war, zeigten die in verschiedener Entfernung vom Diabas genommenen Proben genau dieselbe Umwandlung des Granits wie bei Saltuna. Der Granit selber weist im südwestlichen Teil des Tals eine hellere, rötliche Farbe auf, und sein Hornblendegehalt ist bedeutend geringer als in der Gegend um Saltuna herum.

An der südlichsten Lokalität gegenüber Flæskedals Hus, etwa $0,5 \mathrm{~km}$ von Almindingen, war der Diabas nur innerhalb eines ganz kleinen Gebiets aufgeschlossen, wo er mit einer pegmatitischen Schliere im Granit in Kontakt war. Der nächstbelegene Granit hatte eine feinkörnige, rotgraue Grundmasse, und der Pegmatit war unmittelbar am Diabas in ein feinkörniges, graues oder rotgraues Gestein mit zahlreichen grobkörnigen Quarz-Feldspat-Klumpen umgewandelt. Ein Dünnschliff zeigte, dass die feinkörnige Grundmasse fast ausschliesslich aus Mikropegmatit besteht (vgl. Taf. VII, Fig. 6). Von dunklen Mineralien gibt es nur ein wenig braunen Biotit, zerstreute Erzkörner und vereinzelte Titanitkörner. Der Diabas hat hier eine ein paar cm breite Randzone, deren auffallendster Bestandteil eine helle grüne Hornblende ist, die teils in einer kurzstengligen Form, die zusammen mit kleinen Augitkristallen fächerförmige Aggregate bildet (vgl. Taf. VIII, Fig. 1), teils in etwas 
grösseren Kristallen mit einem Kern aus Augit auftritt. Der Feldspat besteht überwiegend aus leistenförmigem Plagioklas mit $50-55 \%$ An; stellenweise haben die Plagioklasleisten einen äusseren Rand aus Mikroklin oder Mikropegmatit. Untergeordnet kommt brauner Biotit vor, der sich bisweilen an die Erzkörner heftet. Olivinpseudomorphosen wie die oben erwähnten sind recht reichlich vorhanden, sogar in der alleräussersten Zone des Diabases. Ein paar cm innerhalb des Kontaktes besteht der Diabas vorwiegend aus den gewöhnlichen Diabasmineralien, doch treten fächerförmige Hornblendeaggregate untergeordnet auf, und der Augit hat hie und da einen schmalen Hornblendesaum. Ferner findet man hier "Einsprenglinge», die wie im Kontaktgestein aus etwas umgewandelten Ueberresten von Granitplagioklas bestehen. Die Aufschmelzung hat dazu geführt, dass in einigen Teilen der Plagioklaskristalle kleine Erzkörner und schriftgranitähnlicher, skelettartiger Quarz, Augit und Mikroklin ausgeschieden sind. Die kleinen Einlagerungen von Quarz und Augit erweisen sich dadurch als Teile von grösseren skelettartigen Kristallen, dass die Körner innerhalb gewisser Felder gleichzeitige Auslöschung haben, ja diese Kristallskelette können sich sogar durch mehrere verschieden orientierte Plagioklaskristalle hindurch verzweigen. In den auf diese Weise umgewandelten Teilen des Plagioklases ist die Albitlamellierung ganz oder teilweise destruiert worden, wodurch der Kristall eine undulöse Auslöschung erhalten hat, wogegen die Zwillingslamellen in den nicht-umgewandelten Partien des Plagioklases sehr deutlich zu sehen sind.

Wie bereits oben erwähnt, tritt der Diabas im Kjeldseaa Dal nur an der Ostseite an den Tag, und an einer einzelnen Stelle, bei Blaakuls Hus, in der Nähe von Klövegaard, habe ich die gewöhnlichen Anzeichen einer Kontaktmetamorphose im Granit auch in der Westwand des Tals gefunden. Im Ekkodal, das eine Fortsetzung des Kjeldseaa-Spaltentals gegen SW ist, wurde nirgends anstehender Diabas gefunden. Dagegen zeigen Dünnschliffe des Granits sowohl aus der NW-als auch der SOWand des Ekkodal genau dieselbe Umwandlung - Ausscheidung von Mikropegmatit und Destruktion der dunklen Mineralien — wie sie der Granit vom Kjeldseaa Dal in der Nähe des Diabases aufwies. Der Granit im Ekkodal ist der helle, rotgraue, mittelkörnige und schwach gestreifte Alminding Granit, in dem dunkle Mineralien in der Regel nur spärlich vorkommen (vgl. pag. 88 ff. u. Taf. V, Fig. 2 u. 3) und der Mikropegmatit sonst gar nicht beobachtet worden ist. Um so auffälliger ist daher die Mikropegmatitbildung in den Granitproben aus den Wänden des Ekkodal, in denen diese Struktur in derselben Weise entwickelt ist wie im Granit bei Saltuna in einer Entfernung von 1 bis $2 \mathrm{~m}$ vom Diabas (vgl. Taf. VII, Fig. 2). Man kann daraus schliessen, dass der KjeldseaaDiabasgang, der grösste auf Bornholm, sich gegen SW weiter durch das 
Ekkodal fortsetzt, und dass er auch auf dieser Strecke eine Kontaktwirkung auf das Nebengestein ausgeübt hat.

\section{Der Diabasgang bei Kaas.}

Der Diabasgang bei Kaas ist nach dem Kjeldseaa-Gang der grösste auf Bornholm; er ist nur in den Uferfelsen der NO-Küste unterhalb Kaas aufgeschlossen und zwar in einer Breite von $40 \mathrm{~m}$; sein weiterer Verlauf landeinwärts lässt sich nicht verfolgen. Das Gestein ist gleichartig grau; in der Mitte des Ganges ist es mittelkörnig und von ophitischer Struktur. Die ziemlich groben Plagioklasleisten sind oft etwas braunpigmentiert. Der Augit ist bei durchfallendem Licht sehr hellgrau mit einem schwach rotbraunen Ton. In einigen Fällen wurde festgestellt, dass der Achsenwinkel $2 \mathrm{~V}$ in den inneren Teilen der Kristalle bedeutend kleiner ist als in den äusseren. Einige Körner sind teilweise uralitisiert. Der Olivin hat einen optischen Achsenwinkel von etwa $85^{\circ}$ und negative Doppelbrechung; die Körner sind zum Teil völlig frisch, zum Teil mehr oder weniger in Serpentin umgewandelt. Brauner Biotit mit zahlreichen pleochroitischen Höfen ist relativ reichlich vorhanden; zusammen mit ein wenig Quarz füllt er oft die kleinen Zwickel zwischen den älteren Mineralien aus. In einzelnen Fällen tritt Quarz ausserdem schriftgranitisch in der Randzone der Plagioklasleisten eingelagert auf. Braune Hornblende kommt nur spärlich vor. Längs den schmalen, mit Quarz, Chalcedon und Kalkspat angefüllten Spalten im Diabas sind Augit und Olivin in graubraune Pseudomorphosen umgewandelt, die hauptsächlich aus Karbonat und Limonit bestehen.

In der Nähe der Ganggrenze nimmt die Korngrösse beträchtlich ab, ein vollständig dichtes Salband gibt es aber nicht. Die Plagioklasleisten sind verhältnismässig frisch. Augit kommt nicht vor. Statt dessen treten grüne oder braune Aggregate aus Biotit, Chlorit und Eisenerzkristallskeletten sowie variierende Mengen von Kalkspat und Quarz auf.

Eine Kontaktwirkung auf das Nebengestein lässt sich bei diesem Diabasgang nicht nachweisen.

\section{Der Diabasgang von Listed-Tamperdal.}

Bei Listed gibt es neben mehreren kleineren Diabasgängen einen $30 \mathrm{~m}$ mächtigen Gang, der früher unter der Bezeichnung "Listed Hauptgang von CoHen und DeEcke (1. c. pag. 48 ff.) ziemlich ausführlich besprochen worden ist. Er tritt in den Uferfelsen eines kleinen Vorsprunges, Gule Hald, an den Tag und hat hier die Richtung N $10^{\circ} \mathrm{O}$. Der Diabas liegt niedriger als der Granit (vgl. Fig. 34), und die Westseite des Ganges ist gewöhnlich vom Wasser bedeckt. Etwa $500 \mathrm{~m}$ südlich von dieser 
Stelle hat man beim Brunnengraben denselben Diabas gefunden, und etwa $5 \mathrm{~km}$ südlicher tritt der Gang an zwei Stellen im Tamperdal in den Paradisbakker wieder an den Tag. Es fällt hierbei auf, dass eine von Gule Hald in Listed bis zu den Paradisbakker gezogene Gerade mit der Richtung $\mathrm{N} 10^{\circ} \mathrm{O}$ gerade den Diabas im Tamperdal treffen würde. Die Grenzen sind hier nicht aufgeschlossen, aber an der Ostseite steht

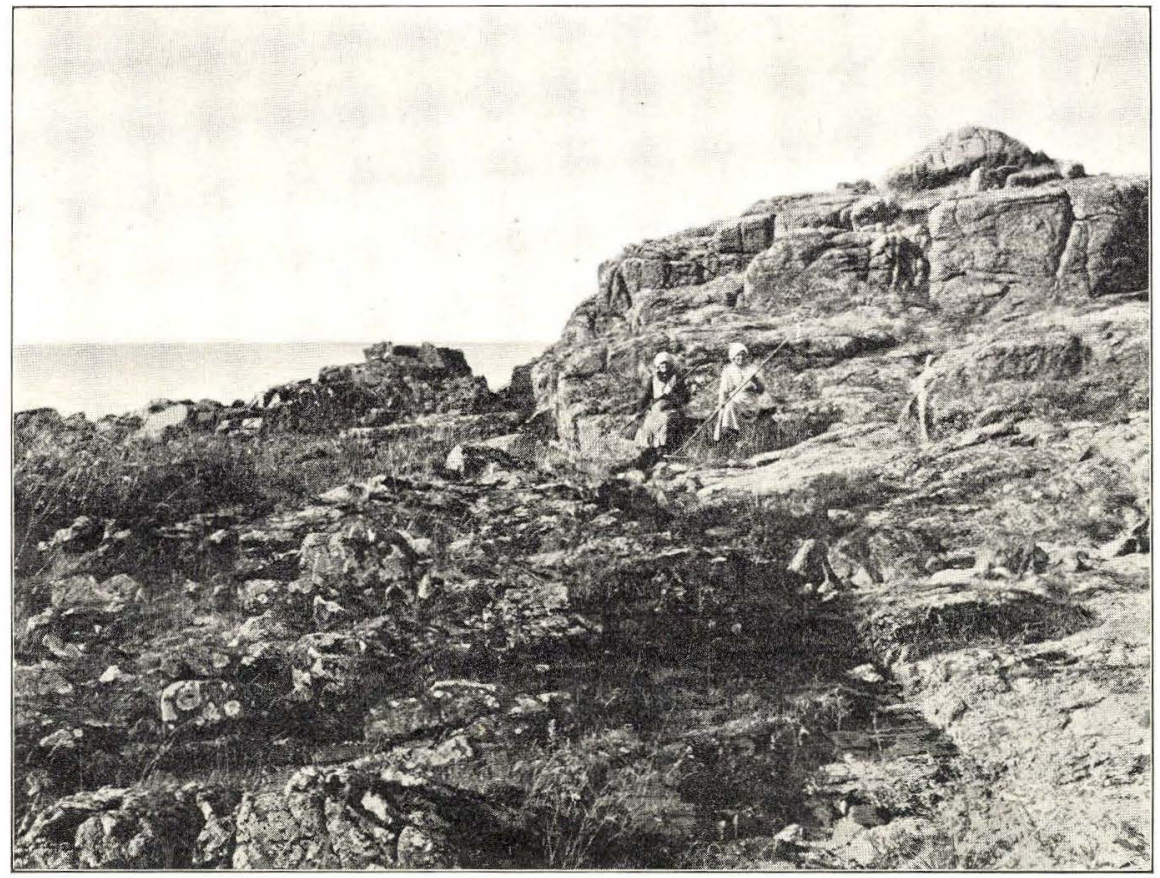

Fig. 34. Gule Hald in Listed. Ostgrenze des grossen Diabasgangs. Rechts Svaneke Granit (etwas zerbröckelnd).

der Granit in einer Entfernung von etwa $1 \mathrm{~m}$ vom Diabas an. Die Breite des Ganges ist schätzungsweise ungefähr $20 \mathrm{~m}$; seine Richtung und Mächtigkeit, die Beschaffenheit des Gesteins und sehr charakteristische Feldspateinschlüsse im Diabas weisen mit Sicherheit darauf hin, dass die Vorkommen bei Listed und im Tamperdal Teile desselben Diabasganges sind. Bei Listed durchsetzt der Gang den recht grobkörnigen Svaneke Granit, im Tamperdal den Paradisbakke Granit.

Das Gestein ist ein dunkelgrauer Olivindiabas. In der Gangmitte ist er grobkörnig und hat eine typisch ophitische Struktur. Der Mineralbestand ist derselbe wie in den oben besprochenen Diabasen von Kjeldseaa und Kaas.

Der Plagioklas ist meistens frisch, kann aber dann und wann von serpentinartigen Umwandlungsprodukten von Olivin oder Augit zer- 
splittert sein. Zwillingsbildung nach dem Periklin-Gesetz kommt in einigen Präparaten häufig, in anderen selten vor. Karlsbader Zwillinge treten recht häufig auf. Der Anorthitgehalt des Kerns beträgt etwa $57 \%$, der der Randzone etwa $24 \%$.

Olivin ist reichlich vorhanden, die Korngrösse ist durchschnittlich etwa $0,5 \mathrm{~mm}$. Der Olivin ist in den Zwischenräumen zwischen den Plagioklasleisten auskristallisiert und nicht selten von einem einzelnen oder häufiger von mehreren, verschieden orientierten Pyroxenkörnern umgeben. Der optische Achsenwinkel $2 \mathrm{~V}$ ist gross, die Doppelbrechung negativ. Der Olivin ist durchsetzt von Rissen, die mit kleinen Erzkörnern und Limonit angefüllt sind; im übrigen ist der Erhaltungszustand der Körner sehr verschieden, indem einige fast ganz frisch, andere dagegen völlig umgewandelt sind. Die Umbildung ist dieselbe wie beim Olivin im Kjeldseaa-Diabas. In einem frühen Stadium sind die Pseudomorphosen pleochroitisch und recht stark doppelbrechend, während das Endprodukt ein gewöhnlicher grüner, schwach doppelbrechender Serpentin ist, der sich durch Risse, welche den Spalten im ursprünglichen Olivin entsprechen, verbreitert und allmählich die pleochroitische Substanz verdrängt. Die pleochroitischen, stark doppelbrechenden Pseudomorphosen nach Olivin, die übrigens in vielen Bornholmer Diabasen auftreten, sind in diesem Gang sehr auffallend. Aehnliche Pseudomorphosen werden oft in der Literatur erwähnt, in der Regel unter dem Namen Iddingsit. Die hier beobachteten Pseudomorphosen stimmen indessen nicht ganz mit den vorliegenden Beschreibungen von Iddingsit überein (vgl. H. Rosenbusch, Mikr. Physiographie, Bd. I, 2, 5. Aufl., 1927, p. 360 und Nachtrag zu p. 360). Wenn die Pseudomorphosen Ueberreste von Olivin enthalten, so haben beide Mineralien gleichzeitige Auslöschung, und soweit es sich feststellen lässt, ist die glimmerartige Spaltrichtung in den Pseudomorphosen parallel (010) im Olivin; ferner sind $\alpha$ und $\gamma$ in beiden Mineralien parallel orientiert. Die Pseudomorphosen sind recht stark doppelbrechend und haben lebhafte Interferenzfarben. Die Doppelbrechung ist negativ. Bisectrix $\alpha$ ist $\perp$ zur Spaltfläche. Der Achsenwinkel ist klein, $2 \mathrm{E}$ wurde zu $27^{\circ}$ gemessen. Der Pleochroismus ist stark in Schnitten $\perp$ zu den Spaltrissen, aber schwach in Schnitten $\|$ den Spaltblättern: $\alpha$ hellgelb bis rötlich gelb, $\beta$ grün, $\gamma$ blaugrün.

Im ophitischen Diabas der Gangmitte ist der Augit hell, graugelb, der Pleochroismus äusserst schwach. Zwillingsbildung nach (100) kommt häufig vor. Der optische Achsenwinkel $2 \mathrm{~V}$ ist etwa $60^{\circ}$ (es wurde gemessen: $2 \mathrm{E}=82^{\circ}$ ). Im $\beta$-Schnitt wurde gemessen e: $\gamma=35^{\circ}$, was auf Magnesiumdiopsid hindeutet. Der Pyroxen ist meistens frisch, doch hie und da ein wenig chloritisiert. Nur spärlich kommt uralitische Hornblende vor, die dann in der Regel mit braunem Biotit verwachsen ist. Biotit tritt überhaupt ziemlich häufig an Erz, Augit und Serpentin ge- 
heftet auf; ausserdem bildet er oft mit Quarz und manchmal mit etwas Hornblende zusammen die Füllmasse in den Zwickeln zwischen den Plagioklasleisten; an einigen Stellen ist Quarz mikropegmatitisch mit dem äussersten Rande der Plagioklasleisten verwachsen. Die Erzkörner haben bisweilen eine skelettartige Form, die auf Titaneisen hinweist.

In der Nähe der Ganggrenze ändern sich der Mineralbestand und die Struktur des Diabases ein wenig. Die Korngrösse nimmt ab, und man beobachtet einzelne mit Chlorit und Kalkspat ausgefüllte Poren. Einige der Plagioklaskörner haben eine breitere und unregelmässigere Form als in der Gangmitte. Olivin fehlt gänzlich. Der Augit tritt teils als schlanke Säulen, teils als kleine rundliche Körner auf. Die schlanken Kristalle sind meistens etwa $1 \mathrm{~mm}$, können aber auch ein paar $\mathrm{mm}$ lang sein. Sie bestehen aus einem farblosen, ziemlich schwach doppelbrechenden Kern und einem äusseren, etwas dunkler gefärbten und stärker doppelbrechenden Mantel, der jedoch in der Regel an den Endseiten der Kristallen fehlt. Im Kern kommen gewöhnlich keine Einschlüsse vor, im Mantel sind oft Erzkörner und manchmal Plagioklas eingewachsen. Die Kristalle sind oft Zwillinge nach (100). In Schnitten | (010) wurde gemessen: im Kern c: $\gamma=40^{\circ}$, im Mantel c: $\gamma=48^{\circ}$. Auch der optische Achsenwinkel variiert. Im Mantel wurde gefunden $2 \mathrm{E}=68^{\circ}$ und die Ebene der optischen Achsen $\|$ (010), im Kern $2 \mathrm{E}=32^{\circ}$ und die Achsenlage normalsymmetrisch $(\mathrm{b}=\alpha)$. Die kleinen rundlichen Augitkörner haben keinen Schalenbau; in Bezug auf ihre optischen Verhältnisse entsprechen sie dem Mantel der Obigen.

Der helle, schwach doppelbrechende Kern des Augits ist oft ganz oder teilweise in faserige oder schuppige Aggregate aus Serpentin umgewandelt, die entweder gelb-grün, pleochroitisch und recht stark doppelbrechend oder grün, schwach doppelbrechend ohne Pleochroismus sein können. In diesen Aggregaten sind in der Regel kleine bräunliche Körner mit starker Lichtbrechung und kräftiger Doppelbrechung eingeschlossen; es war nicht möglich, sie mit völliger Sicherheit zu bestimmen, sie scheinen aber aus Titanit zu bestehen. Uralitische Hornblende beobachtet man in einigen Dünnschliffen recht häufig, in anderen nur selten. Ausserdem tritt Hornblende in Form von selbständigen Körnern, meistens zusammen mit Quarz und Biotit, in den Zwickeln zwischen den übrigen Mineralien auf; in der Regel kommt noch Kalkspat dazu, nur selten dagegen ein wenig Kalifeldspat. Quarz und Biotit sind im allgemeinen reichlicher vorhanden als in der Gangmitte; der Quarz kommt sowohl in Gestalt von relativ grossen Körnern als auch in mikropegmatitischer Verwachsung mit Feldspat vor. Ausser den genannten Mineralien finden sich in den verschiedenen Dünnschliffen wechselnde Mengen von Chlorit und von dünnstengligen, farblosen Amphibolnadeln.

Charakteristisch für den Diabasgang von Listed-Tamperdal ist, dass 
er in einer 3-4 m breiten Zone längs der Ganggrenze ausserordentlich zahlreiche Einschlüsse von grossen, elliptisch abgegrundeten Feldspatkristallen enthält (vgl. Fig. 35). Meistens sind sie ein paar cm lang, der grösste mass $3 \times 2,5 \mathrm{~cm}$. Zwischen diesen Feldspatovoiden liegen im Diabas sowohl in Listed als im Tamperdal einige Quarzkörner von einer solchen Grösse, dass man sie mit blossen Augen sehen kann, aber die Quarzeinschlüsse sind weit seltener als die Feldspate, und nur in Ausnahmefällen erreichen sie die Grösse einer Erbse oder einer Haselnuss. Nur in ein paar vereinzelten Fällen gab es ausserdem unregelmässig

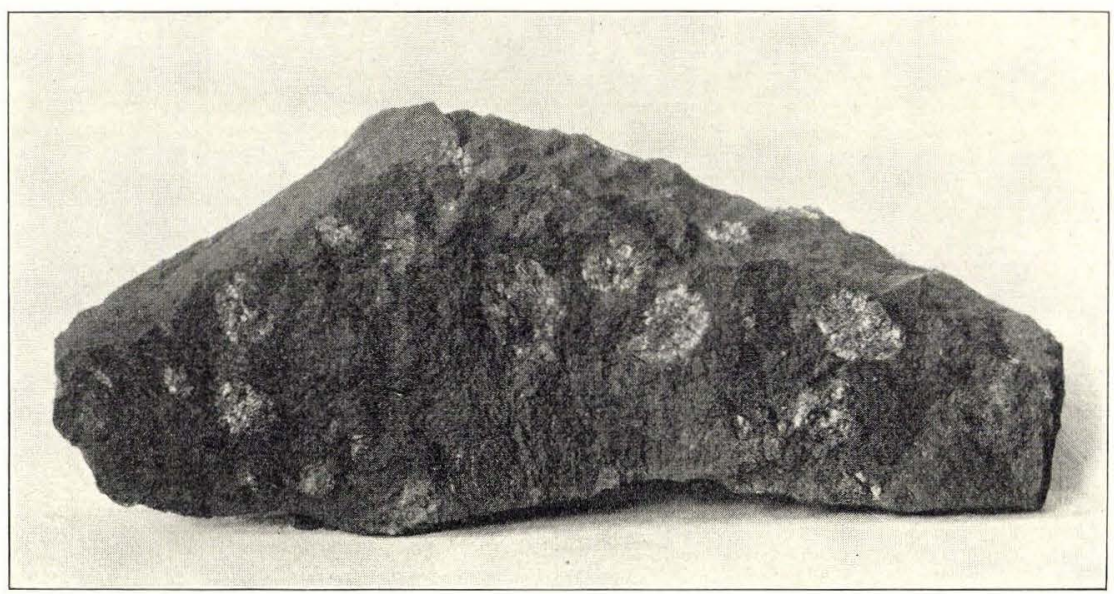

Fig. 35. Diabas mit Einschlüssen von Feldspatovoiden. Tamperdal. 1/2 nat. Gr.

geformte Einschlüsse von granitischem Quarz-Feldspat, der zum Teil schriftgranitisch verwachsen war. Im feinkörnigen oder ganz dichten Salband treten die Feldspatovoide weit seltener auf. In Listed sind sie besonders zahlreich in einer längs der Ostgrenze des Diabases verlaufenden Gürtelzone, in der Gangmitte verschwinden sie, und in der schlecht aufgeschlossenen Westseite sind sie klein und nur spärlich vorhanden. Im Tamperdal, wo die Westseite des Ganges überhaupt nicht zu sehen ist, findet man die Ovoide in grossen Mengen längs der Ostgrenze.

Die Feldspatovoide sind dunkelgrau, haben jedoch meistens hellgraue oder rötliche Flecke von sehr wechselnder Form und Ausdehnung; diese Flecke rühren von dicht gedrängten Einschlüssen oder Umwandlungsprodukten her. Die kleineren Ovoide bestehen in der Regel aus einem einzelnen Feldspat, die grösseren nicht selten aus zwei oder drei verschieden orientierten, abgerundeten Feldspatkristallen, die bisweilen durch eine ganz geringe Menge von eingedrungenem Diabasmaterial getrennt sein können.

Die einzelnen abgerundeten Feldspate haben einen etwas ungleich- 
artigen inneren Bau (vgl. Taf. VIII, Fig. 2). Der Rand gegen den Diabas ist mit einer Zone von kleinen klaren Plagioklaskristallen, die meistens Leistenform haben, bekleidet (Taf. VIII, Fig. 2 und Fig. 3). Im grössten Teil des Innern hat der Feldspat ein charakteristisches gekörneltes Aussehen. Diese Partien sind immer von kleinen, opaken Partikeln getrübt, die stellenweise so stark angereichert sein können, dass der Feldspat fast undurchsichtig wird; ausserdem können gewisse Teile des Feldspats stark serizitisiert sein, und — besonders in der Randzone des Ovoids sind die Diabasmineralien poikilitisch eingewachsen.

Im gekörnelten Teil des Feldspats gibt es in der Regel mehrere längliche, aber sonst unregelmässig begrenzte Einschlüsse von feinkörnigen Aggregaten (Taf. VIII, Fig. 2 und Fig. 3), in denen man stets Quarz findet, teils in Mikropegmatit, teils als kleine klare Körner, die oft Flüssigkeitsinterpositionen enthalten. Im übrigen bestehen die Aggregate aus Augit, der wie im umgebenden Diabas häufig die Form von schlanken Säulen hat, ferner aus brauner Hornblende, die bisweilen Kristallform hat, braunem Biotit und schwarzen Erzkörnern. Chlorit und Kalkspat sind gewöhnlich vorhanden, in einzelnen Fällen hat man Titanit beobachtet. Der Hauptbestandteil ist jedoch Plagioklas, der in klare, oft leistenförmige Kristalle kristallisiert ist, die teils als eine helle Zone die Aggregate umgeben und bewirken, dass diese schon bei schwacher Vergrösserung sehr auffallend werden (Taf. VIII, Fig. 2), teils in das Aggregat hinein oder sogar quer durch dasselbe hindurch ragen. Die Kristalle weisen nur Zwillingsbildung nach dem Albit-Gesetz auf. Im Schnitt || (001) haben die Zwillingslamellen nur eine sehr geringe Auslöschungsschiefe gegen Trace (010); die Lichtbrechung ist höher als die des Canadabalsams und niedriger als die des Quarzes, die Zusammensetzung entspricht also einem Oligoklas. Häufig sind die Kristalle randlich mikropegmatitisch mit Quarz zusammengewachsen, und in den meistens äusserst schmalen Zwischenräumen zwischen den Leisten sieht man einen Mikropegmatit aus Quarz und einem Feldspat, der eine schwächere Doppelbrechung und eine Lichtbrechung hat, die entweder gleich der des Canadabalsams oder ein ganz klein wenig niedriger als diese ist. Ueber die Zusammensetzung dieses Feldspats kann nichts Näheres angegeben werden; eine Mikroklinstruktur konnte nirgends nachgewiesen werden.

Die Plagioklasleisten sind im ganzen Ovoid parallel orientiert, sowohl untereinander als auch mit den Plagioklasleisten in der Randzone des Ovoids (vgl. Taf. VIII, Fig. 3), mit denen sie in allen Beziehungen übereinstimmen; ferner haben alle klaren Plagioklasleisten die gleiche Doppelbrechung und Lichtbrechung und die gleiche Auslöschung wie der dominierende Bestandteil im gekörnelten Teil des Feldspats. Dieses bedeutet also, dass der grösste Teil des Ovoids in Wirklichkeit aus ein 
und demselben Plagioklaskristall, dessen verschiedene Teile nur in verschiedener Weise entwickelt sind, besteht.

Der gekörnelte Feldspat ist, abgesehen von den eingeschlossenen dunklen Mineralien, aus denselben Bestandteilen wie die hellen Zonen aufgebaut, aber nur in einzelnen klaren Partien kann man eine ausserordentlich feine Zwillingsstreifung beobachten. Im dominierenden Plagioklas ist der niedriger lichtbrechende Feldspat in einer netzartigen Weise eingelagert. Im Schnitt || (001) erscheinen diese Einlagerungen als dunkelgraue Streifen, die hauptsächlich parallel Trace (010) und winkelrecht zu ihr angeordnet sind (Taf. VIII, Fig. 4); des weiteren machen sie sich dadurch bemerkbar, dass sie durch das ganze Ovoid gleichzeitig und in einer etwas anderen Stellung als der Plagioklas auslöschen, und ferner dadurch, dass die dunklen Mineralien vorzugsweise in ihnen angereichert sind. Auch hier ist der niedriger lichtbrechende Feldspat oft mikropegmatitisch mit Quarz zusammengewachsen, und stellenweise findet man ganz kleine Quarzausscheidungen an der Grenze zwischen den beiden Feldspaten, wodurch dieselbe schärfer markiert wird. In einigen Ovoiden ist diese Struktur gröber entwickelt, die netzförmigen Einlagerungen scheinen dann nur aus Quarz zu bestehen (Taf. VIII, Fig. 5, rechts), und der Plagioklas ist in kleine, annähernd rechteckige Teile aufgeteilt, die jeder für sich eine etwas undulöse Auslöschung haben, die auf eine Zonarstruktur hindeutet. Die klaren Partien erhalten in solchen Kristallen eine etwas grössere Ausdehnung und weisen deutliche Zwillingslamellen auf. In Schnitten $\perp$ MP (Taf. VIII, Fig. 5) wurde $\alpha^{\prime}: \mathrm{M}=7^{\circ}-8^{\circ}$ gemessen, was einem Oligoklas mit etwa $26 \%$ An entspricht.

Die Feldspatovoide von Listed-Tamperdal sind von CоHEN und Deеске (1. c., pag. 48-49) besprochen worden. Aehnliche Feldspateinschlüsse in Diabas und Basalt sind mehrmals von andern Autoren erwähnt worden; besonders H. ВӓскSтRöм ${ }^{1}$ ) gibt eine sehr eingehende Beschreibung von solchen Einschlüssen aus einem Diabas bei Alsarp, Schweden, und andern Stellen. Sowohl Cohen und DeEcke als auch B̈̈скsтRöm fassen die Ovoide als umgewandelte fremde Einschlüsse auf und geben an, unveränderte Reste aus Granitfeldspat in ihnen gefunden zu haben, wogegen ich in keinem einzigen Falle solche Ueberreste habe nachweisen können. Die eingeschlossenen, feinkörnigen Aggregate sieht Вӓскsтröм für Lösungsräume an, die mit neugebildeten Mineralien ausgefüllt sind, und er meint, dass die neugebildeten Plagioklasleisten längs des Randes der Lösungsräume an dem älteren Feldspat in paralleler Anordnung abgesetzt worden seien.

$\mathrm{Zu}$ einer ganz andern Auffassung von der Entstehung dieser Feld-

1) H. Bäскsтröм: Bih. Sv. Vet.-Akad. Handl., Bd. 16, Afd. II, N:o 1, 1890. 
spate gelangt H. E. Johansson ${ }^{1}$ ), der durchaus ähnliche Feldspatovoide aus einem Diabas von Grängesberg beschreibt, welcher wie der AlsarpDiabas eine weitgehende petrographische Uebereinstimmung mit dem Diabas von Listed-Tamperdal aufweist. JонAnsson nahm an einem möglichst frischen und reinen Material eine Analyse vor, die für das Feldspatovoid die Durchschnittszusammensetzung $\mathrm{Or}_{21 \cdot 2} \mathrm{Ab}_{55 \cdot 9} \mathrm{An}_{22 \cdot 9} \mathrm{er}-$ gab, woran er die Bemerkung knüpft, dass der An.-Gehalt infolge Einschlüssen von Augit wahrscheinlich ein wenig zu hoch ausgefallen ist. Johansson vergleicht diese Feldspate mit Rhombenfeldspaten aus den Rhombenporphyren des Kristianiagebiets und mit verwandten Feldspaten aus Diabas und Basalt. Und ferner bemerkt er (pag. 375) : . . . die Entstehung der gekörnelten Struktur dürfte . . . einer antiperthitischen Entmischung solcher unbeständigen, extrem ternär zusammengesetzten Natronmikroklinfeldspate zugeschrieben werden können, wobei ein Teil des den Mischkristallen ursprünglich homogen beigemengten Kalifeldspates als Orthoklas ausgeschieden worden ist, während der Rückstand gleichzeitig eine weniger ternäre Plagioklaszusammensetzung bekommen hat«. Im Gegensatz zu ВӥскsтRøм und andern älteren Forschern fasst Johansson derartige Feldspate nicht als Fremdlinge, sondern als tatsächliche Ausscheidungen aus dem Diabasmagma auf; aber gleichzeitig betont er, dass sie nicht den Feldspatausscheidungen der frühesten Kristallisationsphase des umgebenden Diabases gleichgestellt werden können; ihre chemische Zusammensetzung zeigt unzweideutig, dass sie von echten Einsprenglingen genetisch verschieden sind. JoHansson nimmt daher an, dass die Ovoide während einer späten »syenitischen« Kristallisationsphase des Diabases ausgeschieden worden sind, und dass die Füllmasse ihrer »Lösungsräume« (d. h. die feinkörnigen Aggregate) den Ausscheidungen der letzten, "granitischen« Kristallisationsphase des Diabases entspricht. Doch stellt er nicht die Möglichkeit in Abrede, dass die Entstehung derartiger Pseudoeinsprenglinge in gewissen Fällen auf eine stattgefundene Resorption von fremdem feldspathaltigem Material zurückgeführt werden kann.

In Bezug auf die Feldspatovoide im Diabase von Listed-Tamperdal bin ich mit H. E. Johansson durchaus darin einverstanden, dass sie in ihrer jetzigen Form tatsächliche Ausscheidungen aus dem Magma, die sich an Ort und Stelle gebildet haben, sind. Dafür spricht in erster Linie die Tatsache, dass es mir ganz unmöglich gewesen ist, auch nur irgendwo Ueberreste von Granitfeldspat in den Ovoiden nachzuweisen. Der umgebende Granit dürfte auch nicht imstande sein, eine solche Menge von grossen Plagioklaskörnern, wie sie hier vorliegt, zu liefern. Es muss in diesem Zusammenhang bemerkt werden, dass der

$\left.{ }^{1}\right)$ H. E. Johansson: G. F. F., Bd. 32, H. 2, 1910, pag. 372-376. 
Diabas den groben Svaneke Granit in Listed und den feinkörnigen Paradisbakke Granit im Tamperdal durchsetzt, während die Ovoide an beiden Stellen ganz gleichartig in Bezug auf Grösse und Bau sind. Vergleicht man des weiteren diese Feldspate mit den teilweise aufgeschmolzenen Feldspatkörnern im Kontaktgestein des Kjeldseaa-Diabases, so wird der Unterschied sehr auffallend, denn ganz abgesehen davon, dass diese letztgenannten Feldspate bedeutend kleiner sind, ist es mir nur in einem einzelnen Falle gelungen, in ihnen eine wahrscheinlich neugebildete Plagioklasstreifung in Verbindung mit Mikroklineinlagerungen, die vielleicht in einem gewissen Grade an die oben beschriebene Körnelung (vgl. oben pag. 160) erinnern dürfte, zu beobachten.

Dagegen sehe ich es für ganz unzweifelhaft an, dass das Diabasmagma seine exzeptionelle Zusammensetzung durch Resorption des Granitnebengesteins erhalten hat. Diese Auffassung begründe ich in erster Linie mit dem recht häufigen Auftreten von Quarzkörnern, die in unmittelbarer Nähe der Feldspatovoide im Diabase eingeschlossen sind. Fig. 6, Taf. VIII zeigt einen Teil eines solchen Quarzkorns, das etwa $0,5 \mathrm{~cm}$ im Durchmesser misst. Das Korn hat eine unregelmässige, aber doch etwas abgerundete Kontur. Längs dem Rande des Korns haben sich vorzugsweise die dunklen Mineralien des Diabases, besonders Augit, abgelagert. Der Quarz hat eine etwas undulöse Auslöschung; er enthält zahlreiche Flüssigkeitsinterpositionen mit Libelle und schliesst ein paar Zirkonkristalle ein. Die Korrosionshohlräume sind mit Diabasmineralien und mit kleinen Feldspaten von derselben Art wie die Ovoide ausgefüllt. Einige kleine Poren im Quarz, von denen die grösste auf Fig. 6, Taf. VIII zu sehen ist, sind mit radialfaserigem Chalcedon angefüllt; Poren mit Glasfüllmasse sind dagegen nicht gefunden worden. Im Diabase, der das abgebildete Quarzkorn unmittelbar umgibt, finden sich des weiteren ein paar kleinere Quarzkörner sowie einige wenige Zirkonkristalle, von denen ein einzelnes in ein Aggregat von Chlorit, Kalkspat und Quarz, das die Füllmasse in einem kleinen Blasenraum im Diabase bildet, eingebettet ist. Diese Quarzkörner und Zirkonkristalle müssen meiner Ansicht nach als Relikte von Granitmineralien aufgefasst werden. Ferner habe ich, wie schon erwähnt, einzelne erkennbare Granitreste in der Nähe der Feldspatovoide gefunden. Diese Fragmente sind scharfkantig und unregelmässig geformt. In einzelnen von ihnen, die deutlich Pegmatit entstammten, gab es kleinere Partien von Schriftgranit, in denen der Quarz unverändert war, während der Feldspat auf verschiedene Weise umgewandelt war. Der grösste Teil des Feldspats war stark getrübt und fast undurchsichtig. In einzelnen Partien waren sphärulitische Massen entstanden, andere Teile schienen im gewöhnlichen Licht unveränderter Feldspat zu sein, aber zwischen gekreuzten Nicols erwies es sich, dass sie aus zahlreichen kleinen Bruch- 
stücken mit annähernd paralleler Auslöschung bestanden. Und schliesslich fand sich in einzelnen Partien die gleiche gekörnelte Struktur wie in den Ovoiden; diese Partien waren von kleinen, klaren Plagioklaskristallen umrändert. Im Gegensatz zu H. E. JoHAnsson möchte ich daher meinen, dass es die Regel und nicht eine Ausnahme ist, dass die Ausscheidung von solchen Feldspatovoiden wie den oben beschriebenen durch Resorption von Granit oder anderem feldspathaltigem Material verursacht wird.

Dass die Graniteinschmelzung in diesem Diabas nicht zur Bildung eines hybriden Kontaktgesteins so wie bei Kjeldseaa geführt hat, kann möglicherweise damit zusammenhängen, dass das Mengenverhältnis von Granit und Diabas hier ein anderes gewesen ist, denn wahrscheinlich rührt das resorbierte Granitmaterial von losgerissenen Brocken her. Bei Listed, wo die Grenze des Diabases gegen den Granit gut aufgeschlossen ist, kann fast keine Kontaktwirkung auf das Nebengestein nachgewiesen werden, nur der Biotit des Granits hat unter Ausscheidung von zahlreichen kleinen schwarzen Erzkörnern eine gefranste Kontur erhalten. Der Diabas hat ein makroskopisch vollständig dichtes Salband. Unter dem Mikroskop sieht man ein Netzwerk von schlanken Plagioklasleisten in einer Grundmasse, in der Erzkörner und dunkle Partikeln in Streifen angereichert sind, die dem Diabas eine Art Fluidalstruktur geben. In der Grundmasse lässt sich Augit einigermassen sicher bestimmen, aber ein Teil kleiner brauner Körner scheint aus Titanit zu bestehen. Ferner kommen nicht wenige Quarzkörner vor, die bis zu $0,05 \mathrm{~mm}$ Durchmesser erreichen können. Mit Chlorit ausgefüllte Blasenräume sind recht häufig. Unmittelbar am Granit ist der Diabas auch mikroskopisch fast vollständig dicht. Es erweist sich, dass die dunklen Streifen hier aus reihenförmig angeordneten, runden dunklen Flecken bestehen, so dass es scheint, dass der Diabas hier eine kleinkugelige Struktur hat.

\section{Kleinere Gänge aus Olivindiabas.}

Wie in der Einleitung bereits erwähnt, sind die meisten Bornholmer Diabasgänge in der Regel nur von geringer Mächtigkeit, selten mehr als 2-3 m und häufig noch schmäler. Das Gestein ist oft porphyrisch entwickelt, jedoch hat eine recht grosse Anzahl der untersuchten Diabase eine körnige Struktur. CoHex und DEecke haben die Bornholmer Diabase in drei Hauptgruppen eingeteilt: 1) Die normalen olivinarmen Diabase, zu denen die oben beschriebenen Diabase bei Kaas und Listed gerechnet werden; 2) die biotitreichen Olivindiabase ohne ophitische Struktur, in denen der Augit durchweg selbständige Begrenzung zeigt und von lichtbräunlicher bis braunvioletter Färbung ist, aber nur aus- 
nahmsweise einen schwachen Pleochroismus zeigt; 3) die Olivindiabasporphyrite. Diese Einteilung scheint mir jedoch nicht ganz zutreffend zu sein, da CoHen und DeEcke, wie bereits bemerkt, den Olivingehalt der grossen Gangdiabase stark unterschätzt haben. - Diabase aller Gruppen sind gelegentlich als Mandelsteine ausgebildet. Gewöhnlich haben die Diabase, sowohl die körnigen als auch die porphyrischen, ein feinkörniges bis dichtes Salband mit mehr oder weniger skelettartig ausgebildeten Einsprenglingen.

\section{Körnige Diabase.}

Die körnigen Diabase scheinen vorzugsweise im nördlichen Teil von Bornholm aufzutreten. Eine ausgesprochen ophitische Struktur ist in diesen Diabasen gewöhnlich nicht vorhanden, kommt jedoch vor und zwar schön entwickelt, z. B. in einem Diabas von Hammeren (am Hause des Leuchturmwärters); in diesem Diabas sind die richtungslos angeordneten Plagioklasleisten von völlig allotriomorphem Augit verkittet. Der Augit hat eine helle, gelbgraue Färbung und tritt in Form von relativ grossen Körnern in reichlicher Menge auf. Olivin ist spärlich vorhanden und zum Teil in gelbbraune Zersetzungsprodukte umgewandelt. Braune Hornblende kommt teils als kleine wohlentwickelte Kristalle, teils mit Augit verwachsen vor. Brauner Biotit ist spärlich, Erz und Apatit sind relativ reichlich vorhanden. In den Zwickeln beobachtet man oft kleine Quarzkörner oder Mikropegmatit. Dieser Diabas entspricht somit CoHen und DEEcke's erster Gruppe. Im übrigen fällt der Gang durch eine für die Bornholmer Diabase ungewöhnliche Streichrichtung, nämlich $\mathrm{N} 55^{\circ} \mathrm{W}$, auf.

Aber mindestens ebenso häufig findet man Diabase, in denen der Plagioklas nicht nur als Leisten, sondern zugleich als dickere Tafeln auftritt. Der Augit bleibt dann seiner Grösse nach weit hinter den Plagioklaskristallen zurück und besteht sowohl aus rundlichen Körnern als auch aus schlanken Säulen; in den gröberen Diabasen haben viele Augitkörner eine wohlentwickelte Kristallform. Meistens hat der Augit eine deutliche Sanduhrstruktur und einen recht schwachen, jedoch durchaus wahrnehmbaren Pleochroismus: rotviolett bis beinahe farblos. Der ursprüngliche Olivingehalt des Diabases lässt sich in vielen Fällen, wo nur Pseudomorphosen übriggeblieben sind, schwierig beurteilen. Häufig kann man, namentlich in den olivinreichen Diabasen, einen beträchtlichen Gehalt an braunem Biotit feststellen. Apatit ist meistens reichlich vorhanden, wogegen Quarz und Hornblende spärlich sind. Nicht selten treten kleine, feinkörnige Aggregate auf, die aus sämtlichen Mineralien des Diabases bestehen und die aus einem Restmagma entstanden zu sein scheinen, das unregelmässige Zwischenräume zwischen den älteren Gemengteilen ausgefüllt hat. 
Besonders biotitreiche Diabase von diesem Typus findet man bei Möllebæk, Tejn; sie enthalten Olivinpseudomorphosen in beträchtlicher Menge. Die ziemlich dicken Plagioklaskristalle sind aus wenigen Lamellen aufgebaut und manchmal etwas zersetzt. In einigen Diabasen von Möllebæk fanden sich etliche Hohlräume von $1-5 \mathrm{~mm}$ im Querschnitt, die mit Kalkspat und Chlorit ausgefüllt waren. Ein ganz ähnlicher biotitreicher Diabas wurde zwischen Allinge und Sandvig gefunden. In diesem waren die Augitkristalle in der Mitte kräftig gefärbt, an den Enden mehr oder weniger farblos. In $\beta$-Schnitten wurde in der Mitte $\mathrm{c}: \gamma=$ ca. $50^{\circ}$ und an den Enden $c: \gamma=$ ca. $45^{\circ}$ gemessen. Der Olivin war teilweise erhalten, der Plagioklas ziemlich stark zersetzt, aber unregelmässige Zwischenräume zwischen den recht groben Plagioklasleisten oder -tafeln waren mit Aggregaten aus ganz frischem Albit ausgefüllt.

Im allgemeinen ist der Biotitgehalt jedoch nicht so gross wie in den genannten Fällen. Diabase, die übrigens den letzteren sehr nahe stehen, findet man nördlich von Klinteaa in Allinge und in mehreren Gängen von $2-5 \mathrm{~m}$ Mächtigkeit bei Stammershalde und in den Helligdomsklippen.

Auch aus dem südöstlichen Teil des Grundgebirges kennt man einige hierhergehörige Diabase. Der frischeste von diesen ist der etwa $3 \mathrm{~m}$ mächtige Diabas, der das kleine Felsenriff Malkværnen NNO von Nexö durchsetzt. Das Gestein ist schwarzgrau und im grossen und ganzen feinkörnig, einzelne Körner aus Plagioklas und Olivin erreichen jedoch ungefähr die Grösse von Einsprenglingen. Der grösste Teil des Plagioklases tritt als schlanke Leisten von etwa $0,25 \mathrm{~mm}$ Länge auf; sie bestehen aus Labrador mit etwa $57 \%$ An. Der Olivin ist nur teilweise serpentinisiert; im mikroskopischen Bilde wird er stark durch randliche Erzausscheidungen hervorgehoben; häufig schliesst er kleine Körner aus Picotit, selten Flüssigkeitsporen ein. Der Augit hat meistens die Form von schlanken Säulen ohne Kristallflächen. Brauner Biotit ist reichlich vorhanden. - Diesem Diabas verwandt ist ein etwas südlicheres Vorkommen bei der Lerskred Batterie. Dieses Gestein ist jedoch ziemlich stark umgewandelt. Frischer Olivin fehlt, dagegen treten Serpentin und Chlorit reichlich auf, meistens in unregelmässigen Massen. Auch der Augit ist teilweise zersetzt. Unter den chloritischen Umwandlungsprodukten gibt es einige kleine Titanitkörner. Zahlreiche kleine Blasenräume sind mit Kalkspat und Chlorit ausgefüllt. — Ein noch stärker umgewandelter Diabas wurde südlich von Aarsdale an der Mündung des Lisebæk gefunden. Er unterscheidet sich von den soeben erwähnten dadurch, dass der Augit in der Randzone am stärksten gefärbt und in der Mitte am hellsten oder ganz farblos ist.

Auf der Insel Christiansö, gleich südlich vom Hafen, gibt es einen 
recht ansehnlichen Diabasgang, dessen Gestein am ehesten den soeben erwähnten verwandt ist. Der grösste Teil des Diabases ist jedoch durch Erosion abgetragen. In den Uferfelsen hat der Gang eine Breite von etwa $3 \mathrm{~m}$ und die Richtung $\mathrm{N} 10^{\circ} \mathrm{O}$, aber ein wenig landeinwärts verzweigt er sich in mehrere schmale Ausläufer, die in verschiedenen Richtungen verlaufen. Im Gegensatz zu den meisten anderen Bornholmer Diabasen schliesst dieser einige Granitfragmente ein, darunter ein einzelnes von 0,5 m Länge; an beiden Seiten des Ganges ist der Granit stark brecciös. An einigen Stellen besteht die Breccie aus stark zerteiltem Granitmaterial, das von sehr feinkörnigem Diabas verkittet ist, an anderen Stellen, wo kleine Granitfragmente verstreut im Diabase liegen, erhält das Gestein dadurch ein porphyrähnliches Aussehen. Spuren von Aufschmelzung des Granits wurden nicht beobachtet.

Der Diabas ist grau und selbst in der Gangmitte ziemlich feinkörnig. Nach dem Rande zu ist das Gestein äusserst feinkörnig und etwas porphyrisch ausgebildet. Das Diabasmaterial in der Breccie hat eine etwas hellere graugrüne Färbung als im Gang selbst. Das Gestein ist im wesentlichen vom gleichen Typus wie die obigen. Der Plagioklas ist etwas zersetzt. Die Augitkristalle haben Säulenform; in einem Dünnschliff waren sie völlig frisch, in einem anderen in grüne schuppige Aggregate umgewandelt. Olivinpseudomorphosen treten in recht grosser Menge auf, nur selten enthalten sie Ueberreste von frischem Olivin; ausser Serpentin findet man oft in den Pseudomorphosen Karbonat aus Kalk und Eisenerz sowie Quarz und kleine Titanitkörner. Feinkörnige Partien scheinen in diesem Diabas ungewöhnlich häufig aufzutreten, bisweilen sind sie schlierenförmig angeordnet, bisweilen bilden sie unregelmässige Klumpen, in deren Mitte man Blasenräume, die mit Karbonat und Chlorit ausgefüllt sind, finden kann. - In der äusserst feinkörnigen Grenzzone sind einige Pseudomorphosen nach skelettartigen Einsprenglingen vorhanden; sie bestehen aus Quarz und Serpentin und schliessen oft kleine Titanitkörner ein.

\section{Olivindiabasporphyrite.}

Die porphyrischen Diabase weisen einige Variationen von feldspatreicheren zu feldspatärmeren Gesteinen auf. Ausserdem gibt es einige wenige Gänge von körnigem oder schwach porphyrischem Diabas, dessen Plagioklasgehalt weit hinter dem Augit- und Olivingehalt zurückbleibt.

Als Beispiel eines schwach porphyrischen Diabases kann ein Gang an der NO-Küste von Bornholm zwischen Dynddaleaa und Vellingsaa genannt werden. Das ziemlich stark zersetzte Gestein hat eine feinkörnige Grundmasse, deren Plagioklasleisten in den verschiedenen Teilen desselben Dünnschliffes an Grösse etwas variieren. Einige der Plagioklaskristalle haben jedoch den Charakter von Einsprenglingen; sie kön- 
nen bisweilen eine Länge von $4 \mathrm{~mm}$ erreichen. Auch die Olivinpseudomorphosen haben variierende Dimensionen.

Der eigenartigste von den feldspatreichen Diabasen ist das Gestein in einem 0,5 m mächtigen Gang im Steinbruch bei Korsbjerg, etwa $1200 \mathrm{~m}$ nördlich von Ols Kirke. Auch die Richtung des Ganges N $60^{\circ} \mathrm{O}$ weicht etwas von der Norm ab. Der Diabas ist feinkörnig und ganz schwarz. Mit blossem Auge sieht man leistenförmige Plagioklaskristalle

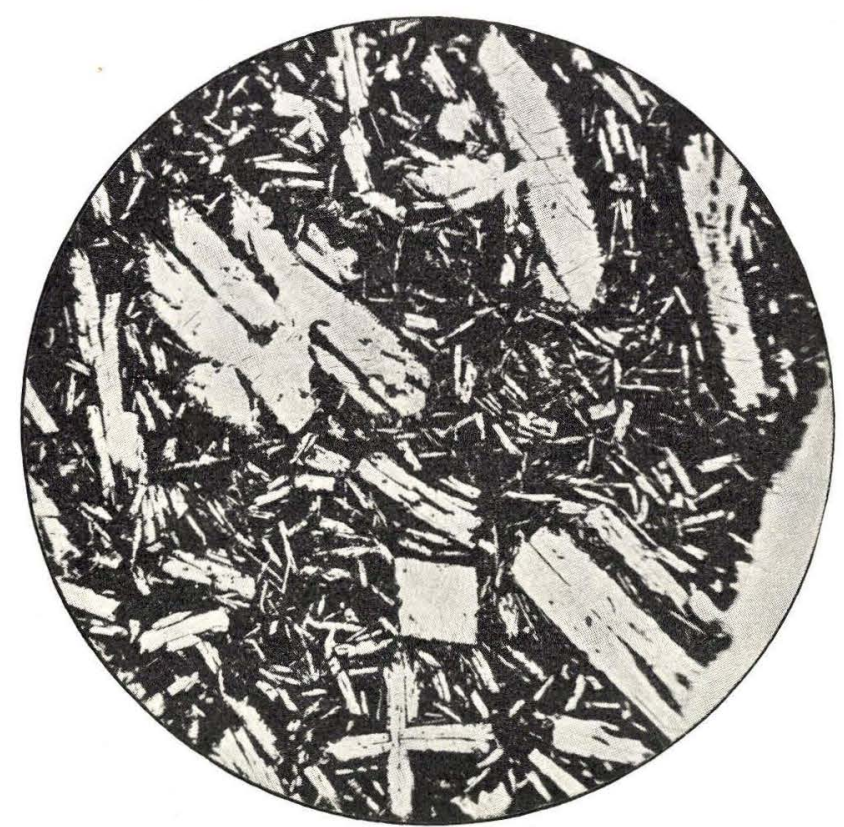

Fig. 36. Diabas von Korsbjerg, nördlich von Ols Kirke. Nic. $\|$. Vergr. $40 \times$.

von 1-1,5 mm Länge; diese Körner treten als Einsprenglinge in einer Grundmasse auf, deren Plagioklasleisten durchschnittlich eine Länge von 0,15 mm (siehe Fig. 36) haben. Der weit überwiegende Bestandteil des Diabases ist Plagioklas; er ist ausserordentlich frisch und klar. Längs dem Rande ist er mit Magnetitkristallskeletten verwachsen; die kleinen Plagioklaskristalle können sogar durch und durch damit gespickt sein. In der Regel sind die Plagioklaskristalle aus nur wenigen Zwillingslamellen aufgebaut; Kombinationen nach den Albit-, Karlsbader- und Periklingesetzen wurden beobachtet. Die grösseren Körner bestehen aus Labrador mit etwa $60 \%$ An., die kleineren enthielten etwa $55 \%$ An. Die Olivinkörner variieren etwas in Bezug auf die Grösse, erreichen jedoch selten mehr als 1,2 mm im Durchmesser. Die Körner sind rundlich und liegen oft in kleinen Haufen. Der optische Achsenwinkel $2 \mathrm{~V}$ ist etwa $90^{\circ}$. Der Olivin ist in der Regel frisch, einige Körner sind jedoch in helle Serpentinpseudomorphosen umgewandelt. In der Grundmasse 
sind eine Menge ganz kleiner, stark doppelbrechender Körner, von denen einige gegabelte Kristallskelette sind, während andere sich im Dünnschliff als hohle Skelette von rhombischem Querschnitt erweisen. Ein grosser Teil dieser Körner besteht zweifellos aus Olivin, aber möglicherweise findet sich auch Augit darunter. Als bestimmbare Körner wurde Augit nicht gefunden, doch besteht sicher ein wesentlicher Teil der dunklen Zwischenklemmungsmasse zwischen den hellen Kristallen aus diesem Mineral. Bei starker Vergrösserung beobachtet man in dieser Masse ein doppelbrechendes und stark lichtbrechendes, meistens stengeliges Mineral, das jedoch von Magnetitkristallskeletten und dunklen Partikeln bis zur Unkenntlichkeit getrübt ist. - Magneteisenerz tritt nur selten als grössere Körner auf, ist aber reichlich als kurze Stäbchen und stellenweise als gestrickte Kristallskelette vorhanden. Das Erz lässt sich aus dem Gesteinspulver mittels eines Magnets extrahieren und gibt eine schwache Ti-Reaktion.

Ein recht eigentümlicher Diabas tritt in einem kleinen Aufschluss etwa 400-500 m östlich vom Tornewerk bei Rönne zu Tage. In der völlig schwarzen, sehr feinkörnigen Grundmasse liegen grosse Feldspattafeln eingebettet; sie sind etwa $2 \mathrm{~mm}$ dick und haben eine Ausdehnung von mehreren $\mathrm{cm}$; ausserdem findet man einzelne dunkle, fast rechteckige Körner, etwa $2 \times 5 \mathrm{~mm}$ gross, die sich bei näherer Untersuchung als Serpentinpseudomorphosen herausstellten. Im Dünnschliff sieht man, dass die grossen Feldspattafeln aus mehreren verschiedenartig orientierten, aber zum grössten Teil stark zersetzten Plagioklaskristallen aufgebaut sind. An frischen Stellen im Feldspat und zwar besonders in der Randzone desselben beobachtet man deutliche Zwillingslamellen, die in den meisten Fällen die Feldspattafeln schräg durchsetzen; nư in einzelnen Körnern liegt die Zwillingsstreifung parallel dem Rande. Sicher orientierte Schnitte wurden nicht gefunden, die ziemlich geringe Auslöschungsschiefe deutet aber auf einen recht sauren Plagioklas hin. Die Lichtbrechung ist höher als die des Canadabalsams. Die Olivinpseudomorphosen liegen in der Verlängerung der Feldspattafeln oder zwischen den Plagioklaskristallen, mitunter auch in denselben eingelagert. Sie bestehen aus einer schwach doppelbrechenden, grünen und etwas pleochroitischen oder ganz farblosen, faserigen Substanz, die in eine Menge kleiner Felder von verschiedener Auslöschung aufgeteilt ist. An mehreren Stellen längs dem Rande und in Rissen im Innern der Pseudomorphosen haben sich körnige Aggregate aus Eisenkarbonat ausgeschieden.

Die Grundmasse hat eine recht variierende Korngrösse; gewisse kleinere Partien in der Nähe der Plagioklastafeln sind ausserordentlich feinkörnig, aber im grössten Teil der Grundmasse beobachtet man Plagioklasleisten, deren Länge von etwa $0,75-0,1 \mathrm{~mm}$ variiert. Längs dem Rande sind diese Plagioklaskristalle, wie im Korsbjerg Diabas, mit einer 
Menge von kleinen stabförmigen Magneteisenerzkristallen verwachsen. Auch hier lässt sich kein Augit mit Sicherheit feststellen, aber in den Zwischenräumen zwischen den Plagioklasleisten, die aus Magnetitkristallskeletten, zerstreuten kleinen Olivinpseudomorphosen und grünen Zersetzungsprodukten bestehen, findet man einige kleine, schlanke grüne Säulen, die wahrscheinlich umgewandelter Augit sind. Hierzu kommen häufig kleine Aggregate aus Kalkspat oder Eisenspat.

Diabas mit Einsprenglingen aus Plagioklas und Olivin wurde im Steinbruch bei Sjelle Mose gefunden, wo er einen kleinen, 0,6 $\mathrm{m}$ mächtigen

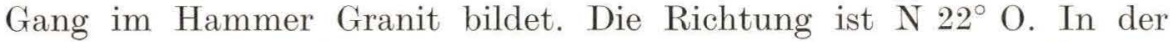
schwarzgrauen, feinkörnigen Grundmasse unterscheidet man mit blossem Auge nur die kleinen Plagioklaseinsprenglinge. Frischer Olivin ist nicht vorhanden, dagegen findet man deutliche Pseudomorphosen nach Olivin. Die Grundmasse hat am ehesten ophitische Struktur; zwischen den Plagioklasleisten liegen ein recht heller, braungrauer Augit und zahlreiche kleine Erzkörner. Biotit tritt spärlich auf. - Ein ähnlicher, jedoch stark zersetzter Diabas kommt in Klömberne an der NO-Küste vor; er hat eine Mächtigkeit von $1 \mathrm{~m}$ und die Richtung $\mathrm{N} 10^{\circ} \mathrm{O}$.

Ein sehr schön ausgebildeter porphyrischer Diabas durchsetzt den Svaneke Granit an der Ost- und Südseite der kleinen Bucht Nörrevig nördlich von Svaneke. Die Richtung des Ganges ist $\mathrm{N} 28^{\circ} \mathrm{O}$, seine Mächtigkeit 20-30 cm. Auf einer kurzen Strecke spaltet sich der Gang in zwei Zweige, die sich wieder vereinigen. Ein kleiner Fusspfad benutzt die durch den Diabas bedingte Vertiefung in der jäh abfallenden Granitwand. Das Gestein macht einen ausserordentlich frischen Eindruck, aber im Dünnschliff sieht man, dass gewisse Partien stark zersetzt sind. Der Diabas ist schwarz und die Grundmasse sehr feinkörnig. Die Einsprenglinge bestehen zum grössten Teil aus Plagioklas, doch sind auch Olivin und Augit in recht beträchtlicher Menge vorhanden. Die Plagioklaskristalle erreichen eine Länge von $3-3,5 \mathrm{~mm}$; meistens sind sie frisch und ohne Einschlüsse, nur selten findet man einen einzelnen eingelagerten Augitkristall. Der Plagioklas besteht aus Labrador mit 62\% An. Die Augiteinsprenglinge haben einen Durchmesser von $1-2 \mathrm{~mm}$. Die Farbe ist hell braunviolett. Die Kristalle haben im allgemeinen Schalenbau. Die optische Achse B zeigt eine deutliche Dispersion $\varrho>v$. Zwillinge nach (100) sind häufig vorhanden. Oft liegen die Augitkristalle in Haufen zusammen mit Olivin, in einzelnen Fällen ist Olivin im Augit eingeschlossen. Ein Teil des Olivins ist gut erhalten, aber einige Körner weisen eine beginnende Umwandlung in Serpentin auf, andere wieder sind völlig serpentinisiert. Eine Umwandlung in Hornblende und Biotit, wie Cohen und Deecke sie für den Olivin in diesem Diabas angeben, wurde dagegen nirgends beobachtet. An Einschlüssen führt der Olivin nur Magnetit und in einzelnen Fällen Picotit. In der Grundmasse hat 
der Plagioklas vorwiegend die Form von Leisten, kann aber manchmal als gänzlich unregelmässig begrenzte Individuen auftreten. Augit ist sehr reichlich vorhanden und ist hier etwas dunkler als die Einsprenglinge; meistens tritt er in Form von schlanken Säulen auf, an denen bisweilen einzelne Kristallflächen beobachtet werden. Biotit und Magneteisenerz kommen reichlich vor. Kleine runde Mandeln bestehen aus Kalkspat und Chlorit, wozu oft Epidot, seltener Quarz hinzukommen.

Bei Listed gibt es westlich vom grossen Gang auf Gule Hald einige kleinere Diabasgänge. Im flachen, bewachsenen Terrain sind sie schlecht aufgeschlossen, wogegen sie in einigen kleinen Schären sichtbar werden. Laut Johnstrup's Mitteilung an Cohen und Deecke (vgl. letztere, p. 56-57) sollen im ganzen 15 Gänge mit einer Mächtigkeit von 9,5 m insgesamt gefunden worden sein, "welche bald dichte, bald porphyrische, bald mandelsteinartige Struktur besitzen«. Nur aus wenigen dieser Gänge verfügte ich über Material zur Untersuchung. Die meisten haben porphyrische Struktur. Das Gestein variiert etwas. In Stufen, die ich selbst einem der bestaufgeschlossenen Gänge entnommen habe, führte das Gestein aus der Mitte des Ganges kleine Einsprenglinge aus Augit und etwa $0,5 \mathrm{~cm}$ lange Plagioklasleisten in einer sehr feinkörnigen Grundmasse ohne Blasenräume, während der Diabas aus der Randzone desselben Ganges Mandelsteinstruktur hatte. In diesem und in ein paar anderen Gängen gab es ausserdem einige grössere Feldspattafeln, die eine Länge von 3-4 cm und eine Dicke von etwa $3-6 \mathrm{~mm}$ erreichen können. Sie bestehen aus einem Aggregat aus stark zersetztem Feldspat, der sich nicht näher bestimmen lässt; in einzelnen kleinen Partien war Plagioklasstreifung zu beobachten, und die Lamellen zeigten stets eine geringe Auslöschungsschiefe, die auf Oligoklas hindeuten dürfte; möglicherweise liegen in der Tat Einschlüsse von Feldspat aus durchquerten Pegmatitgängen vor. Die kleineren, leistenförmigen Plagioklaseinsprenglinge sind ebenfalls stark zersetzt, während der Plagioklas der Grundmasse etwas besser erhalten ist. Olivin kommt nicht vor, dagegen mehrere charakteristische Pseudomorphosen. Nur der Augit ist meistens völlig frisch. Die grösseren Körner haben eine helle grauviolette Färbung, die in der Randzone in eine recht dunkle braunviolette übergehen kann. Der Pleochroismus ist schwach. Meistens haben die Kristalle einen zonaren Aufbau, doch in einer einzelnen Gesteinsprobe haben sie eine deutliche Sanduhrstruktur. Die kleinen Augitkristalle der Grundmasse haben öfters eine annähernd rechteckige Form; sie sind meistens dunkler gefärbt als die grösseren und haben in der Regel eine ausgesprochene Sanduhrstruktur. In diesem Diabas gab es eine recht beträchtliche Menge von rotbrauner, kräftig pleochroitischer Hornblende. Die Mandeln in der Randzone des Diabases messen durchschnittlich 1-2 mm im Durchmesser, können aber bis zu $0,5 \mathrm{~cm}$ erreichen. 
Sie bestehen in der Hauptsache aus körnigem Karbonat, von dem ein Teil stark braunpigmentierter Eisenspat ist; hierzu kommen häufig etwas Chlorit und stets Albit; der letztere hat sich an den Wänden des Hohlraums abgesetzt, von wo aus sich die Kristalle nach der Mitte zu erstrecken. Proben aus ein paar der übrigen kleinen Gänge bei Listed — teils von mir eingesammelt, teils älteres Material — stimmen in allen wesentlichen Zügen mit dem erwähnten Gestein aus der Gangmitte überein. Augit ist stets das am besten erhaltene Mineral; Olivin scheint immer vorhanden gewesen zu sein, nur in einem einzelnen Präparat fanden sich nur undeutliche Pseudomorphosen.

Die Gesteinsproben aus zwei der anderen Gänge bestanden aus ausgesprochenem Mandelstein. In einem der Diabase gab es Einsprenglinge aus Augit und aus zahlreichen deutlichen Pseudomorphosen nach Olivin sowie aus stark zersetzten Plagioklaskristallen, im anderen spielten die Einsprenglinge eine ganz untergeordnete Rolle. Die Augitkörner haben eine deutliche Sanduhrstruktur; sie sind längs dem Rande dunkel, in der Mitte hell und haben oft eine recht gute Kristallbegrenzung. In der farbigen Randzone beobachtete man einen sehr kleinen optischen Achsenwinkel $2 \mathrm{~V}$, während die hellen Teile den beim Augit gewöhnlichen Achsenwinkel von etwa $60^{\circ}$ aufwiesen. Häufig ist der Augit randlich mit brauner Hornblende verwachsen. - Ausser Mandeln des obenerwähnten Typus, die mit Kalkspat, Chlorit und Augit ausgefüllt sind, kommt hier daneben ein anderer Typus von Hohlraumsfüllungen vor, der aus Albit, kleinen länglichen Blättern aus braunem Biotit, bisweilen schlanken Kristallen aus brauner Hornblende sowie Kristallskeletten aus Magneteisenerz besteht. Der Albit tritt in relativ grossen Kristallen auf, die meistens Einschlüsse aus den übrigen Mineralien führen. In einigen Fällen sind diese Aggregate durch einen Kranz von kleinen Augit- und Magnetitkörnern vom umgebenden Diabas scharf getrennt, in anderen Fällen ist die Grenze unscharf. Diese Aggregate dürften zweifellos aus einem Restmagma entstanden sein, das durch Differentiation während der Kristallisation des Diabases eine saurere Beschaffenheit erlangt hat. Bisweilen sieht man Kalkspat und Chlorit in den Zwischenräumen zwischen den genannten Kristallen, seltener kommt in der Mitte dieser Partien ein wohlabgegrenzter, mit Kalkspat und Chlorit ausgefüllter Blasenraum vor.

Im östlichen Teil von Listed gibt es ebenfalls mehrere schmale Diabasgänge. Der grösste von ihnen, etwas östlich von Vaseaa, ist ungefähr 1,5 m mächtig. Er zeichnet sich durch einige Ausscheidungen von weissem oder leicht rötlichem Plagioklas in groben, etwa handgrossen Aggregaten aus. Die einzelnen Körner massen bis zu 2-3 cm im Durchmesser; in einigen Individuen konnte man mit blossem Auge Zwillingsstreifung beobachten, im Dünnschliff aber stellte sich der Plagioklas 
als ziemlich stark serizitisiert und stellenweise epidotisiert heraus, so dass er sich nur mit Unsicherheit als Labrador mit etwa 65\% An. bestimmen liess. Zwischen den Plagioklaskörnern lagen etwas Chlorit und serpentinartige Umwandlungsprodukte. Im übrigen war der Diabas feinkörnig, schwarzgrün und recht stark zersetzt. Von Einsprenglingen waren nur noch Pseudomorphosen übrig, einige von ihnen deuteten entschieden auf Olivin. Das vorherrschende Mineral der Grundmasse war ein rötlicher Augit, der fast völlig frisch war und der in jeder Hinsicht dem Augit in den obenerwähnten Diabasmandelsteinen entsprach. Der Plagioklas war stark zersetzt und blieb an Menge wesentlich hinter dem Augit zurück. Erz, braune Hornblende und Biotit waren relativ reichlich vorhanden. Einige Aggregate von Chlorit und Kalkspat schienen die Füllmasse der Blasenräume auszumachen.

Die übrigen untersuchten Diabase aus diesen Gängen boten nichts Bemerkenswertes dar. In der Grundmasse spielte der Plagioklas eine grössere Rolle als im letztgenannten Diabas. Unter den Einsprenglingen gab es nur wenige Augit- und Plagioklaskristalle, die meisten waren Pseudomorphosen nach Olivin und bestanden hauptsächlich aus Serpentin, wozu etwas Karbonat hinzukam.

An der Südseite einer kleinen Bucht bei Nörremarks Huse nördlich von Nexö ist ein kleiner Diabasgang, der in mehreren Beziehungen an die kleinen Gänge bei Listed erinnert. Das Gestein ist schwarzgrau und feinkörnig. Als Einsprenglinge treten nur Augit und Olivin auf, letzterer grossenteils als gut erhaltene Kristalle, die einen Durchmesser von ein paar mm erreichen können; kleinere Olivinkörner liegen vorwiegend in kleinen Haufen gesammelt. Der Olivin führt einzelne Flüssigkeitsinterpositionen und schliesst stellenweise kleine Körner aus Augit und Plagioklas ein. Der optische Achsenwinkel $2 \mathrm{~V}$ ist fast $90^{\circ}$. Gewisse Teile der Olivinpseudomorphosen sind glimmerähnlich und recht stark doppelbrechend. Grosse Augitkristalle sind nur spärlich vorhanden; sie sind fast farblos bis hellgrau. Ein einzelner dieser Kristalle zeichnet sich dadurch aus, dass Olivin in mikropegmatitähnlicher Weise in der Randzone des Augits eingelagert ist (vgl. Fig. 37). Der Randaugit hat nicht ganz dieselbe Auslöschung wie der Augit im Kerne; ferner ist er ein wenig dunkler und in der äussersten Zone leicht rotviolett, ungefähr wie die kleinen Augitkristalle in der Grundmasse. Die Olivineinlagerungen im Randaugit sind ausserordentlich zahlreich und treten in Form von kleinen, runden oder länglichen Körnern auf, die gruppenweise gleichzeitig auslöschen. Ausserhalb dieses Mantels setzt sich in einer etwas breiteren Zone eine starke Anreicherung von Olivin fort, ebenfalls in stark durchlöcherten Kristallindividuen, deren Löcher mit Plagioklas ausgefüllt sind. - Die Grundmasse besteht aus ein wenig zersetzten Plagioklasleisten, aus rotviolettem Augit, einigen kleinen 
Olivinkörnern, Biotit und Erzkörnern. Im Gegensatz zu den Einsprenglingen sind die kleinen Augitkristalle ziemlich stark gefärbt, sie haben keine Kristallbegrenzung und sind häufig in unregelmässigen, von Feldspatleisten unterbrochenen Körnern ausgebildet. Die optische Achse B war stark dispergiert und zwar $\varrho>v$ um die spitze Bisectrix $\gamma$. Die optische Achse A zeigte eine kaum merkbare oder sehr schwache Dispersion in demselben Sinne. Die Dispersion der Auslöschung war kräftig.

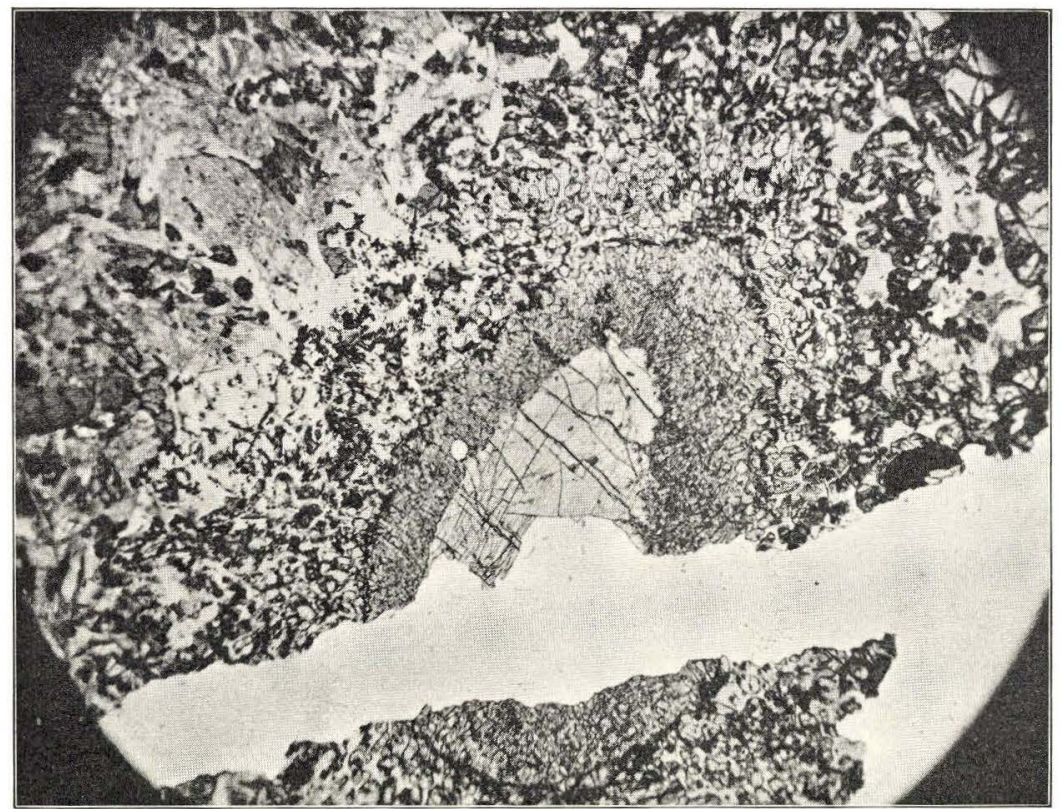

Fig. 37. Diabas bei Nörremarks Huse, nördlich von Nexö. In der Mitte ein grosser Augitkristall, in dessen Randzone Olivin eingewachsen ist.

Nic. ||. Vergr. $23 \times$.

In den Paradisbakker südlich von den Paradisgaarde hat JoHNSTRUP 9 schmale Diabasgänge mit einer Mächtigkeit von etwa $10 \mathrm{~m}$ insgesamt observiert. Die Gangrichtung variiert von $\mathrm{N} 22^{\circ} 30^{\prime} \mathrm{O}$ bis $\mathrm{N} 32^{\circ} 30^{\prime} \mathrm{O}$. Zusammen mit dem dazwischenliegenden Granit nimmt dieser kleine Schwarm von Diabasgängen ein Areal von etwa $36 \mathrm{~m}$ Breite ein. Vom Gestein liegt nur eine einzelne Probe vor. U. d. M. beobachtet man mehrere charakteristische Olivinpseudomorphosen, jedoch nur selten Ueberreste von Olivin. In der Regel bestehen die Pseudomorphosen aus Serpentin, aber in einzelnen von ihnen findet man auch Quarzausscheidungen. Ferner kommen vereinzelt Einsprenglinge aus einem fast farblosen Augit vor, die in einigen Fällen kleine Einschlüsse aus Plagioklas führen. Der Augit der Grundmasse ist recht hell, hat aber häufig eine schwach braunviolette Randzone; meistens bildet er 
rundliche Körner ohne jede Kristallbegrenzung. Die Plagioklasleisten sind etwas zersetzt. Biotit ist recht reichlich vorhanden.

\section{Feldspatarme Diabase.}

Wesentlich feldspatärmer als die bisher besprochenen ist ein Diabas, der an der NO-Küste, etwa $400 \mathrm{~m}$ SO von der Mündung des Kobbeaa ansteht. An dieser Stelle erwähnt Ussing (Tagebuch 1899, p. 26) eine Menge schlecht aufgeschlossener Gänge, von denen die meisten ganz schmal sind, z. B. $1 \mathrm{dm}$, Richtung $\mathrm{N} 10^{\circ} \mathrm{O}$. Als ich den Ort aufsuchte, war nur ein einziger von diesen Gängen sichtbar, aber im Gerölle des Ufers waren viele Diabasblöcke. Der Diabas ist schwarzgrau. Der vorherrschende Bestandteil ist ein rötlicher Augit. Deutliche Olivinpseudomorphosen sind reichlich vorhanden; sie bestehen vorwiegend aus Serpentin, in dem stellenweise Karbonatausscheidungen zu beobachten sind. Von frischem Olivin findet man nur spärliche Ueberreste. Der Plagioklas ist in der Regel etwas zersetzt; an Menge bleibt er wesentlich hinter den obengenannten Gemengteilen zurück. Erzkörner und braune Hornblende sind relativ reichlich vorhanden, Biotit etwas spärlicher. Der Augit tritt häufig in knäuelartigen Verwachsungen auf, die Korngrösse ist etwas variierend, doch dürften kaum zwei Generationen von Augitkristallen vorliegen. Die Form der Körner ist ganz unregelmässig; sie haben alle eine ausgesprochene Sanduhrstruktur. Der optische Achsenwinkel war etwas kleiner als gewöhnlich beim Augit, $2 \mathrm{E}$ wurde zu $78^{\circ}$ gemessen. Die optische Achse B zeigte eine starke Dispersion um die spitze Bisectrix $\gamma$, die optische Achse A war kaum merkbar dispergiert. Den Auslöschungswinkel c $: \gamma$ gelang es nicht zu bestimmen. Häufig ist der Augit randlich mit Hornblende verwachsen. Die Hornblendekristalle sind oft in der Mitte rotbraun und haben in der Regel eine stark grüne Randzone.

Einige wenige andere Diabase von der NO-Küste Bornholms scheinen ebenfalls sehr feldspatarm zu sein, aber in ihnen allen sind grüne Umwandlungsprodukte so stark vertreten, dass sich die ursprüngliche $\mathrm{Zu}$ sammensetzung des Gesteins schwierig beurteilen lässt. In einem einzelnen Diabas aus einem kleinen Gang bei Saltuna ist sogar der Augit in goldbraune, limonitähnliche Pseudomorphosen umgewandelt. Erkennbare Olivinpseudomorphosen sind ebenfalls in reichlicher Menge vorhanden. Frischer Plagioklas ist kaum nachzuweisen, und nach dem Gehalt deutlicher Augit- und Olivinpseudomorphosen zu urteilen, kann der Plagioklas nur eine untergeordnete Rolle gespielt haben.

In ein paar kleineren Gängen in der Nähe von Randklevegaard und in den Uferfelsen etwas nordwestlich von Saltuna ist der Diabas als Mandelstein entwickelt. Namentlich der letztgenannte Gang erinnert stark an die Diabasmandelsteine bei Listed. Trotz dem schlechten Er- 
haltungszustand des Gesteins hat es doch den Anschein, als ob dieser Diabas ursprünglich einen wesentlich geringeren Plagioklasgehalt gehabt hat. Deutliche Olivinpseudomorphosen sind reichlich vorhanden, aber zugleich sind unregelmässige Aggregate von Serpentin und Chlorit stark verbreitet; Epidot wird häufig beobachtet. Der wesentlichste Bestandteil ist aber Augit; er ist ganz frisch und hat eine helle grauviolette Färbung. Die grösseren Kristalle liegen oft in kleinen knäuelförmigen Gruppen. Braune Hornblende ist in ungewöhnlich reichlicher Menge vorhanden, teils in randlicher Verwachsung mit Augit, teils als kleine Körner, die oft Spuren von Kristallbegrenzung aufweisen. Biotit kommt verhältnismässig spärlich vor. Der Plagioklas ist stark zersetzt und sein Gehalt schwierig festzustellen, einzelne Körner erreichen eine recht beträchtliche Grösse. Die Erzkörner sind zum Teil durch Titanit ersetzt. Die Mandeln bestehen grösstenteils aus Kalkspat und Chlorit; wie in den Listed-Mandelsteinen treten auch hier runde oder unregelmässige Felder auf, die hauptsächlich aus kleinen, unregelmässig begrenzten Feldspatkristallen und brauner Hornblende bestehen; wahrscheinlich sind sie durch Kristallisation des letzten Restmagmas entstanden.

Der Diabas von Randklevegaard scheint dem letztgenannten genau $\mathrm{zu}$ entsprechen, ist aber noch stärker umgewandelt. In gewissen Partien ist der Augit ganz frisch, in anderen ist er in gelbgrüne Pseudomorphosen umgewandelt, und zwar unter Ausscheidung ganz kleiner, dunkler, skelettartiger Körner mit hoher Lichtbrechung und Doppelbrechung, vermutlich Titanit.

\section{Zersetzte Diabase.}

Eine recht grosse Anzahl der Bornholmer Diabase ist stark zersetzt. Nichtsdestoweniger lassen sich die wesentlichsten Gemengteile in einigen Fällen einigermassen sicher feststellen. Die meisten dieser Diabase scheinen recht feldspatreich gewesen zu sein, und nicht selten ist Plagioklas das am besten erhaltene Mineral. Ferner findet man oft deutliche Pseudomorphosen nach Olivin. In anderen Fällen liegen sozusagen nur Umwandlungsprodukte vor. Nichts deutet darauf, dass es unter diesen Diabasen andere Gesteinstypen als die schon erwähnten gegeben hat. Die Umwandlungsprodukte weisen keine grösseren Variationen auf. Der Plagioklas ist mehr oder weniger serizitisiert. Nur selten findet man Ueberreste von frischem Augit. Die Pseudomorphosen nach Olivin bestehen vorwiegend aus Serpentin, der in einigen Diabasen von schlanken Amphibolnadeln durchwoben sein kann; nicht selten enthalten sie zugleich Karbonatausscheidungen. In mehreren dieser Diabase bestehen die Einsprenglinge aus Pseudomorphosen aus Chlorit, und in solchen Fällen lässt es sich meistens nicht entscheiden, von welchem Mineral sie herrühren. Die übrigen Umwandlungsprodukte, die in grösserer oder 
kleinerer Menge auftreten, bestehen hauptsächlich aus Chlorit, Karbonat, Quarz, Epidot und bisweilen aus Chalcedon; in einigen Diabasen spielen limonitische Ausscheidungen eine sehr bedeutende Rolle.

Von den stark zersetzten Diabasen ist der bekannteste der Gang bei Jons Kapel, dessen Zerstörung zum Entstehen der bekannten malerischen Kluft mit steilen Felsenwänden geführt hat. In der Tiefe der Kluft tritt der Diabas noch stellenweise als eine zähe, chloritische Masse auf. Er enthält kleine Nester und Adern aus Quarz; hie und da treten auch kleine Quarzkristalle auf. U. d. M. beobachtet man, dass das Gestein deutlich porphyrisch ist, die Einsprenglinge aber bestehen ausschliesslich aus gelbgrünen, schwach pleochroitischen Pseudomorphosen aus Serpentin, der bisweilen sehr feinkörnige Aggregate aus Quarz einschliesst; dagegen wurde kein Karbonat gefunden. Die meisten Pseudomorphosen sind recht unregelmässig begrenzt, doch haben mehrere derselben die Kristallumrisse und die charakteristische Zerklüftung des Olivins bewahrt. In der Grundmasse sind Plagioklasleisten deutlich zu erkennen, doch ist es nicht gelungen, sie genauer zu bestimmen. Alle übrigen Mineralien sind stark zersetzt; auch das Eisenerz ist teilweise in Limonit umgewandelt.

Das ansehnliche Spaltental Kleven in der Gemeinde Klemensker wird von mehreren Diabasgängen, die ungefähr in nord-südlicher Richtung verlaufen, gekreuzt. Die vorliegenden Stücke bestehen aus stark zersetztem Diabas. Der Plagioklas ist das am besten erhaltene Mineral; er hat die Form von Leisten und eine recht ungleichartige Korngrösse und schliesst eine ziemlich beträchtliche Menge kleiner Muskovitblätter ein. Die Einsprenglinge bestehen aus Pseudomorphosen aus Chlorit, der oft kleine Titanitkörner und Kalkspat enthält. In der Regel lässt es sich nicht entscheiden, ob die Pseudomorphosen aus Augit oder Olivin entstanden sind, aber - nach den Umrissen zu urteilen hat doch in einigen Fällen zweifellos Olivin vorgelegen. Kalkspat, Epidot und Chlorit sind überall in der Grundmasse reichlich vorhanden und bilden stellenweise kleine, nesterförmige Ausscheidungen. Das Salband hat eine äusserst feinkörnige Grundmasse; ausser den grünen Pseudomorphosen gab es hier auch zahlreiche Einsprenglinge aus Plagioklas. Im Nebengestein (grauer, streifiger Gudhjem Granit) hatte sich um die dunklen Mineralien und zwar besonders um den Biotit herum ein Filzwerk von äusserst feinen, doppelbrechenden, dunklen Kristallnadeln, wahrscheinlich Amphibol, gebildet.

Einige der zersetzten Diabase haben eine einigermassen deutliche Mandelsteinstruktur, z. B. ein paar Diabase von Aarsdale; als Füllmasse in den Mandeln treten Albit, Epidot und Chlorit auf. In einem Diabas von Lille Krusegaard bei Øleaa waren Mandeln aus Chlorit 
und körnigem Quarz oder Chalcedon, die Blasenräume auszufüllen schienen, vorhanden.

Zu den übrigen untersuchten zersetzten Diabasen wäre nichts Sonderliches zu bemerken.

\section{Kontaktwirkungen bei den kleineren Diabasgängen.}

Im allgemeinen lassen sich bei den kleineren Diabasgängen auf Bornholm keine Kontaktwirkungen nachweisen. Die Strukturänderung des Diabases im Salbande beschränkt sich meistens auf eine geringere Korngrösse und eine deutlicher ausgesprochene porphyrische Struktur. Das Nebengestein bleibt in der Regel unbeeinflusst und zwar sogar an solchen Stellen, wo der Granit von zahlreichen, dicht beieinander liegenden Diabasgängen durchsetzt ist. Granitfragmente sind nur selten im Diabase eingeschlossen, und Diabas-Granitbreccien wie die obenerwähnten von Christiansö wurden nur an wenigen Stellen gefunden.

Längs der grösseren Olivindiabasgänge in Blekinge ${ }^{1}$ ) wurde an mehreren Stellen eine Kontaktumwandlung des Nebengesteins nachgewiesen, und zwar von derselben Art wie die oben beim Kjeldseaa-Diabas beschriebene. Das Gneis- oder Granitnebengestein hat dadurch eine ziegelrote oder rotbraune Farbe erhalten. Auf Bornholm dagegen habe ich nur in einem einzelnen Falle eine ähnliche Rotfärbung des Granitnebengesteins beobachtet, nämlich bei einem etwa $3 \mathrm{~m}$ mächtigen Diabasgang bei Bölshavn an der NO-Küste. Dieser Gang ist nur in den Uferfelsen aufgeschlossen; er ist durch ein paar dünne, etwa $15-20 \mathrm{~cm}$ breite Granitplatten oder -Linsen in drei parallele Zweige geteilt. Der Diabas ist graugrün mit zahlreichen rostroten Flecken, von denen jedenfalls einige von zersetztem Eisenkies herrühren. Ausserdem enthält der Diabas zahlreiche Kalkspatkluftfüllungen, die oft eine recht beträchtliche Grösse erreichen. Das Gestein ist porphyrisch. Es hat eine feinkörnige, stark zersetzte Grundmasse, in der kleine Erzkörner reichlich vorhanden sind. Die Einsprenglinge bestehen zum Teil aus farblosen Augitkristallen, den grössten Teil aber machen Pseudomorphosen nach Olivin aus; sie bestehen aus Serpentin mit Amphibolnadeln und Erzausscheidungen; oft schliessen sie kleine Titanitkörner ein. Die Ostgrenze des Ganges ist von Schotter bedeckt, und der nächste sichtbare Felsengrund auf dieser Seite besteht aus dem gewöhnlichen grauen, streifigen, ein wenig geflammten Granit der Gegend. Die dazwischenliegenden Granitlinsen dagegen sind kräftig rotbraun ebenso wie der Granit der Westseite des Ganges, wo die rotgefärbte Zone eine Breite von etwa 3,5 m hat. An der Granitoberfläche weist diese Zone eine

1) Herman Hedström och C. Wiman: S. G. U. Ser. A1, a. B1. 5, 1906, p. 78. 
scharfe Grenze sowohl gegen den unveränderten grauen Granit als gegen den Diabas auf. - Im rotgefärbten Granit beobachtet man u. d. M. zahlreiche feine Sprünge, welche teils von kleinen Fragmenten der umgebenden Mineralien, teils von Kalkspat, Chlorit und Limonit ausgefüllt sind. Die Hornblende und der Biotit des Granits sind entweder ganz durch braunschwarze, limonitische Aggregate ersetzt oder noch häufiger chloritisiert unter Ausscheidung von zahlreichen kleinen schwarzen Erzpartikeln und grünen radialfaserigen Mikrolithen. Der Feldspat ist mit einem feinverteilten, rotbraunen Pigment stark imprägniert. Die Struktur des Granits ist im übrigen unverändert. Die Kontaktwirkung ist somit nur eine geringe gewesen.

Wesentlich stärker eingreifende Veränderungen haben bei ein paar anderen, bedeutend grösseren Diabasgängen, die nördlicher an der Küste bei Ypnasted und Salene vorkommen, stattgefunden.

Im tiefliegenden Ufer an der Ostseite einer kleinen Bucht bei Y pnasted ist der Granit von zwei Diabasgängen durchsetzt, die je eine Mächtigkeit von mindestens $7 \mathrm{~m}$ haben; ausserdem gibt es wenigstens einen kleinenGang, der knapp 0,5 m mächtig ist. Die Entfernung zwischen den beiden grossen Gängen beträgt $40-50 \mathrm{~m}$. Sowohl die Diabase und der dazwischenliegende Granit als auch der Granit in einer Zone von mehreren Metern Breite nach beiden Seiten dieses Gebietes sind ausserordentlich stark von Quarzadern durchsetzt, in denen oft zahlreiche wohlentwickelte Quarzkristalle vorkommen. Abgesehen von reichlichen Quarzausscheidungen ist der Diabas eine ziemlich gleichartige, graugrüne, feinkörnige oder dichte Masse. Mit einer Lupe beobachtet man kleine klare Quarz- und Plagioklaskörner. U. d. M. stellt es sich heraus, dass der Diabas stark chloritisiert und saussuritisiert ist. Der Hauptbestandteil ist ein heller, grünlicher, äusserst schwach pleochroitischer Chlorit mit sehr schwacher Doppelbrechung und bräunlichen Interferenzfarben. Auch mikroskopisch spielt der Quarz eine sehr grosse Rolle und tritt sowohl als Spaltenausfüllung als auch in Gestalt von sehr unregelmässig geformten Körnern auf. Plagioklas kommt teils als ganz kleine Kristalle, teils als grössere Körner vor, die stets eine äusserst unregelmässige Kontur und meistens eine eigenartige Zwillingsstruktur aufweisen, indem sie aus kurzen, alternierenden Lamellen nach dem Albitgesetz aufgebaut sind; stellenweise erinnert das Bild an Schachbrett-Albit. Ganz sicher orientierte Schnitte wurden nicht gefunden, aber im Schnitt ungefähr $\perp \mathrm{MP}$ war $\alpha^{\prime}: \mathrm{M}=$ etwa $15^{\circ}$ und im Schnitt beinahe $\| \mathrm{M}$ war $\alpha: \mathrm{P}=$ etwa $17^{\circ}$; die Lichtbrechung ungefähr wie die des Canadabalsams; der Plagioklas scheint demnach aus Albit zu bestehen. Kleine Epidotkörner sind häufig im Plagioklas eingeschlossen. Epidot ist überhaupt ziemlich reichlich vorhanden, grösstenteils jedoch als ganz kleine Körner. Die Erzkörner sind teilweise in ein bräunliches, feinkörniges Aggregat um- 
gewandelt, das — der hohen Lichtbrechung und der Doppelbrechung nach zu urteilen - aus Titanit besteht.

Im Salbande ist der bedeutendste Bestandteil der obenerwähnte hellgrüne Chlorit, der hier mit ganz kleinen schwarzen Erzpartikeln und kleinen bräunlichen Titanitaggregaten sowie mit zahlreichen kleinen Muskovitschuppen dicht gespickt ist. Ferner kommen einige wenige, teilweise erhaltene Plagioklasleisten und eine recht reichliche Imprägnation von Kalkspat vor.

Der unmittelbar an den Diabas angrenzende Granit ist stark mit Kalkspat imprägniert und hat infolge eines reichlichen Chloritgehaltes eine grünliche Färbung. Wo keine Quarzadern das Gestein durchsetzen, scheint dessen Quarzgehalt ungefähr derselbe $\mathrm{zu}$ sein wie sonst im Granit. Der Feldspat scheint ausschliesslich aus Plagioklas zu bestehen. Völlig sicher orientierte Schnitte wurden nicht gefunden, aber der Lichtbrechung $\left(\gamma^{\prime}>\right.$ n-Canadabalsam $\left.=\alpha^{\prime}\right)$ nach scheint der Plagioklas ein Oligoklas-Albit zu sein; in Uebereinstimmung damit ergab ein Schnitt ungefähr $\perp \mathrm{MP}: \alpha^{\prime}: \mathrm{M}=$ etwa $8-9^{\circ}$, was einem Oligoklas-Albit mit etwa 12\% An. entspricht. Der grösste Teil des Gesteins besteht jedoch aus Kalkspat und Serizit. Der Serizit hat einen sehr kleinen optischen Achsenwinkel und lebhafte, etwas übernormale Interferenzfarben. Der Kalkspat ist äusserst unregelmässig verzweigt und lässt sich mit derselben kristallographischen Orientierung $1-2 \mathrm{~cm}$ im Dünnschliff verfolgen; er schliesst eine Menge Serizitschuppen und oft Quarzkörner ein; ferner ist er häufig intim verwachsen mit Plagioklas. Auch im Plagioklase sind zahlreiche Serizitschuppen eingeschlossen. Der Biotit des Granits ist völlig in Chlorit oder in ein blättriges Aggregat von Chlorit und Muskovit umgewandelt. Die Chloritblätter liegen am ursprünglichen Platze des Biotits in etwas unregelmässigen Streifen und Haufen. Als untergeordnete Gemengteile im Gestein treten schwarze, metallglänzende Erzkörner auf, die teilweise die Form kurzer Stäbe haben; ferner kommt Anatas vor, der infolge seiner hohen Lichtbrechung und hohen Doppelbrechung sehr auffällt; zur Identifizierung des Anatases trug ferner der Umstand bei, dass Schnitte senkrecht zur optischen Achse quadratische Form hatten sowie rechtwinkelige Spaltbarkeit und negative Doppelbrechung aufwiesen. Die Farbe des Anatases ist gelbbraun, jedoch öfters von schwarzen Partikeln etwas getrübt. Meistens ist er mit dem Chlorit vergesellschaftet, und seinem Platz unter den übrigen Gemengteilen nach zu urteilen, ist er aus Titanit entstanden. Der Apatit des Granits ist ganz unverändert geblieben.

Bei Salene, etwa $500 \mathrm{~m}$ östlich von der Mündung des Bobeaa und etwas östlich von einem kleinen, von Verwerfungen begrenzten Sandsteingebiet ${ }^{1}$ ), gibt es in den Küstenfelsen einen völlig umgewandelten

1) Kartenblatterläuterung, p. 123. 
Diabasgang. Die Mächtigkeit des Ganges beträgt 20-22 m; seine Richtung wurde von N. V. Ussing zu N $15^{\circ} \mathrm{O}$ bestimmt. Zu beiden Seiten des Ganges ist der Granit stark epidotisiert, und die Grenze zwischen dem Gange und dem Granit besteht aus einer ebenfalls stark epidotisierten Breccie. Es ist nicht gelungen, eine Fortsetzung dieses Ganges landeinwärts nachzuweisen; dies beruht möglicherweise darauf, dass er von derselben Verwerfung, die den Sandstein vom Granit trennt, schräg durehquert wird.

Das Ganggestein ist ziemlich gleichartig, dunkel graugrün, feinkörnig oder ganz dicht. In Bezug auf Mineralbestand und Struktur erinnert es durchaus nicht an Diabas. Der Hauptbestandteil ist ein feinkörniger Prehnit mit etwas rötlichen oder lederbraunen Interferenzfarben, die nur in geringem Masse von den normalen abweichen. Die Auslöschung ist nicht so ausgesprochen abnorm wie es sonst oft bei Prehnit der Fall ist; viele Körner erlöschen gänzlich, aber in den meisten ist die Auslöschung unruhig, undulös und mosaikartig. $2 \mathrm{~V}$ etwa $70^{\circ}$. Dispersion kaum merkbar. Pulver in Acetylentetrabromid ergab Lichtbrechung $\alpha^{\prime}<1,637<\gamma^{\prime}$. In etwas geringerer Menge als Prehnit tritt ein heller, gelbgrüner, pleochroitischer Chlorit mit violetten Interferenzfarben und mit stark pleochroitischen Höfen um Apatit und andere Einschlüsse herum auf. Einen wesentlichen Gemengteil macht ferner Epidot aus. Einige Epidotkörner haben einen braunen, isotropen oder ausserordentlich schwach doppelbrechenden Kern, wahrscheinlich aus Orthit. Titanit ist in recht beträchtlicher Menge vorhanden, meistens vergesellschaftet mit Chlorit, jedoch auch zerstreut unter den übrigen Gemengteilen; bisweilen hat er die Form von Kristallen; hie und da findet man Zwillingslamellen. Schliesslich tritt Apatit in verhältnismässig schweren Kristallen auf. Erzkörner dagegen sind so gut wie gar nicht vorhanden.

Ein Dünnschliff des Gesteins der Ganggrenze zeigt einen wesentlich grösseren Epidotgehalt, im übrigen aber denselben Mineralbestand wie oben beschrieben. Stellenweise bildet der Epidot feinkörnige Anhäufungen; die mehr zerstreut liegenden Epidotkristalle haben oft eine wohlentwickelte Kristallform. Der Chlorit und der grösste Teil des Titanits und des Apatits liegen in unregelmässigen Streifen angeordnet; sie sind auch makroskopisch zu beobachten und erinnern sehr stark an die Anordnung von Biotit, Erz, Titanit und Apatit im streifigen Granit. Von Quarz und Feldspat ist in diesem Dünnschliff nichts zu sehen; auch Erzkörner fehlen.

Die Breccie längs den Seiten des Ganges ist ein in der Hauptsache feinkörniges, graugrünliches Gestein, in dem Aggregate von millimetergrossen, roten Mikroklinkörnern in unregelmässigen Streifen oder Flammen liegen. Im feinkörnigen Teile des Gesteins ist Epidot sehr reichlich 
vorhanden, und zwar teils als körnige Massen, teils als längliche Kristalle, die doch nur selten Kristallflächen aufweisen; die grösseren Individuen haben häufig einen Orthitkern. Chlorit, Titanit und Apatit liegen in der oben beschriebenen Weise in Streifen angeordnet. Prehnit wurde nicht gefunden. Dagegen tritt als eine Art Grundmasse ein schwach lichtbrechender Feldspat auf (Lichtbrechung niedriger als die des Canadabalsams), der teils ein äusserst feinkörniges Aggregat bildet, teils in einzelnen etwas grösseren Körnern vorkommt, in denen Mikroklinstruktur beobachtet werden kann. Stellenweise ist dieses Feldspataggregat stark serizitisiert, an anderen Stellen ist es mit einer hellen, schwach gelben, chloritartigen Substanz ganz ohne Doppelbrechung eng verwachsen. Dieses Feldspat-Chlorit-Aggregat scheint Risse oder Hohlräume der Breccie auszufüllen.

In noch grösserer Entfernung vom Gange ist der Granit deutlich brecciös und hat einen beträchtlichen Epidotgehalt, der stellenweise in Haufen gesammelt ist, die auf Kosten des Granitplagioklases entstanden zu sein scheinen. Fast der gesamte Mikroklin ist in kleine Bruchstücke aufgeteilt, zwischen die der Epidot oft hineingedrungen ist. Der Biotit ist vollständig in Chlorit umgewandelt. Titanit scheint etwas reichlicher als sonst im Gudhjem Granit vorhanden zu sein.

In Johnstrup's Sammlungen befindet sich ein kleines Stück eines Diabases, das von der Mündung des Bobbeaa stammt. Auch dieser Diabas ist stark zersetzt, doch äussert sich die Umwandlung hier im wesentlichen in Karbonatbildung und Chloritisierung. Die Plagioklasleisten des Diabases sind noch erkennbar.

An dieser Stelle muss noch eine Verwerfungsbreceie, die das kleine Sandsteingebiet vom Granit trennt, kurz erwähnt werden. Am ausführlichsten wurde dieses Vorkommen früher von GrönwaLL und MrLthers ${ }^{1}$ ) besprochen, die sowohl den Sandstein als auch einige ihn begleitende graue, gelbe und rote Tonschichten zum Rhät-Lias rechnen. Die Schichten sind steil gestellt und fallen $60^{\circ}-75^{\circ}$ nach Norden. Nach Süden $\mathrm{zu}$ werden sie von einer Verwerfung mit der Richtung $\mathrm{N} 30^{\circ} \mathrm{O}$ begrenzt. Gegen Westen werden die Sedimente durch eine Breccie, deren Streichen von Grönwall auf N 25 W, von O. B. BøGGILD auf N $10^{\circ} \mathrm{W}$ bestimmt wurde, vom Granit getrennt. Laut der Kartenblatterläuterung besteht die Breccie im wesentlichen aus den Gemengteilen des Granits, die mit Kalkspat und Quarz verkittet sind. Einige von O. B. BøGGILD eingesammelte Stücke bestehen dagegen aus feinzermalmten Granitmaterial, das von einem grünlichen oder bräunlichen, tonartigen Bindemittel verkittet ist. Ein Teil des Feldspats der Breccie ist kräftig rotpigmentiert. Der Biotit ist völlig chloritisiert, aber im grossen und ganzen

1) Kartenblatterläuterung. D. G. U. I. R., Nr. 13, 1916, pag. 123 ff. 
ist Chlorit recht spärlich vorhanden. Die Erzkörner sind gänzlich in schwarzbraune Massen umgewandelt.

Diese Breccie dürfte zuerst von H. C. Ørsted und L. Esmarch ${ }^{1}$ ) entdeckt worden sein. Sie fassten sie als einen Porphyrgang auf und geben an, dass er den Bach schräg durchquert. Im »Gange« (d. h. in der Breccie) fanden sie Braunspat, Quarzkristalle, Eisenglanz und Roteisenerz; im Laufe der seitdem verflossenen Jahre ist die Mineraliensammlung von dort etwas erweitert worden. Quarz tritt im wesentlichen in grobkörnigen Aggregaten auf, kommt aber auch als wohlausgebildete Kristalle von einigen wenigen Zentimetern Länge vor; stellenweise ist er amethystgefärbt. Auch Kalkspat ist reichlich vorhanden, bisweilen kristallisiert in Rhomboedern und Skalenoedern von einigen Zentimetern Durchmesser. Der Braunspat, der auf den alten Etiketten angegeben wird, scheint jedoch ein braungefärbter Kalkspat zu sein; durch kalte Salzsäure wird er unter starkem Aufbrausen gelöst. Ein brauner, dichter Mergelkalkstein wurde als Füllmasse gefunden, und in gleicher Weise treten grüner und brauner Jaspis auf. Eisenglanz kommt in der Breccie in ganz kleinen Mengen teils als dichtes Roteisenerz, teils als Blättchen von Eisenglimmer vor.

Der Granit an der Westseite der Breceie weist im Dünnschliff ganz schmale Quetschzonen auf. Der Feldspat ist durch limonitische Partikel etwas getrübt, im übrigen aber frisch. Biotit fehlt gänzlich; an seiner Statt gibt es Ausscheidungen von Muskovit und Limonit. Frische Erzkörner sind spärlich vorhanden und haben meistens eine skelettartige Form. Epidot wurde weder in diesem Granit noch in den untersuchten Breccienstücken gefunden. Dagegen tritt Epidot in einem Granitstück aus Johnstrup's Sammlung auf, das der Etikette zufolge »bei der rotbraunen gangähnlichen Masse SO vom kleinen Hause in Bobbeaa« gesammelt ist. Vermutlich entstammt dieses Stück dem Nebengestein der Breccie. Dieser Granit ist wie der obengenannte etwas zerquetscht. Der Feldspat ist stark rotpigmentiert. Biotit und Muskovit fehlen. Von Erzkörnern gibt es nur spärliche Ueberreste, die mit Titanit und Kalkspat zusammen in dunklen limonitischen Massen eingelagert liegen; ihnen schliesst sich bisweilen Epidot an. Sonst tritt der Epidot nur als Spaltenausfüllung im Granit auf.

Während es kaum einem Zweifel unterliegen dürfte, dass die Umwandlung des Diabases und seines Granitnebengesteins bei Ypnasted durch epimagmatische Prozesse in Anknüpfung an die Intrusion des Diabases verursacht worden ist, so fragt es sich nun, ob auch dasselbe mit dem 22 m mächtigen Diabasgang östlich vom Sandsteingebiet bei Salene der Fall gewesen ist, oder ob dieser Diabas und sein Neben-

1) H. C. Ørsted und L. Esmarch: Beretning 1819, pag. 15-16. 
gestein ihre Metamorphose in Verbindung mit der relativ jungen Verwerfung durchgemacht haben, welche die Sedimente vom Granit trennt. Für eine epimagmatische Metamorphose des grossen Salene-Diabases spricht jedoch die Tatsache, dass die Granitbreccie längs diesem Gange sich durch ihren beträchtlichen Gehalt an Epidot, Chlorit und Titanit wesentlich von der Verwerfungsbreccie unterscheidet. In die gleiche Richtung weist auch der Umstand, dass der kleine Diabasgang, den Johnstrup an der Mündung des Bobeaa fand, nicht in derselben Weise wie der grosse umgewandelt worden ist.

\section{Das Alter der Diabasgänge und ihre Beziehung zu den Spaltentälern.}

Zur Beurteilung des Alters der Bornholmer Diabase hat man nur wenige sichere Stützpunkte, die mehrmals früher in der Literatur angeführt worden sind. Schon allein aus dem Grunde, dass die Diabase ausschliesslich innerhalb des Granitgebietes auftreten und nirgends in den paläozoischen Sedimenten nachgewiesen worden sind, ist es ausserordentlich wahrscheinlich, dass die Diabase präkambrisch sind. Aus dem oben Dargelegten geht hervor, dass die Diabase keine besonders grossen petrographischen Verschiedenheiten aufweisen. Alle untersuchten Gesteine lassen sich in die Gruppe der Olivindiabase einreihen. Man kann daher mit guten Gründen annehmen, dass sie alle innerhalb derselben Eruptionsperiode gefördert worden sind. Dabei muss noch ein Umstand in Betracht gezogen werden, nämlich dass der grosse Listed-Diabasgang von Sandsteingängen gekreuzt wird, die nach Ussing's ${ }^{1}$ ) Untersuchungen wahrscheinlich desselben Alters sind wie der kambrische Nexö Sandstein. Auch dies spricht für ein präkambrisches Alter des Listed-Diabases und damit zugleich für ein präkambrisches Alter sämtlicher übrigen Gänge.

Mehr Anhaltspunkte für eine Altersbestimmung gibt es auf Bornholm nicht, ein Vergleich mit den südschwedischen Diabasgängen vermag aber einer weiteren Beleuchtung dieser Frage eine gewisse Stütze $\mathrm{zu}$ bieten.

Hier muss noch einmal daran erinnert werden, dass die Diabasgänge im grossen und ganzen das gleiche Streichen haben, das vorwiegend zwischen N-S und NO-SW liegt; nur an einzelnen Stellen findet man etwas grössere Abweichungen nach Osten zu, und nur an der Westküste, z. B. auf Hammeren und im Abstieg zur Jons Kapel wurden Gänge mit einem Streichen zwischen $\mathrm{N}-\mathrm{S}$ und WNW-OSO gefunden.

1) N. V. Ussing: Sandstensgange i Granit paa Bornholm. D. G. U. II. R., Nr. 10, 1899, pag. 100.

Danmarks Geologiske Undersøgelse. II. R. Nr. 50 . 
In Schonen haben die postsilurischen Diabasgänge ein Streichen, das fast winkelrecht $\mathrm{zu}$ demjenigen der Bornholmer Gänge ist, indem sie den Spaltensystemen in der Richtung NW-SO folgen. Auch petrographisch unterscheiden sich diese Diabase (Konga- und Öved-Diabas) wesentlich von den Bornholmer Diabasen. Dagegen muss laut Hadding ${ }^{1}$ ) ein anderes Spaltensystem mit der Richtung $\mathrm{N} 20^{\circ}-40^{\circ} \mathrm{O}$ für präkambrisch angesehen werden, da es ausschliesslich im Gneise gefunden wurde, weswegen man vermuten darf, dass dieses System mit Dislokationen in präkambrischer Zeit in Verbindung steht. Und ferner schreibt Hadding: "Vergleichen wir das Röstångagebiet mit den übrigen Teilen der südlichen Randzone Fennoskandias, finden wir, dass sie sämtlich die gleichen morphologischen und tektonischen Züge aufweisen. So sind z. B. die in der Richtung NNO-SSW verlaufenden Dislokationslinien überall die ältesten.« Diabasgänge mit diesem Streichen kommen im östlichen Schonen und besonders in Blekinge ${ }^{2}$ ) vor. Diese Diabase weisen eine weitgehende Uebereinstimmung mit den Bornholmer Diabasen auf. Sie haben im wesentlichen dieselbe Streichrichtung $\mathrm{N} 10^{\circ}-25^{\circ} \mathrm{O}$, sie sind alle Olivindiabase mit einem etwas wechselnden Gehalt an Olivin und haben auch sonst denselben Mineralbestand und dieselbe Struktur wie die Bornholmer Diabase. Es ist daher am wahrscheinlichsten, dass die Bornholmer Diabase eine südliche Fortsetzung der Diabasgänge in Blekinge bilden, und dass sie während derselben Eruptionsperiode gefördert worden sind.

Die südschwedischen Olivindiabase durchsetzen alle Gesteine des Grundgebirges, selbst die jüngsten. Einige derselben enthalten Fragmente nicht nur desjenigen Gneis- oder Granitnebengesteins, das jetzt zu Tage tritt, sondern auch von Quarzit; um diese Fragmente herum ist die Beschaffenheit des Diabases etwas verändert, während die fragmentfreien Teile des Diabases völlig mit den übrigen Gängen übereinstimmen. Sowohl in diesen Beziehungen als auch in der Streichrichtung der Gänge zeigen sich die Blekinger Diabase in vollständiger Uebereinstimmung mit dem sogenannten Diabaskonglomerat, dem fragmentführenden Diabase, der die algonkische Almesåkraserie durchsetzt, deren Quarzite als Muttergestein der Fragmente im Diabaskonglomerat angesehen werden. Darauf fussend, nimmt man bekanntermassen an, dass die Blekinge Diabase in jotnischer oder postjotnischer Zeit intrudiert sind, und dass

1) A. Hadding: Tektoniska och petrografiska undersökningar inom Fennoskandias södra randzon. Medd. från Lunds geol. fältklubb. Ser. B. Nr. 13, 1922, pag. 44.

2) Joh. Chr. Moberg: Untersuchungen über die Grünsteine des westlichen Blekinge und der angrenzenden Theile Schonens. S. G. U. Ser. C, Nr. 158, 1896. - H. Hedström och C. Wiman: Beskr. till blad 5. S. G. U. Ser. A 1 a. 1906. 
die Gesteine der Almesåkraserie zu jener Zeit über grössere Teile des südlichen Schwedens verbreitet gewesen sind.

Auf Grund des oben Dargelegten dürfen wir annehmen, dass auch die Bornholmer Diabase jotnischen oder postjotnischen Alters sind. Dagegen hat man in den Bornholmer Diabasen keine Quarzitfragmente gefunden, die darauf deuten könnten, dass sich die Gesteine der Almesåkraserie so weit gegen Süden erstreckt haben.

Wie oben (pag. 149) erwähnt, haben Grønwall und MiLthers schon früher darauf aufmerksam gemacht, dass die Diabasgänge im wesentlichen dieselbe Richtung wie die Spaltentäler haben; desgleichen haben sie darauf hingewiesen, dass ein Zusammenhang zwischen der Bildung der Spaltenzonen und der Intrusion des Diabases besteht. In derselben Verbindung erwähnen sie auch, dass die Spaltentäler die durchgreifende Zerklüftung, die im Granit vorliegt und die am besten in den steilen Küstenfelsen beobachtet werden kann, widerspiegeln.

Es ist ja eine öfters vertretene Auffassung, dass die Neigung zur Spaltenbildung schon während der epimagmatischen Periode der Granite entsteht. In Bezug auf das fennoskandische Grundgebirge haben u. a. Sederholm und Sundus ${ }^{1}$ ) diese Auffassung geltend gemacht. Aber man muss doch annehmen, dass die weitere Entwicklung und Erweiterung der Spalten zu ganz verschiedenen Zeiten vor sich gegangen ist, und dass die Auslösung von späteren Spannungen im Gesteinsgrund neue Spaltenbildungen mit sich geführt haben kann.

Auf Bornholm stimmen die Richtungen der Spaltentäler mit hervortretenden Kluftrichtungen im streifigen Granit überein. Ein Blick auf die Karte aber zeigt, dass die Täler in mehreren Fällen die Granitgrenzen überqueren. So z. B. setzen sich mehrere Spaltentäler mit geradlinigem Verlauf vom Vang Granit in den Hammer Granit und vom Paradisbakke Granit in den Svaneke Granit hinein fort. Die Entwicklung der Spaltenzonen muss also zu einer Zeit vor sich gegangen sein, während welcher die gesamte Bornholmer Granitplatte einheitlich reagierte. Erst durch eine weit spätere Erosion sind die jetzigen Spaltentäler herausgebildet worden, und, wie die früheren Forscher bemerken, muss eine letzte Ausräumung der Täler während der Eiszeit stattgefunden haben.

Betrachten wir das Verhältnis der Diabasgänge zu den Spaltentälern, so fällt es sofort auf, dass ein paar der bedeutendsten Gänge gerade in hervortretenden Spaltentälern liegen, nämlich im Kjeldseaa Tal und im Tamperdal, und selbstverständlich ist es möglich, dass Diabas auch in anderen Tälern, deren Grund heute von Schutt und glazialen Ab-

1) J. J. Sederholm: Om de jotniska och s. k. subjotniska bergarterna. G. F. F. Bd. 49, 1927. - N. Sundius: Über die spaltentektonischen Verhältnisse der Gegend südöstlich vom Valdemarsvik im südöstlichen Schweden. Fennia 50, Nr. 24, 1928. 
lagerungen bedeckt ist, verborgen sein kann. Bei einer grossen Anzahl von Diabasgängen lässt sich aber ein solcher Zusammenhang nicht nachweisen, und schon beim Tamperdal-Diabas ist es auffällig, dass sich auf der Strecke von den Paradisbakker bis zur Fortsetzung des Ganges in Listed nicht die geringste Andeutung von einem Spaltental findet. In den Paradisbakker gibt es ausserdem Diabasgänge, die in den "Horsten" neben den Spaltentälern liegen. So z. B. zeigt Fig. 38 zwei schmale

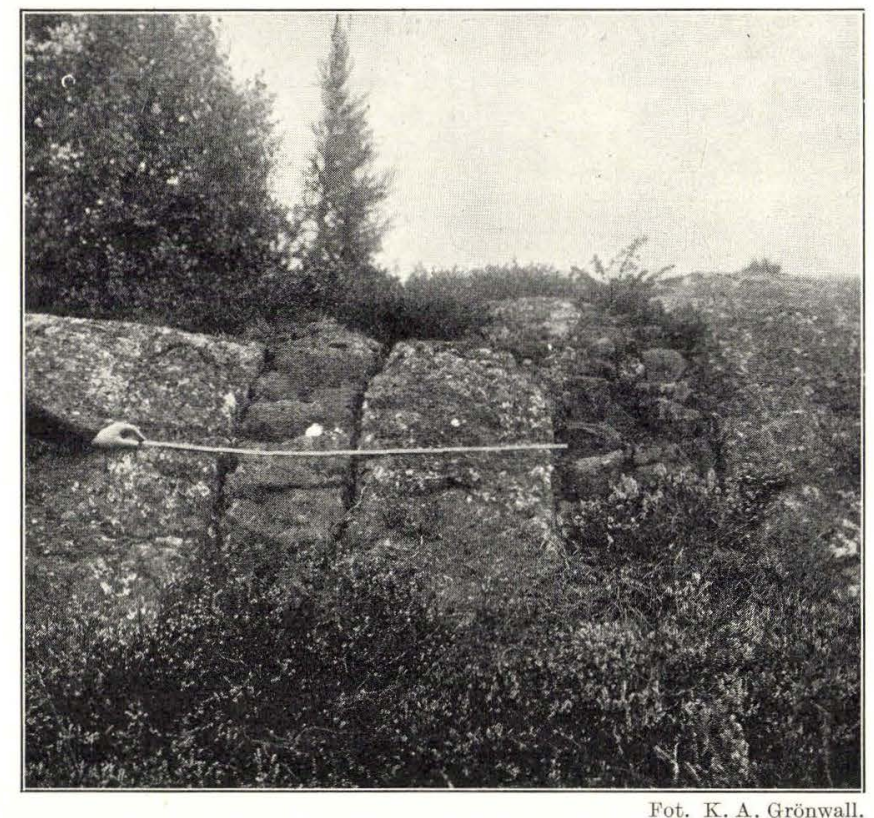

Fig. 38. Diabasgänge westlich von Dybdal in den Paradisbakker.

Gänge, die auf dem Plateau westlich von Dybdal zutage treten. Der 40 Meter mächtige Diabasgang bei Kaas, der zweitgrösste auf Bornholm, lässt sich mit keinem Spaltental in Verbindung setzen. Etwa $50 \mathrm{~m}$ innerhalb der niedrigen Uferfelsen, in denen der Diabas zu Tage tritt, erhebt sich das Gelände in einem ziemlich steilen Hügel. Schliesslich wäre noch zu erwähnen, dass in dem ansehnlichen Spaltental Kleven, in dem die Eisenbahn zwischen Klemensker und Rö geht, mehrere Diabasgänge sind, welche das Tal in nord-südlicher Richtung kreuzen.

Diese Verhältnisse deuten darauf, dass der Diabas bei seiner Intrusion den bereits vorhandenen Schwächezonen im Granit gefolgt ist, und dass er zur Entwicklung der Spaltenzonen beigetragen hat; ferner deuten sie aber auch darauf, dass zum mindesten einige der Spaltenzonen, die heute zu tiefen Tälern ausgestaltet sind, bei der Diabasintrusion nicht 
den bequemsten Zugang gewährten, sondern sich erst später entwickelt haben.

Auch andere Umstände lassen auf eine fortgesetzte Entwicklung der Spalten schliessen. So ist es charakteristisch, dass der Diabas im Kjeldseaa-Tal in der südöstlichen Talseite liegt, wo er auf weite Strecken hin die fast senkrechte Talwand in deren vollen Höhe bekleidet. In der gegenüberliegenden Talseite wurde nirgends Diabas vorgefunden. An mehreren Stellen senkt sich der Talgrund bedeutend gegen NW, und ferner wurden bei Saltuna kleine Rutschflächen im Diabas gefunden (in zwei zueinander winkelrecht verlaufenden Richtungen). Dies deutet darauf hin, dass im Diabas und längs demselben eine Verschiebung stattgefunden hat. Möglicherweise ist dadurch die Nordwestseite im Verhältnis zur Südostseite gesunken. Die Sprunghöhe lässt sich jedoch nicht beurteilen, ist aber vermutlich nicht gross gewesen. Das Granitnebengestein ist an beiden Seiten des Ganges ganz gleichartig, und es gibt keinen wesentlichen Höhenunterschied zwischen den Talseiten, nur bei Saltuna liegt die Südostseite deutlich etwas höher als die Nordwestseite; doch könnte ein früherer Höhenunterschied auch durch Erosion nivelliert worden sein. - Auch im Tamperdal liegen aufragende Partien von Diabas in der Ostseite des Tales, was vielleicht in dieselbe Richtung weisen dürfte.

Die Sandsteingänge, die sich bei Listed als jünger als der Diabas erweisen, liegen fast alle innerhalb eines begrenzten Gebiets im östlichen Teil von Bornholm, nämlich bei Listed, Lyrsby, Aarsdale, Grisby und in den Paradisbakker. Ihre Mächtigkeit ist meistens ganz gering, von $0,5 \mathrm{~cm}$ bis $\mathrm{zu}$ einigen wenigen Zentimetern, doch bei Listed wird eine Breite von $133 \mathrm{~cm}$ erreicht. Ausserhalb dieses Gebiets wurden nur einige wenige Sandsteingänge gefunden, nämlich ein kleiner, 13-15 mm breiter Gang mit dem Streichen N 20 O im Hügel Skaglfaldet nördlich von Aakirkeby und ein $7 \mathrm{~cm}$ breiter Gang mit ungefähr nord - südlichem Streichen bei Tækkeregaard NNO von Hasle. Diese letzteren Sandsteingänge folgen somit denselben Richtungen wie die Diabasgänge und die Spaltentäler. Den Gang bei Tækkeregaard fand ich in einem kleinen Steinbruch, wo er einen Pegmatitgang durchsetzt. Der Sandstein ist grünlich und hat eine ziemlich ungleichartige Korngrösse, die Quarzkörner sind recht scharfeckig oder nur teilweise abgerundet; ferner enthält der Sandstein Fragmente vom Pegmatitfeldspat. In abgebrochenen Pegmatitblöcken wurde ausserdem ein kleiner, etwa $1 \mathrm{~cm}$ breiter, heller, grauer Sandsteingang aus gleichartig feinkörnigem Material gefunden.

Im östlichen Teile von Bornholm liegen die Streichrichtungen der Sandsteingänge um $\mathrm{OSO}-\mathrm{WNW}$ herum, grösstenteils etwa $\mathrm{O} 15^{\circ}-20^{\circ} \mathrm{S}$. Zu erwähnen wäre noch, dass es auch auf Græsholmen bei Christiansö ein paar Sandsteingänge mit diesem Streichen gibt. Spaltentäler mit 
dieser Richtung treten nur in den Paradisbakker auf. Dagegen wurden bisher in diesem Gebiet keine Sandsteingänge mit nördlichem oder nordöstlichem Streichen gefunden. Dieses zeigt, dass das OSO-Spaltensystem bereits entwickelt und klaffend vorlag, als die Spalten mit Sand gefüllt wurden, wahrscheinlich in unterkambrischer Zeit. Hieraus folgt aber nicht, dass das NO-Spaltensystem nicht vorgelegen hat, sondern nur, dass es zu der Zeit weniger klaffend gewesen sein muss, zum mindesten in diesem Teile von Bornholm. 


\section{Kaolin.}

\section{Das Kaolingebiet bei Rönne.}

Ein paar Kilometer östlich von Rönne, wo sich das Granitgebiet über die Ebene erhebt, liegt der Kaolin unmittelbar unterhalb des Granitrandes. Er bildet eine schmale Zone, höchstens $500-600 \mathrm{~m}$ breit und etwa $3 \mathrm{~km}$ lang, ungefähr von Store Almegaard bis Brandsgaard (siehe die Karte Fig. 39). Innerhalb dieses Gebiets gräbt man seit mehr als 100 Jahren den Kaolin in mehreren Tagebauten. Mehrere der Gruben sind nun verlassen, andere sind zeitweise in Betrieb, zeitweise mit Wasser gefüllt gewesen. Gegenwärtig wird nur in der zuletzt angelegten Schlämmerei, dem Tornewerk, geschlämmt, während das ältere, das Buskewerk, welches 1871 angelegt wurde, 1924 ausser Betrieb gesetzt wurde, und das Rabekkewerk, 1874 angelegt, still steht, da der Kaolinabbau in den alten Gruben bei Buskegaard und Rabekkegaard eingestellt ist.

\section{Lagerungsverhältnisse.}

Der Kaolin liegt auf primärer Lagerstätte und ist entstanden aus Rönne Granit $\left.{ }^{1}\right)$, von dem mehr oder weniger vollständig umgewandelte Brocken $a b$ und $\mathrm{zu}$ im Kaolin anzutreffen sind. Pegmatitgänge treten deutlich in der Kaolinmasse hervor. An verschiedenen Stellen in den Gruben, besonders in der Tornewerk-Grube, sind umgewandelte Diabasgänge gefunden worden, deren ursprüngliche Struktur, feinkörniges Salband and gröbere Mitte, oft erkennbar ist. Ussing hat 1899 das Streichen für einige derselben mit $\mathrm{N} 10^{\circ} \mathrm{O}$ angeben können.

Der Kaolin wird laut GrönwalL ${ }^{2}$ ) von Rhät-Lias Bildungen überlagert; später hat MALLING ${ }^{3}$ ) die Schichten über dem Kaolin bei Buskegaard und Rabekkegaard zum Wealden gerechnet. Schon Johnstrup hat laut Ussing (D. G. U. II. R. Nr. 12) an mehreren Stellen »kohleführende Bildungen auf dem Kaolin in einer solchen Weise beobachtet, dass er

1) N. V. Ussing, D. G. U. II. R. Nr. 12. 1902, p. 64-65.

2) D. G. U. I. R. Nr. 13, 1916.

3) C. Malling, 1920. D. G. F. Bd. 5, 1916-20, p. 56. 
diesen für älter als jene ansehen musste«, und als Ussing und GRönwaLL 1899 das Buskewerk besuchten, machte der damalige Direktor, Herr Schеibye, sie auf eine Stelle aufmerksam, wo eine derartige Auflagerung sichtbar war. Ussing sagt hierüber (D. G. U. II. R. Nr. 12, p. 66. In deutscher Uebersetzung): »Es zeigte sich hier, dass unmittelbar über der Kaolinmasse Schichten von Sand und Kies von genau derselbe Art lagen, wie der Schlämmungsrückstand des Kaolins in der Fabrik; diese Schichten sind offenbar vom Wasser abgesetzt worden, als dieses seinerzeit den Kaolin überflutete, und sie sind somit sicher jünger als dieser.«

Grönwall gibt an, dass der Sand in der alten Buskegaardsgrube Kohlefragmente und unregelmässige Brocken oder abgerundete Stücke eines graugrünen Sandsteins enthielt, in welchem ein Reptilienzahn, Schalen von Estheria sowie Samen von Cykadéen gefunden wurden. In der neuen Kaolingrube bei Buskegaard wurden über dem Kaolin sowohl Schichten von weissem Sand als von gelbgrünem und grauem Ton gefunden, jedoch nur von unbeträchtlicher Mächtigkeit; der Sand war etwa $0,7 \mathrm{~m}$ mächtig.

In der Grube des Rabekkewerks wurde unmittelbar über dem Kaolin eine Sandschicht gefunden, welche stark nach Süden und Südwesten einfiel. Der Sand, dessen Mächtigkeit kaum 2 m übertraf, war zum grössten Teil schwarz von Kohlefragmenten und unbestimmbaren Pflanzenresten; ausserdem war etwas Eisenkies vorhanden. Weiter westlich in derselben Grube lag grüner Ton, der zwar stark verrutscht war, aber doch deutlich den Sand im Hangenden des Kaolins überlagerte. Der Ton war sehr fett und plastisch. In einer grösseren Anzahl von Bohrungen auf dem Boden des Rabekkewerks wurde über dem Kaolin Sand gefunden und darüber grüner Ton. Als grösste Mächtigkeit des Sandes werden $4,1 \mathrm{~m}$, als geringste $0,6 \mathrm{~m}$ angegeben. In zwei Bohrprofilen wird angegeben, dass grüner Ton direkt den Kaolin überlagert, und in beiden Fällen ist der Ton sehr mächtig; die grösste festgestellte Mächtigkeit ist 50 Fuss $(15,7 \mathrm{~m})$. Ueberall lag zu oberst Moränenton, und nirgends wurden andere mesozoische Schichten über dem grauen Ton gefunden.

Auch am Tornewerk fand man bei Grabungen zwecks Anlage eines Wasserbehälters für die Schlämmerei unter 6 Ellen $(3,8 \mathrm{~m})$ Moränenton 3 Ellen $(1,9 \mathrm{~m})$ schwarzen Ton, der zu unterst eine Kohlenschicht mit vielen Eisenkieskristallen enthielt und darunter schlechten Kaolin (wobei es sich aber vielleicht eher um Sand gehandelt haben dürfte). Südlich vom südlichen Trockenhaus lag unter 1-2 Ellen Moränenton 1 Elle plastischer Ton.

Im Jahre 1928 war am nördlichen Ende der Buskewerksgrube ein Profil durch die Schichten oberhalb des Kaolins (Fig. 40) freigelegt worden. Unmittelbar über dem Kaolin fand sich grauer Ton, der am äussersten Westende $6 \mathrm{~m}$ und ungefähr gegenüber der Mitte der Grube 


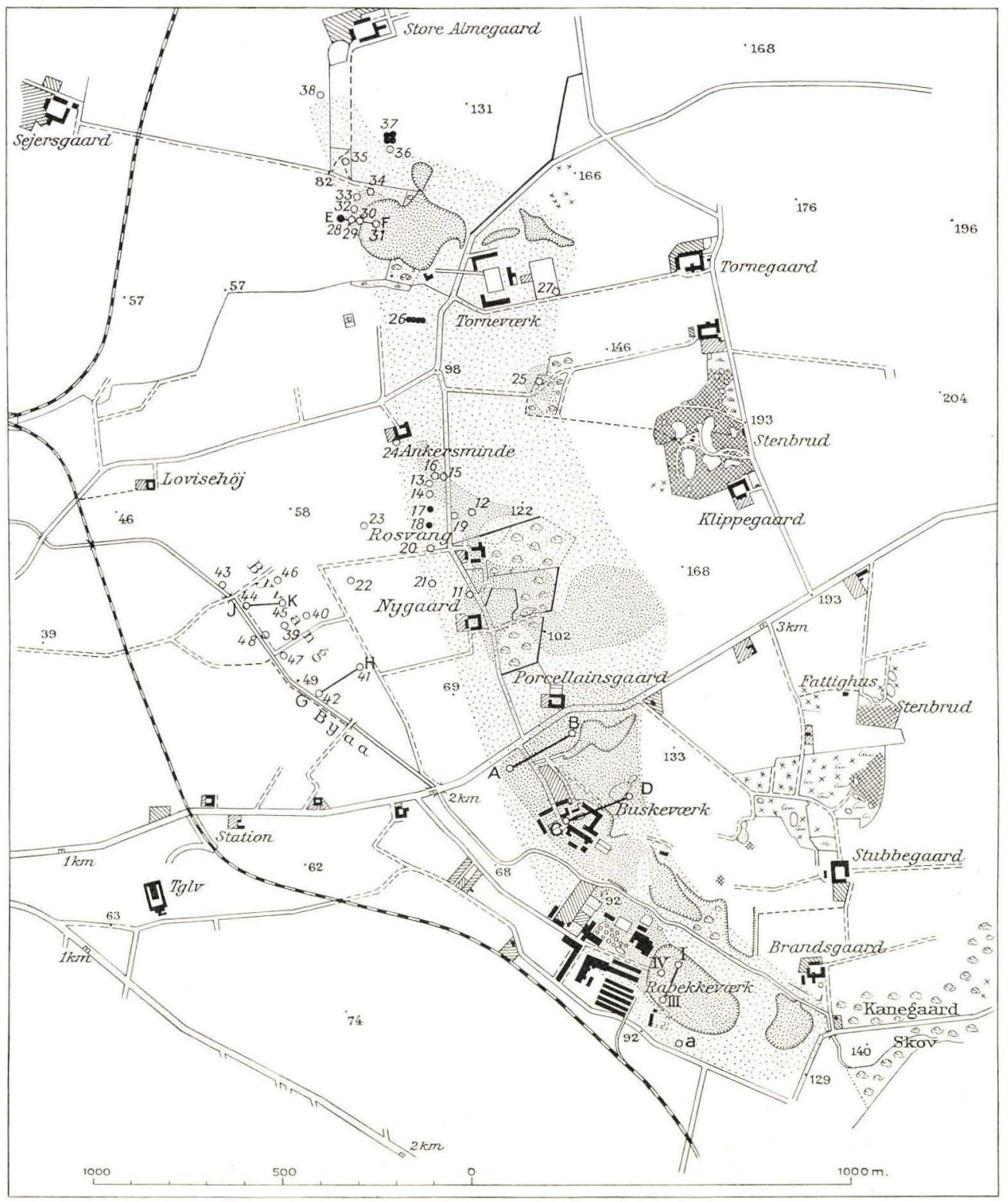

Fig. 39. Karte des Kaolingebiets bei Rönne. Das Kaolingebiet ist durch weite Punktierung gekennzeichnet. In dichter Punktierung sind die Stellen angegeben, wo Kaolin abgebaut oder durch Bohrungen nachgewiesen wurde. Die im Text besprochenen Bohrungen sind mit $\bigcirc$ bezeichnet und mit Kursivzahlen nummeriert. bedeutet Bohrungen wo der Felsgrund unmittelbar unter der Moräne angetroffen wurde. Senkrechte Zahlen geben die Meereshöhe in Fuss an $(1 \mathrm{Fuss}=0.3139 \mathrm{~m})$. Kreuzmuster und einzelne Kreuze: zu Tage tretender Granit. 
nur $2 \mathrm{~m}$ mächtig war. Hierüber lag Moränenton, der ebenfalls nach Osten zu auskeilt; an den erwähnten Stelle betrug seine Mächtigkeit 5 bezw. 4 m. Eine Sandschicht zwischen dem grauen Ton und dem Kaolin war nirgends zu sehen. Im grauen Ton wurden gelegentlich unbestimmbare Pflanzenreste gefunden.

Um den Mineralbestand und speziell den Feldspatgehalt im grauen Ton und im Kaolin zu vergleichen, nahm ich eine kleine Serie Proben

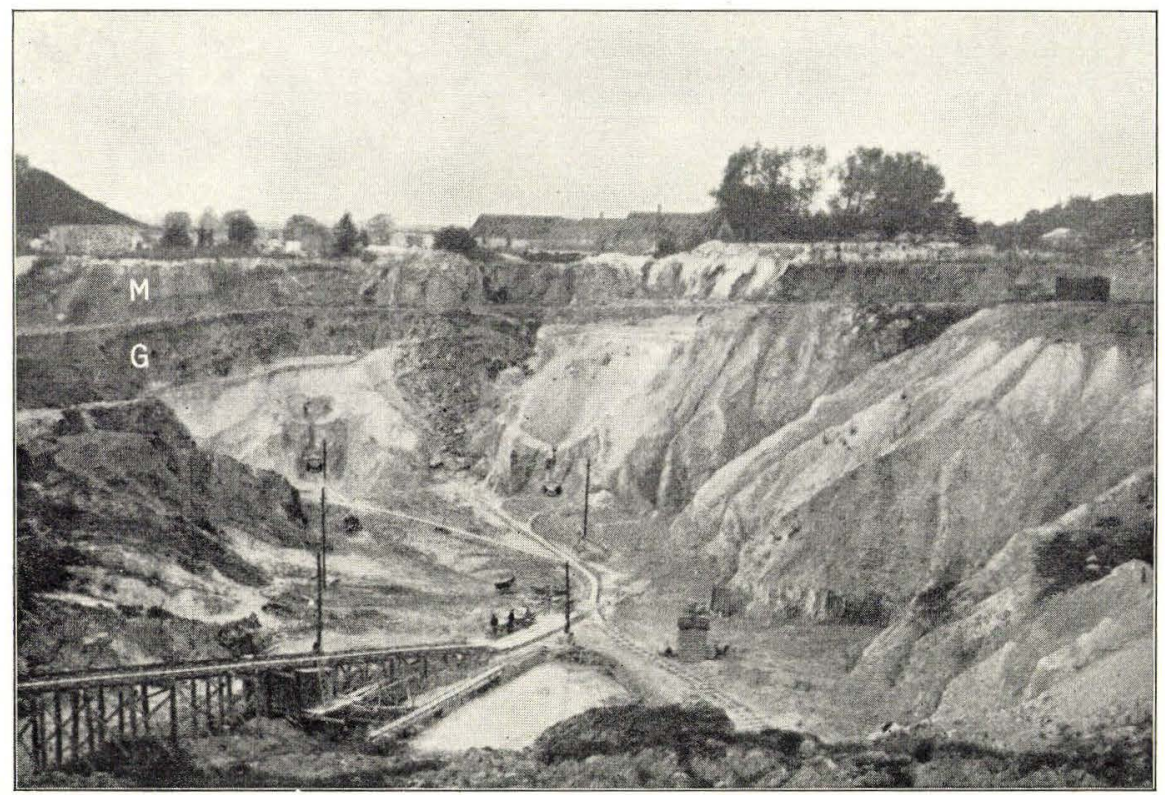

Fig. 40. Kaolintagebau Buskegaard. $\mathrm{M}=$ Moräne, $\mathrm{G}=$ Grauer Ton.

aus der Uebergangszone zwischen dem grauen Ton und dem Kaolin. Der graue Ton enthält eine grosse Menge Quarz, schätzungsweise mehr als $50 \%$. Im oberen Teile des Tons, etwa $2 \mathrm{~m}$ über dem Kaolin, variiert die Grösse der Quarzkörner im allgemeinen von etwa $1 \mathrm{~mm}$ Durchmesser bis zu ganz feinen Körnchen, ausserdem sind ziemlich oft grössere Körner von etwa $5 \mathrm{~mm}$ und mehr Durchmesser vorhanden. Feldspat wurde in diesen Proben nicht gefunden. Nach unten zu nimmt die Grösse der Körner ab.

Die Grenze zwischen dem Kaolin und dem grauen Ton ist in der Natur scharf und deutlich. Unmittelbar über dem Kaolin aber war der graue Ton etwas rotgeflammt, und nach Trocknung bei gewöhnlicher Zimmertemperatur wurde er fast ganz weiss. Auch diese Probe enthielt eine ansehnliche Menge Quarz; ausserdem waren eine nicht unbeträchtliche Menge von Mikroklinresten, sowie ein recht wesentlicher Gehalt von kaolinartigen Aggregaten vorhanden. Ein kleiner Teil dieser Aggre- 
gate ähnelte genau denjenigen, welche die Hauptmasse des Rohkaolins bildeten, d. h. es waren kleine farblose, feinblätterige Aggregate mit sehr schwacher Doppelbrechung und einer Lichtbrechung von ca.1,561,57. Die meisten der Aggregate im grauen Ton sind aber dunkel und bräunlich; einige haben ein wenig höhere Interferenzfarben als die farblosen Kaolinschuppen, andere sind stark getrübt von dunklen undurchsichtigen Partikeln. Ein ähnliches Aussehen haben übrigens viele der Aggregate in den unreinen oder unvollständig kaolinisierten Partien des Rohkaolins.

Der Kaolin unmittelbar unter dem grauen Tone war etwas gräulich, aber die feinblätterigen Aggregate waren grösstenteils klar und farblos. Quarz war reichlich vorhanden, Feldspat dagegen fand sich nicht. Im Kaolin etwa 0,5 m unter der Grenze gegen den grauen Ton fand sich ein dunkler, horizontaler Streifen von 8-10 cm Mächtigkeit. Der Kaolin war hier von dunklen, unbestimmbaren Partikeln verunreinigt und enthielt einige nicht umgewandelte Mikroklinreste. Der Rohkaolin etwa 2,5 m unter dem grauen Ton war ebenfalls etwas verunreinigt und enthielt etwas Mikroklin. Typische Kaolinaggregate waren hier reichlich vorhanden. Ausser den genannten Mineralien wurden in allen Proben sowohl des grauen Tons als auch des Kaolins akzessorische Zirkon- und Erzkörner gefunden, die letzteren häufig etwas verwittert.

Ausser diesen Proben habe ich einige Bohrproben untersucht, die nunmehr näher besprochen werden sollen. Sie zeigten, dass der Feldspatgehalt nicht nur von Ort zu Ort, sondern auch in den verschiedenen Niveaus recht beträchtlich wechselt. Die Bohrungen durchteuften mehrmals abwechselnd feldspatführende und feldspatfreie Schichten. Nicht selten enthält der graue Ton mehr Feldspat als der darunter liegende Kaolin, auch findet man gelegentlich in ein und derselben Bohrung einen grösseren Feldspatgehalt in den oberen Teilen des Kaolins als in den tieferen. Ferner kann hinzugefügt werden, dass in ein paar alten Proben im Mineralogischen Museum: „Schwarze Tonschicht über dem Kaolin, Rabekkegaard" und "Grüne Sandschicht über dem Kaolin, Rabekkegaard", etwas Feldspat gefunden wurde, in denen schätzungsweise der Feldspat in wesentlich grösserer Menge vorhanden war als gewöhnlich im Rohkaolin.

Der Umstand, dass im grauen Ton oft ein grösserer Feldspatgehalt gefunden wird als im Kaolin, zeigt, dass die Lösungen, welche die Kaolinbildung verursacht haben, nicht zuerst durch den grauen Ton gedrungen sind. Uebrigens machen es schon die Mächtigkeit und die fettige Beschaffenheit der Tonschicht im höchsten Grade unwahrscheinlich, dass das Oberflächenwasser die Tonschicht durchdrungen und danach auf den Felsgrund kaolinisierend eingewirkt haben sollte.

Als die Beschreibung zum Kartenblatt ausgearbeitet wurde, lag eine 
Reihe älterer Bohrungen aus der Umgebung des Rabekkewerkes vor. Auf Grund dieser Bohrungen gibt Grönwall an, dass der Kaolin O und SO der Grube des Rabekkewerks nur eine geringe Verbreitung hat; in diesem Gebiet fand sich nur "grauer Kaolin«. Dagegen zeigten die Bohrungen, dass der Kaolin nach Westen an Mächtigkeit und Reinheit
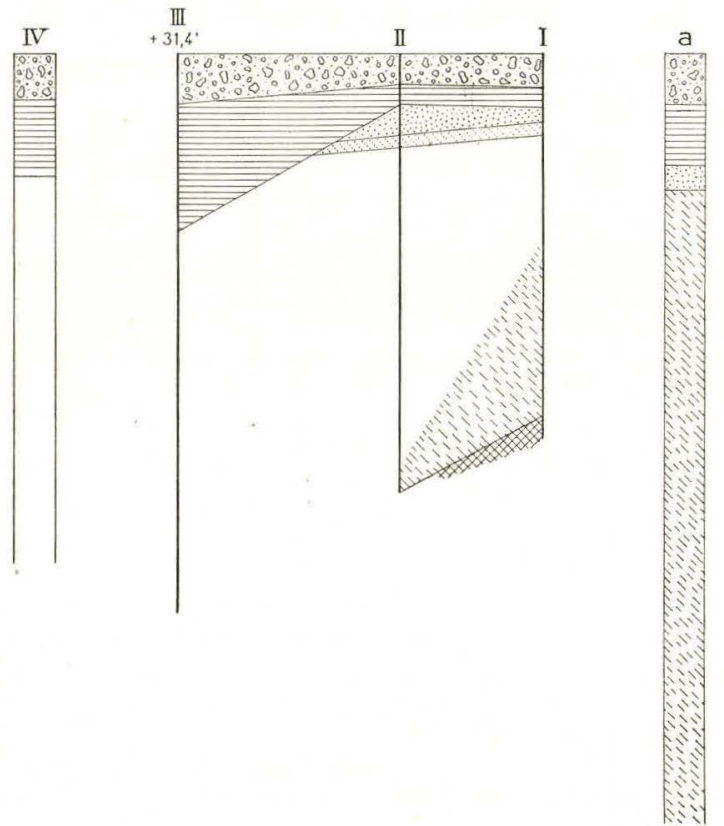

Fig. 41. Profil durch den Kaolin bei Rabekkegaard. Länge von $\mathrm{I}-\mathrm{III}=90 \mathrm{~m}$. Richtung: SW-NO. Höhe zu Länge $=2: 1$. Zeichenerklärung s. Fig. 42.

zunimmt; gleichzeitig wird auch die Decke über dem Kaolin mächtiger, je weiter man sich vom Granit entfernt. In der Beschreibung zum Kartenblatt werden 5 von diesen Bohrungen angeführt, die ich hier wiedergebe. Hiervon bilden I-III ein Profil (Fig. 41) in ungefähr NO-SW Richtung quer über die Grube des Rabekkewerks hinweg (siehe Karte Fig. 39).

Bohrung I.

Abraum.......... 13' (4,1 m)

Grauer Ton................ $8^{\prime}(2,5 »)$

Feiner Sand......... 6. 6 $6^{\prime}(1,9 »)$

Gelber Kaolin......... $5^{\prime}(1,6 »)$

Weisser Kaolin...... 4. 40 $0^{\prime}(12,5$ »)

Grauer Kaolin....... . 70' 22,0 »)

Unverwitterter Granit . $10^{\prime}(3,1 ")$

$152^{\prime}(47,7 \mathrm{~m})$
Bohrung II.

Abraum ................... $12^{\prime}(3,8 \mathrm{~m})$

Grüner Ton......... $\quad 8^{\prime}(2,5 »)$

Sand........... 12' (3,8»)

Gelber Kaolin. ....... . $5^{\prime}(1,6 »)$

Weisser Kaolin. . . . . . 126' (39,5»)

Grauer Kaolin........ 10 10' (3,1 »)

$173^{\prime}(54,3 \mathrm{~m})$ 
Bohrung III.

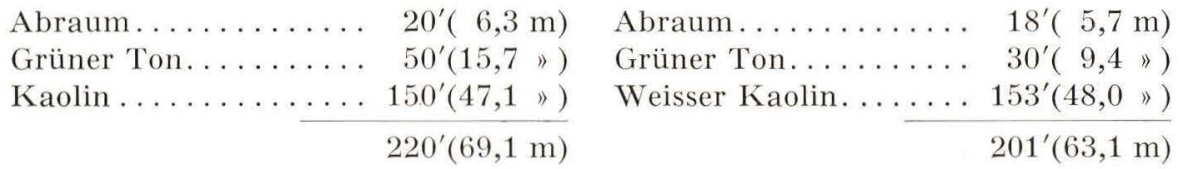

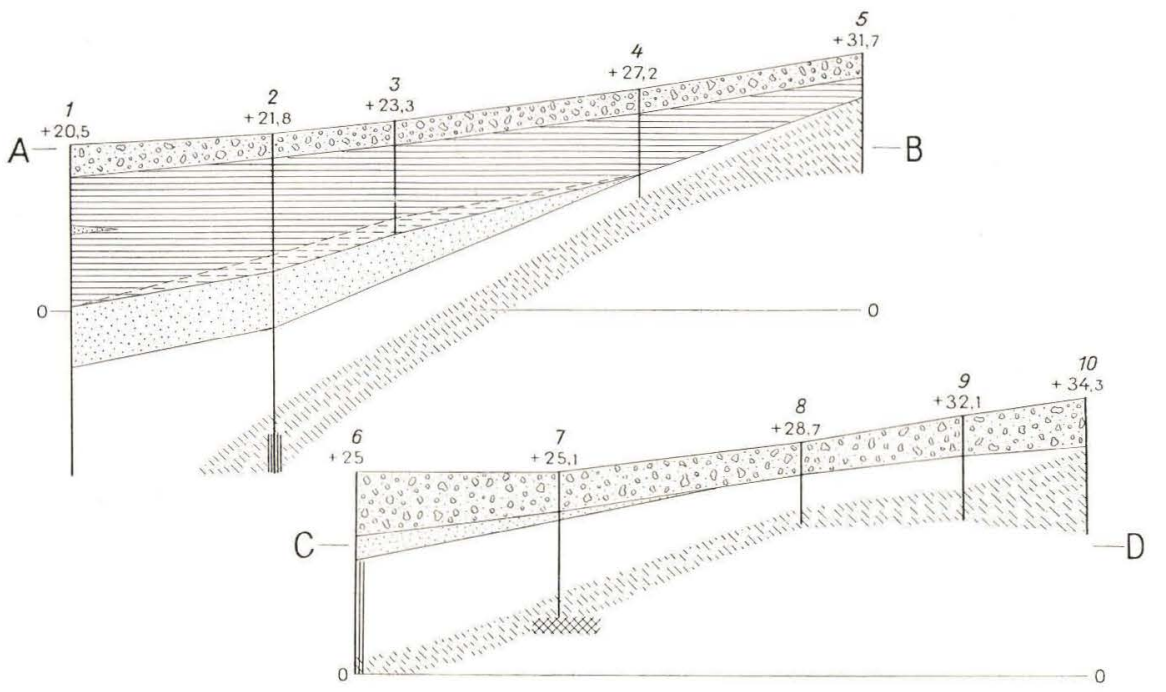
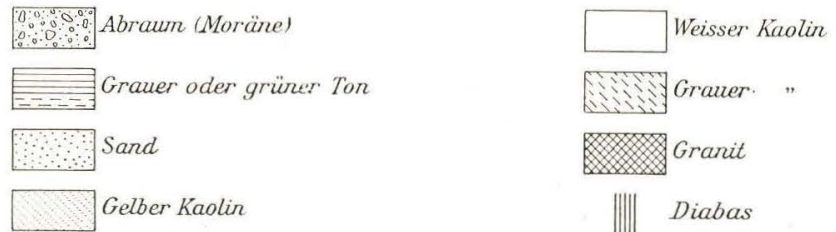

Fig. 42. Profil durch den Kaolin nördlich von Buskegaard. $A-B=195 \mathrm{~m}, \mathrm{C}-\mathrm{D}=180 \mathrm{~m}$. Höhe : Länge $=2: 1$. Senkrechte Zahlen geben die Meereshöhe in Meter an.

Die Decke über dem Kaolin hat in diesen und einigen anderen Bohrungen, die nicht näher angegeben werden, eine Mächtigkeit von 10-20 m. Sie besteht zu oberst aus Moränenton (Abraum), darunter liegt grauer oder grüner Ton, von GRönwalL als »Juraton« bezeichnet, und Sand. Der unverwitterte Granit unter dem Kaolin wurde in Bohrung I und ausserdem in noch einer Bohrung $140 \mathrm{~m}$ NW von I, also in der Längsrichtung der Kaolinlagerstätte, erreicht; diese zeigt ebenfalls $3 \mathrm{~m}$ unverwitterten Granit.

Schliesslich erwähnt GRönwall die tiefste der Bohrungen, die etwa $50 \mathrm{~m} \mathrm{SO}$ von der südöstlichsten Ecke des alten Rabekkegaards ${ }^{1}$ ) nieder-

1) Auf der Karte Fig. 39 ist die frühere Lage des Rabekkegaard mit gestrichelten Linien angegeben. 
gebracht wurde. Bei dieser Bohrung, die hier mit a bezeichnet ist, wurden keine vollständigen Proben genommen, die Schichtenfolge wird aber folgendermassen angegeben:

Bohrung a.

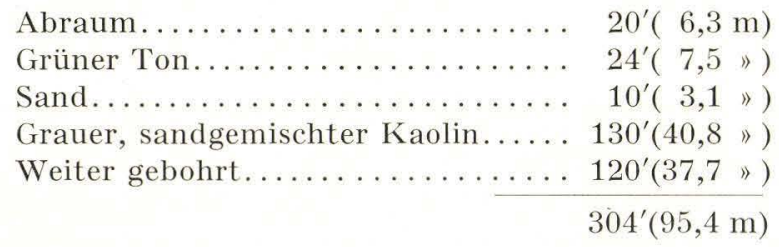

GRönwalt hält es für wahrscheinlich, dass das Material in den letzten $250^{\prime}(78,5 \mathrm{~m})$ der Bohrung ein relativ wenig umgewandelter Granit gewesen ist. Von der Beschaffenheit der untersten $37 \mathrm{~m}$ wird nur mitgeteilt, dass das Material sandhaltig war, und dass der Felsgrund nicht erreicht wurde.

In den letzten Jahren hat die »A/S Hasle Klinker- og Chamottestensfabrik, Bornholms Kaolin-, Chamotte- og Klinkerfabriker eine umfassende Abbohrung des Gebiets zwischen dem Buskewerk und dem Tornewerk vorgenommen. Ich bin dem Direktor der Gesellschaft, Herrn Ingenieur J. C. Clausen und dem früheren Leiter der Werke in Rönne, Herrn Ingenieur Viggo Nielsen, zu grossem Dank verpflichtet für das ausserordentliche Entgegenkommen, mit dem sie die Resultate dieser Bohrungen für die vorliegende Untersuchung zur Verfügung gestellt haben.

In den Jahren 1927-28 wurde eine Reihe von Bohrungen zwischen dem Buskewerk und der Landstrasse Rönne-Almindingen ausgeführt, also in der östlichen Randzone des Kaolins. Auf Grund dieser Bohrungen sind zwei Querprofile A-B und C-D (Fig. 42) konstruiert worden, die ca. 500-600 m NNW von Profil I-III liegen. Bei der Mehrzahl der Bohrungen wurde zwischen der Moräne und dem Kaolin eine Schicht von grauem Ton gefunden; in selteneren Fällen war der Ton grün, gelblich oder bläulich. An der Ostseite wird der Kaolin unmittelbar von Moräne überlagert. Die Bohrproben ergeben, dass der Ton in Bezug auf Quarzgehalt und auf die Grösse der Quarzkörner etwas variiert, und dass gröbere und feinere Schichten stellenweise wechsellagern. Durchschnittlich sind jedoch die Quarzkörner in den oberen Tonschichten am grössten, und hier treten in der Regel auch einzelne Mikroklinkörner auf; in den tiefer liegenden Tonschichten wurde Feldspat nicht beobachtet.

Im westlichen Teil des abgebohrten Gebiets lag eine Sandschicht zwischen dem grauen Ton und dem Kaolin; auch diese Schicht keilt nach Osten zu aus und hat ihre grösste Mächtigkeit, $10 \mathrm{~m}$, nach Westen 
zu. Der Sand besteht zum weit überwiegenden Teil aus Quarz, kann aber eine geringe Menge von hellem Glimmer, kleinen Turmalinkristallen und hie und da ein wenig Eisenkies enthalten; in einer einzelnen Probe wurde ein wenig Eisenspat gefunden.

Im folgenden werden nur diejenigen Bohrungen erwähnt, die den Querprofilen A-B und C-D zugrunde liegen.

Bohrung Nr. 1. $\left.(33)^{1}\right)$.

\begin{tabular}{|c|c|}
\hline TII. & 4 \\
\hline Grauer Ton............. & 6 \\
\hline Toniger Sand............. & 1 \\
\hline Grauer Ton............. & 9 \\
\hline 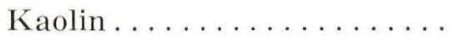 & 1 \\
\hline 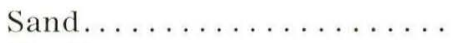 & 2 \\
\hline Kaolin . . . . . . . . . . . & 1 \\
\hline Sand $\ldots \ldots \ldots \ldots \ldots$ & 3,5 \\
\hline Kaolin . . . . . . . . . . . & 4,5 \\
\hline Dunkler Kaolin............ & 3 \\
\hline Kaolin . . . . . . . . . . . & 6 \\
\hline
\end{tabular}

Bohrung Nr. 3. (23).

Abraum............... $3 \mathrm{~m}$ Grauer Ton............ 9 "

Kaolin................ 2 "

Grüner Ton............ 1 " Grüner, kalkreicher²) Sand...

$15 \mathrm{~m}$

Bohrung Nr.5. (21).

Abraum............. $3 \mathrm{~m}$

Gelber Ton............ 1,5 "

Grauer Ton............... 1 "

Kaolin . . . . . . . . .... 3 "

Uebergang zum grünen Kaolin 3,5 "

Grüner Kaolin

$\begin{array}{rrr}\ldots \ldots \ldots & 3 \quad \text { " } \\ 15 & \text { m }\end{array}$

Bohrung Nr.7. (10).

Abraum............... $5 \mathrm{~m}$

Wasserführender Sand...... 1 "

Kaolin............... 6 "

Dunkler Kaolin........... 6 "

Felsengrund

$18 \mathrm{~m}$
Bohrung Nr.2.(24).

Abraum............. $3 \mathrm{~m}$

Grauer Ton............. 12 »

Geschlämmter Kaolin....... 2 »

Wasserführender Sand..... 7 7"

Guter Kaolin............. 10 »

Grünlicher Kaolin......... 5 »

$39 \mathrm{~m}$

Bohrung Nr.4. (22).

Abraum.............. $3 \mathrm{~m}$

Grauer Ton............. 5 "

Gelber Ton........... 2,5

Kaolin ................ 3

Dunkler Kaolin. $13,5 \mathrm{~m}$

Bohrung Nr.6. (6).

Abraum............ $8 \mathrm{~m}$

Wasserführender Sand...... 3 "

Kaolin.................. 3 "

Gelber Ton............... 3 "

Gelblich-grüner Ton...... 6 ,

Grüner Sand............ 2 "

$25 \mathrm{~m}$

Bohrung Nr. 8. (15).

Abraum............. $4 \mathrm{~m}$

Gefärbter Kaolin ......... 1 ,

Guter Kaolin............. . 3 \#

Dunkler Kaolin........... 2 "

1) Die Zahlen in Klammern bedeuten die ursprünglichen Bezeichnungen der Bohrjournale.

2) Ueberwiegend $\mathrm{FeCO}_{3}$. 
Bohrung Nr.9. (32).
Bohrung Nr. 10. (16).

Die genauere Untersuchung der Proben gab in einigen Punkten Veranlassung, die Auffassung von der Beschaffenheit der durchbohrten Schichten zu ändern, und die Profile A-B und C-D entsprechen daher nicht ganz den Bezeichnungen in den Journalen.

In den Bohrungen Nr. 1, 2 und 3 wird zwischen dem grauen Ton und der Sandschicht eine dünne Schicht "Kaolin« angegeben, und in Nr. 3 ferner eine dünne Schicht von feinem, sandigem Kaolin tiefer unten in der Sandschicht. In den Bohrungen Nr. 2 und 3 enthält dieser »Kaolin« nur wenige Quarzkörner von der im Rohkaolin gewöhnlich vorkommenden . Grösse, wogegen kleine Quarzkörner von $0,05 \mathrm{~mm}$ und darunter überaus zahlreich sind. Im übrigen besteht diese Schicht aus kleinen braunen, feinschuppigen, glimmerartigen Aggregaten, die sich durch ihre dunklere Färbung und höhere Doppelbrechung von den reinen Kaolinschuppen im Rohkaolin unterscheiden und eher den entsprechenden Aggregaten im grauen Ton ähneln. Diese Schicht muss daher richtiger als »feiner heller Ton« bezeichnet werden, der in seiner Beschaffenheit sehr an den weissgrauen, feuerfesten Rhät-Lias-Ton von Bagaa erinnert, welch letzterer jedoch einen geringeren Quarzgehalt als die vorliegenden Proben aufweist. In Bohrung Nr. 1 enthalten die entsprechenden Schichten mehr Kaolin, besonders die unterste, die überhaupt sehr ungleich ist, mit ziemlich grossen Quarzkörnern und fast reinen Klümpchen aus Kaolin; diese Schichten müssen am ehesten als toniger, etwas kaolinhaltiger Sand bezeichnet werden. Die relativ grossen Schuppen von hellem Glimmer, die in dieser Sandschicht vorkommen, haben einen ziemlich kleinen optischen Achsenwinkel; in mehreren Körnern wurde $2 \mathrm{E}=$ etwa $40^{\circ}-56^{\circ}$ gemessen, also weniger als gewöhnlich beim Muskovit. Derselbe Glimmer kommt im Kaolin unmittelbar unter der Sandschicht vor, und in mehreren anderen Kaolinproben wurde ein ganz ähnlicher heller Glimmer gefunden. Es besteht kein Zweifel, dass der Biotit in einem gewissen Stadium seiner Umwandlung einen solchen hellen, zweiachsigen Glimmer mit kleinem optischem Achsenwinkel ergibt. Ferner hat in dieser Bohrung der obere Teil des Kaolins schätzungsweise einen geringeren Gehalt an eigentlichen Kaolinschuppen als der untere. Diese Verhältnisse sprechen dafür, dass die Sandschicht tatsächlich, wie von früheren Verfassern behauptet, durch Ausschlämmung des Kaolins gebildet und somit jünger ist als dieser.

Bohrung Nr. 3 dürfte sicher nicht bis zum eigentlichen Kaolin hinab- 
geführt worden sein, sie bleibt in grünem, ziemlich grobem Sand stecken, der im Journal als kalkreich bezeichnet wird. Karbonat scheint jedoch ziemlich spärlich vorhanden zu sein und im wesentlichen aus Eisenspat $\mathrm{zu}$ bestehen.

Ueberall wo »dunkler Kaolin« angegeben wird, stellte ich fest, dass das Gestein recht wenig umgewandelt war, und dass es Mikroklinreste, sowie auch eine reichliche Menge von gefärbtem Biotit enthielt. Meistens findet sich auch Karbonat in geringen Mengen, besonders Eisenspat. Ein derartiger dunkler Kaolin wurde in Bohrung Nr. 1 in einer Teufe von $32-35 \mathrm{~m}$ gefunden. Darunter lag der beste und am stärksten umgewandelte Kaolin dieser Bohrung. Im übrigen ist es in der Regel so, dass die Bohrungen in einem nur teilweise kaolinisierten Gestein endigen, und in den östlichsten Bohrungen war sozusagen der gesamte Kaolin von dieser Beschaffenheit. In Bohrung Nr. 7 und in vier anderen Bohrungen, von welchen keine Proben für die Untersuchung zur Verfügung standen, wurde unter halbverwittertem Granit unverwitterter Felsgrund angegeben. Es dürfte daher kein Zweifel darüber bestehen, dass der dunkle Kaolin im allgemeinen in diesen Bohrungen die Untergrenze des Kaolins bildet; wie aber schon oben erwähnt, kennt man auch mehr oder weniger umgewandelte Granitpartien in der eigentlichen Hauptmasse des Kaolins, und auf eine solche Partie ist man offenbar in Bohrung 1 gestossen.

In Bohrung 6 gibt das Journal unter $3 \mathrm{~m}$ Kaolin gelben und gelblichgrünen Ton und zu unterst grünen Sand an. Leider sind nur zwei Bohrproben aus 12 beziehungsweise $16 \mathrm{~m}$ Teufe entnommen worden, von denen die obere aus gutem Kaolin besteht. Die untere, die als "gelber Ton « bezeichnet wird, besteht indessen aus kaolinisiertem Diabas, und das Wahrscheinlichste ist, dass die Bohrung durch einen Diabasgang hindurch fortgesetzt worden ist. Vermutlich sind die untersten $2 \mathrm{~m}$ "grüner Sand" in der Tat ein halbverwitterter Diabas. Im Profil C-D ist daher der ganze unterste Teil von Bohrung 6 als Diabas bezeichnet worden.

In einigen Bohrungen, z. B. Nr. 8, 10 u. a., ist der obere Teil des Kaolins etwas gefärbt. Die Farbe rührt von einem bräunlichen Pigment her, vermutlich von Ferrihydroxyden, die eine dünne Rinde auf den Mineralkörnern, und zwar sowohl auf Quarz als auf Kaolin bilden, und die zweifellos von durchsickerndem Wasser abgesetzt worden sind.

Nördlich der Landstrasse ist der Kaolin an einigen begrenzten Stellen nachgewiesen, die auf der Karte Fig. 39 durch dichte Punktierung gekennzeichnet sind. Als der Kaolinabbau bei Rönne ungefähr im Jahre 1775 began, wurden die ersten Schürfungen östlich des Porcellainsgaard vorgenommen. Dieses Vorkommen ist längst aufgelassen. M. Jespersen ${ }^{1}$ )

1) M. Jespersen, Liden Vejviser. 1865, S. 11.

Danmarks geologiske Undersøgelse. II. R. Nr. 50 
teilt mit, dass der Kaolin hier nach Norden von anderen Gesteinen begrenzt wird.

Die Bohrungen der letzten Jahre sind vornehmlich in dem Gebiet zwischen den Höfen Nygaard, Rosvang und Ankersminde niedergebracht worden. Östlich von Nygaard sind ca. 140 Bohrungen niedergebracht worden, von denen der grösste Teil im Kaolin stecken geblieben ist. Die Bohrungen zeigten, dass der Kaolin nach Osten hin nur geringe Mächtigkeit besitzt, dass er aber näher beim Hof in etwas grösserer Menge vorkommt. Etwa 400-500 m östlich von Nygaard liegt er in einem ganz flachen Becken von 200 m Durchmesser. Am Rande dieses Beckens wurden an mehreren Stellen nur 2-4 m Kaolin gefunden, der häufig mager und gefärbt war. In der Mitte erreicht der Kaolin eine Mächtigkeit von $6-7$ m. Im Liegenden des Kaolins vermerken die Bohrjournale »blauen Sand«, d. h. Granitgrus. Das Hangende des Kaolins ist 2-4 m mächtig und besteht wahrscheinlich ausschliesslich aus Moräne. Gegen Westen wird dieses Becken teilweise von einem schmalen Granitrücken begrenzt, wo die Bohrungen in 3-8 m Teufe in Granitgrus stecken geblieben sind, ohne auf Kaolin gestossen zu sein. In der Waldparzelle ca. $150 \mathrm{~m}$ östlich von Nygaard wurde durch die Bohrungen 0,63-2,52 m Hangendes (Moräne) über dem Kaolin nachgewiesen; darunter wurde bis 13,54 m durch Kaolin gebohrt, ohne denselben zu durchteufen. Zwischen dem Wald und Nygaard wird das Hangende des Kaolins allmählich mächtiger und unmittelbar beim Hof traf man Kaolin in einer Tiefe von 10-13 m. Etwa $100 \mathrm{~m}$ südlicher wurde 15,12 m tief gebohrt, ohne dass Kaolin erreicht wurde. Da Kaolinabbau unter einer so mächtigen Abraumschicht sich kaum bezahlen würde, wurde der grösste Teil der Bohrungen nur bis zu einer Teufe von ca. $15 \mathrm{~m}$ niedergebracht. Nur eine einzelne Bohrung, Nr. 11, etwa $50 \mathrm{~m} \mathrm{~N}$ von Nygaard hat bei $17 \mathrm{~m}$ Granitgrus unter Kaolin erreicht, der in den Journalen als »Sand « bezeichnet wird.

Bohrung Nr. 11 gehört zu einer Serie von Bohrungen, die in den Jahren 1933-1934 zwischen Nygaard und dem Tornewerk ausgeführt wurden. Diese Bohrungen, von denen einige unten angeführt werden, geben ausführliche Auskunft über die durchbohrten Schichten. Sie haben gezeigt, dass der Kaolin, wie es scheint in einem recht schmalen Streifen, nach Norden unter dem Hof Rosvang fortsetzt und von dort noch $200 \mathrm{~m}$ weiter nach NNW. Die Bohrungen Nr. 12, 13, 14 und 15 ergaben guten Kaolin, der aber nur eine geringe Mächtigkeit hat und nach unten zu mager wird. Die Bohrungen hören im Granitgrus auf. Bohrung Nr. 16 ergab $2 \mathrm{~m}$ mageren Kaolin und auch noch $40 \mathrm{~m}$ westlicher fanden sich Spuren von Kaolin. Die westlichsten Bohrungen stiessen dagegen nicht auf Kaolin. In zwei Fällen, Nr. $1 \%$ und 18, stiess man auf Fels unter 6,4 bezw. 5,5 m Moräne. Die übrigen Bohrungen, von denen fünf unten unter Nr. 19-23 angeführt werden, erreichten unter der Moräne 
verschiedenfarbigen Ton, dessen Mächtigkeit nach Westen zunahm. Dieser Ton ist ohne Zweifel eine Fortsetzung des fetten Juratones, der im südlichen Teil des Kaolingebiets den Kaolin überlagert. Im Liegenden des Tones erreichten einige der Bohrungen Sand, der möglicherweise der früher besprochenen Sandschicht zwischen dem Juraton und dem Kaolin entspricht. Unmittelbar beim Hof Ankersminde (Bohrung Nr. 24) wurden $6 \mathrm{~m}$ Moräne durchteuft und darauf $7 \mathrm{~m}$ feiner, weisser Sand, worauf die Bohrung in $13 \mathrm{~m}$ Teufe stecken blieb. Etwas östlicher fand man in Bohrung Nr. 25, etwa $200 \mathrm{~m} \mathrm{~S}$ des Wasserbassins des Tornewerks, guten Kaolin unter $6 \mathrm{~m}$ Moräne. $\mathrm{Zu}$ unterst wird der Kaolin mager und in $15 \mathrm{~m}$ Tiefe erreichte man den Fels. Diese Bohrung ist bis jetzt die einzige an dieser Stelle, so dass über die Erstreckung des Kaolins hier keine näheren Angaben gemacht werden können.

Von den erwähnten Bohrungen sollen die folgenden angegeben werden. Neben der Nummer der Bohrung ist in Klammern die Bezeichnung des Bohrloches in den Originaljournalen hinzugefügt.

Bohrung Nr. 11. (nA).

Moräne

Bei $2.5 \mathrm{~m}$ gelber, etwas sandiger Ton

" $3.0 \mathrm{~m}$ bräunlicher, etwas sandiger Ton

» $5.0 \mathrm{~m}$ gräulicher, etwas sandiger Ton

" $6.0 \mathrm{~m}$ gelblicher, sandiger Ton

" $9.0 \mathrm{~m}$ gräulicher, sandiger Ton

》 $10.0 \mathrm{~m}$ Kaolin

" $11.0 \mathrm{~m}$ "

" $12.0 \mathrm{~m}$ "

" $13.0 \mathrm{~m}$ "

" $14.0 \mathrm{~m}$ Kaolin, der anfängt, grau und mager zu werden

" $16.0 \mathrm{~m}$ magerer Kaolin

" $17.0 \mathrm{~m}$ sehr magerer Kaolin

darunter Sand (d. h. halbkaolinisierter Granitgrus)

Bohrung Nr. 12. (X).

Moräne

Bei $12.0 \mathrm{~m}$ weisser Kaolin, aber mit einzelnen blauen Flecken

》 $13.0 \mathrm{~m}$

) $14.0 \mathrm{~m}$

" $15.0 \mathrm{~m}$ " " noch etwas magerer

» $16.0 \mathrm{~m}$ " $\quad$ recht sandig

" $17.0 \mathrm{~m} \mathrm{"} \mathrm{"} \mathrm{sehr} \mathrm{mager,} \mathrm{mit} \mathrm{grobem} \mathrm{Sand}$

》 $19.0 \mathrm{~m}$ Granitgrus mit Spuren von Kaolin

Bohrung Nr. 13. (A).

Moräne

» $\quad 4.5 \mathrm{~m}$ feiner weisser Kaolin

» $7.0 \mathrm{~m}$ recht guter Kaolin

) $\quad 7.0-10.0 \mathrm{~m}$ magerer Kaolin

》 $10.0-18.0 \mathrm{~m}$ sehr magerer Kaolin 
Bohrung Nr. 14. (B).

Moräne

Bei 4.0-7.0 m guter Kaolin

" $7.0 \mathrm{~m}$ und darunter: grüner Sand (d. h. halbkaolinisierter Granitgrus)

Bohrung Nr. 15. (I).

Moräne

Bei $5.0 \mathrm{~m}$ feiner weisser Kaolin

" $6.0 \mathrm{~m}$ " " "

" $7.0 \mathrm{~m}$ recht guter Kaolin

" $8.0 \mathrm{~m}$ grauer, tonartiger Kaolin

" $9.0 \mathrm{~m}$ grauer Sand

» $11.0 \mathrm{~m}$ grober, grauer Sand mit Spuren von Kaolin

Bohrung Nr.16. (aA).

Moräne

Bei $5.0 \mathrm{~m}$ magerer Kaolin

» $6.0 \mathrm{~m} \gg$

» $7.0 \mathrm{~m} \mathrm{»}$

" $8.0 \mathrm{~m}$ grauer Sand mit einzelnen Kaolinschmitzen (d. h. Granitgrus)

1) $10.0 \mathrm{~m}$

Bohrung Nr. 19. (XX).

Moräne

Bei $4.0 \mathrm{~m}$ Grauer Ton mit Sand
$5.0 \mathrm{~m}$ " " " "
$6.0 \mathrm{~m}$ "
$7.0 \mathrm{~m} \mathrm{"} \mathrm{"} \mathrm{beinahe} \mathrm{reiner} \mathrm{Sand}$
$9.0 \mathrm{~m}$ dunkler Sand
" $11.0 \mathrm{~m}$ heller, feiner Sand, schwach tonig
» $13.0 \mathrm{~m} \mathrm{\#} \mathrm{"}$
» $15.0 \mathrm{~m}$ "

Bohrung Nr. 20. (F).

Moräne

Bei $\quad 6.0 \mathrm{~m}$ dunkelgrüner, fetter Ton

» $7.0 \mathrm{~m}$ gräulicher, fetter Ton

» $8.0 \mathrm{~m}$ grüner, sandiger Ton

» $9.0 \mathrm{~m}$ brauner, sandiger Ton

" $10.0 \mathrm{~m} \mathrm{"} \mathrm{"} \mathrm{"}$

» $11.0 \mathrm{~m}$ recht fetter, grauer Ton mit etwas Sand

" $12.0 \mathrm{~m}$ hellerer Ton mit Sand

» $13.0 \mathrm{~m}$ hellgrauer, etwas toniger Sand

Bohrung Nr. 21. (H).

Moräne

Bei $6.0 \mathrm{~m}$ Grauer Ton

» $7.0 \mathrm{~m}$ " ".

》 $8.0 \mathrm{~m}$ brauner Ton mit gelben Schmitzen

" $9.0 \mathrm{~m} \mathrm{"} \mathrm{"} \mathrm{"} \mathrm{"}$

" $10.0 \mathrm{~m}$ gelblicher, etwas sandiger Ton

» $11.0 \mathrm{~m}$ grauer Ton mit ziemlich grobem Sand 
Bohrung Nr.22. (J).

Moräne

Bei $6.0 \mathrm{~m}$ grauer Sand

" $8.5 \mathrm{~m}$ magerer Ton

") $10.0 \mathrm{~m}$ grünlicher Ton

" $12.0 \mathrm{~m}$ dunkelgrauer Ton mit braunen Schmitzen

" $14.0 \mathrm{~m}$ "marmorierter Ton

" $16.0 \mathrm{~m}$ dunkelgrüner Ton

" $18.0 \mathrm{~m}$ hellgrüner Ton

" $20.0 \mathrm{~m}$ grüner, mit Ton untermischter Sand

Bohrung Nr. 23. (XXX).

Moräne

Bei $8.0 \mathrm{~m}$ Sand mit etwas grünem Ton

" $8.5 \mathrm{~m}$ " " grauem "

" $9.0 \mathrm{~m} "$ " " "

" $10.0 \mathrm{~m}$ grauer Ton mit lila Schmitzen

" $11.0 \mathrm{~m}$ bunter Ton mit grauen Schmitzen

" $12.0 \mathrm{~m}$ " " " "

" $13.0 \mathrm{~m}$ brauner, lila, marmorierter Ton

" $15.0 \mathrm{~m}$ " " " "

" $17.0 \mathrm{~m}$ grauer Ton mit braunen Schmitzen

" $19.0 \mathrm{~m}$ " " " "

» $21.0 \mathrm{~m}$ gelber Ton mit grauen und braunen Schmitzen

Bohrung Nr.25. (T).

Moräne

Bei $6.0 \mathrm{~m}$ guter Kaolin

$7.0 \mathrm{~m}$ " "
" $8.0 \mathrm{~m}$ " "
" $9.0 \mathrm{~m}$ " $10.0 \mathrm{~m} "$
" $11.0 \mathrm{~m}$ " "
" $12.0 \mathrm{~m}$ "
" $13.0 \mathrm{~m}$ magerer Kaolin
" $15.0 \mathrm{~m}$ Felsengrund

Des weiteren sind in den Jahren 1933-1934 um das Tornewerk herum verschiedene Bohrungen niedergebracht worden, wo der Kaolin durchgehends etwas magerer ist, als in den alten Tagebauten des Buskewerks und des Rabekkewerks. Gegenwärtig wird im westlichen Teil des grossen Tagebaus des Tornewerks abgebaut, während der östliche Teil sowie die kleineren Tagebauten der Umgebung erschöpft sind. Die Bohrungen werden durch Schürfungen ergänzt, die bis zu 3-4 m unter die Sohle des Tagebaus geführt werden. Etwa $130 \mathrm{~m}$ südlich des Tagebaus (Lokalität Nr. 26) fand man in 4 Bohrungen unter ca. $8 \mathrm{~m}$ Abraum »recht reinen Quarzstein", also vermutlich Pegmatit. Im östlichen Teil des Gebiets wurde nur eine Bohrung Nr. 27 angesetzt und zwar in der 
SO-Ecke des Wasserbassins. Hier fand man zu oberst ca. $4 \mathrm{~m}$ Ton, darunter ca. $4 \mathrm{~m}$ weissen Sand, der bei $9,5 \mathrm{~m}$ gröber wurde und mit etwas Kaolin gemischt war; in 12 m Teufe wurde der Felsgrund erreicht. Die übrigen Bohrungen sind westlich und östlich des Tagebaus angesetzt worden und zeigten, dass der Kaolin in einer schalenförmigen Vertiefung liegt, die im Süden, Westen und Nordwesten einen recht steilen Rand hat. Der weisse Kaolin der Grube hat eine ursprüngliche Mächtigkeit von 13-15 m; darunter wird er mager. Wie tief der magere Kaolin sich ins Liegende erstreckt, ist unbekannt, da keine der Bohrungen den

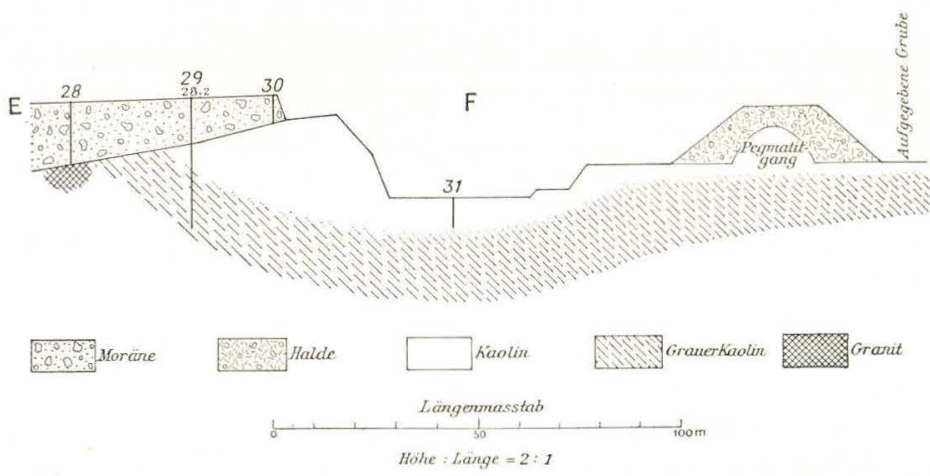

Fig. 43. Profil durch den Tagebau des Tornewerks (Profil E-F). Richtung W-O. Kursiv zahlen bezeichnen die Nummer der Bohrungen, senkrechte Zahlen die Meereshöhe in Meter.

Kaolin durchteuft hat. An Hand von vier Bohrungen, Nr. 28, 29, 30 und 31, sowie der Vermessung des Tagebaus durch das Werk ist Profil E-F (Fig. 43) konstruiert worden, welches den Tagebau in ost-westlicher Richtung überquert. Die Decke über dem Kaolin besteht aus Moräne und die westlichste Bohrung des Profils, Nr. 28, endigt im »Stein« unter $8 \mathrm{~m}$ Moräne. Natürlich ist es möglich, dass diese Bohrung hier in einem erratischen Block stecken geblieben ist. Da aber eine Reihe anderer Bohrungen nördlich von dieser und in derselben Entfernung vom Kaolin ebenfalls in »Stein « unter 5-6 m Moräne stecken geblieben sind, ist es am wahrscheinlichsten, dass diese Bohrungen den Felsgrund erreicht haben. Näher beim Tagebau wurde eine schmale Kaolinzone erbohrt, welche nach $\mathrm{W}$ schnell auskeilt. Bohrung Nr. 30 zeigte weissen Kaolin unmittelbar unter der Moräne, Nr. 31 wurde bis $3 \mathrm{~m}$ unter die Sohle des Tagebaus niedergebracht. In den Bohrungen Nr. 29, 32, 33 und 34 fand man im Liegenden des Kaolins halbkaolinisierten Granitgrus, der in den Journalen als »grüner, scharfer Sand« bezeichnet wird. Diese Bohrungen werden unten angeführt; die Bezeichnungen der Originaljournale sind in Klammern beigefügt. 
Bohrung Nr.29. (J,3).

Moräne

Bei $6.0 \mathrm{~m}$ sehr sandiger, weisser Kaolin

" $8.0 \mathrm{~m}$ leicht gefärbter Kaolin mit scharfem Sand

() $16.0 \mathrm{~m}$ sehr magerer Kaolin mit scharfem Sand

Bohrung Nr. 32. (F,4).

Moräne

Bei $6.0 \mathrm{~m}$ magerer, weisser Kaolin

» $7.0 \mathrm{~m}$ " "

» $9.0 \mathrm{~m}$ 》 $~ 》$

») $11.0 \mathrm{~m}$ sehr magerer, weisser Kaolin

" $13.0 \mathrm{~m} \mathrm{"} \mathrm{"} \mathrm{"}$ " mit scharfem Grus

" $16.0 \mathrm{~m}$ sehr magerer Kaolin, beinahe reiner Grus

Bohrung Nr. 33. (C,4).

Moräne

Bei $8.0 \mathrm{~m}$ gefärbter, magerer Kaolin

" $10.0 \mathrm{~m}$ grünlicher Sand (d. h. Granitgrus)

" $12.0 \mathrm{~m}$ scharfer Sand

" $17.0 \mathrm{~m}$ scharfer, grünlicher Sand

Bohrung Nr.34. (A,1).

$0-5.0 \mathrm{~m}$ Moräne

$5.0-7.0 \mathrm{~m}$ gefärbter Kaolin

7.0-11.0 m grüner Sand (d. h. Granitgrus)

Nördlich vom Tornewerk sind einige Bohrungen angesetzt worden. In zwei von diesen wurden Spuren von Kaolin angetroffen. Die Journale hierzu sind sehr kurz gefasst.

Bohrung Nr. 35. ("a»).

Ton, grünlicher Sand

gefärbter Kaolin

grüner Sand (d. h. Granitgrus)

Bei $20.2 \mathrm{~m}$ Felsengrund

In Bohrung Nr. 36, ungefähr $140 \mathrm{~m}$ nördlich vom Kaolintagebau wurde bis $19 \mathrm{~m}$ Teufe durch Granitgrus gebohrt und etwa $40 \mathrm{~m}$ nördlicher erreichten 4 Bohrungen (Nr. 3\%) den Fels unter 7-8 m Moräne. Bei der nordwestlichsten Bohrung Nr. 38 (»Nord«) fand man Moränenton und Sand und von 13-17 m Teufe sscharfen Sand mit einzelnen Kaolinschmitzen«.

Westlich von dem auf der Karte (Fig. 39) eingetragenen Gebiet sind eigentliche Kaolinlager bisher nicht nachgewiesen. Ueber die Verhältnisse in einem Teil dieses Gebiets werden wir durch Bohrungen unterrichtet, welche das Wasserwerk von Rönne in den Jahren 1931-33 in 
Byvangen angesetzt hat. Auf der Karte sind diese Bohrungen mit Nr. $39-48^{1}$ ) bezeichnet. Man erbohrte hier kaolinhaltigen Sand, der auf Granit auflag und von einer beträchtlichen Schicht eines fetten Tones überlagert wurde. Gewöhnlich bildete diese Tonschicht das unmittelbare Liegende der Moräne, aber in 2 Bohrungen fand sich eine dünne Schicht feinen Sandes zwischen dem fetten Ton und der Moräne. Ebenso wie in den oben besprochenen Bohrungen war der Ton verschiedenfarbig: grau,
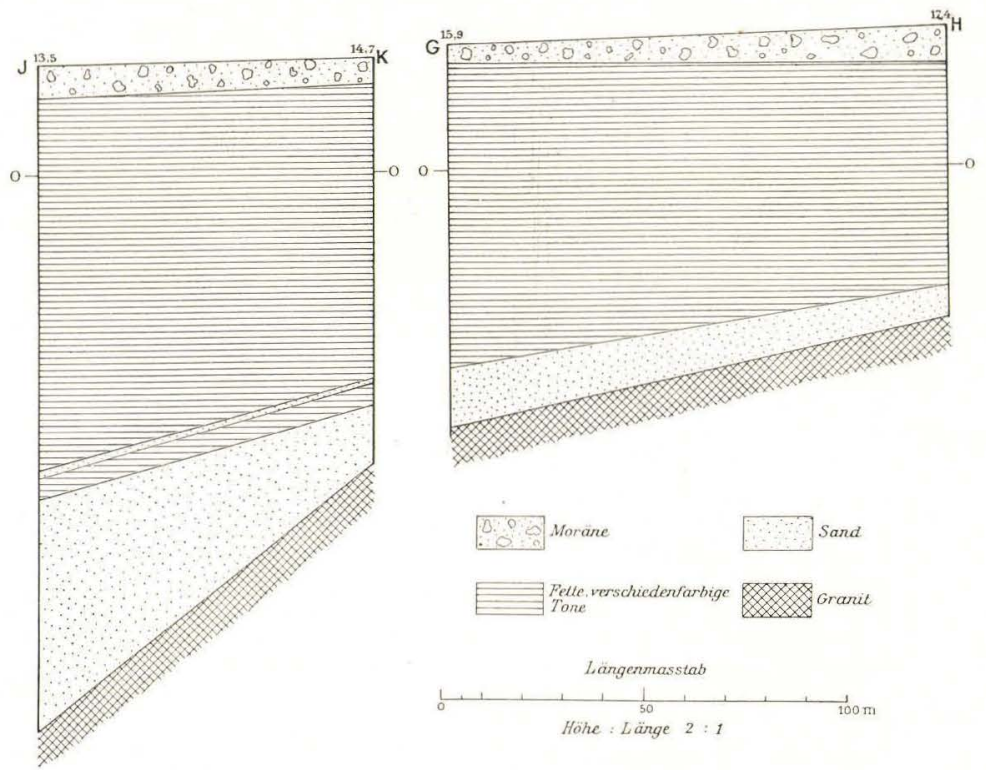

Fig. 44. Profil durch Byvangen östlich von Rönne. Richtung ungefähr W-O. (Vergl. die Karte Fig. 39). Die Zahlen geben die Meereshöhe in Meter an.

rötlich, gelblich, grünlich; stellenweise war er schwarz und enthielt Kohlebruchstücke. Die unteren Schichten waren durchgehends sandig.

Die Mächtigkeit der Sedimente nimmt nach Westen und Nordwesten rasch zu, wie man auf Fig. 44 sieht. Diese Abbildung zeigt zwei Profile: $\mathrm{G}-\mathrm{H}$ und J-K quer über Byvangen in ungefähr west-östlicher Richtung. Profil G-H verläuft etwa $250 \mathrm{~m}$ südöstlich von Profil J-K. Der Granituntergrund fällt also bedeutend steiler ein als die Terrainoberfläche, die bei Byvangen ganz schwach nach NW geneigt ist (vergl. die Höhenmarken auf der Karte Fig. 39). Die Mächtigkeit des Tones, die bei Nygaard und Rosvang ca. 5-6 m ausmacht, erreicht im östlichen Teil von Byvangen (Bohrungen Nr. 40-41) ca. 28-30 m und steigt im äussersten Nordwesten (Bohrung Nr. 43) auf gut $55 \mathrm{~m}$. Die Mächtigkeit der Sandschicht nimmt noch schneller zu. Die Bohrungen, welche den Profilen auf Fig. $44 \mathrm{zu}$ Grunde liegen, werden im Folgenden angeführt:

1) Danmarks Geologiske Undersøgelses Borearkiv: 246, 47-54 und 60-61. 
Profil G-H:

Bohrung Nr. 42 (D. G. U. 246, 50).

Moräne

Bei $2.5 \mathrm{~m}$ schwarzer Ton

" $9.0 \mathrm{~m}$ grünlicher Ton

》 $11.0 \mathrm{~m}$ schwarzer Ton mit Kohlestückchen

$12.0 \mathrm{~m}$ grauer Ton mit Schwefelkies

$16.0 \mathrm{~m}$ grauer Ton mit Sandschichten

$17.0 \mathrm{~m}$ heller Ton

$18.1 \mathrm{~m}$ rötlicher Ton

$18.5 \mathrm{~m}$ grünlicher Ton

$24.0 \mathrm{~m}$ schwarzer Ton

$26.0 \mathrm{~m}$ grünlicher Ton

$28.5 \mathrm{~m}$ etwas sandiger Ton

$40.0 \mathrm{~m}$ toniger Sand

» $43.5 \mathrm{~m}$ grober, stark mit Kaolin gemischter Sand. (Drei Proben bestanden aus fast reinem Quarzsand mit Spuren von Kaolin. Der Sand wurde nach unten zu gröber).

Bohrung Nr.41. (D. G. U. 246, 49).

Moräne

Bei $4.5 \mathrm{~m}$ fetter Ton in verschiedenen Farben

" $20.0 \mathrm{~m}$ sandiger Ton

" $21.0 \mathrm{~m}$ fetter Ton

" $28.0 \mathrm{~m}$ mit Grus untermischter Ton

" $29.0 \mathrm{~m}$ mit Sand untermischter Ton

" $32.0 \mathrm{~m}$ sandiger Kaolin. (Feiner fast reiner Quarzsand mit abgerollten Körnern. Spuren von Kaolin und Feldspat.)

" 35.75 m Granit

Profil J-K:

Bohrung Nr. 44. (D. G. U. 246, 52).

Moräne

Bei $4.0 \mathrm{~m}$ Ton in verschiedenen Farben

" $50.0 \mathrm{~m}$ Kaolinhaltiger Sand

" $51.25 \mathrm{~m}$ Ton (richtiger: toniger Sand)

» $53.5 \mathrm{~m}$ wasserführender Sand von mittlerer Krongrösse mit Kohlestückchen

" $64.0 \mathrm{~m}$ sandiger Kaolin. (Unsortierter Granitgrus).

" $72.0 \mathrm{~m}$ steiniger Sand (d. h. grober Granitgrus)

" $74.0 \mathrm{~m}$ feiner, mit Ton untermischter Sand (d. h. fein zerteilter Granitgrus)

" $82.0 \mathrm{~m}$ Fels. Ende der Bohrung

Bohrung Nr. 45.(D. G. U. 246,53).

Moräne

Bei $3.3 \mathrm{~m}$ grünlicher, fetter Ton

" $4.4 \mathrm{~m}$ schwarzer, fetter Ton

" $8.0 \mathrm{~m}$ gräulicher, fetter Ton

» $13.0 \mathrm{~m}$ rötlicher, fetter Ton

" $14.0 \mathrm{~m}$ grünlicher, fetter Ton

" $29.0 \mathrm{~m}$ gelblichgrüner, fetter Ton

" $39.8 \mathrm{~m}$ sehr harte Sandschicht 
Bei $40.1 \mathrm{~m}$ sandiger Ton

" $43.0 \mathrm{~m}$ feiner, kaolinhaltiger Sand ${ }^{1}$ )

" $46.0 \mathrm{~m}$ gräulicher, mittelgrober, etwas kaolinhaltiger Sand ${ }^{2}$ )

" $50.5 \mathrm{~m}$ Granit. Ende der Bohrung.

In den Bohrjournalen wird der Sand öfters als kaolinhaltig bezeichnet, stellenweise sogar als »sandiger Kaolin«. Bei der Entnahme der Bohrproben bei den Spülbohrungen ist der Kaolin aber so gut wie vollständig verloren gegangen. Im übrigen zeigen die Proben, dass der Sand aus wechsellagernden gröberen und feineren Schichten besteht, während innerhalb der einzelnen Schichten die Korngrösse recht gleichmässig ist. Der grösste Teil der Sandschicht besteht fast ausschliesslich aus Quarz, während Feldspat nur selten angetroffen wird. Die Körner sind in der Regel mehr oder weniger abgerollt und mattgeschliffen, was davon zeugt, dass der Sand über eine gewisse, jedoch keinesfalls längere Strecke transportiert worden ist. In zwei der Bohrungen fanden sich Kohlefragmente in $55-60 \mathrm{~m}$ Teufe. In den drei tiefsten Bohrungen, Nr. 43, 44 und 46, wurde dagegen im Liegenden unsortierter, scharfkantiger, ganz sicher nicht umgelagerter Granitgrus erbohrt. Ausser Quarz enthielt dieser Grus etwas verwitterten Feldspat in bedeutender Menge, sowie andere Gemengteile des Granits. In der Bohrung Nr. 44 ( $\mathrm{J}$ auf Fig. 44) enthielt der Grus reichlich grünen Biotit und vollkommen frische Erzkörner, was insofern bemerkenswert ist, als die Erzkörner im Kaolin stets eine leukoxenartige Rinde aufweisen. Das Bohrjournal gibt an, dass die obersten $8 \mathrm{~m}$ des Granitgruses kaolinhaltig waren. Darunter folgte eine Schicht groben Granitgruses und zu unterst, unmittelbar im Hangenden des festen Felsgrundes, ein bedeutend feinerer Grus. In allen Proben fanden sich Spuren von Kaolin. Der Granitgrus in Bohrung Nr. 43 hatte ungefähr dieselbe Beschaffenheit, es fehlte aber der Biotit, und die Erzkörner hatten eine rostige Rinde.

Unter der Sandschicht wurde der Granit in 6 Bohrungen erbohrt. Proben hiervon liegen jedoch nicht vor, da der Granit so hart war, dass die Bohrungen nicht fortgesetzt werden konnten. Man findet in den Journalen den Vermerk, dass Sprengungen ergebnislos bleiben, da hierdurch nur kleinere Platten gelockert werden konnten. Kaolinisierten oder zersetzten Granit gibt es also nicht unterhalb der Teufe, welche die Bohrungen erreichten.

Die untersuchten Proben zeigen also, dass die Sandschicht zwischen dem fetten Ton und dem granitischen Untergrund in Byvangen nicht mit der Sandschicht zu parallelisieren ist, welche sich in den alten Gruben

1) In Wirklichkeit Quarzsand von recht ungleichmässiger Korngrösse. Die Körner deutlich abgerollt.

2) Gröberer Quarzsand mit einzelnen Feldspatkörnern. Korngrösse gleichmässiger, Körner deutlich abgerollt. 
zwischen dem grauen Ton und dem Kaolin fand. Dieser letztgenannte Sand ist als eine Residualbildung des Kaolins aufzufassen. Die Sandschicht in Byvangen ist dagegen von dem höher gelegenen Gebiet eingespült worden. Man muss daher annehmen, dass auch der Kaolingehalt dieses Sandes den höher liegenden Kaolinlagern entstammt.

Es ist nun die Frage, ob die Granitoberfläche in Byvangen bereits kaolinisiert war, als der Sand zur Ablagerung kam. In einem grossen Teil des Gebiets ist jedenfalls keine Spur einer solchen Kaolinisierung nachweisbar, denn in den Bohrungen Nr. 40, 41, 42 und 45 fand man den festen Fels unmittelbar unter der eingeschwemmten Sandschicht, deren Körner deutlich abgerollt und sortiert waren. Der Granit lag an diesen Stellen 31.5, bezw. 18.5, 31.5 und $36 \mathrm{~m}$ unter dem Meeresspiegel. Der unsortierte Granitgrus unter der Sandschicht wurde in den drei nordwestlichsten Bohrungen Nr. 43, 44 und 46 angetroffen. Von diesen erreichte Nr. 43 nicht den festen Granit, Nr. 44 traf auf Fels bei $68.5 \mathrm{~m}$ und Nr. 46 bei $55 \mathrm{~m}$ unter dem Meeresspiegel. Dieser Granitgrus muss als zersetzter Fels angesehen werden. Vermutlich war er bis zu einem gewissen Grade kaolinisiert, als der darüber liegende Sand zur Ablagerung kam, aber die Anwesenheit von reichlichem Feldspat zeigt doch, dass die Kaolinisierung nicht besonders fortgeschritten und auch nicht sehr tiefgehend gewesen sein kann. Es scheint mir daher unrichtig zu sein, Byvangen in das Kaolingebiet einzubeziehen, umsomehr als ein Teil des Kaolingehaltes im Granitgrus möglicherweise eingeschwemmtes Material ist $^{1}$.

Unsere augenblicklichen Kenntnisse von dem Vorkommen und der Verbreitung des Kaolins kann somit folgendermassen zusammengefasst werden: Der Kaolin lagert in einer schmalen Zone längs des Granitrandes. Er bildet kein zusammenhängendes Lager, sondern tritt in mehreren Becken auf, die von einander durch aufragende Granitrücken mehr oder weniger wohl geschieden sind. Im östlichen Teil der Kaolinzone sind die Becken durchgehend flach und schalenförmig; im westlichen Teil des Gebiets hat der Kaolin eine grössere Mächtigkeit und auch sein Hangendes wird mächtiger. Die maximale Mächtigkeit des Kaolins ist unbekannt, aber sowohl der Abbau wie die Bohrungen zeigen, dass der Kaolin im grössten Teil des Gebiets nach unten zu mager wird.

1) In einer kürzlich erschienenen Arbeit: Beiträge zur Stratigraphie, Tektonik und Paläogeographie des südbaltischen Rhät-Lias, insbesondere auf Bornholm, (Abh. a. d. geol.-paläont. Inst. d. Univ. Greifswald, XII, 1933) hat R. HöHNE das Kaolinvorkommen bei Rönne kurz besprochen (p. 29 -30). HöHNe meint, dass die Bohrungen in Byvangen gezeigt haben, dass das Kaolinlager sich über dieses Areal hinaus erstreckt und also eine grössere Ausdehnung nach Westen hin hat, als bisher angenommen. Wie aus dem oben Gesagten zu entnehmen ist, muss Herrn HöHNE's Auffassung auf einer Misdeutung dieser Bohrungen beruhen. 
Oft bleiben die Bohrungen in Granitgrus mit geringem Kaolingehalt stecken und merere Bohrungen sind im Liegenden dieses Granitgruses auf den Felsgrund gestossen.

Die grösste Mächtigkeit des Kaolins ist im Tagebau des Rabekkewerks nachgewiesen worden, wo bis $48 \mathrm{~m}$ durch weissen Kaolin gebohrt wurde, ohne das Liegende zu erreichen. Es ist zweifelhaft, ob der Kaolin an allen Stellen des Tagebaus diese Mächtigkeit erreicht hat, da dieser jetzt aufgelassen ist, ohne dass ein Abbau, soweit bekannt, in so grosser Tiefe vorgenommen worden ist. Dagegen kann man annehmen, dass die Grenze für den guten Kaolin an den Seiten des Tagebaus erreicht worden ist. In diesem Zusammenhang ist die tiefe Bohrung a (siehe p. 204 - 206) südlich vom Tagebau des Rabekkewerks von Interesse. Grönwall hat sicher die spärlichen Angaben des Bohrjournals vollständig richtig gedeutet, wenn er annimmt, dass hier ein verhältnismässig wenig umgewandelter Granit erbohrt worden ist. Ueber die untersten $37.7 \mathrm{~m}$ weiss man nur, dass das Material sandig war. Darüber lagen $40.8 \mathrm{~m}$ "grauer, mit Sand gemischter Kaolin«. Diese Bezeichnung findet in den Bohrjournalen gewöhnlich auf die untersten Schichten des Kaolins Anwendung, wenn diese reichlich unverwittertes Granitmaterial enthalten. Die Bohrung bestätigt also, dass der gute Kaolin im Tagebau des Rabekkewerks keine Fortsetzung nach Süden findet. Sie zeigt weiterhin, dass der Granit hier bis zu einer ungewöhnlichen Tiefe locker und bröckelig ist. Da im grossen und ganzen der Felsgrund in diesem Gebiet ziemlich stark zerklüftet ist, so ist es wahrscheinlich, dass diese Bohrung an einer Stelle angesetzt ist, wo der Granit an einer Kluft umgewandelt ist. Am Nordende des Kaolinfeldes liegen die Verhältnisse ähnlich. Beim Tornewerk (siehe Fig. 43) wird der Kaolin nach unten zu durch eine Zone von teilweise kaolinisiertem Granit begrenzt. In den Bohrungen zwischen dem Tagebau und Store Almegaard fand sich ein schwach kaolinhaltiger Granitgrus, welcher anscheinend dem in Bohrung a gefundenen Material gleichgestellt werden kann.

Zwischen dem Tornewerk und dem Rabekkewerk kann eine Westgrenze des Kaolinvorkommens nicht mit Sicherheit festgelegt werden. Die beiden Bohrungen (Nr. 17 und 18), in denen bei Rosvang der Felsgrund unmittelbar unter der Moräne angetroffen wurde, sowie die Resultate der Bohrungen in Byvangen deuten jedoch darauf hin, dass das Kaolingebiet sich nicht bedeutend weiter nach Westen erstreckt als es auf der Karte Fig. 39 angegeben worden ist.

Es scheint also, dass das Kaolinvorkommen auf eine schmale, langgestreckte Zone beschränkt ist, welche am Westhang des Granitgrundgebirges liegt, und zwar in einem höheren Niveau als der westlich davon gelegene Teil des Granits, in dem bisher keine wesentliche Kaolinisierung sich hat nachweisen lassen. Die Tatsache, dass diese Zone in der Ver- 
längerung des Granithorstes zwischen Hasle und Rönne liegt, legt den Gedanken nahe, dass die Vertiefungen, in denen der Kaolin angetroffen wird, ihre Entstehung einem System von Verwerfungen im Granit ver-

- danken. Diese Vermutung findet darin eine Stütze, dass der Kaolin im Tagebau des Rabekkewerks sich in eine Tiefe von mindestens $40 \mathrm{~m}$ unter dem Meeresspiegel erstreckt, während die unverwitterte Granitoberfläche in der östlichsten Bohrung (Nr.41) von Byvangen $20 \mathrm{~m}$ unter dem Meeresspiegel angetroffen wurde. Dieses könnte jedenfalls darauf hindeuten, dass das Kaolingebiet nach Westen zu von einem Granitrücken begrenzt wird. Von diesem Gesichtspunkt aus könnte man die Erwartung hegen, dass sich ähnliche Kaolinzonen längs westlicher gelegener Verwerfungen finden lassen könnten. Jedoch würden solche Vorkommen, wenn sie gefunden würden, wohl kaum eine praktische Bedeutung erlangen, da man annehmen kann, dass die Granitoberfläche nach Westen zu von bedeutenden Massen von lockeren Erdschichten bedeckt ist.

\section{Mineralbestand und chemische Zusammensetzung des Kaolins.}

Die Gemengteile des Kaolins. Während der geschlämmte Kaolin ein blendend weisses Pulver ist, das nur sehr wenig Verunreinigungen enthält, im wesentlichen kleine Quarzkörner und dunkle undurchsichtige Partikeln, ist der Rohkaolin im allgemeinen eine lockere, grauweisse Masse, die sich infolge des Quarzgehalts etwas scharf in der Hand anfühlt. Die nähere Untersuchung hat festgestellt, dass der weit überwiegende Teil der nicht umgewandelten Granitreste aus Quarz besteht.

Die Hauptmenge des Rohkaolins, etwa $60 \%$, besteht aus Kaolin in Blättchen oder schuppigen Aggregaten, die einen Durchmesser von 2-3 mm erreichen können, doch in den meisten Fällen unter 0,2 $\mathrm{mm}$ bleiben. Sie enthalten einige dunkle, undurchsichtige Partikeln und öfters kleine Quarzkörner. Die Doppelbrechung ist sehr schwach, die Interferenzfarbe kommt nie über Grau I. Ordnung hinaus. Die Lichtbrechung liegt zwischen 1,55 (Anisöl) und 1,58 (Anilin). Ganz kleine Körner zeigen ausgezeichnete glimmerähnliche Spaltbarkeit. Ausserdem beobachtet man einige kleine buschige oder stenglige Aggregate mit etwas höherer Lichtbrechung und Doppelbrechung als die der Kaolinschuppen; diese Gemengteile scheinen Reste von Biotit zu sein. Der Quarzgehalt macht etwa 35\% des Rohkaolins aus.

Zur näheren Bestimmung der untergeordneten Gemengteile im Rohkaolin wurden diese durch Schlämmung und darauf folgende Separation der schwereren Gemengteile mittels Bromoform in HaRADA's Trichter konzentriert. Hierdurch wurde ausser dem Kaolin der grösste Teil des Quarzes und die vorhandene geringe Menge von Feldspat (Mikroklin) entfernt. $100 \mathrm{~g}$ des analysierten Rohkaolins (siehe unten p. 224) aus der Grube des Tornewerks ergaben hierbei etwa $1 \mathrm{~g}$ Rückstand in Bromo- 
form. Auf dieselbe Weise wurde 1,7 g Rückstand in Bromoform von einer Probe von $50 \mathrm{~g}$, die aus der Mitte der Schlämmrinne im Buskewerk genommen war, gewonnen. Der Mineralbestand der beiden auf diese Weise erzeugten Konzentrate stimmte vollkommen überein. Von leich- . teren Gemengteilen waren noch ein wenig Quarz sowie einzelne Mikroklinkörner und Kaolinschuppen übrig, von einer weiteren Reinigung wurde jedoch abgesehen, da ja nur eine Isolierung der schwereren Mineralien in einer für eine mikroskopische Untersuchung genügenden Menge bezweckt war.

Zur Unterscheidung der Mineralien in einer pulverförmigen Mischung ist in erster Reihe eine Bestimmung der Lichtbrechung von wesentlicher Bedeutung. Hierzu wurden eine Serie von Flüssigkeiten mit bekannten Brechungsexponenten benutzt, und speziell wurden stark brechende Lösungen von Phosphor in Methylenjodid hergestellt. Diese Lösungen, die ziemlich unbeständig sind, wurden während der Arbeit mehrmals mittels Mineralien mit bekannten Brechungsindices kontrolliert; im folgenden werden sie als Lösung A und B bezeichnet:

Lösung A mit Brechungsexponent $\mathrm{n}_{\mathrm{A}}: 1,931<\mathrm{n}_{\mathrm{A}}<1,993$; die angeführten Indices sind $\omega$ bezw. $\varepsilon$ für Zirkon von Miask, der als Kontrolle für diese Lösung benutzt wurde.

Lösung B mit Brechungsexponent $\mathrm{n}_{\mathrm{B}}: 1,997<\mathrm{n}_{\mathrm{B}}<2,093$; die angegeben Indices sind $\omega$ und $\varepsilon$ für Zinnstein aus Schlaggenwald, der zur Einstellung der Flüssigkeit benutzt wurde.

Der grösste Teil der schweren Gemengteile besteht aus dunklen, undurchsichtigen Körnern, von denen nur wenige Metallglanz haben; nur äusserst wenige lassen sich mit einem Magneten extrahieren. Die frischen Erzkörner sind daher wahrseheinlich Titaneisen oder titanhaltiger Magnetit. Die allermeisten der dunklen Körner dagegen haben einen grauen oder graubraunen Ueberzug. Am Rande können sie ein wenig durchscheinend sein und zeigen in diesem Fall hohe Interferenzfarben. Die Lichtbrechung ist hoch, ungefähr wie die des Zirkons. Beim Glühen auf Platinblech werden die Körner gelbbraun, sie sind danach nicht magnetisch, geben aber eine schöne Titanreaktion in der Phosphorsalzperle. Sie bestehen somit aus Titanit (Leukoxen) und sind sicher zum grössten Teil aus den Erzkörnern des Granits entstanden, von denen noch eingeschlossene Ueberreste hie und da gefunden werden. Ferner traten einzelne Körner mit einem Ueberzug von einer rötlicheren Farbe auf, welcher sicher von Ferrihydroxyden herrührt, und schliesslich fanden sich noch einige wenige rotbraune hämatitähnliche Schuppen mit höherer Lichtbrechung als die der Lösung B.

Eisenkies tritt in kleinen Würfeln, Oktaedern oder unregelmässigen Körnern auf, ist aber doch im allgemeinen nur spärlich vertreten. 
Zirk on bildet die Hauptmasse von Kristallen mit hoher Lichtbrechung und hoher Doppelbrechung. Mittels der positiven Doppelbrechung und der Lichtbrechung: $\omega<\mathrm{n}_{\mathrm{A}}<\varepsilon$ konnten die Kristalle mit vollkommener Sicherheit bestimmt werden. Flüssigkeitsinterpositionen sind oft und Spaltrisse nach (110) manchmal vorhanden.

Rutil kommt viel seltener als Zirkon vor. Die Kristalle sind meistens wohl ausgebildet, bräunlich oder rotbraun; beide Brechungsindices sind wesentlich höher als $n_{B}$. Der positive Charakter der Doppelbrechung konnte bestimmt werden.

Anatas kommt vor, wenn auch sehr spärlich. Die Kristalle sind als tetragonale Pyramiden mit Basis entwickelt; die Doppelbrechung ist sehr hoch, negativ; die Lichtbrechung grösser als $n_{B}$. Die Farbe ist bräunlich. Auf der Basis sieht man Spaltrisse nach (111).

Eisenspat ist im allgemeinen recht spärlich vorhanden, kommt aber doch vor und zwar teils in Form kleiner gelblicher oder beinahe farbloser Rhomboeder, teils in Form kleiner abgerundeter Körner, in denen Spaltrisse meistens erkennbar sind.

Glimmer tritt selten auf und dann nur in kleinen Körnern. Muskovit unterscheidet sich durch seine höhere Lichtbrechung und durch sein deutliches Achsenbild in konvergentem Lichte $\left(2 \mathrm{E}=\right.$ ca. $\left.70^{\circ}\right)$ von den Kaolinschuppen. Biotit ist in Form einzelner hellbrauner, ziemlich frischer Körner vorhanden, deren Lichtbrechung etwas unter 1,58 (Anilin) war. In konvergentem Lichte zeigten sie ein einachsiges negatives Achsenbild.

Schliesslich traten noch einzelne Körner eines ganz klaren, farblosen, isotropen Minerals auf, dessen Lichtbrechung höher war als $\mathrm{n}_{\mathrm{B}}$. Das Mineral scheint oktaederähnliche Spaltbarkeit zu haben, ist vermutlich ein Spinell, eine genauere Bestimmung war jedoch nicht möglich.

Von den hier genannten Mineralien sind ausser dem Kaolin selber nur Leukoxen, Rutil, Anatas und Eisenspat als dem Granit fremd zu betrachten. Zum Vergleich wurde in derselben Weise ein Konzentrat der schweren Mineralien des Rönnegranit untersucht. In diesem Pulver wurde ein einzelnes Korn des soeben genannten stark lichtbrechenden, isotropen Minerals mit Oktaederspaltbarkeit gefunden. Von den übrigen Gemengteilen des Granits fehlen Hornblende und Apatit vollständig im Kaolin, und Titanit, der im Granit in Form von frischen, gelbbraunen Körnern auftrit, wurde im Kaolin nur in der Gestalt von Leukoxen gefunden.

Früher hat H. RösLeR ${ }^{1}$ ) Bestimmungen der Mineralien in Kaolinproben aus den Gruben des Rabekkewerks und des Buskewerks vorgenommen, und er gelangte dabei zu Resultaten, die einigermassen von

1) H. Rösler: Beiträge zur Kenntnis einiger Kaolinlagerstätten. N. JB. B. B. Bd. 15. 1902. p. $329-332$. 
den oben angeführten abweichen. Ausser den von mir gefundenen Mineralien nennt Röscer Hussakit, Andalusit, Sillimanit und Topas. Hiervon beruht die Angabe von Hussakit auf einer irrtümlichen Bestimmung, indem RösLER meinte, dies Mineral durch eine höhere Interferenzfarbe von Zirkon unterscheiden zu können. Dies Unterscheidungsmerkmal ist jedoch unzulänglich, da der Unterschied in der Doppelbrechung nur gering ist. Schon bei der Untersuchung eines Pulverpräparats in Methylenjodid stellt es sich heraus, dass diejenigen Kristalle, die für Hussakit angesehen werden könnten, in allen Lagen eine höhere Lichtbrechung als die der Flüssigkeit $(1,74)$ haben, während Hussakit $(\omega=1,721$, $\varepsilon=1,816)$ in einigen Fällen eine niedrigere Lichtbrechung zeigen müsste. Mittels Lösung A $\left(1,931<\mathrm{n}_{\mathrm{A}}<1,993\right)$ konnte leicht festgestellt werden, dass sämtliche in Frage kommende Mineralien Zirkon waren. Hussakit wurde überhaupt nicht im Kaolin beobachtet. — Selbstverständlich habe ich ebenfalls sehr sorgfältig nach Andalusit, Sillimanit und Topas gefahndet, jedoch umsonst.

Chemische Zusammensetzung des Kaolins. Die chemische Zusammensetzung des Rohkaolins geht aus folgender Analyse hervor. Zum Vergleich werden zwei Analysen von Rönne Granit angeführt.

\begin{tabular}{|c|c|c|c|c|c|}
\hline & A & B & I & $\begin{array}{l}\text { Mineralbestand } \\
\text { des Rohkaolins }\end{array}$ & $\%$ \\
\hline $\mathrm{SiO}_{2} \ldots \ldots \ldots \ldots$ & 64,49 & 64,39 & 64,99 & \multirow{15}{*}{ 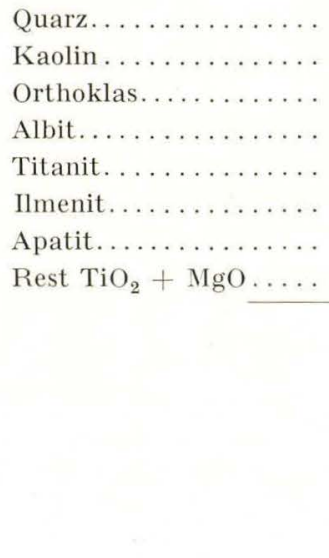 } & 35,3 \\
\hline $\mathrm{TiO}_{2} \ldots \ldots \ldots \ldots$ & 1,22 & 0,28 & 1,96 & & 58,1 \\
\hline $\mathrm{Al}_{2} \mathrm{O}_{3} \ldots \ldots \ldots \ldots$ & 13,67 & 14,32 & 23,67 & & 2,3 \\
\hline $\mathrm{Fe}_{2} \mathrm{O}_{3} \ldots \ldots \ldots \ldots$ & 1,63 & 7,85 & 0.35 & & 1,5 \\
\hline $\mathrm{FeO} \ldots \ldots \ldots \ldots$ & 4,42 & 一 & - & & 0,7 \\
\hline $\operatorname{MnO} \ldots \ldots \ldots \ldots$ & 0.14 & 0,00 & - & & 0,7 \\
\hline $\operatorname{MgO} \ldots \ldots \ldots \ldots$ & 1,38 & 1,12 & 0,02 & & 0,1 \\
\hline $\mathrm{CaO} \ldots \ldots \ldots \ldots \ldots$ & 3,12 & 3,53 & 0,27 & & 1,3 \\
\hline $\mathrm{Na}_{2} \mathrm{O} \ldots \ldots \ldots \ldots$ & 3,57 & 3,64 & 0,18 & & 100,0 \\
\hline $\mathrm{K}_{2} \mathrm{O} \ldots \ldots \ldots \ldots$ & 4,40 & 4,40 & 0,39 & & \\
\hline $\mathrm{P}_{2} \mathrm{O}_{5} \ldots \ldots \ldots \ldots$ & 0,58 & - & 0,05 & & \\
\hline $\mathrm{H}_{2} \mathrm{O}$ über $110^{\circ} \ldots \ldots$ & 1,11 & & & & \\
\hline $\mathrm{H}_{2} \mathrm{O}$ unter $110^{\circ} \ldots \ldots$ & 0,46 & & & & \\
\hline \multirow[t]{2}{*}{ Glühverlust ....... } & & 0,13 & 7,97 & & \\
\hline & 100,19 & 100,66 & 99,85 & & \\
\hline
\end{tabular}
A. Rönne Granit. Anal. M. Ditrrich.
B. Rönne Granit. Anal. C. Detreffsen.
I. Rohkaolin, Tornewerk. Anal. C. Detlefsen.

Bei der Berechnung des Mineralbestands des Kaolins ist der ganze Eisengehalt der Analyse in $\mathrm{FeO}$ umgerechnet und zu Titaneisen gerechnet, und der CaO-Gehalt ist zu Apatit und Titanit gerechnet. Nichtsdesto- 
weniger zeigt die Analyse einen Ueberschuss an $\mathrm{TiO}_{2}$, der viel zu gross ist, um dem äusserst spärlichen Gehalt von Rutil im Kaolin zugeschrieben werden zu können. Möglicherweise liegen hier Titanhydrate vor, wie es H. Harrassowitz ${ }^{1}$ ) in Bezug auf Laterit annimmt. Er sagt hierüber: "Titanhydrate scheinen ebenfalls als Kolloide eine Rolle zu spielen, obgleich man sie nicht mineralogisch feststellen kann. In Lateriten, die keine Spur von Ilmenit enthalten, stellt man in der sauren Lösung Titan fest, das als $\mathrm{TiO}_{2}, \mathrm{H}_{2} \mathrm{O}$ angenommen wird «.

Der Vollständigkeit halber and zur Darstellung der variierenden Zusammensetzung des Kaolins werden noch zwei Analysen, die mir von Herrn Direktor Viggo NieLsen freundlichst überlassen wurden, angeführt:

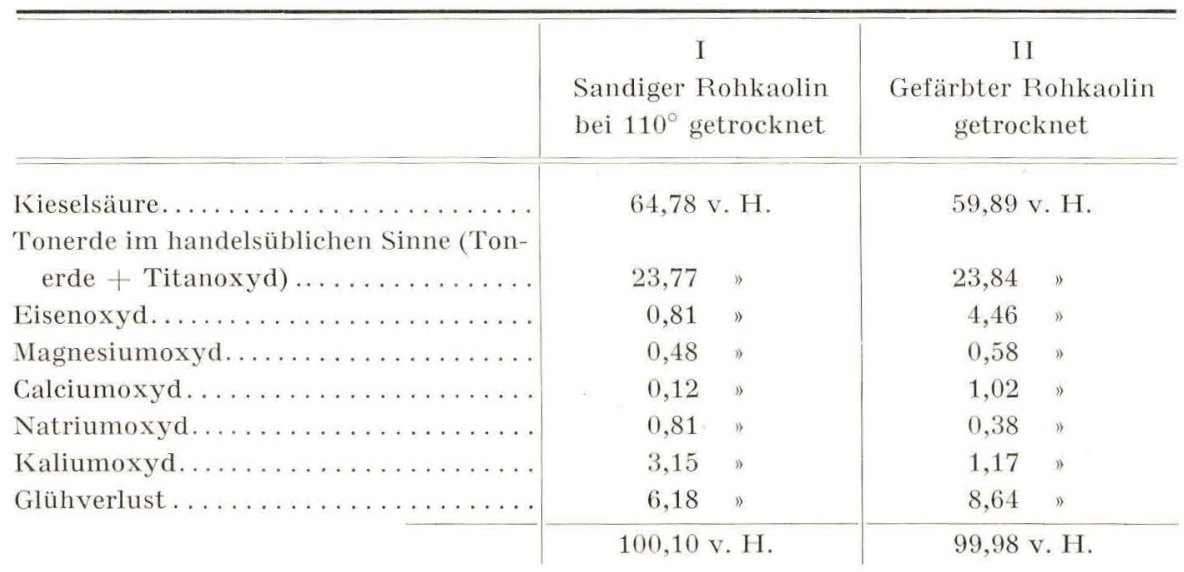

I-II. Rohkaolin, Bornholm. Anal. Chemisches Laboratorium für Tonindustrie, Berlin 1927.

Untergeordnete Bildungen im Kaolin. Wie oben erwähnt besteht der Kaolin bei Rönne nicht aus einer vollständig gleichartigen Masse. Hie und da sind rötliche oder gelbliche Partien vorhanden; besonders scheint dies an der Oberfläche der Fall zu sein. Die Farbe rührt von Ferriverbindungen her, welche teils in kleinen undurchsichtigen Körnern vorkommen, teils einen Ueberzug auf den meisten der Körner, besonders auf den Quarzkörnern, bilden; manchmal ist der Ueberzug in feinen Rissen des Kaolins ausgeschieden. Im übrigen ist der Mineralbestand, soweit sich dieser trotz den Verunreinigungen bestimmen lässt, derselbe wie in der Hauptmasse des Kaolins. Von ähnlicher Beschaffenheit ist eine Kaolinprobe, die 1882 von Johnstrup bei Kanegaard an der SO-Grenze des Kaolingebiets genommen wurde.

1) H. Harrassowitz: Laterit. Fortschritte der Geologie und Palaeontologie, herausgegeb. von Prof. Dr. W. Soergel. Bd. IV. Heft 14. 1926. p. 330.

Danmarks geologiske Undersøgelse. II. R. Nr. 50. 
Der aus den Diabasgängen entstandene Kaolin ist in der Regel etwas gefärbt, gelblich, rötlich oder grünlich, seltener ist er ganz weiss (Fig. 45). Gewöhnlich bildet er eine recht zähe und einigermassen zusammenhängende Masse, die sich sehr glatt anfühlt. Quarz fehlt, Zirkon,

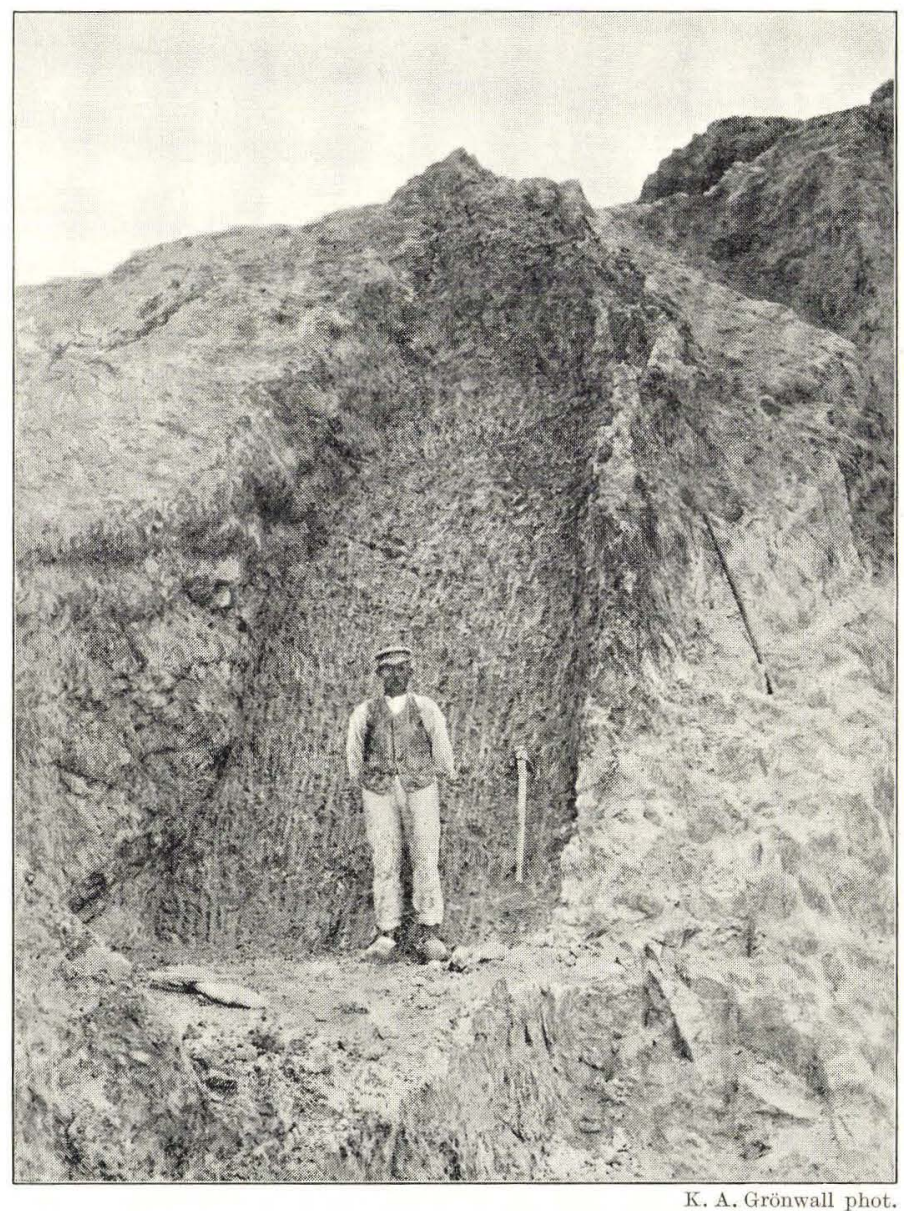

Fig. 45. Diabasgang im Kaolin. Tagebau des Tornewerks.

Rutil und Anatas wurden nicht gefunden und Eisenspat nur in geringer Menge. Die Kaolinschuppen sind durchschnittlich von wesentlich kleineren Dimensionen als diejenigen im Granitkaolin, und Hydrargillitähnliche Aggregate sind reichlich vorhanden. In den grünlichen Varietäten kommt ein nicht unwesentlicher Gehalt von Chlorit sowie von etwas braunem oder braungrünem Biotit hinzu. Die gefärbten Varietäten enthalten überhaupt ziemlich viele undurchsichtige, dunkle Partikelchen, wogegen frische Erzkörner selten sind. Im rötlichen Diabaskaolin sind die Körner von rotbraunen Ferrihydroxyden, die einen gelb- 
lichen, etwas durchscheinenden dünnen Ueberzug bilden, stark getrübt.

In den Pegmatitgängen ist oft verhältnismässig viel nicht umgewandelter Feldspat übrig geblieben. Die grossen Mikroklinindividuen sind sehr widerstandsfähig gewesen, hie und da findet man zusammenhängende, aber durchlöcherte Ueberreste von etwa $10 \mathrm{~cm}$ Durchmesser. Die Löcher sind mit einer fetten, weissen oder schwach gelblichen Kaolinmasse angefüllt. Manchmal sind in dieser Masse zahllose winzige gelbe Körper eines stark lichtbrechenden Minerals mit hoher Doppelbrechung ausgeschieden. Die Körper sind in warmer Salzsäure löslich und bestehen wahrscheinlich aus Eisenspat.

Ferner wurden unter den aus dem Kaolin ausgeschlämmten Steinen einige Konkretionsbildungen gefunden. Johnstrup hat $1882 \mathrm{im}$ Abraum des Buskewerks einige unregelmässige Konkretionen gesammelt, die etwa so gross wie Hasel- oder Walnüsse waren. Sie bestehen hauptsächlich aus zusammengekitteten kleinen, ein wenig abgerundeten Quarzfragmenten, aus einer geringeren Menge von unfrischen Feldspat- und Erzkörnern sowie ein wenig Zirkon. Das Bindemittel besteht wesentlich aus Fe-Mg-Karbonat; es löst sich langsam in kalter Salzsäure und gibt eine schwache Ca- und Mn-Reaktion. Im unlöslichen Rückstand fand sich eine recht beträchtliche Menge von ganz weissem und sehr feinem Kaolin. Im Dünnschliff wurde neugebildeter Quarz als Spaltenfüllung in einer derartigen Konkretion beobachtet.

Eine andere Art von Konkretionen besteht aus Hornstein oder aus jaspisähnlichen rötlichen Klumpen, deren Farbe von einem rotbraunen, limonitischen Pigment herrührt. In der äusserst feinkörnigen Grundmasse sind Quarzkörner und einzelne Zirkonkristalle eingeschlossen. Kaolinschuppen lassen sich nicht direkt wahrnehmen, wahrscheinlich weil sie vom Pigment bedeckt sind. Dagegen enthalten sie einige von Kaolin und Quarzkörnern oder dunklen Partikelchen angefüllte Hohlräume. Diese Konkretionen, deren Form sehr unregelmässig ist, sind zweifellos dadurch entstanden, dass sich die durch die Kaolinisierung frei gewordene Kieselsäure im Kaolin als Bindemittel ausgeschieden hat. Aehnliche Bildungen wurden auch von RoESLER ${ }^{1}$ ) beobachtet.

Im Mineralogischen Museum werden Proben von »dem sogenannten schwarzen Kaolin dicht neben dem Stollen« in der Grube vom Rabekkegaard aufbewahrt. Dieser Kaolin rührt offenbar von einer weniger vollständig umgewandelten Granitpartie her, denn er enthält relativ viele frische Mikroklinkörner; schätzungsweise ist der Mikroklin hier in einer ungefähr gleich grossen Menge wie die Kaolinschuppen vorhanden. Frische Erzkörner dagegen treten selten auf, die meisten sind mit dem gewöhnlichen rotbraunen Ueberzug bekleidet, und der Gehalt an dunklen Partikelchen ist in diesen Proben überhaupt ziemlich gross.

$\left.{ }^{1}\right)$ N. JB. B. B. 15, 1902. pag. 330. 
Die untere Grenze des Kaolins und der Uebergang zum frischen Granit.

Wie oben (p. 199) gesagt, wurden hie und da im Kaolin einige grosse, beinahe kugelrunde Granitklumpen gefunden (Fig. 46). Sie werden schon von Rawert und Garlieb ${ }^{1}$ ) erwähnt, und später wurden dann und wann einige derartige Blöcke beim Kaolinabbau blossgelegt, die meisten jedoch halbverwittert. Im Jahre 1899 fand Ussivg ${ }^{2}$ ) in der damals

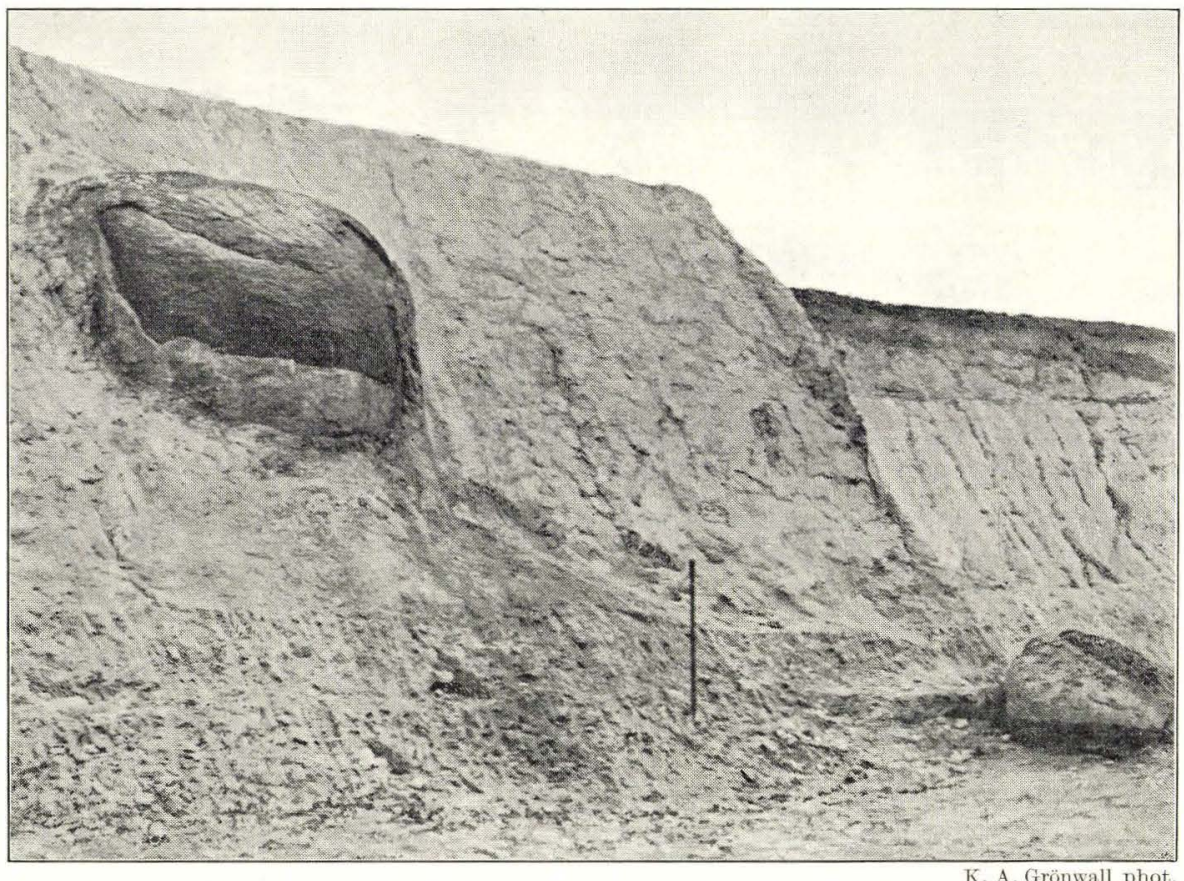

Fig. 46. Granitblock im Kaolin. Tagebau des Tornewerks. In der Mitte des Bildes ein Spatenstiel von ca. $1 \mathrm{~m}$ Länge.

kürzlich erschlossenen Tornegaards-Grube eine grössere Anzahl derartiger Blöcke. Sie hatten einen Durchmesser von $2-3 \mathrm{~m}$ und bestanden im Innern aus ganz frischem Rönne-Granit. Nach aussen zu bröckelte das halbkaolinisierte Gestein in konzentrischen Schalen ab, und schöne Uebergänge zwischen ganz und halb umgewandeltem Granit wurden beobachtet $\left.^{3}\right)$.

Im Sommer 1928 hatte ich Gelegenheit, eine Serie Proben von dem teilweise umgewandèlten Granit, welcher das Nebengestein des Kaolins

1) Rawert og Garlieb. Bornholm beskreven paa en Reise i Aaret 1815. Kjöbenhavn 1819, p. 161.

2) D. G. U. II. R. Nr. 12, 1902, p. 64 65; Kartenblatterläuterung, D. G. U. I. R. Nr. 13, 1916, p. 28.

${ }^{3}$ ) Dies geht aus Ussing's Tagebuch, 1899, p. 18, hervor. 
in der Ostwand der Buskewerksgrube bildet, einzusammeln. Das Kluftsystem des Granits war hier sehr deutlich, und namentlich waren die saigeren Klüfte ausgeprägt und etwas klaffend, sowie ziemlich stark wasserführend. Die frischesten Proben vom östlichsten Teil der Uebergangszone sind ziemlich fest, und in trockenem Zustande graugrün und ziemlich hell. Näher dem Kaolin zu war der Granit stärker umgewandelt, heller und etwas rötlich gefärbt, und die Spalten waren hier weniger deutlich. Nirgends fand ich Spuren von konzentrischer Abschälung wie es an den Granitüberresten in der Tornewerksgrube beobachtet wurde.

In den vorliegenden Proben von teilweise kaolinisiertem Granit ist es möglich, den Verlauf der Kaolinisierung bis zu einem gewissen Grade $\mathrm{zu}$ verfolgen. Gemeinsam für sämtliche Proben ist, dass die ursprünglichen Verwachsungen von Mikroklin und Quarz noch vollkommen, oder jedenfalls meistens, erhalten sind, was das Gestein so fest und zusammenhängend macht, dass sich Dünnschliffe aus demselben herstellen lassen. In den frischesten Proben ist der Mikroklin ebenso frisch wie gewöhnlich im Rönne-Granit; in den am stärksten umgewandelten Proben ist der Mikroklin nur in geringem Masse getrübt worden, und die Umwandlung geht dann von den perthitisch eingelagerten Albitschnüren aus. Der Plagioklas ist in den frischesten Proben etwas getrübt; seine Umwandlung besteht wesentlich in der Ausscheidung von zahlreichen kleinen Muskovitschuppen; gewöhnlich werden Zwillingslamellen beobachtet. Bei fortschreitender Umwandlung werden zuerst die zentralen Teile des Plagioklas angegriffen, während der vorhandene Albitrand sich am längsten hält.

Von den Mineralien im Granit wird die Hornblende zuerst und am stärksten angegriffen. Selbst in den am besten erhaltenen Proben ist die Hornblende in schmutzig-grüne oder gelbgrüne serpentinähnliche Pseudomorphosen umgewandelt. Die Pseudomorphosen nehmen den Platz der Hornblende ein, so dass man deutlich die für den Rönne Granit charakteristischen unregelmässigen Komplexe von Hornblende mit angewachsenen Biotitläppchen und eingeschlossenen Apatitkristallen sowie kleinen Quarzkörnern wiedererkennt. Die Pseudomorphosen bestehen aus einem feinschuppigen oder faserigen, manchmal ein wenig pleochroitischen Serpentinaggregat, dessen Lichtbrechung grösser als die des Canadabalsams ist, und das in den am wenigsten angegriffenen Partien etwas Doppelbrechung hat. Bei fortschreitender Umwandlung nimmt die Doppelbrechung bis auf Null ab; die Umwandlung lässt sich in Streifen, die den Spaltrissen der Hornblende entsprechen, verfolgen. Bei stärkerer Umwandlung wird das Aggregat heller und teilweise beinahe farblos, enthält jedoch ständig ein Netzwerk von gelbgrünen, doppelbrechenden Fasern. Gleichzeitig hiermit breitet es sich über die ursprüngliche Kontur der Hornblende hinaus aus, und füllt nicht nur die Hohlräume nach dem 
Plagioklas, sondern tritt ebenfalls in Spalten und Rissen im Mikroklin und Quarz auf.

Der Biotit ist durchgehends ausserordentlich gut erhalten, selbst in Präparaten, in denen der Plagioklas gänzlich verschwunden ist. Er ist stark pleochroitisch: $\alpha$ hell gelb, $\gamma$ sehr dunkel, braun oder olivenbraun; stark pleochroitische Höfe werden häufig beobachtet. In der am stärksten umgewandelten Probe von der Ostwand der Buskewerksgrube ist der Biotit jedoch ganz entfärbt. Die Biotit- und Hornblendepseudomorphosen lassen sich hier nicht von einander unterscheiden, sie fliessen in eine farblose oder fast völlig farblose Masse zusammen. Diese hat zwar ihre Doppelbrechung gänzlich verloren, lässt aber doch noch immer ein Netzwerk von gelbgrünen, doppelbrechenden Fasern erkennen. In den frischesten Granitproben ist der Apatit in den Hornblendepseudomorphosen erhalten; diese Kristalle verschwinden aber noch bevor der gesamte Plagioklas in Kaolin umgewandelt ist. Die Erzkörner sind grösstenteils frisch; erst im stärker umgewandelten Granit beginnt der oben (p. 222) beschriebene graubraune Leukoxenüberzug sich einzufinden. Titanit tritt nicht in Form von gewöhnlichen gelbbraunen Körnern auf, doch lassen sich manchmal leukoxenähnliche Ausscheidungen in den grünen Umwandlungsprodukten beobachten. Es kommen jedoch in den untersuchten Dünnschliffen verschiedene Unregelmässigkeiten vor. Eigentümlich ist es z. B., dass der Biotit gerade in der sonst frischesten der Granitproben seine braune Farbe eingebüsst hat, indem er grünlich und ziemlich hell geworden ist. Die Doppelbrechung ist trotzdem recht kräftig und der Pleochroismus deutlich: grünlich - graugelb, so dass Biotitläppchen, welche ursprünglich mit der Hornblende verwachsen waren, einigermassen deutlich in den Hornblendepseudomorphosen hervortreten. In demselben Präparat ist der Mikroklin völlig frisch und der Plagioklas relativ wenig umgewandelt. Frische Erzkörner fehlen gänzlich. An ihrer Stelle werden Häufchen von kleinen braunen Kristallen beobachtet, die besonders zusammen mit Biotit und den Hornblendepseudomorphosen auftreten. Der Form und der hohen Doppelbrechung nach bestehen sie aus Titanit, jedoch sind die Kristalle so wenig durchsichtig, dass sie sich nicht mit Sicherheit bestimmen lassen.

Namentlich die ungleichmässige Umwandlung des Biotits scheint mir bemerkenswert. Es ist lange bekannt gewesen, dass der Biotit in der Natur oft eine eigentümliche Umwandlung in eine weisse, blättrige Substanz zeigt, welche F. Rinne Bauerit genannt hat. Die Baueritisierung geht in der Weise vor sich, dass die basischen Bestandteile des Biotits ausgelaugt werden, so dass das endgültige Umwandlungsprodukt nur aus Kieselsäure und aus neuaufgenommenem Wasser besteht. Dass derselbe Prozess sich im Laboratorium durch die Behandlung des Biotits 
mit Säuren ausführen lässt, ist von Rinne, V. M. Goldschmidt u. a. ${ }^{1}$ ) gezeigt worden. RINnE bezeichnet diesen Umwandlungsprozess als »Krystallographischen Abbau« oder »Krystallographischen Umbau«, d. h. Aenderungen, die sich ohne Einsturz des Kristallgebäudes vollziehen. Der Austausch von Kali gegen Wasser geht nicht nur an der Oberfläche der Glimmerkristalle, sondern auch im Innern der Kristalle auf ähnliche Weise vor sich wie der Stoffwechsel in den Zeolithen und im Permutit.

Möglicherweise muss es dieser Fähigkeit zum Basenaustausch zugeschrieben werden, dass der Biotit in den sonst stark umgewandelten Granitproben ein so frisches Aussehen hat, während er in verhältnismässig wohlerhaltenen Gesteinen ausgelaugt erscheinen kann. Möglicherweise hat es der baueritisierte Biotit in einem späteren Stadium vermocht, einen gewissen Eisengehalt wieder aufzunehmen und denselben eine Zeitlang festzuhalten. Dieses würde zum mindesten das anscheinend ungeregelte Verhalten des Biotits im Kaolingestein erklären.

Karbonate treten gewöhnlich spärlich auf und fehlen in mehreren der Dünnschliffe ganz. Eine Ausnahme bilden in dieser Hinsicht die aufbewahrten Proben von den Blöcken der Tornewerksgrube, in denen Kalkspat in so grosser Menge vorhanden ist, dass das Gestein mit kalter Salzsäure eine kräftige Kohlensäureentwicklung gibt. Der Mikroklin ist hier meistens gut erhalten. Plagioklas tritt nur in Form von Lamellen in Perthit auf. Der Biotit ist - jedenfalls anscheinend — völlig frisch, braun und stark pleochroitisch. Die Hornblende ist gänzlich verschwunden, auch sind keine Pseudomorphosen in erkennbarer Form erhalten. Die Erzkörner sind frisch und nur andeutungsweise mit Leukoxen überzogen. Die Hohlräume nach Plagioklas sind im allgemeinen nur teilweise mit Kaolin, im Uebrigen mit Karbonat oder dem serpentinähnlichen Umwandlungsprodukt gefüllt, und in vielen Fällen bildet Kalkspat die einzige Füllsubstanz. Eine geringe Menge Karbonat ist in Form kleiner rhomboederförmiger Eisenspatkristalle mit einem Durchmesser von etwa 0,2 $\mathrm{mm}$ ausgeschieden. In der Regel sind sie zonar gebaut, wobei die äussere Zone stark mit Limonit erfüllt ist. Diese Kristalle kommen in den Zwischenräumen zwischen den primären Mineralien des Gesteins zerstreut vor und sind in Ausscheidungen von Kalkspat und serpentinähnlichen Aggregaten eingebettet. In den Hohlräumen bildet der Kalkspat Aggre-

1) F. Rinne. Baueritisierung, ein krystallographischer Abbau dunkler Glimmer. Ber. Verh. d. k. sächs. Ges. d. Wiss. zu Leipzig. Math.-phys. Kl. Bd. 63, 1911.

O. Dreibrodt. Beitrag zur Kenntnis des diopsidführenden Brockengranitits und zur Baueritisierung. Inaug. Diss. Leipzig, 1912.

E. Blanck. Journal für Landwirtschaft, Bd. 60, 1912, pag. 97.

V. M. Goldschmidt. N. G. U. No. 108, 1922. 
gate von einer Korngrösse von $0,5-1 \mathrm{~mm}$; ferner dringt er in die Zwischenräume zwischen den anderen Mineralien ein und füllt die Spalten im Mikroklin und die Risse im Quarz aus. Sowohl Kalkspat als Eisenspat sind im Dünnschliff gräulich, doch kann der Kalkspat stellenweise ganz klar sein.

Charakteristisch für den Verlauf der Kaolinisierung ist also, dass die Hornblende zuerst angegriffen wird und danach die übrigen Mineralien, und zwar in nachstehender Reihenfolge: Plagioklas, Apatit, Mikroklin, Titanit, Biotit, Erzkörner; doch kommen Ausnahmen von dieser Reihenfolge vor. Als Reliktmineralien treten Zirkon und Quarz auf. Karbonate sind im Rohkaolin sehr spärlich vorhanden, können aber stellenweise in halbkaolinisierten Granitpartien angereichert sein; dies ist jedoch ein Zwischenstadium; bei fortschreitender Umwandlung werden sie aufgelöst und verschwinden. Eine Zementationszone wurde weder in der Grenzzone des Kaolins noch im Nebengestein nachgewiesen.

\section{Kaolinvorkommen anderswo auf Bornholm.}

In der Erläuterung zum Kartenblatt (pag. 40-42) erwähnt GRönwaLL fünf kleine Kaolinvorkommen ausserhalb des Kaolingebiets bei Rönne, nähmlich Skaglfaldet NO von Aakirkeby, Nørrebæk NW von Nexø, Nyker Meierei, den Granithorst der Mulebyaa (Mulebybach) und der Blykobbeaa (Blykobbebach), sowie im Allinger Hafen. Nur von einigen dieser Lokalitäten stand mir Material zur Verfügung.

Von diesen scheint mir der halbkaolinisierte Granithorst zwischen Hasle und Rönne das grösste Interesse beanspruchen zu können, da seine Richtung von Norden nach Süden eine Fortsetzung in der Längsrichtung der Kaolinlagerstätte bei Rönne ist. Dieser Horst trennt die Trias-Jura-Schichten im Westen von den Grünsandbildungen der Kreideformation östlich vom Horst. In der Landschaft tritt er nicht hervor; nur wo das Wasser sich einen Weg durch die Decke von lockeren Erdschichten gebahnt hat, wird hie und da ein verwitterter und bröckliger Granit beobachtet, und bei Grabungen in der Flussohle kann stark zersetzter Granit zu Tage gebracht werden. Eine sehr detaillierte Beschreibung der Lagerungsverhältnisse verdanken wir M. Jespersen ${ }^{1}$ ), der diese Gesteine jedoch nicht als einen Horst, sondern als eruptive Massen aufgefasst hat, welche die Sedimente gangförmig durchbrochen haben.

Am besten erhalten ist der feinkörnige braunrote Granit, der von Jespersen »Eurit« genannt wird, und welcher dort zu Tage tritt, wo der Weg nach Rönne die Blykobbeaa passiert. In Bezug auf die Korngrösse und Struktur entspricht er genau dem feinkörnigen »Hasle Granit«

1) M. Jespersen. Liden geognostisk Vejviser paa Bornholm. 1865, p. 11. und M. Jespersen. Bidrag til Bornholms Geotektonik. 1867. 
aus dem Bruch von Frigaard. Dunkle Mineralien sind ursprünglich spärlich vorhanden gewesen. Nun ist der Biotit in Chlorit umgewandelt und die Erzkörner haben einen braunen Ueberzug erhalten; ausserdem sind einige chloritische Umwandlungsprodukte zwischen die übrigen Mineralkörner eingedrungen. Der Chlorit enthält immer einige dunkle, undurchsichtige Körner, die bei auffallendem Lichte braun sind; sie bestehen wahrscheinlich aus Leukoxen. Sowohl Plagioklas als Mikroklin sind von angehender Kaolin- und Serizitbildung etwas getrübt; manchmal wird auch Epidot beobachtet. Der Granit ist von zahlreichen dünnen Rissen durchsetzt, die mit Kalkspat angefüllt sind.

Stärker umgewandelt und mehr kaolinisiert ist der Granit bei JESPERSEN's Lokalität 2 an der Mulebyaa (Aabyaa). Das Gestein ist mittelkörnig und entspricht dem gewöhnlichen streifigen Granit in der Gegend nordöstlich von Hasle. Der Mikroklin ist etwas unfrisch, der Plagioklas stärker angefressen und von dunklen Partikelchen getrübt; die Serizitbildung ist sehr untergeordnet. Der Biotit ist chloritisiert; der Chlorit ist teils grün und relativ stark pleochroitisch, teils beinahe farblos und hat dann fast keine Doppelbrechung; alle Uebergänge sind vorhanden, und im Endprodukt wird nur ein Netzwerk von nicht entfärbten Fasern beobachtet. In diesem Aggregat wird oft gut erhaltener Apatit angetroffen. Das ganze Gestein ist mit Kalkspat stark imprägniert. Dieser füllt eine Menge von Spalten und Rissen aus, die sämtliche Mineralien des Granits durchsetzen. Dank dieser Verkittung ist das Gestein ziemlich fest, doch sind die blaugrünen chloritischen und die weissen oder rötlichen Verwitterungsprodukte in nassem Zustande fettig und plastisch. Von ganz ähnlicher Beschaffenheit, jedoch bröckliger, ist der Granit bei Jespersen's Lokalitäten 13 und 16 in der Blykobbeaa; im übrigen kann die Umwandlung etwas verschieden ausfallen. An mehreren Stellen in der Blykobbeaa findet man stark rostfarbigen Granitgrus, der kaolinähnliche und chloritische Partien oder tonartige Massen von braunroter oder blaugrüner Farbe mit weissen Flecken enthält.

Im mittleren Teile des Horstes tritt eine Granitbreccie auf, in welcher das Bindemittel zwischen den scharfeckigen Quarz- und Feldspatfragmenten aus Eisenspat und Chlorit besteht. Der Feldspat ist etwas kaolinisiert. An der Ostgrenze des Horstes ist recht stark umgewandelter, von Kalkspatadern durchsetzter Diabas gefunden worden. Die am besten erhaltenen Proben zeigen, dass der Diabas ziemlich grobkörnig gewesen ist.

Im Granithorst ist die Unwandlung des Gesteins also von einer etwas anderen Art als im Kaolinvorkommen bei Rönne. Im Granit des Horstes ist die Kaolinisierung weniger fortgeschritten, während die Chloritisierung und die Karbonat- und Limonitbildung eine weit grössere Rolle spielen. 
Ueber das Kaolinvorkommen im Allinger Hafen teilt Johnstrup ${ }^{1}$ ) folgendes mit: 1861 beobachtete ForchHAmmen »bei der Vergrösserung des Hafens von Allinge ein System von 9 Gängen, von denen sich der westlichste als ein unverwitterter, 8 Fuss $(2,5 \mathrm{~m})$ mächtiger Diabasgang erwies, während die übrigen in gefärbten Thon umgewandelt waren«. Laut Jespersen (Liden Vejviser p. 8) war die Streichrichtung der Gänge $\mathrm{N} 22^{\circ} \mathrm{O}$.

Im Jahre 1914 erhielt das Mineralogische Museum von Herrn Bankbuchhalter E. Kofoed zwei Proben von kaolinisiertem Granit aus einem Kaolingang im Allinge Hafen. Die eine Probe besteht aus einem recht festen Granit. In Spalten und Hohlräumen sind einige rotbraune Ferriverbindungen ausgeschieden. Die hellen Gemengteile bestehen hauptsächlich aus Quarz und aus teilweise frischem Mikroklin. Eigentliche Kaolinschuppen sind spärlich, dagegen sind halbkaolinisierte Brocken, die öfters Quarzfragmente enthalten, ziemlich zahlreich vorhanden. Die Verteilung der dunklen Mineralien im Gestein ist stellenweise deutlich zu erkennen. Diese Partien enthalten ziemlich viel grünen Biotit, der stark chloritisiert ist. Der Chlorit schliesst kleine Leukoxen-ähnliche Ausscheidungen sowie Apatit, Zirkon und einige Erzkörner mit grauschwarzem Metallglanz ein.

Die andere Probe besteht ebenfalls grösstenteils aus Quarz und Mikroklin, enthält aber schätzungsweise mehr Kaolin als die eben erwähnte. Der Kaolin ist hier stärker doppelbrechend als es auf Bornholm im allgemeinen der Fall ist, und es scheint, als ob einige der Aggregate sowohl aus Kaolin- als aus Serizitschuppen bestehen; vermutlich ist der Kaolin durch weitere Umwandlung des Serizits entstanden. Biotit, Erzkörner und Apatit sind nicht gefunden worden. Das Gestein ist von Ferriverbindungen gelbbraun und rotgelb gefärbt.

Diese Proben aus dem Allinger Hafen bestehen aus teilweise umgewandeltem Hammergranit, der in frischem Zustande nur eine ziemlich geringe Menge von dunklen Mineralien enthält. Von den primären Gemengteilen scheint nur der Plagioklas völlig verschwunden zu sein. Aus den spärlichen Mitteilungen über das Vorkommen geht mit Sicherheit hervor, dass die Kaolinisierung an diesem Ort an die Klüfte des Granits geknüpft ist.

Im Mineralogischen Museum werden Handstücke aus den von ForcHнаммеR aufgefundenen Gängen aufbewahrt. Alles in allem existieren Proben von 12 Gängen, die alle aus zersetztem Diabas bestehen. In den meisten Fällen ist das Gestein graugrün und nur in geringem Grade kaolinisiert. Eine der Proben besteht aus einem serpentinartigen Gestein

1) F. Johnstrup. Abriss der Geologie von Bornholm. IV. Jahresber. der Geographischen Gesellschaft zu Greifswald 1889-1890, pag. 10. Greifswald 1891. 
von ähnlicher Natur wie die meisten umgewandelten Diabasgänge auf Bornholm. In einigen der Proben kann man allerdings deutlich weisse, kaolinisierte Plagioklasleisten erkennen, und drei Proben bestehen aus wirklich kaolinisiertem Diabas. Das Gestein dieser Proben ist weich, aber mit gut erhaltenem Gefüge. Die eine der Proben ist kräftig rotpigmentiert, die anderen sind heller, aber auch mit schwach rötlichem Anstrich. Kleine weisse Pseudomorphosen nach Plagiosklaskristallen sind deutlich erkennbar; sie bestehen aus ganz weissen Kaolinschüppchen mit sehr schwacher Doppelbrechung. Im übrigen besteht das Gestein aus schwach gefärbten, kaolinartigen Aggregaten mit etwas höherer Doppelbrechung, und ausserdem kommen einzelne frische, gelegentlich oktaederförmige Erzkörner vor.

GRöNWALL hat in der Erläuterung zum Kartenblatt (p. 40-42) einen bei der Anlage eines Wasserbehälters für das Nexö-Wasserwerk gemachten kleinen Fund von kaolinisiertem Granit recht eingehend geschildert. Während der Grabungsarbeiten wurde bei Nörrebæk etwa 1500 m NW von Nexö ein gletschergeschrammter Granitfels blosgelegt, in welchem eine Zone von parallelen wasserführenden Spalten gefunden wurde, die in der Richtung etwa $\mathrm{N} 60^{\circ} \mathrm{W}$ verliefen. Dabei stiess man auf zwei Zonen von kaolinisiertem Granit von 60 beziehungsweise $90 \mathrm{~cm}$ Breite, die von einer $80 \mathrm{~cm}$ breiten Zone von unverwittertem Granit getrennt waren. Nach Grönwall war die Umwandlung noch nicht so weit vorgeschritten, als dass das ganz weisse Kaolinpulver entstanden wäre. Das Gestein (der Svanekegranit) war ziemlich mürbe und sehr leicht zu zerschlagen.

Durch einen reinen Zufall ist mir ein Stück von diesem umgewandelten Granit in die Hände gekommen, indem Herr Steueramtsvorsitzender K. A. Petersen in Nexö mir dasselbe freundlichst überliess. Diese Probe entspricht gut GrönwaLL's Beschreibung des Gesteins. Die grobkörnige Struktur und die grossen roten Feldspate des Svaneke Granits sind deutlich erkennbar. In den Spalten sind einige Quarzkristalle und dunkle eisenschüssige Krustenbildungen ausgeschieden. U. d. M. sieht man, dass eine Kaolinisierung nur in geringem Masse stattgefunden hat. Sowohl der Mikroklin wie der Plagioklas sind beinahe ebenso frisch wie im gewöhnlichen Svaneke Granit. Die Umwandlung der Feldspate hat in ebenso hohem Grad zur Serizitisierung wie zur Kaolinisierung geführt. Der Apatit ist vollkommen erhalten. Biotit und frische Erzkörner wurden dagegen nicht gefunden. Anstatt des Biotits tritt ein farbloser zweiachsiger Glimmer mit ziemlich starker Doppelbrechung, recht kleinem optischem Achsenwinkel $2 \mathrm{~V}$ und Lichtbrechung $(\gamma)=$ etwa 1,58 (Anilin) auf. Dieser Glimmer schliesst zahlreiche kleine Epidotkristalle, etwas Apatit sowie ein rotbraunes, limonitisches Pigment ein, welches besonders zwischen den Spaltblättern ausgeschieden ist. Er ist zweifellos durch 
Auslaugung des Biotits entstanden. Oft werden diese Glimmerblätter von feinblättrigen oder feinschuppigen serizitähnlichen Massen umgeben. Die schwarzen oder bräunlichen Eisenverbindungen, die in den Spalten und Rissen des Gesteins in zahlreicher Menge auftreten, sind von Eisenspat begleitet, der sich teils in Form kleiner, flacher Rhomboeder, teils in Gestalt von körnigen Aggregaten ausgeschieden hat. Der Eisenspat bildet oft die äussere Kontur der limonitischen Ausscheidungen. Des weiteren enthalten diese Ausscheidungen oft kleine, ungefähr spindelförmige Kristalle, die aus Titanit zu bestehen scheinen.

Die Umwandlung, die das Gestein hier durchgemacht hat, unterscheidet sich also in wesentlichen Punkten von den Umwandlungsvorgängen, welche zur Entstehung der eigentlichen Kaolinlagerstätten führen, und zwar besonders dadurch, dass sich die Eisenverbindungen des Gesteins in so reichlicher Menge in Form von Limonit ausgeschieden haben.

Von den zwei Vorkommen, erstens bei Nyker Meierei, wo der kaolinisierte Granit ebenfalls bei der Anlage eines Brunnens gefunden wurde, und zweitens von Skaglfaldet stand mir bei der Untersuchung kein Material zur Verfügung. Nach der Untersuchung des Materials von Nörrebæk muss es als sehr zweifelhaft angesehen werden, ob eine eigentliche Kaolinisierung im wasserführenden Granit bei Nyker stattgefunden hat.

Ferner ist zu erwähnen, dass bei Arnager kaolinhaltiger Sand gefunden wurde, und dass an der Mündung der Grödbya kaolinreicher weisser Ton als eine unbedeutende Schicht in einem weissen, fossilienfreien Sandstein auftritt, der zum Rhät-Lias gerechnet wird. Die kaolinhaltigen Schichten bestehen aus äusserst feinkörnigem Material und enthalten ausser den eigentlichen Kaolinkörnern Quarz und Muskovit sowie in ganz kleinen Mengen: Erzkörner mit braunem Ueberzug, Turmalin, Zirkon und ein wenig Karbonat. Dieser Ton wurde im 18. Jahrhundert für die kgl. Porzellanmanufaktur in Kopenhagen gegraben; er wurde damals Porzellanerde und später Kaolin genannt. Gegen Westen ist der Sandstein von dem oberen Graptolithenschiefer durch eine Verwerfung getrennt (siehe Erläuterung zum Kartenblatt p. 91).

\section{Alter und Entstehung des Kaolins.}

Während über die Entstehung des Bornholmer Kaolins verschiedene Ansichten geäussert worden sind, herrscht unter denjenigen Geologen, welche die Verhältnisse an Ort und Stelle untersucht haben, darüber Einigkeit, dass die Kaolinisierung stattgefunden hat, bevor die mesozoischen Schichten über dem Kaolin abgelagert wurden. Sowohl UssixG wie Grönwall betonen, dass die obersten Schichten des Kaolins aus- 
geschlämmt sind, und dass die Sandschicht, die in der Regel zwischen dem Kaolin und den darüber lagernden Tonschichten auftritt, als ein Schlämmungsrückstand des Rohkaolins aufgefasst werden muss. Auch die vorliegende Untersuchung kann dieser Auffassung beistimmen.

Als erster hat sich Forchinamer ${ }^{1}$ ) über die Entstehung des Kaolins geäussert. Er nahm an, dass der Kaolin aus einer Quarz-Feldspatmasse, Pegmatit oder Schriftgranit entstanden sei, und zwar durch Einwirkung von überhitztem Wasserdampf, der durch Spalten aus dem Innern der Erde hervorquoll. Durch Versuche stellte er fest, dass Wasser bei $125^{\circ}$ $222^{\circ}$ dem Feldspat Alkalisilikat entziehen konnte, und meinte danach ${ }^{2}$ ), "dass diese Versuche es über allen Zweifel erheben, dass es wenigstens zum Teil Wasserdämpfe unter hohem Drucke sind, die den Pegmatit in Kaolin verwandelt haben.《

Cohen und Deecke (l. c., p. 33) nahmen ebenfalls an, dass die Kaolinbildung aus Spaltensystemen entstanden oder jedenfalls von solchen begünstigt worden sei; dagegen nahmen sie Abstand von Forсннаммев's Theorie über Thermalwasser als Agens.

$\mathrm{UsSING}^{3}$ ) dagegen meint, dass der Kaolin durch einfache, vom herabsickernden Wasser verursachte Verwitterung bei gewöhnlicher Temperatur entstanden sei. Zur Unterstützung dieser Theorie führt er an, dass mehrere Beobachtungen gezeigt haben, dass der Kaolin nach unten zu allmählich in Rönne Granit übergeht, während keine Spuren derjenigen Spalten nachgewiesen worden sind, von denen die Umwandlung, wenn sie auf Dampfausströmungen beruhte, ausgegangen sein müsste. UsSING meint, dass die Verwitterung nicht in der Gegenwart vor sich gegangen sei, in welcher die Einwirkungen der Witterung auf den Bornholmer Granit wesentlich in einer langsamen Frostzersprengung besteht, sondern in der Vergangenheit bei dem milden und feuchten Klima, das am Ende des Paläozoikums über weite Strecken der Erde hin herrschte. Seiner Ansicht nach ist die obere Partie des gesamten Granitgebiets wahrscheinlich schon während der Triaszeit in Kaolin umgewandelt gewesen, von dem jedoch der grösste Teil im Lauf der Zeit fortgespült worden ist, so dass die Lagerstätte bei Rönne nur einen kleinen Ueberrest ausmacht, der sich infolge seiner geschützten Lage hinter dem hohen Granitrand erhalten hat; vor allem hat diese Lage während der Eiszeit, als das Eis vom Nordosten über die ganze Insel hinwegging, den Kaolin geschützt.

1) G. ForсннаммеR. Undersøgelse om Oprindelsen og de nærmere Bestanddele af nogle af de vigtigste Leerarter. Vid. Selsk. phys. og math. Skr. V. Deel. Kjöbenhavn 1832.

2) G. Forchнammer. Ueber die Zusammensetzung der Porcellanerde und ihre Entstehung aus dem Feldspath. Poggendorff's Annal., Bd. 35, 1834, p. 355 .

$\left.{ }^{3}\right)$ D. G. U. II. R. Nr. 12, 1902 und D. G. U. III. R. Nr. 2, 1904. 
H. RöSLER ${ }^{1}$ ), der aus eigener Anschauung das Kaolinvorkommen bei Rönne kennt, tritt Forchinamer's Theorie bei. Wie oben (p. 223) zitiert hat er Mineralbestimmungen des Bornholmer Kaolins vorgenommen. Die wesentlichste Stütze für seine Auffassung von den Ursachen der Kaolinbildung an dieser Stelle sucht RösLen in den geologischen Verhältnissen, in dem räumlich sehr eng begrenzten Vorkommen und in der grossen Tiefe der Lagerstätte. Ferner betont er, wie unwahrscheinlich es an und für sich sei, dass die atmosphärische Verwitterung gerade an dieser Stelle längs der Spaltensysteme so intensiv gewirkt haben sollte, während doch im übrigen, stark zerklüfteten Granitgebiet keine Kaolinisierung stattgefunden hat. RösLer meint daher, dass die Kaolinisierung von unten nach oben vor sich gegangen sein muss.

A. STAHL ${ }^{2}$ ) hat der Vermutung Ausdruck gegeben, dass der Kaolin bei Rönne im Zusammenhang mit der Rhät-Lias-Kohle entstanden sei, geht aber nicht näher derauf ein. Auch H. Stremme ${ }^{3}$ ) rechnet den Bornholmer Kaolin zu dieser Art von Vorkommen. Dadurch hat sich diese Auffassung in der deutschen Literatur eingebürgert, wo sie bei jeder weiteren Zitierung mit immer grösserer Sicherheit vertreten wird. 1926 sagt H. HARRAssowitz ${ }^{4}$ ): "Lange bekannt ist der Zusammenhang der Liaskohle von Bornholm mit der tieferen Kaolinisierung", und ferner (1. c. p. 505): "Der kohlenführende Lias von Bornholm mit seinen feuerfesten Tonen liegt auf einer kaolinisierten Landoberfläche. Hier sind also die gesuchten Zusammenhänge ohne weiteres vorhanden.«Hierzu ist zu bemerken, dass die verkohlten Pflanzenresten im Hangenden des Kaolins viel zu klein und unbedeutend sind, als dass sie für die Entstehung des Kaolins verantwortlich gemacht werden könnten - ganz abgesehen davon, dass man auch auf anderem Wege zu dem Ergebnis kommt, dass die Kaolinbildung auf Bornholm der Ablagerung der Sedimente vorausgegangen sein muss.

Endlich hat GrönwaLL ${ }^{5}$ ) sich dahin geäussert, dass Einwirkungen aus der Tiefe als natürlichste Erklärung für die Umwandlung des Granits in Kaolin an dieser Stelle herangezogen werden müssen. Die wesentlichste Stütze für diese Erklärung findet er in RösLER's Untersuchungen. Des weiteren betont er, dass die Bohrungen beim Rabekkewerk eine bedeutende Mächtigkeit des Kaolins und eine starke Neigung seiner unteren

1) H. Röscer. Beiträge zur Kenntniss einiger Kaolinlagerstätten. N. JB. B. B. Bd. 15, 1902, p. 231-393.

$\left.{ }^{2}\right)$ A. Stahl. Die Verbreitung der Kaolinlagerstätten in Deutschland. Arch. f. Lagerstätten-Forschung. Hrsg. v. d. Kgl. Preuss. Geol. Landesanst. Heft 12, 1912.

3) H. Stremme, in C. Doelter: Handbuch der Mineralchemie, Bd. II, 2. Abt., 1917, pag. 134 .

4) H. Harrassowitz. Laterit. Fortschritte d. Geol. u. Palaeont, Bd. IV, 1926, pag. 298.

$\left.{ }^{5}\right)$ K. A. Grönwall. D. G. U. I. R. Nr. 13, 1916. 
Grenze beweisen. Ich selbst habe mich früher $\left.{ }^{1}\right)$ GrönwaLL's Auffassung angeschlossen, indem ich vor allen Dingen in Betracht zog, dass die langgestreckte, schmale Form des Kaolingebiets und seine Lage in der Verlängerung des Granithorstes auf die Anwesenheit einer Verwerfungsspalte hindeuten könnte, von der die Kaolinisierung ihren Ausgang genommen haben könnte.

Es sind also, wie man sieht, von verschiedenen Seiten so gut wie alle bisher über Kaolinbildung aufgestellten Hypothesen auch zur Erklärung der Entstehung des Bornholmer Kaolins herangezogen worden.

Die Bedingungen für die Kaolinbildung und die damit verbundenen Prozesse sind noch nicht völlig aufgeklärt. Z. B. kann man sich sehr gut vorstellen, dass die wichtigste Umwandlung, nämlich die Kaolinisierung des Feldspats, auf mehr als eine Art und Weise erfolgt ist. O. TAмM ${ }^{2}$ ) hat experimentell nachgewiesen, dass Feldspat durch Hydrolyse in Kaolin umgewandelt werden kann. Die alte Forchнамmer'sche Нyроthese erscheint damit wieder in neuer Beleuchtung. Aber selbst wenn man annehmen kann, dass die Hydrolyse eine wichtige Rolle bei der Zersetzung der Gesteine in der Natur spielt, so scheint es doch sicher, dass wirkliche Kaolinlager nicht allein auf diesem Wege gebildet worden sind. Hierzu sind Prozesse erforderlich, in deren Verlauf nicht nur Kaolin entsteht, sondern wobei gleichzeitig andere Umwandlungsprodukte, insbesondere Eisenverbindungen, entfernt werden. Am naheliegendsten ist es, kohlensäurehaltiges Wasser für das wichtigste Agens zu halten. Die Kohlensäure ist nämlich imstande, Eisen, Alkalien und Erdalkalien in Lösung fortzuführen, geht aber keine Verbindung mit dem Aluminium der Gesteine ein, welches zusammen mit Kieselsäure und Wasser Kaolin bilden kann. Die Umwandlung des Feldspats in Kaolin kann durch die bekannte Gleichung ausgedrückt werden:

$$
\mathrm{K}_{2} \mathrm{O} \cdot \mathrm{Al}_{2} \mathrm{O}_{3} \cdot 6 \mathrm{SiO}_{2}+2 \mathrm{H}_{2} \mathrm{O}+\mathrm{CO}_{2}=\overbrace{\mathrm{Al}_{2} \overline{\mathrm{O}}_{3} \cdot 2 \mathrm{SiO}_{2} \cdot 2 \mathrm{H}_{2} \mathrm{O}}^{\text {Kaolin }}+\mathrm{K}_{2} \mathrm{CO}_{3}+4 \mathrm{SiO}_{2}
$$

Man darf indessen nicht vergessen, dass die Kaolinisierung ein verwickelter Vorgang ist, wobei auch viele andere Mineralien ausser Feldspat zu Kaolin umgewandelt werden können. Die obige Gleichung gilt daher nur für eine einzige von den möglichen Umsetzungen.

Bei vielen Vorkommen hat es sich gezeigt, dass die Kaolinbildung Prozessen zuzuschreiben ist, die von der Tiefe ausgegangen sind, wie pneumatolytische Prozesse und die Wirkungen von Thermen oder kalten Säuerlingen. Charakteristisch für diese en d o g e n e n Kaoline ist es im Allgemeinen, dass die Intensität der Kaolinisierung nach unten zunimmt,

1) D. G. U. V. R. Nr. 4, 1928.

$\left.{ }^{2}\right)$ O. ТАмм: Chemie der Erde. Bd. 4, 1930, p. $420 \mathrm{ff}$. 
und dass die Lager sehr tief sind und oft eine langgestreckte, schmale Form haben, die von dem Vorhandensein einer Spalte Zeugnis ablegt, von der die Zersetzung ausgegangen ist. In anderen Fällen wieder muss man annehmen, dass die Kaolinisierung durch Sickerwässer verursacht ist. Solche ex o g e nen Vorkommen sind in der Regel nur von geringer Mächtigkeit, selten mehr als $20-30 \mathrm{~m}$. Sie liegen oft in flachen schüsselförmigen Vertiefungen und gehen nach unten in das unverwitterte Gestein über.

In der umfangreichen Kaolinliteratur ist die Frage nach der Entstehungsweise des exogenen Kaolins immer wieder behandelt worden. Während man früher ziemlich allgemein annahm, dass die atmosphärische Verwitterung die Ursache der Kaolinbildung wäre, ist diese Auffasung in den letzten Jahrzehnten von verschiedener Seite scharf bekämpft worden ${ }^{1}$ ). Vor allem Stremme hat betont, dass die atmosphärische Verwitterung besonders durch Oxydationsvorgänge gekennzeichnet ist. Dieses bringt es mit sich, dass die Eisenverbindungen nicht in besonders hohem Grade in Lösung gehen, sondern grösstenteils als Ferrihydroxyde ausgeschieden werden. Die Kaolinisierung dagegen wird von reduzierenden Vorgängen begleitet, in deren Verlauf das Eisen in Lösung geht oder in Form von Ferroverbindungen entfernt wird oder teilweise als Schwefelkies oder Eisenspat zurückbleibt. Sтвемме belegt diese Aufassung mit einem grossen Analysenmaterial, aus dem weiterhin hervorgeht, dass nicht nur der Eisengehalt, sondern in noch höherem Grade auch der Magnesiagehalt prozentual mit der atmosphärischen Verwitterung steigt und mit der Kaolinisierung abnimmt.

Als eine wahrscheinlichere und weit wichtigere Ursache der Kaolinbildung nennen Stremme und StahL die Einwirkung von Moorwässern auf darunterliegende Eruptivgesteine. Hierbei nehmen sie an, dass $\mathrm{CO}_{2}$ der aktive Faktor im Moorwasser ist, während den Humusstoffen nur die Rolle eines Reduktionsmittels eingeräumt wird. Auf der Basis dieser Theorie haben diese Autoren in völlig befriedigender Weise die Entstehung vieler deutscher Kaolinvorkommen in Verbindung gebracht mit darüberliegenden tertiären Mooren oder Braunkohlenlagern. Eine notwendige Bedingung für die Kaolinisierung auf diesem Wege ist es natürlich, dass zwischen dem Moor und dem darunterliegenden Eruptivgestein nur dünne und leicht durchdringbare Schichten $\mathrm{zu}$ finden sind.

Aber auch gegen diese Theorie haben in den letzten Jahren verschiedene

1) S. u. a. H. RösLer's oben erwähnte Arbeit.

H. Stremme, Über Kaolinbildung. Zeitschr. f. prakt. Geol. 16. 1908.

A. Stahl's oben erwähnte Arbeit.

E. Blanck \& A. Rieser, Chemie der Erde, 2, 1925, p. 15.

H. Harrassowitz, Laterit. 1926. 
Verfasser $^{1}$ ) Widerspruch erhoben, die bei der Untersuchung rezenter Moore zu dem Resultat gelangt sind, dass unter nord- und mitteleuropäischen Klimaverhältnissen die Morrverwitterung nicht zu Kaolinbildung führt, sondern nur zu einer Bleichung der Gesteine im Liegenden der Moore. Diese Form von Kaolinisierung scheint also an ein wärmeres Klima geknüpft zu sein.

Schliesslich hat Harrassowitz die Verwitterungstheorie in eine neue Form gekleidet, indem er annimmt, dass die exogenen Kaoline aus Laterit entstanden sind, die durch eine spätere Auflagerung von Moor und Kohle zersetzt sind. Er sagt darüber: „Unter der Kohle, dem Moor, war der Laterit der Einwirkung von saurem Humus und wohl auch späterer Vorgänge ausgesetzt und wurde dabei entfärbt, schwach enteisent und enttont und sulfidische, karbonatische Eisenmineralien bildeten sich an Stelle der Oxyde und Oxydhydrate. Bodenkundlich tritt das ein, was man als Degradierung bezeichnet."

Es ergibt sich nun die Frage, ob irgend eine der bisher aufgestellten Theorien eine befriedigende Erklärung für die Bildung des Bornholmer Kaolins gibt.

Da jetzt bekannt ist, dass der Kaolin im grössten Teil des Gebiets nur eine geringe Mächtigkeit hat und nach unten zu in unverwitterten Granit übergeht, so ist kaum anzunehmen, dass der Bornholmer Kaolin endogenen Ursprunges ist. Dagegen sprechen die Lagerungsverhältnisse dafür, dass der Untergrund stark zerklüftet war, als die Kaolinbildung vor sich ging, und dass die Umwandlung daher stellenweise bis in verhältnismässig bedeutende Tiefen gehen konnte.

Bei einem Versuch, den Bornholmer Kaolin als eine exogene Bildung zu deuten, stellt sich sofort die Schwierigkeit ein, dass man nichts darüber weiss, welche Verbreitung der Kaolin möglicherweise früher einmal gehabt hat. Wie erwähnt, ist es denkbar, dass die Vertiefungen, in denen der Kaolin bei Rönne liegt, durch eine Zerklüftung des Untergrundes bedingt sind, die durch Verwerfungen verursacht oder jedenfalls verstärkt worden ist. Mit Bezug auf die Kaolinisierung des Granithorstes bei Hasle kann ein solcher Zusammenhang nicht in Zweifel gezogen werden. Im Allinger Hafen ist Kaolin in "Gängen«, d. h. Spalten gefunden worden. Das Vorkommen in Skaglfald liegt in stark zerklüftetem Granit in unmittelbarer Nähe der grossen Verwerfung mit Streichen NNW_--OSO, die am Südrande des Granitgebiets an mehreren Stellen die Grenze zwischen dem Granit und dem Nexö Sandstein bildet. Die beiden von GrönwalL genannten Vorkommen bei der Nyker Meierei und bei Nörre-

1) E. Blanck \& A. Rieser, Chemie der Erde, 2, 1925.

K. Endell, N. JB. B. B. 1911, p. 18 -28. Centralbl. f. Min. etc., 1913, p. 676.

О. ТАмм, Bull. Upsala. 13, 1915-16, p. 183.

Danmarks geologiske Undersogelse. II. R. Nr. 50 . 
bæk können, wie oben (p. 236) erwähnt, nicht als wirklicher Kaolin betrachtet werden, aber im übrigen liegen auch diese Vorkommen nahe der Verwerfungsgrenze zwischen dem Granit und den Sedimenten. Es kann daher die Möglichkeit nicht von der Hand gewiesen werden, dass die Kaolinvorkommen nur Reste grösserer Massen sind, die wegen ihrer geschützten Lage in Vertiefungen erhalten geblieben sind, während das Uebrige wegerodiert wurde. Allerdings scheint es unwahrscheinlich, dass das gesamte Granitgebiet, wie Ussing annahm, früher mit Kaolin bedeckt gewesen sein sollte, denn in diesem Falle müsste man erwarten, ähnliche Reste an vielen anderen Stellen in dem stark zerklüfteten Granit zu finden. Das ist aber nicht der Fall. Hierzu kommt, dass die Umwandlung des Granits nicht bei allen Vorkommen gleichartig ist. Bei Rönne hat diese Umwandlung zur Bildung von wirklichen Kaolinlagern geführt, die, was die Intensität der Kaolinisierung angeht, den besten in Mitteleuropa, z. B. Zettlitz, gleichgestellt werden können. Aber in dem Granithorst wenige Kilometer nördlicher ist die Kaolinisierung untergeordnet, und die Umwandlung hat im Wesentlichen zu einem Zerfall des Granits unter Ausscheidung von Kalkspat und chloritischen, limonitischen und tonartigen Produkten geführt. Dieser Unterschied im Endergebnis der Umwandlung an zwei so nahe beieinander gelegenen Lokalitäten kann darauf hindeuten, dass die Intensität der Kaolinisierung von lokal wirkenden Faktoren bedingt gewesen ist.

Wenn man nun in Betracht zieht, dass der Kaolin bei Rönne ganz oder teilweise in isolierten Nestern auftritt, so muss es einem unter allen Umständen am wahrscheinlichsten dünken, dass die Kaolinbildung hier durch Moorverwitterung verursacht ist. Demgegenüber bietet sich aber sofort die Schwierigkeit dar, dass wir keine sicheren Spuren davon nachweisen können, dass solche Moore existiert haben. Jedenfalls muss man dann annehmen, dass die Moore wegerodiert worden sind, bevor die Sedimente zur Ablagerung kamen, und dass gleichzeitig die obersten Lagen des Kaolins fortgespült oder ausgeschlämmt wurden. Im übrigen würde diese Theorie die befriedigendste Erklärung für die Entstehung des Kaolins geben, und da man annehmen muss, dass der Kaolin in der Trias oder im Perm entstanden ist, so könnte man dann auch günstige Klimabedingungen für eine Kaolinisierung auf einem solchen Wege voraussetzen. Weiterhin würde die Lage des Kaolingebiets mitten auf der abfallenden Granitfläche eine natürliche Erklärung finden, wenn man annähme, dass die Moore als Quellmoore entstanden wären. Gleichzeitig wäre es denkbar, dass die Quellen bei Rönne kohlensäurehaltig gewesen sein könnten und dadurch die Kaolinisierungsfähigkeit des Moorwassers verstärkt haben könnten, dass dieses aber nicht beim Granithorst der Fall gewesen wäre. 
Es scheint mir somit, dass die Theorie der Moorverwitterung als Ursache der Kaolinbildung diejenige ist, die mit den lokalen Verhältnissen am besten übereinstimmt. Da aber die Existenz dieser Moore nicht direkt beweisbar ist, so kann diese Theorie nur als die im Augenblicke wahrscheinlichste angesehen werden. Die Frage nach der Entstehung des Bornholmer Kaolins hat jedenfalls noch keine endgültige Antwort erhalten. 


\section{Nachtrag.}

Nachdem der erste Teil dieser Arbeit im Dezember 1932 als Sonderdruck erschienen war, veröffentlichte Professor S. v. Bubnoff und Dr. R. Kaufuann eine Abhandlung mit folgendem Titel: "Zur Tektonik des Grundgebirges von Bornholm" (Geologische Rundschau, Bd. 24, 1933, S. 379). In dieser Arbeit nehmen die genannten Autoren einige Änderungen an meiner Karte über die Verteilung der Bornholmer Granite vor.

Die erste dieser Änderungen besteht darin, dass die Signatur für den Paradisbakke Granit weiter gegen SW und zwar ungefähr bis Skovgaard eingetragen wird (siehe Fig. 6, p. 13). Diese Modifikation nehme ich sehr gerne an, denn sie bedeutet unzweifelhaft eine Verbesserung der Karte und ist zudem in voller Uebereinstimmung mit den von mir auf Seite 85 gemachten Angaben. Hier führe ich an, dass der Granit in dem südlichen Gebiet von Osten nach Westen zu nach und nach seinen Charakter ändert, indem nämlich der Granit seinen Charakter als Paradisbakke Granit verliert, je weiter man nach Westen kommt.

Hingegen kann ich mit Dr. KaUfmanN nicht übereinstimmen, wenn er angibt, dass eine Granitvarietät von derselben petrographischen Beschaffenheit wie sie der Svaneke Granit aufweist, an mehreren Stellen südlich des Hauptgranits ${ }^{1}$ ) bei Hallegaard vorkommt, und dass dieser "Hallegaard-Granit« offenbar die südwestliche Fortsetzung des Svaneke Granits bildet.

Professor S. v. Bubnoff, Greifswald, hat mit grösster Liebenswürdigkeit das von Dr. Kaufmann gesammelte Material dieses Granits für eine petrographische Untersuchung zu meiner Verfügung gestellt. Für dieses ausserordentliche Entgegenkommen sage ich ihm hiermit meinen besten Dank. Fernerhin habe ich im Januar 1934 mit Dr. KaUfmann zusammen eine Exkursion nach Bornholm unternommen und weiteres Material gesammelt.

Die behandelte Granitvarietät tritt in einem stark erdbedeckten Terrain

1) Wie bereits auf Seite 22 gesagt, finde ich die Bezeichnung "Hauptgranit» wenig treffend. 
S von Skovgaard in Bodilsker zu Tage, das heisst in der südöstlichsten Ecke des Granitgebiets in der Gegend zwischen Skovgaard, Egeby und Katteslet. Die untersuchten Proben sind ca. $600 \mathrm{~m} \mathrm{~S}$ von Skovgaard im Hallegaard Wald gesammelt worden. Da Skovgaard wegen des mächtigen Pegmatitvorkommens (siehe weiter oben Seite 93) eine altbekannte Lokalität ist, so will ich es im Folgenden vorziehen, diesen Granit als Skovgaard-Hallegaard Granit zu bezeichnen. Eine ähnliche Varietät steht weiterhin S von Katteslet Gaard an.

Auf Grund meiner eigenen früheren Untersuchungen kann ich hier die Bemerkung einschieben, dass der Granit unmittelbar südlich des Landweges bei Skovgaard zum Paradisbakke Typ gehört: Er ist recht feinkörnig, dunkelgrau, rotschlierig und hat eine deutliche Parallelstruktur. Südlicher, an Dr. Kaufmann's Lokalität, im Hallegaard Wald ist der Granit dagegen mittelkörnig, rötlich und es fehlt jede Parallelstruktur. Schon bei makroskopischer Beobachtung sieht man doch deutlich, dass dieser Granit eine geringere Korngrösse, eine dunklere Farbe und einen bedeutend grösseren Hornblendegehalt hat als der Svaneke Granit.

Die petrographische Untersuchung bestätigt, dass der Granit von Skovgaard-Hallegaard nich t Svaneke Granit ist, hingegen de m R önne Granit sehr nahe steht. Seine Ähnlichkeit mit dem Svaneke Granit besteht allein darin, dass die Parallelstruktur fehlt und dass die Farbe ebenfalls rötlich ist. Diese Rotfärbung ist jedoch unzweifelhaft nur eine Oberflächenerscheinung, die überall im Granitgebiet wohl bekannt ist, und auch an mehreren Stellen im eigentlichen Rönne Granit angetroffen wird, so z. B. in der Gegend zwischen Kroggaard und Skovgaard in der südwestlichsten Ecke des Granitgebiets in der Nähe des Bahnhofs von Robbedale.

Eine geometrische Analyse des Granits von Skovgaard-Hallegaard zeigte eine sehr genaue Übereinstimmung mit dem Rönne Granit. Das Ergebnis ist in der untenstehenden Tabelle mit einer entsprechenden Analyse des Rönne Granits niedergelegt.

Als Nummer 3 in der Tabelle ist weiter zum Vergleich eine geometrische Analyse des Svaneke Granits aufgeführt, und weiter habe ich eine Messung des Gehalts an dunklen Mineralien in dem hornblendereichsten Dünnschliff des Svaneke Granits, der zu meiner Verfügung stand, vorgenommen. Das Ergebnis ist als Nummer 4 in der Tabelle aufgeführt. Dieses letzte Präparat ist besonders hornblendereich, und man darf hiernach nicht annehmen, dass der Svaneke Granit nach Süden zu hornblendereicher wird, da andere Dünnschliffe von noch weiter südlich gelegenen Lokalitäten denselben geringen Hornblendegehalt wie der übrige Teil des Svaneke Granits aufweisen. Die Tabelle zeigt also, dass der Svaneke Granit normalerweise hornblendearm ist und auch nicht 


\begin{tabular}{|c|c|c|c|c|c|}
\hline & & 1 & 2 & 3 & 4 \\
\hline Quarz.......... V & Vol. \% & 19,82 & 20,96 & 27,55 & 24,00 \\
\hline Mikroklinperthit..... & $" \quad "$ & 30,97 & 30,49 & 31,30 & \multirow{2}{*}{57,54} \\
\hline Plagioklas........... & $"$ & 34,59 & 32,61 & 31,29 & \\
\hline Hornblende......... & $" \Rightarrow$ & 7,02 & 8,28 & 1,54 & 4,78 \\
\hline Biotit. . . . . . . & $">$ & 5,25 & 4,46 & 5,47 & 8,35 \\
\hline Erz $\ldots \ldots \ldots \ldots$ & $" 》$ & 1,23 & 1,83 & 0,35 & 0,98 \\
\hline Titanit . . . . . . . . . & $" \Rightarrow$ & 0,36 & 0,63 & 2,23 & 2,39 \\
\hline Apatit............ & $" \quad "$ & 0,75 & 0.76 & 0,19 & 0,55 \\
\hline \multirow[t]{2}{*}{ Epidot............. } & $"$, & - & - & - & 1,40 \\
\hline & & 99,99 & 100,02 & 99,92 & 99,99 \\
\hline
\end{tabular}

1. Granit, Hallegaard Wald, südlich von Skovgaard in Bodilsker.

2. Rönne Granit, Klippegaard ${ }^{1}$ ).

3. Svaneke Granit, Durchschnitt von 6 Rosiwal-Messungen.

4. Hornblendereichster Dünnschliff des Svaneke Granits, Rabækkegaard, Helvedesbakker.

ausnahmsweise einen so grossen Hornblendegehalt wie der SkovgaardHallegaard Granit und der Rönne Granit erreicht. Weiter sieht man aus der Tabelle, dass der Svaneke Granit deutlich quarzreicher als die beiden anderen Granite ist. (Vgl. ferner Tab. III, pag. 39 und Tab. XII, pag. 113). Endlich muss bemerkt werden, dass der Svaneke Granit konstant einen bedeutenden Titanitgehalt aufweist, während der Titanit in dem Granit von Skovgaard-Hallegaard nur spärlich vorkommt.

Die Uebereinstimmung zwischen dem Rönne Granit und dem Skovgaard-Hallegaard Granit zeigt sich im übrigen nicht nur in den Mineralproportionen sondern auch in der Struktur der Gesteine und in der Entwicklung der einzelnen Bestandteile; der Rönne Granit ist jedoch etwas feinkörniger. Der Plagioklas ist in beiden Graniten in der Regel von einem parallel orientierten Mikroklinperthit-Mantel umgeben. Diese Struktur ist für den Rönne Granit speziell charakteristisch, und man trifft ihn gewöhnlich bei den übrigen hornblendereichen Granitvarietäten, aber ich habe nirgendwo im Svaneke Granit einen vollständigen Mikroklinmantel um einen grösseren Plagioklaskristall gefunden (Vgl. pag. 112). Weiter hat der Plagioklas des Hallegaard Granits dieselbe unregelmässige Auslöschung, die im Plagioklas des Rönne Granits so gewöhnlich ist (Vgl. Tag. I, Fig. 3). Die Hornblende stellt die gewöhnliche Varietät mit dem kleinen optischen Achsenwinkel $2 \mathrm{~V}$ dar, und sowohl die Hornblende wie auch der Biotit haben meistens eine unregelmässige Kontur und führen ebenso wie im Rönne Granit zahlreiche Einschlüsse von den übrigen Mineralien des Gesteins (Vgl. Figur 7 und 8).

1) Diese Analyse ist zu Gewicht \% umgerechnet worden in Tab. IV, b, geometr. Analyse, pag. 56. 
Der Granit von Katteslet Bakke ist etwas zersetzt, der Quarz und Feldspat ist von Ferrihydroxyden rot gefärbt, die einen Ueberzug an der Mineralkörnern bilden und in Risse eingedrungen sind. Der Plagioklas ist derselbe wie im vorher besprochenen Granit. In einem Schnitt $\perp$ MP wurde in den unregelmässig verteilten Feldern der Plagioklase gemessen: $\alpha^{\prime}: \mathrm{M}=6^{\circ}$ entsprechend zu ca. $24 \%$ An., und $\alpha^{\prime}: \mathrm{M}=$ ca. $15^{\circ}$, was etwa $30 \%$ An. entspricht. Der Biotit ist chloritisiert und die Hornblende stark umgewandelt in beiden Fällen unter reichlicher Ausscheidung von Ferrihydroxyden. Der ursprüngliche Hornblendegehalt kann schwer bestimmt werden, aber es scheint, als wäre er etwas geringer gewesen als im Hallegaard-Skovgaard Granit. Weiter hat dieser Granit einen etwas grösseren Quarzgehalt. Im ganzen erinnert er sehr an den Rönne Granit bei Kroggaard in dem südwestlichsten Teil des Granitgebiets (Vergl. pag. 50 unten).

Der Nachweis dieses »Rönne Granits« an dieser Stelle südlich von den Paradisbakker war an und für sich ein unerwartetes Ergebnis der Untersuchung, obwohl man nach dem Nachweis der »blauen Granite« bei Hallegaard, Gudhjem und bei Tækkeregaard darauf vorbereitet sein musste, Plagioklas- und hornblendereiche Gesteinsvarietäten überall innerhalb der älteren Granitabteilung zu finden. Der Granit von Skovgaard-Hallegaard steht jedoch dem eigentlichen Rönne Granit bedeutend näher, besonders hinsichtlich der Struktur, als den genannten kleinen Vorkommen von »blauem Granit«, und es scheint mir von weiterem Interesse dabei zu sein, dass eine gewisse Analogie zwischen dem südwestlichen und dem südöstlichen Teil der älteren bornholmischen Granitabteilung besteht. Ich habe weiter oben Seite 54 und in Tabelle IV auf Seite 56 auf die Uebereinstimmung aufmerksam gemacht, die zwischen dem Paradisbakke Granit und dem porphyrischen Gestein in der östlichen Randzone des Rönne Granits besteht; entsprechende Varietäten finden sich an mehreren Stellen der Gegend um Aakirkeby (Vgl. pag. 59 und pag. 86). Wir finden also diesen Gesteinstyp in einer Zone am Südrand der älteren Granitabteilung. Ausserhalb dieser Zone liegt im Westen Rönne Granit, im Osten Skovgaard-Hallegaard Granit. Möglicherweise haben diese letztgenannten Granite eine zusammenhängende äussere Zone gebildet, die nun durch Verwerfungen zerstört ist. Aber es muss ausdrücklich hervorgehoben werden, dass wir die Ausbreitung des SkovgaardHallegaard Granits nicht kennen, und dass diese sich in dem stark erdbedeckten Gebiet kaum mit Sicherheit festlegen lässt; möglicherweise kommt dieser Granit nur innerhalb eines eng begrenzten Gebiets vor.

Weiter will ich gern mit einigen Worten Dr. Kaufmann's Angabe begegnen, dass in dem gestreiften Granit dicht an der Kontaktgrenze gegen den Svaneke Granit bei Listed ein »Glimmerschiefer« vorkommt. Mein Einwand gilt jedoch nur der Bezeichnung: „Glimmerschiefer«. Zusammen 
mit Dr. Kaufmann habe ich diese Stelle, die ich von vornherein gut kannte, besucht, und ich habe nun neue Proben des Gesteins untersucht. Dieses muss nach meiner Meinung als Gneis bezeichnet werden. Das Gestein ist, innerhalb eines kleinen, eng begrenzten Gebiets schiefriger und hat einen mehr ausgesprochenen Gneishabitus als es der gestreifte Granit gewöhnlich hat. Aber er zeichnet sich nicht durch irgend einen hervortretenden Glimmer- und Quarzgehalt aus. Der Hauptbestandteil ist Mikroklin. Plagioklas tritt in bedeutender Menge auf und bildet sogar relativ grobkörnigere Lagen oder Linsen, in denen einzelne Plagioklaskristalle einen Durchmesser von ca. $5 \mathrm{~mm}$ erreichen können. Im ganzen genommen ist sowohl der Mineralbestand wie das Mengenverhältnis zwischen den Bestandteilen dasselbe, wie man es gewöhnlich im Gudhjem Granit findet. Darum ist es irreführend, dieses Gestein als Glimmerschiefer zu bezeichnen. Ich kann es nur als eine lokal stärker gneisartig entwickelte Varietät auffassen, während ich im übrigen sämtliche bornholmer Gesteinsvarietäten zu den Gneisgraniten rechne. 


\section{Résumé.}

Bornholms Grundfjeld indtager et Areal af ca. $400 \mathrm{~km}^{2}$ eller to Trediedele af hele Øen. En Fortsættelse deraf udgøres af Ertholmene (Christiansø). I Modsætning til det sedimentære Lavland mod Syd og Vest ligger Granitterrainet højt, for Størstedelen over $100 \mathrm{~m}$ over Havet. Under Istiden er Øens Overflade bleven afrundet i store Træk, men i Virkeligheden er Graniten stærkt forkløftet, hvilket ses i de skarpe, takkede Klippeformer langs Kysterne, hvor der paa sine Steder findes dybe Kløfter. I endnu større Maalestok giver Forkløftningen sig tilkende i de talrige, ofte flere Kilometer lange Sprækkedale i det Indre af Øen.

\section{De bornholmske Graniter.}

Pag. 12-17 gives en Oversigt over Granitvarieteterne, som inddeles i en ældre og en yngre Afdeling. Aldersforskellen mellem disse maa anses for ringe. Til den ældre Afdeling hører Rønne Graniten samt de stribede Granitvarieteter, som udgør Størstedelen af Granitomraadet, nemlig Paradisbakke Granit, Vang Granit, den stribede graa Granit (Gudhjem Granit), hvilken sidste med nogen Variation i Sammensætning findes i et bredt Bælte langs NØ-Kysten omtrent fra Ruts Kirke til Østermarie, samt lignende stribede Varieteter i Egnen omkring Aakirkeby; endvidere henregnes hertil den lyse røde, mellemkornede Alminding Granit samt den lyse, finkornede »Hasle Granit«; den sidstnævnte optræder i flere smaa Forekomster, særlig i Egnen mellem Hasle og Gudhjem. - Den yngre Afdeling bestaar af Hammer Granit og Svaneke Granit. Hammer Graniten har en tydelig eruptiv Grænse og en smal aplitisk Randzone imod Vang Graniten. Ogsaa Svaneke Graniten har en aplitisk Randzone, som dog er mindre iøjnefaldende end Hammer Granitens; dens yngre Alder fremgaar yderligere deraf, at den indeslutter talrige Brudstykker af den tilgrænsende stribede Granit.

Pegmatitgange med et uregelmæssigt Forløb er almindelige overalt i Granitterrainet. Desuden forekommer pegmatitiske Slirer i betydelig Mængde navnlig i de stribede Granitvarieteter. Aplit optræder sjelden i Gangform undtagen i Vang Graniten, hvor Gangene er Udløbere af Hammer Granitens Randaplit.

Pag. 18-22 indeholder et Résumé af tidligere Arbejder vedrørende Bornholms Grundfjeld. Som Resultat af den foreliggende Undersøgelse fremsættes den Anskuelse, at de enkelte Granitvarieteter er Differentiationsprodukter af et oprindelig ensartet Magma. De yngre Hammer- og Svaneke Graniter opfattes som sene Differentiationsprodukter af samme Magma. Det bornholmske Grundfjeld maa henregnes til den ældre Afdeling af Archæicum (Gnejsgraniter). Sluttelig paapeges, at Betegnelserne „Knudsbakkegranit» for 
Ronne Granit og "Klondyke« for Vang Granit, som fra de tidligere Beskrivelser er gaaet over i Udlandets Literatur, er uheldigt valgte.

Pag. 23-125: Geologisk-petrografisk Beskrivelse af Bjergarterne. Af den ældre Afdelings Bjergarter beskrives først de plagioklasog hornblenderige Varieteter, derefter de hornblendeførende eller hornblendefrie Biotitgraniter og sidst de saliske Mikroklingraniter og Apliter.

Rønne Graniten indtager et smalt Omraade langs Granitterrainets SVRand fra Almegaard NNØ for Rønne til Baunklint i Vestermarie. Omraadets Længde er $8-9 \mathrm{~km}$, dets Bredde næppe mere end $3 \mathrm{~km}$. Denne Granit har længe været Genstand for Brydning, den egner sig saavel til Bygningssten som til Monumenter. De største Brud findes ved Klippegaard, Stubbegaard og i Baunklint. Rønne Graniten er mørkegraa, mellemkornet, men har dog lidt varierende Kornstørrelse. I Overfladen er den altid lidt rødlig. Feldspaten bestaar af Kalifeldspat og Plagioklas, hvoraf sidstnævnte udgør godt og vel Halvdelen. Kalifeldspaten bestaar i Reglen af Mikroklinperthit, men i enkelte Prøver fandtes udelukkende Orthoklasperthit. Plagioklasen er en Oligoklas. I polariseret Lys har den ofte et karakteristisk plettet Udseende, som hidrører fra, at Udslukningsvinklen varierer paa en uregelmæssig Maade i det Indre af Krystallerne. Dette skyldes, at Plagioklaskernen har uens Sammensætning i forskellige Felter, varierende fra $28-20 \%$ An. Plagioklasen er omgiven af parallel tilvoxet Mikroklin. Paa Steder, hvor Mikroklinen ikke danner en fuldstændig Kappe, har Plagioklasen en yderste Randzone af Albit med ca. 10\% An. I enkelte Tilfælde er funden $2-3 \mathrm{~cm}$ store, strøkornsagtige Plagioklaskrystaller (Labrador med 54\% An.). — Blandt de mørke Mineraler er Hornblende overvejende. Hornblenden er en Hastingsit-lignende Varietet, karakteriseret ved blaagrøn Absorptionsfarve $\gamma$, en ret lille optisk Axevinkel og et højt Indhold af $\mathrm{FeO}$. Kornene har altid en meget uregelmæssig Form, de er konstant sammenvoxet med Biotit og indeslutter talrige Kvartskorn o. a. Mineraler. Samme Hornblende genfindes i alle de andre hornblendeførende Granitvarieteter paa Bornholm. Ogsaa Biotiten har en meget uregelmæssig Form (se Fig. 9). Accessorisk findes titanholdig Magnetit, Titanit (ofte i Krans om Magnetit), Apatit og Zirkon, sjeldnere Svovlkis og Orthit. Paa enkelte Steder findes ret betydelige Mængder af Epidot, Serpentin, Muskovit og Klorit. Analyse af Rønne Granit pag. 39.

Basiske Udskillelser forekommer hyppigt i Rønne Graniten (pag. 40). Som Indeslutning i Graniten SV for Knuds Kirke er funden en ejendommelig Bjergart, der næsten udelukkende bestaar af Kvarts og Titanit; underordnet optræder Feldspat, og i visse Partier af Indeslutningen er Klorit og Svovlkis rigelig tilstede (pag. 41 ff.). Endvidere findes af og til nævestore Klumper af Pegmatitfeldspat som Indeslutninger i Rønne Graniten (pag. 48). De bestaar af Mikroklinperthit og er undertiden omgivne af en smal Bræmme af skriftgranitisk sammenvoxet Kvarts og Plagioklas.

Pag. 53. Rønne Granitens Overgangsbjergart. Mod Øst gaar Rønne Graniten gennem en porfyrisk og stedvis tydelig stribet Overgangsbjergart, hvori Hornblendeindholdet lidt efter lidt aftager, over i den graa, hornblendefattige, stribede Granit. Strøkornene bestaar af Plagioklas, Grundmassen af en finkornet Blanding af Mikroklin og Kvarts samt varierende Mængder af mørke Mineraler.

Pag. 60. Paradisbakke Graniten staar i Sammensætning den sidst nævnte meget nær. Dens mørkegraa, hvidflammede Udseende skyldes, at de lyse Bestanddele fortrinsvis er samlede i aplitiske Slirer; de mørke Partier har 
en meget finkornet Grundmasse med Strøkorn af Plagioklas. Mest typisk forekommer denne Granit i Paradisbakkerne NV for Nexø, men den flammede Karakter kan spores mod Nord næsten til Listed. Analyse pag. 65.

Pag. 66. Vang Graniten har ligesom de foregaaende et betydeligt Indhold af Plagioklas og Hornblende. Den danner et Bælte tvers over Øen mellem Fiskerlejerne Vang og Tejn. I de høje Kystklipper Syd for Vang, Stenbruddet "Klondyke", er Graniten fuldstændig jevnkornet. Farven er mørk graa med et rødligt Anstrøg. Plagioklasen er for endel udviklet som større firkantede, graalig-klare Korn. Kvartsen er ofte lidt røgfarvet. De mørke Mineraler er samlede i karakteristiske Hobe. I Størstedelen af Omraadet er Vang Graniten dog noget stribet, hvilket skyldes, at Hobene af mørke Mineraler er flade og parallelt ordnede; mod Syd gaar den jævnt over i den graa stribede Granit (Gudhjem Granit). Det er karakteristisk for Vang Granitens Struktur, at Kvarts og Mikroklin i udstrakt Grad optræder i granofyrisk Sammenvoxning. Analyse af Vang Granit pag. 69.

Pag. 76. Mindre Forekomster af hornblendeførende Granit findes bl. a. ved Haldegaard S for Gudhjem og ved Tækkeregaard NNØ for Hasle. I Struktur og Sammensætning har Graniten i disse Forekomster stor Lighed med Rønne Granitens Overgangsbjergart, Plagioklas- og Hornblendeindholdet er endog større end i nogen anden Granitvarietet paa Bornholm (pag. 77)

Pag. 78. Stribet Granit. Størstedelen af Bornholms Granit udgøres af en mere eller mindre tydelig skifret, middel- til finkornet og hyppig porfyrisk Bjergart af graa Farve, som i Overfladen sædvanlig gaar over i det rødlige. Stribningen skyldes, at mørke og lyse Bestanddele er mere eller mindre udpræget ordnet i vexlende tynde Lag; ofte bliver Graniten derved tydelig skifret. I Stenbruddene og i Kystklipperne kan det konstateres, at Stribningen over store Strækninger har en nogenlunde konstant Retning: VNV— ØSØ eller V- $\varnothing$. Den stribede Granit er i Almindelighed stærkt forkløftet. I Kystklipperne gør navnlig to Kløftretninger sig stærkere gældende, en parallel med og en paa tvers af Stribningens Retning; den sidste svarer til Spaltedalenes og Diabasgangenes Retninger. Den bedste Spaltelighed i Graniten ligger parallel med Skifrigheden, den er væsentligst betinget af Glimmerbladenes Retning. I Almindelighed danner denne Retning kun smaa Vinkler med Horizontalen, sjelden over $30^{\circ}-40^{\circ}$. (Fig. 14 og 15).

Den stribede Granit varierer noget i Sammensætning. Gudhjem Graniten i den nordlige Del af Omraadet bestaar overvejende af Kvarts og Mikroklin, men Plagioklas optræder dog i relativ store Korn. Hornblende er i Almindelighed sparsom. Mod Øst paa Strækningen fra Kjeldseaaen over Skrulle, Østermarie, Lyrsby indtil Paradisbakkerne har Graniten en mørkere graa Farve og et større Indhold af Plagioklas, Biotit og Hornblende. Stribningen er her ofte udviklet som en linear Parallelstruktur. Denne Granit gaar jævnt over i Paradisbakke Graniten. - I den sydlige Del af Granitomraadet vexler Bjergarten paa lignende Maade. Mellem Paradisbakkerne og Aakirkeby er Graniten ret mørk, glimmerrig og stærkt stribet. De større Feldspatkorn bestaar næsten udelukkende af Plagioklas. I Egnen omkring Aakirkeby optræder ogsaa Mikroklin i større Korn, ofte sammenvoxet med Plagioklas. Hornblende er rigelig tilstede. Vest for Aakirkeby bliver Graniten mere rødlig. Kornstørrelsen er meget uensartet, og større Feldspatkorn ligger ofte samlede i Hobe. Denne »dobbeltkornede struktur giver Stenen et porfyrisk Udseende. Hornblende kan paa nogle Steder være det fremherskende mørke 
Mineral, paa andre Steder helt mangle. Denne Granit gaar jævnt over i den stribede Granit i Egnen Øst for Rønne.

Pag. 88. Rød, svagt stribet Granit. Alminding Granit. I den centrale Del af Granitomraadet er Bjergarten mellemkornet og lys rødgraa. Den røde Farvetone skyldes dels Feldspatens røde Farve, dels Udskillelser af Ferriforbindelser i Sprækker i Kvarts og Feldspat. Denne Bjergart har baade i Udseende og i Sammensætning overordentlig stor Lighed med Hammer Graniten. Den indeholder kun faa mørke Bestanddele, som for Størstedelen bestaar af Biotit; de er ordnede i uregelmæssige Pletter, der i Reglen ikke breder sig ud over større Flader, Stribningen er derfor kun lidet udtalt. Alminding Graniten er ret kvartsrig. Plagioklas staar i Mængde væsentlig tilbage for Mikroklin. Analyse pag. 89. Alminding Granitens Udbredelse kan ikke angives med Sikkerhed, da det Indre af Bornholm er ret stærkt dækket af løse Jordlag; saa vidt det kan ses, gaar den mod Nord og Syd jævnt over i den graa stribede Granit, mod Vest synes Overgangen at være temmelig brat. - Paa Christiansø findes en Granit, som staar Alminding Graniten meget nær (pag. 90).

Pag. 91. Rød, finkornet, aplitisk Granit, "Hasle Granit", optræder i flere smaa, snævert begrænsede Forekomster, hvoraf den betydeligste ligger ved Frigaard $2 \mathrm{~km}$ NØ for Hasle. Her brydes denne Granit til Brosten. I Henseende til Mineralbestand og Struktur staar "Hasle Graniten" den graa Gudhjem Granit meget nær, men adskiller sig fra denne ved sin Fattigdom paa mørke Mineraler og sin gennemgaaende ringe Kornstørrelse; ofte er Graniten meget kvartsrig, men Hovedbestanddelen er dog altid Mikroklin. Hornblende mangler næsten altid.

Pag. 92. I den stribede Granit findes endel betydelige Pegmatitforekomster. Vest for Almindingen blev Pegmatiten en Tid lang brudt til Brug for Porcellainsfabrikation, men denne Anvendelse maatte opgives, fordi Feldspaten var for uren. Pegmatiten i Hvidehald $\mathrm{N}$ for Aakirkeby indeholder stærkt labradoriserende Plagioklas. Ved Skovgaard i Bodilsker findes en ca. $30 \mathrm{~m}$ mægtig Pegmatitgang, hvori man mente at have fundet Beryl; dette synes ikke at være Tilfældet. Pegmatiten paa Bornholm har overalt en meget simpel Sammensætning; Hovedbestanddelen er rød Mikroklinperthit, Kvarts kan stedvis optræde i større Masser (f. Ex. i "Sølvklippen« ved Gudhjem). Ofte bestaar en stor Del af Pegmatiten af Skriftgranit. Plagioklas forekommer hyppigt i underordnet Mængde. Biotit og Magnetit findes sparsomt, sjeldnere findes Flusspat og i enkelte Tilfælde Blyglans. - Aplitgange er sjeldne i den stribede Granit. Apliten har i Reglen samme Sammensætning som den foran nævnte aplitiske Granit, men i en enkelt Gang ved Tvillinggaarde VNV for Aakirkeby er Bjergartens Hovedbestanddel Oligoklas-Albit med $12 \%$ An., dernæst indeholder denne Aplit Kvarts og Mikroklin i omtrent samme Mængde samt accessorisk Biotit og Magnetit.

Pag. 94. Yngre Afdeling. Hammer Graniten i Bornholms nordligste Spids er en lys rødgraa, mellemkornet Granit, hvis Hovedbestanddele er Mikroklin, Plagioklas og Kvarts. Mørke Mineraler er i det hele sparsomt tilstede, de udgøres væsentligst af Biotit. Analyse pag. 97. Hammer Graniten anvendes i udstrakt Grad til Bygnings- og Brosten; den brydes i talrige Brud, hvoraf det største ligger paa Sydsiden af Hammeren.

Grænsen mellem Hammer- og Vang Granit fandt jeg blottet paa flere Steder, de vigtigste er Kystklipperne ca. $125 \mathrm{~m} \mathrm{~N}$ for Havnen i Vang, et Stenbrud ved Sjelle Mose ca. $2 \mathrm{~km}$ S for Allinge og Kystklipperne paa NØ- 
Kysten ca. $1 \mathrm{~km}$ SSØ for Allinge. Mest instruktivt er Stenbruddet ved Sjelle Mose, hvor man baade i Bruddets Nordvæg og Sydvæg ser Vang Granit liggende over Hammer Granit. I Størstedelen af Bruddet har Hammer Graniten sit normale Udseende, men i Nærheden af Grænsen mod Vang Graniten bliver den først noget porfyrisk med aplitiske og pegmatitiske Slirer, tilsidst helt finkornet. Den finkornede Grænsebjergart er lidt pegmatitsliret, og de sparsomme mørke Mineraler er ordnede i langstrakte Hobe, saa at Bjergarten bliver tydelig stribet langs med Grænsefladen. Denne Stribning fortsæetter sig et Stykke ind i den noget grovere Hammer Granit. I selve Kontakten er Hobene af de mørke Mineraler i Vang Graniten noget udtrukne og udtværede (Fig. 18). Hammer Granitens Randaplit bestaar hovedsagentlig af perthitfattig Mikroklin og Kvarts. Kornene er yderst uregelmæssig begrænsede, og Kornstørrelsen er noget uens. Plagioklas optræder kun i smaa Korn, som ofte er noget omdannede i det Indre; de bestaar af OligoklasAlbit. De mørke Mineraler er Biotit, Magnetit og Titanit. I den porfyriske Bjergart nogle Meter fra Kontakten optræder baade Kvarts, Mikroklin og Plagioklas saavel i større Korn som i finkornet Blanding. Plagioklasen er noget anorthitrigere. Myrmekit, som i den finkornede Bjergart er ret sparsom, er her rigelig tilstede. De underordnede Mineraler er de samme som i den finkornede Zone. - Hammer Granitens Randaplit gennemsætter Vang Graniten i talrige Gange med et højst uregelmæssigt Forløb. I Bruddets Nordvæg ses en Aplitgang (A-A i Fig. 17), som er en direkte Udløber af Hammer Graniten. Detailtegningen Fig. 19 viser, hvorledes Randaplitens slirede Struktur fortsætter sig langs Ganggrænsen i Aplitgangen, medens Bjergarten i Midten af Gangens nederste, tragtformige Del er mere grovkornet. De samme Figurer viser endvidere en Pegmatitgang, P-P, som fra Hammer Graniten fortsætter sig ind i Vang Graniten og overskærer Aplitapofysen.

Paa samme Maade er Granitgrænsen udviklet i Kystklipperne udfor Sandkaas Station. Den finkornede Zone er her kun 0,25-0,5 m mægtig; derimod er Hammer Graniten indtil en Afstand af ca. $500 \mathrm{~m}$ fra Kontakten ret tydelig porfyrisk, stedvis glimmerrig og udtalt stribet. I Nærheden af Grænsen er den overordentlig pegmatitrig; Flusspat forekommer ret hyppigt, undertiden som Krystaller i Hulrum.

Det samme Forhold mellem de to Graniter ses i Kystklipperne $\mathrm{N}$ for Havnen i Vang. Den finkornede Zone har her en Bredde af mindst $10 \mathrm{~m}$. Dette betyder dog ikke, at Randapliten har en saa stor Mægtighed, thi som det ses i Fig. 20-21, strækker Hammer Graniten sig ogsaa her ind under Vang Graniten, og Strandbredden repræsenterer derfor et skraat Snit gennem Grænsefladen. Syd for Vang ser man paa en længere Strækning langs den nedlagte Jernbane til Stenbruddet "Klondyke» en anselig Aplitmasse i Foden af den stejle Klippevæg. Aplitens Overgrænse er ret uregelmæssig bugtet, Undergrænsen er ikke synlig. Bjergarten er den samme som i Hammer Granitens Randaplit, og sandsynligvis er det Kontakten mellem de to Graniter, som her atter træder frem i Dagen.

En ganske lignende Aplit optræder i større Masser noget sydligere ved Korsbjerg. I et Par af de mange smaa Stenbrud i denne Egn ses Vang Granit over Apliten. I et af Bruddene ser man, at Apliten danner Gange i Vang Graniten og i store Træk følger dennes Stribning. Apliten ledsages af Pegmatit og indeholder endel stærkt udtrukne, tydeligt stribede Linser af Vang Granit (Fig. 22). Da der lidt Syd herfor i et lille Omraade mellem Ols Kirke, Dalegaard og Maegaard forekommer saavel typisk mellemkornet som por- 
fyrisk Hammer Granit, er det sandsynligt, at Apliten ved Korsbjerg udgør en Del af Hammer Granitens Randaplit.

Pag. 108. Svaneke Graniten indtager den østligste Del af Granitomraadet $\mathrm{i}$ en Zone af $3-4 \mathrm{~km}$ Bredde. Grænsen mod den stribede Granit forløber som en næsten lige Linie fra Listed paa NØ-Kysten til Sydøstspidsen af Helvedesbakkerne. Svaneke Graniten er betydelig mere grovkornet end de øvrige Granitvarieteter, Feldspatkornene maaler ofte $1-2 \mathrm{~cm}$ i Tversnit. Kvarts staar i Mængde langt tilbage for Feldspat og gør sig makroskopisk kun lidet bemærket. Hovedbestanddelen er en lys rødlig Mikroklinperthit, men ogsaa Plagioklas (Oligoklas med ca. 25-27\% An.) optræder i betydelig Mængde og danner ofte centimeterstore Korn. Indholdet af mørke Mineraler er betydeligt, Biotit er fremherskende, Hornblendemængden er noget varierende men i Almindelighed ringe. Titanit forekommer i større Mængde end i nogen af de andre Bornholmergraniter. Blandt de underordnede Bestanddele ses af og til Flusspat, sjeldnere Kobberkis, i et enkelt Tilfælde er funden Jernglans. Analyse pag. 113. Basiske Udskillelser er ret almindelige. Pegmatit er overalt rigelig tilstede, Aplit er sjelden.

Mod Syd er Svaneke Graniten skilt fra Nexø Sandstenen ved en Forkastning. Langs Grænsen er Graniten stærk breccieret. Bindemidlet mellem Brudstykkerne bestaar af Klorit og jernholdige Forbindelser, som giver Stenen en meget mørk Farve. I Breccien findes Udskillelser af Flusspat og Kvartskrystaller samt smaa Mængder af Blyglans og Kobberkis, der har givet Anledning til det gamle Navn "Kobbergangen« ved Nexø.

Svaneke Granitens yngre Alder fremgaar af, at den indeslutter talrige Brudstykker af den graa stribede Granit. Indeslutningerne har nøjagtig samme Beskaffenhed som den nærmest tilgrænsende stribede Granit. Ved Kodalhuse i den nordøstlige Del af Paradisbakkerne fandt jeg en Blok af typisk flammet Paradisbakke Granit indesluttet i Svaneke Graniten, og ved Listed talrige Blokke af graa stribet, men ikke flammet Granit. De mindre Indeslutninger har afrundede Former, og langs Overfladen er Biotit ofte udskilt i større Mængde; dette har givet Anledning til, at Indeslutningerne er blevne forvexlede med basiske Udskillelser. - Ved Listed ses Grænsen mellem de to Graniter tydelig i Strandklipperne (Fig. 26-27). Umiddelbart ved Kontakten gaar Svaneke Graniten over i en relativ finkornet, svagt porfyrisk Grænsebjergart, som gennemsætter den stribede Granit i talrige smaa Apofyser og uregelmæssige Slirer.

Svaneke Graniten er ofte stærkt forkløftet. En stor Del af Sprækkerne forløber ganske uregelmæssigt, men hyppigt er en parallelepipedisk Forkløftning iøjnefaldende (Fig. 23). Paa flere Steder er Svaneke Graniten meget tilbøjelig til at smuldre, hvorved Spalterne udvides og fordybes. Navnlig ved Aarsdale har Granitens Smuldring ført til Dannelse af mægtige Gruslag, medens store, runde, modstandsdygtigere Klippeblokke rager op over Gruset og giver Landskabet en ejendommelig Karakter (Fig. 28). Aarsagen til Granitens Smuldring maa først og fremmest søges i den gennemgribende Forkløftning, som har banet Vej for en dybtgaaende atmosfærisk Forvitring. I Svaneke Graniten findes jævnlig Glideflader, som viser, at Forkløftningen ialfald delvis hidrører fra Jordskorpebevægelser. Dernæst har Svaneke Granitens Struktur været gunstig for Smuldringen. De store Feldspatkorn har ret jævne Overflader. Mellemrummene udfyldes dels af mørke Mineraler, dels af en finkornet Blanding, hvori Plagioklas spiller en stor Rolle. I en saadan Bjergart vil Temperaturvariationer eller smaa Jordskorpebevægel- 
ser let frembringe Revner, hvor igennem Vandet kan trænge ind og bevirke en kemisk Forvitring af Plagioklas og Biotit. Derved ødelægges Stenens Sammenhæng, og de øvrige, friske Mineraler falder fra hinanden. Saaledes opstaar det grove Grus, som væsentligst bestaar af Mikroklin eller smaa Granitbrudstykker, der ikke har noget synderligt Indhold af mørke Mineraler.

Pag. 126-138 omtales Graniternes kemiske Forhold. Det maa antages, at de forskellige Granitvarieteter er opstaaet ved Differentiation af et oprindeligt ensartet Magma. En Differentiationstheori, som her kan komme i Betragtning, maa kunne tolke Graniternes Struktur med den mere eller mindre tydelige Aldersfølge mellem Mineralbestanddelene, deres mere eller mindre udviklede Parallelstruktur og gnejsagtige Habitus; endvidere at Bjergarternes geologiske Optræden er karakteriseret ved jævne Overgange indenfor Størstedelen af Granitomraadet, men at der dog findes en tydelig Aldersforskel markeret ved en skarp geologisk Grænse mellem den stribede Granit og de jævnkornede Graniter: Hammer- og Svaneke Graniterne. Den Omstændighed, at Parallelstrukturen over Størstedelen af Granitterrainet har samme Retning, og at Granitvarieteterne i dette Omraade gaar jævnt over i hinanden, viser, at de enkelte Bjergarter ikke er dannet successivt, men at Størkningen af hele denne Del af Graniten maa være foregaaet nogenlunde samtidig, og at Magmaet allerede før Størkningen til en vis Grad har været spaltet i flere Dele med forskellig Sammensætning. Parallelstrukturen lader sig simplest tolke som en Fluidalstruktur opstaaet ved, at der paa et vist Tidspunkt under Differentiationen er indtraadt Bevægelse i det helt eller delvis flydende Magma. - Hammer- og Svaneke Graniterne maa antages at være saliske Differentiationsprodukter af samme Magma, som har intruderet den stribede Granit, efter at denne var størknet.

Pag. 139-147 forsøges en Sammenligning mellem det bornholmske og det sydsvenske Grundfjeld. Nogen sikker Afgørelse af Spørgsmaalet om, hvorvidt de bornholmske Graniter bør henregnes til den ældre eller den yngre Grundfjeldsafdeling, lader sig ikke uddrage deraf. Dog synes de fleste geologiskpetrografiske Karaktertræk at pege i Retning af den ældre Grundfjeldsafdeling. Bestemmende for min Opfattelse af de bornholmske Graniter som Gnejsgraniter har først og fremmest været Bjergarternes granulerede Struktur, deres mere eller mindre udviklede Parallelstruktur og særlig den i Detailler optrædende Differentiation og den slireagtige Anordning af Differentiationsprodukterne, som giver Bjergarterne en gnejsagtig Habitus.

\section{Diabas.}

Pag. 148. Diabasgange forekommer i stor Mængde indenfor Granitomraadet, de er derimod aldrig fundne i Sedimenterne paa Bornholm. Diabasen gennemsætter Graniten i regelmæssige Gange, som ofte staar lodrette eller kun afviger faa Grader fra denne Stilling. Gangenes Strygningsretning ligger i Reglen mellem $\mathrm{N}-\mathrm{S}$ og falder i det væsentlige sammen med Spaltedalenes Retninger. Kun paa Vestkysten, paa Hammeren og ved Jons Kapel, findes Gange med Retning mellem N-S og VNV-ØSø. Mægtigheden af Gangene varierer fra $20-30 \mathrm{~cm}$ til ca. $60 \mathrm{~m}$, men de fleste naar dog næppe et Par Meter i Bredde. Smaa Diabasgange optræder paa nogle Steder i Sværme, f. Ex. paa Kyststrækningen mellem Helligdommen og Tejn; saavel Diabasen som 
Granitmellemrummene kan da gaa ned til en Bredde af mindre end $20 \mathrm{~cm}$. Bjergarten er Olivindiabas; dens Sammensætning kan variere lidt efter Mængdeforholdet mellem Olivin og monoklin Pyroxen. Biotit forekommer almindeligt som underordnet Bestanddel, og i nogle Diabaser er den forholdsvis rigelig tilstede. Hornblende er sjeldnere. Smaa Mængder af Kvarts er hyppigt tilstede. I enkelte Tilfælde er funden rhombisk Pyroxen. Nogle faa Diabaser er ret feldspatfattige. I nogle Tilfælde er Diabasen overordentlig frisk og velbevaret, men oftest indeholder den endel Serpentin og Klorit. Adskillige Gange er meget stærkt omdannede under Udskillelse af Serpentin, Sericit, Klorit, Kalkspat, Kvarts m. m., hvilket i Forbindelse med Diabasens stærke Forkløftning har givet Anledning til, at enkelte Gange er blevet helt borteroderet, f. Ex. en Gang ved Jons Kapel.

Pag. 150. Kjeldseaaens Diabasgang er den største paa Bornholm, ved Saltuna har den en Bredde af ca. $60 \mathrm{~m}$. Herfra kan Gangen følges ca. $6 \mathrm{~km}$ gennem Aadalen. Dens Strygningsretning er N $40^{\circ} \varnothing$. Bjergarten erindrer meget om Åsbydiabas. Over Størstedelen af Gangen er den mellemkornet og i Randzonen finkornet. Strukturen er i Reglen ofitisk. Men visse Partier af Diabasen er temmelig grovkornede og har nærmest gabbroid Struktur. Disse Partier er i paafaldende Grad fri for Sprækker. Paa nogle Steder er Diabasen ret stærkt omdannet, og paa Sprækker findes da Udskillelser af Kalkspat, Serpentin, Svovlkis, Prehnit, Epidot og Albit, de to sidstnævnte undertiden i smukke Krystaller.

I Modsætning til de øvrige Diabasgange har Kjeldseaaens Gang udøvet en kraftig Kontaktvirkning paa Sidestenen. I 5-10 m Afstand fra Diabasen er Graniten kun svagt paavirket, hvilket viser sig ved, at de mørke Mineraler er blevne flossede i Kanten og fyldte med smaa Ertspartikler. Men ca. $1 \mathrm{~m}$ fra Diabasen optræder tillige mikropegmatitiske Sammenvoxninger af Kvarts og Feldspat (Tavle VIII, Fig. 2), som nærmere ved Diabasen tiltager i Mængde (Tavle VII, Fig. 3). I selve Kontakten er opstaaet en finkornet, sortegraa Blandingsbjergart af Granit og Diabas, som indeholder Brudstykker af Granitens Feldspat og Kvarts. Denne Kontaktbjergart faar derved et porfyrisk Udseende og er tidligere af Ussing omtalt som "Granitporfyr * Ganske lignende Omdannelser forekommer i Graniten paa begge Sider af Ekkodalen, som er en Fortsættelse af Kjeldseaaens Dal. Det maa derfor antages, at Diabasgangen fortsætter sig videre mod SV og ligger skjult i Bunden af Ekkodalen.

Pag. 164. Ved Kaas paa NØ-Kysten findes den næststørste af Diabasgangene, den er $40 \mathrm{~m}$ bred. Gangen er kun blottet i Kystklipperne og kan ikke folges indefter i Landet. Diabasen er mellemkornet og har ofitisk Struktur, langs Ganggrænsen er den finkornet. Bjergarten er den samme som i Kjeldseaaens Gang. Kontaktvirkninger spores ikke.

Pag. 164 173. En tredie anselig Diabasgang optræder i Listed paa det lille Næs »Gule Hald«; den er $30 \mathrm{~m}$ mægtig og har Strygning N $10^{\circ} \varnothing$. Den samme Diabas fandtes ved en Brøndgravning $500 \mathrm{~m} \mathrm{~S}$ for dette Sted, og i Tamperdalen i Paradisbakkerne ca. $5 \mathrm{~km} \mathrm{~S}$ for Listed træder Diabasen atter i Dagen paa to Steder. En Linie med Retning N $10^{\circ} \varnothing$ fra Listed til Paradisbakkerne træffer netop paa disse Forekomster. Gangen har i Tamperdalen en Bredde ca. $20 \mathrm{~m}$. I Midten af Gangen er Bjergarten den samme som i de foran omtalte Gange; men i en 3-4 m bred Zone langs Ganggrænsen har Diabasen saavel i Listed som i Tamperdalen en noget afvigende Mineralbestand og Struktur. Plagioklasen har en bredere og mere uregelmæssig 
Form; Augit optræder dels som rundagtige Korn, dels som slanke Søjler; Olivin mangler helt. I denne Zone optræder endvidere talrige Indeslutninger af store, elliptisk afrundede Feldspatkrystaller (Fig. 35), som ofte kan naa 2-3 cm paa den længste Led. I Nærheden af disse Feldspatovoider findes jævnlig smaa Kvartsindeslutninger, der kan blive saa store som en Ert eller en Hasselnød. Feldspatovoiderne bestaar ofte af to eller tre afrundede Feldspatkrystaller, mellem hvilke lidt Diabasmateriale er trængt ind. Disse Feldspater er i Reglen mørkegraa med rødlige Pletter, hvorfor Conen og DeEcke har anset dem for Orthoklas. Den nærmere Undersøgelse har dog vist, at de bestaar af Plagioklas (Oligoklas) med en surere Sammensætning end Diabasplagioklasen. De har en ret kompliceret indre Bygning (se Tavle VII, Fig. 2-5) og indeslutter finkornede Aggregater, som væsentlig bestaar af Kvarts, Plagioklas, Augit, brun Hornblende og Biotit. Lignende Feldspatkrystaller, særlig fra svenske Diabasgange, er tidligere beskrevet, og deres Oprindelse er tolket paa forskellig Maade. I Beskaffenhed afviger de i lige høj Grad fra Diabasens som fra Granitens almindelige Feldspat. Mest sandsynligt er det, at Diabasmagmaets Sammensætning er blevet forandret ved Indsmeltning af løsrevne Granitblokke, og at dette har resulteret i Udkrystallisationen af disse ejendommelige Plagioklaskrystaller. Ved Ganggrænsen, som i Listed er udmærket blottet, har Diabasen tæt Struktur, hvilket viser, at Magmaet er blevet hurtigt afkølet ved Berøring med Sidestenen.

Pag. 173. De mindre Diabasgange bestaar ligesom de foran næunte af Olivindiabas, men i mange Tilfælde er Olivinen helt eller delvis omdannet til Serpentinpseudomorfoser. Bjergarten er ofte porfyrisk, men adskillige Diabaser har dog en jævnkornet Struktur. Flere Steder er Diabasen udviklet som Mandelsten, hvori Mandlerne i Reglen bestaar af Kalkspat og Klorit. I de mindre Diabasgange har Augiten ofte Timeglasstruktur og en svag men dog tydelig Pleokroisme; den optræder dels som slanke Søjler, dels som rundagtige Korn.

Pag. 174. Jævnkornede Diabaser, som hyppigt er meget biotitrige, forekommer bl. a. ved Møllebæk i Tejn, ved Stammershalle og i Helligdomsklipperne samt i det lille Skær "Malkværnen" NNØ for Nexø. Af lignende Beskaffenhed er en Diabas strax Syd for Havnen paa Christiansø; den udmærker sig ved at indeslutte endel Granitfragmenter, og paa nogle Steder er den udviklet som en Diabas-Granit-Breccie.

Paj. 176-184. Olivindiabasporfyrit. I de fleste mindre Gange er Diabasen porfyrisk. Mængden af Feldspat kan variere noget. Ved Korsbjerg $\mathrm{N}$ for Ols Kirke forekommer en lille 0,5 m mægtig Gang med en usædvanlig Strygningsretning: $\mathrm{N} 60^{\circ} \varnothing$. Bjergarten er finkornet og helt sort. Dens mest fremtrædende Bestanddel er Plagioklas (se Fig. 36). Mellem disse Krystaller ligger smaa Olivinkorn, som sjelden maaler mere end godt en Millimeter i Tversnit. Augit kan ikke paavises med Sikkerhed men findes antagelig i den mørke Grundmasse, hvori et stænglet Mineral med høj Lysbrydning og Dobbeltbrydning kan ses med stærk Forstørring. Magnetjernsten er rigelig tilstede, mest i Form af Krystalskeletter, som er indvoxede i Plagioklaskrystallernes Randzone. - Af lignende Art, men med mere uregelmæssig Kornstørrelse, er Grundmassen i en Diabas ca. $400-500 \mathrm{~m} \varnothing$ for Torneværket ved Rønne; men denne Diabas fører desuden store Tavler af Feldspat, ca. $2 \mathrm{~mm}$ tykke og flere $\mathrm{cm}$ i Udstrækning. Tavlerne er sammensat af flere forskellig orienterede Plagioklaskrystaller, mellem hvilke Serpentinpseudomorfoser efter store Olivinkorn er indlejret. 
Diabaser med Strøkorn af Plagioklas og Olivin findes bl. a. ved Sjelle Mose og i Klømberne. Hyppigere bestaar Strøkornene dog af baade Plagioklas, Olivin og Augit, og de to sidstnævnte ligger da ofte sammen i Smaahobe. Grundmassens Augit har gerne en mørkere Farve end Strøkornene. En meget smukt udviklet Diabas af denne Type findes i Østsiden af Nørrevig i Svaneke. Ved Listed optræder foruden den foran omtalte store Gang adskillige mindre Diabasgange med ret vexlende Beskaffenhed. Nogle af dem er udviklet som Mandelsten, og særlig er dette Tilfældet i Gangenes Randzone. Disse Diabaser indeholder ofte rigelig brun Hornblende, som tildels danner Kappe om Augit. I en finkornet, sort Diabas Ø for Vaseaaen i Listed fandtes endel nævestore Udskillelser af storkornet, hvid eller rødlig Plagioklas.

Endel andre Diabaser fører kun Strøkorn af Olivin og Augit. Blandt dem er den mest ejendommelige en Diabas ved Nørremarks Huse N for Nexø, hvori enkelte store Augitkrystaller udmærker sig ved, at deres Randzone er skriftgranitisk sammenvoxet med Olivin; uden om dette Komplex findes en meget olivinrig Zone (se Fig. 37).

Pag. 184. Feldspatfattige Diabaser er kun funden paa enkelte Steder. Den mest karakteristiske forekommer paa NØ-Kysten ca. $400 \mathrm{~m} \mathrm{~S}$ for K o b b ea aens Udløb. Dens fremherskende Mineral er en rødlig Augit. Olivinpseudomorfoser er rigelig tilstede, men Rester af frisk Olivin findes kun sparsomt. Plagioklas staar i Mængde langt tilbage for disse Bestanddele. Magnetjernsten og brun Hornblende er forholdsvis rigelig forhaanden.

Pag. 185. Adskillige Diabaser er meget stærkt omdannede, men ikke sjeldent kan dog de væsentligste Bestanddele og Bjergartens Struktur nogenlunde sikkert genkendes. Plagioklas er hyppigt det bedst bevarede Mineral, og Olivinpseudomorfoser er ofte tydelige, derimod findes sjelden Rester af Augit. Intet tyder paa, at der blandt disse Diabaser har været andre Bjergartstyper end de allerede omtalte. Omdannelsesprodukterne bestaar af Serpentin, der undertiden er gennemsat af fine Amfibolnaale, endvidere af Klorit, Karbonater, Kvarts og Epidot; af og til findes Chalcedon, og i nogle Tilfælde spiller rustagtige Forbindelser en betydelig Rolle. Saadanne Gange kan træffes overalt paa Bornholm, den mest bekendte findes i Nedgangen til Jons Kapel.

Pag. 187. Kontaktvirkninger kan i Almindelighed ikke paavises ved de mindre Diabasgange. En Rødfarvning af Sidestenen, som ofte forekommer langs de sydsvenske Diabasgange, er paa Bornholm kun funden ved en $3 \mathrm{~m}$ mægtig Gang i Bølshavn paa NØ-Kysten. Denne Gang er ved et Par smalle Granitmellemrum delt i tre parallele Grene. Diabasen selv er temmelig stærkt forvitret. I Granitsidestenen er de mørke Mineraler dels kloritiserede, dels forvandlede til et brunsort, rustagtigt Produkt, som er trængt ind i talrige fine Sprækker i Stenen og har givet denne en brunrød Farve.

Pag. 188. Mere indgribende Forandringer er dog foregaaet ved et Par andre Diabasgange, nemlig ved Ypnasted og ved Salene.

Ved Ypnasted findes to Diabasgange, som hver har en Mægtighed af mindst $7 \mathrm{~m}$; Afstanden mellem Gangene er $40-50 \mathrm{~m}$. Saavel Diabaserne som Graniten imellem dem og i en bred Zone paa begge Sider af Gangene er gennemsat af talrige Kvartsaarer, hvori der ofte findes veludviklede Kvartskrystaller. Diabasen er i høj Grad kloritiseret og saussuritiseret og desuden stærkt imprægneret med Kvarts; Plagioklasen bestaar udelukkende 
af Albit; endvidere indeholder Bjergarten ret rigelig Epidot og endel Titanit. I Granitsidestenen har der udskilt sig en saa stor Mængde Klorit, at Stenen derved har faaet en grønlig Farve. Kvartsindholdet er, bortset fra de nævnte Aarer, omtrent som sædvanlig i Graniten. Feldspaten synes derimod udelukkende at bestaa af Plagioklas (Oligoklas-Albit). Men Bjergartens mest fremtrædende Bestanddele er dog Kalkspat og finskællet, lys Glimmer (Sericit). Kalkspaten omslutter de øvrige Mineraler og er ofte intimt sammenvoxet med Plagioklasen. De underordnede Bestanddele udgøres af metalglinsende Ertskorn, Apatit og smaa, gulbrune Krystaller af Anatas.

Pag. 189. En fuldstændig omdannet Diabasgang af en anden Type findes ved Salene, ca. $500 \mathrm{~m} \varnothing$ for Bobeaaens Udløb og lidt $\varnothing$ for det lille Sandstensomraade (se Kortbladsbeskrivelsen pag. 123). Gangens Bredde er 20$22 \mathrm{~m}$, dens Retning er af Ussing bestemt til N $15^{\circ} \varnothing$. Det er ikke lykkedes at finde nogen Fortsættelse af Gangen længere inde i Landet, hvilket muligvis skyldes, at Gangen er blevet skraat overskaaret af den Forkastning, som skiller Sandstenen fra Graniten. Gangbjergarten er ret ensartet, mørk, graagrøn, finkornet eller tæt. I Mineralbestand og Struktur ligner den slet ikke Diabas. Hovedbestanddelene er Prehnit, Klorit og Epidot. Titanit findes i ret betydelig Mængde, derimod mangler Ertskorn næsten fuldstændig. Apatit forekommer i forholdsvis store Krystaller. Ved Ganggrænsen findes en Breccie, som er stærkt epidotiseret og kloritiseret, og hvori Aggregater af millimeterstore, røde Mikroklinkorn danner uregelmæssige Striber og Flammer. Graniten er endnu i flere Meters Afstand fra Gangen tydelig breccieret og indeholder rigelig Epidot og Klorit.

Det lille Sandstensomraade ved Salene begrænses mod Syd af en Forkastning med Retning $\varnothing 30^{\circ} \mathrm{N}$. Mod Vest dannes Grænsen af en Forkastningsbreccie, hvis Retning er N $25^{\circ} \mathrm{V}$ eller N $10^{\circ} \mathrm{V}$. I Kortbladsbeskrivelsen omtales, at Breccien væsentlig bestaar af Granitbrudstykker sammenkittet af Kalkspat og Kvarts. Nogle af O. B. BøgGild indsamlede Prøver bestaar dog af finmalet Granitmateriale sammenkittet af et grønligt eller brunligt, leragtigt Bindemiddel. Endel af Feldspaten i Breccien er stærk rødpigmenteret, Biotiten er fuldstændig kloritiseret, og af Ertskornene er opstaaet rustagtige Masser. Denne Breccie er vistnok først opdaget af H. C. Ørsted og L. Esmarch, som antog den for en Porfyrgang. I Breccien er funden smukke Krystaller af Kvarts og Kalkspat samt smaa Mængder af Jernglans. Mellem Krystallerne findes af og til en brun Kalksten eller grøn Jaspis. Den tilstødende Granit er lidt breccieret og indeholder endel Epidot, Kalkspat og rustagtige Udskillelser.

Pag. 193-198. Diabasgangenes Alder og deres Relation til Spaltedalene. For en Bestemmelse af Diabasgangenes geologiske Alder har man paa Bornholm kun faa sikre Holdepunkter, som alle tidligere har været anført. Allerede af den Grund, at Diabasgangene optræder i stor Mængde i Graniten men aldrig er fundne i Sedimentbjergarterne paa Sydog Vest-Bornholm, er det afgjort sandsynligst, at de er af prækambrisk Alder. Da endvidere alle de undersøgte Diabaser kan henregnes til Olivindiabaserne, tør det antages, at de alle hører til samme Eruptionsperiode. Derved kommer endnu en Omstændighed i Betragtning, nemlig at den store Listed-Diabasgang overskæres af Sandstensgange, som efter Ussings Undersøgelse snarest maa antages at være af samme Alder som Nexø Sandstenen. Ogsaa dette taler for, at denne Diabasgang - og dermed tillige alle de øvrige — er af prækambrisk Alder. 
En Sammenligning med sydsvenske Diabasgange kan imidlertid belyse Spørgsmaalet yderligere. De postsiluriske Diabasgange i Skaane har i det store og hele Strygningsretninger NV-SØ, altsaa nærmest paa tvers af de bornholmske Gange; desuden er de af en anden petrografisk Type (Kongaog Öved-Diabaser); de adskiller sig altsaa skarpt fra de bornholmske Diabaser. Derimod findes en vidtgaaende Overensstemmelse i Mineralbestand, Struktur og Strygningsretning mellem de bornholmske Diabaser og de sydsvenske Olivindiabaser, som i Blekinge og de tilgrænsende Dele af Skaane væsentligst har Retninger $\mathrm{N} 10^{\circ}-25^{\circ} \varnothing$. Det er derfor sandsynligst, at de bornholmske Diabaser er en sydlig Fortsættelse af de sydsvenske Olivindiabaser. I Sverige gennemsætter disse Diabaser alle Grundfjeldets Bjergarter, ogsaa de yngste Graniter. Da endvidere nogle af Diabaserne indeslutter Fragmenter af Kvartsit foruden Brudstykker af Sidestenen, og da de tillige $\mathrm{i}$ andre Henseender stemmer fuldstændig overens med det s. k. Diabaskonglomerat eller den brudstykkeførende Diabas, som gennemsætter den algonkiske Almesåkraserie, saa antages det, at de sydsvenske Olivindiabaser er af jotnisk eller postjotnisk Alder. Den samme Alder maa vi derfor antage for de bornholmske Diabaser.

Grönwall og Milthers har tidligere gjort opmærksom paa, at Diabasgangene og Spaltedalene paa Bornholm i det væsentlige har samme Retninger, og at Spaltedalene afspejler fremtrædende Sprækkesystemer i Graniten. Endvidere bemærker de, at en Udtømning af det gennemkløftede Materiale i Dalene maa have fundet Sted under Istiden.

Det maa antages, at Anlæget til Sprækkesystemerne er opstaaet i nær Tilknytning til Granitmagmaets Størkning. Udviklingen af visse Sprækkesystemer til Dale maa derimod være foregaaet i senere Tider, da hele Granitterrainet eller ialfald store Dele deraf reagerede under ét. Dette fremgaar af, at nogle Dale overskærer Granitgrænserne, f. Ex. fortsætter flere Spaltedale sig med retliniet Forløb fra Vang Graniten ind i Hammer Graniten og fra Paradisbakke Graniten ind i Svaneke Graniten. Det er strax iøjnefaldende, at et Par af de største Diabasgange ligger i fremtrædende Spaltedale, nemlig i Kjeldseaaens Dal og i Tamperdalen; men for et stort Antal Diabasganges Vedkommende kan en saadan Sammenhæng ikke paavises, f. Ex. kan den $40 \mathrm{~m}$ mægtige Diabasgang ved Kaas ikke sættes i Forbindelse med nogen Spaltedal. I Paradisbakkerne findes Diabasgange, som ligger i "Horstene" mellem Dalene (Fig. 38), og den anselige Spaltedal Kleven mellem Rø og Klemensker overskæres af flere Diabasgange med nord sydlig Retning. Disse Forhold tyder paa, at Diabasen ved sin Intrusion har fulgt de forhaandenværende Svaghedszoner i Graniten og har bidraget til Udviklingen af Spaltezonerne; men de tyder tillige paa, at ialfald nogle af de Spaltezoner, som nu er udpræpareret til dybe Dale, ikke paa det Tidspunkt frembød de lettest gennemtrængelige Veje for Diabasen. Ogsaa andre Forhold tyder paa en fortsat Udvikling af Sprækkesystemerne, f. Ex. viser smaa Glideflader i Diabasen ved Saltuna (i to paa hinanden vinkelrette Retninger), at der er foregaaet Forskydninger i Diabasen. Antagelig drejer det sig dog ikke om større Forkastninger, da Granitsidestenen er ganske ensartet paa begge Sider af Gangen.

Sandstensgangene, som ved Listed viser sig at være yngre end Diabasen, ligger næsten alle i den østlige Del af Granitterrainet. De fleste er kun faa cm mægtige, i Listed naar den største dog en Bredde af $133 \mathrm{~cm}$. Udenfor dette Omraade kendes nogle Sandstensgange paa Græsholmen ved Christiansø 
samt to smaa Gange, nemlig i Skaglfaldet $\mathrm{N}$ for Aakirkeby og ved Tækkeregaard NNØ for Hasle. Medens de to sidstnævnte Gange har Retninger hhv. N $20^{\circ} \varnothing$ og ca. N-S, følger alle de øvrige Gange Sprækkesystemer med Retning $\varnothing \mathrm{S} \varnothing-\mathrm{VNV}$, for Størstedelen ca. Ø $15^{\circ}-20^{\circ} \mathrm{S}$. Spaltedale med denne Retning findes kun i Paradisbakkerne, og Sandstensgange med nordsydlig Retning er hidtil ikke funden i den østlige Del af Bornholm. Dette viser, at ØSØ-VNV Sprækkesystemet har været udviklet og aabentstaaende dengang, da Sprækkerne blev sandfyldte, sandsynligvis i underkambrisk Tid; men heraf følger ikke, at NØ - SV Sprækkesystemet ikke har existeret, kun har det paa den Tid været mindre aabentstaaende, ialfald i den østlige Del af Bornholm.

\section{Kaolin.}

Pag. 199. Kaolinomraadet ved Rønne indtager et ca. $3 \mathrm{~km}$ langt og 500 - 600 m bredt Bælte langs med Granitens Vestrand. Paa Kortet Fig. 39 er dette Areal betegnet med aaben Punktering, og de Steder, hvor Kaolinen er gravet eller paavist ved Boringer, er angivet med tæt Punktering. Boringerne er betegnet med cursiverede Tal, staaende Tal angiver Højden over Havet i Fod.

Lejringsforhold. Kaolinen ligger paa primært Leje; den er opstaaet af Rønne Granit, hvoraf mere eller mindre fuldstændig omdannede Klumper af $\mathrm{og}$ til træffes i Kaolinen (Fig. 46). Pegmatitgange træder ofte tydelig frem i Kaolinmassen. Flere Steder er fundet kaoliniserede Diabasgange, hvis oprindelige Struktur, finkornede Grænse og grovere Midtparti hyppigt kan erkendes (Fig. 45). I de nordlige Grave ved Torneværket og langs Omraadets Østside er Kaolinen kun dækket af Moræne. I den vestlige Del af Feltet fra Gaarden Rosvang og sydpaa ligger mellem Kaolinen og Morænen et Lerlag (se Fig. 40), som indeholder sparsomme Kulfragmenter og ubestemmelige Planterester. Leret er i Reglen fedt, graat eller grønt, undertiden gulligt eller rødbroget. Flere Steder fandtes mellem Leret og Kaolinen et Lag skarpt Sand, hvis Beskaffenhed nøjagtig svarer til den Rest, som efterlades ved Kaolinens Slemning i Fabriken. Dette Sandlag er aabenbart en Slemmerest, som er dannet dengang, da Vandet i sin Tid brød ind over Kaolinen. Sandet indeholder hist og her Kulfragmenter, og stedvis er det sammenkittet til Sandstensklumper, hvori der er funden Cykadéfrø o. a. Forsteninger. GröNwall har derfor regnet Lagene over Kaolinen til Jura, senere har MaLling henført dem til Wealden.

Pag. 204-221 gengives Journalerne for endel af de talrige Boringer, som er foretaget i Kaolinomraadet; paa Grundlag deraf er konstrueret Profilerne Fig. 41, 42 og 43 (smlgn. Kortet Fig. 39). Boringerne saa vel som Kaolingravningen har vist, at Kaolinen ikke danner et sammenhængende Leje men optræder i flere, mere eller mindre vel adskilte Bækkener, som i den østlige Del af Omraadet gennemgaaende er flade og skaalformige. Imod Vest har Kaolinen større Mægtighed, og samtidig bliver Lagene over den tykkere. Omkring Nygaard fandtes Kaolinen i 10-13 m Dybde; Syd og Vest herfor boredes $15-20 \mathrm{~m}$, uden at Kaolin blev truffen. Kaolinens maximale Mægtighed kendes ikke; i de fleste Bækkener er den gode Kaolin kun 10-15 m mægtig, derunder bliver den mager og gaar nedefter over i Granitgrus med et ringe Kaolinindhold. Adskillige Boringer har under Granitgruset truffet fast Klippe.

Den største Mægtighed er funden i Rabekkeværkets Grav, hvor der boredes 
$48 \mathrm{~m}$ gennem hvid Kaolin uden at naa Bund (Boring IV); dog har Kaolinen næppe haft denne Mrgtighed over hele Graven, da denne nu er opgivet, uden at Brydning, saavidt vides, nogensinde har funden Sted i denne Dybde (smlgn. Fig. 41, Profil I-III). Endvidere tør man gaa ud fra, at Grænserne for den gode Kaolin er naaet til Siderne i Graven, før denne blev forladt. Den dybeste Boring a paa 95,4 m (Fig. 41 og pag. 206) er sandsynligvis sat ned i en forholdsvis lidet omdannet Granit. Journalerne angiver kun, at fast Klippe ikke blev naaet, og at Materialet var »sandholdigt", en Betegnelse, der i Journalerne sædvanlig anvendes om halvkaoliniseret Granitgrus. Boringen bekræfter altsaa, at den gode Kaolin i Rabekkeværkets Grav ikke fortsætter sig mod Syd; den viser endvidere, at Graniten paa dette Sted er løs og smuldrende indtil en usædvanlig Dybde. Da Undergrunden i det hele er stærkt forkløftet i dette Omraade, tør det antages, at Boringen har truffet et Sted, hvor Graniten er forvitret langs en Spalte. — I den nordligste Del af Kaolinomraadet frembyder Forholdene en vis Analogi med de nysnævnte. Ved Torneværket begrænses Kaolinen af en Zone halvkaoliniseret Granit (se Profil Fig. 43); Syd og Vest for denne Grav har Boringerne vist fast Klippe under Morænen, og Boringerne Nr. 36 og 38 mellem Torneværkets Grav og Store Almegaard traf Granitgrus, som synes at kunne paralleliseres med det i Boring a fundne Materiale.

Mellem Torneværket og Rabekkeværket kan en Vestgrænse for Kaolinen ikke angives med Sikkerhed. To Boringer, Nr. 17 og $18 \mathrm{NV}$ for Rosvang traf fast Klippe under Morænen. Forholdet belyses yderligere gennem en Række Boringer, som Rønne Vandværk har udført i Byvangen, 500-600 m Vest for Rosvang og Nygaard (Nr. 39-48, se Kortet Fig. 39 samt Profilerne G-H og J-K, Fig. 44). Disse Boringer viste, at de fede, brogede Lerarter tiltager stærkt i Mægtighed mod Vest og Nordvest; østligst i Byvangen var Leret 28-30 m mægtigt, længst mod NV naaede det godt $55 \mathrm{~m}$. Leret hviler paa et Sandlag, som endnu stærkere tiltager i Mægtighed mod Vest. Under Sandet traf flere af Boringerne paa Klippe, der var saa fast, at Boringerne maatte standses, Sprængning blev forsøgt men uden Resultat. Prøver af Graniten foreligger ikke. Granitundergrunden har en betydelig Hældning mod Nord og Nordvest. Boringerne Nr. 40, 41, 42 og 45 traf Graniten hhv. 31,5, 18,5, 31,5 og $36 \mathrm{~m}$ under Havfladen, medens Graniten i Boring Nr. 44 laa $68,5 \mathrm{~m}$ og i Boring 46 paa $55 \mathrm{~m}$ under Havets Overflade. Sandlaget bestaar for Størstedelen af Kvartskorn, som er tydelig rullede og sorterede i finere og grovere Lag; i to af Boringerne fandtes Kulfragmenter i Sandet paa 55- $60 \mathrm{~m}$ Dybde. Ifølge Journalerne er Sandet kaolinholdigt, men ved Optagelse af Prøverne er Kaolinindholdet saa godt som fuldstændig gaaet tabt. Efter Prøvernes Beskaffenhed at dømme kan der ikke være Tvivl om, at Kaolinindholdet er nedskyllet Materiale, som stammer fra de ovenfor liggende Kaolinlejer. I de tre dybe nordvestlige Boringer, Nr. 43, $44 \operatorname{og} 46$, fandtes under dette Sandlag usorteret, skarpkantet Granitgrus, som indeholdt alle Granitens Mineraler; under dette traf Boringerne Nr. 44 og 46 fast Klippe. Prøver af Granitgruset indeholder Spor af Kaolin, men den store Feldspatmængde viser dog, at Graniten kun kan have været i meget ringe Grad kaoliniseret, da Sandlaget blev aflejret. Det vil derfor være ukorrekt at regne Byvangen med til Kaolinfeltet; Vestgræensen for dette forløber antagelig som angivet paa Kortet Fig. 39.

Det synes altsaa, at Kaolinen ved Rønne er indskrænket til en langstrakt, smal Zone paa Granitgrundfjeldets Vestskraaning. Denne Zone ligger i et 
højere Niveau end den Vest for liggende Del af Graniten, hvori ingen væsentlig Kaolinisering har kunnet paavises. Kaolinen naar derimod i Rabekkeværkets Grav ned til en Dybde af $40 \mathrm{~m}$ under Havets Overflade, medens den uforvitrede Granitoverflade i den østligste Boring i Byvangen blev truffen $20 \mathrm{~m}$ under Havfladen. Tager man nu i Betragtning, at Kaolinzonen ligger i Forlængelse af Granithorsten mellem Hasle og Rønne, saa ligger den Tanke nær, at de Fordybninger, hvori Kaolinen findes, er betinget af et System af Forkastningsspalter, og at Undergrundens Forkløftning har gjort det muligt for Kaoliniseringen paa sine Steder at trænge ned til forholdsvis stor Dybde.

Pag. 221. Kaolinens Mineralbestand og kemiske Sammensætning fremgaar i alt væsentlig af Analysetabellen pag. 224. Analysen viser en intensiv Kaolinisering. Titanindholdet er paafaldende stort og kan ikke antages at være bunden alene i de paaviste titanholdige Mineraler, endel deraf er muligvis tilstede som kolloide Titanhydrater. Titanit optræder udelukkende i Form af Leukoxen, der danner graabrune Skorper omkring Magnetjernkornene. Underordnet forekommer Svovlkis, Zirkon, Rutil, Anatas, Jernspat og sjelden Glimmer. De af H. Röster angivne Mineraler: Topas, Hussakit, Andalusit og Sillimannit har ikke kunnet paavises. Medens den slemmede Kaolin er et blendende hvidt Pulver, er Raakaolinen i Almindelighed en løs graahvid Masse, som i Haanden føles noget skarp paa Grund af Kvartsindholdet. I visse underordnede Partier, særlig i Nærheden af Overfladen, er Kaolinen gullig eller rødlig farvet af Jernforbindelser. Diabasgangene har leveret et rødligt eller grønligt Produkt. Pegmatitgangenes store Mikroklinindivider er i Reglen forholdsvis lidt kaoliniserede. Hist og her findes mindre Konkretioner sammenkittede af Karbonater eller Kiselsyre. "Mørk Kaolin" bestaar erfaringsmæssig altid af forholdsvis lidt omdannet Granit.

Pag. 228. Overgangen mellem Kaolin og frisk Granit kan følges dels i Kaolinens Grænselag, dels i de foran omtalte Klumper af delvis kaoliniseret Granit (Fig. 46). Undersøgelsen har vist, at Hornblenden er det Mineral, som først angribes; den omdannes til et serpentinagtigt Aggregat, der efterhaanden afbleges og forgrener sig gennem hele Massen. De øvrige Mineraler omdannes derefter i følgende Orden: Plagioklas, Apatit, Mikroklin, Titanit, Biotit og Magnetjernsten; dog findes Undtagelser fra denne Rækkefølge, specielt kan Biotiten optræde lunefuldt. Karbonater optræder i Almindelighed sparsomt. Kun i de halvkaoliniserede Granitklumper fra Torneværkets Grav er funden en større Mængde Kalkspat; denne synes dog at betegne et Overgangsstadium, ved fortsat Omdannelse gaar Karbonaterne i Opløsning. Nogen Cementationszone er ikke funden hverken i Kaolinens Grænselag eller i Sidestenen.

Pag. 232. Kaolinforekomster andet Steds paa Bornholm. I Kortbladsbeskrivelsen omtales nogle smaa Forekomster, nemlig ved Skaglfaldet NO for Aakirkeby, Nyker Mejeri, Nørrebæk NV for Nexø, Granithorsten mellem Hasle og Rønne samt i Allinge Havn. Fra de to førstnævnte Steder har intet Materiale foreligget til Undersøgelse. Den betydeligste af Forekomsterne er Granithorsten, som skiller Rhæt-Lias-Lagene mod Vest fra Kridtformationens Grønsandsdannelser mod Øst. I Landskabet gør Horsten sig ikke bemærket, kun hvor Vandløbene har skaaret sig ned gennem de løse Jordlag, ses en forvitret og smuldrende Granit, og ved Gravning i Aabunden kan stærkt omdannet Granitgrus bringes for Dagen. Mindst omdannet er den finkornede, brunrøde Bjergart, som M. Jespersen kaldte "Eurit». Den er faststaaende ved Broen over Blykobbeaa. I Kornstørrelse og Struktur 
svarer den nøje til den finkornede »Hasle Granit«i Frigaards Brud (se pag. 91). Feldspaten er noget kaoliniseret og sericitiseret, Biotiten er kloritiseret, Epidot forekommer jævnligt. Stenen er gennemsat af talrige Sprækker fyldte med Kalkspat. Iøvrigt er Størstedelen af Graniten saavel ved Blykobbeaa som ved Mulebyaa af samme mellemkornede Type som den stribede Granit i Egnen $\mathrm{N}$ for Hasle. For det meste er den stærkt smuldrende. Dens Omdannelse er paa forskellige Steder falden noget forskelligt ud. Ved Mulebyaa træffes (paa Jespersens Lokal. 2) en temmelig stærkt kaoliniseret Granit. Mikroklinen er dog ret frisk, Plagioklasen stærkere angrebet, Sericitdannelsen er her underordnet. Biotiten er dels kloritiseret, dels affarvet, Apatit er velbevaret. Bjergarten er saa stærkt imprægneret med Kalkspat, at den derved bliver ret fast og sammenhængende. Andre Steder finder man rustfarvet Granitgrus, som indeholder kaolinagtige og kloritiske Partier eller lerede Masser af brunrød eller blaagrøn Farve. I den mellemste Del af Horsten forekommer en Granitbreccie, som bestaar af skarpkantede Kvarts-Feldspatfragmenter sammenkittede af Jernspat og Klorit. Nær ved Østgrænsen er funden stærkt omdannet Diabas. I Granithorsten er Kaoliniseringen altsaa betydelig mindre fremskreden end i Kaolinfeltet ved Rønne, hvorimod Kloritisering, Karbonat- og Limonitdannelse spiller en langt større Rolle.

I Allinge Havn er Kaolin funden paa "Gange». Nogle Prøver, indsamlet af Bankbogholder E. Kofoed, bestaar af delvis kaoliniseret Hammer Granit. Bjergarten indeholder Rester af Mikroklin, derimod er Plagioklas helt forsvunden, i Stedet forekommer finskællede Aggregater, som synes at bestaa af en Blanding af Kaolin og Sericit. I et af Stykkerne fandtes tillige Biotit og Rester af andre mørke Mineraler. Da det angives, at Prøverne stammer fra en "Kaolingang", kan der kun være Tale om, at Kaoliniseringen er foregaaet langs en Spalte i Graniten. Endvidere foreligger endel Prøver, som Forchhammer har samlet i Allinge Havn. De bestaar alle af omdannet Diabas. Tre af Gangene svarer temmelig nøje til de kaoliniserede Diabaser i Gravene ved Rønne. De øvrige bestaar af serpentinagtige Bjergarter af lignende Beskaffenhed som de fleste andre stærkt omdannede Diabaser paa Bornholm.

Prøver fra Forekomsten ved Nørrebæk NV f. Nexø har vist, at Kaolindannelse her spiller en meget underordnet Rolle. Feldspaten er næsten lige saa frisk som i almindelig Svaneke Granit, og dens Omdannelse bestaar for en stor Del i Sericitisering. Desuden er Stenen stærkt imprægneret med Jernspat og sorte eller brune, rustagtige Forbindelser.

Endelig findes ved Arnager kaolinholdigt Sand, og ved Udløbet af Grødbyaa er i det 18. Aarh. gravet kaolinholdigt, hvidt Ler, som anvendtes paa den kgl. Porcellænsfabrik i Kjøbenhavn.

Pag. 236. Kaolinens Alder og Dannelsesmaade. Efter Ussings og Grönwalls Undersøgelser kan der næppe rejses berettigede Indvendinger imod den af dem fremsatte Opfattelse, at Kaolinen er ældre end de overliggende Lag. Kaolindannelsen maa altsaa være foregaaet i Trias eller maaske i den yngre Del af palæozoisk Tid.

Til Forklaring af Kaolinens Oprindelse har derimod saa godt som alle hidtil fremsatte Theorier om Kaolindannelse været bragt i Anvendelse. Forсhнамmer antog (1832-1834), at Kaolinen var opstaaet af en KvartsFeldspatmasse ved Indvirkning af overhedet Vanddamp, som var udstrømmet fra Dybet gennem Spalter i Graniten. Cohen og Deecke (1891) satte ligeledes Kaolindannelsen i Forbindelse med Spalter i Undergrunden men 
tog Afstand fra Forchnammers Theori om Thermalvand som Aarsag til Kaoliniseringen. Ussing (1902) mente derimod, at Kaolinen var opstaaet ved simpel Overfladeforvitring begunstiget af Fortidens milde og fugtige Klima, og han ansaa de nuværende Lejer for sparsomme Rester af en tidligere mægtig Forvitringsskorpe. Röscer (1902) antager, at Kaolinen er af endogen Oprindelse og stotter sig væsentlig paa Mineralbestemmelser, som dog ikke alle synes holdbare; endvidere bemærker han, at hvis Kaolinen var dannet ved Forvitring, skulde man vente at finde Rester deraf paa flere Steder i det stærkt forkløftede Granitterrain, men saadanne kendes ikke. A. Stahl (1912) og H. Stremme (1917) antager, at Kaolinen er opstaaet ved Forvitring under Moser eller Kullag og mener, at Kaolindannelsen ved Rønne er foraarsaget af Rhæt-Lias-Kullene, en Opfattelse, som derefter almindelig træffes i tysk Literatur. Da Kaolinen som nævnt maa anses for at være ældre end Kullagene, kan denne Sammenhæng betragtes som udelukket. Grönwall har (1916) antaget, at Lejerne ved Rønne er af endogen Oprindelse; han støtter sig derved til Röslens Undersøgelser men fremhæver tillige, at Kaolinen i Rabekkeværkets Grav har en betydelig Dybde og en stærkt hældende Undergrænse. Selv har jeg tidligere (1928) sluttet mig til Grönwalls Opfattelse.

Da de foran omtalte talrige Boringer ved Rønne har vist, at Kaolinen over Størstedelen af Omraadet kun har ringe Mægtighed, kan det næppe antages, at den er af endogen Oprindelse. Derimod taler Lejringsforholdene for, at Undergrunden har været stærkt forkløftet, dengang da Kaolindannelsen foregik, saaledes at Kaoliniseringen paa sine Steder har kunnet trænge forholdsvis dybt ned.

For Tydningen af den bornholmske Kaolin som en exogen Dannelse møder strax den Vanskelighed, at Kaolinens tidligere Udbredelse ikke er bekendt. Ved Rønne ligger Kaolinen i en Række Fordybninger, og de øvrige smaa Forekomster synes knyttede til Spalter i Graniten. Den Mulighed kan derfor ikke afvises, at samtlige Forekomster kan være Rester af en tidligere større Masse, som er blevne bevarede paa Grund af deres beskyttede Beliggenhed. Imidlertid er det gentagne Gange fremhævet i de senere Aars Kaolinliteratur, at simpel Overfladeforvitring ikke kan føre til Dannelse af rene Kaolinlejer, da den atmosfæriske Forvitring for en væsentlig Del bestaar i Iltningsprocesser, hvorved bl. a. Størstedelen af Bjergarternes Jernforbindelser udskilles som uopløselige Ferrihydroxyder. Kaoliniseringen derimod ledsages af reducerende Processer, hvorved Jernforbindelserne gaar i Opløsning som Ferroforbindelser eller for en mindre Del efterlades som Jernspat og Svovlkis. Den Omstændighed, at Kaoliniseringens Intensitet er saa uensartet paa de forskellige Forekomster (smlgn. Granithorsten og Lejerne ved Rønne), tyder endvidere paa, at Kaolindannelsen skyldes lokalt virkende Aarsager.

Tager man nu i Betragtning, at Kaolinen ved Rønne ligger i en Række Fordybninger, som tildels er flade Bækkener, saa forekommer det sandsynligst, at den er opstaaet ved Moseforvitring. Da Lejerne er beliggende midt oppe paa Granitens Vestskraaning, maa det forudsættes, at Moserne har været Vældmoser. Nyere Undersøgelser har imidlertid vist, at Moseforvitring under nord- og mellemeuropæiske Klimaforhold ikke fører til Kaolindannelse; men da det maa antages, at Kaolinen er opstaaet i Trias eller yngre palæozoisk Tid, er det muligt, at Klimabetingelserne dengang har været gunstige for en saadan Kaolinisering. Endelig kan det tænkes, at nogle Kilder langs For- 
kastningen har været kulsyreholdige og derved paa sine Steder har forstærket Mosevandets Kaoliniseringsevne. Theorien om Moseforvitring som Aarsag til Kaolindannelsen synes for saa vidt at stemme med de lokale Forhold paa Bornholm. Men imod denne Hypothese kan strax indvendes, at der hidtil ikke er paavist sikre Spor af, at saadanne Moser har existeret. Spørgsmaalet om den bornholmske Kaolins Dannelse har derfor endnu ikke fundet sin endelige Løsning.

\section{Efterskrift.}

Pag. 244. Efter at første Del af dette Arbejde var udkommen som Særtryk i 1932, har Professor S. v. Bubnoff og Dr. R. Kaufmann publiceret en Afhandling: "Zur Tektonik des Grundgebirges von Bornholm" (Geol. Rundschau, Bd. XXIV, 1933), hvori de fremsætter et Par Ændringer til mit Kort over Granitvarieteternes Udbredelse. Den første Endring bestaar i, at Signaturen for Paradisbakke Graniten trækkes lidt længere mod SV omtrent til Skovgaard. Da dette er i god Overensstemmelse med det af mig foran (pag. 85) anførte, at Karakteren af Paradisbakke Granit efterhaanden taber sig mod Vest, har jeg som Fig. 6, pag. 13 indsat et nyt Kort, hvori denne Ændring er indtegnet.

Dernæst har Dr. KaUfmann ment, at en Fortsættelse af Svaneke Graniten forekommer i Hallegaard Skov S f. Skovgaard samt ved Katteslet Gaard i Bodilsker. Ved elskværdig Imødekommen fra Professor v. Bubnoff i Greifswald har jeg haft Lejlighed til at undersøge Dr. Kaufmanns Materiale, og paa en Excursion sammen med Dr. Kaufmann har jeg selv indsamlet yderligere Prøver. Undersøgelsen viste, at denne Granit ikke bestaar af Svaneke Granit men af en Rønne Graniten nærstaaende, hornblenderig Varietet uden Parallelstruktur. Ogsaa dette er angivet paa Kortskitsen Fig. 6. Forekomsten af denne "Rønne Granit" ved Skovgaard antyder en vis Analogi i Fordelingen af Granitvarieteterne i det sydvestlige og det sydøstlige Hjørne af Grundfjeldsterrainet: Yderst ligger paa begge Steder Rønne Granit, indenfor kommer mod Vest Rønne Granitens Overgangsbjergart, og mod Øst Paradisbakke Granit; den nære Overensstemmelse mellem de to sidstnævnte Varieteter er omtalt pag. 54-56; lignende Varieteter optræder flere Steder i Egnen omkring Aakirkeby (pag. 59 og 86).

Endelig angiver Dr. Kaufmann, at der i den stribede Granit nær ved Grænsen mod Svaneke Graniten ved Listed forekommer en "Glimmerskifer". Graniten er her indenfor et lille Omraade noget stærkere skifret og har en mere udtalt gnejsagtig Habitus end sædvanlig i den stribede Granit. Men dens Sammensætning er Granitens almindelige, Feldspat er Hovedbestanddelen, og de øvrige Mineraler optræder i samme Mængdeforhold som i Egnens øvrige Granit. Det er derfor misvisende at betegne denne Bjergart som Glimmerskifer; den kan kun opfattes som et underordnet, stærkt gnejsagtigt udviklet Parti af den bornholmske Gnejsgranit.

\section{Berichtigung.}

Pag. 55. Auf der Karte Fig. 11 ist die Südgrenze des Rönne Granits verkehrt angegeben. Weiterhin fehlt die Zeichenerklärung für Kaolin. Die notwendigen Berichtigungen können der beigelegten farbigen Karte im Masstabe 1:100000 entnommen werden.

Pag. 191, Z. 10 v. u. lies O $30^{\circ} \mathrm{N}$ statt $\mathrm{N} 30^{\circ} \mathrm{O}$.

Pag. 217. Bei Bohrung Nr. 42 ist hinzuzufügen: „Bei $47,5 \mathrm{~m}$ Granit». 


\section{Erklärung der Tafel I.}

Fig. 1. Rönne Granit, Klippegaard. Plagioklas mit Mantel aus Mikroklinperthit. Verg. 20. (Vergl. pag. 25).

Fig. 2. Plagioklas mit unregelmässiger Auslöschung. Rönne Granit, Klippegaard. Vergr. 30. (Vergl. pag. 27).

Fig. 3. Derselbe Plagioklas wie Fig. 2, um $10^{\circ}$ gedreht. Vergr. 30. (Vergl. pag. 27).

Fig. 4. Plagioklas, schriftgranitisch verwachsen mit Quarz, Mikrolin (ein helles Körnchen ungefähr im Zentrum), und Hornblende (unten links). Rönne Granit, Klippegaard. Vergr. 20. (Vergl. pag. 28).

Fig. 5. Hornblende im Rönne Granit, Klippegaard. Vergr. 33. (Vergl. pag. 28).

Fig. 6. Labradorkristall im Rönne Granit, Klippegaard. Vergr. 18. (Vergl. pag. 28). 

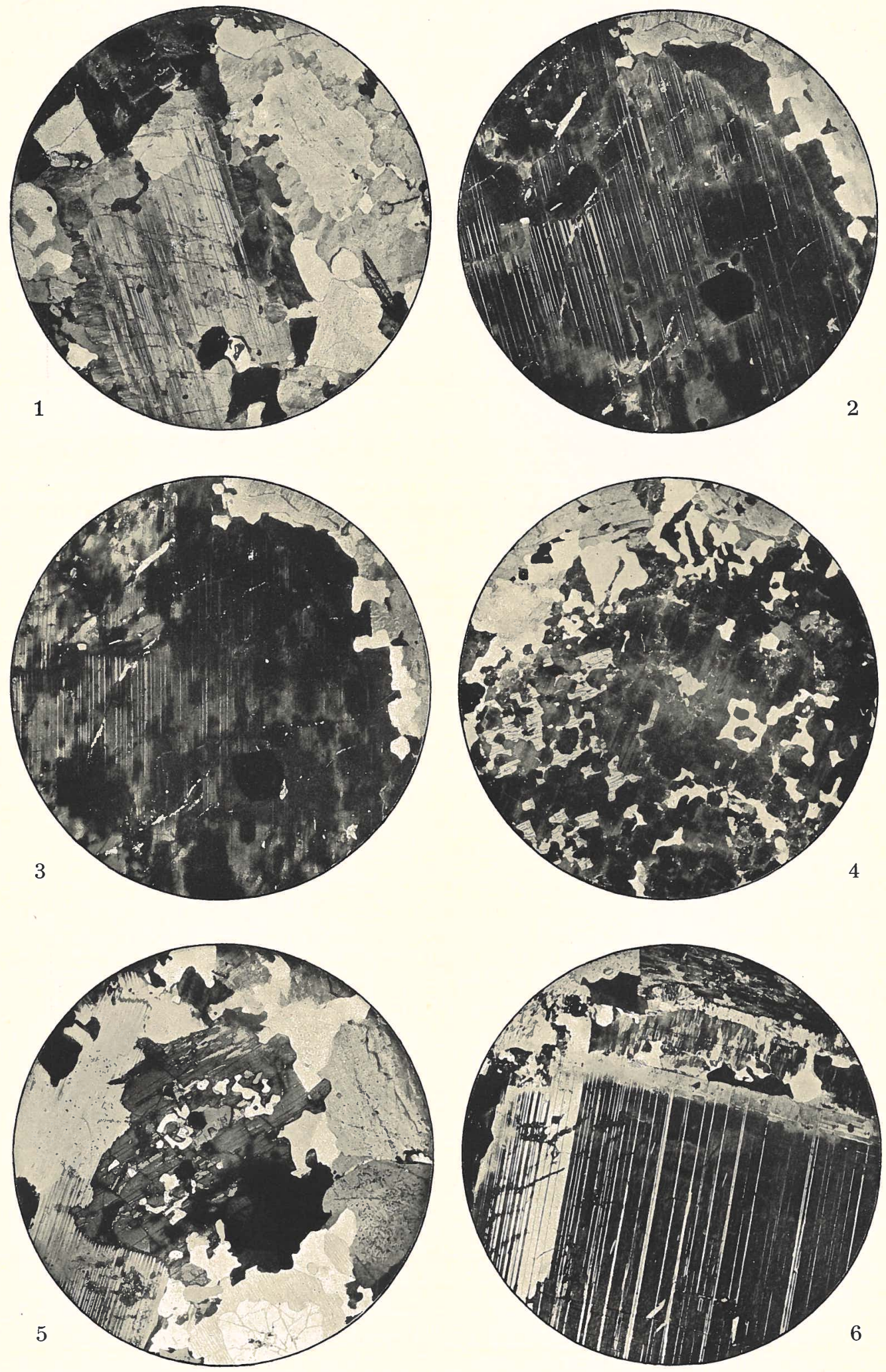


\section{Erklärung der Tafel II.}

Fig. 1. Biotit-Quarz-Symplektit im Rönne Granit, Klippegaard. Vergr. 33. (Vergl. pag. 34).

Fig. 2. Basische Ausscheidung im Rönne Granit, Klippegaard. Die dunklen Mineralien sind fast ausschliesslich Hornblende. Nic.||. Vergr. 13. (Vergl. pag. 40).

Fig. 3. Quarz-Titanit-Gestein, Einschluss im Rönne Granit SW von Knuds Kirke. Die dunklen Körner in den Zwickeln zwischen den Quarzkörnern sind Titanit. Nic.||. Vergr. 32. (Vergl. pag. 42).

Fig. 4. Quarz-Titanit-Gestein, Einschluss im Rönne Granit SW von Knuds Kirke. Man beachte den Mikroklin als Füllmasse in den Zwickeln. Nic. +. Vergr. 32. (Vergl. pag. 42).

Fig. 5. Einschluss von Mikroklinperthit im Rönne Granit, Klippegaard. Schnitt || (001). Der Mikroklin hat stellenweise submikroskopische Gitterstruktur. Vergr. 28. (Vergl. pag. 49).

Fig. 6. Mikroklinperthit (unten links) mit Plagioklas-Quarz-Mantel. Schnitt $\perp$ MP von dem in Fig. 10 pag. 49 abgebildeten Feldspateinschluss im Rönne Granit, Klippegaard. Vergr. 18. (Vergl. pag. 48-50). 

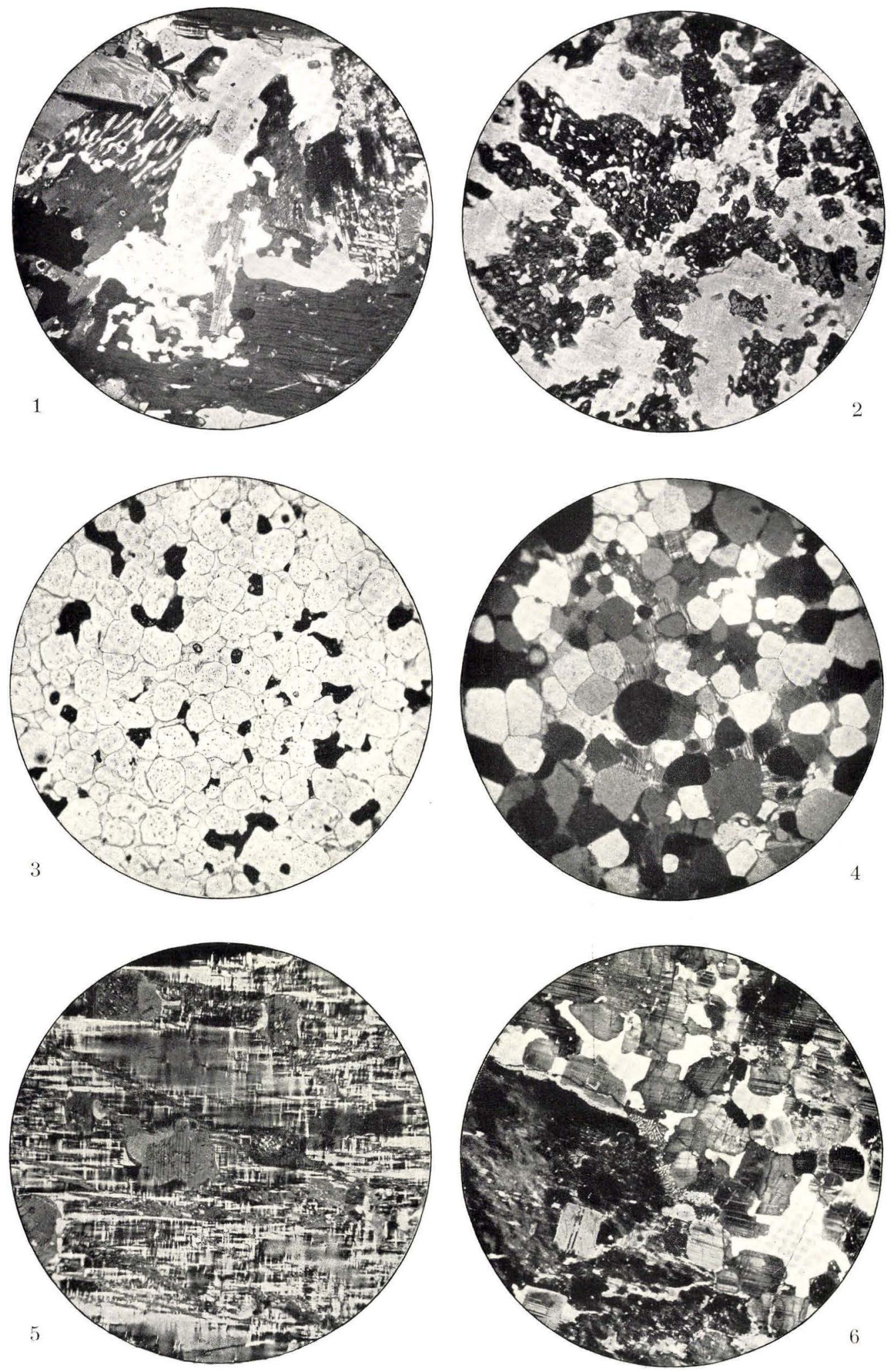


\section{Erklärung der Tafel III.}

Fig. 1. Porphyrischer Rönne Granit, NNO von Store Almegaard, Lok. 54. Nic. + . Vergr. 13. (Vergl. pag. 56).

Fig. 2. Porphyrischer Rönne Granit, NNO von Store Almegaard, Lok. 54. Nic. ||. Die dunklen Mineralien bestehen weit überwiegend aus poikilitischer Hornblende. Vergr. 13. (Vergl. pag. 56).

Fig. 3. Paradisbakke Granit, Steinbruch bei Præstebogaard. Vergr. 13. (Vergl. pag. 62).

Fig. 4. Paradisbakke Granit, Slamrebjerg. Plagioklaseinsprenglinge in biotitreicher Grundmasse. Vergr. 13. (Vergl. pag. 62 und 66).

Fig. 5. Vang Granit, $1200 \mathrm{~m}$ SW von Ols Kirke. Mikroklin mit zonarer Anordnung von Perthitspindeln. Vergr. 13. (Vergl. pag. 67).

Fig. 6. Vang Granit, Steinbruch »Klondyke« S von Vang. Plagioklas parallel umwachsen von Mikroklin, der wieder mit Quarz granophyrisch verwachsen ist. Vergr. 13. (Vergl. pag. 67). 

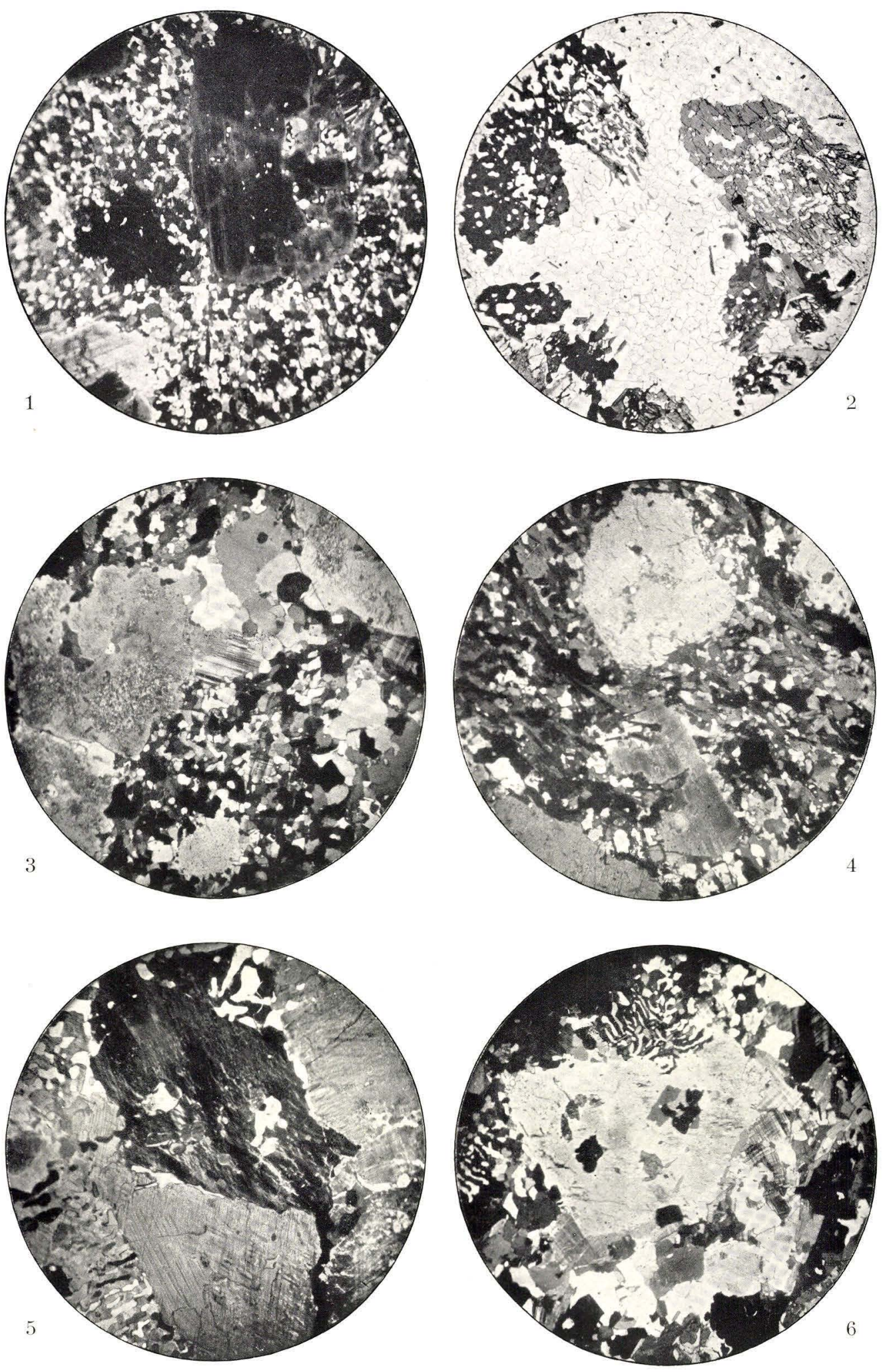


\section{Erklärung der Tafel IV.}

Fig. 1. Haufe von dunklen Mineralien im Vang Granit, Steinbruch "Klondyke» S von Vang. Nic. II. Vergr. 13. (Vergl. pag. 68).

Fig. 2. "Blauer Granit«, Tækkeregaard. Oben links ein grosses, helles Plagioklaskorn. Vergr. 13. (Vergl. pag. 76 und 78).

Fig. 3. Streifiger Granit, Gudhjem. Vergr. 13. (Vergl. pag. 80).

Fig. 4. Streifiger Granit, Kjeldse Aa (Kjeldse Bach). Rechts ein grösseres Plagioklaskorn parallel verwachsen mit Mikroklin. Plagioklas im übrigen dunkel in der Phot. Vergr. 13. (Vergl. pag. 80).

Fig. 5. Streifiger Granit, Kjeldse Aa. Derselbe wie Fig. 4, Nic. ||. Zeigt die Anordnung in Streifen von dunklen Mineralien, hauptsächlich Biotit. Vergr. 13. (Vergl. pag. 80).

Fig. 6. Streifiger Granit, südlich von Hvidehald bei Aakirkeby. Die dunklen Mineralien bestehen teils aus stark durchlöcherter Hornblende, teils aus Biotit und Erz. Die getrübten Flecke im Bilde sind zersetzter Plagioklas. Nic. I. Vergr. 13. (Vergl. pag. 86). 

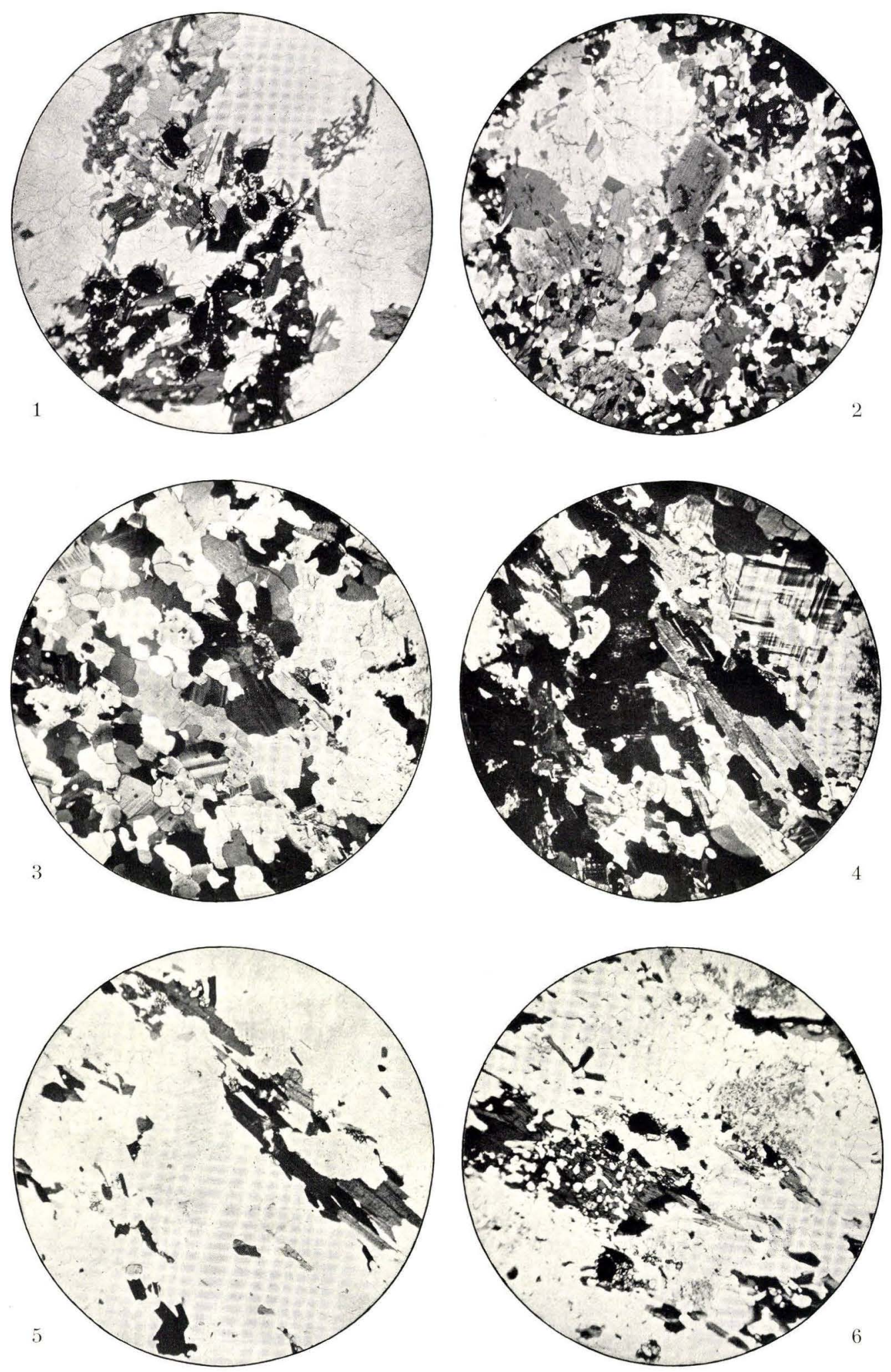


\section{Erklärung der Tafel V.}

Fig. 1. Streifiger Granit mit doppelkörniger Struktur, Hakonsgaard O von Rönne. Vergr. 13. (Vergl. pag. 59 und 86).

Fig. 2. Alminding Granit, Bjergbakke Steinbruch. Vergr. 13. (Vergl. pag. 89).

Fig. 3. Alminding Granit, Bjergbakke Steinbruch. Mikroklin mit Plagioklaseinlagerungen. Vergr. 32. (Vergl. pag. 89).

Fig. 4. Roter feinkörniger aplitischer Granit (»Hasle Granit«), Kongensmark Huse SO von Gudhjem. Vergr. 13. (Vergl. pag. 92).

Fig. 5. Hammer Granit, Hammeren. Vergr. 13. (Vergl. pag. 95).

Fig. 6. Hammer Granit, Hammeren. Vergr. 13. (Vergl. pag. 95). 

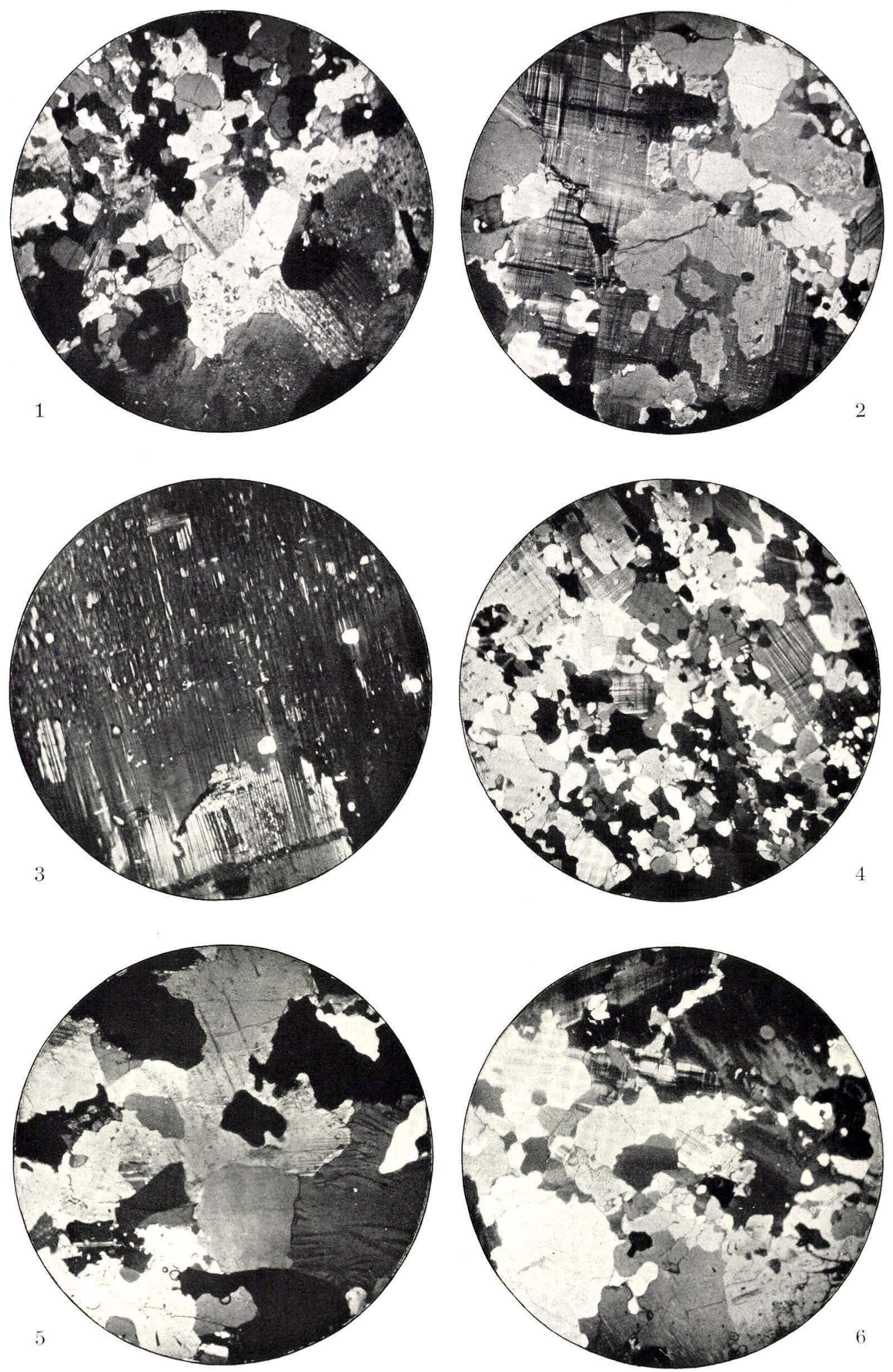


\section{Erklärung der Tafel VI.}

Fig. 1. Grenzfazies des Hammer Granits, Steinbruch bei Sjelle Mose. Vergr. 13. (Vergl. pag. 100).

Fig. 2. Porphyrische Grenzfazies des Hammer Granits $2 \mathrm{~m}$ vom Kontakt mit dem Vang Granit. Küstenfelsen, Sandkaas. Vergr. 13. (Vergl. pag. 100 und 103).

Fig. 3. Plagioklas mit antiperthitisch eingelagertem Mikroklin. Hammer Granit-Pegmatit, Sjelle Mose. Vergr. 32. (Vergl. pag. 103).

Fig. 4. Svaneke Granit, Rabækkegaard, Helvedesbakker. Unten ein Mikroklinkristall, in dem das eine System von Zwillingslamellen stark dominiert. Vergr. 13. (Vergl. pag. 112).

Fig. 5. Svaneke Granit, ONO von Ibs Kirke. Plagioklas, etwas zersetzt, von Mikroklin parallel umwachsen. Vergr. 13. (Vergl. pag. 112).

Fig. 6. Feinkörnige Grenzfazies des Svaneke Granits, Listed. Vergr. 13. (Vergl. pag. 119). 

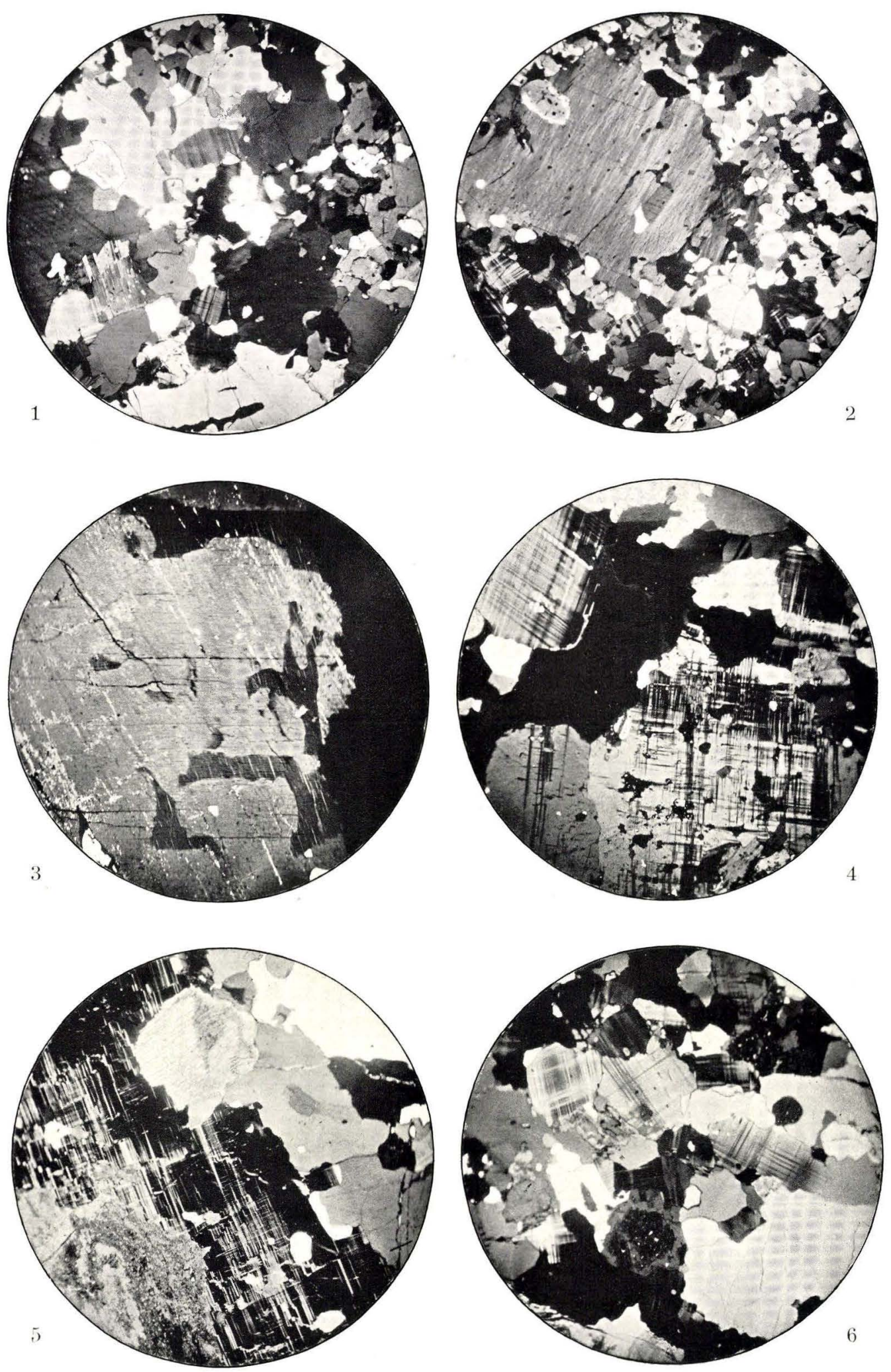


\section{Erklärung der Tafel VII.}

Fig. 1. Streifiger Granit etwa $1 \mathrm{~m}$ vom Diabas, Saltuna. Die dunklen Mineralien sind am Rande stark gefranst. Nic.||. Vergr. 60. (Vergl. pag. 159).

Fig. 2. Derselbe Granit wie Fig. 1. Mikropegmatitische Neubildungen; in der Mitte Basisschnitt von einem Quarzkorn. Vergr. 40. (Vergl. pag. 159).

Fig. 3. Streifiger Granit beim "Granitporphyr", Saltuna. Die Grundmasse ist grösstenteils in Mikropegmatit umgewandelt. Vergr. 30. (Vergl. pag. 159).

Fig. 4. Feinkörnige Grundmasse des Kontaktgesteins ("Granitporphyr«), Saltuna. Vergr. 40. (Vergl. pag. 160).

Fig. 5. Feinkörnige Grundmasse des Kontaktgesteins, Saltuna. Man beachte die langen, schmalen Hornblendekristalle mit hellem Augitkern. Nic.||. Vergr. 34. (Vergl. pag. 161).

Fig. 6. Kontakt zwischen Diabas (links) und Mikropegmatit, Flæskedals Hus, $0,5 \mathrm{~km}$ von Almindingen. Vergr. 33. (Vergl. pag. 162). 

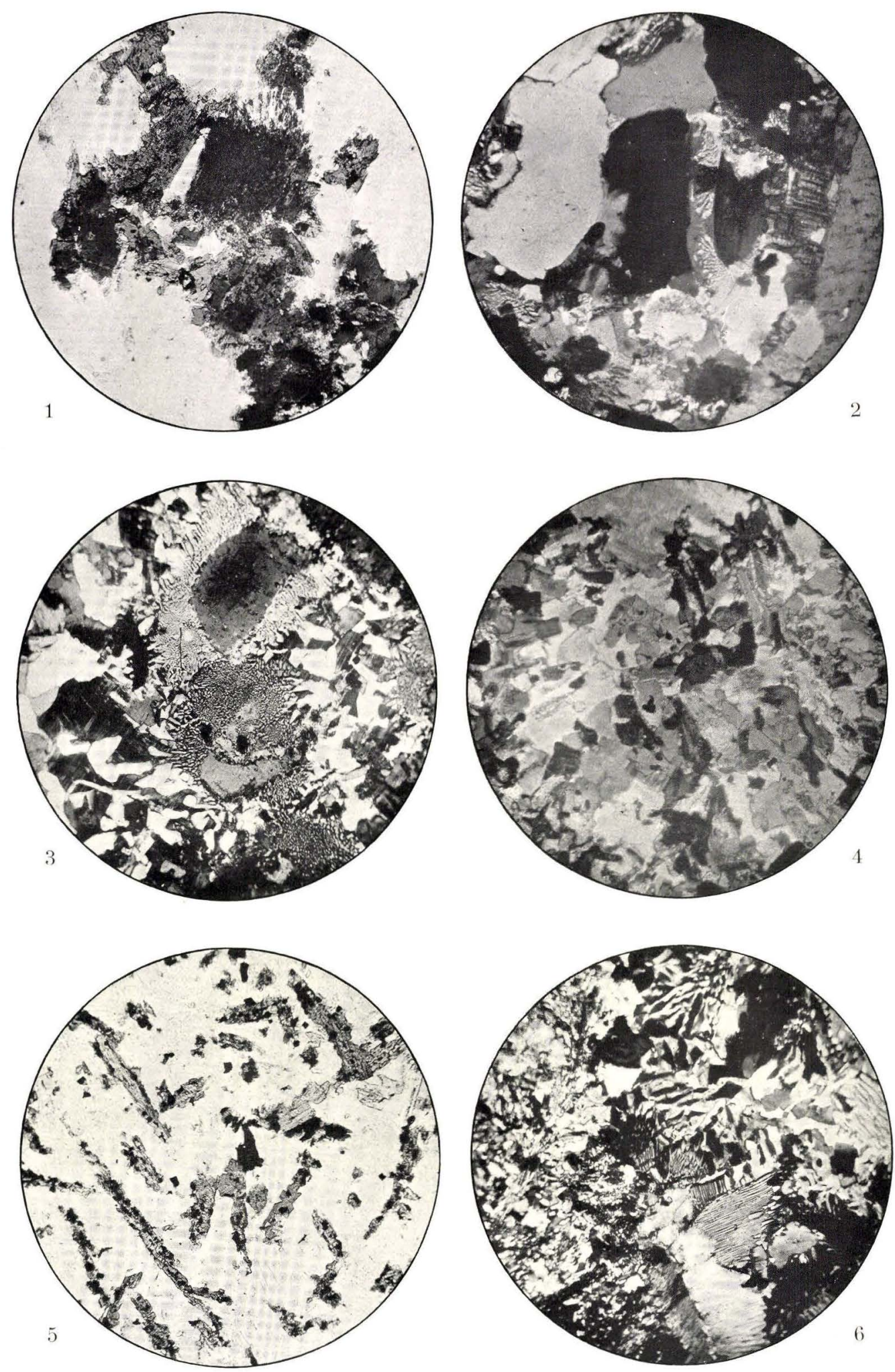


\section{Erklärung der Tafel VIII.}

Fig. 1. Randzone des Diabases mit fächerförmigen Hornblende-Augit-Aggregaten. Dasselbe Präparat wie Fig. 6, Taf. VII, ein wenig nach rechts verschoben. Nic.||. Vergr. 33. (Vergl. pag. 162).

Fig. 2. Feldspatovoid im Diabas von Gule Hald, Listed. Vergr. 13. (Vergl. pag. 169).

Fig. 3. Derselbe Feldspat wie Fig. 2, etwas verschoben. Die Randzone des Ovoids gegen den Diabas ist mit kleinen Plagioklaskristallen bekleidet. Vergr. ca. 60. (Vergl. pag. 169).

Fig. 4. Gekörnelter Teil eines Feldspatovoids im Diabas von Gule Hald, Listed. Nic. +. Vergr. 300. (Vergl. pag. 170).

Fig. 5. Feldspatovoid mit klaren, zwillingslamellierten Feldern; rechts mikropegmatitische Quarzeinlagerungen. Aus dem Diabas von Gule Hald, Listed. Vergr. 60. (Vergl. pag. 170).

Fig. 6. Quarzkorn im Diabas eingeschlossen. Tamperdal. Nic. + . Vergr. 13. (Vergl. pag. 172). 

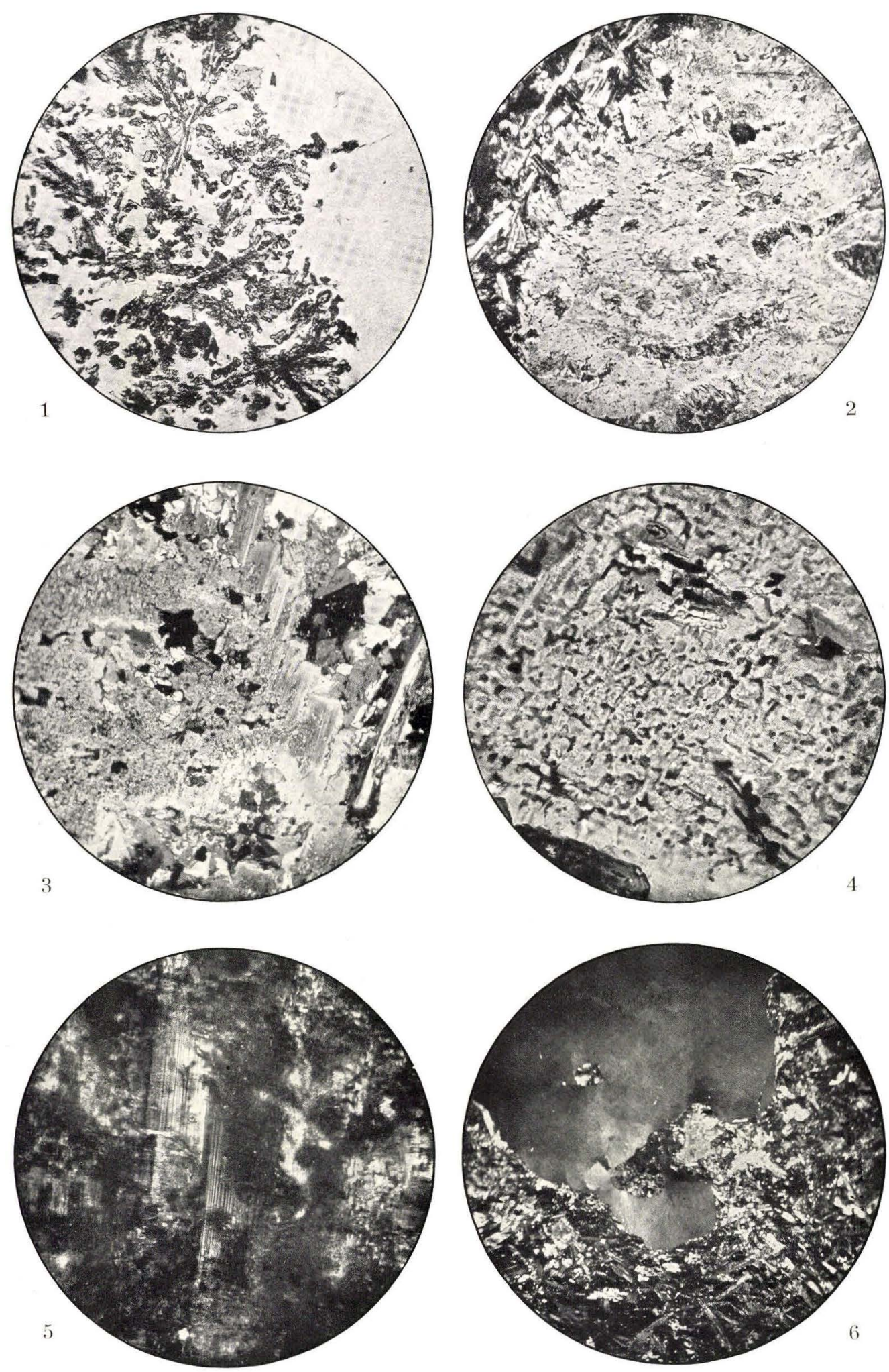

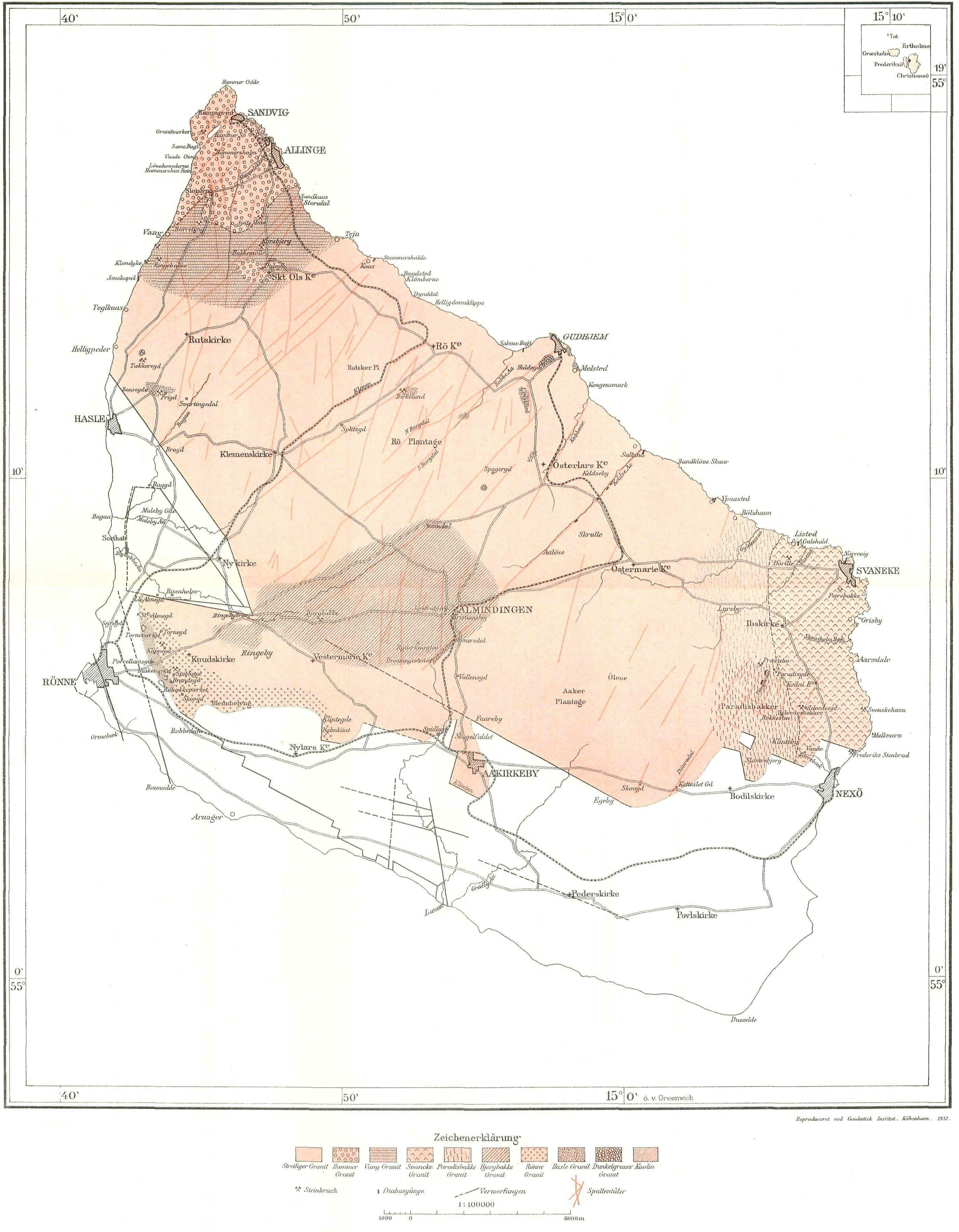

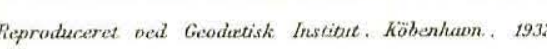

